UNIVERSIDAD POLITÉCNICA DE MADRID

DEPARTAMENTO DE AUTOMÁTICA, INGENIERÍA

ELECTRÓNICA E INFORMÁTICA INDUSTRIAL

ESCUELA TÉCNICA SUPERIOR DE INGENIEROS INDUSTRIALES

\title{
SISTEMAS DE AYUDA AL DIAGNÓSTICO Y A LA TERAPIA FUNCIONAL EN ENFERMEDADES NEURODEGENERATIVAS
}

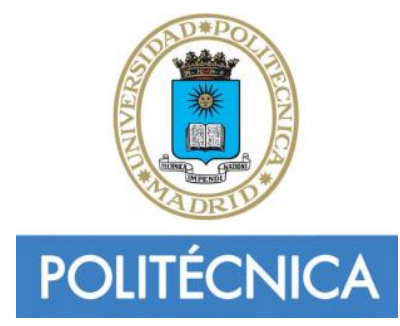

TESIS DOCTORAL

\author{
Autor: Roberto González Herranz \\ Ingeniero Industrial \\ Tutor: Antonio Barrientos Cruz \\ Dr. Ingeniero Industrial
}



Tribunal nombrado por el Magnífico y Excmo. Sr. Rector de la Universidad Politécnica de Madrid, el día de de 2015.

Presidente:

Vocal:

Vocal:

Vocal:

Secretario:

Suplente:

Suplente:

Realizado el acto de defensa de la Tesis el día de de 2015 en la E.T.S.I.I.

EL PRESIDENTE

LOS VOCALES

EL SECRETARIO 



\section{Agradecimientos}

Quiero agradecer en primer lugar a mi familia: mis padres y mi hermana, la cercanía, el cariño y la comprensión que siempre han tenido conmigo. Mucho o poco sea el camino andado, sin ellos no hubiera sido posible recorrerlo.

A mi director Antonio porque en todo momento conté con su apoyo y ánimo. Él me dio la oportunidad de trabajar en el campo y los objetivos de esta tesis que resultó ser durante todos estos años, apasionantes y enriquecedores.

A Jaime y a Basil por ser como son y estar siempre ahí cuando hace falta. Además de compañeros, amigos.

Quiero también agradecer a Adrián y a Jose Luis, con los que trabajé muy estrechamente durante los años de diseño y de campo. Fue un placer compartir esos momentos con vosotros. Formamos un buen equipo. Gracias a su ayuda y contribución este trabajo de tesis pudo también llevarse a cabo.

Agradecer también a mis alumnos (proyectantes), que han sido muchos, a lo largo de todos estos años. Tanto de Trabajo Final de Carrera en la División de Ingeniería de Sistemas y Automática (DISAM) de la ETSII en la UPM, como de Trabajo Final de Carrera, Trabajo Fin de Grado y Trabajo Fin de Máster en el departamento de Electrónica, Automática e Informática Industrial (ElAI) de la ETSIDI en la UPM. Todos han contribuido con sus aportaciones a que esta línea de trabajo-investigación haya dado sus frutos. No voy a nombrarles a todos porque no quiero olvidarme de ninguno. Ha sido un placer trabajar con todos vosotros. Gracias.

Quiero también agradecer a mis profesores de DISAM, a todos los compañeros del departamento y a todo el personal: los maestros de laboratorio Enrique y Ángel, a las chicas de la secretaría: Tere y Rosa, y a Carlos. Con todos ellos compartí una época muy bonita de mi vida en la ETSII, desde que empecé mi trabajo final de carrera, hasta que comencé como profesor en la Escuela de Embajadores.

Y por último, pero no menos importante, mi agradecimiento también a los que han sido y son mis compañeros en esta etapa de profesor en la ETSIDI. A todos los profesores y a Maite, Javi y Pablo, con los que siempre me he sentido muy a gusto trabajando con ellos. Quiero darles las gracias por lo fácil que me han hecho las cosas y por la ayuda y el apoyo que me han prestado. 



\section{Resumen}

El incremento de la esperanza de vida en los países desarrollados (más de 80 años en 2013), está suponiendo un crecimiento considerable en la incidencia y prevalencia de enfermedades discapacitantes, que si bien pueden aparecer a edades tempranas, son más frecuentes en la tercera edad, o en sus inmediaciones. Enfermedades neuro-degenerativas que suponen un gran hándicap funcional, pues algunas de ellas están asociadas a movimientos involuntarios de determinadas partes del cuerpo, sobre todo de las extremidades. Tareas cotidianas como la ingesta de alimento, vestirse, escribir, interactuar con el ordenador, etc... pueden llegar a ser grandes retos para las personas que las padecen.

El diagnóstico precoz y certero resulta fundamental para la prescripción de la terapia o tratamiento óptimo. Teniendo en cuenta incluso que en muchos casos, por desgracia la mayoría, sólo se puede actuar para mitigar los síntomas, y no para sanarlos, al menos de momento. Aun así, acertar de manera temprana en el diagnóstico supone proporcionar al enfermo una mayor calidad de vida durante mucho más tiempo, por lo cual el esfuerzo merece, y mucho, la pena.

Los enfermos de Párkinson y de temblor esencial suponen un porcentaje importante de la casuística clínica en los trastornos del movimiento que impiden llevar una vida normal, que producen una discapacidad física y una no menos importante exclusión social. Las vías de tratamiento son dispares de ahí que sea crítico acertar en el diagnóstico lo antes posible. Hasta la actualidad, los profesionales y expertos en medicina, utilizan unas escalas cualitativas para diferenciar la patología y su grado de afectación. Dichas escalas también se utilizan para efectuar un seguimiento clínico y registrar la historia del paciente.

En esta tesis se propone una serie de métodos de análisis y de identificación/clasificación de los tipos de temblor asociados a la enfermedad de Párkinson y el temblor esencial. Empleando técnicas de inteligencia artificial basadas en clasificadores inteligentes: redes neuronales (MLP y LVQ) y máquinas de soporte vectorial (SVM), a partir del desarrollo e implantación de un sistema para la medida y análisis objetiva del temblor: DIMETER. Dicho sistema además de ser una herramienta eficaz para la ayuda al diagnóstico, presenta también las capacidades necesarias para proporcionar un seguimiento riguroso y fiable de la evolución de cada paciente. 



\section{Abstract}

The increase in life expectancy in developed countries in more than 80 years (data belongs to 2013), is assuming considerable growth in the incidence and prevalence of disabling diseases. Although they may appear at an early age, they are more common in the elderly ages or in its vicinity. Nuero-degenerative diseases that are a major functional handicap, as some of them are associated with involuntary movements of certain body parts, especially of the limbs. Everyday tasks such as food intake, dressing, writing, interact with the computer, etc ... can become large debris for people who suffer.

Early and accurate diagnosis is crucial for prescribing optimal therapy or treatment. Even taking into account that in many cases, unfortunately the majority, can only act to mitigate the symptoms, not to cure them, at least for now. Nevertheless, early diagnosis may provide the patient a better quality of life for much longer time, so the effort is worth, and much, grief.

Sufferers of Parkinson's and essential tremor represent a significant percentage of clinical casuistry in movement disorders that prevent a normal life, leading to physical disability and not least social exclusion. There are various treatment methods, which makes it necessary the immediate diagnosis. Up to date, professionals and medical experts, use a qualitative scale to differentiate the disease and degree of involvement. Therefore, those scales are used in clinical follow-up.

In this thesis, several methods of analysis and identification / classification of types of tremor associated with Parkinson's disease and essential tremor are proposed. Using artificial intelligence techniques based on intelligent classification: neural networks (MLP and LVQ) and support vector machines (SVM), starting from the development and implementation of a system for measuring and objective analysis of the tremor: DIMETER. This system besides being an effective tool to aid diagnosis, it also has the necessary capabilities to provide a rigorous and reliable monitoring of the evolution of each patient. 

LISTA DE FIGURAS

LISTA DE TABLAS $\quad \mathrm{X}$

1 INTRODUCCIÓN 1

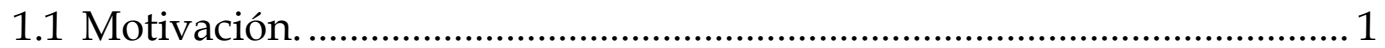

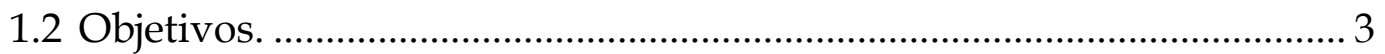

1.2.1 Sistema para la medida del temblor. ……………............................................... 3

1.2.2 Desarrollo de los patrones y los protocolos de las pruebas clínicas....................... 4

1.2.3 Filtrado del temblor. Dispositivo de acceso al ordenador para personas discapacitadas por temblor. ....................................................................................... 4

1.2.4 Estudio de técnicas de análisis y clasificación del temblor. Obtener un clasificador eficaz para ayuda al diagnóstico.......................................................... 4

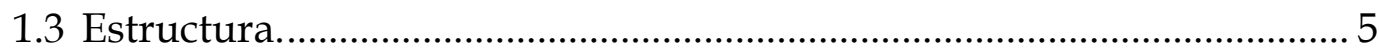

2 EL TEMBLOR, CARACTERÍSTICAS. ESTADO DEL ARTE

2.1 Definición del temblor. …….................................................................... 7

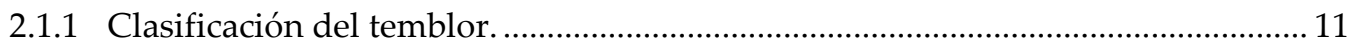

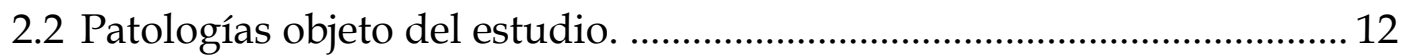

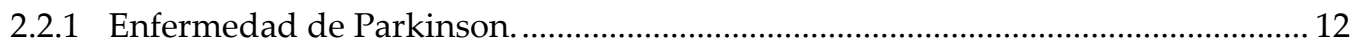

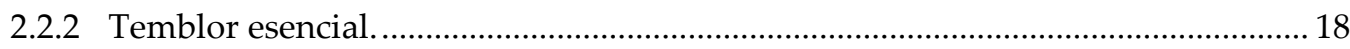

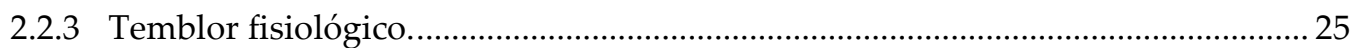

2.3 Ayudas técnicas en el área de la salud. ................................................... 26

2.4 Ayudas técnicas en la medida del temblor. ............................................ 30

2.4.1 Actígrafos y teleactígrafos (Teleactigraphs, TAG) .................................................... 30

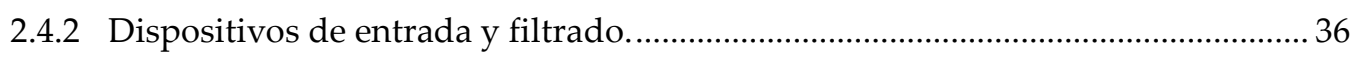

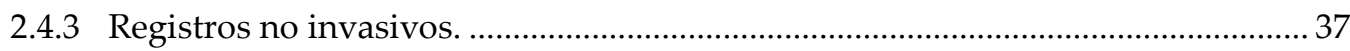

2.4.4 Registros invasivos. Registros de microelectrodo (MicroElectrode

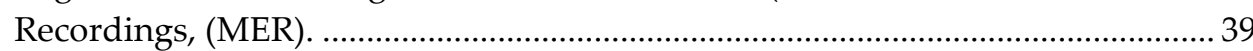

2.4.5 Sistemas basados en imagen médica. ..................................................................... 39

2.4.6 Origen múltiple de información. Fusión de señales.................................................. 40 


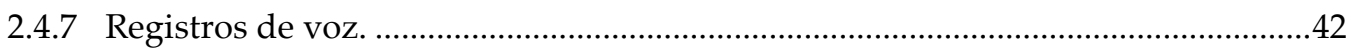

2.4.8 Visión por computador (Computer Vision, CV) ................................................42

3 Plataforma de AyUda Al diagnóstico (DIMETER).

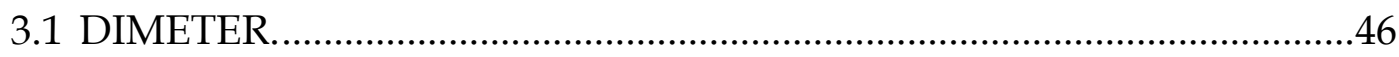

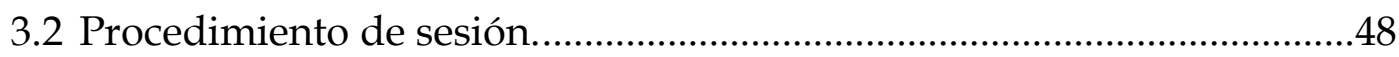

3.3 Definición de los patrones..........................................................................53

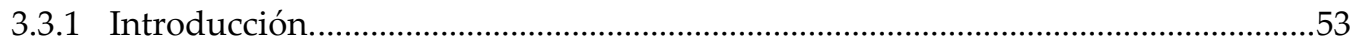

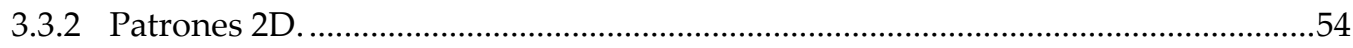

3.3.3 Patrón 3D (Espacio real) …............................................................................61

3.3.4 Patrones con Reflexión de Fuerza........................................................................64

3.4 Aplicación SW del DIMETER...................................................................68

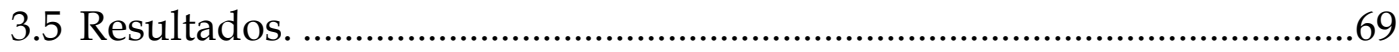

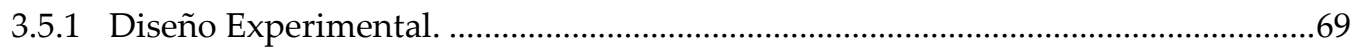

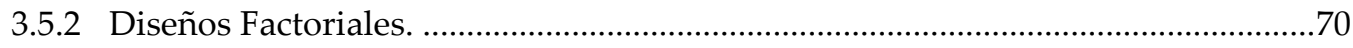

4 HERRAMIENTAS MATEMÁTICAS Y CLASIFICADORES $\quad 85$

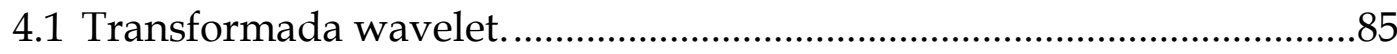

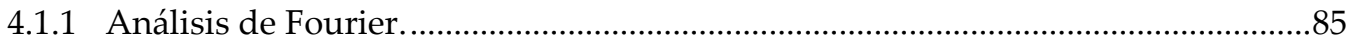

4.1.2 Análisis de Fourier por intervalos. ......................................................................86

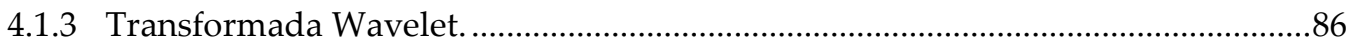

4.1.4 Análisis mediante Transformada Wavelet. .......................................................8

4.1.5 Cálculo de la Transformada Wavelet.................................................................89

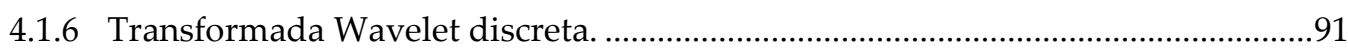

4.1.7 Aplicaciones de las Wavelets....................................................................................94

4.1.8 Aplicación a la detección de discontinuidades. ...................................................95

4.2 Densidad espectral de potencia...............................................................97

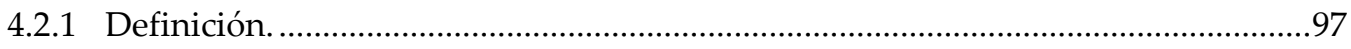

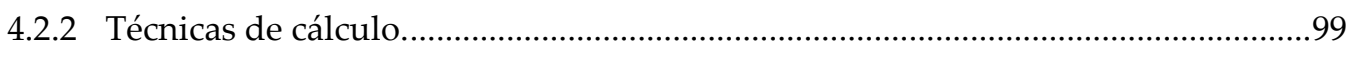

4.3 Análisis de Componentes Principales (ACP) ............................................101

4.4 Coeficiente de Curtosis.................................................................................105

4.5 Distancia de Mahalanobis.............................................................................105

4.6 Clasificadores neuronales. .....................................................................106

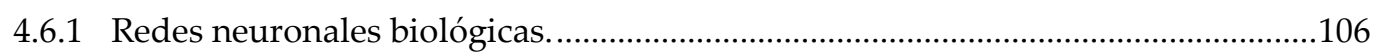

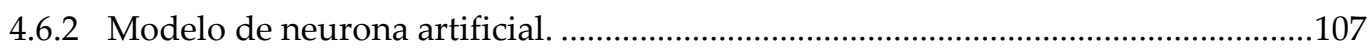

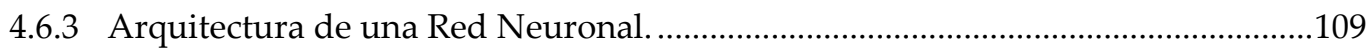

4.6.4 Principales características de las redes.............................................................110 
4.6.5 Modo de operación de una red neuronal.............................................................. 111

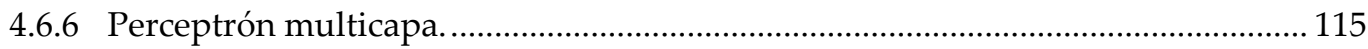

4.6.7 Redes LVQ (Learning Vector Quantization).............................................................. 123

4.7 Máquinas de Soporte Vectorial (SVM) .................................................. 127

4.7.1 Clasificación de clases con SVM ......................................................................... 128

4.7.2 Superficies de decisión (hiperplanos) ......................................................................... 130

4.7.3 Cálculo de distancia de un hiperplano al origen ..................................................... 132

4.7.4 Concepto de margen máximo de un hiperplano ...................................................... 132

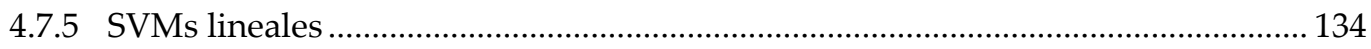

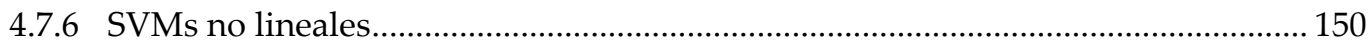

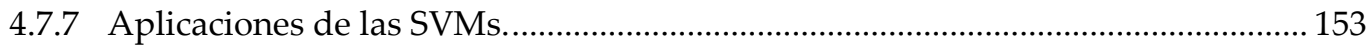

5 CLASIFICACIÓN-FILTRADO DEL TEMBLOR MEDIANTE PERCEPTRONES MULTICAPA (MLP).

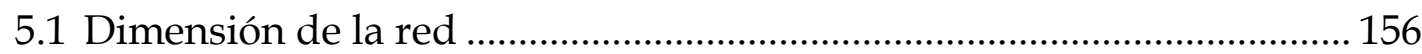

5.2 Filtrado del temblor mediante MLP's................................................ 157

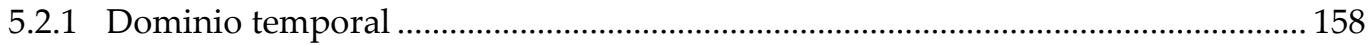

5.2.2 Procedimiento ......................................................................................................... 167

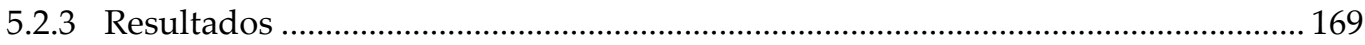

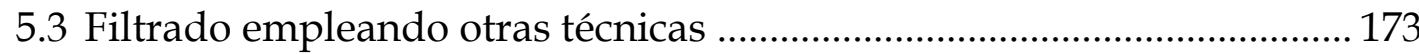

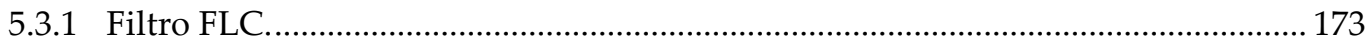

5.3.2 Filtro WFLC.......................................................................................................... 174

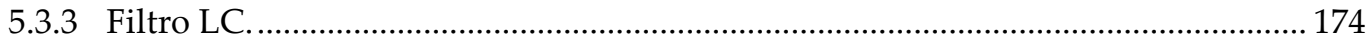

5.4 Procedimiento de uso del sistema ACORTE ......................................... 177

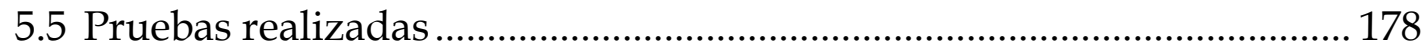

5.5.2 Pruebas sobre uso de un navegador de Internet..................................................... 179

5.6 Caracterización o clasificación del temblor mediante MLPs................... 184

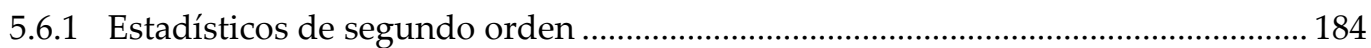

5.6.2 Estadísticos de orden superior (HOS) ................................................................. 185

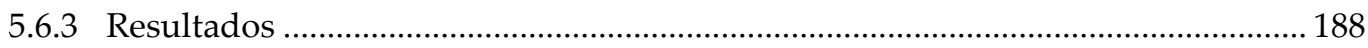

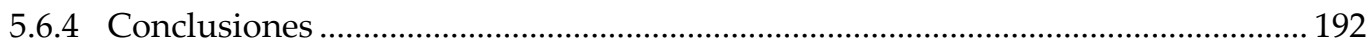

6 CLASIFICACIÓN DEL TEMBLOR CON REDES NEURONALES LVQ.

6.1 Procedimiento para el cálculo de discontinuidades................................ 193

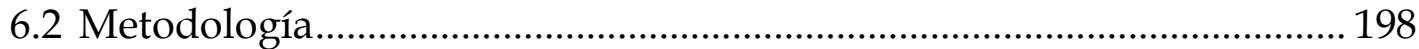

6.3 Importancia de la elección del número de pesos ..................................... 199

6.4 Resultados en el espacio de características inicial. .................................. 200 
6.4.1 Diferenciación entre temblor patológico y temblor fisiológico................................200

6.4.2 Diferenciación entre temblor de Párkinson y temblor esencial ............................201

6.4.3 Incluyendo el análisis de componentes principales (ACP) ..................................202

$\mathbf{7}$ CLASIFICACIÓN DEL TEMBLOR MEDIANTE MÁQUINAS DE SOPORTE VECTORIAL (SVM) $\quad 215$

7.1 Selección de la función kernel. ...............................................................215

7.2 Selección de parámetros. Validación cruzada.............................................216

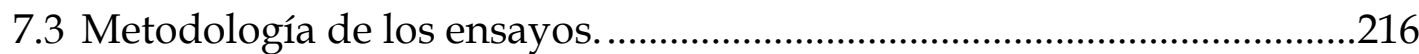

7.4 Análisis con la amplitud y la frecuencia del temblor.................................217

7.5 Análisis con PSD y HOS ........................................................................219

7.6 Clasificación mediante análisis de componentes principales (ACP) .....227

8 ANÁlisis DE RESUltados.

8.1 Resultados del filtrado del temblor. Dispositivo ACORTE. .....................233

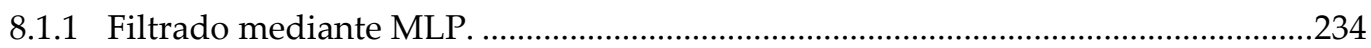

8.1.2 Filtros FLC, WFLC y LC.......................................................................................... 234

8.2 Resultados de los clasificadores. ............................................................234

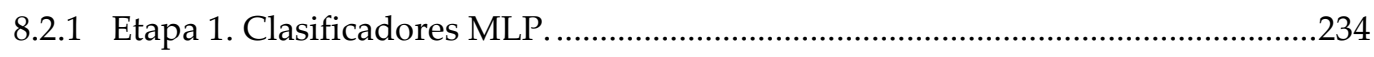

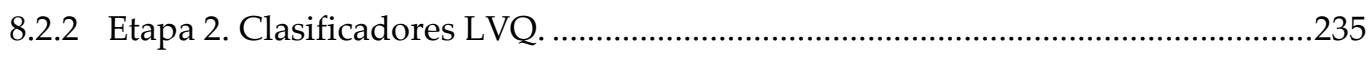

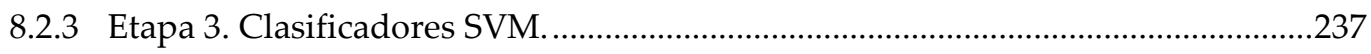

$\underline{9}$ CONCLUSIONES. 241

9.1 Principales logros de la tesis.....................................................................241

9.2 Contribuciones más destacables. ……………………………………......243

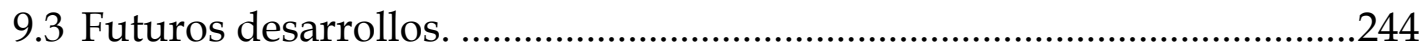

10 BIBLIOGRAFIA 247

ANEXO I - EsCaLA UNIFICADA PARA LA EVALUACIÓN DEL PÁRKINSON (UNIFIED PARKINSON DISEASE RATING SCALE UPDRS) 257

ANEXO II - EsCALA DE TEMBLOR DE FAHN, TOLOSA Y MARÍN (FTM). \begin{tabular}{lr}
\hline CRITERIOS DE VALORACIÓN Y DEFINICIONES & 269 \\
\hline
\end{tabular}

ANEXOIII PROTOCOLO DE PRUEBAS DIMETER 


\section{Lista de figuras}

Figura 2.1: Espiral realizada con: Párkinson, temblor esencial y temblor fisiológico. ................8

Figura 2.2: Principales fuentes del temblor.......................................................................... 9

Figura 2.3: Lazos centrales y periféricos en el sistema nervioso. ............................................ 9

Figura 2.4: Vías que involucran el origen del temblor.......................................................... 10

Figura 2.5: Situación de las dianas del tálamo y subtálamo. .................................................. 18

Figura 2.6: Medida del temblor mediante acelerómetro y EMG................................................... 31

Figura 2.7: Registros de acelerómetro. Paciente con temblor (izq.) y sano (der.) ......................... 32

Figura 2.8: Disposición de los acelerómetros triaxiales en cada extremidad. ............................. 32

Figura 2.9: Medición del temblor por medio de giróscopos...................................................... 34

Figura 2.10: Sistema ambulatorio para monitorización del temblor. .......................................... 36

Figura 2.11: Medición del temblor postural y de reposo, con carga y sin carga por EMG y acelerómetros................................................................................................... 38

Figura 2.12: Registro de EMG de un paciente con temblor esencial bilateral. ............................38

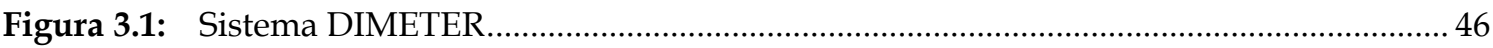

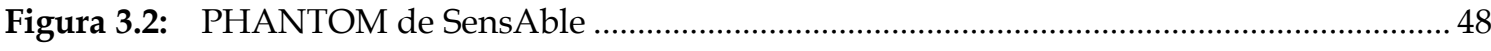

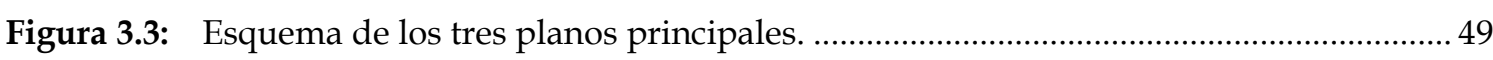

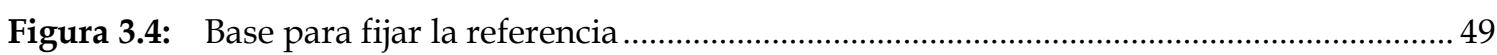

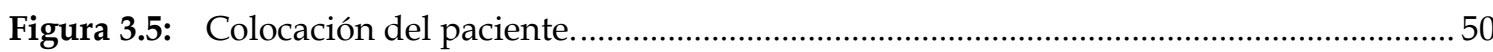

Figura 3.6: Puesto real de pruebas (Servicio de Neurofisiología - Hospital Ramón y Cajal)...... 50

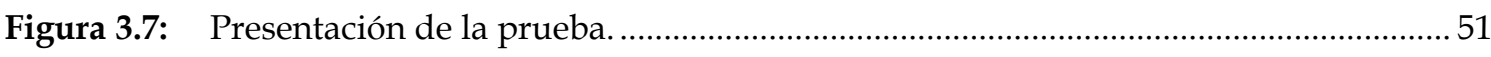

Figura 3.8: Vista en planta de la plataforma de pruebas 3D ...................................................... 51

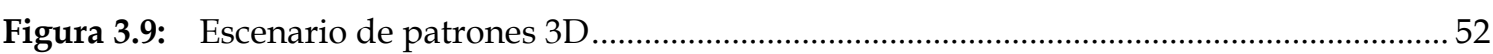

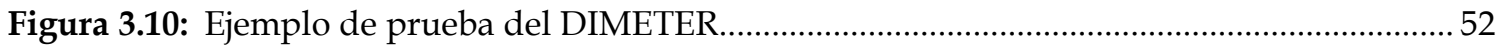

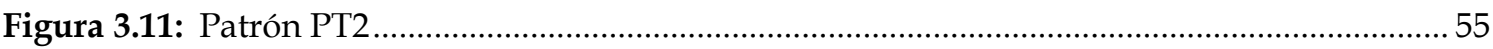

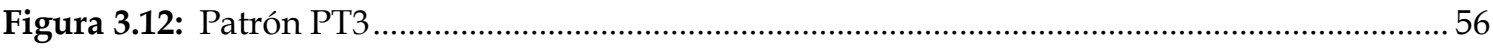

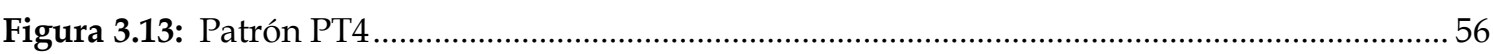

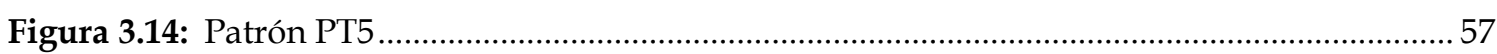

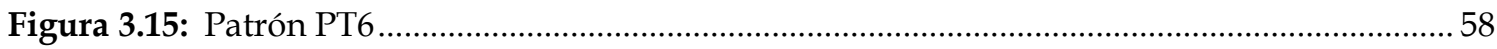

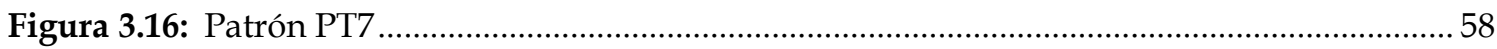




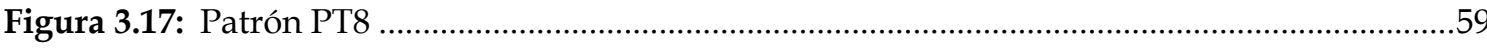

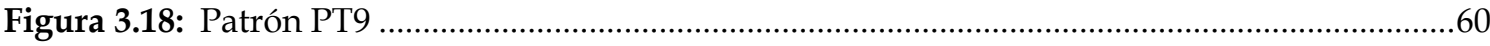

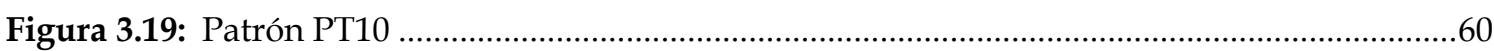

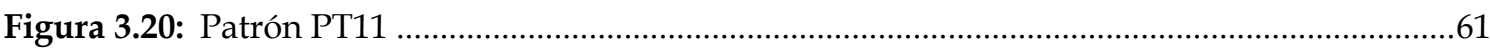

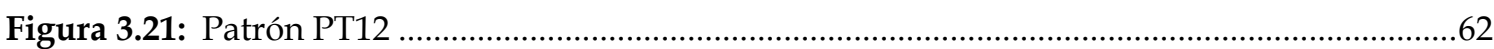

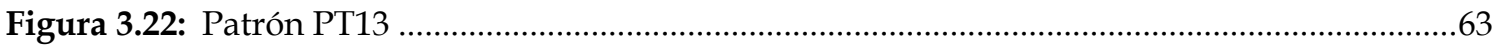

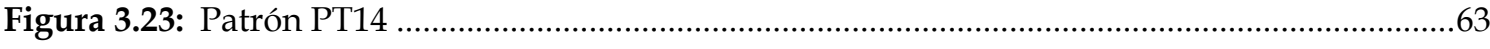

Figura 3.24: Modelo de resorte más rozamiento viscoso. ....................................................................65

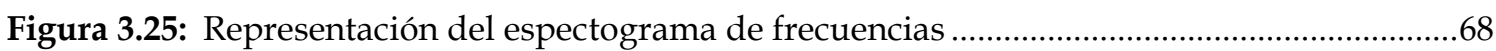

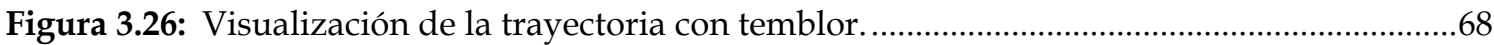

Figura 3.27: Resumen de armónicos principales con su amplitud asociada ......................................69

Figura 3.28: Residuos para la hipótesis del análisis todos los individuos. Diseño 1 .......................71

Figura 3.29: Residuos para primer análisis individuos sanos. Diseño 2.........................................72

Figura 3.30: Residuos para el segundo análisis individuos sanos. Diseño 3 …………………….....73

Figura 3.31: Residuos para el análisis individuos enfermos. Diseño 4 ............................................74

Figura 3.32: Residuos para el primer análisis de enfermos de Parkinson. Diseño 5 ........................77

Figura 3.33: Residuos para el segundo análisis enfermos de Parkinson. Diseño 6 ...........................78

Figura 3.34: Graficas de residuos para el primer analisis con pacientes con temblor esencial. Diseño 7.

Figura 3.35: Gráficas de residuos para el segundo análisis con pacientes con temblor esencial.

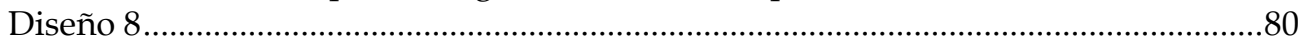

Figura 4.1: Transformada de Fourier Short Time ……................................................................... 86

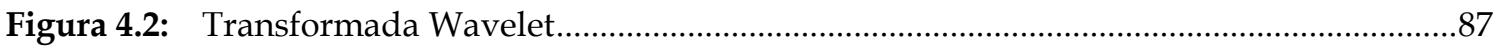

Figura 4.3: Transformada wavelet (der.) de una señal no estacionaria ...........................................8

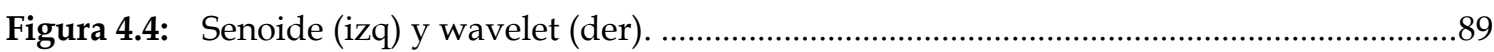

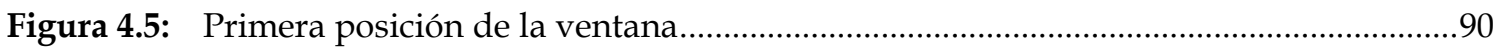

Figura 4.6: Traslación de la ventana para el nuevo cálculo ..............................................................90

Figura 4.7: Variando el parámetro s vuelve a repetirse el procedimiento.......................................91

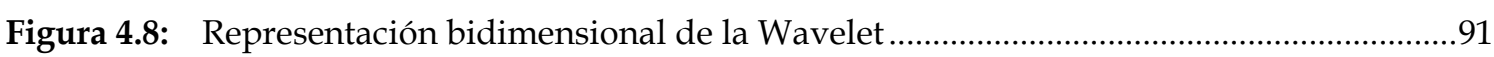

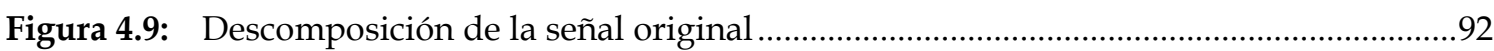

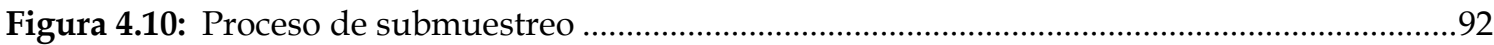

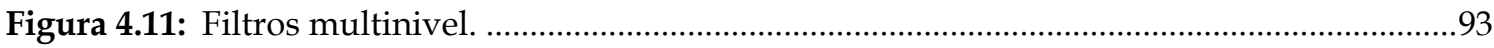

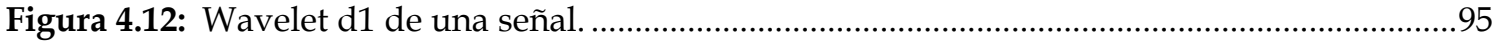

Figura 4.13: Transformada Wavelet de un paciente sano Patrón 3 ................................................96

Figura 4.14: Transformada Wavelet de un paciente sano Patrón 8 ……………………………......96

Figura 4.15: Resumen del análisis de discontinuidades del DIMETER ………................................97

Figura 4.16: Neurona y conexiones sinápticas ………………………..........................................107

Figura 4.17: Modelo de una neurona............................................................................................108 


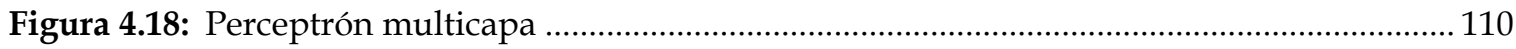

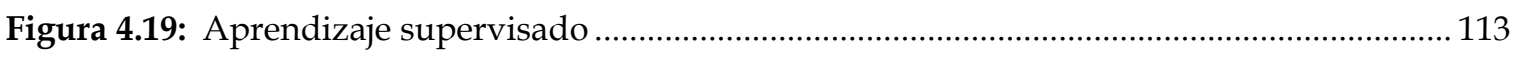

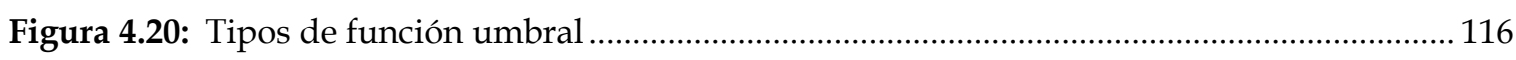

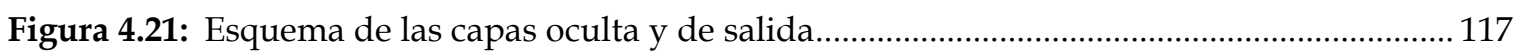

Figura 4.22: Relaciones vía pesos entre la capa oculta y la salida ...................................................... 119

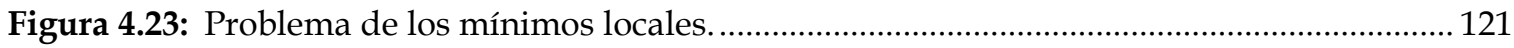

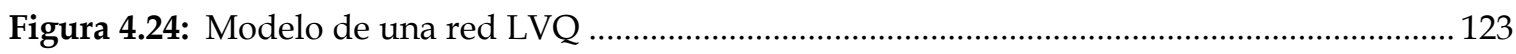

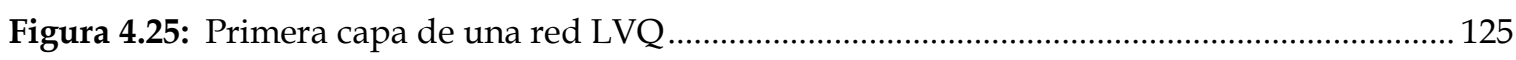

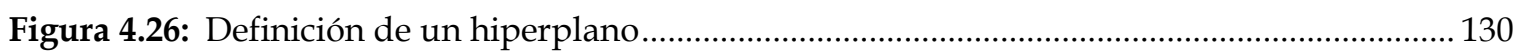

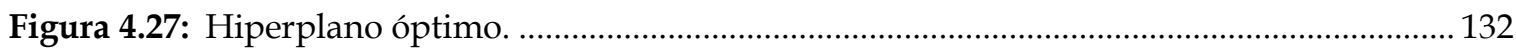

Figura 4.28: Hiperplano de separación de margen máximo (HSO) …………………………….... 133

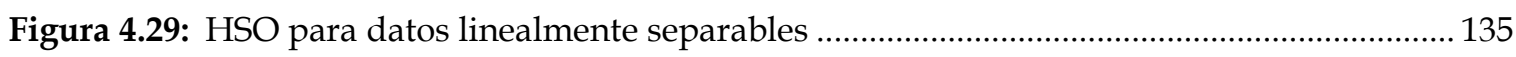

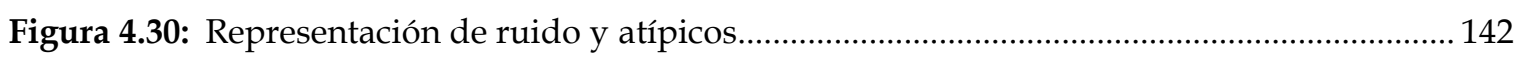

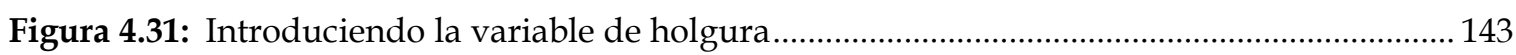

Figura 4.32: Influencia de C. C grande izq., C pequeño der. ............................................................ 145

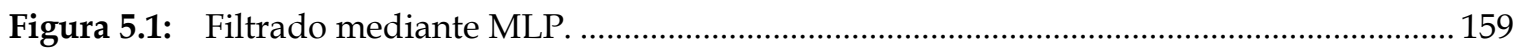

Figura 5.2: Resultados de modelado del temblor para una única red MLP................................. 160

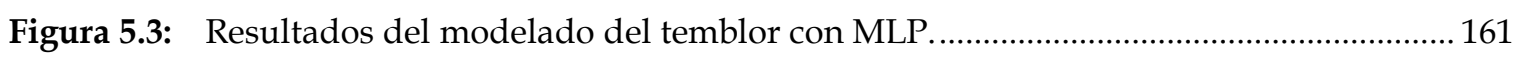

Figura 5.4: Señales filtradas. Sup.: utilizando las MLPs. Inf.: utilizando un filtro paso bajo...... 161

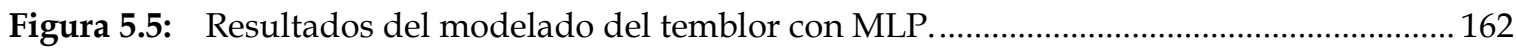

Figura 5.6: Señales filtradas. Sup.: utilizando las MLPs. Inf.: utilizando un filtro paso bajo. ..... 162

Figura 5.7: Resultados del modelado del temblor con MLP........................................................... 163

Figura 5.8: Señales filtradas. Sup.: utilizando las MLPs. Inf.: utilizando un filtro paso bajo...... 163

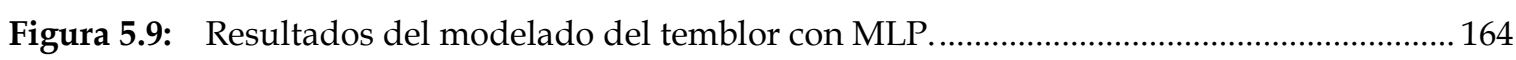

Figura 5.10: Señales filtradas. Sup.: utilizando las MLPs. Inf.: utilizando un filtro paso bajo. ...... 165

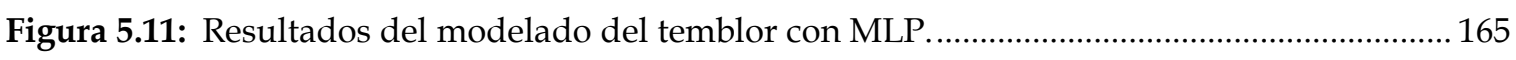

Figura 5.12: Señales filtradas. Sup.: utilizando las MLPs. Inf.: utilizando un filtro paso bajo. ..... 166

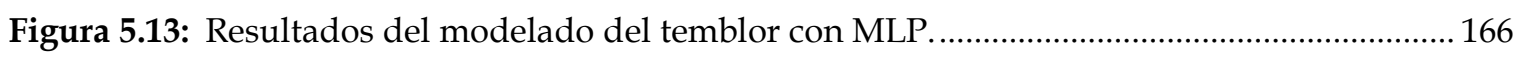

Figura 5.14: Señales filtradas. Sup.: utilizando las MLPs. Inf.: utilizando un filtro paso bajo...... 167

Figura 5.15: Diferenciación entre una señal "pico" (izq.) y una señal "meseta" (der.) .................... 168

Figura 5.16: Error medio de clasificación total (señales "pico" y “meseta") ...................................... 170

Figura 5.17: Error entre clases (señales "pico" y "meseta").............................................................. 170

Figura 5.18: Error medio de clasificación total (señales "pico" y "meseta") .................................... 171

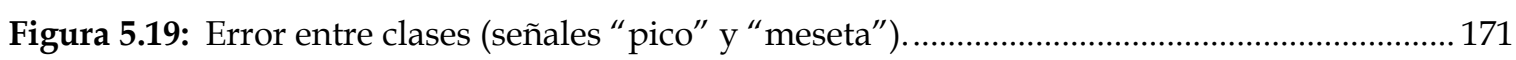

Figura 5.20: Error medio de clasificación total (señales "pico" y "meseta"). .................................... 172

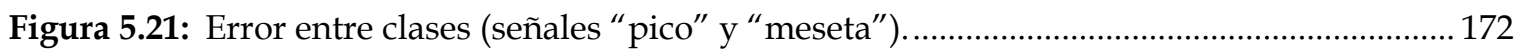

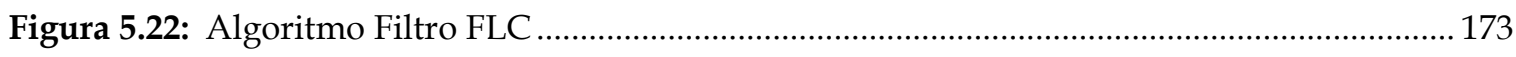


Figura 5.23: Algoritmo filtro WFLC

Figura 5.24: Captura de la salida del filtro LC sobre una muestra tomada a un paciente de Parkinson. La línea roja es la salida y la azul la original ..................................................175

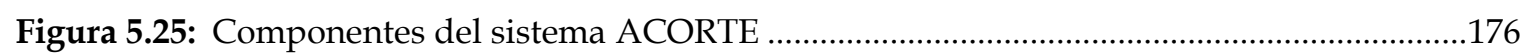

Figura 5.26: Dispositivo de entrada y sistema de filtrado. …………………………………..........177

Figura 5.27: Análisis frecuencial de un enfermo de Párkinson, de temblor esencial y fisiológico o

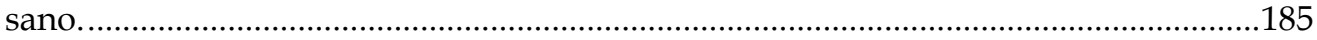

Figura 5.28: Error medio con las primeras 9 características (PSD) ................................................188

Figura 5.29: Error en cada clase con las primeras 9 características (PSD) …………........................189

Figura 5.30: Error medio con las características 10 a 26 (HOS) ....................................................189

Figura 5.31: Error en cada clase con las características 10 a 26 (HOS) ............................................190

Figura 5.32: Error medio con todas las características (PSD+HOS) ………………..........................191

Figura 5.33: Error en cada clase con todas las características (PSD+HOS) .........................................191

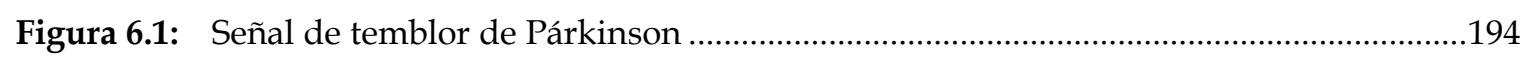

Figura 6.2: Señal de temblor de Párkinson con muestras especulares............................................194

Figura 6.3: Distribución de la potencia y energía en función de la frecuencia ................................195

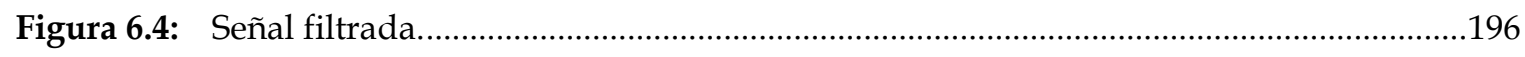

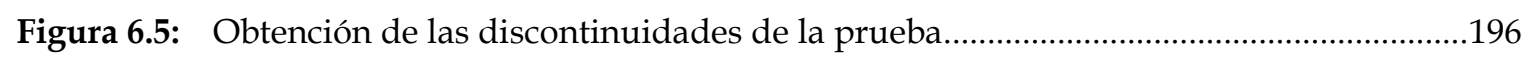

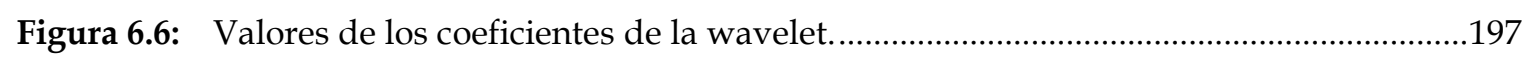

Figura 6.7: Componentes de alta frecuencia para un individuo sano.............................................198

Figura 6.8: Variación del error obtenido en función del número de pesos ......................................199

Figura 6.9: Diagrama de barras del tanto por ciento de varianza explicada...................................203

Figura 6.10: Gráfico de Pareto de las 10 primeras componentes .......................................................204

Figura 6.11: Espacio muestral representado respecto de dos componentes originales...................204

Figura 6.12: Espacio muestral representado mediante dos componentes principales .....................205

Figura 7.1: Clasificación Temblor Fisiológico vs Temblor Patológico............................................217

Figura 7.2: Clasificación Temblor Esencial vs Temblor de Párkinson. ………….........................218

Figura 7.3: Clasificación Temblor Fisiológico vs Temblor Patológico...........................................222

Figura 7.4: Clasificación Temblor Esencial vs Temblor de Párkinson (Todos los patrones).....223

Figura 7.5: Clasificación Temblor Esencial vs Temblor de Párkinson (Patrones estáticos).......224

Figura 7.6: Clasificación Temblor Esencial vs Temblor de Párkinson (Patrones cinéticos). .....224

Figura 7.7: Clasificación Temblor Esencial vs Temblor de Párkinson (Patrones dinámicos)...225

Figura 7.8: Clasificación Temblor Fisiológico vs Temblor Patológico...........................................228

Figura 7.9: Clasificación A: Temblor Esencial vs Temblor de Párkinson (Todos los patrones).

Figura 7.10: Clasificación Temblor Esencial vs Temblor de Párkinson (Patrones estáticos).......230

Figura 7.11: Clasificación Temblor Esencial vs Temblor de Párkinson (Patrones cinéticos). .....231

Figura 7.12: Clasificación Temblor Esencial vs Temblor de Párkinson (Patrones dinámicos). ..231 


\section{Lista de tablas}

Tabla 2.1: Categorías del temblor

Tabla 2.2: $\quad$ Prevalencia de la enfermedad de Parkinson en España, según la etapa de la enfermedad.

Tabla 2.3: Incidencia de la enfermedad de Parkinson en España, según la edad..........................13

Tabla 2.4: Etapas de la escala de Hoehn y Yahr. ..............................................................................

Tabla 2.5: Escala de calificación del temblor para la escala WHIGET.............................................22

Tabla 2.6: Rango de valores para cada elemento de cada prueba de la escala TETRAS..............24

Tabla 2.7: Resultados de los datos registrados obtenidos para 10 sujetos de control y 10 sujetos con Párkinson

Tabla 2.8: Resultados sobre las frecuencias encontradas por el sistema de medición mediante

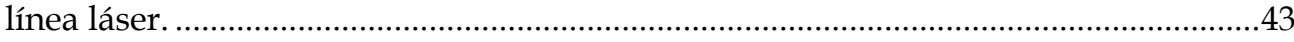

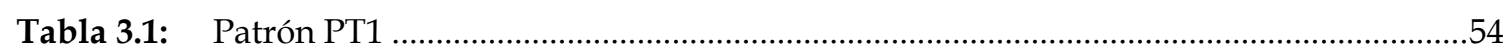

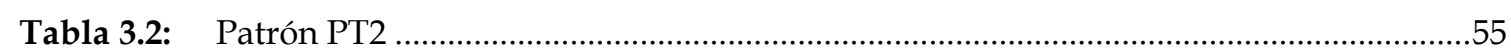

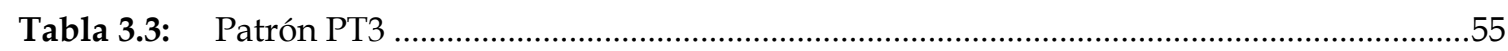

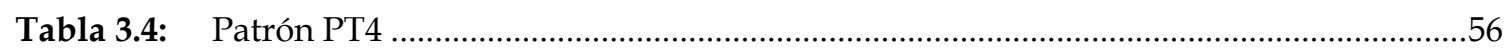

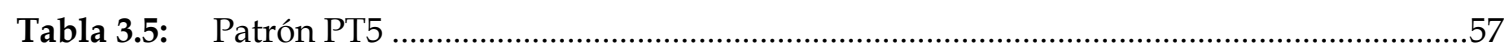

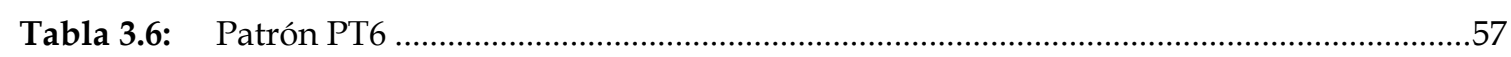

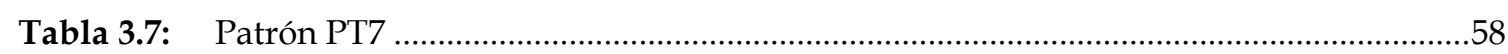

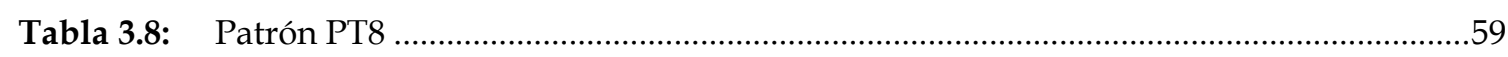

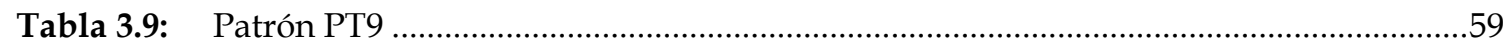

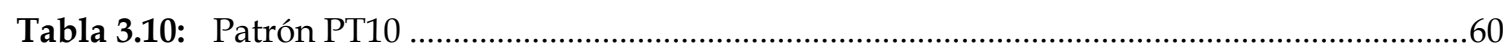

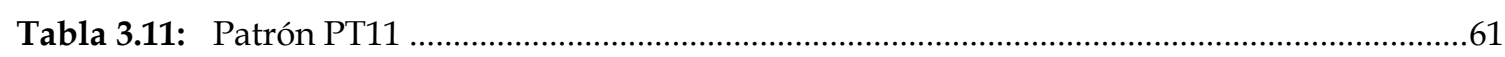

Tabla 3.12: Patrón PT12 ……………………………...................................................................62

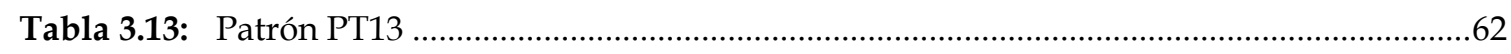

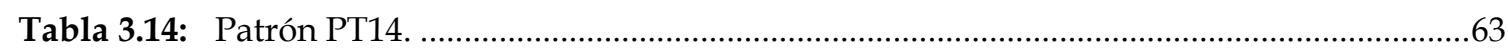

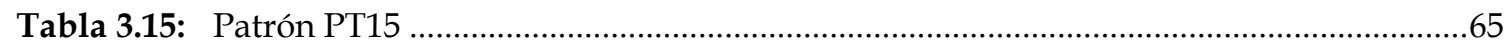

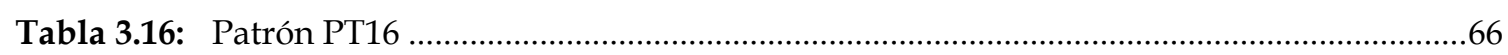

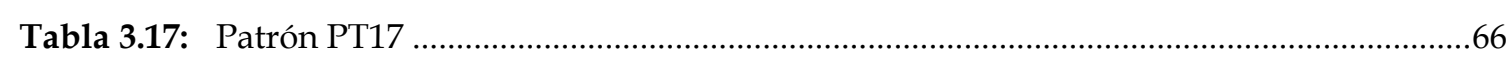

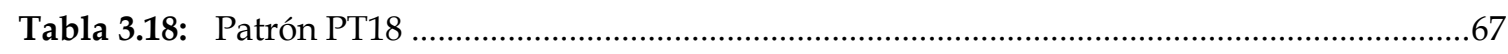


Tabla 3.20: Análisis de la influencia del tipo de población . 82

Tabla 3.21: Análisis influencia de los patrones .83

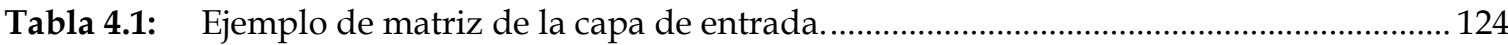

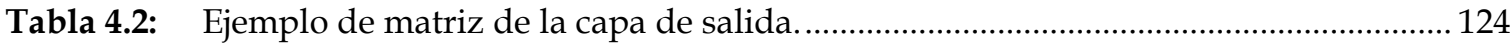

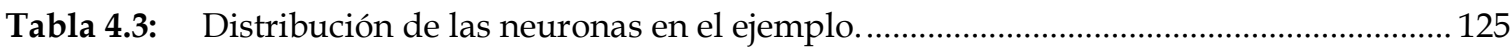

Tabla 4.4: Distinción entre clases de la etapa de salida. ............................................................... 125

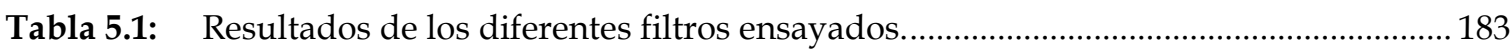

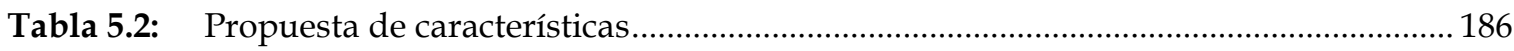

Tabla 6.1: Varianza explicada de cada característica tras el Análisis de Componentes Principales

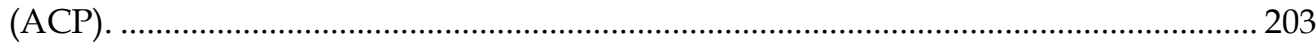

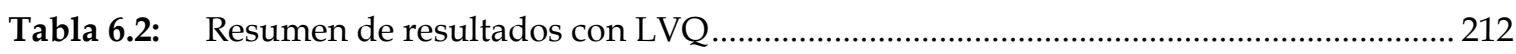

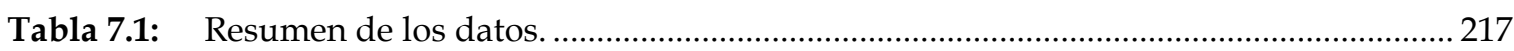

Tabla 7.2: Clasificación Temblor Fisiológico vs Temblor Patológico............................................ 218

Tabla 7.3: Clasificación Temblor Esencial vs Temblor de Párkinson............................................. 219

Tabla 7.4: Clasificación Temblor Esencial vs Temblor de Párkinson......................................... 219

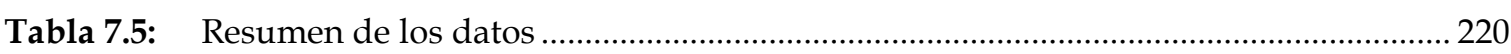

Tabla 7.6: Valores del coeficiente de Curtosis para las dos primeras componentes del ACP ... 221

Tabla 7.7: Distancia de Mahalanobis de los vectores de Párkinson respecto de su media ......... 221

Tabla 7.8: Clasificación Temblor Fisiológico vs Temblor Patológico.............................................. 222

Tabla 7.9: Condiciones de los modelos de clasificación. ………………………………………........ 223

Tabla 7.10: Clasificación Temblor Esencial vs Temblor de Párkinson (Todos los patrones).... 223

Tabla 7.11: Clasificación Temblor Esencial vs Temblor de Párkinson (Patrones estáticos)....... 224

Tabla 7.12: Clasificación Temblor Esencial vs Temblor de Párkinson (Patrones cinéticos)...... 225

Tabla 7.13: Clasificación Temblor Esencial vs Temblor de Párkinson (Patrones dinámicos)... 225

Tabla 7.14: Clasificación Temblor Esencial vs Temblor de Párkinson (Todos los patrones).... 226

Tabla 7.15: Clasificación Temblor Esencial vs Temblor de Párkinson (Patrones estáticos)...... 226

Tabla 7.16: Clasificación Temblor Esencial vs Temblor de Párkinson (Patrones cinéticos)...... 226

Tabla 7.17: Clasificación Temblor Esencial vs Temblor de Párkinson (Patrones dinámicos)... 227

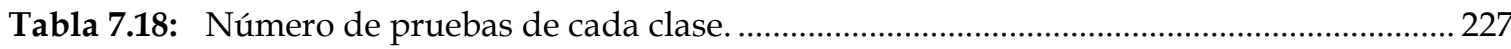

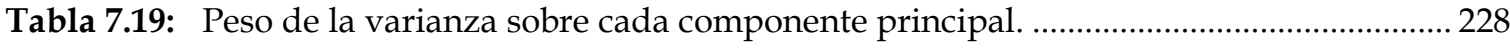

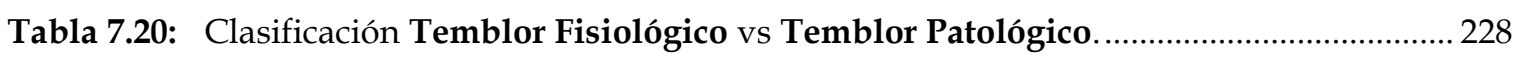

Tabla 7.21: Condiciones de los modelos de clasificación. …………………………….......................... 229

Tabla 7.22: Clasificación A: Temblor Esencial vs Temblor de Párkinson (Todos los patrones).

Tabla 7.23: Clasificación B: Temblor Esencial vs Temblor de Párkinson (Todos los patrones).

Tabla 7.24: Clasificación Temblor Esencial vs Temblor de Párkinson (Patrones estáticos)....... 230 
Tabla 7.25: Clasificación Temblor Esencial vs Temblor de Párkinson (Patrones cinéticos). .....231

Tabla 7.26: Clasificación Temblor Esencial vs Temblor de Párkinson (Patrones dinámicos). ..232 



\subsection{Motivación.}

El temblor es un movimiento involuntario, rítmico, alternante y oscilante que se produce cuando los músculos se contraen y se relajan de forma repetida. Todo el mundo presenta cierto grado de temblor, denominado temblor fisiológico, aunque en algunos casos es tan leve que ni se percibe. Los temblores se clasifican según la lentitud o rapidez de los mismos, el ritmo, dónde y con qué frecuencia se producen y su gravedad. Los temblores de acción se producen cuando los músculos se hallan en actividad y el temblor de reposo se produce cuando los músculos se encuentran en reposo. El temblor en reposo puede producir sacudidas en las extremidades aunque la persona se encuentre relajada, lo cual puede ser un síntoma de la enfermedad de Parkinson. Los temblores de intención se producen cuando la persona realiza ciertas tareas cotidianas que requieren de atención y de cierta precisión para efectuarlas con éxito, por ejemplo beber de un vaso, comer la sopa con una cuchara, etc...

Son varias las enfermedades que se han convertido en un problema creciente en las sociedades modernas actuales con una alta esperanza de vida. Por una parte, son patologías neurodegenerativas, como la enfermedad de Parkinson, la enfermedad de Alzheimer o la esclerosis, que pueden manifestarse con mucha frecuencia (incidencia). Por otro lado, los enfermos las padecen durante una mayor cantidad de tiempo debido a la mayor longevidad y no son patologías que en sí mismas causen el fallecimiento a corto plazo. El incremento de la esperanza de vida también permite manifestarse a otros trastornos no degenerativos, pero incapacitantes en similar medida, como es el caso del temblor esencial.

El temblor esencial, cuya causa se desconoce, aparece por lo general en adultos jóvenes y progresivamente se vuelve más notorio. Los temblores seniles son temblores esenciales que se inician en las personas de edad avanzada. Los temblores esenciales que se manifiestan en varios miembros de la familia a veces, se denominan temblores familiares. 
No se puede obviar el dato de que la enfermedad de Párkinson en Europa puede llegar a afectar hasta 340 personas de cada 100000 al año, según diferentes estudios [1], [2] y [3], y hasta el momento ningún producto farmacológico cura la dolencia, aunque algunos alivian sus síntomas o mejoran la calidad de vida de los afectados.

Las personas que padecen este tipo de enfermedades, en las que los síntomas van acompañados con movimientos involuntarios de las extremidades, se ven afectados de una discapacidad que les impide llevar a cabo una vida normal. Entre estas patologías, unas de las más usuales o frecuentes son el temblor de Parkinson y otra el temblor esencial. Debido a la técnica actual de diagnóstico, se han visto en algunas ocasiones en la tesitura de no ser diagnosticadas con precisión, no beneficiándose así de un tratamiento efectivo desde los primeros momentos en los que se manifiesta la enfermedad.

El avance de las distintas áreas de la técnica, permiten hoy en día contribuir por un lado a medir y objetivizar el procedimiento de las pruebas, y por otro, a suministrar una estimación de las posibles conclusiones para ayudar al diagnóstico. Esta tesis propone el empleo de un sistema de adquisición y medida mediante el uso de un dispositivo háptico. Los dispositivos hápticos han sido empleados hasta el momento en aplicaciones de teleoperación y entornos virtuales (robótica y simulación). Se propone su utilización, para extender las capacidades de los sistemas de medida del temblor utilizados hasta la fecha, proporcionando al enfermo estímulos (realimentación de fuerza) en la extremidad que se esté evaluando, para conseguir respuestas diferenciadoras. Del mismo modo, también se propone el utilizar los registros de las pruebas conseguidos para clasificar las patologías y ofrecer, de esta manera, una ayuda al diagnóstico eficaz. Los avances también en el área de la inteligencia artificial, y más concretamente en el reconocimiento de patrones, sumados al progresivo abaratamiento y capacidades de los sistemas digitales, han permitido el desarrollo de soluciones eficientes y fiables en tareas de ayuda al diagnóstico. En esta tesis se propone un doble objetivo, primero el encontrar un clasificador que permita diferenciar entre el temblor fisiológico y el temblor patológico, y segundo, y más ambicioso, el de encontrar uno que nos permita diferenciar entre el temblor esencial y el temblor de Párkinson.

En esta tesis se analizarán diferentes técnicas para el reconocimiento de patrones que puedan ser utilizadas para obtener clasificaciones certeras de estas patologías, mejorando así la precisión y la fiabilidad de los diagnósticos. Se pretende proporcionar por tanto, un resultado adicional objetivo y determinista, a los profesionales y expertos del área de la medicina (neurólogos, neurofisiólogos,...). Más concretamente, el estudio se centrará en las enfermedades o patologías que cursan con trastornos del movimiento como la enfermedad de Párkinson, el temblor esencial y el temblor fisiológico.

Otro aspecto que se estudiará es la manera de filtrar dichos temblores. A día de hoy proliferan por doquier infinidad de dispositivos (ordenadores, móviles, tablets, etc...), que requieren de la interacción entre las máquinas y el hombre. Interacción que todavía plantea barreras casi insalvables a un sector de la sociedad (por ejemplo 
los enfermos de Parkinson). Los individuos afectados se ven imposibilitados para manejar este tipo de sistemas debido a las dificultades que presenta el temblor. A este sector de la población le resulta complicado realizar operaciones tan sencillas como teclear el código en su cajero automático o mantener el ratón del ordenador en una posición concreta. Operaciones que no suponen ninguna contrariedad para el resto de personas.

\subsection{Objetivos.}

Esta tesis tiene como objetivo principal el desarrollo de un sistema para la adquisición (pruebas clínicas), análisis y clasificación del temblor en ciertas enfermedades. Se pretende que éste proporcione al neurólogo, al neurofisiólogo, a los técnicos clínicos y en general, a los profesionales de la medicina en las áreas afines, las estimaciones e información suficientes para conseguir que la labor de diagnóstico sea más veraz y objetiva, permitiendo así, aumentar la capacidad de respuesta para proponer las terapias más eficientes para cada paciente.

Para llevarlo a cabo, podemos desglosar el objetivo principal en varios:

\subsubsection{Sistema para la medida del temblor.}

Son muy variadas las técnicas y los dispositivos empleados para la medida del temblor, desde acelerómetros, hasta giróscopos posicionados a lo largo de los miembros o extremidades en las que se quiere evaluar el movimiento. Cada tecnología tiene sus ventajas y al mismo tiempo adolece de ciertos inconvenientes que en muchos casos son difíciles de mitigar. Por ejemplo, las técnicas basadas en acelerómetros son muy flexibles y fáciles de acomodar, puesto que son dispositivos muy livianos. Fijarlos a las extremidades no requiere de grandes ni complejas plataformas ni sistemas de sujeción especiales. Además, la adquisición de la señal es relativamente fácil de obtener. Sin embargo, puesto que la medida es una aceleración, obtener las posiciones y las velocidades del miembro que se pretende estudiar, en algunos casos, resulta una tarea difícil ya que la convergencia de los métodos de integración depende en un grado muy importante de las condiciones iniciales que se fijen. Aun existiendo convergencia puede suceder también que la calidad de la información obtenida no sea la requerida. Los giróscopos por el contrario, si proporcionan una señal más adecuada para los objetivos, pues directamente son capaces de proporcionarnos los giros en los tres ejes del espacio. A partir de esta medida es sencillo obtener velocidades de rotación (derivando) e incluso aceleraciones (segunda derivada), sin embargo, la dificultad estriba en que hay que ser muy precisos y minuciosos con la posición en la extremidad, puesto que deben ir aplicados normalmente en un entorno cercano de las articulaciones del miembro que se pretende observar.

En esta tesis se propone el desarrollo de un sistema capaz de adquirir la señal del temblor de manera sencilla, determinista y metodológica para su posterior análisis. Además, se plantea tener la posibilidad de que el dispositivo no sólo registre la señal del temblor, sino que sea capaz de proporcionar algún tipo de 
estímulo en el miembro o extremidad del paciente. Se pretende estudiar cómo afecta esta característica al trastorno del movimiento que se pretende estudiar, pudiendo ser clave para su identificación y clasificación.

\subsubsection{Desarrollo de los patrones y los protocolos de las pruebas clínicas.}

En estrecha colaboración con los profesionales de la medicina: neurólogos, neurocirujanos y neurofisiólogos, se plantea el desarrollo de una batería de patrones que permita cubrir la casuística de las pruebas basadas en escalas subjetivas empleadas hasta el momento. Del mismo modo, se completará con un número adicional nuevo de patrones, que permitan estudiar el comportamiento de los pacientes ante situaciones hasta ahora no estudiadas (estímulos de pesos, rozamientos viscocos, etc...). En este sentido se contará con la participación y colaboración del personal de neurofisiología clínica y de neurocirugía del Hospital Ramón y Cajal, y del servicio de neurocirugía del Hospital de la Princesa, ambos de Madrid. Dichas pruebas serán la base para el posterior análisis y reconocimiento del temblor empleando diferentes técnicas. Se definirán los patrones y se implementarán en la aplicación software desarrollada del dispositivo para su posterior uso en las pruebas clínicas. En cada prueba se seguirá el protocolo definido y se utilizará la propia aplicación del sistema para poder efectuar un seguimiento clínico de los pacientes (pruebas en diferentes días, en condiciones distintas: mediación $\mathrm{ON}$ - medicación OFF, pre o post operatorio).

\subsubsection{Filtrado del temblor. Dispositivo de acceso al ordenador para personas discapacitadas por temblor.}

Con los datos obtenidos por la plataforma de los diferentes pacientes a los que se sometan a las pruebas (temblor fisiológico, temblor esencial, temblor parkinsoniano), se analizarán las características más significativas e importantes del temblor (estudio de la varianza) para elegir el método más adecuado para el filtrado del temblor. Se probarán diferentes estrategias y finalmente se implantarán en un dispositivo sobre el que se llevarán a cabo pruebas de validación por parte de una muestra de potenciales usuarios. El objetivo será permitir a los enfermos que padecen determinados trastornos en el movimiento poder acceder al ordenador y que su discapacidad les prive lo menos posible de una tarea cada vez más usual (ya cotidiana), evitando que les suponga una exclusión social determinante. Para ello se contará con la generosa y amable colaboración de los miembros de la Asociación de Párkinson de Madrid.

\subsubsection{Estudio de técnicas de análisis y clasificación del temblor. Obtener un clasificador eficaz para ayuda al diagnóstico.}

El objetivo principal de esta tesis es conseguir un clasificador eficiente para que el sistema pueda ser considerado como una plataforma de además de adquisición y análisis, de ayuda al diagnóstico para neurólogos y neurofisiólogos. Deberán ensayarse diferentes clasificadores, haciendo uso de diferentes técnicas de análisis y pre-procesado. Resulta razonable pensar que a partir de los datos de las pruebas, se deberá de concretar un conjunto de características que definan o identifiquen el 
tipo de trastorno de manera eficaz. A partir de ahí plantear diferentes alternativas y estudiar su influencia en la caracterización. Como conclusión final, deberá elegirse la estrategia que proporcione mejores resultados y por lo tanto, resulte viable para la identificación y ayuda al diagnóstico.

\subsection{Estructura.}

La tesis se divide en nueve capítulos, de los cuales tres están destinados a la introducción y las conclusiones, uno a la descripción del sistema desarrollado denominado DIMETER, otro a las herramientas matemáticas y técnicas empleadas a lo largo de esta tesis, otros tres están destinados a desarrollar las diferentes pruebas y ensayos experimentales y por último un capítulo destinado a análisis de resultados.

A continuación se describe brevemente el contenido de cada uno de ellos:

- En el capítulo 1 se describe cuál es la motivación del trabajo de esta tesis, los incentivos que han llevado a afrontar los retos que se han planteado, intentando contribuir en la ayuda al diagnóstico para proporcionar una mejor y más larga calidad de vida a los enfermos afectados por el temblor esencial y la enfermedad de Párkinson. Del mismo modo, se presentan los objetivos que se pretenden cubrir con esta tesis, así como la estructura del documento.

- En el capítulo 2 se plantean los diferentes tipos de temblor así como la relación con sus patologías asociadas. Se muestran las escalas subjetivas empleadas en el diagnóstico y las terapias comunes en función del grado de afectación, las discapacidades provocadas en el paciente, su efecto sobre la vida cotidiana, los efectos secundarios negativos de la medicación después de tiempo de evolución de la enfermedad, etc... En el mismo capítulo también se hace una descripción de las técnicas y dispositivos que se emplean para la medida y registro del temblor. De este modo se puede analizar las bondades y posibles inconvenientes de cada solución.

- En el capítulo 3 se describe en profundidad el sistema desarrollado para la adquisición, medida, análisis y diagnóstico del temblor: DIMETER. Enumerando los componentes que lo integran, la función que cumplen y mostrando el sistema global funcionando en las pruebas clínicas que se llevaron a cabo en el Hospital Ramón y Cajal. También se muestra una descripción pormenorizada de los patrones y las características asociadas, así como el protocolo de pruebas que se siguió.

- En el capítulo 4 se abordan las herramientas matemáticas y las técnicas de clasificación y reconocimiento de patrones, que después serán utilizadas para el análisis y diagnóstico en las pruebas y ensayos experimentales. Las muestras obtenidas por el DIMETER tendrán que ser acondicionadas en cada caso, antes de ser procesadas por los 
clasificadores. Este pre-procesamiento requiere de métodos y algoritmos matemáticos como el análisis de componentes principales (ACP), la transformada wavelet, el coeficiente de curtosis, etc ...

- En el capítulo 5 se muestran los resultados obtenidos con el primer clasificador empleado: el perceptrón multicapa (MLP). Se expondrán las hipótesis planteadas y los resultados de los ensayos realizados. Este es el primer clasificador que se estudió, por lo que las conclusiones obtenidas serán de gran valor al abordar las siguientes técnicas expuestas en los capítulos siguientes. En este capítulo también se muestran los trabajos realizados en el filtrado del temblor así como el dispositivo final implementado: ACORTE.

- En el capítulo 6 se exponen los resultados experimentales obtenidos en la clasificación del temblor mediante redes neuronales LVQ. Se pretende analizar si las características mixtas de este tipo de redes (entrenamiento supervisado y no supervisado) suponen una ventaja que nos permita mejorar los resultados, proporcionados por los perceptrones multicapa (MLP) utilizados en el capítulo anterior en la clasificación del temblor. Es en este capítulo cuando además de emplear otras técnicas de clasificación se incluye el análisis de componentes iniciales (ACP) para mejorar el espacio de características inicial, reduciendo la dimensión del espacio de entrada y la complejidad de la red.

- En el capítulo 7 se propone el último clasificador empleado: las máquinas de soporte vectorial (SMV). Este tipo de máquinas son relativamente novedosas en el área del reconocimiento de patrones y especialmente indicadas para trabajar con dos clases. Hasta este momento, se ha demostrado que la diferenciación entre temblor fisiológico (sanos) y temblor patológico puede cubrirse con un grado de acierto relativamente bajo con los perceptrones multicapa y con un acierto válido con las redes LVQ, sin embargo, la diferenciación entre temblor esencial y parkinsoniano parece una labor más compleja, por lo que merece la pena insistir abordando una nueva técnica.

- En el capítulo 8 se analizan los resultados obtenidos por todas las técnicas empleadas de una manera global. La idea es afrontar una perspectiva concluyente para plantear las premisas que darán lugar a las conclusiones del siguiente capítulo, el capítulo 9.

- En el capítulo 9 se proponen las conclusiones obtenidas en el trabajo de esta tesis tras el trabajo desarrollado. En él se exponen los objetivos cumplidos, las contribuciones más destacables de la tesis y se proponen los posibles futuros trabajos a realizar. 


\section{EL TEMBLOR, CARACTERÍSTICAS. ESTADO DEL ARTE.}

\subsection{Definición del temblor.}

El temblor se define como un movimiento rítmico, involuntario y oscilatorio de una o varias partes del cuerpo que se produce por la contracción alternante de los músculos agonistas y antagonistas [1].

El origen del temblor es muy variado. Puede ser como síntoma o consecuencia de una patología, debido a la ingesta de determinados fármacos o sustancias (te, café, cola,...) o incluso a determinados estados de stress o ansiedad. En esta tesis nos centraremos en la primera de las opciones, afrontando las enfermedades más frecuentes que afectan a la población, y que presentan claras limitaciones funcionales en los sujetos que las padecen.

Las partes del cuerpo a las que afecta el temblor son las extremidades superiores (hombro, codo, muñeca, dedos), extremidades inferiores (cadera, rodilla, articulaciones del tobillo, dedos de los pies) e incluso puede involucrar la cabeza (mentón, cara, lengua, paladar) y el tronco [5]. En condiciones severas puede convertirse en un grave problema, provocando malestar y vergüenza social junto con incapacidad y dificultades a la hora de realizar actividades diarias.

Una de estas patologías es la enfermedad de Parkinson que suele comenzar como un temblor de reposo (en ocasiones puede añadirse temblor de acción) en un brazo y unilateral. Habitualmente se trata de un movimiento flexoextensor del codo o primer dedo o una prono-supinación del antebrazo. Empeora con el stress y disminuye con los movimientos voluntarios. Se acompaña de otros signos como rigidez, bradicinesia, hipertonía en rueda dentada y pérdida de los reflejos posturales.

Otra es el temblor esencial, siendo también una de las alteraciones del movimiento más común. El temblor se inicia con el movimiento y raramente se 
presenta en reposo, siendo más intenso al mantener una postura (por ejemplo mantener los brazos extendidos). El temblor se puede ver en la lengua, la cabeza, puede girar en sentido no-no o sí-sí. Se acentúa con situaciones de stress o que requieran cierta habilidad (contar monedas, tomar un café o realizar una firma). Puede ser realmente incapacitante y mejora con la ingesta de alcohol. En la mitad de los pacientes existe predisposición familiar y tiene menos de 40 años.

Otro grupo de estudio serán los individuos sanos, que pueden presentar en mayor o menor medida un temblor de tipo fisiológico. El temblor fisiológico aparece en todas las personas sanas y puede estar relacionado con muchas causas. Puede pasar desapercibido y hacerse patente al sostener un objeto o apuntar en una dirección. Puede estar causado por situaciones que aumenten el stress, al realizar ejercicio, al presentarse fatiga, por síndromes de abstinencia. También por la ingesta de cafeína, o por hipertiroidismo, hipoglucemia, o hipotermia; incluso después de la ingesta de determinados medicamentos. Se trata evitando la causa desencadenante o usando B-bloqueantes no selectivos, como el propanolol o timolol.

En la Figura 2.1 se presenta una espiral de Arquímedes para evaluar el temblor de tres pacientes mediante una prueba cinética. La representación gráfica corresponde a los datos obtenidos por el sistema DIMETER (descrito en el capítulo 3). La gráfica de la izquierda corresponde a la realizada por un paciente con temblor parkinsoniano. El temblor tiende a disminuir mientras se realiza la tarea, a la vez que los movimientos son entrecortados. La lentitud y la rigidez del movimiento son característicos en esta enfermedad. La gráfica del centro pertenece a un paciente con temblor esencial. El temblor es exacerbado y empeora durante la ejecución de la tarea, se puede apreciar que la frecuencia de oscilación es alta. Por último, la gráfica de la derecha corresponde a la realizada por un paciente con temblor fisiológico donde la amplitud del temblor es poco perceptible, sin llegar afectar a la ejecución de la prueba.
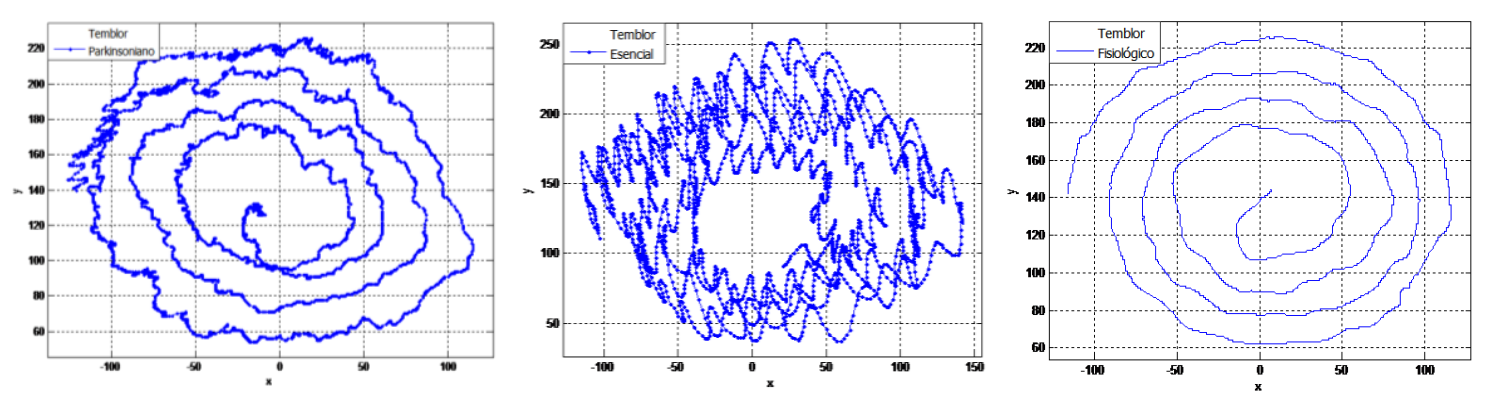

Figura 2.1: Espiral realizada con: Párkinson, temblor esencial y temblor fisiológico.

Siguiendo con los tipos de temblor, cabría mencionar también del temblor cerebeloso, que se presenta como un temblor de intención unilateral o bilateral de baja frecuencia causado por traumatismos, alcoholismo, tumores e infartos cerebrales o esclerosis múltiple. En ocasiones puede ser hereditario. El temblor empeora con movimientos precisos como las maniobras dedo-nariz o dedo-dedo. 
Muchas veces se acompaña de alteraciones de la marcha (ataxia), alteraciones del equilibro, dificultad para hablar o bajada del tono muscular.

Por último el temblor psicógeno es un temblor variable que puede disminuir o desaparecer cuando el paciente no es observado o con psicoterapia o placebo. Se detecta contracción conjunta de músculos antagonistas mediante electrofisiología.

Las principales fuentes del temblor se pueden resumir en tres grupos: mecánico, reflejo y oscilaciones centrales [6], como se muestra en la Figura 2.2.

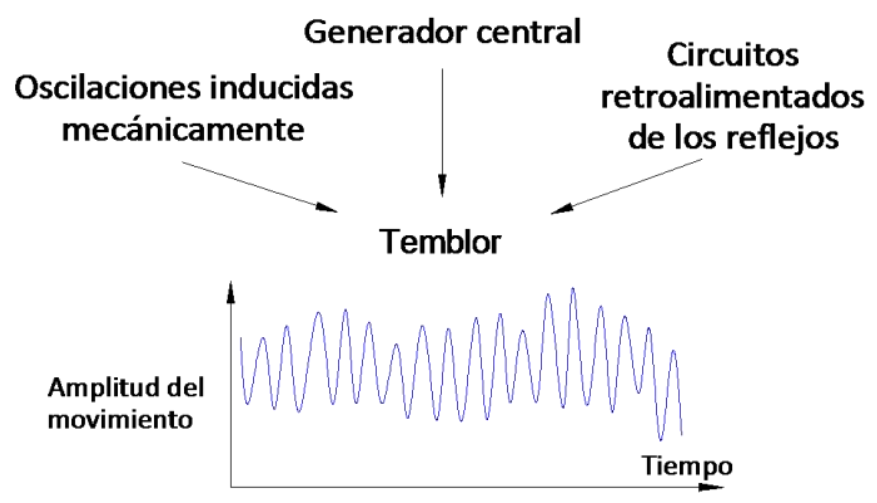

Figura 2.2: Principales fuentes del temblor.

La primera fuente son las oscilaciones mecánicas. El movimiento de las articulaciones y los músculos obedecen a las leyes físicas básicas y el conjunto tendón-músculo-articulación pueden ser asemejados al modelo de una masa con un resorte. La Figura 2.3 indica la interacción entre la neurona motora superior (UMN) y la neurona motora inferior (LMN). La piscina de interneuronas de la médula espinal está indicada por (IN). DP corresponden a los ganglios de la raíz dorsal. El rectángulo azul, es la representación del modelo de músculo de Hill, que comprende una serie de componentes elásticos (SE), y de un procesador de entrada neuronal (NIP) paralelo a un componente viscoso (PE) [8].

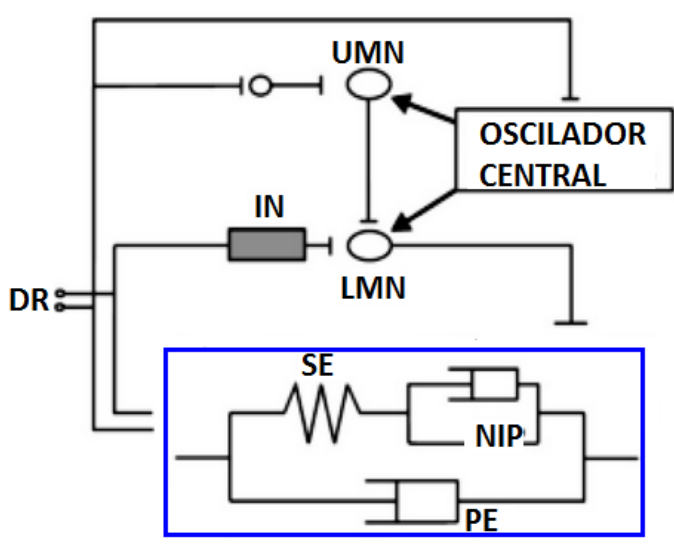

Figura 2.3: Lazos centrales y periféricos en el sistema nervioso. 
La segunda fuente del temblor es la oscilación por reflejos, están relacionados a dos circuitos. Circuito periférico que van desde los músculos hasta la espina dorsal y el circuito central que va desde la periferia a la médula espinal y los segmentos a nivel supraespinal incluyendo el tronco cerebral, el cerebelo, los ganglios basales y la corteza cerebral. En la Figura 2.4 se puede apreciar una representación de esta fuente de temblor, en la que se muestra las vías involucradas. Los husos musculares son receptores localizados en el interior de los músculos, compuesto por fibras sensibles a los cambios de longitud. En respuesta al alargamiento, las señales llegan a los centros espinales y supraespinales donde se generan las órdenes motoras y son enviadas de vuelta a las fibras musculares extrafusales [8].

Una tercera fuente del temblor lo producen las oscilaciones centrales que pueden ser observados desde los primeros registros de electroencefalográficos (EEG). La actividad neuronal sigue un comportamiento rítmico, por lo tanto la corteza cerebral, los ganglios basales, el cerebelo y el tronco cerebral están involucrados en el origen del temblor [8].

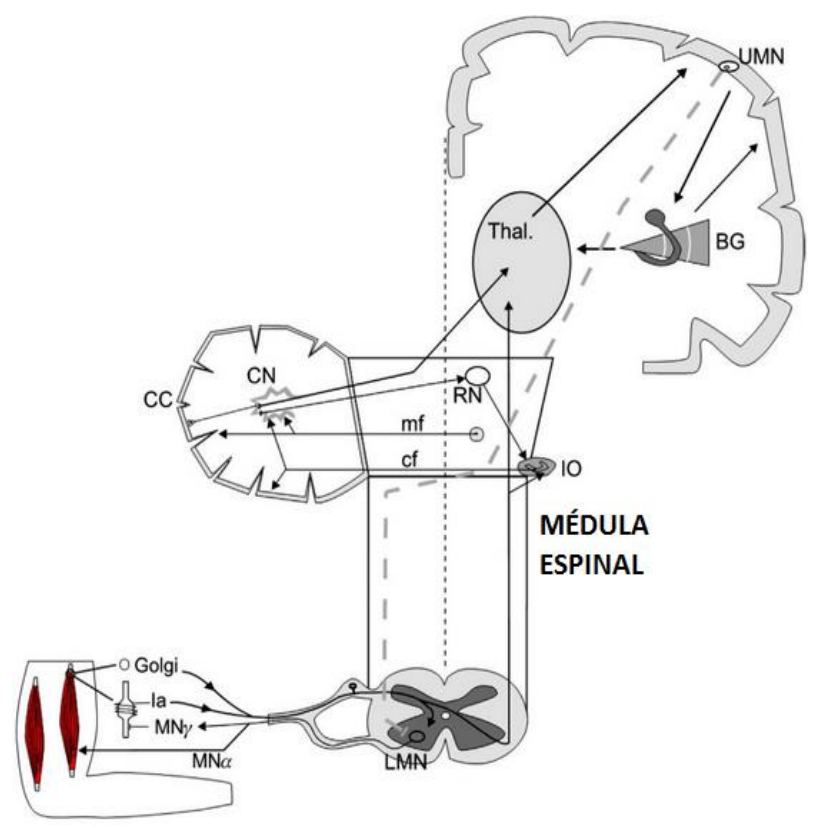

Figura 2.4: Vías que involucran el origen del temblor.

En la Figura 2.4 se muestran las vías que involucran el origen del temblor:

- CN: núcleos cerebelosos

- BG: ganglios basales

- CC: corteza cerebral

- UMN: neurona motora superior

- LMN: neurona motora inferior

- Thal.: Tálamo 
- IO: oliva inferior

- RN: núcleo rojo

- cf: fibras trepadoras

- mf: fibra musgosa

- MNa: neurona motora alfa

- MNY: neurona motora beta

- Ia: fibras aferentes sensoriales.

\subsubsection{Clasificación del temblor.}

La fenomenología es la vía más común de categorizar el temblor de un paciente para llegar a un diagnóstico [9]. Los principales tipos de temblor son el de acción y el de reposo, tal y como se muestra en la Tabla 2.1.

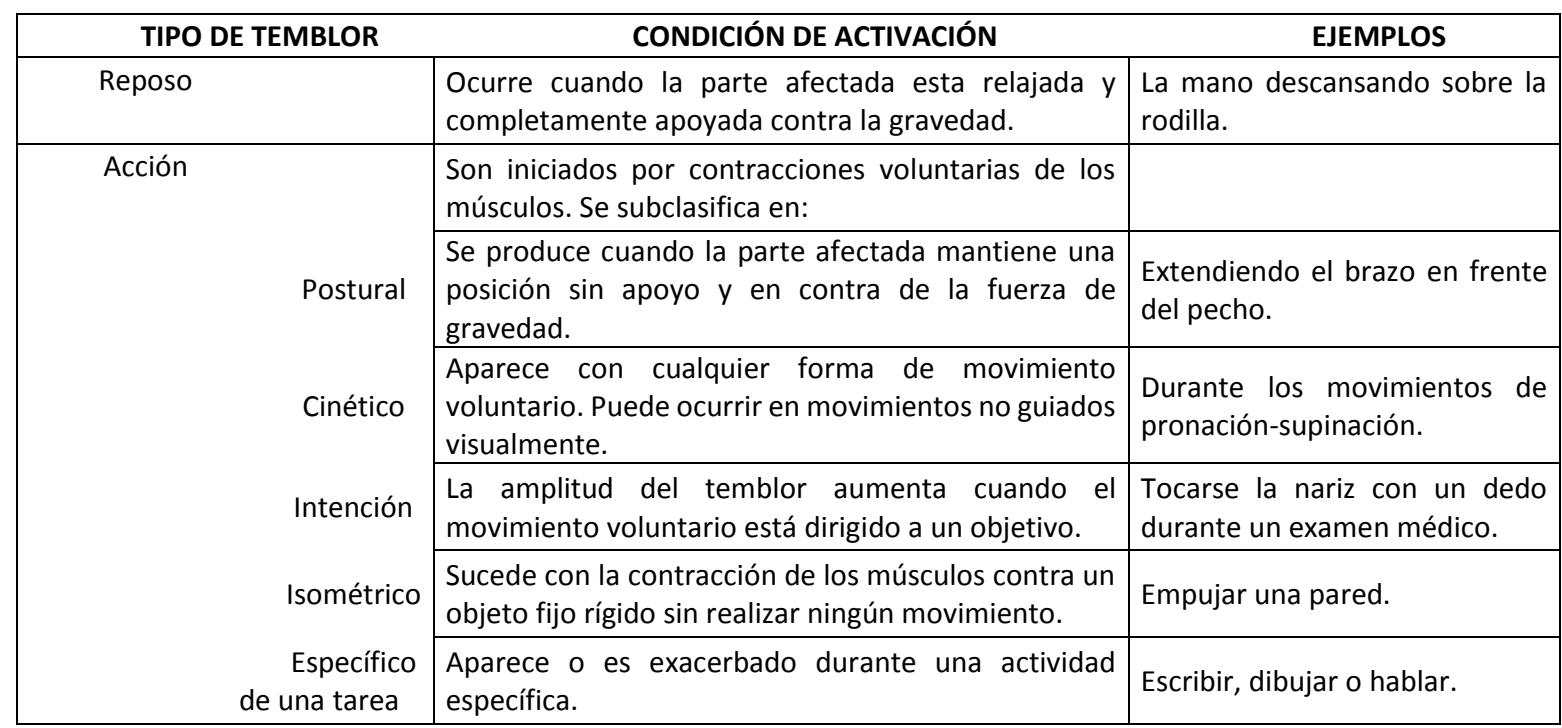

Tabla 2.1: Categorías del temblor

Las etiologías de los temblores no tienen por qué ser únicas. Por ejemplo, la causa más común del temblor de reposo es la enfermedad de Párkinson. Además del temblor de reposo, los pacientes de Párkinson suelen tener también una componente de acción.

En el caso del temblor esencial predomina un temblor de tipo postural y cinético. En algunas ocasiones incluso en reposo pueden producirse oscilaciones de la extremidad, por lo que resulta tremendamente complicado establecer un patrón diferencial entre el Párkinson y el temblor esencial.

El temblor fisiológico es un temblor de acción-postural y está presente en todas las personas sanas en determinadas circunstancias como se explicará más adelante. 


\subsection{Patologías objeto del estudio.}

\subsubsection{Enfermedad de Parkinson.}

La enfermedad de Parkinson (Parkinson's disease) [10] es el ejemplo más común de una familia de trastornos neurodegenerativos que se caracterizan por una acumulación neuronal de la proteína presináptica sinucleína alfa y por grados variables de parkinsonismo. Éste se define como una escasez y lentitud del movimiento (bradicinesia), temblor en reposo, rigidez, marcha arrastrando los pies y postura flexionada. Casi todas las formas de parkinsonismo tienen como consecuencia una reducción en la transmisión dopaminérgica dentro de los ganglios basales. La enfermedad de Parkinson esporádica e idiopática (origen desconocido) constituye cerca del $75 \%$ de todos los casos de parkinsonismo, mientras que la proporción restante tiene un origen genético o como consecuencia de otros trastornos neurodegenerativos, de enfermedades cerebrovasculares o del uso de ciertos fármacos.

\subsubsection{Epidemiología.}

La enfermedad de Parkinson afecta a más de un millón de individuos en Estados Unidos (alrededor del 1\% de las personas con más de 55 años) [7]. La edad máxima de inicio es de 60 años (límites: 35 a 85 años) y la evolución de la enfermedad fluctúa entre 10 y 25 años. Los grupos familiares (hereditario) de la enfermedad de Parkinson constituyen cerca del $5 \%$ de los casos. Se caracterizan por una edad de inicio más temprana (característicamente antes de los 50 años) y evolución más prolongada que la de la enfermedad de Parkinson más típica. Si bien en la mayoría de los pacientes con enfermedad de Parkinson parecen no tener un origen genético claro, las pruebas epidemiológicas señalan una interacción compleja entre la vulnerabilidad genética y los factores ambientales. Entre los factores de riesgo destacan antecedentes familiares positivos, sexo masculino, lesión craneal, exposición a pesticidas, consumo de agua de bebederos, y residencia en medios rurales. Son factores ligados con menor frecuencia a la enfermedad de Parkinson el consumo de café, tabaquismo, uso de algunos antiinflamatorios y reposición de estrógeno en mujeres posmenopáusicas.

\subsubsection{2 Índices de prevalencia e incidencia.}

La prevalencia y la incidencia de la enfermedad de Parkinson son especialmente importantes por varios motivos [11]:

- Los estudios epidemiológicos pueden dar luz sobre los factores de riesgo probables, factores de protección, y principales causas de la enfermedad. Todos estos tipos de datos se pueden utilizar para investigar la historia natural de la enfermedad de Párkinson.

- Pueden proporcionar información importante sobre los efectos económicos de la enfermedad sobre la población, ayudando a realizar una correcta planificación sanitaria. Esto ha sido de interés fundamental en los últimos años, debido al aumento de la longevidad de la población. 
En España, diversos estudios realizados entre 1995 y 2004 reflejan índices de prevalencia que van desde 161.5/100,000 hasta 1500/100,000. La frecuencia de la enfermedad de Parkinson, de acuerdo a la escala de Hoehn y Yahr, es la que aparece en la Tabla 2.2:

\begin{tabular}{|c|c|}
\hline Etapa & Prevalencia (\%) \\
\hline I & 10.1 \\
\hline II & 63.8 \\
\hline III & 16.7 \\
\hline IV & 6.7 \\
\hline V & 3.3 \\
\hline
\end{tabular}

Tabla 2.2: Prevalencia de la enfermedad de Parkinson en España, según la etapa de la enfermedad.

Las tasas de incidencia brutas, de las que se informa en varios estudios europeos, van desde 5/100,000 hasta 26/100,000. En España, estudios realizados entre 1994 y 1998 muestran incidencias que van desde 8.2/100,000 hasta $186.8 / 100,000$.

\begin{tabular}{|c|c|}
\hline Edad & Incidencia \\
\hline$<50$ & 0.28 \\
\hline $50-54$ & 7.70 \\
\hline $55-59$ & 6.84 \\
\hline $60-64$ & 20.72 \\
\hline $65-69$ & 39.39 \\
\hline $70-74$ & 51.78 \\
\hline $75-79$ & 30.81 \\
\hline $80-84$ & 32.28 \\
\hline$>84$ & 35.94 \\
\hline
\end{tabular}

Tabla 2.3: Incidencia de la enfermedad de Parkinson en España, según la edad.

\subsubsection{Manifestaciones clínicas.}

Se puede establecer un diagnóstico de la enfermedad de Parkinson con cierto grado de seguridad en pacientes que presentan por lo menos dos de los tres signos principales: temblor en reposo, rigidez y bradicinesia. El temblor es muy importante, ya que se presenta en el $85 \%$ de los pacientes con enfermedad de Parkinson; el diagnóstico de Parkinson es más complejo cuando no hay temblor. El inicio unilateral y gradual de los síntomas apoya además el diagnóstico. Las facies 
de máscara (incapacidad para mostrar expresiones faciales), la disminución del parpadeo, la postura encorvada y una menor oscilación del brazo completan el cuadro clínico. El inicio también va precedido de sensaciones vagas de debilidad y fatiga, incoordinación, dolor y malestar.

\subsubsection{Manifestaciones motoras.}

La manifestación más discapacitante de la enfermedad de Parkinson [10] es la bradicinesia, que complica todos los aspectos de la vida cotidiana, como es el caminar, levantarse de una silla, girarse en la cama o vestirse. El control motor fino también se ve alterado dando lugar a una merma en la destreza manual y en la escritura a mano (micrografía). La hipofonía (habla suave) y la sialorrea (excesiva producción de saliva) son otras manifestaciones molestas de la bradicinesia (bulbar). Típicamente, el temblor de reposo, con una frecuencia de $4 \mathrm{a} 6 \mathrm{~Hz}$, aparece en un solo lado, primero en la parte distal, afectando a los dedos de la mano y a la muñeca. El temblor, por lo general, se disemina en sentido proximal, y en ocasiones, hacia la pierna antes de cruzar al otro lado después de un año o más. Puede aparecer más tarde en los labios, la lengua y la mandíbula, pero suele no afectar a la cabeza. La rigidez se percibe como una resistencia uniforme al movimiento pasivo de una articulación en todo el rango de la misma, lo cual da origen a un comportamiento "plástico" característica. Las interrupciones breves y regulares de la resistencia durante el movimiento pasivo de la articulación, pueden dar como resultado una sensación de "rueda dentada". La distonía que afecta a la parte distal (extrema) del brazo o de la pierna puede presentarse en una etapa temprana de la enfermedad, sin relación con el tratamiento, ante todo en pacientes más jóvenes. También es desencadenada por los fármacos del tratamiento para la enfermedad de Párkinson.

Los trastornos de la marcha con pasos cortos y arrastrando los pies, y una tendencia a girar todo el cuerpo en bloque, son también características frecuentes en la enfermedad de Parkinson. La marcha festinante, un signo parkinsoniano típico, es consecuencia de la combinación de una postura encorvada y la pérdida de los reflejos posturales, que hace que el paciente acelere el paso para tratar de "alcanzar" el centro de gravedad del cuerpo. La ralentización de la marcha, una característica de la enfermedad de Parkinson más avanzada, ocurre comúnmente al inicio del movimiento (vacilación de inicio). Al tratar de cambiar de dirección o girar, y al entrar en un espacio estrecho, como sería un pasillo.

Las anormalidades del equilibrio y la postura tienden a aumentar conforme avanza la enfermedad. La flexión de la cabeza, el encorvamiento y la inclinación de la parte alta del tronco, así como la tendencia a conservar el brazo en una postura flexionada mientras se camina, son también frecuentes, lo mismo que los cambios en la postura de los dedos de las manos. La inestabilidad postural es una de las características más incapacitantes de la enfermedad de Parkinson avanzada, contribuyendo a caídas y lesiones y a una morbilidad y mortalidad importantes. No obstante, la inestabilidad postural y las caídas en los primeros años de la enfermedad, son indicativas de un diagnóstico diferente al de la enfermedad de Parkinson. 


\subsubsection{Dignóstico.}

El diagnóstico diferencial de los síndromes parkinsonianos requiere una exploración física cuidadosa y minuciosa. Las neuroimágenes por resonancia magnética (Magnetic Resonance Imaging, MRI) resultan útiles para descartar trastornos como hidrocefalia con presión normal o enfermedad vascular. La tomografía mediante emisión de positrones (positron emission tomography, PET) es útil para confirmar las formas atípicas. El temblor esencial (essential tremor, ET) a veces se confunde con el temblor de reposo de la enfermedad de Parkinson, pero la ausencia de otros signos de parkinsonismo y la bilateralidad, la mayor frecuencia (8 a $10 \mathrm{~Hz})$ y la dependencia postural de los enfermos de temblor esencial, más la disminución importante incluso con una pequeña cantidad de alcohol, ayudan a distinguir esta forma de temblor en reposo de la enfermedad de Parkinson. En individuos de menos de 40 años de edad es importante descartar la enfermedad de Wilson. En individuos más jóvenes, la enfermedad de Huntington (Huntington's disease) a veces se manifiesta por signos parkinsonianos claros. El parkinsonismo también se desarrolla tras la exposición a determinadas neurotoxinas, como monóxido de carbono o manganeso.

\subsubsection{Escala de Hoehn y Yahr.}

Es una escala que se utiliza principalmente para describir el avance de los síntomas de la enfermedad de Parkinson. La escala original [12] incluía varias etapas: desde la 1 hasta la 5. Desde entonces, se ha añadido la etapa 0 , y se han propuesto las etapas 1.5 y 2.5 (Tabla 2.4). El número indica el nivel de discapacidad relativo.

\begin{tabular}{|c|l|}
\hline Etapa & \multicolumn{1}{|c|}{ Descripción } \\
\hline 0 & Sin apreciación de la enfermedad \\
\hline 1 & Solamente síntomas unilaterales \\
\hline 1.5 & Afectación unilateral y axial \\
\hline 2 & Síntomas bilaterales. Sin deterioro del equilibrio \\
\hline 2.5 & $\begin{array}{l}\text { Afectación bilateral leve con recuperación en la prueba de } \\
\text { retropropulsión (test del empujón). }\end{array}$ \\
\hline 3 & $\begin{array}{l}\text { Afectación bilateral leve a moderada; cierta inestabilidad postural, pero } \\
\text { físicamente independiente. }\end{array}$ \\
\hline 4 & $\begin{array}{l}\text { Incapacidad grave, aún capaz de caminar o de permanecer en pie sin } \\
\text { ayuda. }\end{array}$ \\
\hline 5 & Permanece en una silla de ruedas o encamado si no tiene ayuda \\
\hline
\end{tabular}

Tabla 2.4: Etapas de la escala de Hoehn y Yahr. 


\subsubsection{Escala unificada para la valoración de la enfermedad de Párkinson (Unified Parkinson Disease Rating Scale, UPDRS).}

Es otra escala complementaria que también sirve para clasificar el grado de afectación y para seguir el curso de la enfermedad de Parkinson. Consta de las siguientes secciones:

- Estado mental, conducta y humor.

- Actividades de la vida diaria.

- Sección motora.

Dichas secciones se evalúan mediante una entrevista. Algunas de ellas pueden requerir que se asignen varias puntuaciones simultáneamente a cada extremidad. La cantidad total de puntos guarda relación directa con la etapa de la enfermedad en la que se encuentra el paciente (Tabla 2.4), de manera que la puntuación máxima (159 puntos) indica que el sujeto está en la etapa 5, mientras que la puntuación nula indica etapa 0 .

Las escalas de puntuación y las diferentes secciones que se evalúan en la escala UPDRS pueden consultarse en el Anexo 1.

\subsubsection{Actividades de la vida diaria de Schwab y England.}

A continuación se presenta otra forma de evaluar el grado de afectación. Según [13] el estadio puede ser asignado por el neurólogo o por el paciente:

- 100\%: Completamente independiente. Capaz de realizar cualquier tarea con/sin lentitud o dificultad.

- 90\%: Completamente independiente. Capaz de realizar cualquier tarea con/sin lentitud o dificultad. Puede tardar el doble de lo normal.

- 80\%: Independiente en la mayoría de las tareas. Tarda el doble. Consciente de la dificultad y enlentecimiento.

- 70\%: No completamente independiente. En algunas tareas tarda 3 ó 4 veces más de lo normal, pudiéndole tomar gran parte del día.

- 60\%: Alguna dependencia. Puede hacer la mayoría de tareas, pero muy lentamente y con mucho esfuerzo.

- 50\%: Más dependiente. Necesita ayuda en la mitad de tareas cotidianas. Dificultad para todo.

- 40\%: Muy dependiente. Sólo puede realizar algunas tareas sin ayuda.

- 30\%: Con mucho esfuerzo puede realizar alguna tarea. Necesita mucha ayuda.

- $20 \%$ : Ninguna tarea solo. Severa rigidez.

- $10 \%$ : Totalmente dependiente. 
- 0\%: Funciones vegetativas como la deglución, función urinaria e intestinal no funcionan. Postrado en cama.

\subsubsection{Tratamiento.}

En los primeros estadios de la enfermedad la terapia suele ser farmacológica, mediante el suministro de dopamina (1-dopa). Sin embargo, los efectos secundarios que se presentan con la evolución de la enfermedad, hace necesaria en muchos casos, la intervención quirúrgica.

En las últimas décadas ha habido un resurgimiento en el tratamiento quirúrgico de la enfermedad de Parkinson y otros trastornos del movimiento. A lo largo de la década de 1950 tanto la palidotomía como la talamotomía fueron las técnicas más utilizadas. El uso de la levodopa a partir de 1960 condujo al abandono virtual del tratamiento quirúrgico. El resurgimiento de la modalidad quirúrgica ha sido motivado por el hecho de que después de cinco años o más de tratamiento, muchos pacientes desarrollan fluctuaciones motoras y discinesias importantes producidas por los fármacos.

También los avances en el conocimiento de la organización funcional de los ganglios basales (modelo basal) y la base fisiopatológica del parkinsonismo han proporcionado un fundamento más claro para la eficacia de estos procedimientos y una guía sobre la orientación a estructuras específicas. La demostración, en modelos animales de enfermedad de Parkinson, de que la ablación de STN (subtalamotomía) producía una reducción espectacular en todas las manifestaciones fundamentales del parkinsonismo fue un descubrimiento decisivo.

La selección de los pacientes apropiados para el tratamiento quirúrgico resulta de gran importancia, ya que en general, los enfermos de Parkinson atípicos no tienen una respuesta favorable. Las principales indicaciones para la cirugía son:

- Un diagnóstico de enfermedad de Parkinson idiopática.

- Una respuesta clara a la levodopa.

- Síntomas intratables importantes de la enfermedad de Párkinson y/o discinesias y fatiga inducida por los fármacos.

Las contraindicaciones para el tratamiento quirúrgico comprenden formas atípicas de enfermedad de Parkinson, alteraciones cognitivas, enfermedades psiquiátricas mayores, trastornos médicos concominantes sustanciales y edad avanzada (un factor relativo). Los signos y síntomas que no responden a la levodopa, como la inestabilidad postural y las caídas, la hipofonía, la micrografía, el babeo y la disfunción autónoma, es muy poco probable que se beneficien del tratamiento quirúrgico. Como regla general, es poco factible que los beneficios de la cirugía superen los beneficios de la medicación antiparkinsoniana. En términos generales, la decisión para el tratamiento quirúrgico deberá tomarla un equipo multidisciplinar especializado en trastornos del movimiento: neurólogos, neurocirujanos, psiquiatras, neurofisiólogos y técnicos capacitados. 
El uso de la ablación (p. ej., palidotomía o talamotomía) ha disminuido considerablemente desde la implantación de la estimulación cerebral profunda (Deep Brain Stimulation, DBS). En la Figura 2.5 puede verse la situación relativa de las dianas objetivo tanto para la ablación como para la estimulación.

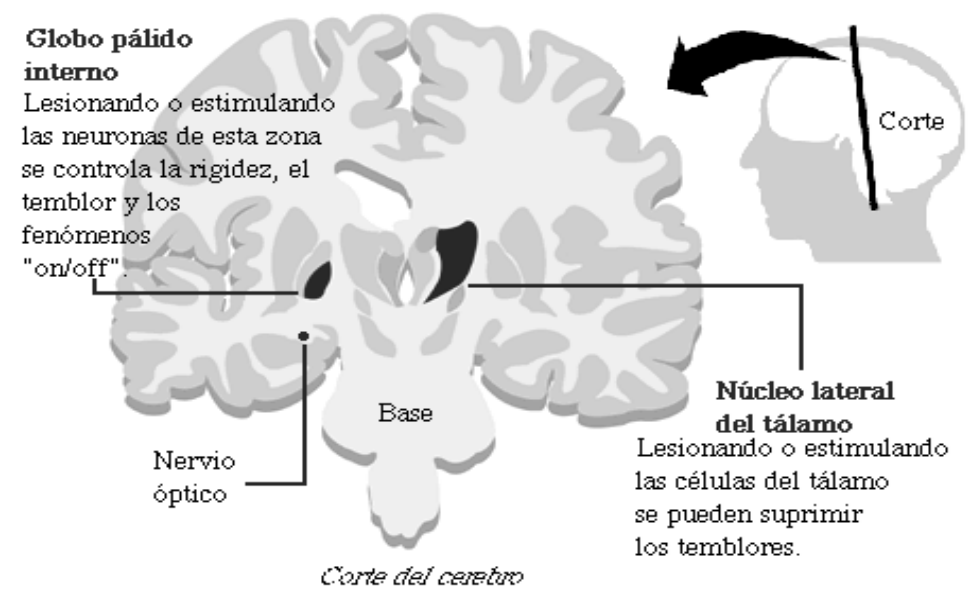

Figura 2.5: Situación de las dianas del tálamo y subtálamo.

Las principales ventajas de la DBS estriban en que es un poco menos invasiva y más reversible que la ablación, y además permite la personalización (ajuste o parametrización) para obtener el mejor efecto después de la implantación. En la actualidad se realizan estudios clínicos para comparar estas dos dianas. Los datos disponibles sugieren que ambos son eficaces para todas las manifestaciones de la enfermedad de Parkinson y para las discinesias y fluctuaciones motoras. La estimulación unilateral es apropiada en pacientes con enfermedad asimétrica, aunque en general es necesaria la cirugía bilateral en pacientes que se encuentran en etapas más avanzadas, y aquéllos con manifestaciones bilaterales importantes. Las reducciones en las dosificaciones de fármacos parecen ser más fáciles con las intervenciones en el STN que con los procedimientos en el globo pálido.

Sigue siendo controvertido el mecanismo de acción de la DBS. Dado que desde el punto de vista clínico parece que la ablación y la estimulación de una determinada diana tienen un efecto similar. Se ha asumido que la estimulación produce un bloqueo funcional, sin embargo, es probable que intervengan múltiples factores. La base para la mejoría puede ser la restitución de la actividad neural anormal por un patrón de actividad más tolerable. Después de la ablación o la DBS, los sistemas motores remanentes en el tronco encefálico, el tálamo y la corteza, pueden compensar de manera más eficaz la actividad anormal inherente al estado parkinsoniano. Cualquiera que sea el mecanismo, está claro que estos métodos ofrecen resultados impresionantes en pacientes seleccionados de manera aleatoria.

\subsubsection{Temblor esencial.}

El temblor esencial es una enfermedad usualmente benigna [14]. Se caracteriza por un temblor postural y simétrico de 6 a $12 \mathrm{~Hz}$ que afecta a los brazos casi en todos 
los casos. En orden de frecuencia decreciente, otras partes corporales que también resultan afectadas son la cabeza (titubeo), las piernas, la laringe (temblor de la voz) y el tronco. Es probable un patrón hereditario, por consiguiente, un antecedente familiar positivo es de gran utilidad, lo mismo que un antecedente de respuesta parcial al consumo de alcohol.

En comparación con la enfermedad de Parkinson, los síntomas de temblor esencial suelen ser de inicio bilateral y de evolución más lenta. Un pequeño subgrupo de pacientes tiene enfermedad de Parkinson simultáneamente. El temblor esencial puede acompañarse de una discapacidad importante, dependiendo de la amplitud del temblor y de la región corporal afectada. La ansiedad como causa se presenta en un número importante de casos y, al igual que en todos los trastornos del movimiento, los signos y síntomas se exacerban durante estados de tensión emocional y fisiológica. No hay un consenso respecto a algún proceso patológico inherente al temblor esencial, y las imágenes diagnósticas del cerebro son normales.

Se considera temblor esencial cuando no existe otra causa identificable de temblor, como el efecto de fármacos, toxinas o causas metabólicas [14]. El temblor esencial clásico es de tipo postural, bilateral y simétrico, y tiende a ser asincrónico. $\mathrm{Al}$ principio suele tener solamente componente cinético o ser asimétrico, y en las formas más tardías y graves puede ser también de reposo.

Sus presentaciones clínicas pueden ser:

- Postural y de acción, en $49.4 \%$.

- Solamente postural, en $26.7 \%$.

- Solamente de acción, en 9.1\%.

- Con afección de las manos, en 94.9\%.

- Con afección de la cabeza, en $26.5 \%$.

- Con afección de la voz, en $16.99 \%$.

- Con afección de la pierna, en $11.30 \%$.

- Con afección de la lengua, en 3.78\%.

- Con afección del tronco, en $1.88 \%$.

El componente postural se aprecia al adoptarse ciertas posiciones como extender los brazos al frente. Generalmente el componente cinético es más intenso que el postural, observándose durante la ejecución de ciertas tareas como escribir a mano o colocar un dedo sobre la nariz.

\subsubsection{Epidemiología.}

Es un trastorno del movimiento que afecta de cinco a 10 millones de adultos y algunos niños en Estados Unidos [10]. 


\subsubsection{2 Índices de prevalencia e incidencia.}

Se ha calculado que existe desde el 1 hasta el 22\% de la población mayor de 65 años, con una prevalencia desde 5 hasta 20 veces mayor a la enfermedad de Parkinson. Esta variabilidad se debe a diferencias raciales. Según consta en [15], se puso de manifiesto que en España central, fruto del estudio se concluyó con una prevalencia del $4.8 \%$ para la población general, del $4.6 \%$ en hombres y del $5.0 \%$ en mujeres. En otras latitudes, como Sicilia [16], se constató una prevalencia global de 405.1 por 100,000 habitantes, aumentando hasta 1074.9 por 100,000 habitantes en la población mayor de 40 años.

La incidencia anual del temblor esencial se ha estimado en 18 por cada 100,000 habitantes. En [7] fueron evaluados 5278 participantes españoles utilizando los datos del Centro Español de Enfermedades Neurológicas, con el objeto de estudiar la incidencia de temblor esencial en una población española. Al inicio del estudio y durante el seguimiento (promedio de 3.3 años) se rastreó la presencia de temblor esencial a través de cuestionarios y del examen físico-neurológico. De la población estudiada, el $4.9 \%$ presentaba la enfermedad. De 3942 individuos hubo 83 casos nuevos durante el seguimiento, de los cuales el $77.1 \%$ no habían sido diagnosticados antes del estudio. La incidencia anual ajustada en una población anciana fue de 616 casos cada 100,000 personas. Los autores concluyen que la incidencia podría ser mayor a la previamente considerada, dado que una gran proporción de la población estudiada afectada nunca había recibido atención médica previa.

\subsubsection{Diagnóstico.}

El diagnóstico del temblor esencial se basa fundamentalmente en las características clínicas del temblor [14]: su comportamiento con el reposo y la actividad, su predominio en extremidades superiores, y por la ausencia de signos de alteración extrapiramidal o cerebelosa.

Se puede diferenciar del temblor fisiológico haciendo que el paciente sostenga un peso moderado durante un tiempo, tras el cual el temblor disminuye. Dicho fenómeno está relacionado con el efecto balistocardiaco que se exagera con el aumento de la adrenalina.

Una prueba para fundamentar el diagnóstico es la mejoría con la ingestión del alcohol y con la administración de propranolol o primidona. Dicha acción puede considerarse una acción terapéutica.

En el estudio electrofisiológico es característico que la electromiografía (EMG) muestre descargas sincrónicas en los músculos agonistas-antagonistas, pudiéndose observar también una actividad alternante. La amplitud puede ser leve a moderada y en ocasiones intensa, condicionando la incapacidad del paciente.

Deberían considerarse otras causas: si el temblor es unilateral, si existen dificultades en la marcha, rigidez, bradicinesia, temblor de reposo o de inicio rápido, lo cual es indicativo de temblores de otro tipo. 
Otros temblores que pueden confundirse con el temblor esencial son el temblor posneurítico (síndrome de Guillain-Barré) o temblor con polineuropatía dismielinizante (en donde el temblor es lento, aleteante, grueso y de gran amplitud).

La causa número uno del temblor postural es el temblor esencial en aproximadamente el $77 \%$ de los casos, pero la siguiente causa es la enfermedad de Parkinson, por lo cual debe tenerse en cuenta ésta como diagnóstico diferencial.

\subsubsection{Escala de Fahn, Tolosa y Marín (FTM).}

También llamada escala de calificación del temblor esencial (Essential Tremor Rating Scale, ETRS). Está subdividida en tres apartados: (A) graduación del temblor en nueve partes del cuerpo; (B) valoración del temblor en acción de los miembros superiores en escritura, delinear con dos manos y vertido de líquidos y (C) incapacidad funcional. Cada uno de ellos genera una puntuación subtotal que debe sumarse para completar la puntuación total o puede ser utilizada de manera independiente para análisis diversos. En cada visita, además de la valoración cuantitativa de tareas específicas, se realiza una valoración global (por el paciente y por el experto) de la intensidad del temblor. Se puede encontrar el formulario correspondiente en [17] y en el Anexo 2.

\subsubsection{Escala WHIGET (Washington Heights-Inwood Genetic Study of Essential Tremor).}

En los individuos sanos, especialmente los más mayores, al mantener una postura o durante una acción presentan un temblor leve, pero constatable (puntuación 1 WHIGET). Diferenciar este temblor fisiológico del temblor esencial puede resultar muy difícil, aunque los pacientes con temblor esencial tienen habitualmente una puntuación +2 al mantener el brazo extendido, verter agua, y dibujando espirales. Muy pocos pacientes sanos tienen una puntuación +2 en estas tres pruebas. En la Tabla 2.5 se presenta la puntuación de la escala, así como la definición de las pruebas y observaciones al que se somete al paciente. 


\begin{tabular}{|c|l|}
\hline Puntuación & \multicolumn{1}{c|}{ Definición } \\
\hline 0 & Absolutamente ningún temblor visible. \\
\hline 1 & $\begin{array}{l}\text { Temblor leve, intermitente o continuo; similar al de un sujeto normal } \\
\text { o con temblor fisiológico exagerado. }\end{array}$ \\
\hline 2 & $\begin{array}{l}\text { Temblor obvio que sea el esperado en pacientes con temblor esencial. } \\
\text { Debe cumplir todos los siguientes criterios: } \\
\text {-Amplitud moderada. } \\
\text {-Usualmente presente. } \\
\text {-Claramente oscilatorio (la mano oscila claramente entre dos } \\
\text { extremos). }\end{array}$ \\
\hline 3 & $\begin{array}{l}\text { Gran amplitud, temblor espasmódico. Ejemplos incluyen: } \\
\text {-Al manipular líquidos el paciente los derrama, pero puede } \\
\text { completar la tarea sin derramar todo el líquido. } \\
\text {-Cuando se toca la nariz con el dedo el paciente tiene dificultad para } \\
\text { acertar, y se aproxima realizando círculos alrededor muchas veces. } \\
\text {-Cuando dibuja una espiral se aprecia temblor con oscilaciones de } \\
\text { gran amplitud, pero puede dibujar la espiral. }\end{array}$ \\
\hline $\begin{array}{l}\text { Amplitud extremadamente grande, temblor espasmódico. Ejemplos } \\
\text { incluyen: } \\
\text {-Al manipular líquidos el paciente es incapaz de completar la tarea } \\
\text { sin derramar todo el líquido. } \\
\text {-Cuando se va a tocar la nariz con el dedo el paciente tiene } \\
\text { dificultad para acertar, y realiza círculos alrededor muchas veces; el } \\
\text { paciente es reacio a tocarse la cara por miedo a autolesionarse. } \\
\text {-Cuando quiere dibujar la espiral el paciente no puede hacer o } \\
\text { mantener el contacto del bolígrafo con el papel; incapaz de dibujar } \\
\text { una espiral. }\end{array}$ \\
\hline 4
\end{tabular}

Tabla 2.5: Escala de calificación del temblor para la escala WHIGET.

Junto a la escala, los autores proporcionaron una serie de videos donde se muestra la información de los protocolos a seguir durante las evaluaciones. En dichos vídeos, que se habían creado para fijar los procedimientos para la clasificación de diferentes trastornos del movimiento, no se había concretado una manera de actuar en el caso del temblor esencial. En [18] se concretó la manera de realizar los tests para que conseguir que calificación del temblor esencial fuese más fiable.

La escala de calificación del temblor WHIGET revisada se usa para calificar el temblor desde 0 hasta 4 en seis pruebas:

- Extensión del brazo.

- Verter líquido. 
- Beber.

- Usar una cuchara.

- Tocarse la nariz con el dedo.

- Dibujar espirales.

\subsubsection{Escala de evaluación del temblor esencial (The Essential Tremor Rating Assessment Scale).}

La escala WHIGET fue desarrollada para el temblor de acción, pero solamente proporciona una evaluación graduada para el temblor en la extremidad superior. La escala Fahn-Tolosa-Marín proporciona una evaluación más comprensible de los temblores de acción y reposo, pero no fue desarrollada específicamente para el temblor esencial.

Para puntuar el grado de afectación se utiliza una escala entre 0 y 4, pudiendo utilizarse incrementos de 0.5 .

Elementos de evaluación de la prueba de TETRAS:

- Temblor en la cabeza.

- Temblor en la cara (incluyendo la mandíbula) al sonreír, cerrar los ojos, abrir la boca y apretar los labios.

- Temblor de la lengua.

- Temblor de la voz.

- Temblor en miembro superior durante tres maniobras: alcanzar la postura horizontal hacia adelante ("forward horizontal reach posture"), postura lateral de golpeo de ala ("lateral wing beating posture"), y la prueba dedo-nariz-dedo.

- Temblor en miembro inferior: extendido y paralelos al suelo durante 5 segundos, y entonces maniobra "talón a espinilla".

- Espirales de Arquímedes.

- Manuscrito en cursiva: "Este es un ejemplo de mi mejor escritura", usando solamente la mano dominante.

- Tarea de aproximación de punto: el sujeto mantiene la punta del bolígrafo tan cerca como sea posible de un punto sobre un trozo de papel, pero sin llegar a tocarlo.

- Temblor postural: las rodillas están $10-20 \mathrm{~cm}$ separadas y flexionadas de 10 a $20^{\circ}$. Los brazos están bajados. 
Todos los elementos del examen, exceptuado el temblor postural, son realizados con el sujeto sentado cómodamente. A los pacientes se les indica que no reduzcan el temblor, sino que lo dejen manifestarse. En la Tabla 2.6 se muestran las pruebas y la puntuación asignada.

\begin{tabular}{|c|c|c|c|c|}
\hline \multirow{2}{*}{$\begin{array}{c}\text { Elemento de } \\
\text { prueba }\end{array}$} & \multicolumn{4}{|c|}{ Puntuación } \\
\hline & 1 & 2 & 3 & 4 \\
\hline Cabeza & $<0.5 \mathrm{~cm}$ & $\begin{array}{l}0.5 \text { hasta } \\
<2.5 \mathrm{~cm}\end{array}$ & 2.5 hasta $5 \mathrm{~cm}$ & $>5 \mathrm{~cm}$ \\
\hline Cara y lengua & Apenas visible. & Evidente & $\begin{array}{l}\text { Obvio, } \\
\text { presente en la } \\
\text { mayoría de } \\
\text { contracciones } \\
\text { faciales. }\end{array}$ & $\begin{array}{l}\text { Enorme, } \\
\text { causando } \\
\text { desfiguración. }\end{array}$ \\
\hline $\mathrm{Voz}$ & $\begin{array}{l}\text { Leve, sólo } \\
\text { durante aaah o } \\
\text { eee. }\end{array}$ & $\begin{array}{l}\text { Durante aaah o } \\
\text { eee, y mínimo } \\
\text { durante el } \\
\text { habla. }\end{array}$ & $\begin{array}{l}\text { Temblor } \\
\text { evidente al } \\
\text { hablar. }\end{array}$ & $\begin{array}{l}\text { Algunas } \\
\text { palabras son } \\
\text { difíciles de } \\
\text { entender. }\end{array}$ \\
\hline $\begin{array}{l}\text { Extremidad } \\
\text { superior }\end{array}$ & Apenas visible. & 1 hasta $3 \mathrm{~cm}$ & $\begin{array}{l}5 \text { hasta } \\
<10 \mathrm{~cm}\end{array}$ & $\begin{array}{l}\text { Mayor o igual } \\
\text { a } 20 \mathrm{~cm} .\end{array}$ \\
\hline $\begin{array}{c}\text { Extremidad } \\
\text { inferior }\end{array}$ & Apenas visible. & $\begin{array}{l}\text { Obvio, pero } \\
\text { leve. }\end{array}$ & $<5 \mathrm{~cm}$ & $>5 \mathrm{~cm}$ \\
\hline Espirales & Apenas visible. & Temblor obvio. & $\begin{array}{l}\text { Parte de la } \\
\text { forma no es } \\
\text { reconocible. }\end{array}$ & $\begin{array}{l}\text { Forma no } \\
\text { reconocible. }\end{array}$ \\
\hline Manuscrito & Apenas visible. & $\begin{array}{l}\text { Temblor obvio, } \\
\text { pero es legible. }\end{array}$ & $\begin{array}{l}\text { Algunas } \\
\text { palabras } \\
\text { ilegibles. }\end{array}$ & $\begin{array}{l}\text { Completament } \\
\text { e ilegible. }\end{array}$ \\
\hline $\begin{array}{c}\text { Aproximación } \\
\text { al punto }\end{array}$ & Apenas visible. & 1 hasta $<3 \mathrm{~cm}$ & $\begin{array}{l}5 \text { hasta } \\
<10 \mathrm{~cm}\end{array}$ & $>20 \mathrm{~cm}$ \\
\hline Posición & Apenas visible. & $\begin{array}{l}\text { Obvio, pero } \\
\text { leve. }\end{array}$ & Moderado. & Severo. \\
\hline
\end{tabular}

Tabla 2.6: Rango de valores para cada elemento de cada prueba de la escala TETRAS.

TETRAS tiene una fiabilidad muy buena para el temblor de la cabeza y el de la extremidad superior, que son los más preocupantes en la mayoría de pacientes con temblor esencial. Mientras que no suele dar muy buenos resultados para el temblor de lengua, voz, pierna y cara, por lo que en muchos casos éstos suelen suprimirse de la evaluación. 


\subsubsection{Tratamiento.}

El temblor esencial no tiene cura, pero los síntomas pueden tratarse adecuadamente mediante fármacos en casi el 50\% de los casos y con intervenciones quirúrgicas en el $80 \%$ de los pacientes. La primidona y el propranolol son los tratamientos de primera línea para el temblor esencial; ambos han sido eficaces en estudios doble ciego, controlados con placebo. Alrededor del $80 \%$ de los pacientes resistentes o intolerantes a los fármacos responden a la talamotomía y a la estimulación cerebral profunda en el núcleo ventral intermedio del tálamo.

En general, se considera que el uso de fármacos y el tratamiento quirúrgico otorgan un beneficio de hasta el $80 \%$ para los pacientes con temblor esencial.

Aun cuando el alcohol produce buena respuesta en los pacientes con temblor esencial, no se aconseja su uso con este fin de forma constante, puesto que se ha asociado a enfermedad coronaria y modificaciones en la presión sanguínea.

\subsubsection{Temblor fisiológico.}

El temblor fisiológico [19] es un temblor de baja amplitud originado por el efecto mecánico de la sístole cardíaca. Este movimiento desarrollado durante el reposo de los miembros no es apreciable clínicamente y su registro precisa instrumentación. Aunque el temblor fisiológico no origina síntomas, todos los sujetos normales pueden tener en alguna ocasión un temblor de acción visible y con repercusión clínica. A este último tipo de temblor se le denomina temblor fisiológico exagerado y se desarrolla bajo una serie de circunstancias que aumentan la amplitud del temblor fisiológico, alcanzando una frecuencia más monorrítmica.

\subsubsection{Causas.}

La más usual es la producida por fármacos (agonistas beta-2-adrenérgicos). El suministro de isoproterenol en pacientes con temblor esencial familiar reproduce los mismos efectos cardiológicos que en sujetos sanos. Otras causas de temblor fisiológico exagerado están en relación con el aumento de los niveles circulantes de adrenalina endógena: ansiedad, ejercicio muscular, feocromocitona (tumor poco común de la piel de la glándula suprarrenal) y estrés. El temblor fisiológico exagerado puede ocurrir en otros estados: abstinencia de alcohol, opiáceos y sedantes; ingestión de anfetaminas, levodopa, café, té o cola y los estados hipoglucémicos. Los corticoides, las sales de litio y los antidepresivos (tricíclicos y neurolépticos) pueden inducir un temblor similar al fisiológico, aunque su mecanismo no está claramente definido. El temblor producido por el litio no es dependiente de la dosis o concentración sanguínea, pudiendo estar presente en reposo y durante el movimiento.

En los músculos se encuentran unos órganos sensibles receptores, que registran el estado de tensión de los mismos, son los husos musculares. Actúan como controladores del estado de la tensión y extensión de los mismos. Cuando un músculo se estira, también se estiran los husos musculares, que en ese instante envían impulsos a la médula espinal informando sobre dicho estiramiento. En la 
médula espinal se produce una sinapsis y como respuesta, se envía la orden al músculo para que este se contraiga. El objetivo de este reflejo es proteger al músculo de una extensión excesiva. Es un mecanismo de defensa, para evitar una lesión muscular provocada por una posible extensión brusca y excesiva.

Las aferencias Ia (neuronas encargadas de la recepción de sensaciones) de los husos musculares son muy sensibles, pudiendo ser activadas por estiramientos musculares diminutos producidos por el temblor fisiológico. La entrada en la médula espinal de estas señales en el temblor fisiológico no afecta a las propiedades de descarga neuronal. En los estados con una exageración del temblor fisiológico, la adrenalina circulante aumenta la velocidad de contracción muscular y la sincronización de la descarga de distintas motoneuronas, sensibilizando los husos neuromusculares. El mayor incremento de la oscilación muscular se produce con el agrupamiento de la descarga neuronal a 10-12 Hz. Esta falta de amortiguación de las oscilaciones musculares en el servomecanismo motor es causa y efecto de un aumento de la actividad Ia. Las terminales del huso muscular son activadas por estiramientos de los músculos cíclicos y recurrentes. Las propiedades inherentes de las motoneuronas en la actividad voluntaria muscular, las oscilaciones musculares por la sincronización de las neuronas y las descargas recurrentes, que producen un mayor acortamiento de músculo, producen un temblor fisiológico de mayor amplitud visible y/o sintomático, al que se denomina temblor fisiológico exagerado benigno. La tendencia a la oscilación del temblor fisiológico exagerado a $8-12 \mathrm{~Hz}$ se superpone a una oscilación más lenta de $4-6 \mathrm{~Hz}$, posiblemente dependiente de reflejos de larga latencia.

\subsubsection{Tratamiento.}

El temblor fisiológico exagerado puede ser reducido en amplitud por el uso de fármacos (bloqueadores beta-2-adrenérgico). Los temblores inducidos por tricíclicos, litio o ácido valproico precisan dosis altas de propranolol. Es un temblor que disminuye su frecuencia con la edad. Es ostensible durante estados hiperadrenérgicos (niveles altos de adrenalina) y depende de la integridad del arco reflejo miotático (sistema de recepción de los husos neuromusculares), lo que le diferencia claramente del temblor esencial familiar.

\subsection{Ayudas técnicas en el área de la salud.}

Desde hace algunas décadas los sistemas digitales se han ido integrando progresivamente en los ámbitos de la medicina. El éxito de la utilización de las ciencias de la computación y de la informática es consecuencia de que facilitan y abaratan la gestión y el almacenamiento de una cantidad de información cada vez más elevada.

La utilización de la tecnología para la toma de decisiones hace posible que puedan ser utilizadas por personal médico para iniciar una determinada secuencia de acciones, establecer estrategias, determinar las consecuencias de cada decisión, y adoptar las mejores soluciones en cada momento. Desgraciadamente, estas decisiones pueden tener consecuencias no deseadas a causa de la falta de 
experiencia previa en situaciones similares, provocando diagnósticos incorrectos o tratamientos no apropiados. La toma de decisiones debe ser, por tanto, llevada a cabo considerando criterios óptimos, de manera que a veces se asumen riesgos de cierta gravedad pero con una probabilidad muy escasa de producirse. Existen publicaciones que afirman que en los Estados Unidos de América entre 44,000 y 98,000 defunciones fueron provocadas por errores médicos prevenibles. Aunque la mayoría de estos errores estaban relacionados con la terapia, incluyendo medicación y errores quirúrgicos, una cantidad significativa de ellos fueron de diagnóstico [20].

También es cada vez más frecuente la utilización de sistemas informáticos para la administración de fármacos, facilitando la gestión gracias a los sistemas de registro de datos, individualizados para cada paciente. Dicho tratamiento personalizado permite ajustar tanto las dosis como los momentos de administración, de manera que se consigue un tratamiento personalizado y adaptado a las necesidades de cada paciente [21].

Los sistemas automáticos de toma de decisiones, en combinación con la gestión de información recopilada a lo largo de las sucesivas pruebas, pueden llegar a ser herramientas interesantes para la toma de decisiones en el ambiente sanitario o de la salud. El desarrollo de estos sistemas generalmente requiere de un largo y costoso período de investigación y desarrollo, recurriendo al uso de la automática y el control, centrándose en técnicas avanzadas de inteligencia artificial.

Al principio del uso de estas técnicas, para la ayuda a la toma de decisiones, se encontraron ciertos problemas para su implementación. En el caso de los denominados sistemas expertos, en los primeros desarrollos, se presentaba disparidad y discrepancia en las conclusiones. Entre otros problemas a los que se enfrentaban los desarrolladores, era el conseguir trasladar el conocimiento del experto al sistema. Es común que un experto que lleve trabajando años en tareas muy parecidas llegue a tener un perfeccionamiento tal en su trabajo que éstas lleguen a convertirse en cotidianas para él, siendo difícil expresar sus conocimientos en términos técnicos o utilizando el lenguaje necesario para concretar un algoritmo que trabaja sobre un ordenador. El experto lleva tanto tiempo desarrollando la misma tarea que no requiere seguir un procedimiento establecido, ya que lo desarrolla de manera natural. Además, es frecuente que el experto tenga ciertas reticencias a comunicar de manera clara cómo realiza su trabajo, ya que cuenta con indicios suficientes para sospechar de que va a ser sustituido en su puesto por algo o por alguien.

La utilización de dichos sistemas no es algo tan reciente. Es a principios de los años 70 cuando hubo avances en este sentido.

El primer sistema automático de asistencia para la toma de decisiones fue DENDRAL en 1965. Su propósito era explorar la posibilidad de usar el ordenador para modelar el pensamiento científico en el ámbito de la química molecular. La necesidad surgió a partir del problema del conocimiento de la estructura molecular. 
Para conocerla, un espectrómetro másico permite dividir la molécula en distintos iones, que después son acelerados y medidos uno a uno, ordenándose por su número másico. En moléculas más complejas esta fragmentación se produce de manera más aleatoria. Se buscaba un sistema que permitiera enumerar todas las estructuras posibles que se ajustaran a los datos de partida y los datos obtenidos del espectrómetro másico. La concepción del sistema se realizó en dos fases [22]:

- Calcular todos los compuestos que podían proporcionar el número másico de la molécula original, considerando el número másico de cada uno de los átomos en los que se dividía el compuesto y las restricciones de valencia. Así era posible eliminar las ramas del árbol de posibles soluciones, reduciendo el espacio de búsqueda de la búsqueda exhaustiva que se llevaba a cabo.

- Modelar el procedimiento inferencial del experto químico para encontrar la estructura molecular de la combinación que se consideraba solución, representando la estructura en forma de grafo.

Otro sistema basado en conocimiento (Knowledge Based System, KBS) fue MACSYMA (Project MAC's Symbolic Manipulator), desarrollado entre 1968 y 1982 por Carl Engelman, William Martin y Joel Moses, en los laboratorios de inteligencia artificial del Instituto Tecnológico de Massachusetts (Massachusetts Institute of Technology, MIT). Fue el primer entorno de computación interactivo y comprensible utilizado por matemáticos, científicos e ingenieros. Contaba con un gran número de funciones algebraicas y de representación gráfica.

DENDRAL fue el precursor de los KBS. Pero el primer sistema experto que entró en servicio para aplicaciones reales fue MYCIN.

El sistema MYCIN [23] sirvió a los profesionales de la medicina en la ayuda al diagnóstico de enfermedades infecciosas. Se basaba principalmente en un sencillo motor de inferencia que manejaba una base de conocimiento de aproximadamente 500 reglas. Consiguió unas cuotas de éxito significativas seleccionando terapias basadas en antibióticos [24]. En [24] se expone como es la representación, el diseño del sistema y las restricciones que permitían usar MYCIN como sistema de consulta. También se explica la estructura de control y la representación del conocimiento empleada para la producción de las reglas.

Para evaluar el rendimiento de MYCIN, colaboraron especialistas en enfermedades infecciosas, valorando las recomendaciones de terapia propuestas por el sistema [25]. Los resultados de la evaluación mostraron que el sistema proporcionaba decisiones aceptables (según los expertos de Stanford) en el 90,9\% de los casos.

Sin embargo, se comprobó que sistemas como MYCIN presentaban importantes limitaciones a causa del sistema de representación de las reglas. Personal ajeno al desarrollo de estas reglas, encontraban cierta dificultad para modificar el conjunto de las mismas [26], además de que eran difícilmente portables a otros entornos. El 
origen de estos problemas estaba en la propia elección de la representación de las reglas de MYCIN, que se basaban en relaciones del tipo si-entonces (if-then). Esto conllevaba un excesivo coste de mantenimiento en general para los sistemas expertos de la época, ya que resultaba bastante complejo implementar el conocimiento de los expertos y el motor de inferencia con este tipo de estructuras básicas.

También se desarrollaron sistemas de asistencia al diagnóstico basados en redes de asociación causal [27] [28]. CASNET [29] Es un ejemplo de ello. Usaba un modelo de la enfermedad para realizar un diagnóstico y recomendar terapias. El sistema estaba constituido por tres aplicaciones: un algoritmo para la construcción del modelo, una interfaz de consultas y un programa de bases de datos (que tenía más de 100 estados, 400 pruebas, 75 tablas de clasificación y 200 sentencias de diagnóstico y tratamiento). Un modelo CASNET estaba formado por 3 elementos principales: observaciones de un paciente, estados fisiopatológicos y los clasificaciones de la enfermedad. Las observaciones se registraban y asociaban con los estados apropiados. Los estados estaban relacionados de manera causal, formando una red que resumía los mecanismos o síntomas de la enfermedad. Las sugerencias para un grupo de clases de tratamiento se disparaban mediante las clases de diagnóstico correspondientes. El sistema fue aplicado para diagnósticos complejos, y para tratamientos de glaucomas.

En el terreno de la genética molecular se desarrolló MOLGEN. Este sistema basado también en conocimiento [30] tenía el objetivo de diseñar procedimientos para experimentos de clonación de genes, teniendo en cuenta las restricciones que aparecían de forma dinámica en las planificaciones jerárquicas. La decisión de qué actividad es la siguiente que hay que realizar siempre es la parte más difícil en problemas con recursos limitados. Generalmente, se han de conseguir ciertas metas en un orden determinado. El desarrollo de este sistema [31] implementa y extiende dos estrategias de planificación: la de menor compromiso y las estrategias heurísticas. Con esto se pretendía explorar la meta-planificación en un sistema automático de toma de decisiones: pretendía hacer reflexionar a los usuarios sobre los propios procesos de razonamiento que empleaban.

También en el terreno del diagnóstico, a principios de los 80, se desarrolló el sistema PUFF [32], para interpretación de datos de pacientes con enfermedades pulmonares. El sistema podía diagnosticar la presencia de graves enfermedades de pulmón. Era el primer desarrollado utilizando EMYCIN, e incluía las características de independencia de dominio (módulos) de MYCIN:

- Intérprete de reglas para proporcionar un diagnóstico.

- Explicación del sistema para responder sencillas cuestiones, justificando las opciones propuestas.

- Adquisición de conocimiento para implementar nuevas reglas.

El sistema no requería la interacción directa con un médico. La representación del conocimiento se conseguía mediante la utilización de 75 parámetros 
relacionados con pruebas de función pulmonar: como la capacidad pulmonar total o el volumen residual. En cuanto a la estructura de control, utilizaba un sistema de encadenamiento hacia atrás orientado a objetos. Esta forma de trabajar se basaba en proponer una solución hipótesis del problema, y el algoritmo navegaba hacia atrás en las reglas buscando la confirmación de dicha hipótesis. Si no se obtenía esta confirmación entonces el sistema preguntaba al usuario en busca de más información. Un fisiólogo pulmonar comprobaba el informe generado por el sistema, y si era necesario lo modificaba antes de su impresión. Se determinó que no eran necesarias modificaciones en un $85 \%$ de los casos y, cuando eran necesarias, la mayoría de las veces eran del tipo "es coherente con la última visita". La base de conocimiento básica de PUFF se distribuyó en cientos de copias a nivel mundial durante la década de los 80 .

\subsection{Ayudas técnicas en la medida del temblor.}

En el área del diagnóstico de la enfermedad de Parkinson se han introducido avances que mejoran la toma de decisiones médicas.

En este apartado vamos a tratar algunos ejemplos de sistemas automáticos de toma de decisiones en el terreno del diagnóstico de enfermedades neurodegenerativas. Cada uno de los sistemas presentados puede clasificarse en alguno de los siguientes grupos:

- Sistema automático implantado.

- Sistema automático similar que podría entrar en servicio de una manera inmediata, aunque sea susceptible de mejoras y evoluciones.

- Tecnología que no participa directamente en la toma de decisiones, pero que es utilizada con éxito para la adquisición.

También se presentan los avances que se han dado en la investigación en ayuda al diagnóstico de trastornos del movimiento desde el punto de vista de la evolución, cuantificación o caracterización. De manera, que son sistemas o técnicas susceptibles de ser mejoradas y que, a su vez, son fruto de otros desarrollos anteriores. La información presentada abarca desde estudios meramente estadísticos en base a datos extraídos de sencillos registradores de movimientos hasta complejas técnicas asociadas a la teoría de control que trabajan en base a modelos del comportamiento de las células asociadas a la causa del trastorno.

\subsubsection{Actígrafos y teleactígrafos (Teleactigraphs, TAG).}

Es una manera de monitorizar la actividad del cuerpo humano, midiendo la actividad motora del paciente. El actígrafo suele situarse en la muñeca de manera similar a la de un reloj de pulsera. La unidad registra continuamente los movimientos, y los datos son descargados posteriormente en un equipo, donde son analizados. Los actígrafos de movimiento son generalmente más grandes por lo que se suelen llevar en el hombro del brazo dominante. El actígrafo suele medir en tres ejes, aunque puede haberlos únicamente monoaxiales. Pueden trabajar con 
frecuencias de muestreo variables, disponiendo de una memoria para guardar los registros. Se suelen utilizar solamente durante unas pocas horas (poca autonomía), para determinar problemas con la marcha y otros impedimentos físicos. Generalmente, los componentes que incluye son:

- Acelerómetros piezoeléctricos.

- Filtro paso-bajo a baja frecuencia para eliminar vibraciones externas.

- Memoria para almacenar la actividad registrada.

- Alguna interfaz (por ejemplo USB) para descargar los datos.

El temblor fisiológico es un movimiento oscilatorio y rítmico que puede afectar a cualquier parte del cuerpo y que, generalmente, se produce en la banda de los 7 $15 \mathrm{~Hz}$. Donde mejor se mide es en el dedo. El temblor patológico es la consecuencia de alguna enfermedad como la enfermedad de Parkinson (4.5-6.5 Hz), el temblor cerebeloso $(4 \mathrm{~Hz})$ o el temblor esencial $(6-10 \mathrm{~Hz})$. Un tratamiento eficaz se consigue con un diagnóstico diferencial correcto. Éste puede ser obtenido cuantificando la amplitud y la frecuencia del temblor. El diagnóstico puede efectuarse con las escalas ya mencionadas anteriormente, pero las puntuaciones asignadas dependen en gran medida de los criterios subjetivos de los evaluadores, por lo que es necesaria una forma más precisa y objetiva de registrar las manifestaciones del trastorno. La actividad proporcionada por los sensores se registra para su posterior análisis. Con ello se consigue una forma más precisa de clasificar los posibles trastornos. En [33] se describe un sistema de análisis espectral de bajo coste para medir el temblor, mediante un acelerómetro. Una vez obtenidos los datos temporales, son transformados al dominio de la frecuencia, usando la transformada rápida de Fourier (Fast Fourier Transform, FFT). En la Figura 2.6 se muestra la ubicación de un acelerómetro en la palma de la mano para medir la señal del temblor, mientras que el sensor de EMG colocado en el brazo proporciona una medida de la actividad muscular.

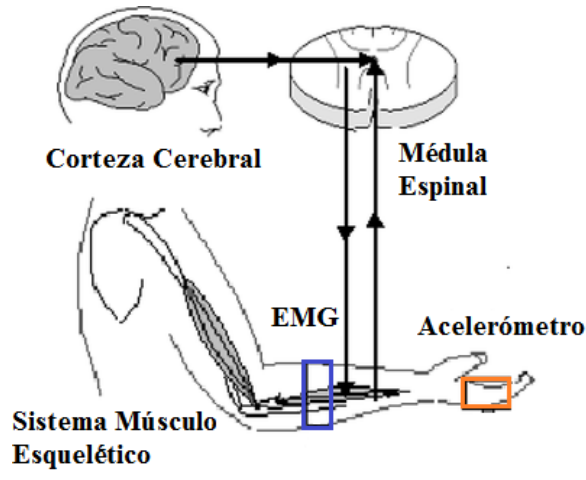

Figura 2.6: Medida del temblor mediante acelerómetro y EMG. 
En [34] se utiliza un actígrafo para cuantificar y estudiar el temblor fisiológico, el temblor esencial y el temblor parkinsoniano. Este tele-actígrafo (Tele-Actigraph, TAG) muestrea datos con una frecuencia de $27.3 \mathrm{~Hz}$ trabajando con un convertidor de una resolución de 12 bit. El dispositivo va situado en la muñeca del sujeto, contando con una autonomía de 5 horas y 20 minutos. A través de un puerto serie permite volcar los datos adquiridos para su posterior procesamiento. También permite la conexión con el ordenador para enviar datos en tiempo real. Basándose en este dispositivo se comenzó a trabajar en un objetivo directamente relacionado con la caracterización del temblor, a partir de las muestras obtenidas.

En [36] utilizan la medida del acelerómetro para adquirir el movimiento del temblor. En la Figura 2.7 puede apreciarse la diferencia entre dos registros de acelerómetro entre un paciente con temblor y uno sano.
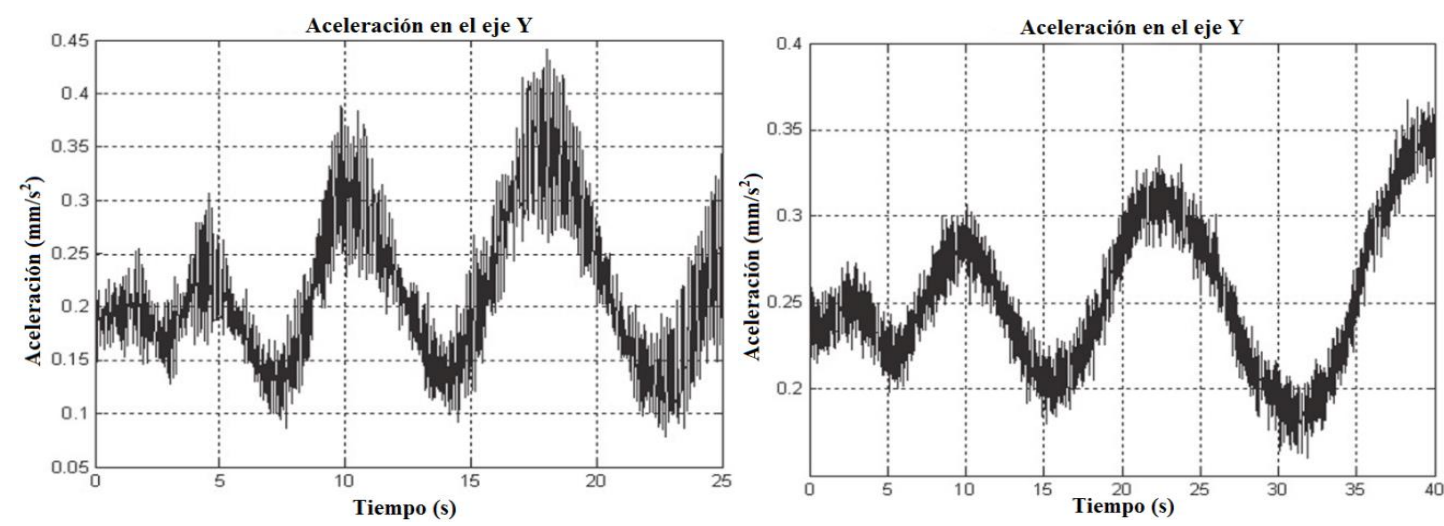

Figura 2.7: Registros de acelerómetro. Paciente con temblor (izq.) y sano (der.)

En [37] se realiza una evaluación de la discinesia inducida por levodopa en pacientes con la enfermedad de Parkinson basándose en el análisis de las señales registradas por los acelerómetros, que se colocaron en el cuerpo del paciente mientras realizaba tareas específicas. En la Figura 2.8 se muestra la disposición de los acelerómetros triaxiales en cada una de las extremidades.

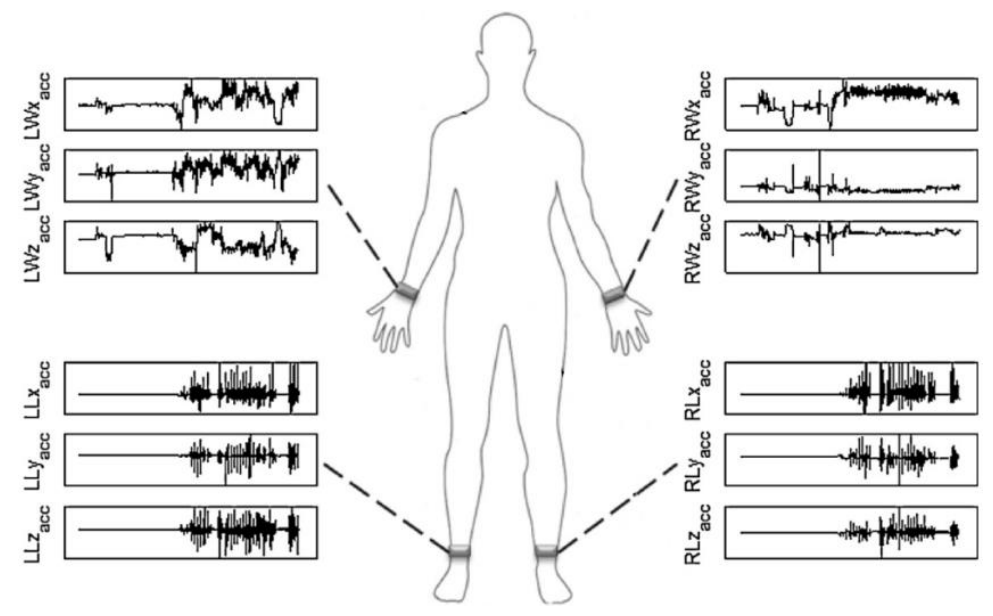

Figura 2.8: Disposición de los acelerómetros triaxiales en cada extremidad. 
En [35] se utiliza una muestra de 128 muestras para obtener una transformada, con 64 valores característicos en el dominio de la frecuencia. De estos valores se descartan los dos valores más altos y los dos más bajos, con el fin de utilizar un vector con los 60 puntos más significativos. Estos 60 datos se utilizan como entrada a un clasificador basado en redes neuronales. Los datos disponibles eran de 12 sujetos con temblor patológico y 10 pacientes normales. Obteniéndose espectros típicos en sujetos con enfermedad de Párkinson y sanos:

- Enfermedad de Párkinson: El espectro de potencia estaba concentrado en dos frecuencias: por una parte se apreciaba la componente de temblor fisiológico, cercana a los $2 \mathrm{~Hz}$, y por otro lado la del temblor parkinsoniano, entre 5 y $6.5 \mathrm{~Hz}$.

- Sano: La magnitud espectral de potencia tenía valores mayores en torno a los $2 \mathrm{~Hz}$, típicos del temblor fisiológico.

La optimización mediante enjambres de partículas (Particle Swarm Optimization, PSO) es una técnica computacional inspirada en la simulación del comportamiento social. La PSO es parecida a un algoritmo genético en el que el sistema se inicializa con una población de soluciones aleatorias. A diferencia de los operadores genéticos tradicionales, cada partícula se comporta de acuerdo con su experiencia y la de su compañera. En el mencionado trabajo se utilizó la PSO para determinar los pesos de la red e, indirectamente, para desarrollar la estructura de la misma. Así se pretende diferenciar el temblor fisiológico y el patológico, y no se hacía distinción, por lo tanto, entre temblor esencial y parkinsoniano. La red utilizada fue una red neuronal realimentada de 60 entradas, 12 neuronas en la capa oculta y 2 salidas (una por clase).

En [38] se utiliza estadísticos de orden superior (Higher Order Statistics, HOS) y redes neuronales para la caracterización del temblor parkinsoniano, esencial y fisiológico, usando unos acelerómetros situados en los dedos de los sujetos. En este estudio se sugirió que la estadística típica de segundo orden no era una herramienta suficientemente válida para la caracterización del temblor, y por éso era necesario emplear HOS.

Otros métodos propuestos para medir el temblor son los giróscopos [39], que son dispositivos para evaluar el desplazamiento angular, en estos casos provocado por el temblor, detectando el cambio de orientación de la parte afectada, no siendo afectados por la fuerza de la gravedad. Pueden ser empleados para medir posición y velocidad. En la Figura 2.9 se muestra la posición de los sensores (giroscopios: 1 sobre el metacarpiano, 2 sobre el borde del antebrazo, 3 abajo del olécranon, 4 sobre el olécranon) en la extremidad superior. En [40] se presenta un sistema ambulatorio para la detección y cuantificación del temblor y la bradicinesia asociados a la enfermedad de Parkinson. Para registrar los movimientos de las extremidades superiores se utilizaron unos giróscopos fijados al antebrazo del sujeto. Se propone y valida un algoritmo para detectar y cuantificar el temblor y otro para cuantificar la bradicinesia. Se realizaron dos estudios clínicos: 
- En el primero, 10 pacientes con enfermedad de Párkinson y 10 sujetos de control participaron un un protocolo de 45 minutos de 17 actividades o tareas comunes. El algoritmo para la detección del temblor demostró una sensibilidad total del $99.5 \%$ utilizando una referencia de vídeo. La estimación de la amplitud del temblor obtuvo una alta correlación (0.87) con la escala UPDRS. También se encontró una alta correlación (-0.83) entre la bradicinesia estimada y la respectiva escala UPDRS.

- En el segundo, se registraron los movimientos de las extremidades superiores de 11 sujetos con enfermedad de Párkinson durante periodos desde 3 a 5 horas, en los que los pacientes se movían libremente. También se encontraron altas correlaciones en este caso.

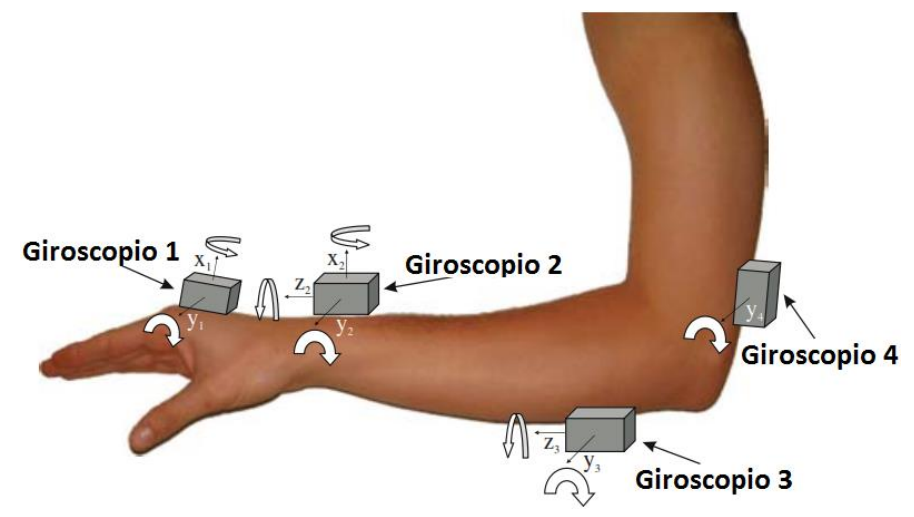

Figura 2.9: Medición del temblor por medio de giróscopos.

Se concluyó que es posible una evaluación del temblor y de la bradicinesia objetiva, precisa y simultánea para pacientes con Párkinson durante la realización de actividades cotidianas.

En [41] se desarrolla un sistema de monitorización sin cables (Digital Personal Assistant, PDA) con el objetivo de permitir la monitorización de pacientes con enfermedad de Parkinson. Este tipo de sistema está orientado, según los autores, a dos grandes grupos de usuarios: el primero sería personal biomédico no técnico, que buscaría analizar el temblor desde el punto de vista de los procedimientos clínicos estándar; el segundo serían usuarios que trabajan en diferentes campos de la investigación del temblor. Para el primer grupo es necesario una presentación intuitiva y eficiente de los datos. Para el segundo grupo sería necesaria una mayor libertad para configurar los diferentes parámetros del sistema. El sistema adquiere la información mediante un acelerómetro triaxial analógico (consiguen trabajar a una frecuencia de muestreo de $196 \mathrm{~Hz}$ ) filtrando la componente de la gravedad terrestre (mediante un filtro analógico paso-alto de primer orden con frecuencia de corte de $0.3 \mathrm{~Hz}$ ) y de posibles componentes de ruido en el temblor (Butterworth de $4^{\mathrm{o}}$ orden con frecuencia de corte de $30 \mathrm{~Hz}$ ). Tanto los entornos de la PDA como del ordenador del centro sanitario utilizan LabVIEW 8.2. El usuario puede realizar un análisis cuantitativo off-line de las aceleraciones medidas. Para llevarlo a cabo, 
primero se elimina el valor medio y después se estima el espectro de frecuencia usando la trasformada rápida de Fourier (FFT). Es fácil también determinar el pico de mayor intensidad de la señal su frecuencia así como la amplitud del mismo.

En el apartado de resultados se obtuvo que el temblor en los pacientes con Párkinson habitualmente aparece entre los 4 y los $6 \mathrm{~Hz}$, mientras que en los sujetos sanos está alrededor de los $2 \mathrm{~Hz}$. Un análisis estadístico sobre los resultados, analizando las bajas (1-4 Hz) y las altas $(4-7 \mathrm{~Hz})$ frecuencias reveló los siguientes resultados:

\begin{tabular}{|l|c|c|}
\hline \multicolumn{1}{|c|}{ Parámetros del temblor } & Control $(\mathrm{n}=10)$ & $\mathrm{PD}(\mathrm{n}=10)$ \\
\hline Frecuencia de pico $(\mathrm{Hz})$ & $2.6 \pm 1.5$ & $5.4 \pm 1.5$ \\
\hline Amplitud de pico $(\mathrm{g})$ & $0.0021 \pm 0.0011$ & $0.091 \pm 0.0791$ \\
\hline $\begin{array}{l}\text { Potencia alrededor de la frecuencia de } \\
\text { pico }\left(m V^{2}\right) .\end{array}$ & $0.003 \pm 0.003$ & $6.7 \pm 9.5$ \\
\hline Potencia total $\left(m V^{2}\right)$ & $0.022 \pm 0.0068$ & $42.1 \pm 48.1$ \\
\hline Potencia en baja frecuencia $\left(m V^{2}\right)$ & $0.007 \pm 0.003$ & $9.2 \pm 14.0$ \\
\hline Potencia en alta frecuencia $\left(m V^{2}\right)$ & $0.006 \pm 0.004$ & $24.6 \pm 25.8$ \\
\hline
\end{tabular}

Tabla 2.7: Resultados de los datos registrados obtenidos para 10 sujetos de control y 10 sujetos con Párkinson.

Los autores determinaron que las tres limitaciones más importantes del estudio fueron:

- Las desviaciones estándar de la densidad de potencia alrededor de la frecuencia de pico y la potencia total eran tan grandes como las propias medias, de manera que es difícil establecer conclusiones firmes acerca de estos parámetros.

- El trabajo estaba orientado a demostrar que el sistema era capaz de realizar una correcta monitorización de los datos fuera del centro sanitario, desde casa del sujeto. Y no se trataba de validar lo bien que. clínicamente, se monitorizaban los resultados en pacientes con enfermedad de Parkinson.

- La información del estudio estaba limitada, ya que solamente se consideraron 10 pacientes con enfermedad de Párkinson, y los autores propusieron la utilización de más información para establecer conclusiones más fiables.

En la Figura 2.10 se muestra un sistema de monitorización ambulatoria dedicada a pacientes con Párkinson [42] . Permite una evaluación motriz completa para la cuantificación de temblores, bradicinesia e hipocinesia. El sistema se compone de cuatro sensores de inercia, ubicados sobre la muñeca, muslo, pie y pecho. Los sensores se conectan a un bus maestro que alimenta, registra y envía la 
información a un ordenador a través de bluetooth, además, permite el registro de los movimientos.

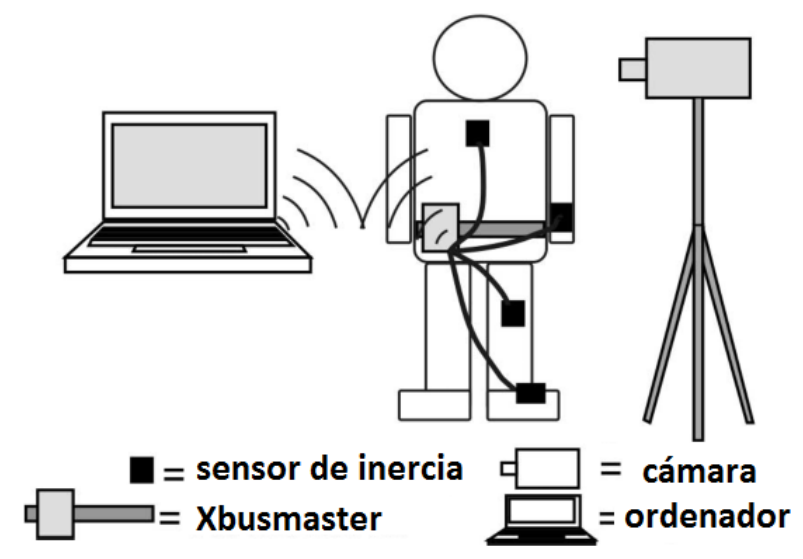

Figura 2.10: Sistema ambulatorio para monitorización del temblor.

\subsubsection{Dispositivos de entrada y filtrado.}

Este apartado se centrará en sistemas que son capaces de registrar datos del sujeto mediante las manifestaciones del trastorno del movimiento, utilizando para ello la realización de alguna tarea simple o cotidiana y utilizando algún tipo de dispositivo de entrada.

Cualquier trastorno del movimiento de las extremidades superiores hace especialmente difícil el manejo de periféricos de entrada, y por extensión, el uso de ordenadores, por ejemplo a través del ratón. El objetivo de paliar estas dificultades ha motivado el desarrollo de algoritmos de filtrado y el uso de dispositivos de interfaz alternativos a los comúnmente utilizados.

En uno de estos trabajos [43] se propuso un algoritmo basado en un filtro adaptativo para permitir el desarrollo de tareas de interacción con interfaces hombre-máquina. En los resultados se obtiene una mejoría en la escritura sobre una tableta conectada a un ordenador, incrementando ligeramente la legibilidad del texto.

Otro desarrollo que utiliza el filtrado óptimo para la eliminación del temblor es el presentado en [44]. Pero en este caso no estaba orientado solamente a sujetos con trastorno del movimiento, sino también a sujetos normales que requirieran mayor precisión del movimiento en tareas que involucraran joysticks o similares para trabajos de teleoperación o realidad virtual, ya que las conexiones entre el maestro y el esclavo no están libres de posibles ruidos o interferencias.

Un paso más allá en el filtrado del temblor es la caracterización mediante el texto escrito por el sujeto. En [46] utilizan un bolígrafo electrónico para registrar los movimientos (sensores de inclinación, de vibración, y de presión registrar la presión ejercida por los dedos del sujeto sobre la superficie del bolígrafo) de los sujetos a una frecuencia de muestreo de $500 \mathrm{~Hz}$. 


\subsubsection{Registros no invasivos.}

\subsubsection{Electroencefalografía (ElectroEncephaloGram, EEG).}

Es una exploración neurofisiológica que se basa en el registro de la actividad bioeléctrica cerebral en condiciones basales de reposo, en vigilia o sueño, y durante diversas activaciones mediante un equipo de electroencefalografía.

\subsubsection{Magnetoencefalografía (MagnetoEncephaloGram, MEG).}

Es una técnica que registra la actividad funcional cerebral, mediante la captación de campos magnéticos, permitiendo conocer las relaciones entre las estructuras cerebrales y sus funciones. La posibilidad de dichos registros viene determinada por la actividad postsináptica neuronal y por la activación sincrónica de millones de neuronas, lo que genera una actividad cerebral uniforme, diferenciada y localizada, capaz de ser registrada mediante magnetómetros localizados a lo largo de la convexidad craneal.

\subsubsection{Electromiografía (ElectroMyoGram, EMG).}

Es una técnica para la evaluación y registro de la actividad eléctrica producida por los músculos esqueléticos. Los registros de EMG se realizan utilizando los electromiógrafos, obteniendo así lo que se denomina un electromiograma. Un electromiógrafo detecta la energía potencial generada por las células musculares. Cuando estas células son activadas neuralmente o eléctricamente, las señales pueden registrarse y ser analizadas para detectar anormalidades a partir del nivel de activación, o para analizar la biomecánica del movimiento de un ser vivo. Se emplean una serie de electrodos (agujas o parches) colocados en la superficie de la piel. Se fijan con adhesivos (parches) en los músculos tensores y flexores. La frecuencia $(\mathrm{Hz})$, la amplitud media $(\mathrm{mV})$ y los patrones (síncronos o alteros) se usan para evaluar el temblor [45].

En [47] se sugiere un sistema dedicado a la identificación de varios síntomas de la enfermedad de Párkinson, incluyendo la cuantificación del temblor. Los datos en los que se basan son registros de electromiografía (electromiogramas) de los músculos del antebrazo y del pie. El objetivo era investigar tanto este tipo de temblor patológico como el temblor fisiológico en sujetos normales, ofreciendo la posibilidad de definir estadísticamente los dos. Se trataba de conseguir un algoritmo automático de diagnóstico del temblor. Para extraer los parámetros utilizaron solamente cuatro valores de partida:

- La frecuencia donde se producía el máximo de la densidad espectral de potencia (PSD)

- La potencia del pico.

- La potencia asociada a la componente continua $(0 \mathrm{~Hz})$.

- El área del espectro. 
El algoritmo permitió aportar información útil acerca de los parámetros de cada sujeto para posteriormente proporcionársela al personal médico y ampliar así, el conocimiento sobre la disparidad de síntomas de los sujetos con Párkinson.

En un estudio realizado [48], se analiza el cambio del temblor fisiológico con relación a la edad de los pacientes mediante electromiografía y acelerometría. Se evalúa la amplitud y la frecuencia del temblor postural y de reposo bajo condiciones con carga y sin carga. Como se aprecia en la Figura 2.11 los electrodos fueron ubicados sobre el músculo extensor del antebrazo y un acelerómetro sobre el dorso de la mano.
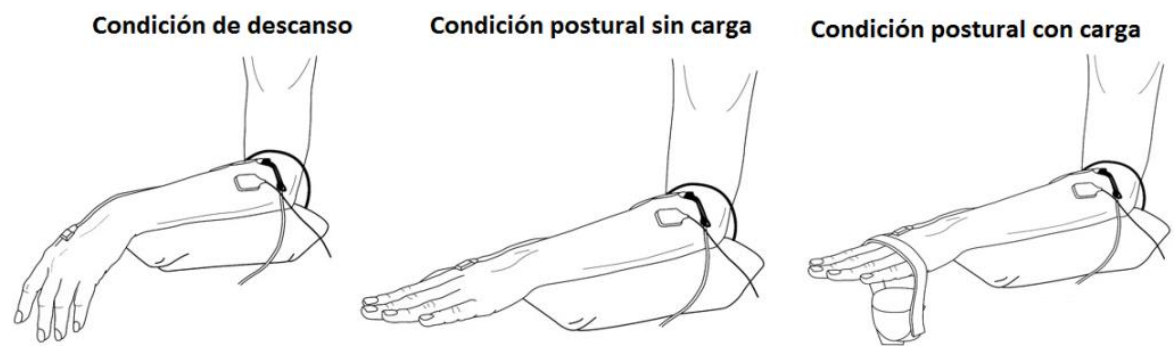

Figura 2.11: Medición del temblor postural y de reposo, con carga y sin carga por EMG y acelerómetros.

En la Figura 2.12 se pueden observar los resultados obtenidos en el trabajo [49], que analiza la señal del temblor no rectificado obtenida por EMG del músculo extensor del antebrazo izquierdo y derecho de un paciente con temblor esencial. En el análisis espectral de frecuencia indica que temblor está en unos $5 \mathrm{~Hz}$ en ambos brazos.
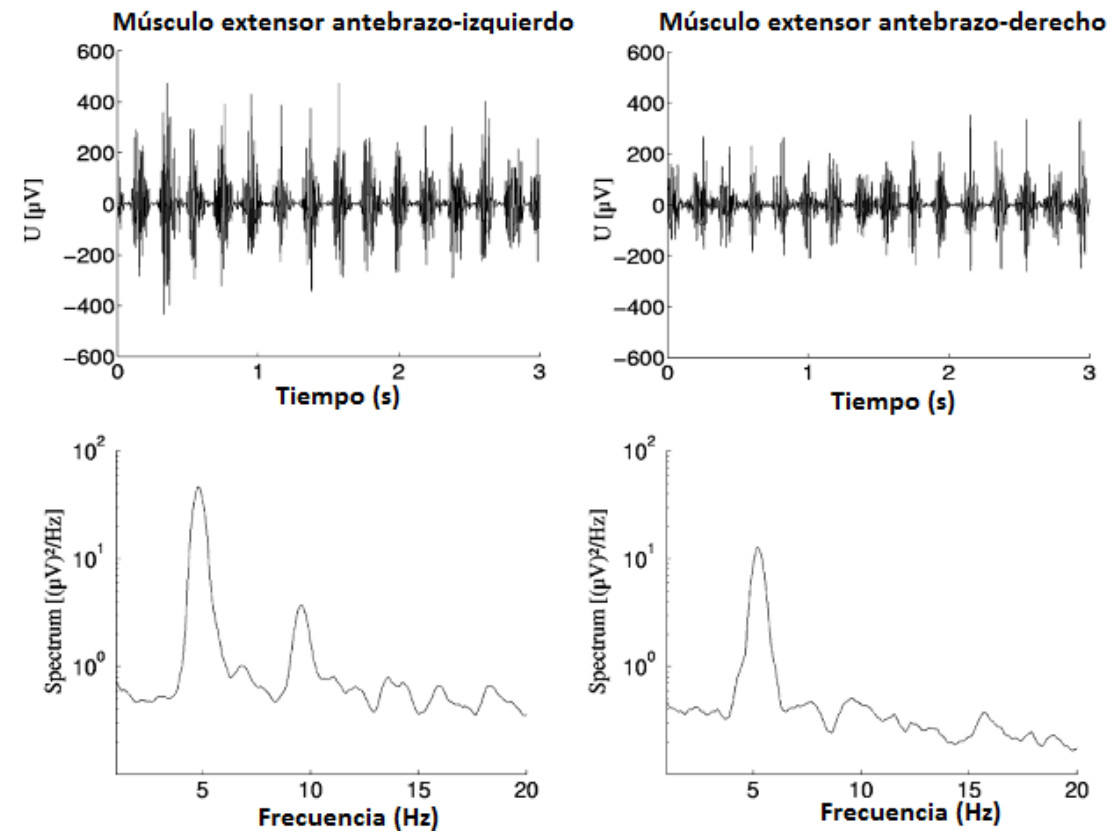

Figura 2.12: Registro de EMG de un paciente con temblor esencial bilateral. 


\subsubsection{Registros invasivos. Registros de microelectrodo (MicroElectrode Recordings, (MER).}

Es una técnica para registrar la actividad individual de las neuronas, así como para realizar una mejor microestimulación con un microelectrodo, ya que permite detectar las dianas más apropiadas para realizar estimulación cerebral profunda (Deep Brain Stimulation, DBS).

\subsubsection{Sistemas basados en imagen médica.}

\subsubsection{Tomografía por emisión de positrones (Positron Emission Tomography, PET).}

Es una técnica no invasiva de diagnóstico capaz de medir la actividad metabólica del cuerpo humano. Al igual que la SPECT, la PET se basa en detectar y analizar la distribución tridimensional que adopta en el interior del cuerpo un radiofármaco de vida media ultracorta administrado a través de una inyección intravenosa. Según qué se desee estudiar se usan diferentes radiofármacos. La imagen se obtiene gracias a que los tomógrafos son capaces de detectar los fotones gamma emitidos por el paciente. La exploración tiene una duración aproximada de 30-45 minutos.

Algunas afecciones distintas a la enfermedad de Párkinson o el temblor esencial, que alteran el movimiento, como la enfermedad de Alzheimer, se pueden estudiar con estas técnicas. En [45] se explica un sistema automático de asistencia al diagnóstico que permite facilitar el diagnóstico del mal de Alzheimer de la demencia leve con cuerpos de Lewy. Usando PET axial convencional y utilizando un mapa del cerebro, junto con métodos estadísticos basados en distribuciones normales, se obtuvo una plantilla de la demencia leve con cuerpos de Lewy. El sistema, operando de manera completamente automática, demostró una precisión del $73 \%$, una sensibilidad del $75 \%$ y una especifidad del $72 \%$ con un amplio banco de pruebas, basado en la información extraída de 71 pacientes (por lo que estos resultados pueden considerarse como suficientemente representativos).

\subsubsection{Tomografía computerizada por emisión de fotones (Single Photon Emission Computed Tomography, SPECT).}

Es una técnica médica de tomografía que utiliza rayos gamma. Muy parecida a una radiografía, pero utiliza una cámara sensible a los rayos gamma y no a los rayos $X$. Como en una radiografía, cada uno de las imágenes que se obtienen es bidimensional, pero pueden combinarse muchas imágenes tomadas desde distintas posiciones alrededor del paciente para obtener una imagen tridimensional. Esta imagen tridimensional puede después tratarse para obtener secciones dimensionales del cuerpo en cualquier orientación. Cada imagen tarda típicamente 15-20 segundos, con lo que el proceso completo tarda de 15 a 20 minutos. Se pueden utilizar también cámaras gamma con varios cabezales para acelerar el proceso. Por ejemplo, se pueden poner dos elementos espaciados 180 grados para obtener dos proyecciones simultáneamente, o tres espaciados 120 grados. 
El desarrollo de diversas técnicas de imagen médica permite disponer de una información muy valiosa en enfermedades relacionadas con el sistema nervioso. Poder "ver" regiones del cerebro sin necesidad de la defunción del paciente (autopsia) ha sido, sin duda, un gran avance en este campo. Varios estudios sobre imagen médica revelan que la pérdida de portadores de dopamina en pacientes con enfermedad de Parkinson es pronunciada.

Existen estudios [54] en los que se muestra que el SPECT es una herramienta útil para el diagnóstico de la enfermedad de Parkinson. En [55] se desarrolló un método de ayuda al diagnóstico del Párkinson. Se utiliza un modelo para la segmentación de los ganglios basales del cerebro. La información del estudio se extrajo de un conjunto de 89 sujetos, de los cuales 65 tenían Párkinson. Y los pasos del método de clasificación fueron:

1. Segmentación de los ganglios basales ajustando un modelo tridimensional sobre la imagen.

2. Extracción de 17 características basadas en la distribución de intensidad de la imagen dentro de la zona segmentada (y etiquetada como zona de ganglio basal), y relativa a la distribución de la intensidad de la imagen de la zona exterior.

3. Clasificación mediante Máquinas de Soporte de Vectores (Support Vector Machine, SVM).

Los resultados de la clasificación automática mostraron una acierto verdadero del $96.9 \%$ y un rechazo verdadero del 91.6\%. La clasificación basada en una cuantificación manual (en la que los especialistas evaluaban las imágenes) tuvo una aceptación verdadera del $98.5 \%$ y un rechazo verdadero del 100\%.

\subsubsection{Origen múltiple de información. Fusión de señales.}

En la actualidad, el interés en la caracterización de señales de temblor adquiridas mediante diferentes técnicas como las mencionadas anteriormente, ha crecido de manera significativa. Resulta cuanto menos curioso que incluso cuando dos señales que representaban el temblor significativo tienen la misma frecuencia medida con diferentes técnicas, estas no son del todo coherentes. Esto hace suponer que el temblor es originado en varios lugares, o que el temblor es modulado por fuentes desacopladas de origen desconocido. Algunos estudios han determinado también que este desacoplamiento varía en el tiempo. Algunos trabajos han propuesto varios índices de acoplamiento de fase, como ratios invariantes en el tiempo ante cambios en la amplitud de la señal. Estos métodos se basan en medidas de la coherencia de fase, la entropía y la información entre dos señales de fase instantáneas. Pero ninguno de estos trabajos ha concluido con resultados concluyentes. En [56] se intentó buscar una medida del acoplamiento de fase más precisa de las que se tenían hasta el momento. Para ello se comparó el índice de correlación tradicional con otros tres índices de acoplamiento de fase en un estudio simulado. En este estudio se compararon dos frecuencias instantáneas que se mezclaban para crear dos señales de temblor con un grado de acoplamiento de fase 
conocido. Para ello, se estimó la fase instantánea (Instantaneous Phase, IP) y la frecuencia instantánea (Instantaneous Frequency, IF) de la señal del temblor. Utilizando un filtro pasobajo, se pudo ratificar que la evolución de las IF a lo largo del tiempo es de pulsación lenta. Se comprobó la fiabilidad del método, midiendo los diferentes valores de los distintos índices de sincronización de fase detallados en el artículo. Después de analizar los resultados se concluyó que no todos eran igual de válidos, y que había uno en particular que era más preciso y especialmente indicado por:

- Abarcaba todo el rango de posibles valores del índice de acoplamiento, con lo que era útil tanto para acoplamientos prácticamente nulos como para acoplamientos de fase elevados.

- Para un determinado grado de acoplamiento, el valor significativo era invariante en la adquisición de datos.

- Se podía generalizar para otorgar más peso a los valores de señales cercanas, de manera que pueden ser utilizadas para acoplamientos de fase que varían con el tiempo en las señales del temblor.

Por todo lo planteado se concluyó que este coeficiente era el más apropiado a la hora de medir el acoplamiento de fase.

El temblor neuronal que se puede obtener mediante microelectrodos situados cerca de las células nerviosas o de las células del cerebro durante neurocirugía estereotáctica, es debido a la fluctuación de la tasa de disparo de las neuronas. La frecuencia de este temblor neuronal cambia a lo largo del tiempo. En [57] se presenta un método de rastreo de la frecuencia usando el filtro extendido de Kalman (Extended Kalman Filter, EKF) para estimar la frecuencia del temblor instantánea de los trenes de pulsos detectados por registros de microelectrodos (MER). Los autores utilizaron un modelo estocástico con el que creaban trenes de pulsos binarios sintéticos. El EKF sirve para estimar el estado de un proceso no lineal recursivamente, de modo que se va reduciendo la media del error cuadrático. Con este algoritmo se consigue actualizar la estimación del estado basándose en el estado anterior y en la nueva medida de datos sin necesidad de emplear un almacenamiento global de toda la información. Entre las pruebas realizadas se probó a utilizar el modelo de varias maneras:

- Cambiando la frecuencia instantánea cada 20 segundos.

- Ante frecuencia aleatoria, evolucionando de manera errática.

- Utilizando un espectrograma de un MER real con temblor.

En todos los casos se consiguió un estimador capaz de rastrear el estado continuamente, incluso cuando el ruido de los trenes binarios no era gausiano. 


\subsubsection{Registros de voz.}

La disfonía es un término general que se refiere a los trastornos de la voz e incluye cualquier problema patológico o funcional relacionado ella: la voz suena ronca, forzada o con esfuerzo. Puede resultar difícil de entender debido a que es muy pausada, restándole protagonismo al contenido del mensaje. En el diagnóstico de Párkinson se han realizado estudios de medición de los trastornos de la voz, en los que los sonidos del habla producidos durante pruebas estándar se registran utilizando un sistema de grabación. Las señales de voz grabadas posteriormente son analizadas para detectar ciertas propiedades.

Existen estudios donde se han propuesto diferentes métodos de medición para evaluar los síntomas de la disfonía. En [58] se realizó una comparación de diversos métodos de diagnóstico del Párkinson utilizando señales de voz. Participaron 31 personas, de las cuales 23 eran pacientes con Párkinson y el resto individuos sanos. Se plantearon diferentes metodologías para comprobar su efectividad:

- Redes neuronales (92.9\% de aciertos).

- Regresión (88.6\% de aciertos).

- Árboles de decisión (84.3\% de aciertos).

Como se puede ver, los mejores resultados fueron encontrados mediante la utilización de redes neuronales, con una tasa de acierto en la clasificación entre sujetos con PD y sanos del 92.9\%.

\subsubsection{Visión por computador (Computer Vision, CV).}

\subsubsection{Detección mediante marcadores.}

En [59] se describe una técnica para analizar los movimientos usando un analizador de movimientos de precisión (PRIMAS) basado en marcadores y cámaras con sensor CDD. Este trabajo tiene como objetivo realizar una medida precisa de la evolución de la enfermedad de Parkinson y también de la eficacia del tratamiento, además de ayudar en el diagnóstico precoz. Utilizan determinados patrones de movimiento por parte del paciente. En este trabajo se observó, por ejemplo, cómo la rigidez muscular podía ser caracterizada mediante el espectro de potencia. Los parámetros más relevantes fueron la frecuencia, la amplitud, la suavidad, la simetría y el efecto o relación del movimiento de una mano sobre el de la otra. También describen cómo cada paciente con Párkinson tiene un comportamiento muy distinto a otros, debido a que el desarrollo de esta enfermedad hace evolucionar los síntomas de una manera muy variada.

\subsubsection{Detección y reconstrucción mediante barrera láser.}

En [60] se presenta un sistema de medida de la enfermedad de Párkinson usando líneas láser y un sensor de imagen CMOS. El sistema detecta la vibración del dorso de la mano de un sujeto en dos situaciones: manteniendo la mano en una postura y en reposo. Utiliza un diodo láser para marcar el dorso de la mano y así 
detectar la forma, frecuencia y frecuencia relativa de las ondas de vibración del temblor.

El método para detectar el temblor es el habitualmente utilizado en reconstrucción de imágenes: la triangulación. Se utiliza la línea láser de manera que el centro recorre la mano, mientras que los dos extremos se proyectan sobre la base plana, tomándola como base de la triangulación. Posteriormente se realiza una reconstrucción que permite determinar la altura (eje z) de la mano en cada punto, utilizando una FFT para determinar las componentes frecuenciales.

Se utilizan métodos de procesamiento subpíxel para incrementar la resolución de la imagen, así como una salida de audio para reproducir las frecuencias en el proceso de calibración. Los errores obtenidos son inferiores al 2.5 \% en la medición de esta frecuencia.

\begin{tabular}{|c|c|c|}
\cline { 2 - 3 } \multicolumn{1}{c|}{} & Promedio $(\mathrm{Hz})$ & Rango $(\mathrm{Hz})$ \\
\hline PD reposo & 4.5 & - \\
\hline PD postural & 1 & $0.5-1.5$ \\
\hline Control reposo & 0.4 & $0-0.8$ \\
\hline Control postural & 0.75 & $0-1.5$ \\
\hline
\end{tabular}

Tabla 2.8: Resultados sobre las frecuencias encontradas por el sistema de medición mediante línea láser.

Los resultados además mostraron que tanto el temblor postural como el estático incrementan su frecuencia a medida que lo hace la duración de la enfermedad.

Las principales ventajas de este sistema eran:

- No se requiere contacto físico entre el paciente y el sistema, por lo que el temblor no se ve modificado por causas externas al trastorno.

- Es un sistema de bajo coste.

- Es portátil, dado su reducido tamaño y peso. 


\section{PLATAFORMA DE AYUdA AL DIAGNÓSTICO (DIMETER).}

Siendo uno de los objetivos de esta tesis obtener una clasificación diferenciada entre el temblor patológico y el temblor fisiológico; así como también una ayuda al diagnóstico diferencial entre el temblor de Párkinson y el temblor esencial, a partir de registros clínicos, y teniendo en cuenta la experiencia proporcionada por otros autores ya referida en el estado del arte, es imprescindible disponer de un sistema de adquisición y registro de los datos del temblor sobre un colectivo de pacientes, si lo que queremos es poder estudiar y analizar los trastornos del movimiento asociados a dichas enfermedades

Después de estudiar y barajar diferentes alternativas, teniendo presente que someter a la extremidad del paciente con temblor a esfuerzos controlados podría ser una vía de estudio de éxito, se eligió como sistema de registro un dispositivo háptico con realimentación de esfuerzos. Se apostó desde un principio por no sólo capturar y guardar los desplazamientos debidos al temblor de los diferentes pacientes, sino también en la posibilidad de generar fuerzas en el extremo para estudiar el comportamiento de las reacciones de los individuos tanto sanos como enfermos.

Bajo el marco del proyecto DIMETER, un convenio de colaboración entre el organismo público CEAPAT (Centro de Referencia Estatal de Autonomía Personal y Ayudas Técnicas), varios centros hospitalarios como el Hospital Ramón y Cajal y el Hospital de la Princesa de Madrid y la Universidad Politécnica de Madrid, se desarrolló dicha plataforma y se realizaron pruebas presenciales en los centros sanitarios durante varios años. Concretamente, la mayoría de los registros de los que hemos dispuesto para el estudio, proceden del Hospital Ramón y Cajal, centro referencial a nivel nacional de la enfermedad del Párkinson. Donde además tienen lugar la mayoría de las intervenciones quirúrgicas en la terapia de la Estimulación Cerebral Profunda (CBS). 


\subsection{DIMETER.}

El DIMETER es un sistema patentado [61], cuyo propósito es la caracterización objetiva del temblor mediante patrones que aplican fuerzas virtuales. El sistema registra tridimensionalmente los movimientos de la extremidad (en posición, velocidad y aceleración), mientras la persona realiza una serie de acciones, propuestas y controladas por el técnico sanitario (neurofisiólogo). El sistema puede ejercer fuerzas virtuales configurables, interfiriendo en el movimiento, permitiendo así conocer los efectos que sobre el mismo tienen las cargas estáticas, rozamientos u otro tipo de fuerzas, proporcionando junto a los datos morfológicos y frecuenciales posibles criterios para la evaluación del temblor.
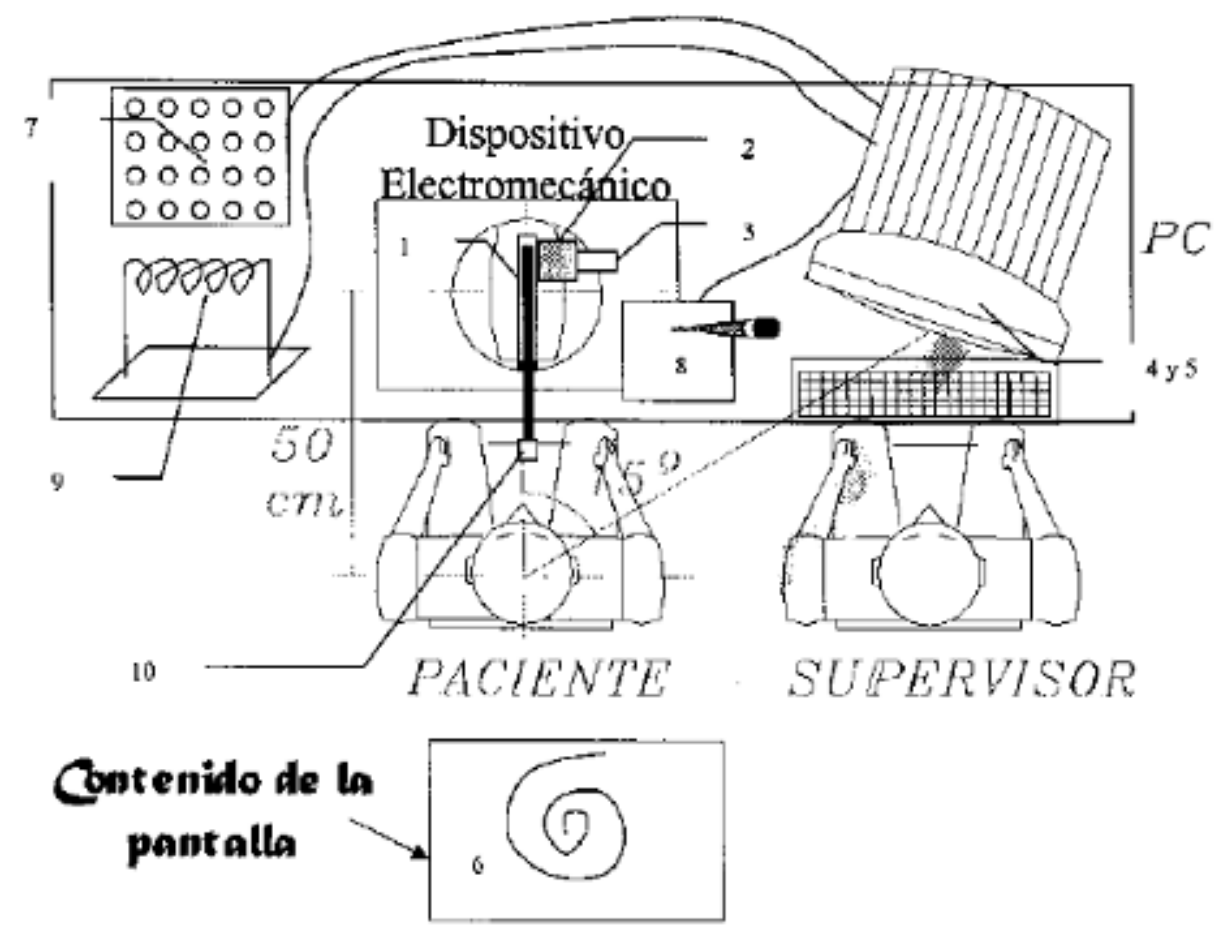

Figura 3.1: Sistema DIMETER.

El sistema está compuesto por:

- Sistema háptico de adquisición y realimentación de esfuerzos (2) y (3).

- Equipo informático (4) y (5).

- Aplicación software para la realización de las pruebas, registro de los datos de las mismas y envío de las consignas de fuerza en función de las tareas previstas (6).

- Elementos auxiliares para la realización de las pruebas $(7,8$ y 9).

El sistema no sólo es un dispositivo de registro sino que además permite la puesta en práctica de una serie de pruebas específicamente destinadas a realizar una serie de tareas para intentar la caracterización del temblor, ya sea fisiológico o 
patológico. Estas pruebas consisten en la realización de diferentes patrones de movimientos realizados por la mano o dedo del usuario, pudiéndose aplicar fuerzas generadas virtualmente sobre la mano o dedo mientras se registran las componentes espaciales de dicho movimiento, al objeto de realizar una cuantificación objetiva de las magnitudes asociadas al temblor.

El sistema mecánico articulado es accionado mediante una serie de servomotores, lo que le permite además de capturar el movimiento, desarrollar fuerzas y pares. La posición de cada articulación se puede conocer con precisión gracias a los encoders (sensores digitales de posición de giro). El dispositivo gracias a sus tres articulaciones (tres grados de libertad), facilita el registro del movimiento del temblor en las tres direcciones del espacio de las extremidades superiores: mano o dedo. El dedo o la mano del paciente se sujeta al extremo (10), y éste al seguir el patrón presentado en pantalla, desplaza el extremo del sistema mecánico articulado, provocando que los sensores (3) de las articulaciones capten el movimiento. La presencia de los motores o actuadores eléctricos (2) en las articulaciones del dispositivo, permite utilizar fuerzas o cargas virtuales para medir el efecto que, sobre el temblor en las extremidades del sujeto a examinar, plantean este tipo de situaciones, mientras el paciente mantiene su extremidad bien en reposo, bien permaneciendo en una postura estática, bien realizando un movimiento espacial conocido a priori, bien escribiendo o dibujando, bien tratando de seguir un objetivo que se mueve tridimensionalmente de manera aleatoria, o bien tratando de tocar partes de su propio cuerpo. El paciente debe realizar una serie de patrones (6), mostrados en el monitor del ordenador (4) o en alguno de los dispositivos externos (7). Los patrones utilizados consisten en trayectorias predefinidas, bien sobre la pantalla del ordenador o bien sobre el espacio real tridimensional. Estos patrones pueden ser simultáneamente de movimiento y fuerza, mantener la posición o realizar una determinada trayectoria. Los patrones se muestran sobre la pantalla del ordenador (4) (trayectorias en 2 dimensiones de tipo lineal, circular, vaivén o espiral), sobre un panel (7) formado por una matriz de LEDs o luces (movimientos reactivos), sobre una tableta digitalizadora (8) (trazado de dibujos y firma) sobre el espacio físico cercano al paciente (movimientos propioceptivos) o sobre otros elementos externos (9).

Se ha desarrollado una aplicación específica para la adquisición, registro y análisis de las pruebas. Ésta posibilita a través de diferentes ventanas y menús, de fácil compresión, realizar una selección del patrón bajo el cual se realizará la adquisición. De igual forma, facilita el seguimiento de la evolución temporal de la enfermedad del paciente, generando diferentes archivos para cada sesión de pruebas realizadas, guardando datos como identificación personal del paciente, fecha y hora en la que se realizó la prueba, anotaciones que se consideren importantes, como condiciones en las que la prueba fue realizada, estado del paciente, medicación a la que se ve sometido, tiempo transcurrido desde que se realizó la última toma, etc. El dispositivo háptico utilizado como prototipo es fabricado por Sensable Tech, bajo el nombre de PHANTOM, y presenta la posibilidad de capturar la posición y orientación de un objetivo en el espacio, así como la capacidad de ejercer diferentes tipos de fuerzas sobre el mismo. Se trata de 
un dispositivo que es ampliamente utilizado en trabajos de investigación en interfaces hombre-máquina, ya que dentro de los diferentes tipos de dispositivos existentes es el que mejor sensación de tacto y fuerza ofrece.

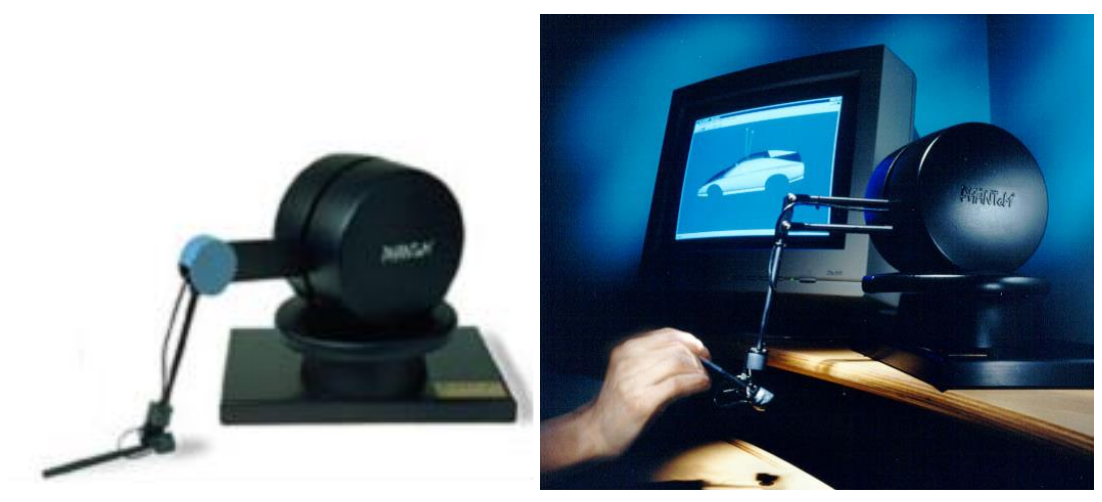

Figura 3.2: $\quad$ PHANTOM de SensAble.

Algunas características del PHANTOM son:

- Precisión : $\quad 0.03 \mathrm{~mm}$

- Espacio de trabajo : $\quad 19.5 \times 27 \times 37.5 \mathrm{~cm}$

- Fuerza máxima ejercida : $8.5 \mathrm{~N}$

- Fricción interna: $\quad 0.04 \mathrm{~N}$

Como interfaz con el PC utiliza una tarjeta PCI que va conectada al control de los motores y de los captadores de posición. El lazo interno de control de los motores se actualiza con una frecuencia de $1 \mathrm{KHz}$, lo que permite una rápida adquisición de las posiciones del efector final. El sistema tiene 6 grados de libertad y permite medir posición y orientación en las tres direcciones del espacio. La velocidad y aceleración se obtienen de forma inmediata derivando la información obtenida de la trayectoria del paciente. El sistema PHANTOM dispone de sus propias librerías para su programación, desarrolladas en $\mathrm{C}++$ y que representan un ambiente "háptico" como un árbol de geometrías y efectos en el espacio. Estas librerías son un conjunto de clases en $\mathrm{C}++$ que tienen las características propias como la herencia y el polimorfismo.

\subsection{Procedimiento de sesión.}

Los pasos seguidos durante la realización de las pruebas han sido:

- Breve reconocimiento médico del paciente. Aquellas observaciones que fueron consideradas importantes, se tuvieron después en cuenta introduciéndose en el campo de "Observaciones". 
- Introducción de datos del paciente. Con la finalidad de poder realizar una sencilla identificación de los ficheros de datos obtenidos en las pruebas, así como poder hacer un seguimiento de la evolución del mismo.

- Posicionamiento del paciente. Es necesario fijar la posición del paciente con respecto al sistema de medición, de tal modo que las medidas después obtenidas se obtengan siempre en condiciones similares, garantizando de esta forma la coherencia. El plano frontal o coronal está formado por los ejes $x$ e $y$ del sistema de referencia, con el eje $y$ apuntando hacia arriba. El plano sagital está formado por los ejes y y $z$, mientras que el plano transversal está formado por los ejes $x$ y $z$. Tal y como puede verse en la Figura 3.3:

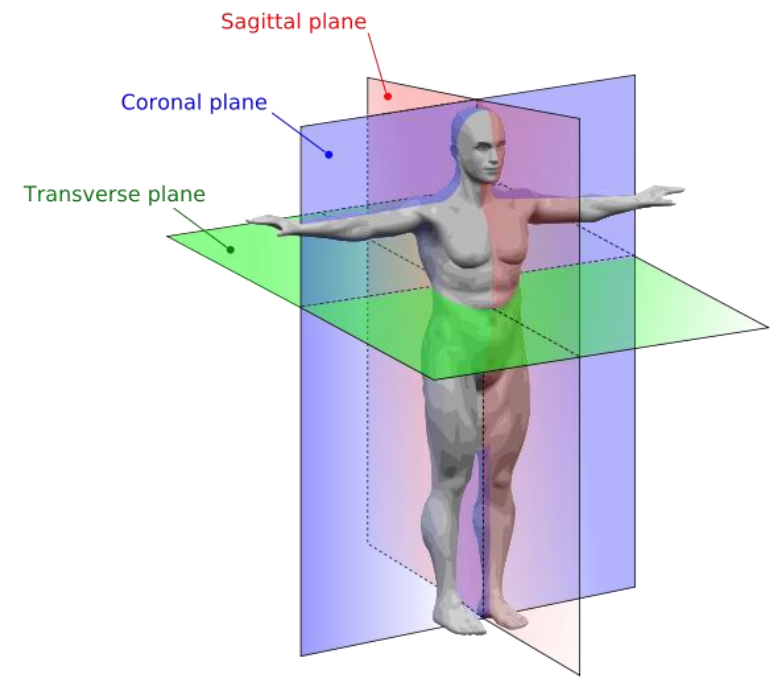

Figura 3.3: Esquema de los tres planos principales.

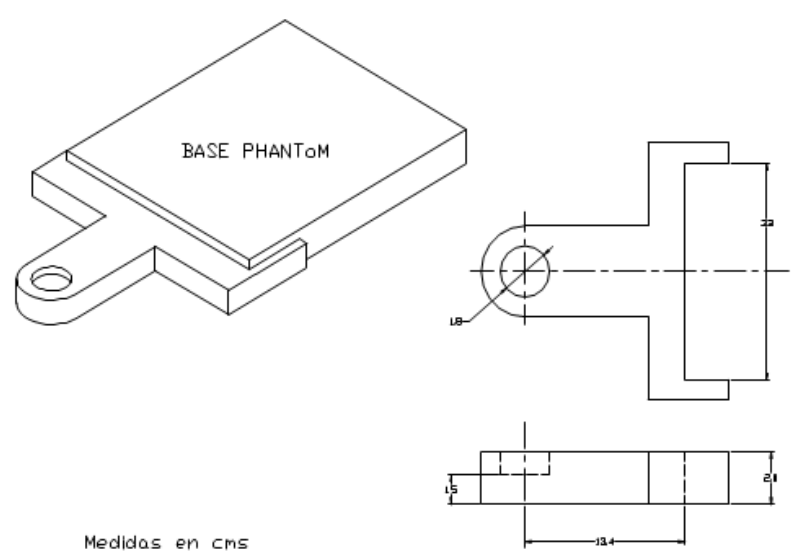

Figura 3.4: Base para fijar la referencia. 
La figura Figura 3.4 muestra la base donde se apoya el PHANTOM y se fija la posición inicial o de calibración.

- Fijación del extremo del sistema de medida al dedo índice del paciente. El dedo del paciente queda a la altura de su hombro, quedando dentro del campo de trabajo del PHANTOM. Es además preciso que el paciente mantenga la orientación de la mano con respecto al sistema de referencia empleado durante la ejecución de la prueba, tal y como se puede apreciar en la Figura 3.5.

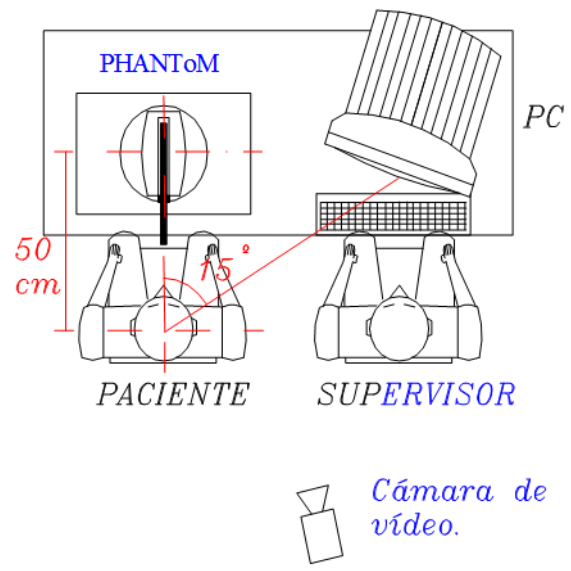

Figura 3.5: Colocación del paciente.

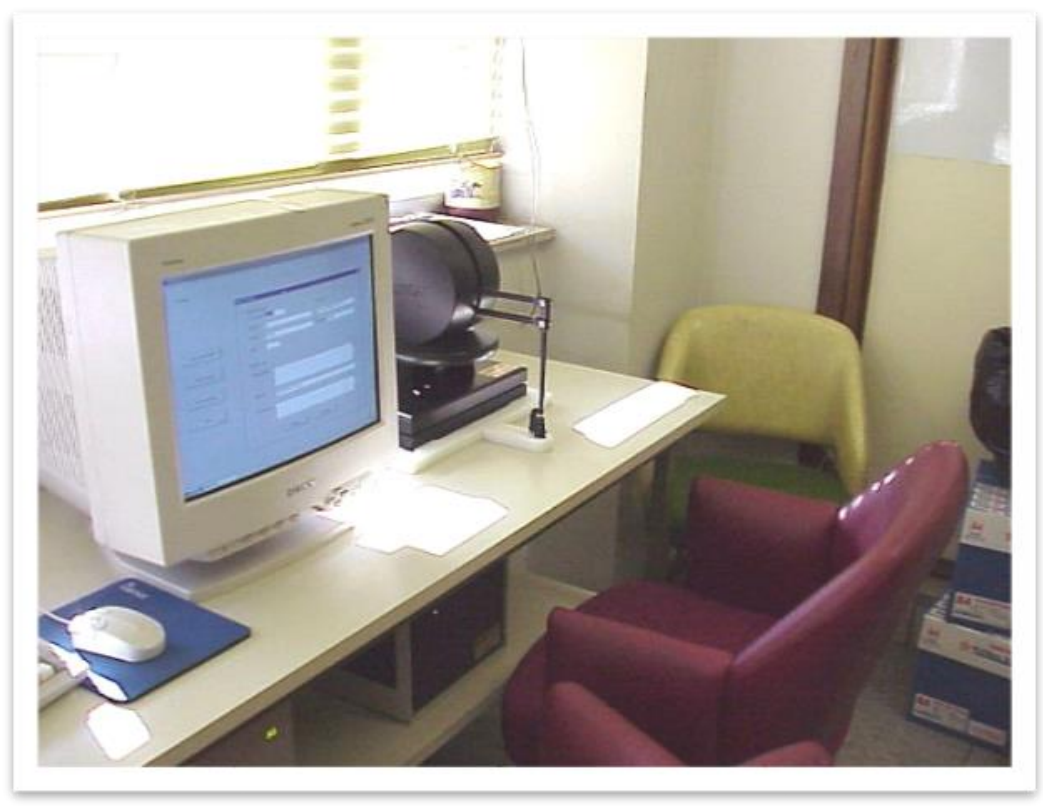

Figura 3.6: Puesto real de pruebas (Servicio de Neurofisiología - Hospital Ramón y Cajal). 
- Descripción verbal de la forma en la que se debe realizar cada patrón de prueba propuesto. Al paciente se le indica qué es lo que debe intentar hacer sobre cada patrón, que se visualiza en la pantalla, o se realiza utilizando una tarea tridimensional. Estas estructuras tridimensionales precisan ser referenciadas respecto al sistema de medida. En la Figura 3.7 se muestra una instantánea del sistema mientras se selecciona uno de los patrones.

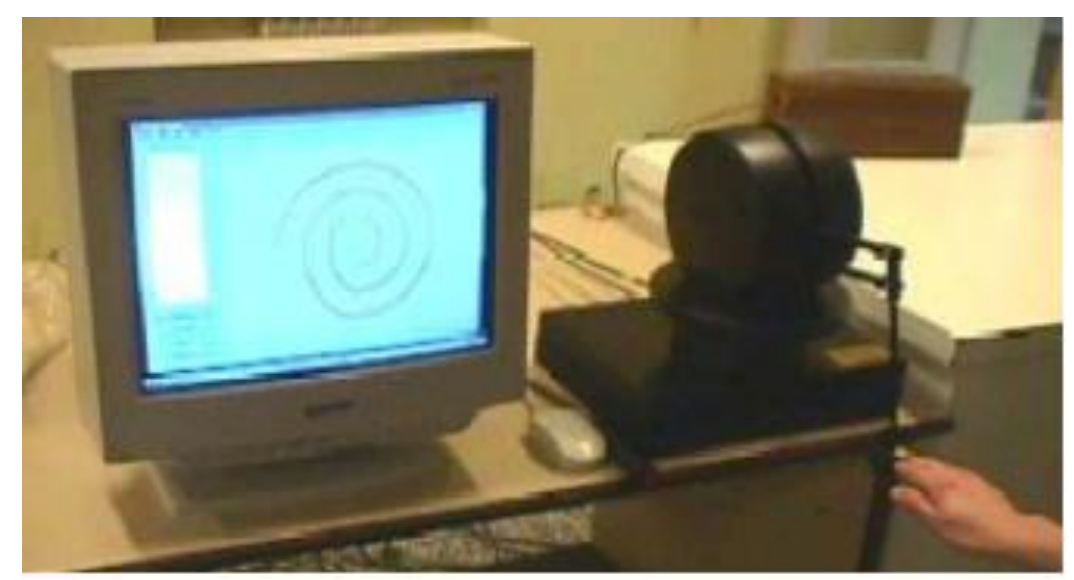

Figura 3.7: Presentación de la prueba.

En la Figura 3.8 y en la Figura 3.9 se muestra el detalle de la plataforma para pruebas 3D.

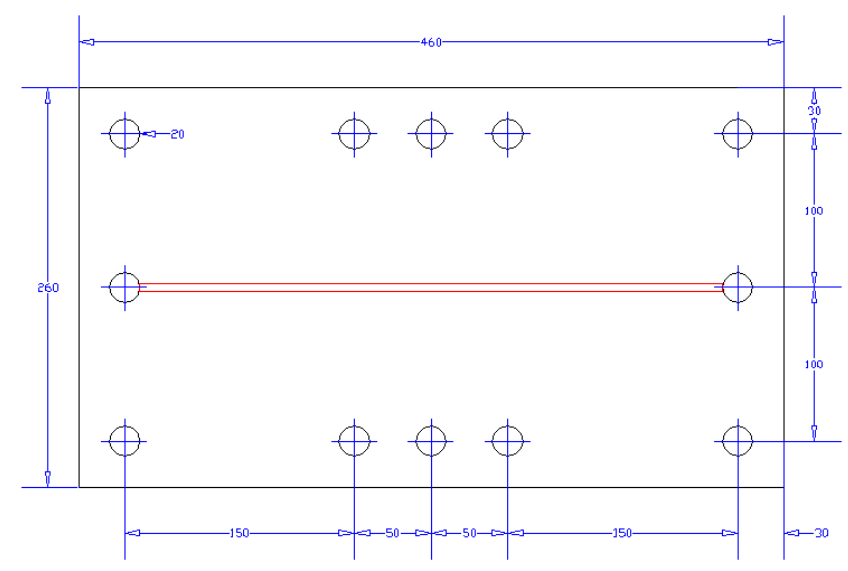

Figura 3.8: $\quad$ Vista en planta de la plataforma de pruebas 3D. 


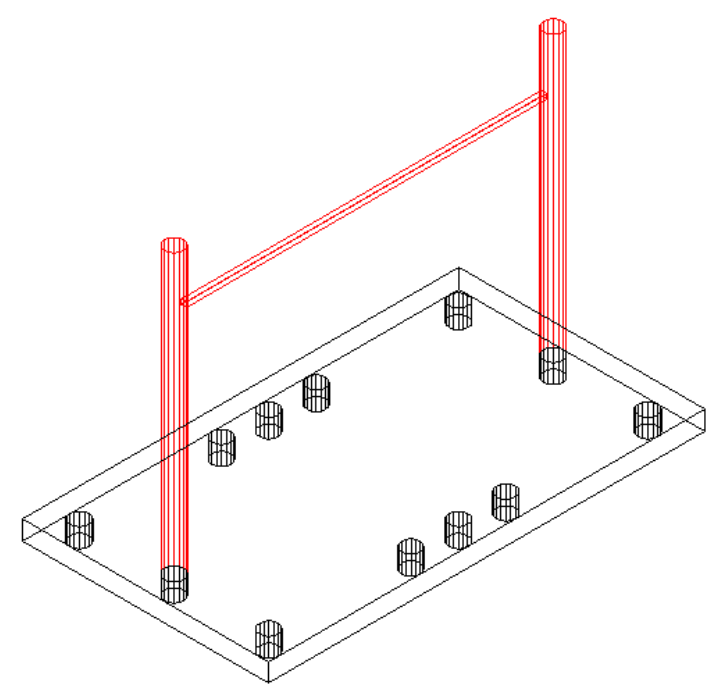

Figura 3.9: $\quad$ Escenario de patrones 3D.

- Realización de varios ejercicios de prueba sobre un mismo patrón. De este modo el paciente se familiariza con la interfaz y el sistema de medida. Al mismo tiempo practica el ejercicio propuesto sobre cada patrón, obteniendo una idea de la dificultad de su ejecución. En la Figura 3.10 se puede observar una instantánea de una sesión (simulada, se preserva así la confidencialidad de los pacientes)

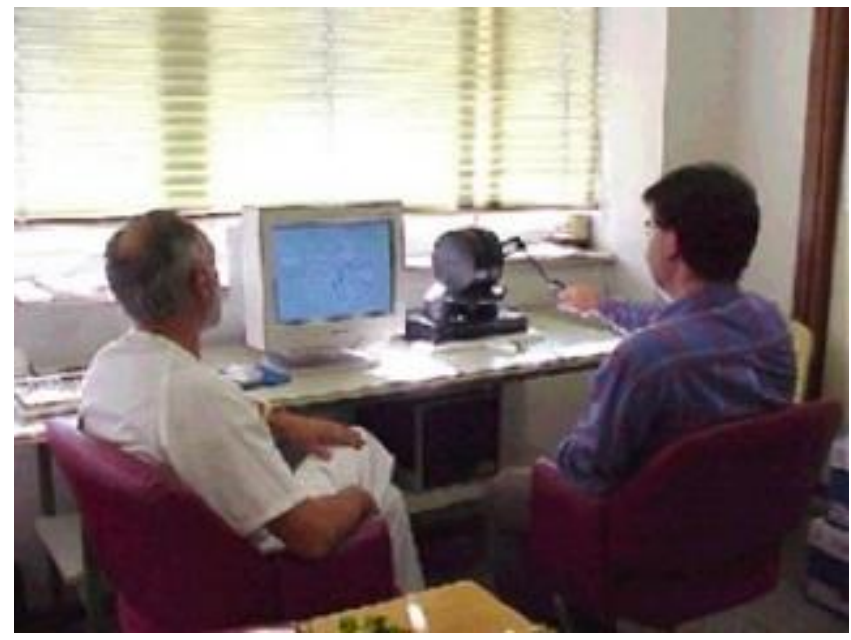

Figura 3.10: Ejemplo de prueba del DIMETER.

- Realización de la prueba para la obtención de los datos. Las pruebas han sido realizadas bajo la supervisión del personal especializado del hospital (servicio de neurofisiología), con la finalidad de descartar aquellas condiciones (estado del paciente, tipo de afectación, estado farmacológico, situación en pre o post operatorio, etc ...), que no cumplan requisitos adecuados desde el punto de vista médico. Motivos de la exclusión podrían ser bien porque el paciente hubiese variado de forma considerable su posición, hubiera aumentado su estado de nerviosismo o los resultados adquiridos se diferenciaran de forma 
notable de los que se hubieran obtenido durante las pruebas de entrenamiento.

- Al término de cada prueba se deja un pequeño descanso, mientras se procede a la validación de los datos y a su almacenamiento. Posteriormente se realizaba el cambio de patrón para la siguiente prueba. En el caso de apreciar cansancio del paciente este receso se aumentaba.

- La realización de cada prueba se realizada tanto con la mano derecha como con la izquierda. Comenzando en todos los casos con la mano que mayor afectación de temblor mostraba.

El orden en el que fueron realizadas las pruebas fue:

- Patrones estáticos.

- Patrones cinéticos.

- Patrones tridimensionales.

- Patrones dinámicos.

- Las pruebas realizadas a los pacientes han sido en horario de mañana a partir de las $10.30 \mathrm{H}$.

- La duración media de las pruebas fue de 90 minutos, presentando mayor duración las pruebas realizadas con la mano de mayor grado de temblor.

\subsection{Definición de los patrones.}

\subsubsection{Introducción.}

Las diferentes pruebas planteadas en el estudio pretenden, a partir de la realización de patrones de movimiento básicos y sencillos, obtener la componente no intencional característica del temblor en el movimiento del paciente, determinado por las desviaciones que se producen respecto a la trayectoria ideal. Un patrón consiste en una trayectoria claramente definida que le indica al paciente un movimiento a realizar, fijando direcciones de intención según la tarea. Son trayectorias básicas, como líneas rectas o curvas en las que se busca cuantificar la desviación causada por el temblor. Para el diseño de las pruebas y de los patrones se tuvo en cuenta principalmente el tipo de circunstancias y habilidades que se requerían para la evaluación del paciente. Es así como se propusieron tareas en las que los movimientos que se tenían que realizar eran sencillos, en direcciones preestablecidas como por ejemplo una línea recta horizontal, círculos, espirales, etc. Además se tuvo en cuenta los estándares que hay sobre pruebas que se realizan en la evaluación clínica, del cómo seguir líneas rectas horizontales sobre papel, estirar el brazo a la altura del hombro, movimientos de extensión y flexión de los brazos y seguimiento de líneas en forma de sinusoides. Los patrones se clasificaron en tres grupos dependiendo de la clase de prueba: estáticos, cinemáticos y dinámicos. Los estáticos son en los que el paciente debe mantener una posición fija durante la 
prueba, buscan evaluar el temblor postural. Los cinemáticos son en los que se debe realizar algún tipo de movimiento intencional de manera activa y en los dinámicos además se involucra algún tipo de fuerza externa de restricción. Estos dos últimos buscan evaluar el temblor cinético. Teniendo en cuenta no sólo el registro del temblor en uno o dos ejes, sino también involucrando tareas en tres dimensiones, se diseñaron pruebas fuera de la pantalla del ordenador. En todo momento se pensó también en la comodidad del paciente e intentando simular en lo posible, situaciones cotidianas, como levantar un vaso, tocarse la nariz, etc ... Debe considerarse que no se puede presuponer que el paciente tenga práctica en el uso del ordenador, y que a las dificultades propias de su temblor se le sume la falta de manejo del dispositivo de interfaz, además del reto en la asociación espacial entre el movimiento de su mano y el reflejado en la pantalla. Por ello se han incorporado pruebas consistentes en seguir líneas físicas en el espacio las cuales son colocadas adecuadamente a las necesidades de la prueba. Por ejemplo, una línea que al seguirla obligará al paciente a realizar movimientos de extensión y flexión del brazo. Adicionalmente a la descripción de la trayectoria que debía seguir el paciente, en algunos patrones se aplicó alguna restricción mecánica en forma de fuerza constante, muelle y rozamiento viscoso, con el fin de posteriormente poder evaluar el efecto de ellos en el temblor. La aplicación de fuerzas como medio de restricción del temblor en pacientes ha sido estudiada ampliamente teniendo resultados positivos como se comentó en el capítulo 2. Hay estudios en los que se demuestra que fuerzas de tipo rozamiento viscoso son especialmente eficaces para la supresión de temblor intencional y que fuerzas debidas a inercias son especialmente efectivas para temblores de baja frecuencia. Los patrones se clasificaron en dos grupos, los que se realizaron utilizando trayectoria definida en la pantalla del ordenador (2D) y los que se realizaron con trayectoria definida en el espacio real (fuera de la pantalla, 3D).

\subsubsection{Patrones 2D.}

\section{- Brazo apoyado.}

\begin{tabular}{|l|l|}
\hline Nombre: & PT1 \\
\hline Trayectoria: & Ninguna \\
\hline Posición del Paciente: & $\begin{array}{l}\text { Frente al dispositivo de captación, brazo totalmente } \\
\text { estirado hacia el frente, a la altura del hombro. }\end{array}$ \\
\hline Objetivo: & $\begin{array}{l}\text { Mantener la mano libre con el codo apoyado en la mesa. } \\
\text { Angulo de } 90 \text { grados entre el brazo y el antebrazo. }\end{array}$ \\
\hline Manos: & Ambas (izquierda y derecha) \\
\hline Medida registrada: & Posición $X, Y, Z$ en el tiempo \\
\hline Observaciones: & Prueba de tipo estática \\
\hline
\end{tabular}

Tabla 3.1: Patrón PT1. 


\section{- Diana en pantalla.}

\begin{tabular}{|l|l|}
\hline Nombre: & PT2 \\
\hline Trayectoria: & Punto en Pantalla \\
\hline Posición del Paciente: & $\begin{array}{l}\text { Frente al dispositivo de captación, brazo totalmente } \\
\text { estirado hacia el frente, a la altura del hombro. }\end{array}$ \\
\hline Objetivo: & Mantener fijo el cursor sobre el punto en la pantalla. \\
\hline Manos: & Ambas (izquierda y derecha) \\
\hline Medida registrada: & Desviación $X, Y, Z$ del punto en el tiempo \\
\hline Observaciones: & Prueba de tipo estática \\
\hline
\end{tabular}

Tabla 3.2: Patrón PT2.

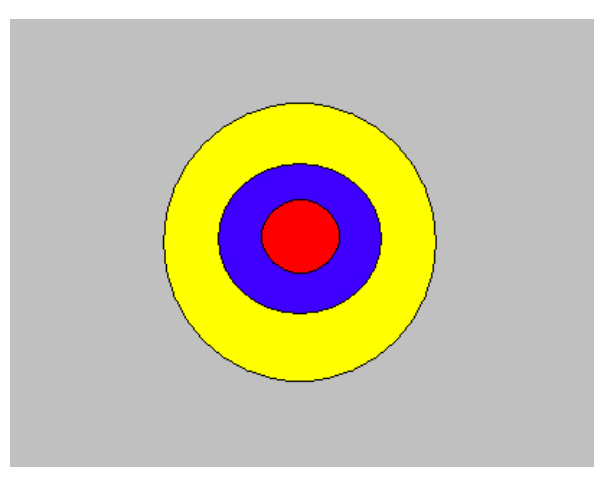

Figura 3.11: $\quad$ Patrón PT2.

- Línea horizontal.

\begin{tabular}{|l|l|}
\hline Nombre: & PT3 \\
\hline Trayectoria: & Línea recta horizontal \\
\hline Posición del Paciente: & $\begin{array}{l}\text { Frente al dispositivo de captación, brazo totalmente } \\
\text { estirado hacia el frente, a la altura del hombro. }\end{array}$ \\
\hline Objetivo: & $\begin{array}{l}\text { Mover el cursor dentro del "camino" del punto inicial } \\
\text { al punto final de la recta. }\end{array}$ \\
\hline Manos: & Ambas (izquierda y derecha) \\
\hline Medida registrada: & Desviación perpendicular a la dirección de la línea. \\
\hline Observaciones: & Prueba de tipo cinemática. \\
\hline
\end{tabular}

Tabla 3.3: Patrón PT3. 


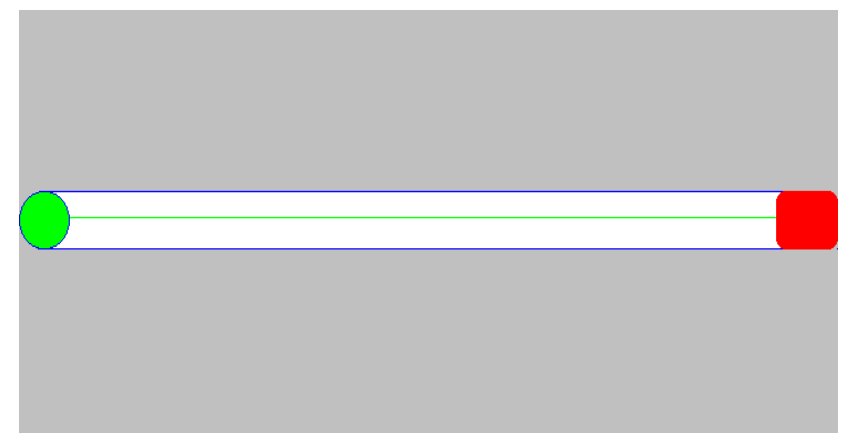

Figura 3.12: Patrón PT3.

- Línea inclinada ascendente.

\begin{tabular}{|l|l|}
\hline Nombre: & PT4 \\
\hline Trayectoria: & Línea ascendente inclinada \\
\hline Posición del Paciente: & $\begin{array}{l}\text { Frente al dispositivo de captación, brazo totalmente estirado } \\
\text { hacia el frente, a la altura del hombro. }\end{array}$ \\
\hline Objetivo: & $\begin{array}{l}\text { Mover el cursor dentro del "camino" del punto inicial al } \\
\text { punto final de la recta. }\end{array}$ \\
\hline Manos: & Ambas (izquierda y derecha) \\
\hline Medida registrada: & Desviación de la trayectoria del movimiento. \\
\hline Observaciones: & Prueba de tipo cinemática. \\
\hline
\end{tabular}

Tabla 3.4: Patrón PT4.

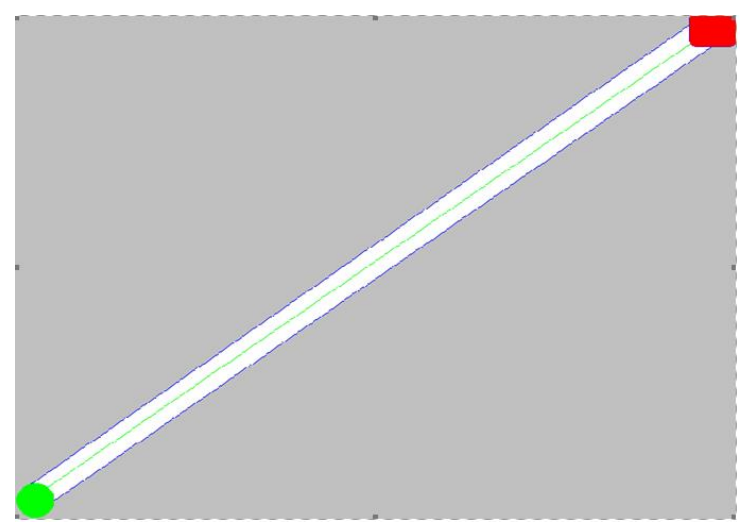

Figura 3.13: Patrón PT4. 


\section{- Línea inclinada descendente.}

\begin{tabular}{|l|l|}
\hline Nombre: & PT5 \\
\hline Trayectoria: & Línea descendente inclinada \\
\hline Posición del Paciente: & $\begin{array}{l}\text { Frente al dispositivo de captación, brazo totalmente } \\
\text { estirado hacia el frente, a la altura del hombro. }\end{array}$ \\
\hline Objetivo: & $\begin{array}{l}\text { Mover el cursor dentro del "camino" del punto } \\
\text { inicial al punto final de la recta. }\end{array}$ \\
\hline Manos: & Ambas (izquierda y derecha) \\
\hline Medida registrada: & Desviación de la trayectoria de movimiento. \\
\hline Observaciones: & Prueba de tipo cinemática. \\
\hline
\end{tabular}

Tabla 3.5: Patrón PT5.

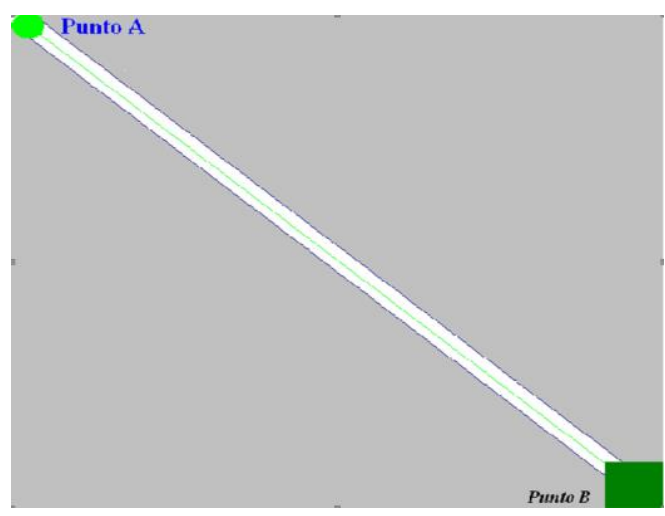

Figura 3.14: $\quad$ Patrón PT5.

- Línea Vertical.

\begin{tabular}{|l|l|}
\hline Nombre: & PT6 \\
\hline Trayectoria: & Línea vertical en pantalla \\
\hline Posición del Paciente: & $\begin{array}{l}\text { Frente al dispositivo de captación, brazo totalmente } \\
\text { estirado hacia el frente, a la altura del hombro. }\end{array}$ \\
\hline Objetivo: & $\begin{array}{l}\text { Mover el cursor dentro del "camino" del punto inicial } \\
\text { al punto final de la recta. }\end{array}$ \\
\hline Manos: & Ambas (izquierda y derecha) \\
\hline Medida registrada: & Desviación de la trayectoria de movimiento. \\
\hline Observaciones: & Prueba de tipo cinemática. \\
\hline
\end{tabular}

Tabla 3.6: Patrón PT6. 


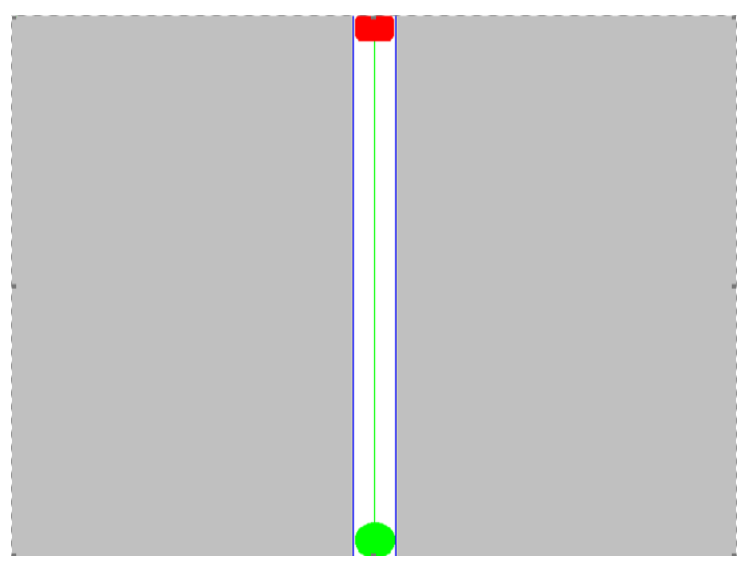

Figura 3.15: Patrón PT6.

- Círculo o elipse.

\begin{tabular}{|l|l|}
\hline Nombre: & PT7 \\
\hline Trayectoria: & Círculo en pantalla. \\
\hline Posición del Paciente: & $\begin{array}{l}\text { Frente al dispositivo de captación, brazo totalmente estirado } \\
\text { hacia el frente, a la altura del hombro. }\end{array}$ \\
\hline Objetivo: & $\begin{array}{l}\text { Mover el cursor a lo largo de la circunferencia dentro del } \\
\text { "camino". }\end{array}$ \\
\hline Manos: & Ambas (izquierda y derecha) \\
\hline Medida registrada: & Desviación de la trayectoria ideal del movimiento. \\
\hline Observaciones: & Prueba de tipo cinemática. \\
\hline
\end{tabular}

Tabla 3.7: Patrón PT7.

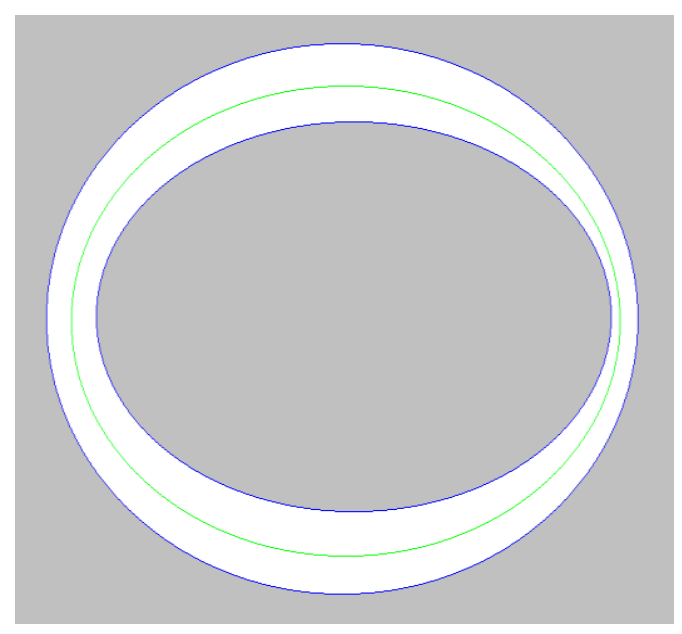

Figura 3.16: $\quad$ Patrón PT7. 
- Espiral.

\begin{tabular}{|l|l|}
\hline Nombre: & PT8 \\
\hline Trayectoria: & Espiral en pantalla. \\
\hline Posición del Paciente: & $\begin{array}{l}\text { Frente al dispositivo de captación, brazo totalmente estirado } \\
\text { hacia el frente, a la altura del hombro. }\end{array}$ \\
\hline Objetivo: & $\begin{array}{l}\text { Recorrer la espiral de afuera hacia adentro por el camino } \\
\text { dibujado. }\end{array}$ \\
\hline Manos: & Ambas (izquierda y derecha) \\
\hline Medida registrada: & Posición X,Y en la pantalla. \\
\hline Observaciones: & Prueba de tipo cinemática. \\
\hline
\end{tabular}

Tabla 3.8: Patrón PT8.

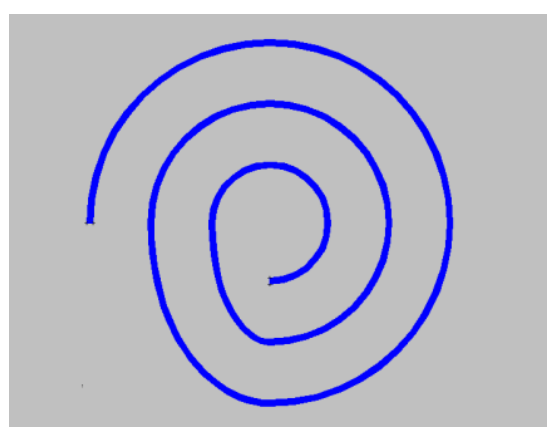

Figura 3.17: $\quad$ Patrón PT8.

- Espiral estrecha.

\begin{tabular}{|l|l|}
\hline Nombre: & PT9 \\
\hline Trayectoria: & Espiral en pantalla con el camino más estrecho. \\
\hline Posición del Paciente: & $\begin{array}{l}\text { Frente al dispositivo de captación, brazo totalmente } \\
\text { estirado hacia el frente, a la altura del hombro. }\end{array}$ \\
\hline Objetivo: & $\begin{array}{l}\text { Recorrer la espiral de afuera hacia adentro por el camino } \\
\text { dibujado. }\end{array}$ \\
\hline Manos: & Ambas (izquierda y derecha) \\
\hline Medida registrada: & Posición X, Y en la pantalla. \\
\hline Observaciones: & $\begin{array}{l}\text { Prueba de tipo cinemática. Se busca que el paciente tenga } \\
\text { que realizar movimientos más precisos que en el caso del } \\
\text { patrón PT8 }\end{array}$ \\
\hline
\end{tabular}

Tabla 3.9: Patrón PT9. 


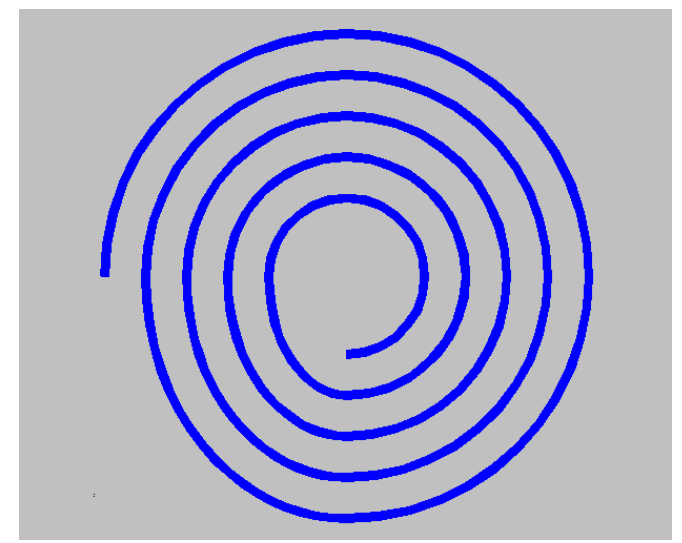

Figura 3.18: $\quad$ Patrón PT9.

- Senoide.

\begin{tabular}{|l|l|}
\hline Nombre: & PT10 \\
\hline Trayectoria: & Curva con forma senoidal \\
\hline Posición del Paciente: & $\begin{array}{l}\text { Frente al dispositivo de captación, brazo totalmente } \\
\text { estirado hacia el frente, a la altura del hombro. }\end{array}$ \\
\hline Objetivo: & Recorrer la línea desde el punto inicial al punto final. \\
\hline Manos: & Ambas (izquierda y derecha) \\
\hline Medida registrada: & Posición X,Y en la pantalla. \\
\hline Observaciones: & Prueba de tipo cinemática. \\
\hline
\end{tabular}

Tabla 3.10: Patrón PT10.

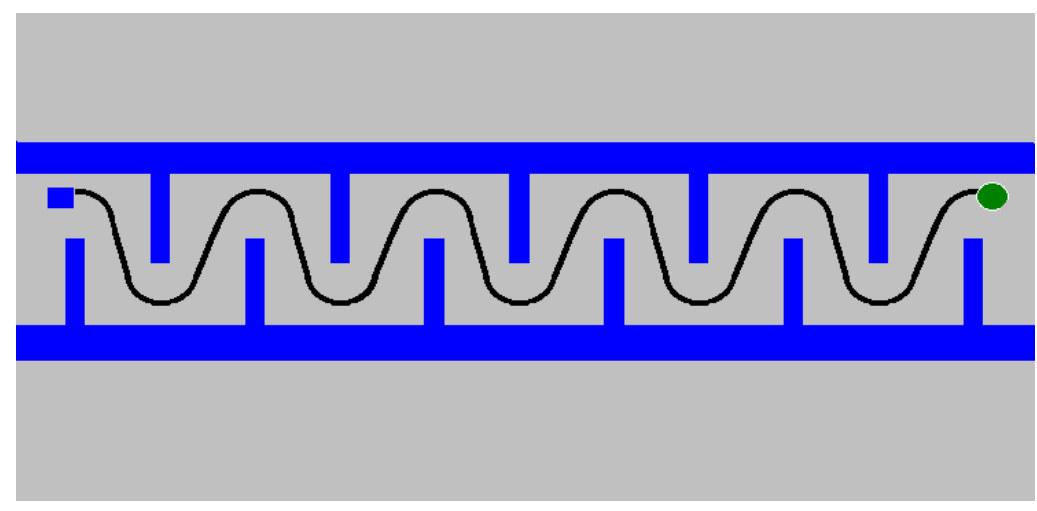

Figura 3.19: Patrón PT10. 


\section{- Senoide con amortiguamiento.}

\begin{tabular}{|l|l|}
\hline Nombre: & PT11 \\
\hline Trayectoria: & Curva senoidal con amplitud variable \\
\hline Posición del Paciente: & $\begin{array}{l}\text { Frente al dispositivo de captación, brazo totalmente } \\
\text { estirado hacia el frente, a la altura del hombro. }\end{array}$ \\
\hline Objetivo: & Recorrer la curva desde el punto inicial al punto final. \\
\hline Manos: & Ambas (izquierda y derecha) \\
\hline Medida registrada: & Posición X, Y en la pantalla. \\
\hline Observaciones: & $\begin{array}{l}\text { Prueba de tipo cinemática. Con la variación de la } \\
\text { amplitud se busca que el paciente tenga que hacer } \\
\text { movimientos más precisos para la ejecución de la tarea. }\end{array}$ \\
\hline
\end{tabular}

Tabla 3.11: $\quad$ Patrón PT11.

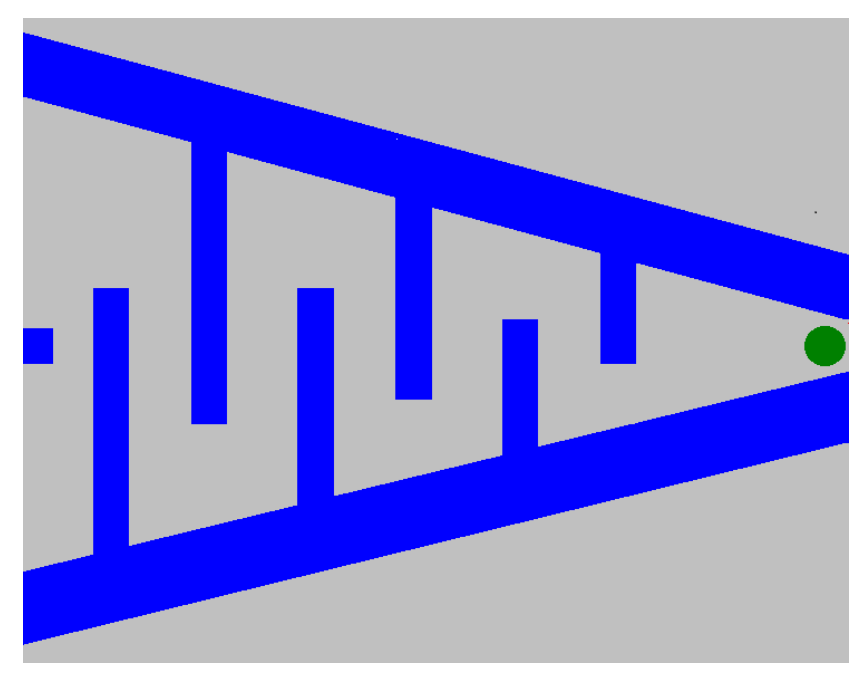

Figura 3.20: Patrón PT11.

\subsubsection{Patrón 3D (Espacio real).}

El patrón 3D consiste en una línea recta en el espacio real en la que el ejercicio de seguimiento de la línea involucra un movimiento a lo largo de los tres ejes coordenados. 
- Línea en plano XY.

\begin{tabular}{|l|l|}
\hline Nombre: & PT12 \\
\hline Trayectoria: & $\begin{array}{l}\text { Línea recta horizontal plano XY (paralelo al plano frontal } \\
\text { del paciente) }\end{array}$ \\
\hline Posición del Paciente: & $\begin{array}{l}\text { Frente al dispositivo de interfaz, brazo totalmente estirado } \\
\text { hacia el frente, a la altura del hombro. }\end{array}$ \\
\hline Objetivo: & Recorrer la línea desde el punto inicial al punto final. \\
\hline Manos: & Ambas (izquierda y derecha) \\
\hline Medida registrada: & Desviación en X,Y,Z de la trayectoria ideal. \\
\hline Observaciones: & $\begin{array}{l}\text { Prueba de tipo cinemática. La línea es real en el espacio, } \\
\text { tiene una longitud de } 40 \text { cms. }\end{array}$ \\
\hline
\end{tabular}

Tabla 3.12: Patrón PT12.

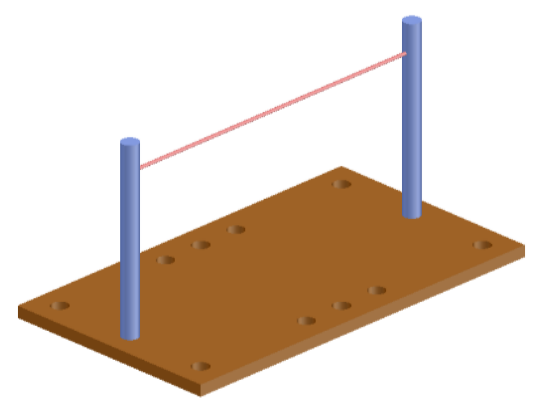

Figura 3.21: Patrón PT12.

- Línea en plano ZY.

\begin{tabular}{|l|l|}
\hline Nombre: & PT13 \\
\hline Trayectoria: & $\begin{array}{l}\text { Línea recta horizontal plano ZY (paralelo al plano sagital del } \\
\text { paciente) }\end{array}$ \\
\hline Posición del Paciente: & $\begin{array}{l}\text { Frente al dispositivo de captación, brazo totalmente estirado } \\
\text { hacia el frente, a la altura del hombro. }\end{array}$ \\
\hline Objetivo: & Recorrer la línea desde el punto inicial al punto final. \\
\hline Manos: & Ambas (izquierda y derecha) \\
\hline Medida registrada: & Desviación en X,Y,Z de la trayectoria ideal. \\
\hline Observaciones: & $\begin{array}{l}\text { Prueba de tipo cinemática. La línea es real en el espacio, tiene } \\
\text { una longitud de } 20 \text { cms. El paciente realiza un movimiento } \\
\text { en todos los planos en el espacio. }\end{array}$ \\
\hline
\end{tabular}

Tabla 3.13: Patrón PT13. 


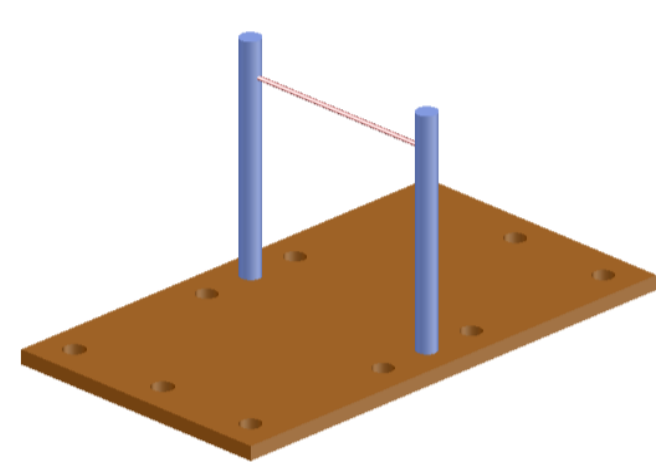

Figura 3.22: $\quad$ Patrón PT13.

- $\quad$ Línea en XYZ.

\begin{tabular}{|l|l|}
\hline Nombre: & PT14 \\
\hline Trayectoria: & Línea recta en el espacio XYZ \\
\hline Posición del Paciente: & $\begin{array}{l}\text { Frente al dispositivo de captación, brazo totalmente } \\
\text { estirado hacia el frente, a la altura del hombro. }\end{array}$ \\
\hline Objetivo: & Recorrer la línea desde el punto inicial al punto final. \\
\hline Manos: & Ambas (izquierda y derecha) \\
\hline Medida registrada: & Desviación en X, Y, Z de la trayectoria ideal. \\
\hline Observaciones: & $\begin{array}{l}\text { Prueba de tipo cinemática. La línea es real en el espacio, } \\
\text { tiene una longitud de } 48 \text { cms. El paciente realiza un } \\
\text { movimiento en todos los planos en el espacio. }\end{array}$ \\
\hline
\end{tabular}

Tabla 3.14: Patrón PT14.

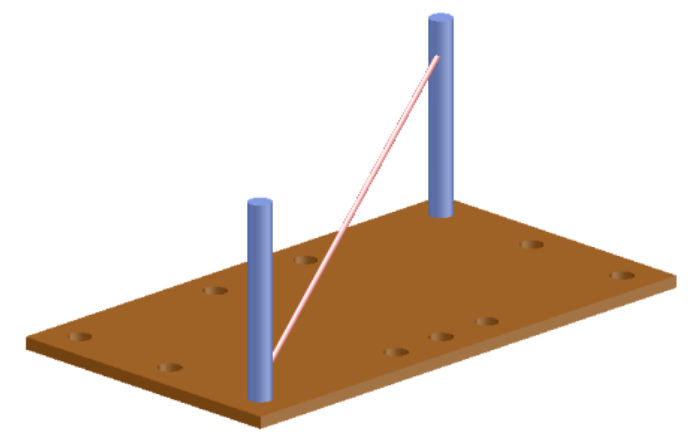

Figura 3.23: Patrón PT14. 


\subsubsection{Patrones con Reflexión de Fuerza.}

Utilizando algunos de los patrones anteriores se realizaron algunas pruebas en las que además del seguimiento de una trayectoria definida se le aplica al paciente una restricción mecánica que interfiere en la realización de la tarea y que además puede ayudar en la clasificación del paciente con miras al diseño del filtro adecuado para el dispositivo de interfaz con el ordenador.

\subsubsection{Tipos de Fuerzas Utilizadas.}

Las siguientes son los tipos de fuerzas que se utilizaron como perturbación en la realización de las diferentes tareas.

\section{Fuerza constante}

La fuerza se aplica de forma constante en todo el tiempo de la prueba. Se pueden aplicar fuerzas hasta máximo $5 \mathrm{~N}$ que corresponden aproximadamente a 500grms en cualquiera de las tres direcciones en el espacio.

\section{Fuerza elástica}

La fuerza que se aplica es proporcional a la elongación (muelle), respondiendo a la expresión (3-1):

$$
F=K \cdot X
$$

Donde $\mathrm{F}$ es la fuerza en $\mathrm{N}, \mathrm{K}$ es la constante elástica del muelle expresada en $\mathrm{N} / \mathrm{m}$ y X es el desplazamiento de la posición de equilibrio del muelle en $\mathrm{m}$.

Esta fuerza permite una cuantificación clara de la cantidad de ésta que se le está ejerciendo al paciente, comportándose de forma tal, que a mayor desviación de la trayectoria ideal del movimiento mayor es la fuerza que siente el paciente para corregirla.

Durante la prueba se aplica esta fuerza elástica de manera progresiva aumentando la constante elástica dentro de unos valores establecidos, con el fin de evaluar el valor de K para el cual la amplitud del temblor se reduce a unos rangos mínimos.

El valor de $\mathrm{K}$ para las pruebas está en un rango entre $0 \leq K \leq\left(0.5 \mathrm{Kg} / 1000 \mathrm{~s}^{2}\right)$.

\section{Inercia y Rozamiento viscoso}

Una fuerza puede ser simulada basándose en el modelo de la Figura 3.24. 


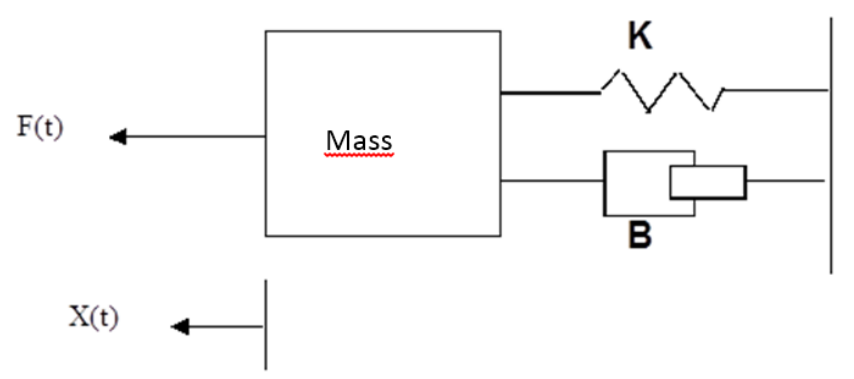

Figura 3.24: $\quad$ Modelo de resorte más rozamiento viscoso.

El anterior modelo está regido por la ecuación (3-2)

$$
F(t)=M \frac{d^{2} x(t)}{d x^{2}}+B \frac{d x(t)}{d x}+K x(t)
$$

Donde B es el coeficiente de rozamiento y K la constante elástica del muelle.

En la expresión se observan claramente tres componentes esenciales, la primera es debida a la inercia propia de la masa, la segunda al rozamiento que depende de la velocidad y la componente elástica que es proporcional al desplazamiento.

Se pretende aplicar al paciente fuerzas en forma de rozamiento viscoso con una leve sensación de inercia que le impida el aumento de la amplitud del movimiento y que al mismo tiempo no se restrinja a una dirección especifica sino que se acomode a los movimientos.

El valor de la fuerza aplicada corresponde a la inercia de una masa de 5 grms más un coeficiente de rozamiento viscoso $B=1.5 \mathrm{Kg} /\left(1000 \mathrm{~s}^{2}\right)$

\subsubsection{Patrones}

\begin{tabular}{|l|l|}
\hline Nombre: & PT15 \\
\hline Trayectoria: & Punto en el espacio (PT2) \\
\hline Posición del Paciente: & $\begin{array}{l}\text { Frente al dispositivo de captación, brazo totalmente } \\
\text { estirado hacia el frente, a la altura del hombro. }\end{array}$ \\
\hline Objetivo: & Mantener el cursor dentro del punto en la pantalla \\
\hline Tipo de Fuerza: & Constante 5N en dirección -Y (hacia el suelo) \\
\hline Manos: & Ambas (izquierda y derecha) \\
\hline Medida registrada: & Desviación en X,Y,Z del punto \\
\hline Observaciones: & Prueba de tipo estática - dinámica. \\
\hline
\end{tabular}

Tabla 3.15: Patrón PT15. 


\begin{tabular}{|l|l|}
\hline Nombre: & PT16 \\
\hline Trayectoria: & Línea horizontal en pantalla (PT3) \\
\hline Posición del Paciente: & $\begin{array}{l}\text { Frente al dispositivo de captación, brazo totalmente } \\
\text { estirado hacia el frente, a la altura del hombro. }\end{array}$ \\
\hline Objetivo: & $\begin{array}{l}\text { Mover el cursor dentro del "camino" del punto inicial al } \\
\text { punto final }\end{array}$ \\
\hline Tipo de Fuerza: & $\begin{array}{l}\text { Elástica aumentando el valor de K. En dirección Y } \\
\text { (perpendicular al movimiento) }\end{array}$ \\
\hline Manos: & Ambas (izquierda y derecha) \\
\hline Medida registrada: & Desviación en Y de la trayectoria \\
\hline Observaciones: & Prueba de tipo dinámica. \\
\hline
\end{tabular}

Tabla 3.16: Patrón PT16.

\begin{tabular}{|l|l|}
\hline Nombre: & PT17 \\
\hline Trayectoria: & Línea horizontal en pantalla (PT3) \\
\hline Posición del Paciente: & $\begin{array}{l}\text { Frente al dispositivo de captación, brazo totalmente } \\
\text { estirado hacia el frente, a la altura del hombro. }\end{array}$ \\
\hline Objetivo: & Recorrer la línea del punto inicial al final \\
\hline Tipo de Fuerza: & Inercia y rozamiento viscoso \\
\hline Manos: & Ambas (izquierda y derecha) \\
\hline Medida registrada: & Desviación en $X, Y, Z$ de la trayectoria ideal \\
\hline Observaciones: & Prueba de tipo dinámica. \\
\hline
\end{tabular}

Tabla 3.17: Patrón PT17. 


\begin{tabular}{|l|l|}
\hline Nombre: & PT18 \\
\hline Trayectoria: & Espiral en la pantalla (PT8) \\
\hline Posición del Paciente: & $\begin{array}{l}\text { Frente al dispositivo de captación, brazo totalmente } \\
\text { estirado hacia el frente, a la altura del hombro. }\end{array}$ \\
\hline Objetivo: & $\begin{array}{l}\text { Recorrer la espiral de afuera hacia adentro por el camino } \\
\text { dibujado. }\end{array}$ \\
\hline Tipo de Fuerza: & Inercia y rozamiento viscoso \\
\hline Manos: & Ambas (izquierda y derecha) \\
\hline Medida registrada: & Posición X,Y en la pantalla \\
\hline Observaciones: & Prueba de tipo dinámica. \\
\hline
\end{tabular}

Tabla 3.18: Patrón PT18.

\begin{tabular}{|l|l|}
\hline Nombre: & PT19 \\
\hline Trayectoria: & Línea recta en el espacio en el plano sagital (PT13) \\
\hline Posición del Paciente: & $\begin{array}{l}\text { Frente al dispositivo de captación, brazo totalmente } \\
\text { estirado hacia el frente, a la altura del hombro. }\end{array}$ \\
\hline Objetivo: & Recorrer la línea recta de un extremo a otro. \\
\hline Tipo de Fuerza: & Inercia y rozamiento viscoso \\
\hline Manos: & Ambas (izquierda y derecha) \\
\hline Medida registrada: & Posición X,Y en la pantalla \\
\hline Observaciones: & Prueba de tipo dinámica. \\
\hline
\end{tabular}

Tabla 3.19: Patrón PT19. 


\subsection{Aplicación SW del DIMETER.}

A continuación se muestran algunas figuras que corresponden a las ventanas proporcionadas por el software desarrollado en el DIMETER. En la Figura 3.25 se puede observar los resultados del análisis espectral de frecuencia de una señal de uno de los pacientes.

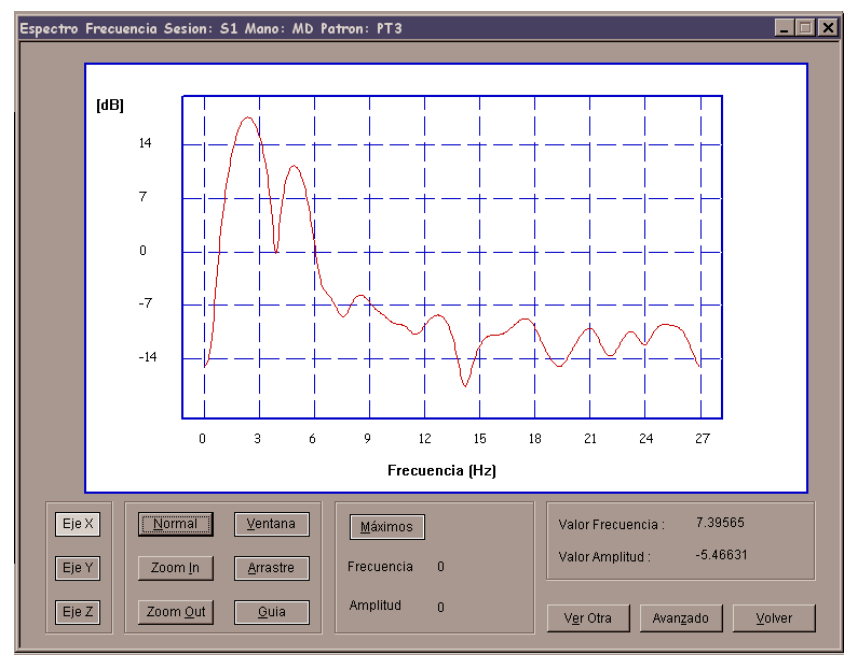

Figura 3.25: Representación del espectograma de frecuencias.

En la Figura 3.26 se puede apreciar el resultado de una trayectoria, en este caso para el patrón PT3 (línea horizontal).

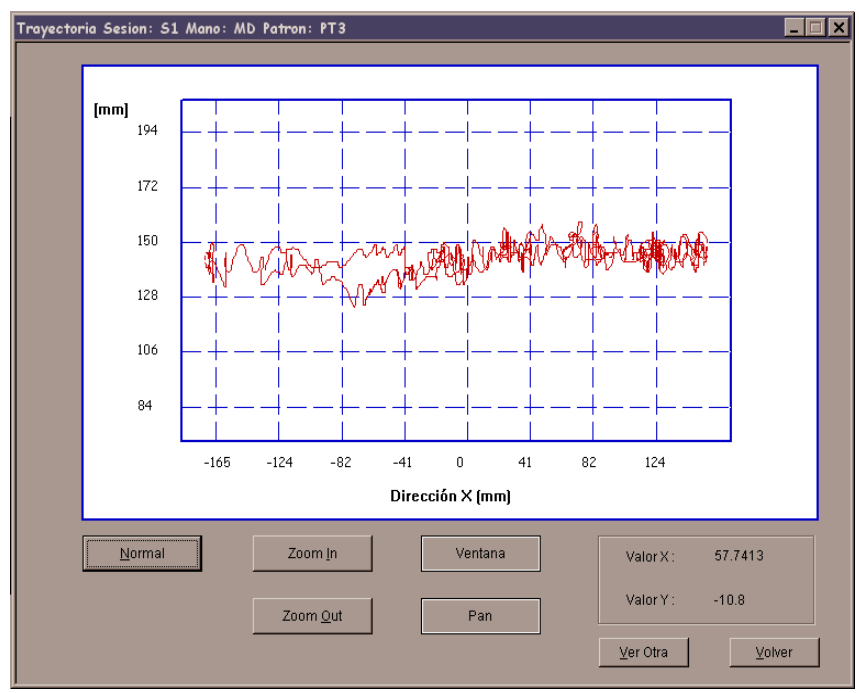

Figura 3.26: Visualización de la trayectoria con temblor.

En la Figura 3.27 aparece un resumen de todos los patrones de una prueba asociada a la mano derecha de la sesión 1 . El resultado se divide en las zonas de lo diferentes tipos de patrones: patrones estáticos (a la izquierda de la primera línea negra vertical), patrones cinéticos (entre las dos líneas negras verticales) y patrones dinámicos (a la derecha de la segunda línea negra vertical). Cada uno de los 
rombitos corresponde a uno de los armónicos seleccionados en la parte inferior. El azul es eje $\mathrm{X}$ y el rojo eje $\mathrm{Y}$. La barra superior es proporcional a la amplitud de la oscilación para ese armónico en concreto.

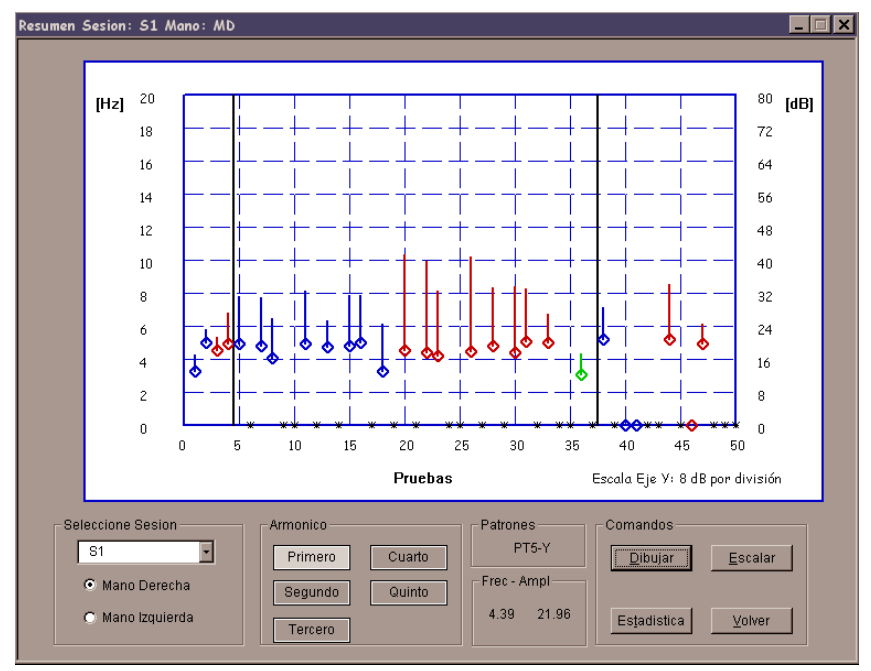

Figura 3.27: Resumen de armónicos principales con su amplitud asociada.

\subsection{Resultados.}

Los datos obtenidos durante 14 meses sobre un total de 47 pacientes distintos, en diversas condiciones de medicación y en ocasiones antes y después de intervención quirúrgica, o con la estimulación electrofuncional profunda en diferentes estados, han sido analizados y clasificados tratando de identificar los parámetros característicos en cada tipo de temblor. También se efectuaron las pruebas a 30 individuos, sin ningún tipo de trastorno del movimiento aparente, como población de control y posible muestra del temblor fisiológico.

Se recoge a continuación el procedimiento de los análisis efectuados y los resultados de los mismos.

\subsubsection{Diseño Experimental.}

Los objetivos del diseño experimental han sido los siguientes:

- Evaluar el efecto de diferentes factores a partir de la información de las muestras del temblor.

- Determinar la eficacia de los registros para afrontar la evaluación del temblor.

Como factores considerados se encuentran: tipos de paciente, mano con que se realiza la prueba, dirección de movimiento y los patrones desarrollados para evaluar el temblor. Dentro de los patrones se ha querido determinar cuáles de ellos aportan información importante y cuales pudieran ser redundantes. 
Como son muchos factores con diferentes niveles se han llevado a cabo diferentes diseños, contrastando los diferentes factores. Se construido dos diseños principales: diseños factoriales y una comparación de medias entre poblaciones.

Puesto que no existe un criterio establecido sobre cuál es la mejor medida del temblor para caracterizarlo: frecuencia, amplitud,... Para todos los diseños se ha efectuado un análisis con ambas variables, contrastando los resultados.

\subsubsection{Diseños Factoriales.}

Dentro de los modelos factoriales se han considerado diferentes diseños estudiando la relación entre diferentes factores y aleatorizando el resto.

\subsubsection{Diseño 1: Todos los individuos.}

Inicialmente se ha realizado un diseño general en el que se han tenido en cuenta todos los factores. Como se esperaba el factor "paciente" resulta un factor significativo, lo que quiere decir que hay diferencias entre las personas sanas y las personas enfermas. El factor "mano" no resulta significativa con lo que no se pueden hacer diferencias entre una $u$ otra. Sí que se encuentra significativo el factor "patrón", lo que lleva a pensar que hay patrones que pueden dar más información que otros o que algunos patrones aporten información adicional a la hora de evaluar el temblor.

En la figura Figura 3.28 se puede observar la gráfica de los residuos para los valores predichos por el modelo, en la que se puede ver que no tienen ninguna distribución determinada, eso nos lleva a la conclusión de que los resultados del contraste tienen validez. 

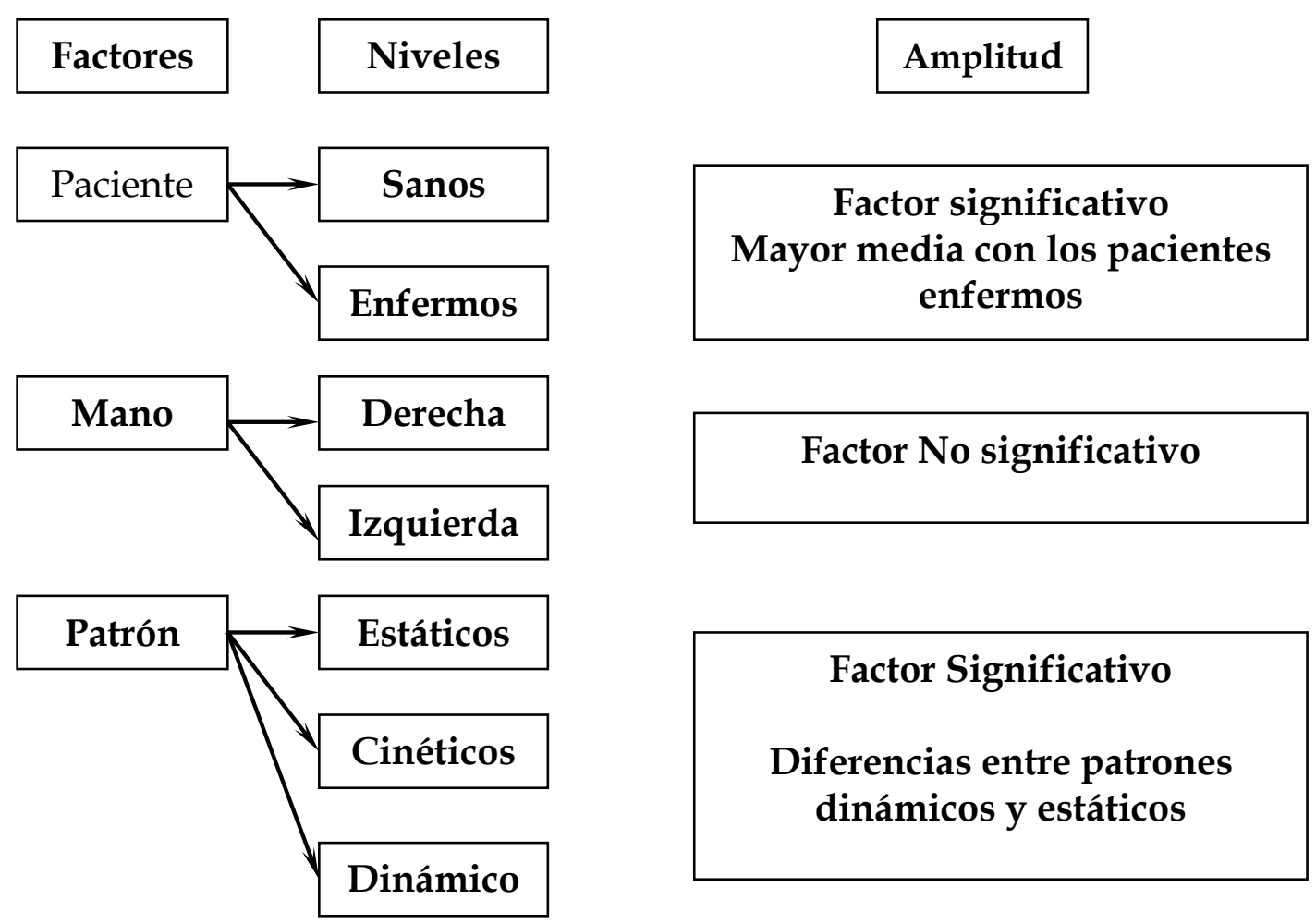

Residual Plot for Amplitud

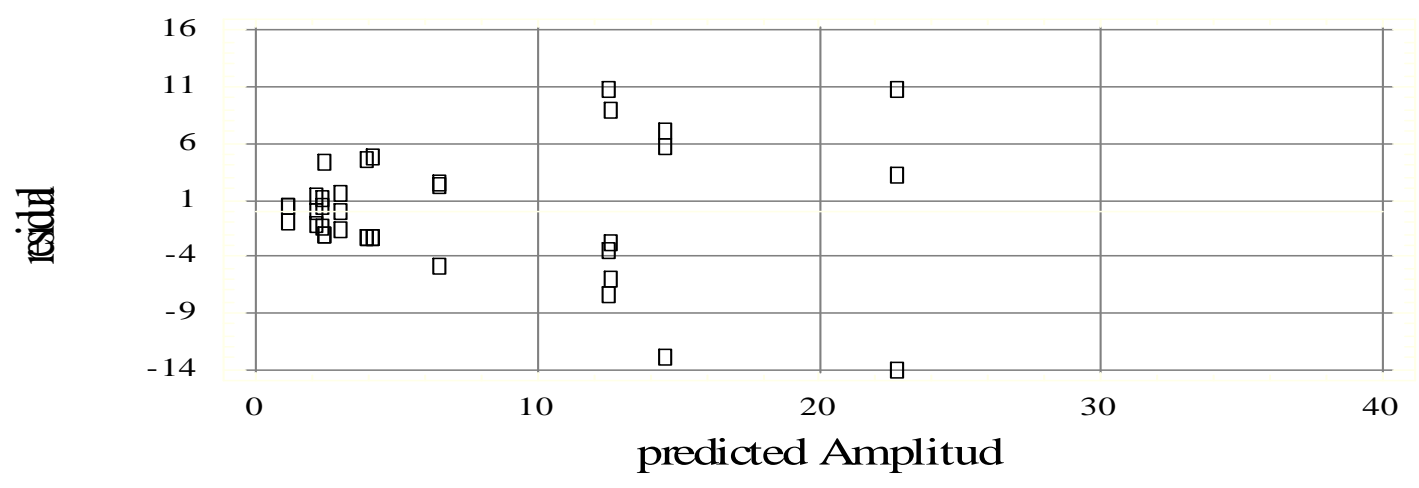

Figura 3.28: Residuos para la hipótesis del análisis todos los individuos. Diseño 1. 


\subsubsection{Diseños 2 y 3: Individuos sanos.}

Partiendo del análisis general anterior se han abordado estudios más específicos. En el primero de ellos se han utilizado solo individuos sanos.
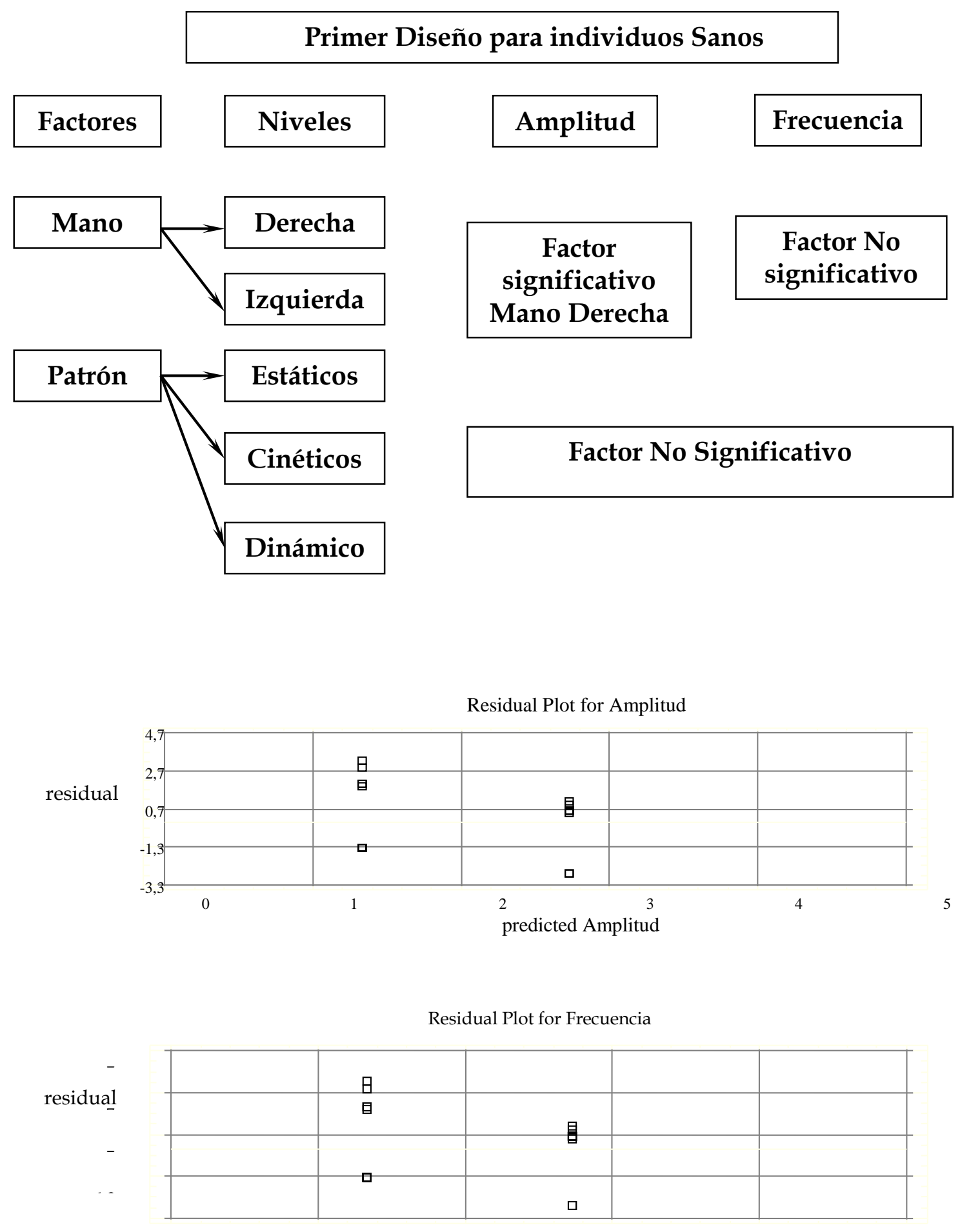

predicted Frecuencia

Figura 3.29: Residuos para primer análisis individuos sanos. Diseño 2. 
En estos resultados se pueden apreciar varios puntos a tener en cuenta. La amplitud respecto de la mano es significativa siendo mayor en la derecha, esto es explicable porque todas las personas estudiadas eran diestras lo que hace que el temblor fisiológico aparezca con mayor importancia en dicha la mano. La variable frecuencia no es significativa debido que todos los individuos comparten una banda similar en dicho valor correspondiente a la del temblor fisiológico

\section{Segundo Diseño para Individuos Sanos}
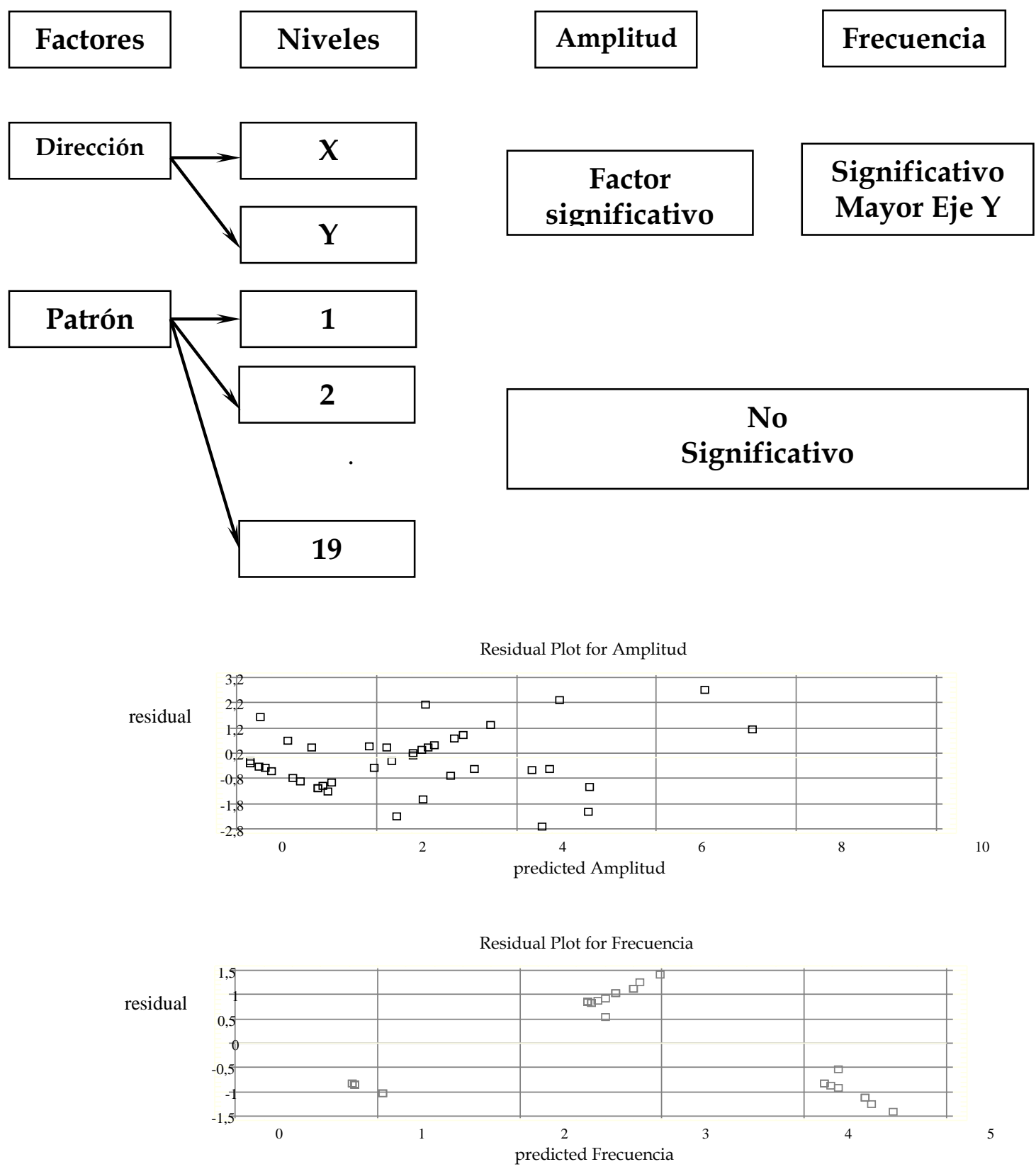

Figura 3.30: Residuos para el segundo análisis individuos sanos. Diseño 3. 
En cuanto a los patrones se encontró que no hay diferencia entre ellos, que todos son iguales, tanto desde el punto de vista de la amplitud como de la frecuencia. Lo que indica que para una persona sana con cualquier patrón se podría estudiar su comportamiento.

\subsubsection{Diseño 4: Individuos enfermos.}

Después de analizar los pacientes sanos se han realizado los mismos análisis para pacientes enfermos (independientemente de la enfermedad).

En las gráficas de residuos se observa que la distribución corresponde al de un modelo que se puede considerar válido para poder sacar conclusiones.
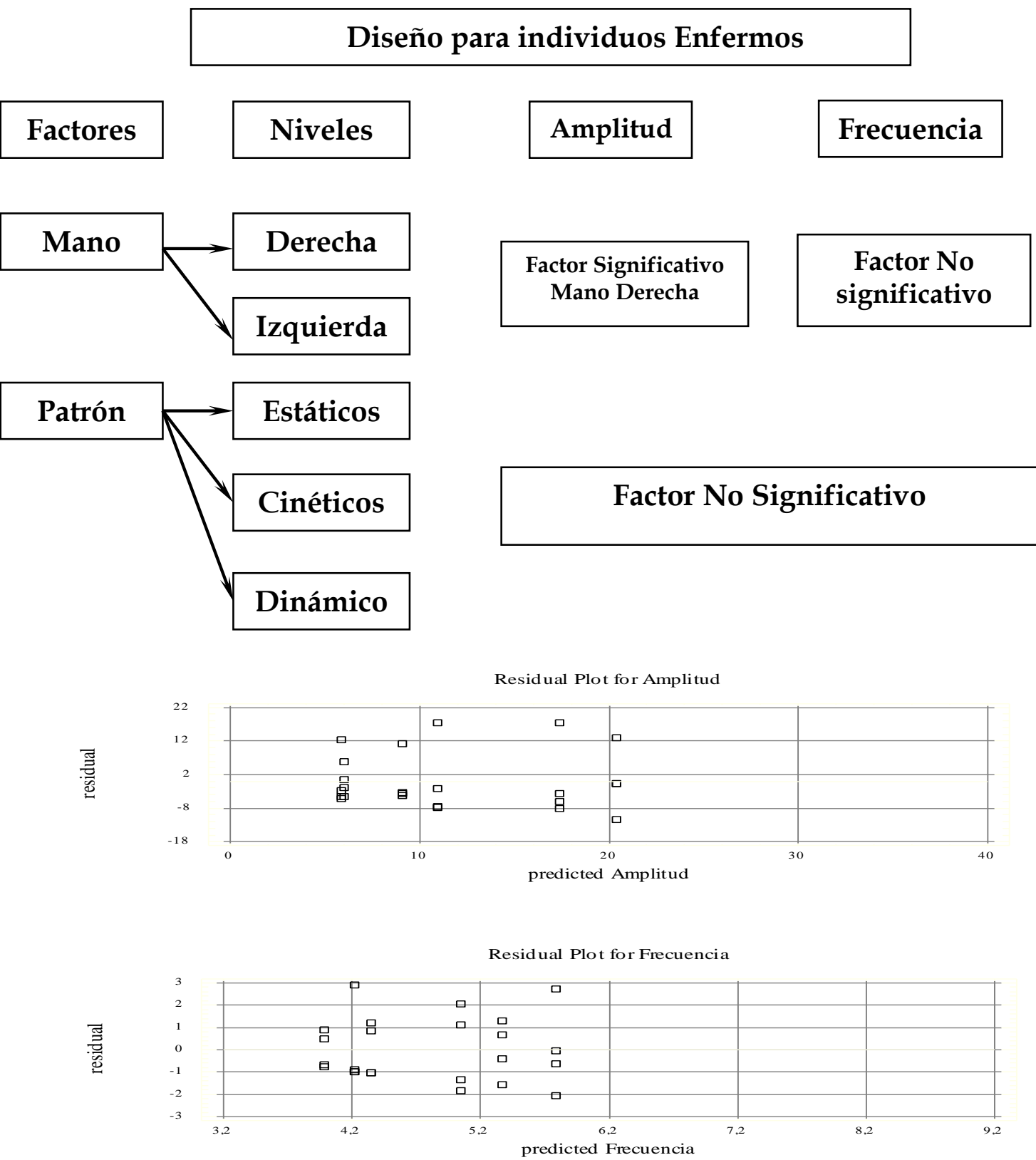

Figura 3.31: Residuos para el análisis individuos enfermos. Diseño 4. 
Del estudio de los pacientes enfermos se desprende que en amplitud hay diferencias entre mano izquierda y mano derecha, siendo mayor la amplitud de oscilación para la mano derecha, esto se debe a que la mayoría de los pacientes eran predominantes diestros.

Desde el punto de vista de la frecuencia no hay diferencias entre la mano, puesto que a priori, salvo en el caso de un paciente, las fichas clínicas indican la presencia de temblor en ambas extremidades, se puede concluir que el sistema DIMETER a diferencia de otros sistemas de adquisición y evaluación, al permitir que las pruebas se efectúen de manera bilateral, es capaz de proporcionarnos información sobre la afectación en ambas extremidades, y poder en futuro evaluar la bilateralidad o no de la enfermedad.

Los patrones no dan diferencias significativas en ninguna de las dos medidas, tanto en frecuencia como en amplitud. Del análisis general se obtuvo que los patrones si eran significativos lo que va en contradicción de lo que se desprende de este análisis. En este caso, el resultado arroja una no significación en el patrón. Podría justificarse por la gran diferencia existente entre pacientes. Algunos padecen enfermedad de Parkinson y otros tienen temblor intencional y entre los dos grupos hay personas que además tienen otras circunstancias que afectan el temblor (temblores mixtos). En cualquier caso, este resultado nos puede indicar que la amplitud y la frecuencia no son suficiente para la significación de los patrones, y por tanto para la caracterización de la enfermedad.

\subsubsection{Diseños 5 y 6: Enfermos de Parkinson.}

En vista de lo expuesto anteriormente, se ha procedido a realizar un análisis sobre pacientes con un tipo de enfermedad específico. Se plantearán estudios independientes para los dos tipos de temblores.

En la Figura 3.32 y en la Figura 3.33 se observan los residuos para el primer análisis con los enfermos de Parkinson. Se puede deducir de la gráfica que el modelo se comporta adecuadamente a los requerimientos tanto en frecuencia como en amplitud.

Al analizar los resultados obtenidos de los pacientes con Parkinson, se puede deducir que la mano es significativa tanto en amplitud como en frecuencia, lo que para este caso se puede explicar porque los pacientes presentan temblor patológico en una extremidad predominante.

Al observar los grupos de patrones, éstos son significativos. Existiendo diferencias entre ellos. Para la amplitud, los patrones cinéticos y los estáticos se confunden, y los dinámicos son diferentes y. Para frecuencia hay igualdad entre estáticos y dinámicos, siendo diferentes los cinéticos.

Cuando de analiza el comportamiento en cuento dirección del movimiento se observa que en amplitud hay diferencia siendo mayor en el eje Y. Es lógico este resultado ya que el temblor se manifiesta predominantemente en la articulación de la muñeca, siendo las oscilaciones más patentes en esta dirección. En frecuencia no 
hay diferencia entre direcciones lo que da una idea que la frecuencia de oscilación afecta por igual a todas las direcciones del movimiento.

Al analizar patrón por patrón se observa que los patrones estáticos no son significativos ni en amplitud ni en frecuencia, lo que nos indica que ambos aportan sobre los enfermos de Párkinson información relevante común a todos ellos. Al existir dos patrones estáticos garantizaremos que aquellos pacientes que por el motivo que sea no completen los dos, no sería un problema en cuanto a que se tendría información parecida con ambos. En cuanto a los cinéticos se encuentra que en amplitud el patrón 13 (Línea en plano Sagital) y el patrón 3 (Línea recta horizontal), aportan claramente información diferente a los demás. En el grupo de cinéticos podríamos obtener información del movimiento desde varios patrones puesto que algunas tareas son similares. Desde el punto de vista de la frecuencia, entre los cinéticos, los que aportan diferencias son el patrón 12 (Línea 3D en el plano XY) y el patrón 7 (Circulo).

En cuanto a los patrones dinámicos resulta que no son significativos en frecuencia pero si en amplitud lo que indica que con la aplicación de fuerzas virtuales al paciente se le puede atenuar el temblor desde el punto de vista de la amplitud pero no de la frecuencia. Además que fuerzas de tipo rozamiento viscoso son más efectivas en esta reducción que las de tipo elástico. 


\section{Primer Diseño para pacientes con Parkinson}
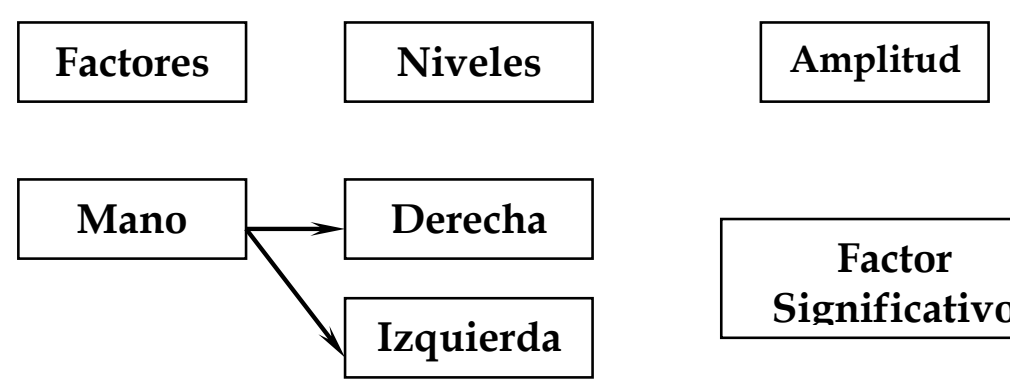

Frecuencia
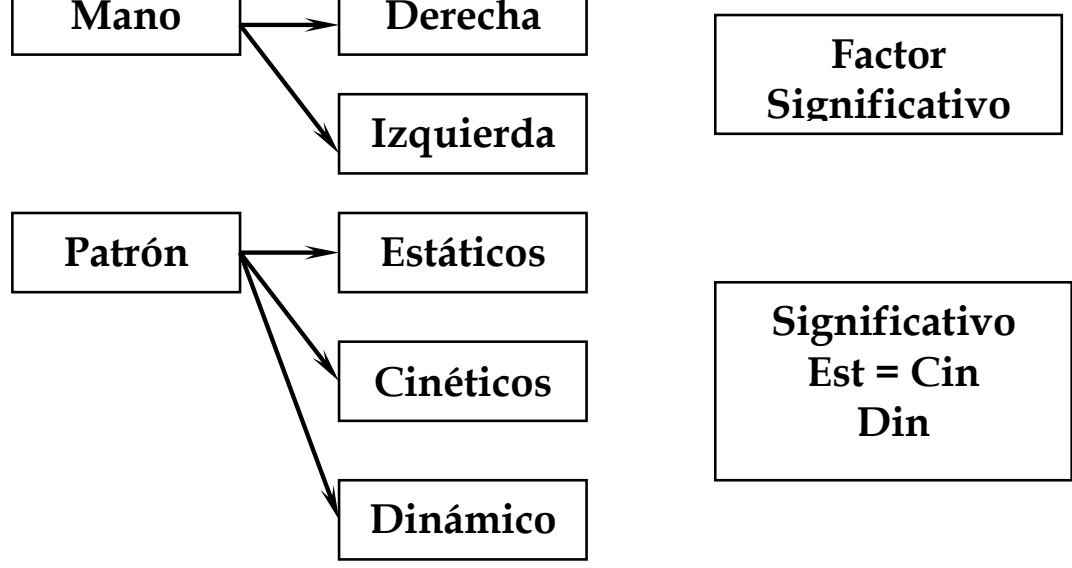
Significativo Mayor

\begin{tabular}{|c|}
\hline Significativo \\
Est $=$ Cin \\
Din
\end{tabular}

Significativo
Est $=$ Din
Cin

Residual Plot for Amplitud

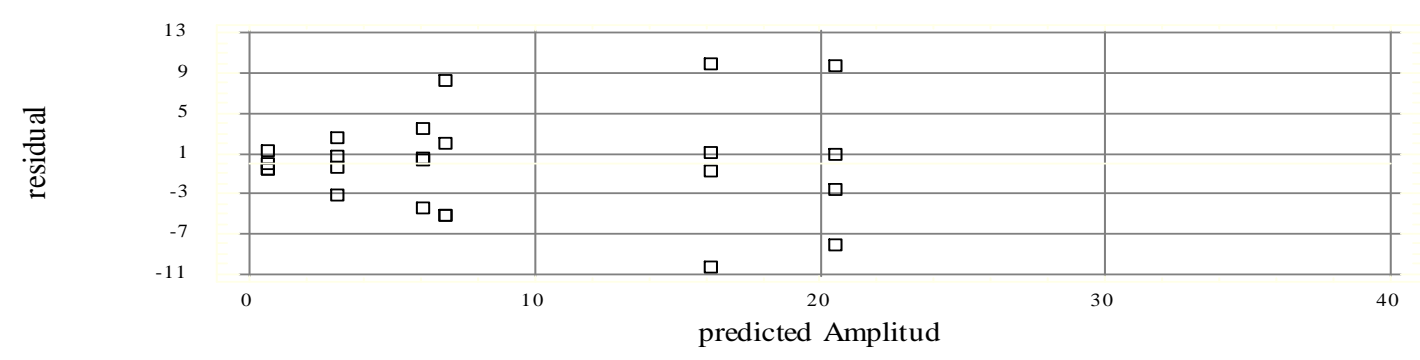

Residual Plot for Frecuencia

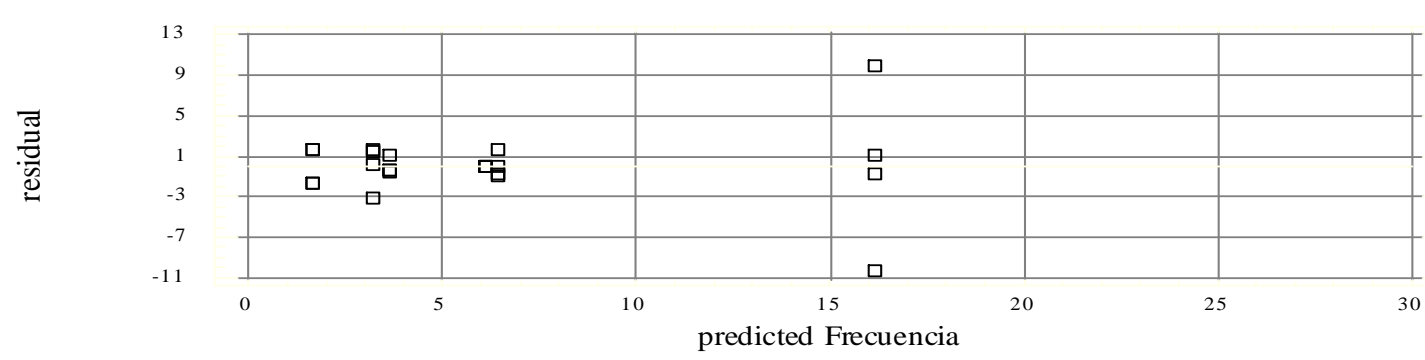

Figura 3.32: Residuos para el primer análisis de enfermos de Parkinson. Diseño 5. 
Segundo Diseño para pacientes con Parkinson

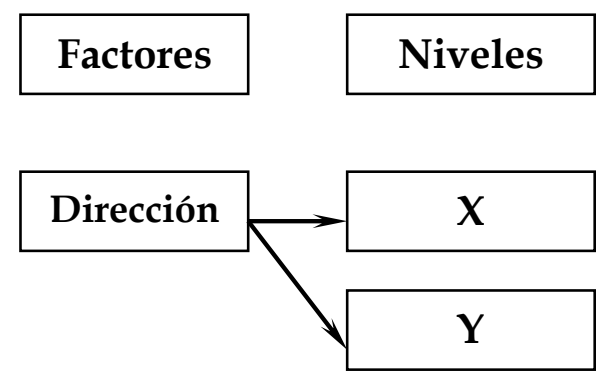

Amplitud

Frecuencia

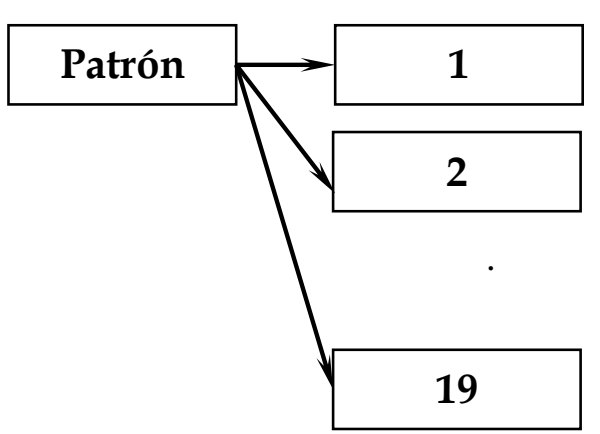

Significativo

Mavor Eje Y
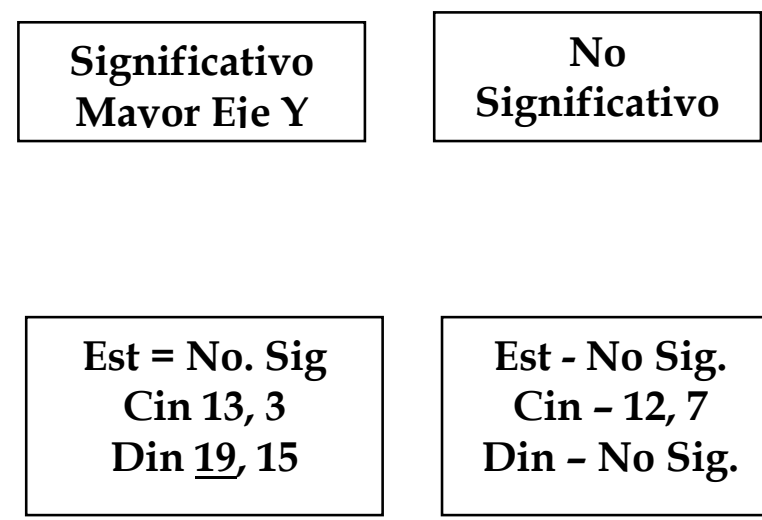

Est - No Sig.

Cin $-12,7$

Din - No Sig.
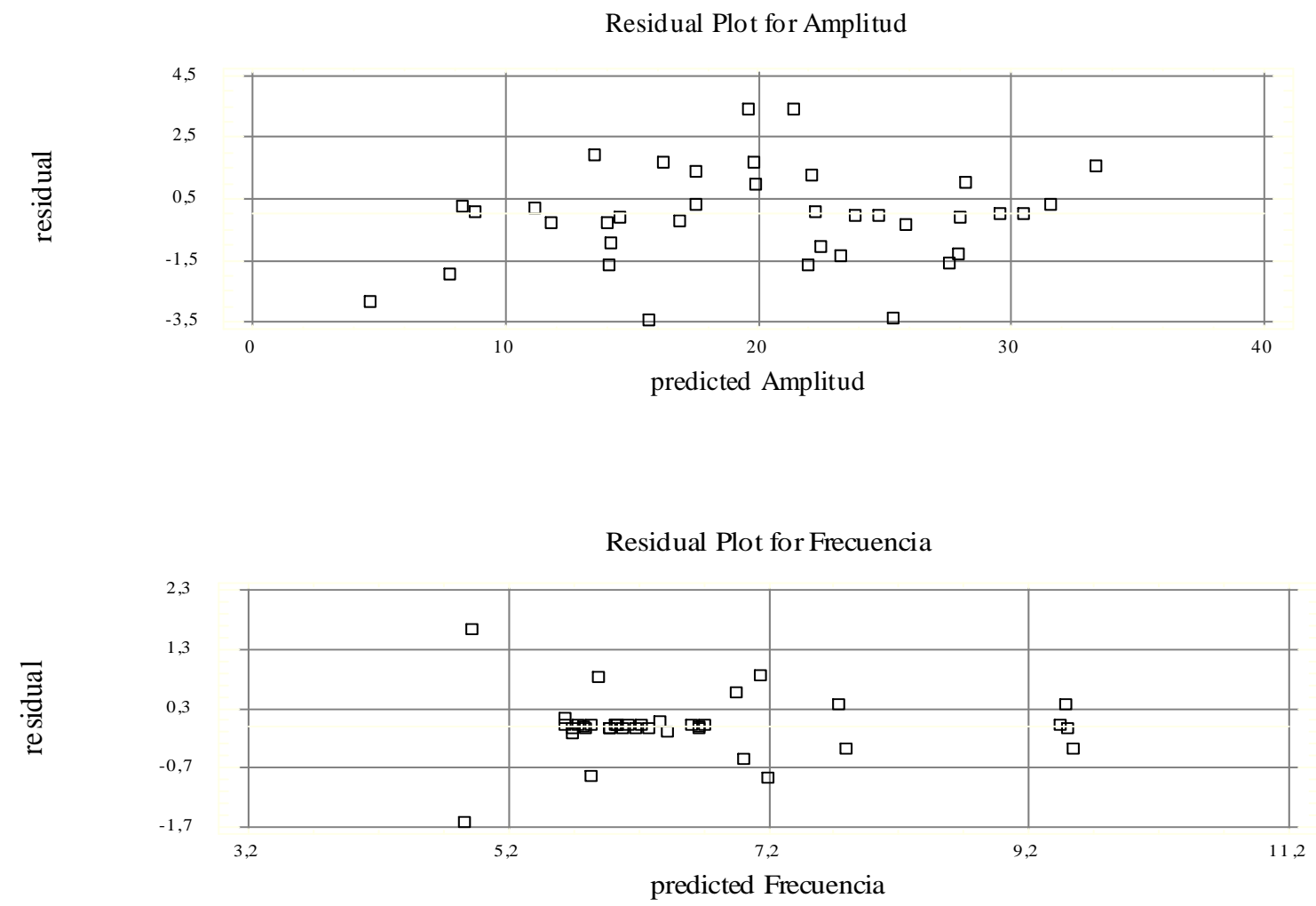

Figura 3.33: Residuos para el segundo análisis enfermos de Parkinson. Diseño 6. 


\subsubsection{Diseños 7 y 8: Enfermos de temblor intencional.}

La Figura 3.34 y la Figura 3.35 reflejan los resultados de los análisis realizados para los pacientes con temblor esencial:

\section{Primer Diseño para pacientes con Temblor}
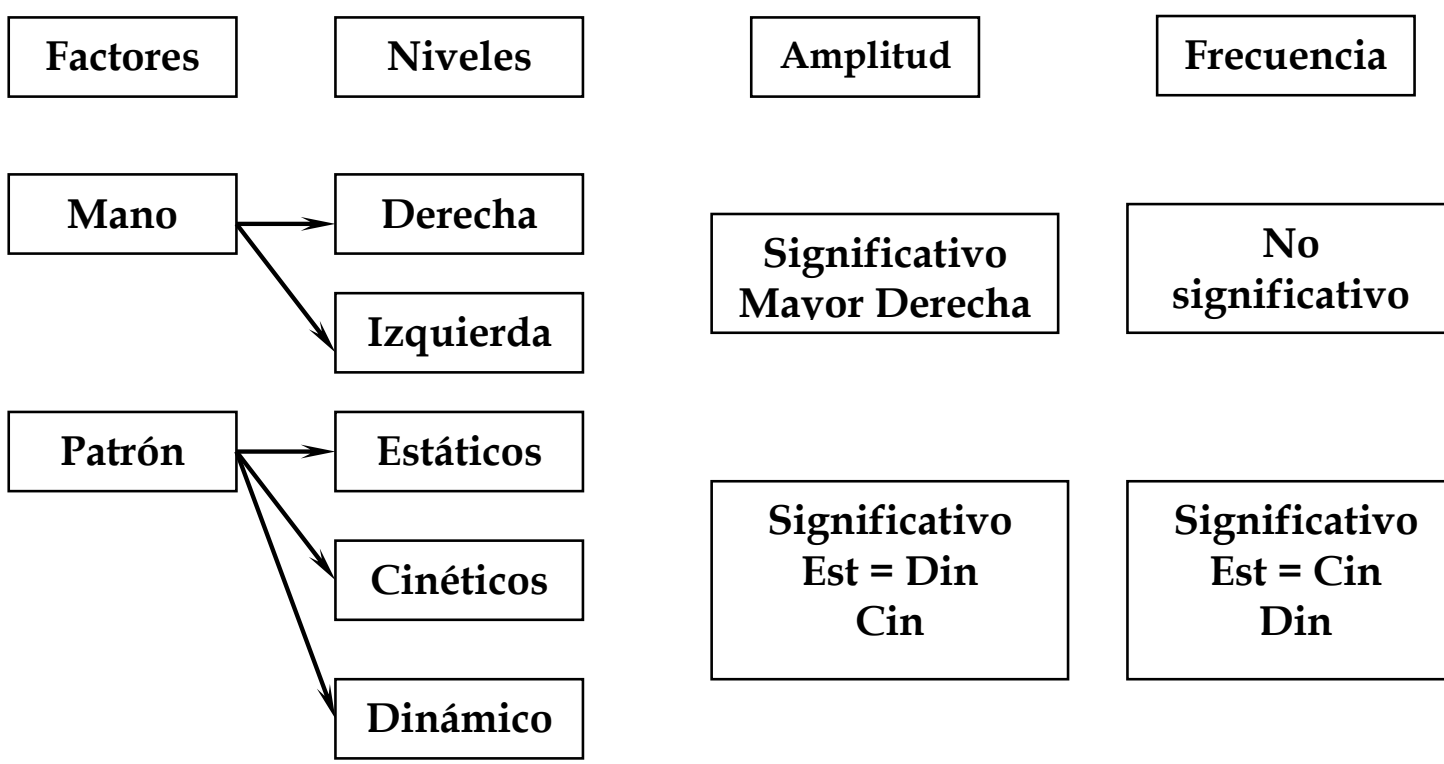

Significativo

Est $=$ Cin

Din
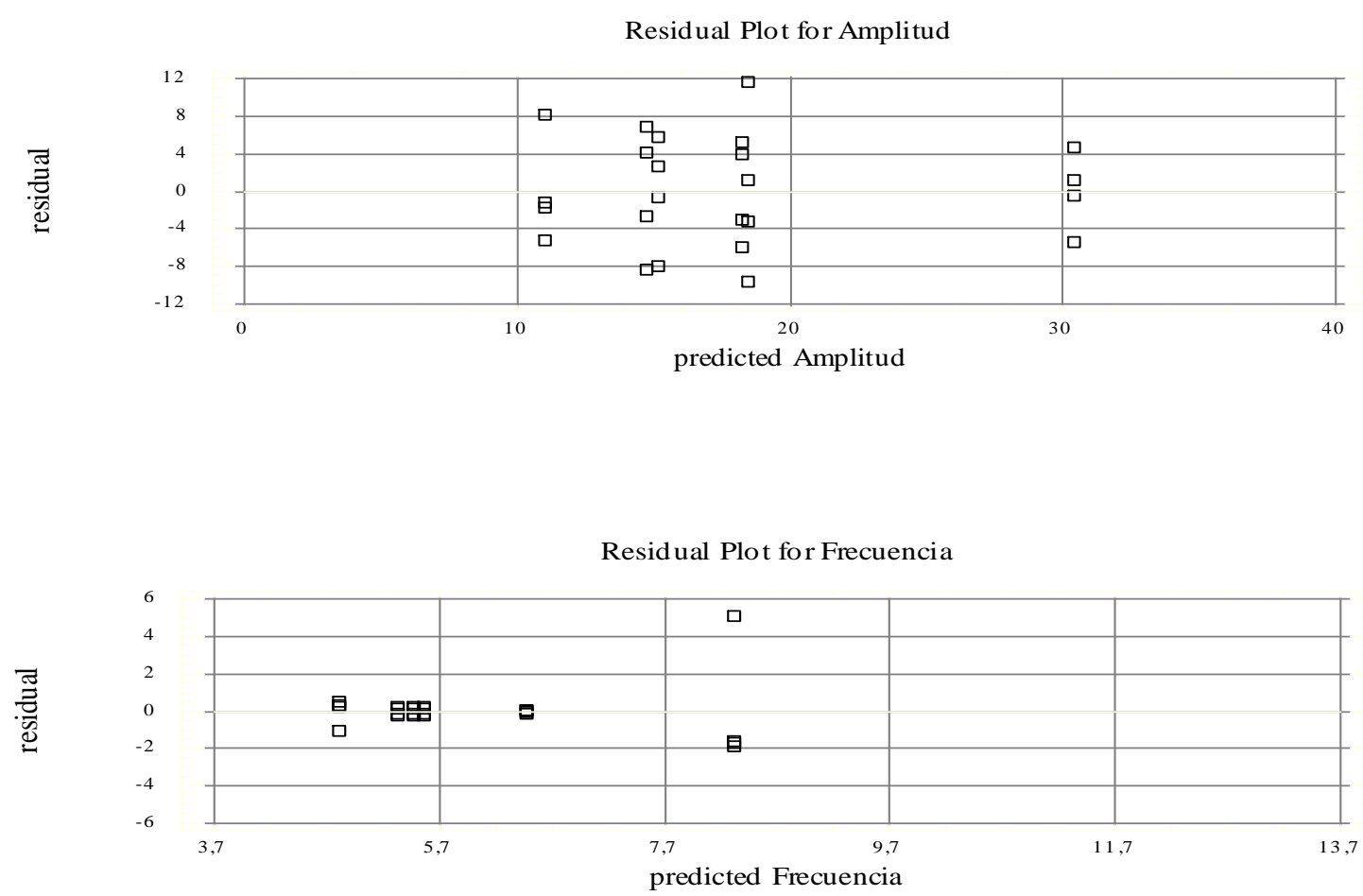

Figura 3.34: Graficas de residuos para el primer analisis con pacientes con temblor esencial. Diseño 7. 


\section{Segundo Diseño para pacientes con Temblor Intencional}
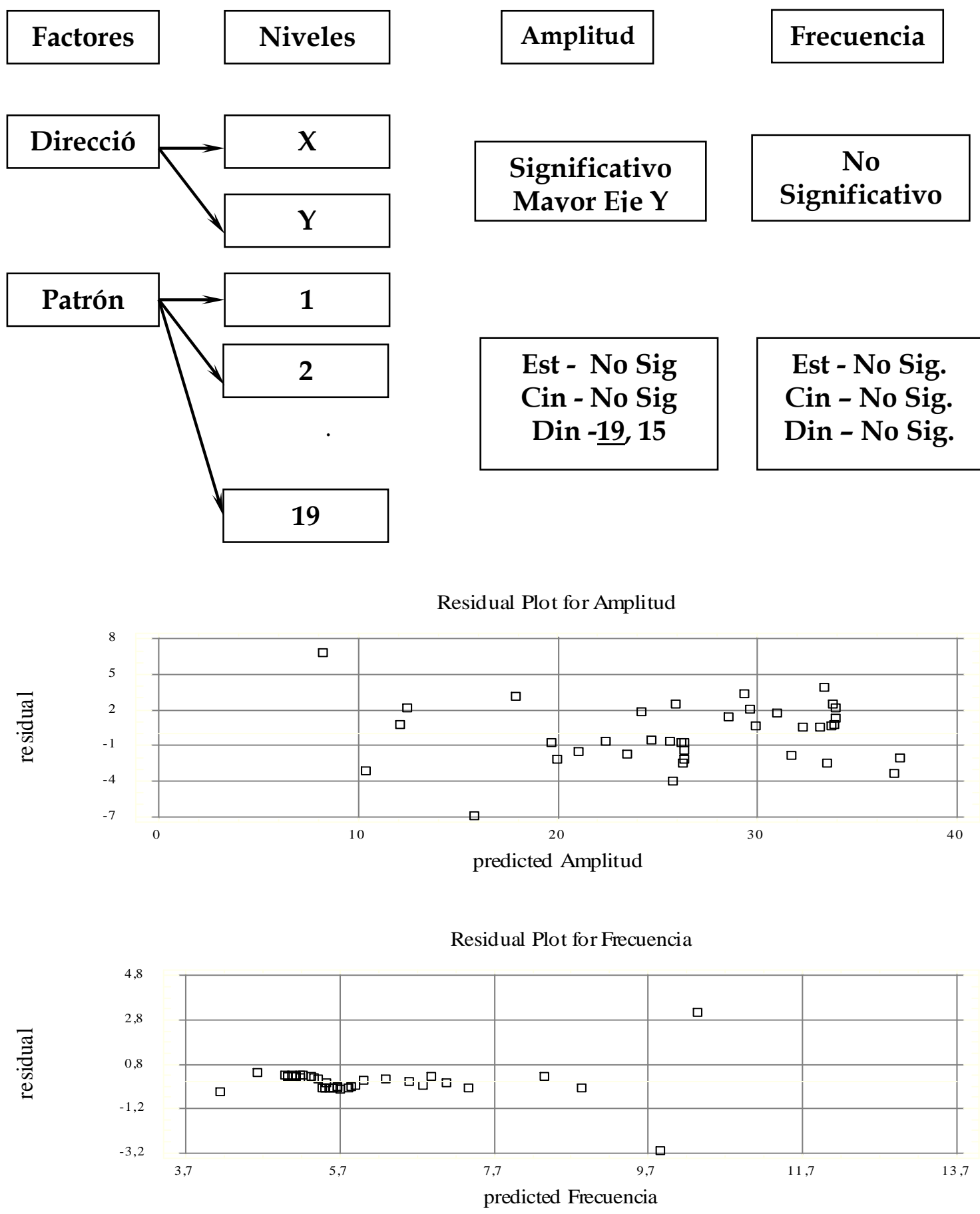

Figura 3.35: Gráficas de residuos para el segundo análisis con pacientes con temblor esencial. Diseño 8. 
Los resultados para los pacientes con temblor esencial en algunos casos coinciden con los de Parkinson como es el caso en que para la amplitud la mano es significativa siendo mayor la derecha, lo mismo que es significativa la dirección, siendo mayor en el eje Y.

Para pacientes de temblor esencial se encontró que la mano no es significativa desde el punto de vista de la frecuencia lo que nos puede llevar a pensar que aunque los pacientes estaban catalogados como enfermos de la extremidad derecha, en la izquierda padecen un pequeño temblor de baja amplitud pero de frecuencia semejante.

Del análisis entre cada patrón se obtiene que tanto en frecuencia como en amplitud los patrones estáticos y cinéticos no son significativos, lo que lleva a pensar que para un paciente con temblor intencional se puede aplicar un solo patrón de estos grupos de patrones y se obtendrían resultados similares. En cuanto a los dinámicos si hay diferencias ya que en amplitud son significativos. Esto significa que el comportamiento es claramente diferenciable con este tipo de estímulos, ya que los temblores esenciales son amplificados por este tipo de fuerzas. En cuanto a la frecuencia no afecta la aplicación de fuerzas (modificación únicamente de la amplitud del movimiento).

\subsubsection{Comparación de Poblaciones.}

El primer objetivo que se desea contrastar con la comparación de poblaciones es la diferencia entre ambas (pacientes afectados con temblor y población de sujetos sanos o población de control). Como variables a analizar se utiliza la frecuencia en la que aparecen aquellos armónicos más importantes (los que poseen mayor amplitud), así como el módulo de la amplitud de los mismos.

Como segundo objetivo se pretende averiguar cuál es el orden del armónico a partir del cual armónicos siguientes no permiten diferenciar entre ambas poblaciones.

Los datos de partida utilizados han sido elegidos de entre una serie de pruebas realizadas a los individuos de ambas poblaciones. Concretamente el número de individuos de ambas poblaciones ha sido: población de control $n=6$, población de pacientes $n=5$. El número de muestras obtenidas de cada sujeto ha sido de $m=50$ para cada mano. De cada prueba se obtienen las cuatro componentes frecuenciales con mayor amplitud en su módulo, guardando la amplitud y la frecuencia.

\section{- Análisis realizados.}

Para la realización de los análisis se ha aleatorizado tanto la variable sujeto dentro de cada población, como las variables patrón y mano. El análisis se ha realizado para cada uno de los cuatro grupos de datos obtenidos, en función del orden del armónico, analizándose los resultados para las dos variables respuesta. 
Inicialmente se considera un tamaño muestral de 100 elementos en ambas poblaciones. Para el análisis de la homocedasticidad de se han utilizado los resultados obtenidos en los residuos.

\begin{tabular}{|c|c|c|c|c|c|}
\hline & & \multicolumn{4}{|c|}{ ARMONICOS. } \\
\hline & & \multicolumn{2}{|c|}{ Primero } & \multicolumn{2}{|c|}{ Segundo } \\
\hline & & Módulo & Frecuencia & Módulo & Frecuencia \\
\hline \multicolumn{2}{|c|}{ Heterocedasticidad } & Sí & Sí & Sí & $\overline{\text { Sí }}$ \\
\hline \multicolumn{2}{|c|}{ Transformación } & $\log$ (Modulo) & $1 /(\text { Frecuencia })^{\wedge} 4$ & log(Modulo) & $1 /(\text { Frecuencia })^{\wedge} 4$ \\
\hline \multicolumn{2}{|c|}{ Evid. Estadíst. dif. Pobl. } & Sí & Sí & Sí & No \\
\hline \multirow[t]{2}{*}{ Sanos } & $n$ & 73 & 73 & 30 & 30 \\
\hline & Media & 0,773376 & 0,00756278 & 0,152276 & 0,00515813 \\
\hline \multirow[t]{3}{*}{ Pacientes } & $n$ & 93 & 93 & 79 & 79 \\
\hline & Media & 1,97728 & 0,00402646 & 1,43789 & 0,00384997 \\
\hline & Varianza & 0,707486 & 1,16186E-05 & 1,01991 & 1,21924E-05 \\
\hline \multirow[t]{2}{*}{ Comp. } & Intervalo $(a=95 \%)$ & $-1,2039+/-0,28563$ & $0,00353632+/-0,000872353$ & $-1,28562+/-0,45591$ & $0,00130816+/-0,00136689$ \\
\hline & $\mathrm{p}$ (Test F) & 0 & 0 & 0 & 0,0605 \\
\hline & & \multicolumn{4}{|c|}{ ARMONICOS. } \\
\hline & & \multicolumn{2}{|c|}{ Tercero } & \multicolumn{2}{|c|}{ Cuarto } \\
\hline \multicolumn{2}{|c|}{ Heterocedasticidad } & Sí & Sí & No & Si. \\
\hline \multicolumn{2}{|c|}{ Transformación } & $\log ($ Modulo) & $1 /(\text { Frecuencia })^{\wedge} 4$ & $\log (1 /$ Modulo $)$ & $\log \left(1 /(\text { Frecuencia })^{\wedge} 4\right)$ \\
\hline \multicolumn{2}{|c|}{ Evid. Estadíst. dif. Pobl. } & Sí & Sí & No & No \\
\hline \multirow[t]{3}{*}{ Sanos } & $n$ & 10 & 10 & 8 & 8 \\
\hline & Media & 0,072689 & 0,00458454 & 0,112918 & $-6,48553$ \\
\hline & Varianza & 1,41776 & 6,74023E-06 & 1,88918 & 1,1625 \\
\hline \multirow[t]{3}{*}{ Pacientes } & $n$ & 56 & 56 & 47 & 47 \\
\hline & Media & 1,17569 & 0,00259792 & $-0,142658$ & $-6,98825$ \\
\hline & Varianza & 1,1017 & 6,91419E-06 & 1,88918 & 2,00624 \\
\hline \multirow[t]{2}{*}{ Comp. } & Intervalo $(a=95 \%)$ & $-1,103+/-0,734237$ & $0,00198662+/-0,00180018$ & $0,255576+/-1,48463$ & $0,502711+/-1,05596$ \\
\hline & $\mathrm{p}$ (Test F) & 0,0038 & 0,0311 & 0,7312 & 0,344 \\
\hline
\end{tabular}

Tabla 3.20: Análisis de la influencia del tipo de población.

\section{Conclusiones.}

Las conclusiones que se pueden obtener de los resultados obtenidos son:

- Existe evidencia estadística de diferencia entre las dos poblaciones analizadas (sanos, enfermos), tanto analizando la variable respuesta módulo como la variable respuesta frecuencia.

- Los tres primeros armónicos son significativos, para ambas variables de respuesta, no así en el cuarto armónico.

- Es preciso realizar transformaciones de las variables respuesta para conseguir homocedasticidad en los residuos, condición que se cumple en los análisis de los tres primeros armónicos, sin embargo para el cuarto aun realizando la transformación, los gráficos muestran que los residuos son claramente heterocedásticos. Por otro lado, los valores de amplitud para el cuarto armónico, son notablemente menores que los valores presentes para el resto de los armónicos.

\subsubsection{Comparación de los patrones (Un Factor).}

Como objetivo en este caso se pretende contrastar la significación entre los diferentes grupos de patrones: estáticos, cinéticos y dinámicos, para ambas poblaciones, pacientes afectados con temblor y población de sujetos sanos o 
población de control. Como variables a analizar se utilizan la frecuencia en la que aparecen aquellos armónicos más importantes, los que poseen mayor amplitud, así como el módulo de la amplitud de dichos armónicos.

\section{Análisis realizados.}

En la realización de los análisis se ha aleatorizado tanto la variable sujeto dentro de cada población, como las variables mano (derecha o izquierda) y la variable patrón dentro de cada grupo.

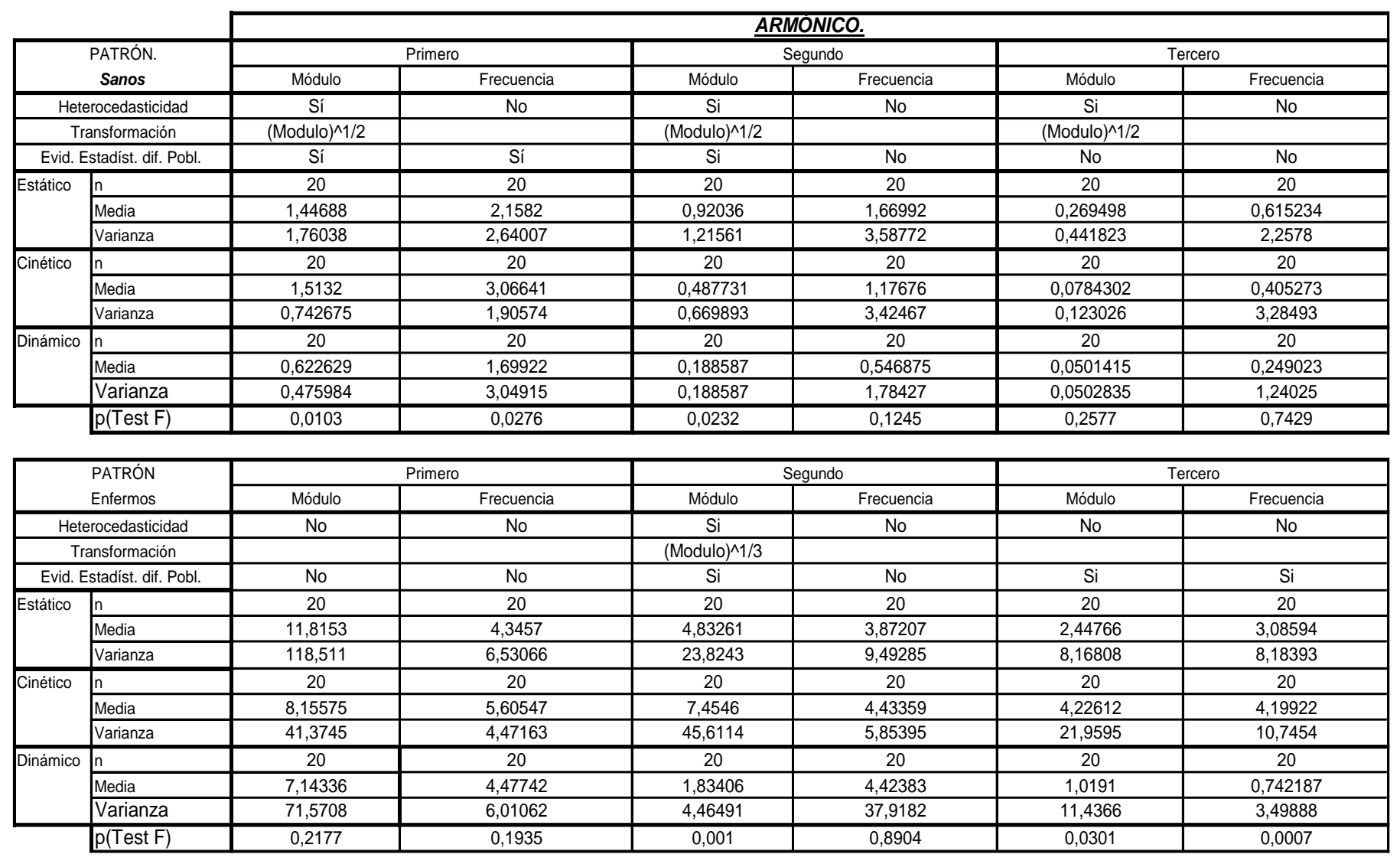

Tabla 3.21: Análisis influencia de los patrones.

El análisis se ha realizado para cada uno de los cuatro grupos de datos obtenidos, en función del orden del armónico, analizando los resultados para las dos variables respuesta. Los valores obtenidos de la realización del análisis sobre el cuarto armónico, no eran significativos pues no arrojaban diferencia entre los grupos de patrones, por lo cual los datos no aparecen en las tablas de resultados. El tamaño muestral considerado ha sido de 20 muestras. 


\section{Conclusiones.}

Para la población de control, el primer armónico permite diferenciar el tipo de patrón realizado. Así para la variable amplitud, el grupo de patrones estáticos y cinéticos forman un macro grupo, mientras que el grupo de patrones dinámico se desmarca claramente. En frecuencia los resultados del análisis muestran que los tres grupos de patrones son diferentes. Sin embargo para la población de pacientes, el primer armónico no permite distinguir entre patrones, esto es, para personas que padecen temblor el primer armónico no ofrece información sobre el tipo de prueba realizada (no es suficiente la variable frecuencia para poder diferenciar las poblaciones patológicas).

\subsubsection{Conclusiones generales sobre la información proporcionada por el sistema DIMETER.}

- Los datos proporcionados por el sistema DMETER permiten apreciar claras diferencias entre el comportamiento entre las personas sanas y enfermas.

- También se aprecian diferencias entre los patrones dependiendo de la naturaleza de las patologías.

- Los armónicos significativos han resultado ser los tres primeros.

- En el primer armónico no existen diferencias entre personas enfermas, al contrario de lo que sucede con las sanas.

- Se ha obtenido evidencia de la existencia de diferencias entre patrones cinéticos y dinámicos.

- Los resultados obtenidos son válidos tanto para la variable amplitud como para la frecuencia. 


\section{HERRAMIENTAS MATEMÁTICAS Y CLASIFICADORES.}

\subsection{Transformada wavelet.}

Entre el gran número de herramientas que se han ido desarrollando con el paso de los años para el análisis de señales, una de ellas es la Transformada de Fourier, utilizada frecuentemente por la posibilidad de proporcionar una representación del contenido de frecuencias que posee una determinada señal. También se han ido desarrollando otro tipo de herramientas que permiten realizar el análisis desde otra perspectiva, cuando las señales no se comportan de forma estacionaria.

La teoría de las wavelets puede enfocarse desde múltiples puntos de partida y su plena formulación y comprensión requiere de una perspectiva global y sintetizadora. Esta diversidad de enfoques, explica también la versatilidad de sus posibles aplicaciones y aún las dificultades de quienes se disponen a decidir una estrategia basada en wavelets frente a problemas específicos.

\subsubsection{Análisis de Fourier.}

Esta transformación permite descomponer una señal en sus componentes sinusoidales. En otras palabras, es una técnica matemática para transformar el dominio de trabajo desde el temporal al frecuencial.

En muchos casos, el análisis mediante Transformada de Fourier resulta extremadamente útil, razón por la cual sería natural preguntarse por qué podría ser necesario el uso de otra herramienta para el análisis de señales; pues bien, al pasar una señal al dominio de la frecuencia se pierde la información referente al tiempo. Más precisamente, cuando se observa una señal producto de la Transformación de Fourier, resulta imposible determinar cuándo ocurre un determinado evento o cuándo está presente una determinada frecuencia. Si las propiedades de la señal que se está analizando no cambian demasiado con el tiempo, es decir, si se está trabajando con una señal estacionaria, esta desventaja no resulta muy relevante 
(como en el caso de señales periódicas). Sin embargo, un importante número de señales de interés presentan características no estacionarias o transitorias, tales como una tendencia, cambios abruptos, comienzos o finales de eventos, etc. A menudo, estas características no estacionarias resultan ser las secciones más interesantes de las señales, y la Transformada de Fourier no es la más idónea para detectarlas y/o analizarlas.

\subsubsection{Análisis de Fourier por intervalos.}

En un esfuerzo por corregir la deficiencia presentada en el punto previo, en 1946 Denis Gabor adaptó la transformada de Fourier para poder analizar una pequeña sección de la señal en un determinado tiempo (mediante una "ventana"). Esta adaptación es la que se conoce como STFT (Short Time Fourier Transform), la cual traslada una señal del plano del tiempo al plano bidimensional de tiempo y frecuencia, tal como se representa esquemáticamente en la Figura 4.1.

Es importante resaltar que la STFT representa una especie de compromiso entre el dominio del tiempo y el de la frecuencia de una señal, ya que provee algo de información acerca de cuándo y a qué frecuencia de una señal ocurre un determinado evento. Sin embargo, solamente se puede obtener dicha información con una precisión limitada, la cual está acotada por el tamaño de la ventana.
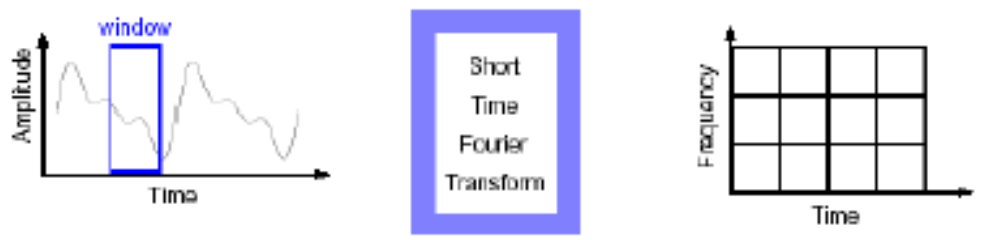

Figura 4.1: Transformada de Fourier Short Time.

Mientras que el compromiso entre la información del tiempo y la frecuencia puede resultar útil, el inconveniente surge cuando una vez que se escoge un determinado tamaño para la ventana de tiempo, dicha ventana es la misma para todas las frecuencias. Muchas señales requieren un acercamiento más flexible, de modo tal que sea posible variar el tamaño de la ventana para determinar con mayor precisión el tiempo o la frecuencia.

\subsubsection{Transformada Wavelet.}

El análisis Wavelet representa el paso lógico siguiente a la STFT: una técnica mediante ventanas con regiones de tamaño variable. El análisis Wavelet permite el uso de intervalos grandes de tiempo en aquellos segmentos en los que se requiere mayor precisión en baja frecuencia, y regiones más pequeñas donde se requiere información en alta frecuencia. Esta idea es la que se muestra en forma esquemática en la Figura 4.2. 

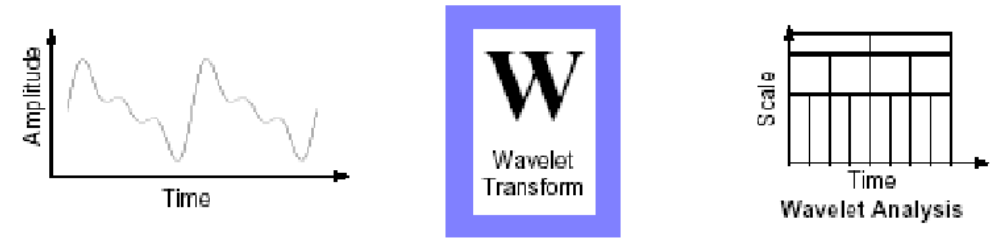

Figura 4.2: Transformada Wavelet.

Una forma sencilla de comprender el modo de operación de esta transformada es pensar que la señal en el dominio temporal es sometida a varios filtros paso-bajos y paso-altos, los cuales permiten separar las porciones de la señal de alta frecuencia de aquellas de baja frecuencia.

Este procedimiento se repite cada vez sobre porciones de la señal correspondientes a aquellas frecuencias que han sido eliminadas de la señal original.

Para clarificar más la forma en que opera esta transformada, se considera el siguiente ejemplo: supóngase que se tiene una señal que posee frecuencias hasta $1000 \mathrm{~Hz}$. En la primera etapa se divide la señal en dos partes, pasándola por un filtro paso-alto y otro paso-bajo. De este modo, se obtienen dos diferentes versiones de la señal original: parte de la señal corresponde al rango $0-500 \mathrm{~Hz}$ y la otra al rango 500$1000 \mathrm{~Hz}$. Posteriormente, se toma una de esas partes (o ambas) y se repite el proceso. Suponiendo que se hace nuevamente este proceso con la parte de baja frecuencia, y que en dicho resultado el proceso se vuelve a repetir en la parte de baja frecuencia, se tienen cuatro partes de la señal original: $0-125 \mathrm{~Hz}, 125-250 \mathrm{~Hz}, 250-500 \mathrm{~Hz}$ y $500-$ $1000 \mathrm{~Hz}$. Se puede continuar con este procedimiento hasta que se haya descompuesto la señal en un determinado número de niveles. De este modo, se tienen un grupo de señales que representan a la misma señal, pero todas ellas corresponden a diferentes bandas de frecuencias.

Dado que se sabe a qué rango de frecuencias corresponde cada una de estas señales, es posible agruparlas y hacer un gráfico en tres dimensiones, teniendo el tiempo en un eje, la frecuencia en otro y la amplitud en el tercero. De este modo, se pueden observar qué frecuencias ocurren a qué tiempo. Este mismo grupo de señales puede servir para regenerar la señal original, puesto que básicamente se trata de una descomposición en una base ortogonal, al igual que otras transformaciones matemáticas. Esto implica que la Transformada Wavelet tiene la propiedad de invertibilidad.

Un ejemplo ilustrativo es el que se muestra en la figura Figura 4.3, donde se observa una señal no estacionaria de frecuencias diferentes en distintos instantes de tiempo. 

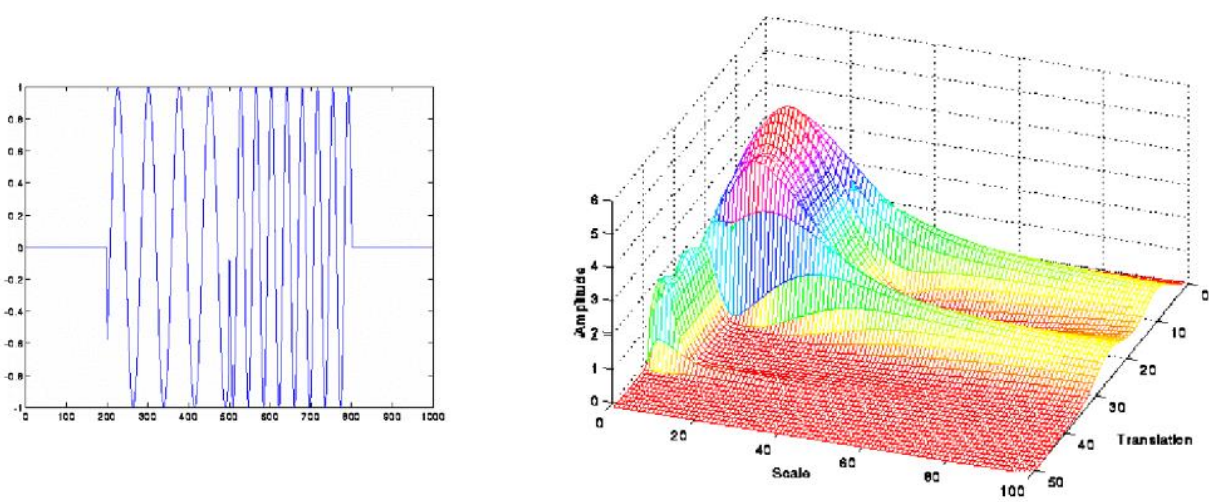

Figura 4.3: Transformada wavelet (der.) de una señal no estacionaria.

En la Figura 4.3 (der.) se puede apreciar la Transformada Wavelet continua de una señal no estacionaria. El eje en profundidad representa el eje de tiempo. El pico pequeño de la figura corresponde a componentes de alta frecuencia de la señal, mientras que el pico más grande corresponde a frecuencias menores, las cuales aparecen antes en el tiempo que las altas frecuencias, como puede verse en la señal original Figura 4.3 (izq).

El parámetro "scale" usado en el análisis Wavelet es similar a la escala usada en la confección de mapas. Las escalas grandes corresponden a vistas globales (no detalladas) mientras que escalas más pequeñas corresponden a vistas con mayor detalle. Similarmente, en términos de frecuencia, las bajas frecuencias (altas escalas) corresponden a la información global de una señal (es decir, lo que generalmente marca la tendencia de la señal), mientras que las altas frecuencias (bajas escalas) corresponden a información detallada de patrones ocultos de la señal (los que usualmente tienen una duración reducida de tiempo).

\subsubsection{Análisis mediante Transformada Wavelet.}

Antes de continuar con las características del análisis de señales mediante la Transformada Wavelet, es necesario señalar que una Wavelet es una señal (o forma de onda) de duración limitada cuyo valor medio es cero.

Comparando las wavelets con las funciones sinusoidales (que son la base del análisis de Fourier), se puede resaltar que la principal diferencia radica en que las señales sinusoidales no tienen duración limitada, dado que se extienden desde $-\infty$ a $+\infty$. Además, mientras las señales sinusoidales son suaves, definidas por una frecuencia y una amplitud, las wavelets tienden a ser irregulares y asimétricas, tal como se puede apreciar en la Figura 4.4. 


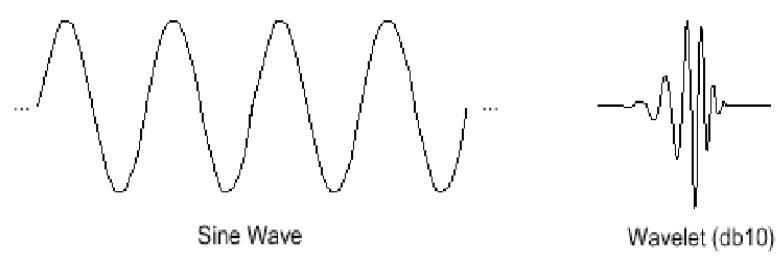

Figura 4.4: Senoide (izq) y wavelet (der).

Tal como se mencionó previamente, el análisis a través de Transformada de Fourier consiste en descomponer la señal original en funciones sinusoidales de diferentes frecuencias. En forma similar, el análisis de señales mediante Transformada Wavelet descompone la señal en versiones trasladadas (en tiempo) y escaladas de la Wavelet original, más conocida como Wavelet madre.

Observando las gráficas de la figura anterior, resulta intuitivo pensar que las señales con cambios bruscos serán mejor analizadas mediante Wavelets irregulares que a través de suaves sinusoides. Como consecuencia de aquello, es que una de las principales ventajas que provee la Transformada Wavelet es su facultad para el análisis de áreas localizadas de señales grandes.

Hasta ahora, solamente se ha discutido acerca del tratamiento de señales de una dimensión, sin embargo, el análisis mediante Transformada Wavelet puede ser aplicado a datos bidimensionales (imágenes), y en principio, también a datos de un número mayor de dimensiones.

\subsubsection{Cálculo de la Transformada Wavelet.}

En este apartado se expone un método sencillo para obtener la Transformada Wavelet de una determinada señal.

Antes de describir los pasos a seguir, debe elegirse una función Wavelet, la que será la Wavelet madre y servirá como prototipo para todas las ventanas que se emplean en el proceso. Existe una importante cantidad de familias de funciones wavelets, entre ellas: la Haar, Daubechies, Biortogonal, Coiflets, Symlets, Morlet, Sombrero mexicano y Meyer, entre otras.

Los pasos a seguir para determinar la Transformada Wavelet de una señal son:

- Comenzando con un determinado valor de s (escala), por ejemplo 1, para la señal Wavelet, se ubica ésta al comienzo de la señal a analizar (en $t=$ 0 ). Luego, se multiplican entre sí ambas señales y el resultado se integra sobre todo el espacio de tiempo. El resultado de dicha integral se multiplica por el inverso de la raíz cuadrada de s, con el objeto de normalizar la energía y de este modo obtener un valor coherente en 
función de la escala utilizada. Este resultado es el valor de la

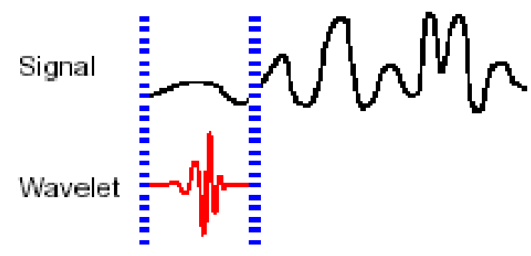

Figura 4.5: Primera posición de la ventana.

Transformación Wavelet en tiempo cero y s $=1$. Este resultado indica cuán correlacionada está la Wavelet con el segmento de la señal original. Lógicamente, el resultado dependerá de la elección de la función Wavelet. Este paso queda representado en la Figura 4.5.

- La función Wavelet (en la misma escala, por ejemplo s =1) se traslada en tiempo (hacia la derecha) en $\tau$, y se vuelve a realizar el procedimiento descrito en el paso 1. Se debe repetir hasta llegar al final de la señal a analizar. Este paso queda ilustrado en la Figura 4.6.

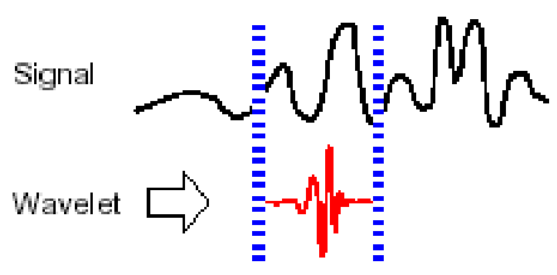

Figura 4.6: Traslación de la ventana para el nuevo cálculo.

- Se varía el valor de s (escala) y se vuelven a realizar los pasos 1 y 2 hasta haber barrido todo el rango de frecuencias que se desea analizar (Figura 4.7). Al tratarse de una Transformación continua, tanto el desplazamiento en el tiempo, como la variación de escala, deben realizarse de forma continua. Sin embargo, si es necesario obtener la Transformada Wavelet por medios discretos (sistemas digitales), la condición anterior se reduce a considerar un paso suficientemente pequeño. Cada cálculo para un determinado valor de s llena la correspondiente fila de datos del plano tiempo-escala. 


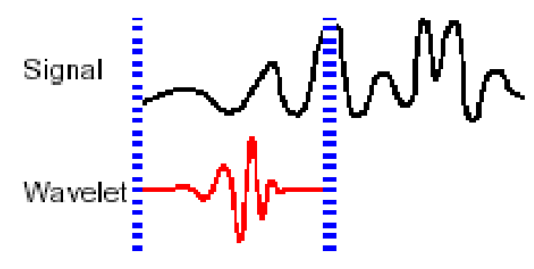

Figura 4.7: Variando el parámetro s vuelve a repetirse el procedimiento.

- Cuando se haya completado el cálculo para todos los valores de s, se habrá obtenido la Transformada Wavelet continua de la señal.

- Además de la representación tridimensional de la Transformada, es posible obtener una representación en la cual el eje $x$ representa el tiempo, el eje y representa la escala, y el color para cada punto $x-y$ representa la magnitud de los coeficientes wavelet, tal como se muestra en el ejemplo de la figura.
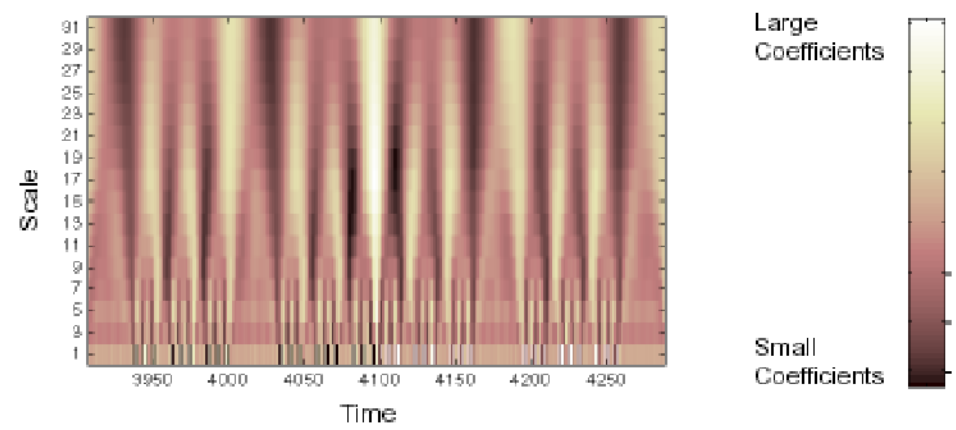

Figura 4.8: Representación bidimensional de la Wavelet.

\subsubsection{Transformada Wavelet discreta.}

Para aplicar la transformada Wavelet a una serie de datos, es necesario utilizar la transformada discreta. La idea fue desarrollada por Mallat en 1988, quien diseñó un algoritmo basado en un banco de filtros para obtener una transformada Wavelet de una manera simple a partir de los datos muestrales.

\subsubsection{Filtros de nivel.}

En la mayoría de los casos son las componentes de alta frecuencia las que le otorgan a la señal la mayor parte de su información. Es por ello que se subdividen las componentes de una señal en dos categorías: 
- Aproximaciones (baja frecuencia)

- Detalles (alta frecuencia)

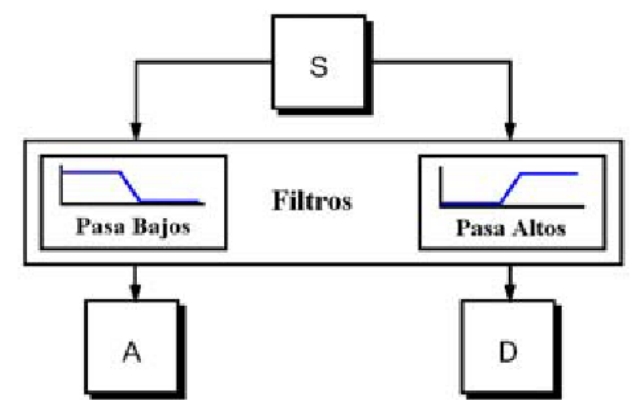

Figura 4.9: Descomposición de la señal original.

S es la señal que se desea analizar, A la salida del paso-bajo y D la salida del filtro paso-alto (Figura 4.9). Naturalmente, los filtros son diseñados de tal manera que sean complementarios, es decir, la suma de A y D debe ser S. Si se diseñaran los filtros con un margen elevado entre los flancos de bandas, se perdería información, o en caso contrario (solape), se estaría amplificando la banda de solapamiento. Este procedimiento tiene el inconveniente de que se aumenta al doble el número de datos originales, pues por cada muestra de $S$ se genera un par de muestras (A, D). Para evitarlo, suele recurrirse a guardar la mitad de los puntos (A,D), sin perder en ello información de la señal S. Este procedimiento es conocido como submuestreo. La idea se ilustra en la Figura 4.10.

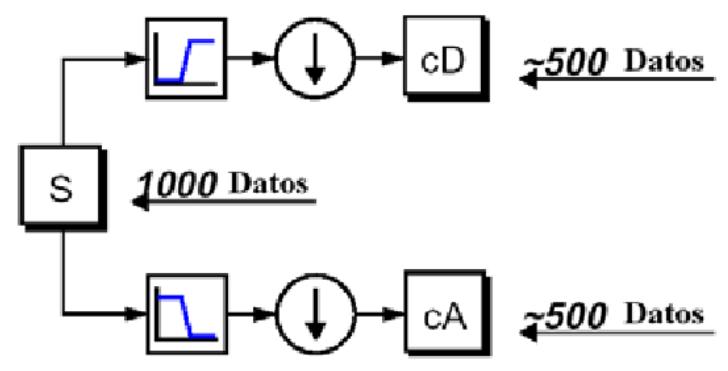

Figura 4.10: Proceso de submuestreo.

Los círculos con flechas representan la eliminación de datos o submuestreo. cD y cA son los nuevos datos obtenidos de la etapa de filtro. Intuitivamente se puede concluir que al tener $\mathrm{cD}$ y cA, en conjunto, se tiene la misma cantidad de datos que las de la señal original S, manteniendo la información necesaria. En la figura anterior se ejemplifica la idea para una señal S de 1000 datos, obteniéndose en la salida dos series de aproximadamente 500 datos cada una. La idea de aproximado, se debe a que el proceso de filtro se realiza por medio de la convolución de la señal de entrada con 
la función de transferencia (discreta) del filtro, lo que puede introducir eventualmente alguna muestra más.

Sin embargo, para señales de mayor complejidad, no basta con dos bandas de frecuencias (alta y baja), sino que debe hacerse una descomposición de más niveles para poder separar las características y poder analizarlas independientemente. Surge la idea entonces de los filtros multinivel.

\subsubsection{Filtros multinivel.}

Para llevar a cabo esta técnica basta con iterar el proceso de filtrado, es decir, aplicar el mismo procedimiento a las señales de salida de la primera etapa, y así sucesivamente hasta el nivel de precisión que se desee. Lo anterior da origen a una descomposición multinivel conocida como ramificación o árbol de descomposición Wavelet, cuya idea se muestra en la Figura 4.11.

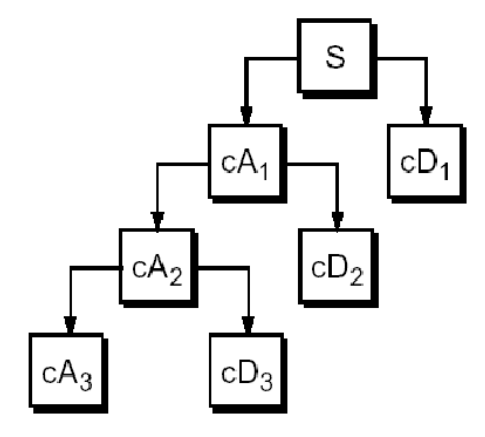

Figura 4.11: Filtros multinivel.

Nótese que cD1 resulta ser la componente de más alta frecuencia de la señal, y cA3 la de menor frecuencia. Al ser descompuesta la señal en una mayor cantidad de bandas de frecuencia se posee una información más detallada acerca de $S$, por lo que esta técnica es conocida como multiresolución.

\subsubsection{Determinación del número de niveles.}

En teoría, como se trata de un proceso recursivo, se podría iterar de forma sucesiva sin límite. Sin embargo, en la práctica, sólo se puede descomponer hasta que un intervalo o nivel posea una sola que un intervalo o nivel posea una sola muestra (o píxel en el caso bidimensional, para análisis de imágenes).

Podría pensarse que se obtienen resultados mejores con un mayor número de niveles de descomposición, sin embargo, esto no siempre es así. Se recomienda una ramificación acorde a la naturaleza de la señal a estudiar, o bien elegir métodos que busquen la descomposición óptima, como por ejemplo, el de la entropía. 


\subsubsection{Aplicaciones de las Wavelets.}

El procesamiento de señales a través de wavelets tiene innumerables aplicaciones en multitud de ámbitos de la ciencia y de la ingeniería. A continuación se exponen una relación de ellos:

\section{Detección de discontinuidades o de puntos de cambio en señales (en una o varias dimensiones):}

Resulta de gran utilidad, en especial en el tratamiento de imágenes, en donde interesa detectar la frontera entre colores y formas, o también en sistemas de alta dinámica en donde interesa determinar cuándo o dónde se producen los cambios. En el presente trabajo se propondrán para intentar identificar las posibles discontinuidades en el movimiento en los registros efectuados en el caso de los enfermos de Párkinson, debido a las bradicinesias que suelen darse con mucha probabilidad tras un periodo de terapia farmacológica.

\section{Estudio de fractales:}

Mediante wavelets se puede reconocer un patrón repetitivo en una señal o imagen, lo que la convierte en una herramienta muy útil en el estudio de fractales.

\section{Identificación de frecuencias puras:}

Como se trata de una transformada compuesta por una base ortogonal de señales (análoga con la base sinusoidal de Fourier), también pueden utilizarse para estudiar el contenido espectral de señales.

\section{Eliminación de ruido:}

El análisis de señales mediante wavelets, también permite la eliminación o filtrado de ruido tanto en señales unidimensionales como en imágenes (bidimensionales).

\section{Compresión de imágenes:}

Se trata de una de las aplicaciones más importantes de Wavelets, se realiza mediante el análisis en dos dimensiones.

\section{Multiplicación rápida de matrices:}

La multiplicación de vectores matriciales se realiza en el dominio Wavelet. Por ejemplo, si se desea multiplicar una matriz cuadrada de orden $n$ en forma sucesiva con $k$ vectores $v$, se debe aproximar o transformar los vectores y la matriz por imágenes (en dominio Wavelet). Después realizar la multiplicación y finalmente aplicar la transformada inversa al resultado obtenido. Si las aproximaciones realizadas son buenas, el error de multiplicación es pequeño con respecto al resultado real por multiplicación ordinaria, pero el tiempo de cálculo es notablemente inferior, especialmente en matrices de grandes dimensiones, o en multiplicaciones de múltiples matrices. 


\section{Aplicaciones en medicina:}

Se ha incorporado el análisis con wavelets a señales biológicas, permitiendo interpretar los resultados de exámenes médicos, facilitando el diagnóstico de las enfermedades. Por ejemplo, se ha aplicado con éxito en el análisis de electroencefalogramas, debido a que la naturaleza este tipo de señales es altamente no estacionaria (no siendo recomendable el uso de la transformada de Fourier).

\subsubsection{Aplicación a la detección de discontinuidades.}

Como se mencionaba en el apartado anterior, en el presente trabajo de tesis se decidió utilizar las wavelets como medio de detección de discontinuidades, y poder detectar aquellas pruebas en las que el paciente tuviera problemas de fluidez. Estos parones son muy frecuentes en los pacientes con Párkinson, ya que en muchos casos padecen de "parones" en el transcurso (al comienzo o durante) del movimiento intencional.

En la Figura 4.12 puede verse la señal original de posición y la wavelet d1 obtenida a partir de ésta

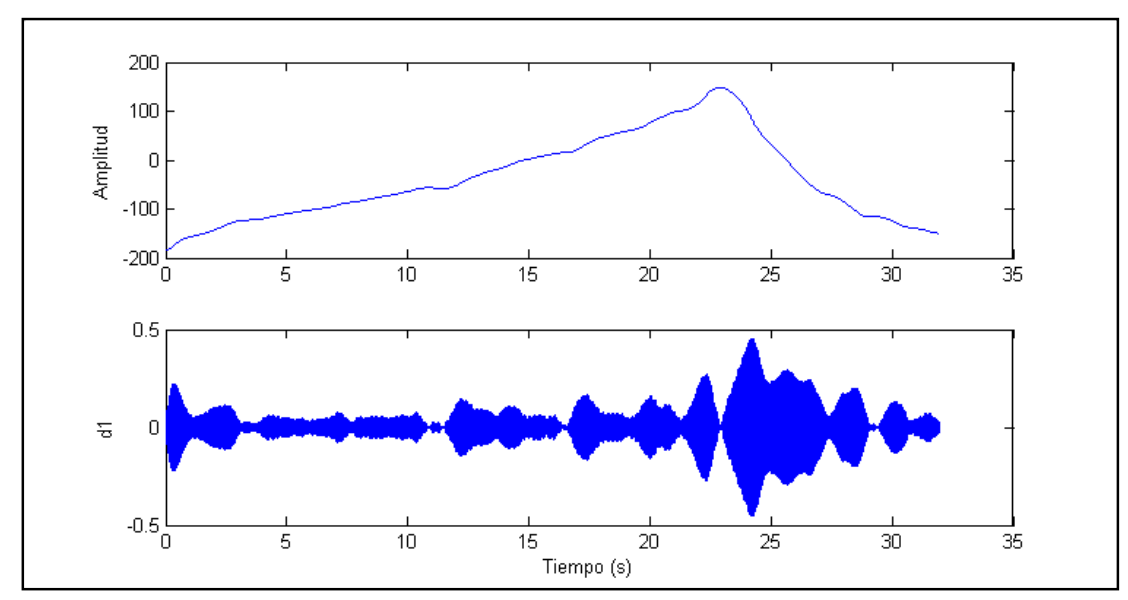

Figura 4.12: Wavelet d1 de una señal.

Los valores cercanos a 0 en la $\mathrm{d} 1$ representan posibles discontinuidades. A continuación, en la Figura 4.13 se presenta la respuesta de un paciente sano y su wavelet asociada: 

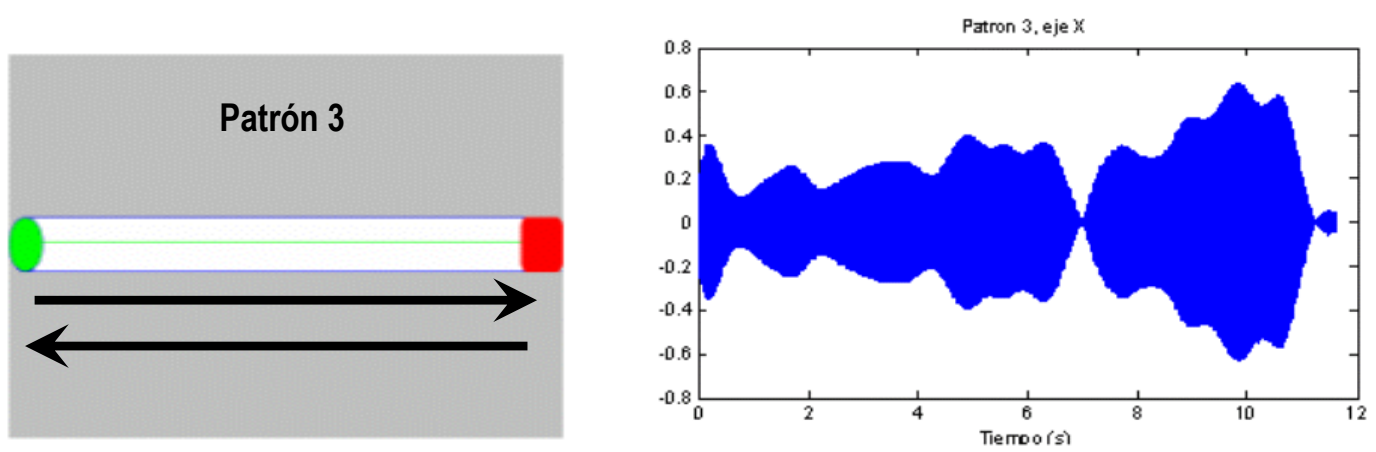

Figura 4.13: Transformada Wavelet de un paciente sano Patrón 3.

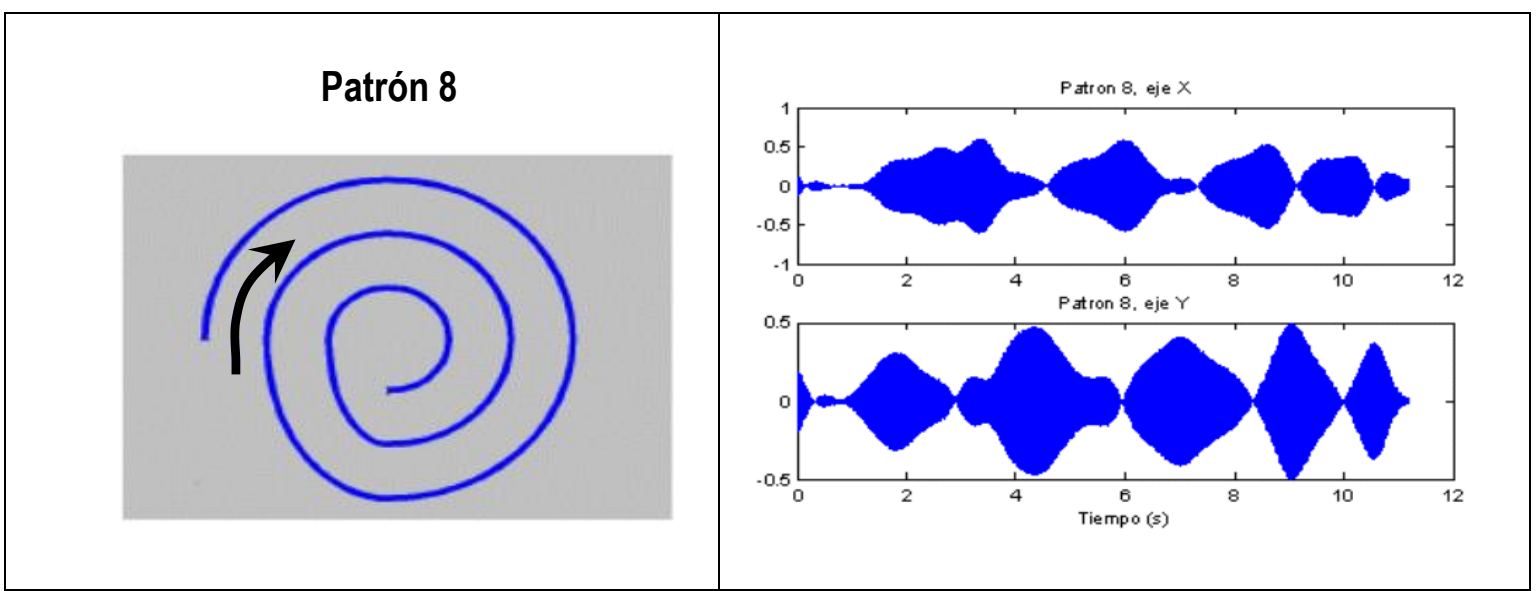

Figura 4.14: Transformada Wavelet de un paciente sano Patrón 8.

Cada patrón tendrá asociado un número intrínseco de discontinuidades debido a la forma geométrica del mismo. En el análisis descontaremos las discontinuidades debidas al patrón para obtener aquellas que se hayan dado por el propio movimiento del paciente.

En la Figura 4.15 se muestra cómo el sistema DIMETER proporciona los resultados del análisis de discontinuidades para el conjunto de los patrones de una prueba: 


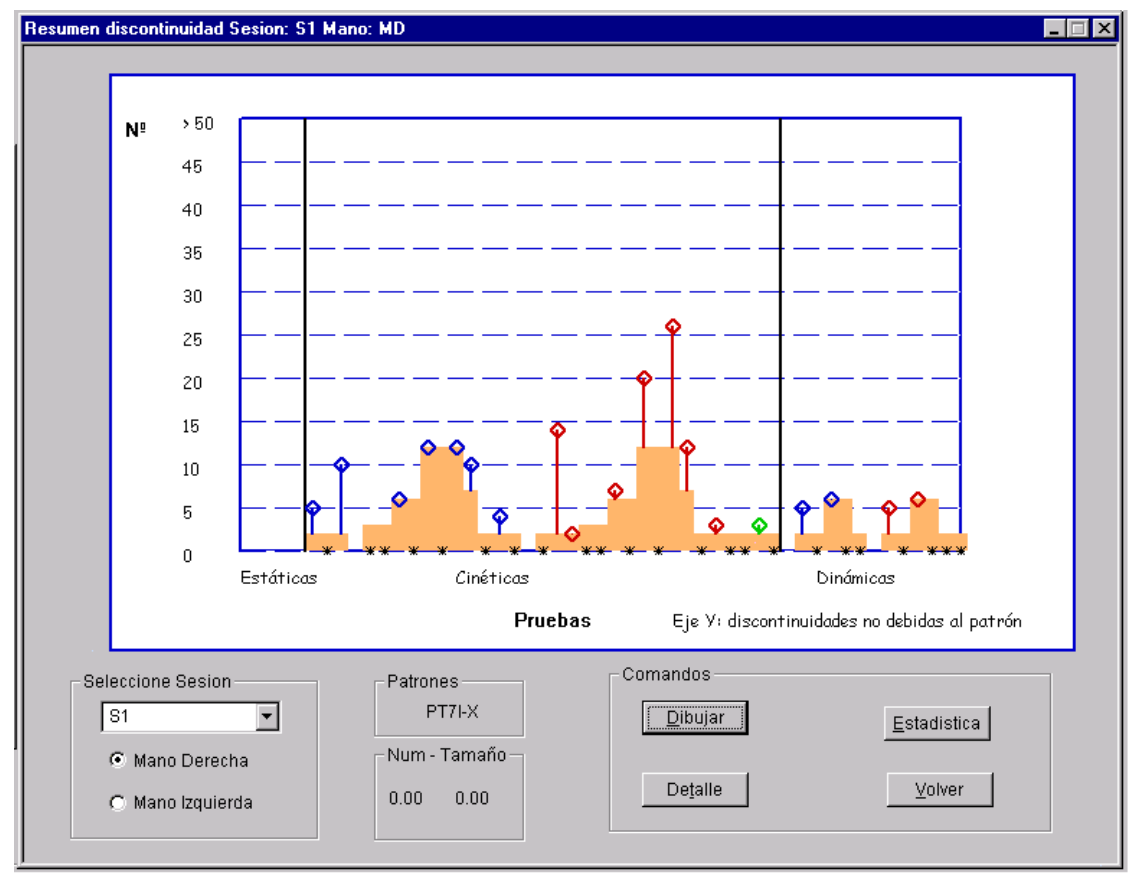

Figura 4.15: Resumen del análisis de discontinuidades del DIMETER.

Los rectángulos naranjas representan las discontinuidades no patológicas de los distintos patrones. Sobre éstos se representa un segmento proporcional al número de discontinuidades obtenidas en cada patrón.

\subsection{Densidad espectral de potencia.}

La densidad espectral, densidad espectral de potencia (Power Spectral Density, PSD) o densidad espectral de energía (Energy Spectral Density, ESD) es una función real y positiva de una variable: la frecuencia, asociada con un proceso estocástico estacionario, que tiene dimensiones de potencia por hertzio, o energía por hertzio. También es la denomina frecuentemente espectro de la señal. Intuitivamente, la densidad espectral mide el contenido de frecuencia de un proceso estocástico y ayuda a identificar las periodicidades.

\subsubsection{Definición.}

La densidad espectral de una señal proporcional a la potencia transportada por la onda por unidad de frecuencia. La PSD es frecuentemente expresada en $\mathrm{W} / \mathrm{Hz}$ o decibelios relativos a un milivatio $(\mathrm{dBm} / \mathrm{Hz})$. Para señales de tensión está extendido el uso de $V^{2} \mathrm{~Hz}^{-1}$ para la PSD y de $V^{2} s \mathrm{~Hz}^{-1}$ para la ESD, o $d B \mu V / \mathrm{Hz}$. Para análisis de vibraciones aleatorias a veces se usan $\mathrm{g}^{2} \mathrm{~Hz}^{-1}$ para la densidad espectral de aceleración.

La ESD describe cómo la energía (o varianza) de una señal o una serie temporal está distribuida con la frecuencia. Si $f(t)$ es una señal de energía finita, la densidad espectral $\Phi(\omega)$ de la señal es igual al cuadrado de la magnitud de la transformada de Fourier continua. 


$$
\Phi(\omega)=\left|\frac{1}{\sqrt{2 \pi}} \int_{-\infty}^{\infty} f(t) e^{-i \omega t} d t\right|^{2}=\frac{F(\omega) F^{*}(\omega)}{2 \pi}
$$

Donde $\omega$ es la frecuencia angular y $F^{*}(\omega)$ es el complejo conjugado de la transformada de Fourier. Si la señal es discreta, con valores $f_{n}$, sobre un número infinito de elementos entonces se define así:

$$
\Phi(\omega)=\left|\frac{1}{\sqrt{2 \pi}} \sum_{n=-\infty}^{\infty} f_{n} e^{-i \omega n} d t\right|^{2}=\frac{F(\omega) F^{*}(\omega)}{2 \pi}
$$

Pero con $F(\omega)$ siendo la transformada de Fourier discreta (Discrete Fourier Transform, DFT). Si el número de valores definidos es finito, entonces la secuencia no tiene una densidad espectral en sí misma, pero puede ser tratada como periódica, usando la DFT para construir un espectro discreto. O puede ser ampliada con valores nulos y la densidad espectral calculada como en el caso de la secuencia infinita.

La PSD describe cómo la potencia de la señal o serie temporal está distribuida con la frecuencia. La potencia puede asemejarse al concepto físico o también ser definida como el valor cuadrático de la señal (en abstracto). En el primer caso representaría la potencia disipada en una carga si la señal fuese la tensión sobre la misma. Esta potencia instantánea, para una señal $s(t)$ viene dada por $P(t)=s(t)^{2}$.

Una señal con potencia media distinta de cero no es de cuadrado integrable, por lo que las transformadas de Fourier no existen en este caso. El teorema de WienerKhinchin proporciona una alternativa más simple: la PSD es la transformada de Fourier de la función de autocorrelación, si la señal se considera como un proceso estocástico en sentido amplio. Estos resultados son expresados en la ecuación (4-4)

$$
S(f)=\int_{-\infty}^{\infty} R(\tau) e^{-2 \pi i f \tau} d \tau=F(R(\tau))
$$

La media del conjunto del periodo-grama promedio cuando el tiempo promedio de intervalo es $T \rightarrow \infty$ puede demostrarse [62] que tiende a la PSD:

$$
E\left[\frac{\left|F\left(f_{T}(t)\right)\right|^{2}}{T}\right] \rightarrow S(f)
$$

Y la potencia de la señal comprendida en una banda de frecuencias puede ser calculada integrando sobre las frecuencias positivas y negativas 


$$
P=\int_{F_{1}}^{F_{2}} S(f) d f+\int_{-F_{2}}^{-F_{1}} S(f) d f
$$

La PSD de una señal existe si la señal es un proceso estacionario.

\subsubsection{Técnicas de cálculo.}

El objetivo de la densidad espectral es calcular la densidad espectral de una señal aleatoria a partir de una secuencia de muestras temporales de la señal. El propósito es detectar cualquier periodicidad en los datos observando picos que se producen sobre las frecuencias correspondientes a esas periodicidades.

Las técnicas para la estimación del espectro pueden ser clasificadas en dos grupos:

- Paramétricas: Asumen que por debajo del proceso estacionario existe una cierta estructura que puede ser descrita utilizando números o parámetros. Por ejemplo, usando modelos autorregresivos o de media móvil. En este caso, la tarea consiste en estimar estos parámetros del modelo que describen el proceso estocástico.

- No paramétricas: Estiman explícitamente la covarianza o el espectro del proceso sin asumir que tiene ninguna estructura particular.

Algunos ejemplos de técnicas de estimación de la densidad espectral son los siguientes:

- Periodograma: Una técnica no paramétrica clásica.

- Estimación de media móvil autoregresiva: Basada en ajustar un modelo ARMA.

- Análisis espectral de mínimos cuadrados: Basada en un ajuste por mínimos cuadrados.

\subsubsection{Método de Burg.}

Los métodos paramétricos están basados en el modelado de una secuencia de datos $x(n)$ como salida de un sistema lineal. En los métodos basados en modelos, el procedimiento de estimación se compone de dos pasos:

- Los parámetros se calculan a partir de una secuencia $x(n)$, con $x(n), 0 \leq$ $n \leq N-1$.

- A partir de los anteriores parámetros se calcula la PSD. 
El método autorregresivo (autoregressive AR) es el usado con más frecuencia dentro de los métodos paramétricos, porque se puede resolver fácilmente mediante ecuaciones lineales. Los datos pueden ser modelados como la salida de un filtro discreto causal cuya entrada es ruido blanco. El método AR de orden p se puede expresar mediante la ecuación (4-6).

$$
x(n)=-\sum_{k=1}^{p} a(k) x(n-k)+w(n)
$$

Donde $\mathrm{a}(\mathrm{k})$ son los coeficientes del sistema $\mathrm{AR}, \mathrm{w}(\mathrm{n})$ es ruido blanco de varianza igual $\mathrm{a} \sigma^{2}$. El modelo $\mathrm{AR}(\mathrm{p})$ se define por los parámetros $\left\{a[1], a[2], \ldots, a[p], \sigma^{2}\right\}$. Y la PSD es

$$
p_{A R}(f)=\frac{\sigma^{2}}{|A(f)|^{2}}
$$

Donde:

$$
A(f)=1+a_{1} e^{-j 2 \pi f}+\cdots+a_{p} e^{-j 2 \pi f p}
$$

Para que el AR sea eficiente hay que tener en cuenta algunas premisas, como la elección del método de estimación óptimo, la determinación del orden del modelo, la longitud de la señal que va a ser modelada y el nivel de variabilidad de los datos.

El método desarrollado por Burg (1967) para la estimación AR se basa en la minimización de los errores de predicción hacia adelante y hacia atrás, así como la estimación de los coeficientes de reflexión, tal y como se explica en [63]. Los errores se definen de la siguiente manera para un modelo de orden $p$ :

$$
\begin{gathered}
\hat{e}_{f, p}(n)=x(n)+\sum_{i=1}^{p} \hat{a}_{p, i} x(n-i) n=p+1, \ldots, N \\
\hat{e}_{b, p}(n)=x(n-p)+\sum_{i=1}^{p} \hat{a}_{p, i}^{*} x(n-p+i) n=p+1, \ldots, N
\end{gathered}
$$

Los parámetros $\mathrm{AR}$ están relacionados con el coeficiente de reflexión $\hat{k}_{p}$ mediante:

$$
\hat{a}_{p, i}=\left\{\begin{array}{c}
\hat{a}_{p-1, i}+\hat{k}_{p} \hat{a}_{p-1, p-i}^{*} i=1, \ldots, p-1 \\
\hat{k}_{p} i=p
\end{array}\right.
$$


El método de Burg considera la recursión para la estimación de $\hat{k}_{p}$, dado que los coeficientes AR de orden $p-1$ ya son conocidos. La estimación del coeficiente de reflexión viene dada por

$$
\hat{k}_{p}=\frac{-2 \sum_{n=p+1}^{N} \hat{e}_{f, p-1}(n) \hat{e}_{b, p-1}^{*}(n-1)}{\sum_{n=p+1}^{N}\left[\left|\hat{e}_{f, p-1}(n)\right|^{2}+\left|\hat{e}_{b, p-1}(n-1)\right|^{2}\right]}
$$

Y los errores de predicción satisfacen las siguientes expresiones de recursión:

$$
\begin{aligned}
& \hat{e}_{f, p}(n)=\hat{e}_{f, p-1}(n)+\hat{k}_{p} \hat{e}_{b, p-1}(n-1) \\
& \hat{e}_{b, p}(n)=\hat{e}_{b, p-1}(n-1)+\hat{k}_{p}^{*} \hat{e}_{f, p-1}(n)
\end{aligned}
$$

A partir de estas expresiones se plantea un procedimiento recursivo para la estimación de los coeficientes AR. De estas estimaciones de los parámetros AR la obtención de la PSD se consigue a partir de:

$$
\hat{p}_{B U R G}(f)=\frac{\hat{e}_{p}}{\left|1+\sum_{k=1}^{p} \hat{a}_{p}(k) e^{-j 2 \pi f k}\right|^{2}}
$$

Y el error de mínimos cuadrados total es

$$
\hat{e}_{p}=\hat{e}_{f, p}+\hat{e}_{b, p}
$$

El método de Burg para la estimación de los parámetros del modelo AR es computacionalmente eficiente y estable.

\subsection{Análisis de Componentes Principales (ACP).}

La técnica de componentes principales (Principal Component Analysis, PCA) tiene por objeto representar un conjunto de variables observadas en un grupo de individuos o elementos, por un pequeño número de nuevas variables, construidas mediante combinaciones lineales de las variables originales. El análisis es especialmente útil cuando las nuevas variables admitan una interpretación lógica explicativa en el contexto del problema.

Desde un punto de vista descriptivo, este procedimiento puede asociarse a la búsqueda de un subespacio o variedad lineal de un número reducido de 
dimensiones que tenga la propiedad de describir o representar adecuadamente la nube de puntos que se tienen en el espacio de las k-variables. Su invención se atribuye a Hotelling aunque sus orígenes se encuentran en los ajustes ortogonales por mínimos cuadrados introducidos por K. Pearson.

La técnica de componentes principales consiste en transformar las $\mathrm{k}$ variables $\mathrm{x}$ en otras $\mathrm{k}$ variables $\mathrm{z}$, con las propiedades siguientes:

- Las nuevas variables deben ser ortogonales entre sí.

- La primera variable $\mathrm{z}$ representará la dirección más representativa del conjunto de variables $x, y$ así sucesivamente.

Geométricamente, con tres variables, los puntos muestrales $\left(x_{1 \mathrm{i}}, x_{2 \mathrm{i}}, x_{3 \mathrm{i}}\right)$ tenderán a distribuirse en el espacio formando un elipsoide. La técnica de componentes principales [64] consiste en un cambio de coordenadas definiendo unos nuevos ejes, los del elipsoide, que serán ortogonales y representarán las direcciones principales del conjunto de puntos. La ventaja de esta representación es que cuando las variables están muy correladas entre sí, se puede representar la nube de puntos adecuadamente con un menor número de variables. Si se suponen k variables $x$, que se asumen medidas en desviaciones a sus medias para que tengan media cero, cuyos $\mathrm{n}$ valores se disponen en una matriz de $\mathrm{n}$ filas y k columnas: $\tilde{X}$. Se constata que si se transforman estas variables $\tilde{X}$ en otras nuevas variables $Z$, también de media cero mediante:

$$
Z=\tilde{X} A
$$

Siendo A una matriz cuadrada de dimensiones $(k \times k)$ cuyas columnas son los vectores característicos de la matriz $\widetilde{X}^{\prime} X$. Las nuevas variables, combinación lineal de las originales, que se llamarán componentes principales, estarán incorreladas y vendrán dadas por:

$$
Z_{i}=\tilde{X} a_{i}
$$

Donde $a_{i}$ es la columna i de A.

En efecto, como $\widetilde{X}^{\prime} X$ es simétrica sus vectores característicos, son ortogonales. Llamando $\lambda_{i}$ a las raíces características:

$$
\operatorname{Cov}\left(Z_{i} Z_{j}\right)=a_{j}^{\prime} \widetilde{Z}^{\prime} \tilde{X} a_{i}=\lambda_{i} a_{j}^{\prime} a_{i}=0
$$

Al ser $a_{i}$ un vector característico de $\tilde{X}^{\prime} \tilde{X}$ :

$$
\tilde{X}^{\prime} \tilde{X} a_{i}=\lambda_{i} a_{i}
$$


Por tanto, las nuevas variables Z están incorreladas. Su varianza será:

$$
\operatorname{Var}\left(Z_{i}\right)=E\left[a_{i}^{\prime} \widetilde{X}^{\prime} X a_{i}\right]=E\left[a_{i}^{\prime} \lambda_{i} a_{i}\right]=\lambda_{i} \sum a_{i j}^{2}
$$

Se supondrá que los vectores característicos $a_{i}$ están normalizados a módulo uno, con lo que:

$$
\operatorname{Var}\left(Z_{i}\right)=\lambda_{i}
$$

En consecuencia, si se obtienen los vectores y raíces característicos de la matriz $\tilde{X}^{\prime} \tilde{X}$, o lo que es equivalente, de la matriz:

$$
S=\frac{1}{n} \widetilde{X}^{\prime} \tilde{X}
$$

De varianzas y covarianzas entre las $\mathrm{X}$, y se definen las variables componentes principales de las X por la Ecuación (4-18), entonces estas nuevas variables estarán incorreladas entre sí y representarán las direcciones principales del elipsoide que encierra el conjunto de puntos. La variable asociada a la raíz característica mayor será la de mayor varianza (o dirección principal) y así sucesivamente.

Cuando alguna de las raíces características de $S$ sea muy pequeña, la varianza de la nueva variable asociada por $\operatorname{Var}\left(Z_{i}\right)=\lambda_{i}$ será también muy pequeña, lo que indica que esta variable será casi constante $y$, por tanto, puede despreciarse para explicar la variabilidad de las X. Esto corresponde a que toda matriz S, simétrica, puede escribirse:

$$
S=A D A^{\prime}
$$

Donde las columnas de A son los vectores característicos de S, y D es diagonal y contiene sus raíces características. La ecuación anterior puede expresarse por:

$$
S=\left[\begin{array}{lll}
a_{1} & \ldots & a_{k}
\end{array}\right]\left[\begin{array}{ccc}
\lambda_{1} & \ldots & 0 \\
\vdots & \ddots & \vdots \\
0 & \ldots & \lambda_{k}
\end{array}\right]\left[\begin{array}{c}
a_{1}^{\prime} \\
\vdots \\
a_{k}^{\prime}
\end{array}\right]
$$

Por tanto:

$$
S=\lambda_{1} a_{1} a_{1}^{\prime}+\cdots+\lambda_{k} a_{k} a_{k}^{\prime}
$$


Descompone la matriz $\mathrm{S}$ como suma de $\mathrm{k}$ matrices $a_{i} a_{i}^{\prime}$, con pesos que dependen de las raíces características. Si una de estas raíces es mucho menor que las demás y próxima a cero, se puede aproximadamente reconstruir la matriz $\mathrm{S}$ con $\operatorname{Var}\left(Z_{i}\right)=$ $\lambda_{i}$ conociendo las $k-1$ raíces características mayores y sus correspondientes vectores característicos. Por tanto, la matriz $S$ queda determinada por $k-1$ variables distintas.

Si en lugar de hacer la regresión con las k variables originales seleccionamos como variables explicativas las $r$ componentes principales $(r<k)$ asociadas con los $r$ valores más grandes de las raíces características, obtendremos estimadores no centrados, pero que pueden tener menor varianza. Llamando $Z_{r}$ a la matriz $r \times n$ de datos de estos componentes, el modelo será:

$$
Y=Z_{r} \beta_{c}^{*}+U
$$

Donde ahora las r variables explicativas son ortogonales por lo que la estimación de cada coeficiente será simplemente:

$$
\hat{\beta}_{c}^{*}(i)=\operatorname{Cov}\left(y, Z_{i}\right) / \operatorname{Var}\left(Z_{i}\right)
$$

Para obtener los coeficientes $\hat{\beta}_{c}$ de las variables originales, como:

$$
Z_{r}=\tilde{X} A_{r}
$$

Donde $A_{r}$ es la matriz $k \times r$ de vectores característicos asociados a los $r$ valores mayores de las raíces características de $S$, sustituyendo en $Y=Z_{r} \beta_{c}^{*}+U$

$$
\hat{Y}=Z_{r} \hat{\beta}_{c}^{*}=\tilde{X} A_{r} \hat{\beta}_{c}^{*}=\tilde{X} \hat{\beta}_{c}
$$

Con lo que expresamos el modelo en las variables originales.

El problema con este procedimiento es que el número de variables $r$ a seleccionar es arbitrario. Este análisis es útil cuando las componentes principales (variables $Z_{r}$ ) admiten una interpretación lógica en términos del problema, pero es mucho más problemático cuando las nuevas variables $Z_{r}$ son completamente artificiales. 


\subsection{Coeficiente de Curtosis.}

Empleando el coeficiente Curtosis se puede determinar la concentración de los datos que se encuentran más cerca de la media de la distribución, independientemente del valor que tome su varianza. El coeficiente de Curtosis está basado en el cuarto momento con respecto a la media. Si se determina que los datos están concentrados alrededor de la media se puede aplicar la distancia de Mahalanobis para determinar aquellos vectores atípicos que puedan estar clasificados previamente muy alejados de la clase tipo, bien porque sean sujetos excepcionales, bien porque su diagnóstico inicial no sea el adecuado, pudiendo provocar errores en la clasificación con la SVM. El coeficiente de Curtosis viene determinado por la expresión:

$$
k=\frac{n \cdot \sum_{i=1}^{n}\left(x_{i}-x_{m}\right)^{2}}{\left(\sum_{i=1}^{n}\left(x_{i}-x_{m}\right)^{2}\right)^{2}}-3
$$

Donde $x_{i}$ es cada uno de los valores; $n$ número de datos y $x_{m}$ media aritmética. Si $k=0$ los datos se distribuyen de forma normal y se denomina mesocúrtica, si $k>0$ la distribución es más empinada que la curva normal se denomina leptocúrtica, si $k<0$ la distribución es más aplanada que la curva normal y se denomina platicúrtica.

\subsection{Distancia de Mahalanobis.}

La distancia de Mahalanobis es una forma de determinar la similitud entre dos variables aleatorias multidimensionales. Es especialmente útil en la detección de valores atípicos. Está definida como:

$$
d_{m}^{2}(\vec{x}, \vec{y})=(\vec{x}-\vec{y})^{T} \sum^{-1}(\vec{x}-\vec{y})
$$

Donde: $\sum$ es la matriz de covarianza entre $\vec{x}$ e $\vec{y}, \Sigma^{-1}$ es su inversa.

Además, su importancia radica en ofrecer medidas de distancia en un espacio invariante ante los cambios de escala (no depende de las unidades de medida) en el que se corrigen las correlaciones entre las variables; es decir, su valor disminuye a medida que aumenta la correlación entre las variables. Se puede hacer algunas observaciones:

- Si las variables no están correladas $r=0$ la distancia de Mahalanobis coincide con la distancia euclídea normalizada. 
- Si la varianza de las variables son iguales a 1 (matriz identidad) o si la distancia de Mahalanobis es calculada en el espacio de los componentes principales, ambas coinciden con la distancia euclídea.

\subsection{Clasificadores neuronales.}

El cerebro humano es un gran procesador de características de manera simultánea o paralela. Es capaz de procesar a gran velocidad una ingente información procedente de los sentidos, combinarla o compararla con la información almacenada y dar respuestas adecuadas, incluso en situaciones nuevas. Puede discernir un susurro en una sala ruidosa, distinguir una cara en una calle mal iluminada o leer entre líneas en una declaración política. Pero lo más impresionante de todo es su capacidad de aprender a representar la información necesaria para desarrollar tales habilidades sin instrucciones explícitas para ello.

Aunque todavía se ignora mucho sobre la forma en que el cerebro aprende a procesar la información, se han desarrollado modelos que tratan de mimetizar tales habilidades. Una de ellos son las denominadas redes neuronales artificiales, también llamadas modelos de computación conexionista, computación neuronal, procesamiento distribuido paralelo (P.D.P) [65].

La elaboración de estos modelos supone en primer lugar la deducción de los rasgos o características esenciales de las neuronas y sus conexiones y, en segundo lugar, la implementación del modelo en un ordenador de forma que se pueda simular. Ni que decir tiene que estos modelos son idealizaciones burdas de las auténticas redes neuronales, en muchos casos de dudosa plausibilidad neurofisiológica, pero que, sin embargo resultan interesantes cuando menos por sus capacidades de aprendizaje.

\subsubsection{Redes neuronales biológicas.}

El cerebro humano está formado por decenas de billones de neuronas interconectadas entre sí formando circuitos o redes que desarrollan funciones específicas.

Una neurona típica recoge señales procedentes de otras neuronas a través de una pléyade de delicadas estructuras llamadas dendritas. La neurona emite impulsos de actividad eléctrica a lo largo de una fibra larga y delgada denominada axón, que se escinde en millares de ramificaciones. En la Figura 4.16 se muestra un esquema representativo de una neurona y sus conexiones. 


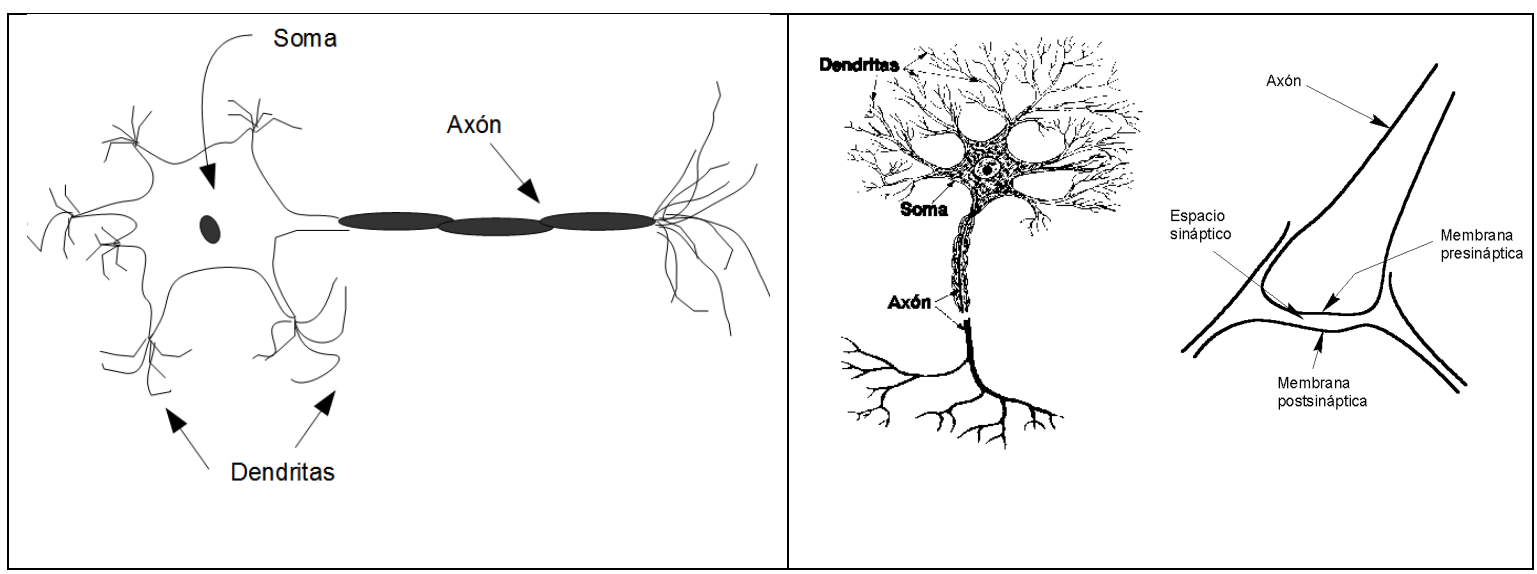

Figura 4.16: Neurona y conexiones sinápticas

Las extremidades de estas ramificaciones llegan hasta las dendritas de otras neuronas y establecen unas conexiones llamadas sinapsis, en las cuales se produce una transformación de los impulsos eléctricos en un mensaje neuroquímico, mediante la liberación de unas sustancias llamadas neurotransmisores.

El efecto de los neurotransmisores sobre la neurona receptora puede ser de excitación o de inhibición, y es variable, de manera que podemos hablar de la fuerza o efectividad de una sinapsis. Las señales de excitación y de inhibición recibidas por una neurona se combinan, y en función de la estimulación total recibida, la neurona toma un cierto nivel de activación, que se traduce en la generación de breves impulsos nerviosos con una determinada frecuencia o tasa de disparo, y su propagación a lo largo del axón hacia las neuronas con las cuales tiene lugar la sinapsis.

De esta manera la información se transmite de unas neuronas a otras y va siendo procesada a través de las conexiones sinápticas y las propias neuronas. El aprendizaje de las redes neuronales se produce mediante la variación de la efectividad de las sinapsis, de esta manera cambia la influencia que unas neuronas ejercen sobre otras, de aquí se deduce que la arquitectura, el tipo y la efectividad de las conexiones en un momento dado, representan en cierto modo la memoria o estado de conocimiento de la red.

\subsubsection{Modelo de neurona artificial.}

El modelo de neurona y la arquitectura de una red neuronal, describen como la red transforma sus entradas en las salidas. Todo esto, puede ser visto simplemente como un cálculo. En la Figura 4.17 se muestra dicho modelo. 


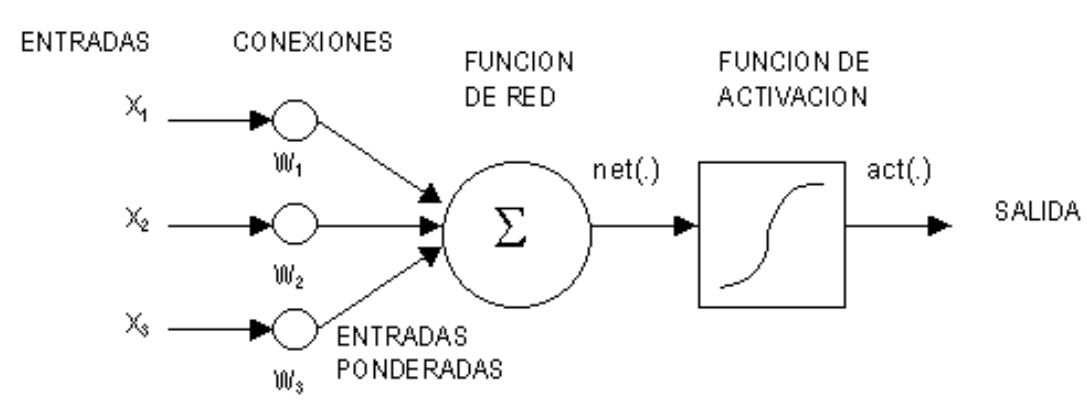

Figura 4.17: $\quad$ Modelo de una neurona.

Los elementos individuales de cálculo que forman la mayoría de los modelos de sistemas neuronales artificiales, reciben el nombre de Elemento de Procesado o Neurona Artificial.

Cada unidad de proceso, también denominado perceptrón, se compone de una red de conexiones de entrada, una función de red o propagación, encargada de computar la entrada total combinada de todas las conexiones, un núcleo central de proceso, encargado de aplicar la función de activación, y la salida, por dónde se transmite el valor de activación a otras unidades.

- Entradas: cada elemento de procesado puede tener múltiples entradas, asociadas a propiedades diferentes. También es posible que tenga entrada de tendencia o bias (valor constante).

- Conexiones ponderadas (Pesos): hacen el papel de las conexiones sinápticas. El peso de la conexión equivale a la fuerza o efectividad de la sinápsis. La existencia de conexiones determina si es posible que una unidad influya sobre otra, el valor de los pesos y el signo de los mismos definen el tipo (excitatorio/inhibitorio) y la intensidad de la influencia. Cada entrada tiene asociada un peso o intensidad de conexión. "Wji": conexión entre la entrada " $\mathrm{i}$ " y el elemento de procesado " $\mathrm{j}$ ". De alguna manera, resaltan la importancia de la entrada a la neurona.

- Función de propagación o de red: calcula el valor de base o entrada total a la unidad, generalmente como simple suma ponderada de todas las entradas recibidas, es decir, de las entradas multiplicadas por el peso o valor de las conexiones. Equivale a la combinación de las señales de excitación e inhibitorias de las neuronas biológicas. La función más utilizada con diferencia es la función de base lineal (LBF), que como ya se ha dicho consiste en el sumatorio ponderado de todas las entradas.

- Función de activación: es quizás la característica principal o definitoria de las neuronas, la que mejor define el comportamiento de la misma. Se usan diferentes tipos de funciones, desde simples funciones de umbral a funciones no lineales. Se encarga de calcular el nivel o estado de activación de la neurona en función de la entrada total. Suele distinguirse entre funciones lineales, en las que la salida es proporcional a la entrada; 
funciones de umbral, en las cuales la salida es un valor discreto (típicamente binario 0/1 - funciones sigmoidales) que depende de si la estimulación total supera o no un determinado valor de umbral; y funciones no lineales, no proporcionales a la entrada.

- Salida: Una vez calculada la activación, se determina el valor de salida, aunque normalmente no se aplica más que la función identidad, y se toma como salida el valor de activación. El valor de salida cumpliría la función de la tasa de disparo en las neuronas biológicas. La función de salida o transferencia actúa como un Limitador de Rango Dinámico.

\subsubsection{Arquitectura de una Red Neuronal.}

Para diseñar una red debemos establecer como estarán conectadas unas unidades con otras y determinar adecuadamente los pesos de las conexiones. Lo más usual es disponer las unidades en forma de capas, pudiéndose hablar de redes de una, de dos o de más de dos capas, las llamadas redes multicapa (Perceptrones Multicapa o MLP).

Aunque los perceptrones simples pueden actúar como clasificadores, su sencillez limita mucho su aplicación a problemas no lineales y a poblaciones de muestras complejas (donde el fenómeno objeto de estudio está fuertemente acoplado y solapado con diferentes variables de entrada). Lo más usual es disponer de tres o más capas. La primera capa actúa como buffer de entrada, almacenando la información bruta suministrada a la red o realizando un sencillo preproceso de la misma, se suele denominar capa de entrada. La capa de salida actúa como interfaz o buffer de salida, proporcionando la respuesta de la red para que pueda ser leída en el exterior. Y por último, capas intermedias, principales encargadas de extraer, procesar y memorizar la información, se denominan capas ocultas.

\section{Características:}

- El número de neuronas de una capa puede ser distinto al de otras.

- Pueden existir neuronas con distintas funciones de activación y salida.

- Puede haber tantas capas ocultas como se desee pero el añadir capas a una estructura no tiene por qué suponer una mejora significativa del sistema. 


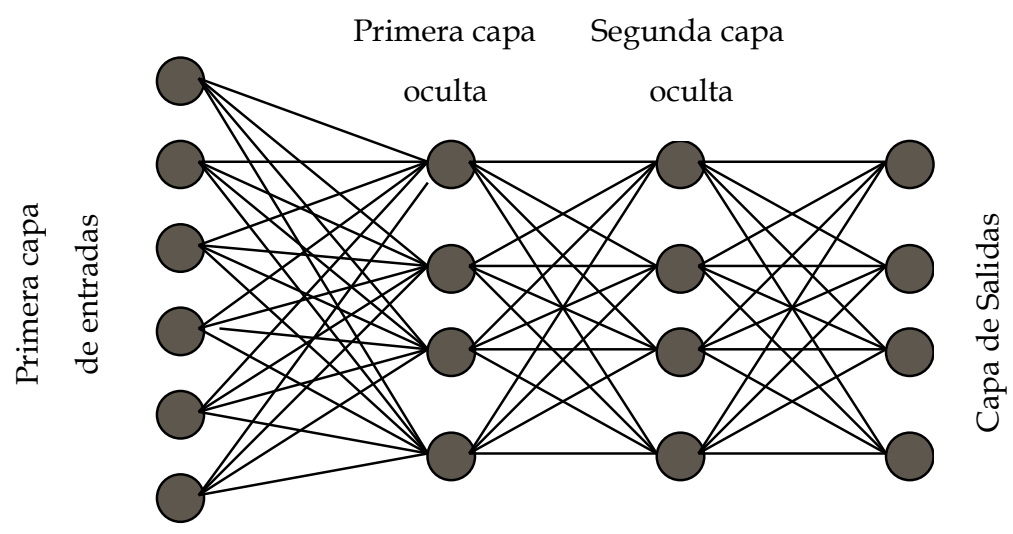

Figura 4.18: Perceptrón multicapa

Además del número de capas de una red, en función de cómo se interconectan unas capas con otras, se puede hablar de redes recurrentes (feed-back) y redes no recurrentes o redes en cascada (feed-forward). En las redes en cascada la información fluye unidireccionalmente de una capa a otra (desde la capa de entrada a las capas ocultas y de éstas a la capa de salida), y además, no se admiten conexiones intracapa. En las redes recurrentes la información puede volver a lugares por los que ya había pasado, formando bucles, y se admiten las conexiones intracapa (laterales), incluso de una unidad consigo misma.

Las conexiones entre una capa y otra pueden ser totales, es decir, que cada unidad se conecta con todas las unidades de la capa siguiente, o parciales, en las cuales una unidad se conecta con sólo algunas unidades de la capa siguiente, generalmente siguiendo algún patrón aleatorio.

Desde una aproximación temporal se puede distinguir además entre conexiones sin retardo y conexiones con retardo. Esto permite modelar aspectos dinámicos.

\subsubsection{Principales características de las redes.}

Aprendizaje inductivo. No se le indican las reglas para dar una solución, sino que extrae sus propias reglas a partir de los ejemplos de aprendizaje, modifican su comportamiento en función de la experiencia. Esas reglas quedan almacenadas en las conexiones y no representadas explícitamente como en los sistemas basados en conocimiento (simbólico-deductivos).

Generalización: Una vez entrenada, se le pueden presentar a la red datos distintos a los usados durante el aprendizaje. La respuesta obtenida dependerá del parecido de los datos con los ejemplos de entrenamiento.

Abstracción o tolerancia al ruido: Las redes neuronales son capaces de extraer o abstraer las características esenciales de las entradas aprendidas, de esta manera pueden procesar correctamente datos incompletos o distorsionados. 
Procesamiento paralelo: Las neuronas reales trabajan en paralelo; en el caso de las redes artificiales es obvio que si se usa un solo procesador no podrá haber proceso paralelo real. Sin embargo hay un paralelismo inherente, lo esencial es que la estructura y modo de operación de las redes neuronales las hace especialmente adecuadas para el procesamiento paralelo real mediante multiprocesadores (caso de hoy en día con la proliferación de los procesadores multinúcleo-multihilo).

Memoria distribuida: El conocimiento acumulado por la red se halla distribuido en numerosas conexiones, esto tiene como consecuencia la tolerancia a fallos: una red neuronal es capaz de seguir funcionando adecuadamente a pesar de sufrir lesiones con destrucción de neuronas o sus conexiones, ya que la información se halla distribuida por toda la red, sin embargo en un programa tradicional un pequeño fallo en cualquier punto puede invalidarlo todo y dar un resultado absurdo o no dar ningún resultado.

Velocidad de respuesta: Comparable una vez concluido el entrenamiento. Es decir, se comportan en este caso de manera similar al cerebro pues los seres humanos no necesitamos pensar mucho para identificar un objeto, una palabra,... una vez hemos aprendido a hacerlo.

\subsubsection{Modo de operación de una red neuronal.}

En cualquier red neuronal cabe distinguir la fase o proceso de aprendizaje, opcionalmente una fase de test, y la fase de aplicación.

El aprendizaje es un proceso por el cual los parámetros libres de una red neuronal son ajustados a través de un proceso continuo de estimulación por parte del entorno en donde se sitúa el sistema. Consiste en la presentación de patrones a la red, y la subsiguiente modificación de los pesos de las conexiones siguiendo alguna regla de que trata de optimizar su respuesta, generalmente mediante la minimización del error o la optimización de alguna "función de energía". El modo de aprendizaje más sencillo consiste en la presentación de patrones de entrada junto a los patrones de salida deseados para cada patrón de entrada, por eso se llama aprendizaje supervisado (por corrección de error). Si no se le presentan a la red los patrones de salida deseados o no los necesita, se trata de aprendizaje no supervisado. No se le indica a la red qué resultados debe dar, sino que se le deja seguir alguna regla de auto-organización, y ésta clasifica los patrones de entrada en categorías según sus rasgos más sobresalientes.

Cualquiera que sea el tipo de aprendizaje usado, una característica esencial de la red es la regla de aprendizaje usada, que indica cómo se modifican los pesos de las conexiones en función de los datos usados en la entrada, es decir, de la historia de aprendizaje de la red. Por ejemplo, entre los algoritmos de aprendizaje supervisado, la regla delta generalizada, modifica los pesos realizando en cada ciclo de aprendizaje un incremento los pesos proporcional a la tasa de variación del error respecto al peso, en sentido negativo. 
El aprendizaje requiere la presentación repetida de un número relativamente amplio de ejemplos de entrenamiento hasta lograr una respuesta satisfactoria del sistema (según la medida de error o función de energía utilizada).

Es usual disponer de un conjunto de datos distintos a los usados para el entrenamiento, para los cuales se conoce la respuesta correcta, y se usan como test, evaluando con ello si la red responde adecuadamente frente a datos distintos a los usados durante el aprendizaje (generalización), si es así se considera que la red funciona bien y se puede pasar a la fase de aplicación, es decir, se puede usar para obtener un resultado frente a datos totalmente nuevos para los que no se conoce la respuesta correcta.

\subsubsection{Aprendizaje supervisado.}

Como ya se ha comentado, en el aprendizaje supervisado se presentan a la red una serie de patrones de entrada junto a los patrones de salida deseados. El aprendizaje consiste en la modificación de los pesos de las conexiones en el sentido de reducir la discrepancia entre la salida obtenida y la deseada. Los pasos generales a seguir por este algoritmo son los siguientes:

- Aleatorizar los pesos de todas las conexiones (preferiblemente con valores pequeños)

- Seleccionar un par de entrenamiento, es decir, un patrón de entrada y el patrón de salida deseado correspondiente.

- Presentar el patrón de entrada y calcular la salida de la red mediante las operaciones usuales: sumatorio de las entradas ponderadas, función de activación y transferencia a la siguiente capa, hasta llegar a la capa de salida. (inicialmente obtenemos salidas aleatorias, ya que los pesos de las conexiones son aleatorios)

- Cálculo del error o discrepancia entre la salida obtenida y la deseada. El error (función objetivo) se suele definir como la suma de los cuadrados de las diferencias entre las salidas reales obtenidas y las deseadas, promediado para todas las unidades de salida y todos los patrones de entrenamiento. Si el error es menor de cierto criterio fijado de antemano, incrementar el número de ejemplos correctos. Si todos los ejemplos se han clasificado correctamente, finalizar, si no continuar.

- Aplicar la regla de aprendizaje, es decir, ajustar los pesos de las conexiones tratando de disminuir el error, generalmente mediante el cálculo de tasas de variación o gradientes del error, por eso hablamos de reglas de aprendizaje por gradiente descendiente. Para reducir el error habrá que modificar los pesos de las conexiones, en proporción a la tasa relativa de variación del error con respecto a la variación del peso, o sea, la derivada del error respecto al peso, EP (error respecto al peso). Una forma de calcular el EP sería perturbar levemente un peso y observar como varía el error, pero no resultaría eficiente si trabajamos con muchas conexiones. 
- Volver al segundo paso o finalizar en caso de que se haya cumplido el criterio de finalización.

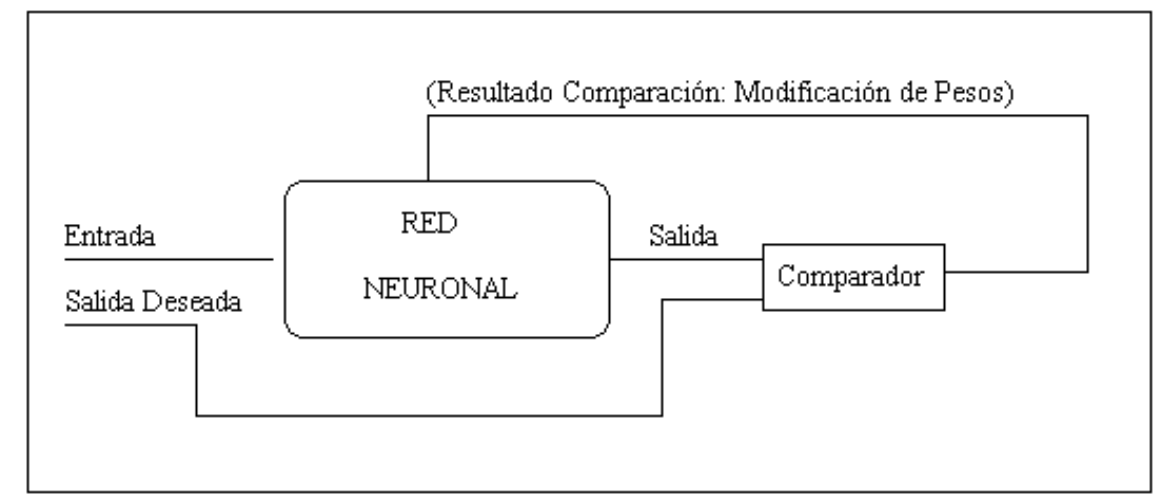

Figura 4.19: Aprendizaje supervisado

El aprendizaje supervisado se usa fundamentalmente en los asociadores de patrones o memorias heterosasociativas.

A este aprendizaje supervisado se le denomina aprendizaje por corrección de error, pero hay otros dos tipos de aprendizaje supervisado, en la medida en que las redes necesitan un profesor que mida el funcionamiento del sistema, aprendizaje por refuerzo y aprendizaje estocástico.

\subsubsection{Aprendizaje por refuerzo.}

Es más lento que el anterior. No se dispone de un ejemplo completo del comportamiento deseado. No se conoce la salida deseada exacta para cada entrada. Se conoce cómo debería de ser el comportamiento de manera general ante diferentes entradas. Relación de entrada-salida a través de un proceso de éxito o fracaso, produciendo una señal de refuerzo que mide el buen funcionamiento del sistema. Esta señal de refuerzo está caracterizada por el hecho de que es menos informativa que en el caso de aprendizaje supervisado mediante ejemplos.

Los pesos se ajustan en base a la señal de refuerzo basándose en un mecanismo de probabilidades. "Si una acción tomada por el sistema de aprendizaje es seguida por un estado satisfactorio, entonces la tendencia del sistema a producir esa particular acción es reforzada. En otro caso, la tendencia del sistema a producir dicha acción es disminuida".

La función del supervisor es más la de un crítico que la de un maestro. Evalúa si la salida producida por la red es correcta o no. 


\subsubsection{Aprendizaje Estocástico.}

Este tipo de aprendizaje consiste básicamente en realizar cambios aleatorios en los valores de los pesos y evaluar su efecto a partir del objetivo deseado y de distribuciones de probabilidad.

Estado de mínima energía: Valores de pesos con los que la estructura se ajusta al objetivo deseado.

\section{Proceso:}

- Se realiza un cambio aleatorio en los pesos.

- Se determina la nueva energía de la red.

- Si la energía no decrece: se aceptaría el cambio en función de una determinada y preestablecida distribución de probabilidades.

\subsubsection{Aprendizaje no supervisado.}

Las redes con aprendizaje no supervisado, conocido también como autosupervisado, no requieren influencia externa para ajustar los pesos de las conexiones entre sus neuronas.

La red no recibe ninguna información por parte del entorno que le indique si la salida generada en respuesta a una determinada entrada es o no correcta; por ello, suele decirse que estas redes son capaces de auto-organizarse.

El funcionamiento de estas redes se basa en la búsqueda de:

- Características.

- Regularidades.

- Correlaciones.

- Categorías.

- Del conjunto de datos de entrada.

Una de las críticas principales al aprendizaje supervisado era su dudosa similitud biológica, pues:

- Requiere propagar cierta información (el error cometido) hacia atrás, en sentido contrario al flujo natural de la información. Como es obvio, esto no sucede en las neuronas reales, sin embargo esta objeción es superficial si tenemos en cuenta que el cerebro es rico en redes que retrogradan de una capas a otras, y podría utilizar estos caminos de múltiples formas para aportar la información del tipo que el aprendizaje supervisado requiere.

- Requiere de un instructor que proporcione la salida deseada. Las personas aprendemos a comprender frases o escenas visuales sin 
instrucciones explícitas para ello, se podría decir que el cerebro posee algún mecanismo de auto-organización. Cuando se le presentan a la red una gran colección de datos sin indicarle que debe hacer con ellos, se encuentra aparentemente sin saber que hacer. No obstante, los investigadores han diseñado varios procedimientos de aprendizaje no supervisado, que son capaces de extraer inductivamente suficiente información de esos datos como para permitir posteriormente su recuperación, estos algoritmos son utilizados en tareas de clusterización y clasificación.

En el aprendizaje no supervisado no se requiere presentar patrones de salida deseados. Sin embargo, el algoritmo y la regla de modificación de las conexiones producen vectores de salida consistentes, esto es, la presentación de un patrón aprendido o parecido a él, produce siempre la misma salida. Se considera que el proceso de aprendizaje es capaz de extraer ciertas propiedades estadísticas de los ejemplos de aprendizaje y agruparlos en categorías o clases de patrones similares. No se sabe a priori que salida corresponderá a cada tipo o grupo de patrones de entrada, ni que atributos usará para clasificarlos, por eso son muy útiles como generadores de categorías. Es lo que llamamos clusterización.

En general, los métodos de aprendizaje no supervisado apelan a alguna noción de la calidad de la representación. Las representaciones de calidad se caracterizan por la economía de la representación (el costo de codificación más el costo de reconstrucción), sin perder la capacidad de reconstruir la información almacenada.

Existen tres métodos de aprendizaje no supervisado para encontrar códigos económicos que al mismo tiempo permitan una buena reconstrucción de la entrada: el aprendizaje por componentes principales, el aprendizaje competitivo y los códigos demográficos.

\subsubsection{Perceptrón multicapa.}

Debido a sus características de funcionamiento, siendo su aprendizaje supervisado, como ya se ha mencionado, la elegiremos como primera opción por su sencillez. Disponemos de los datos proporcionados por el DIMETER con los registros de todos los pacientes, por lo que el proporcionar los vectores de salida no será un problema.

De entre sus características se podrían citar:

- Es la red neuronal más empleada y conocida.

- Se agrupa dentro de las redes asociativas de patrones o heteroasociativas. Conocido un conjunto de patrones entrada/salida la red es capaz de "aprender" mediante un algoritmo de entrenamiento, llamado algoritmo de propagación hacia atrás.

- El "conocimiento" está almacenado y distribuido en los pesos de la red. 
- Es una estructura de computación robusta ante fallos.

- Es una red estática: las ecuaciones de los nodos (neuronas) no cambian con el tiempo (una vez entrenado).

\subsubsection{Función de activación.}

La función de activación determina el nivel o estado de activación de la neurona en función de la entrada total. Se suele distinguir entre funciones lineales, en las que la salida es proporcional a la entrada; funciones de umbral, en las que la salida es un valor discreto, normalmente de tipo binario $(0 / 1)$, y cuyo valor depende de si la estimulación total supera o no un determinado valor umbral; y funciones no lineales, en las que la salida no sigue ninguna regla de proporcionalidad respecto de la entrada.

\begin{tabular}{|c|c|c|c|}
\hline & Función & Rango & Gráfica \\
\hline Identidad & $y=x$ & {$[-\infty,+\infty]$} & \\
\hline Escalón & $\begin{array}{c}y=\operatorname{sign}(x) \\
y=H(x)\end{array}$ & $\begin{array}{l}\{-1,+1\} \\
\{0,+1\}\end{array}$ & \\
\hline $\begin{array}{l}\text { Lineal a } \\
\text { tramos }\end{array}$ & $y=\left\{\begin{array}{c}-1, \text { si } x<-l \\
x, \text { si }+l \leq x \leq-l \\
+1, \text { si } x>+l\end{array}\right.$ & {$[-1,+1]$} & \\
\hline Sigmoidea & $\begin{array}{l}y=\frac{1}{1+e^{-x}} \\
y=\operatorname{tgh}(x)\end{array}$ & $\begin{array}{c}{[0,+1]} \\
{[-1,+1]}\end{array}$ & \\
\hline Gaussiana & $y=A e^{-B x^{2}}$ & {$[0,+1]$} & \\
\hline Sinusoidal & $y=A \operatorname{sen}(\omega x+\varphi)$ & {$[-1,+1]$} & \\
\hline
\end{tabular}

Figura 4.20: Tipos de función umbral

\subsubsection{Algoritmo de retro-propagación (Back-Propagation).}

La regla de aprendizaje del perceptrón de Rosenblatt y el algoritmo LMS de Widrow y Hoff fueron diseñados para entrenar redes de una sola capa y no servían para redes multicapa por lo que el campo de las redes neuronales artificiales estaba estancado.

El primer algoritmo de entrenamiento para redes multicapa fue desarrollado por Paul Werbos en 1974, aunque no fue aceptado por los desarrolladores de redes neuronales de la época. Fue a mediados de los años 80 cuando el algoritmo Backpropagation o algoritmo de propagación hacia atrás o retropropagación fue redescubierto por varios investigadores, David Rumelhart, Geoffrey Hinton y Ronal Williams, David Parker y Yann Le Cun. 
Desde la fecha clave de 1986 han surgido nuevas versiones que han tratado de aumentar la velocidad de convergencia del algoritmo y han tratado de superar algunos de sus inconvenientes.

La retro-propagación consiste en propagar el error hacia atrás, es decir, de la capa de salida hacia la capa de entrada, pasando por las capas ocultas intermedias y ajustando los pesos de las conexiones con el fin de reducir dicho error. Hay distintas versiones o reglas del algoritmo de retro-propagación y distintos arquitecturas conexionistas a las que pueden ser aplicados.

A continuación se explica una versión del algoritmo de propagación hacia atrás para redes con las siguientes características:

- No recurrentes.

- Función de activación sigmoidal.

- Capas totalmente interconectadas.

- Operación totalmente síncrona.

\section{Procedimiento:}

- Se aleatorizan los pesos de las conexiones.

- Se presenta un patrón de entrada y se calcula la salida.

- Dada una unidad j-ésima de la capa de salida y unidades i-ésimas de la capa oculta inmediatamente anterior, calculamos la entrada total ponderada y la salida o activación de la misma.

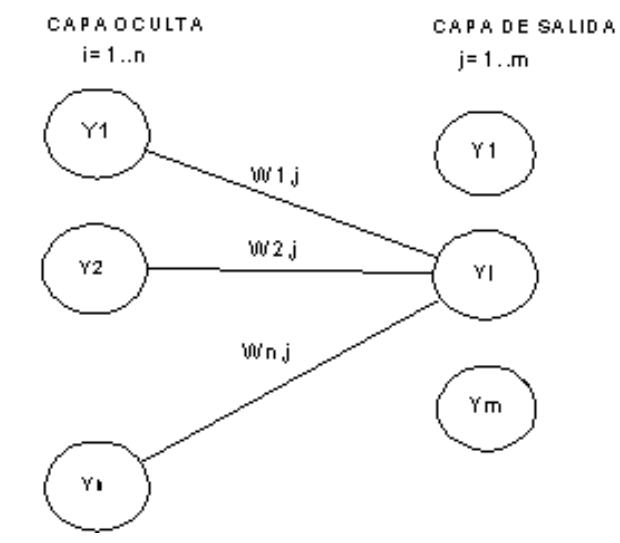

Figura 4.21: Esquema de las capas oculta y de salida

$$
x_{j}=\sum_{i=1}^{n}\left(y_{i} \cdot w_{i j}\right)
$$




$$
y_{j}=\frac{1}{1+e^{-x_{j}}}
$$

- Una vez computadas las actividades de todas las unidades de salida se calcula una estimación del error, generalmente una función cuadrática de los errores individuales cometidos por cada unidad, siendo cada error individual la diferencia entre la salida deseada y la obtenida.

$$
E=\frac{1}{2} \sum_{j}\left(d_{j}-y_{j}\right)^{2}
$$

siendo dj la salida deseada para la unidad j-ésima.

- Cómputo de la rapidez de variación del error al cambiar la actividad de cada unidad de salida (EA, error respecto a la actividad).

$$
E A_{j}=\frac{\partial E}{\partial y_{j}}=d_{j}-y_{j}
$$

Es justamente la diferencia entre la salida deseada y la salida real obtenida, es decir, la diferencia entre la actividad deseada y la actividad real

- Cómputo de la rapidez de variación del error al cambiar la entrada total que recibe cada unidad de salida.

$$
\delta_{j}=\frac{\partial E}{\partial x_{j}}=\frac{\partial E}{\partial y_{j}} \frac{\partial y_{j}}{\partial x_{j}}=E A_{j} y_{j}\left(1-y_{j}\right)=y_{j}\left(1-y_{j}\right)\left(d_{j}-y_{j}\right)
$$

Es igual a la tasa de variación del error al variar su activación multiplicado por la tasa de variación de la activación al cambiar su entrada (que es justamente la derivada de la función sigmoidal).

- Cómputo de la rapidez de variación del error al ser modificado un peso de la conexión aferente a una unidad de salida.

$$
E P_{i j}=\frac{\partial E}{\partial w_{i j}}=\frac{\partial E}{\partial x_{j}} \frac{\partial x_{j}}{\partial w_{i j}}=\delta_{j} y_{i}
$$


Es igual a la tasa de variación del error al variar su entrada, por la tasa de variación de la entrada al variar ese peso.

Hasta ahora se ha indicado cómo calcular el EA sólo para las unidades de salida, pero ¿qué pasa con las unidades ocultas? En este caso no tenemos una estimación directa del error aportado por cada unidad oculta; aquí es donde interviene la retropropagación o propagación hacia atrás del error:

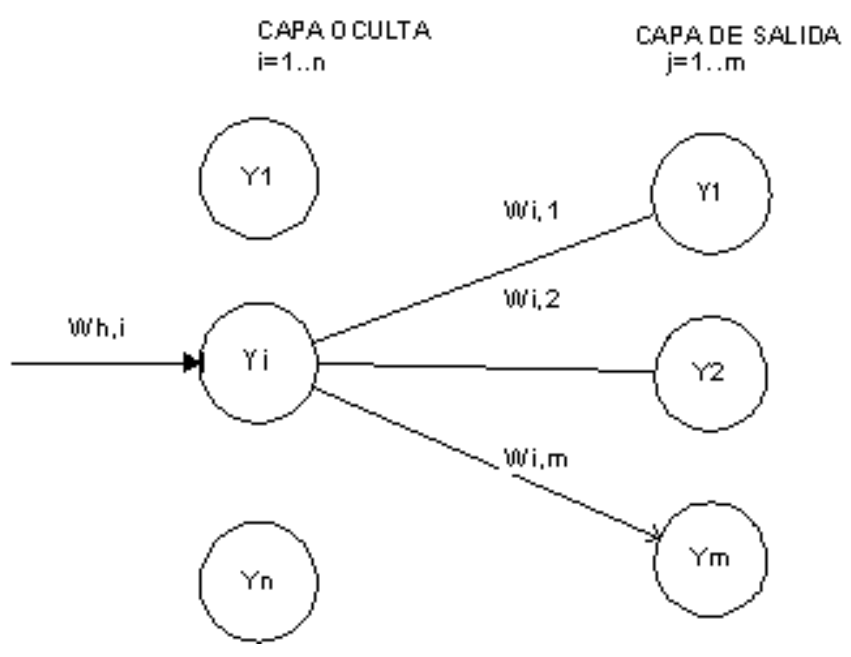

Figura 4.22: Relaciones vía pesos entre la capa oculta y la salida

La unidad i-ésima de la capa oculta afecta a todas las unidades de salida, por lo tanto, para estimar como varía el error al variar la actividad de esa unidad oculta, habrá que sumar los efectos individuales de su actividad sobre todas las neuronas de salida. Cada efecto individual sobre la variación del error, será igual a la tasa de variación del error de la unidad de salida al cambiar su entrada total, multiplicada por la tasa de variación de su entrada al variar la actividad de la unidad oculta.

$$
E A_{i}=\frac{\partial E}{\partial y_{i}}=\sum_{j=1}^{m} \frac{\partial E}{\partial x_{j}} \frac{\partial x_{j}}{\partial y_{i}}=\sum_{j=1}^{m} \delta_{j} w_{i j}
$$

- Conociendo EA para las unidades de cualquier capa podemos calcular $\delta$ y $E P_{k i}$ con las expresiones ya conocidas.

$$
\begin{gathered}
\delta_{i}=E A_{i} y_{i}\left(1-y_{i}\right)=y_{i}\left(1-y_{i}\right) \sum_{j=1}^{m}\left(\delta_{j} w_{i j}\right) \\
E P_{k i}=\delta_{i} y_{k}
\end{gathered}
$$


- Disponiendo de la tasa de variación del error respecto al peso de una conexión (EP), podemos usar distintas reglas para modificar ese peso en aras a reducir dicho error. Una de las primeras reglas que utilizó este algoritmo es la regla delta generalizada, que calcula el incremento a aplicar a un peso como una proporción directa de la tasa de variación del error.

$$
\Delta w_{i j}=\eta \delta_{j} y_{i}
$$

Siendo $\eta$ el coeficiente de aprendizaje, típicamente con valores comprendidos entre 0.01 y 1.0 .

$$
w_{i j}(t+1)=w_{i j}(t)+\Delta w_{i j}
$$

\subsubsection{Valoración del algoritmo de retro-propagación.}

El algoritmo de retro-propagación presenta ciertos problemas, algunos referentes a su dudosa plausibilidad neurofisiológica, y otros referentes a ciertos aspectos computacionales, que son los que vamos a comentar aquí.

Los resultados dependen de los valores iniciales, aleatorios, de las conexiones. Esto hace que sea conveniente entrenar varias redes con distintos valores iniciales y elegir la que mejor funcione. A veces se requiere mucho tiempo para obtener soluciones sencillas

Este problema se reduce gracias al aumento de velocidad de procesamiento de los nuevos procesadores y al uso de nuevas tecnologías, sin embargo, el tiempo de cómputo aumenta mucho al aumentar el tamaño de la red. Si bien el volumen de cálculo es proporcional al número total de conexiones. En la práctica, al aumentar el tamaño de la red, hacen falta más ejemplos de aprendizaje, y eso provoca un aumento mucho mayor del tiempo de aprendizaje. Para incrementar la velocidad de convergencia se han desarrollado diferentes modificaciones del algoritmo.

\section{La "interferencia catastrófica" o empeoramiento en el rendimiento del sistema}

Surge como consecuencia de la incorporación de nuevos ejemplos de aprendizaje. También denominado sobre-aprendizaje.

\section{La parálisis}

Esto sucede cuando los pesos quedan ajustados a valores muy grandes, esto hace operar a las unidades de proceso con una activación muy próxima a 1, y por lo tanto, el gradiente del error, tiende a 0 , en consecuencia no se producen modificaciones en los pesos, el aprendizaje queda detenido. Por eso es conveniente aleatorizar los pesos de las conexiones con valores pequeños y usar la tasa de aprendizaje, también pequeña, a pesar de que se ralentice el aprendizaje. 


\section{Inestabilidad temporal}

Si usamos un coeficiente de aprendizaje elevado, se van a producir incrementos grandes en los pesos, de manera que es fácil pasarse de incremento y tener que tratar de compensarlo en el siguiente ciclo, de manera que se producirían oscilaciones continuas. Esto se soluciona usando un coeficiente pequeño, o, para no tener un aprendizaje muy lento, modificar dicho coeficiente adaptativamente, esto es, aumentarlo si el error global disminuye, y disminuirlo en caso contrario.

\section{El problema de los mínimos locales}

El algoritmo de retropropagación usa una técnica por gradiente descendiente, esto significa que sigue la "superficie del error" siempre hacia abajo, hasta alcanzar un mínimo local, pero no garantiza que se alcance una solución globalmente óptima. Sin embargo, se ha comprobado que el hecho de alcanzar mínimos locales no impide que se consigan resultados satisfactorios. Por otro lado, se han desarrollado métodos para solventar este problema, como el modo de operación asíncrono o probabilístico y el uso de métodos estadísticos, como el equilibrio termodinámico simulado.

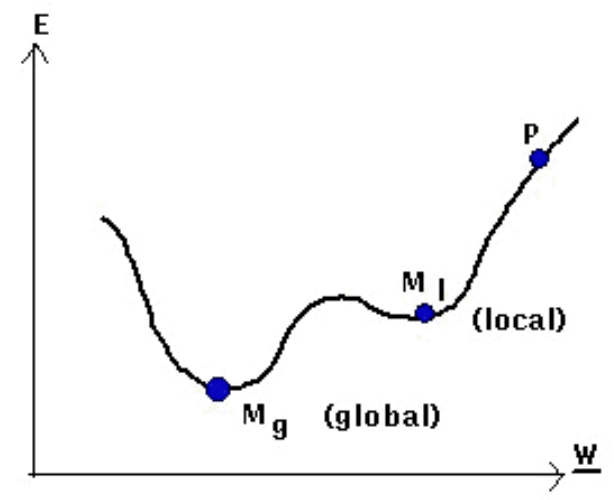

Figura 4.23: Problema de los mínimos locales.

Podemos considerar el error como una superficie llena de desniveles, si soltamos una pelota caerá en algún valle, pero no necesariamente en el más hondo, sino en el más cercano (un mínimo local). Una idea intuitiva para solucionar ésto, sería aplicarle cierta energía a esa superficie agitándola o haciéndola vibrar, esto haría saltar a la pelota de valle en valle, como de los valles más profundos es más difícil salir, tendería a estar en valles cada vez más profundos. Si dejamos de agitar esa superficie poco a poco, al final tendremos la pelota en el valle más profundo de la superficie.

Otras técnicas que pueden ayudar a no caer en mínimos locales consisten en añadir cierto nivel de ruido a las modificaciones de los pesos de las conexiones. Del mismo modo, añadir ruido directamente a las conexiones, puede darle robustez y 
aumentar la capacidad de generalización de la red. Estas medidas, por contra, aumentan el tiempo de aprendizaje.

El algunas ocasiones, se utiliza como concepto el equilibrio termodinámico simulado (método estadístico - simulated annealing). Se inspira en el modo en el que se templa el acero en la industria metalúrgica. Primero se calienta hasta temperaturas muy altas y luego se deja enfriar, de manera que pase de estados de alta energía a estados de baja energía, hasta que alcanza un mínimo energético global, así el acero queda mucho más resistente. La relación entre temperatura y estado energético viene expresada por la distribución de probabilidad de Boltzmann:

$$
p(E)=\alpha e^{-E / k T}
$$
Donde:
E : energía del sistema
$\mathrm{k}$ : constante de Boltzmann
$\mathrm{T}$ : temperatura (grados Kelvin)
a : coeficiente que depende del material

Esta relación indica la probabilidad de estar en un estado de energía E a una determinada temperatura. Con altas temperaturas es igualmente probable tener estados de alta o baja energía; pero a bajas temperaturas se reduce la probabilidad de estar en un estado de alta energía. El estado energético indica la capacidad o probabilidad de cambiar, por lo tanto, al empezar con temperatura elevadas hay muchas probabilidades de cambiar, y se reducen al ir enfriando el sistema.

\subsubsection{Aplicaciones.}

Son muchos y variados los campos de aplicación de las redes neuronales del tipo perceptrón multicapa.

Como ejemplos de algunos de ellos se indican los siguientes:

- Compresión y codificación de la información.

- Clasificación de caracteres.

- Reconocimiento de caras.

- Reconocimiento de nódulos pulmonares.

- Segmentación de imágenes.

Como ejemplos prácticos podríamos mencionar [66] para la predicción de modelos en las poblaciones de seropositivos de VIH en Sudáfrica. También [67] donde plantean una visión general de la aplicación de los perceptrones a la toma de decisiones en el diagnóstico de enfermedades. En la misma línea pero siendo algo 
más concretos en [68] utilizan los perceptrones multicapa para la ayuda al diagnóstico de enfermedades del corazón. En [69] también plantean un MLP para clasificar los pacientes infectados o no infectados con el VIH. Otra aplicación en el área médica puede verse en [70] donde se presenta un trabajo en el que proponen un MLP para la ayuda al diagnóstico de la nefritis. En [71] utilizan un MLP para la clasificación de señales de encefalograma. En [72] proponen la comparación entre MLP y SVMs para la clasificación del temblor.

\title{
4.6.7 Redes LVQ (Learning Vector Quantization).
}

Las redes neuronales de tipo LVQ (Learning Vector Quantization) utilizan un aprendizaje supervisado off line. Por lo que el usuario debe realizar una fase de entrenamiento antes de poner a funcionar la red. Para comprobar si el entrenamiento es realizado correctamente hay que introducir una serie de entradas de las cuales conozcamos el tipo al que pertenecen y comprobar cómo las clasifica la red. A esta fase la denominaremos simulación (el entrenamiento sería la preparación para un examen y la simulación sería el examen).

Las neuronas de la capa de entrada de esta red deben ser entrenadas con vectores de distinta clase. Más adelante detallaremos la regla de aprendizaje mediante la cual se modifica la información de las neuronas. Como usan un aprendizaje supervisado el usuario debe conocer de antemano cuál es la clase a la que pertenece cada entrada durante el entrenamiento. Una vez que se termine el entrenamiento la red debe poder clasificar correctamente las entradas (vectores) que sean parecidos. Durante la fase de funcionamiento la red LVQ devuelve un vector en el que indica la clase a la que pertenece el vector presentado a la entrada.

\subsubsection{Forma.}

La arquitectura de una red neuronal de tipo LVQ es una arquitectura que sólo tiene dos capas, por lo que se puede considerar como relativamente sencilla:

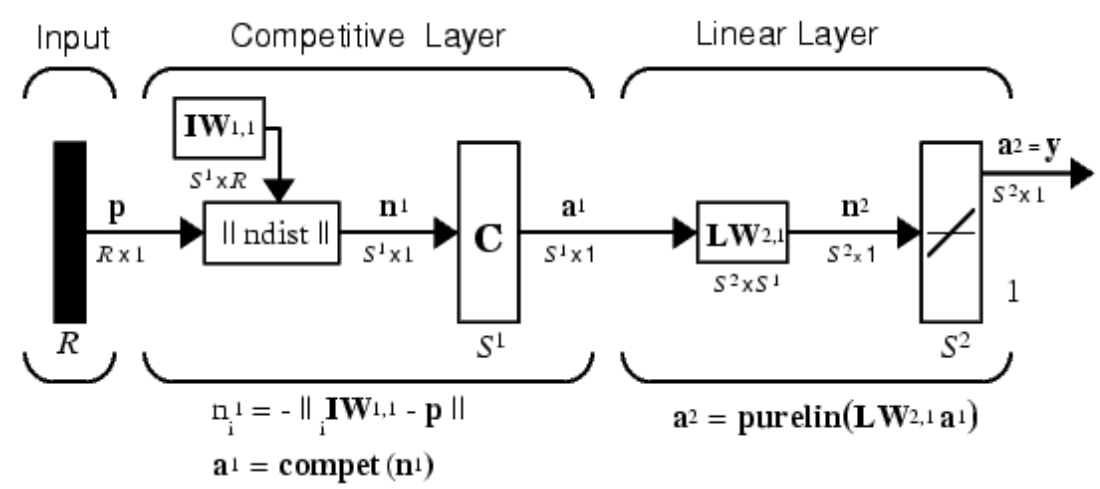

\author{
Where. \\ $R=$ number of \\ elements in \\ input vector \\ $S^{1}=$ number of \\ competitive \\ neurons \\ $S^{2}=$ number of \\ linear neurons
}

Figura 4.24: Modelo de una red LVQ 
En la Figura 4.24 se muestran las dos capas. La primera es una capa competitiva en la que se encuentran las neuronas que son entrenadas. La segunda es una capa lineal en la que se asigna una o varias neuronas de la capa competitiva a una clase. Para lo único que sirve la segunda capa es para designar la clase a la que pertenece cada neurona de la primera capa. La información que contiene cada neurona de la capa de entrada es un vector con tantos elementos como dimensión tenga la entrada ( $R$ en la figura). De ahí que la matriz que representa la primera capa tenga dimensión $S \times R$; porque en realidad es una matriz con tantas filas como neuronas y tantas columnas como dimensión tengan los vectores de la entrada $(R)$. De esta manera, si en la primera capa tuviéramos la siguiente matriz:

\begin{tabular}{|l|l|}
\hline 0,564 & 0,623 \\
\hline 0,865 & 0,459 \\
\hline 0,219 & 0,647 \\
\hline 0,301 & 0,978 \\
\hline 0,587 & 0,421 \\
\hline 0,902 & 0,975 \\
\hline 0,523 & 0,518 \\
\hline 0,668 & 0,542 \\
\hline 0,676 & 0,379 \\
\hline 0,952 & 0,849 \\
\hline
\end{tabular}

Tabla 4.1: Ejemplo de matriz de la capa de entrada.

Querría decir que los vectores presentados como entradas a la red neuronal tienen dimensión 2 y que habría 10 neuronas en la capa de entrada. Más adelante detallaremos el entrenamiento que permite modificar los valores de cada neurona.

La segunda capa está formada por una matriz en la que cada columna representa a una neurona de la primera capa y cada fila es una clase. Cada columna de la segunda capa sólo puede pertenecer a una clase. Por ejemplo si en la matriz tuviéramos lo siguiente:

\begin{tabular}{|l|l|l|l|l|l|l|l|l|l|}
\hline 1 & 1 & 1 & 1 & 0 & 0 & 0 & 0 & 0 & 0 \\
\hline 0 & 0 & 0 & 0 & 1 & 0 & 0 & 0 & 0 & 0 \\
\hline 0 & 0 & 0 & 0 & 0 & 1 & 1 & 1 & 1 & 1 \\
\hline
\end{tabular}

Tabla 4.2: Ejemplo de matriz de la capa de salida.

Entonces querría decir que la red LVQ utiliza un total de diez neuronas: las cuatro primeras serían de clase 1; la quinta de clase 2; y las cinco últimas de clase 3.

Por lo tanto, y siguiendo con el ejemplo, la red LVQ tendría asignada cada neurona de la siguiente manera (cada color representa a una clase): 


\begin{tabular}{|l|l|}
\hline 0,564 & 0,623 \\
\hline 0,865 & 0,457 \\
\hline 0,219 & 0,647 \\
\hline 0,301 & 0,978 \\
\hline 0,587 & 0,421 \\
\hline 0,902 & 0,975 \\
\hline 0,523 & 0,518 \\
\hline 0,668 & 0,542 \\
\hline 0,676 & 0,379 \\
\hline 0,952 & 0,849 \\
\hline
\end{tabular}

Tabla 4.3: Distribución de las neuronas en el ejemplo.

\begin{tabular}{|l|l|l|l|l|l|l|l|l|l|}
\hline 1 & 1 & 1 & 1 & 0 & 0 & 0 & 0 & 0 & 0 \\
\hline 0 & 0 & 0 & 0 & 1 & 0 & 0 & 0 & 0 & 0 \\
\hline 0 & 0 & 0 & 0 & 0 & 1 & 1 & 1 & 1 & 1 \\
\hline
\end{tabular}

Tabla 4.4: Distinción entre clases de la etapa de salida.

\subsubsection{Regla de aprendizaje.}

Para entrenar se debe disponer de una serie de vectores de cada clase, que serán los que se le irán presentando como entradas. Por supuesto, se da por hecho, que ha de conocerse la clase a la que pertenece cada uno los vectores. Cuando se le presenta uno de estos vectores a la primera capa:

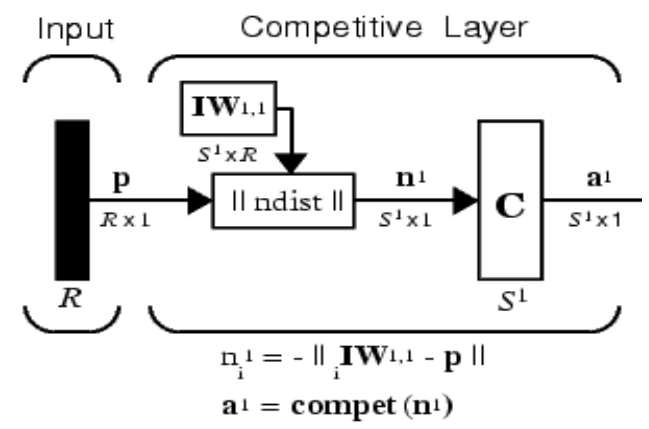

Figura 4.25: Primera capa de una red LVQ

Lo primero que se hace es calcular la norma de dimensión 2 (o lo que es lo mismo, la distancia euclídea entre el vector y cada neurona (nótese la doble barra 
que se indica en la figura). Cada una de esas distancias se guardan en un vector columna de dimensión S1x1, donde S1 es el número total de neuronas de la red. Una vez que se tienen todas las distancias se marca la que sea menor. La filosofía de esta regla es acercar la neurona al vector si la clasificación es correcta y alejarla de él si es incorrecta. Esto es, al presentar el vector, el usuario debe indicar la clase a la que pertenece; cuando se elige a la neurona que está más cerca del vector y resulta que la clase de esa neurona (recuerde la segunda capa de la red) coincide con la del vector entonces los valores del vector de la neurona se corrigen de la siguiente manera:

$$
\text { Nuevo valor }=\text { valor anterior }+ \text { ratio } *(\text { valor vector }- \text { valor anterior })
$$

Donde Nuevo es el nuevo valor de la neurona (una fila de la matriz de la capa de entrada), Anterior es el anterior valor de la neurona (la misma fila), Ratio es el ratio de aprendizaje utilizado por el usuario y Vector es el vector que se le está presentando a la red.

De la misma manera, si esa neurona no fuera de la misma clase que el vector entonces habría que alejarla de la siguiente manera:

$$
\text { Nuevo valor }=\text { valor anterior }- \text { ratio } *(\text { valor vector }- \text { valor anterior })
$$

\subsubsection{Entrenamiento y simulación.}

Como se dijo anteriormente, el aprendizaje off line se realiza en dos fases. La primera, el entrenamiento, es la que pretende modificar la información de la red para que después realice bien la clasificación. En este punto es importante decir que la información que contiene cada neurona debe ser inicializada antes del entrenamiento de alguna manera. Los resultados dependen en gran medida del método utilizado para inicializar los pesos antes del entrenamiento. Para entrenar redes LVQ hace falta tener un juego lo más extenso posible de vectores de cada tipo. Después del entrenamiento hay que realizar una simulación. Como su propio nombre indica, en esta segunda fase se simula el funcionamiento de la red para ver si los resultados son buenos o no. La mejor relación para distribuir los vectores entre estas dos fases es la de $80 \%$ para el entrenamiento y $20 \%$ para la simulación. Es decir que con el $80 \%$ de los vectores disponibles se modifica la información de las neuronas de la red mediante alguna regla de aprendizaje y luego con el $20 \%$ restante se prueba la red.

\subsubsection{Puesta en funcionamiento de la red neuronal.}

Una vez que se tiene una red entrenada se puede pasar a utilizarla. Durante la fase de entrenamiento y simulación se han presentado los vectores a las entradas y, según los resultados que haya dado la red en la clasificación durante la simulación se sabrá si la red es lo suficientemente buena. En las redes LVQ la información aprendida durante el entrenamiento se guarda, fundamentalmente, en la primera capa. En esta capa, las diferentes filas representan a una neurona ya entrenada. Para saber a qué clase pertenece cada neurona hay que recurrir a la información de la 
segunda capa, que es lo única función que tiene asignada. Cuando se usa la red neuronal en el modo simulación los valores de la primera capa (las neuronas) ya no sufren cambios. Para clasificar a un nuevo vector se procede de la misma manera que en la simulación; es decir, se le presenta un vector a la entrada y la red devuelve un vector columna con un único 1 lógico en la fila que corresponde a la clase a la que la red interpreta que pertenece. Las redes LVQ no pueden devolver en la salida un no sabe no contesta; es decir, siempre acaba clasificando en una u otra clase a los vectores.

\subsubsection{Aplicaciones.}

El área de aplicación de las LVQ es amplio y variado también. Mencionando algunos casos como [73] en donde utilizan las LVQ junto con las SVMs en una herrmienta CAD para una aplicación de imágenes de resonancia magnética (MRI) para el diagnóstico de la enfermedad de Alzheimer. En [74] se utilizan LVQ para el análisis de faltas de sensores. Se proporciona una metodología para la actuación ante fallos a nivel sensorial modelizando el estado de los sensores. En [75] se utiliza una red LVQ para estimar las contracciones ventriculares anormales del corazón (premature ventricular contraction-PVC). La entrada a la red la forman los exponentes de Lyapunov obtenidos a partir de la señal del electrocardiograma (ECG). En [76] se aborda la problemática de la ayuda al diagnóstico de procesos de apendicitis aguda. Se utiliza una red LVQ para relacionar los diferentes registros de una base de datos de pacientes y poder así obtener una clasificación eficiente. También en el diagnóstico temprano del cáncer de mama [77] hay aplicaciones de las LVQ. En este caso emplean una estructura jerárquica de varias redes. En uno de los niveles se utiliza una LVQ para disminuir el espacio de características. En un segundo nivel se tiene una segunda LVQ en cascada para proporcionar la salida de la clasificación definitiva. En [78] se presenta un clasificador basado en LVQ para la detección y diagnóstico del cáncer de colon a partir de la información genética. Se utilizan dos redes, la primera para seleccionar las características más efectivas del gen involucrado. Utilizando análisis de componentes principales se provoca un cambio de base o transformación de ejes, para después utilizar este espacio transformado como entrada a la segunda red. El segundo nivel LVQ estaría formado por el clasificador final. También en la línea de ayuda al diagnóstico en [79] se presenta un estudio confrontando las redes neuronales probabilísticas (PNNs) a las LVQ en la ayuda al diagnóstico de la osteoporosis. La conclusión de dicho estudio es que los resultados de aciertos en ambos casos son muy similares, en torno al $96 \%$ para los casos de pacientes en los que existía una patología asociada certera. En [80] recurren también a una LVQ para clasificar pacientes afectados con piedras en la vesícula biliar.

\subsection{Máquinas de Soporte Vectorial (SVM).}

Las Máquinas de Soporte Vectorial (Support Vectors Machines - SVM), son estructuras matemáticas que han sido incorporados al aprendizaje automático. Su buen comportamiento como clasificadores ha supuesto un incremento de uso en los últimos años en multitud de aplicaciones. Especialmente en problemas de reconocimiento de patrones, estimación de regresión y predicción. 
Las SVMs constituyen los primeros modelos matemáticos que en el marco de la Teoría de Aprendizaje Estadístico (SLT), no dependen de una distribución de probabilidad específica, y tienen la capacidad de aprender a partir de un conjunto de datos experimentales, con una distribución dispersa en un espacio de entrada de alta dimensión. A diferencia de otras máquinas fueron desarrolladas a partir de un fundamento teórico matemático sólido.

El fundamento teórico fue desarrollado principalmente por Vladimir Vapnik y sus colaboradores que introdujeron el principio de minimización del riesgo estructural SRM como concepto superior al tradicional principio de minimización de riesgo empírico ERM, para conseguir una mejora sustancial en clasificaciones de datos que no han sido vistos anteriormente.

Basan su aprendizaje en el uso de un espacio de hipótesis lineales, que obtienen elevando la dimensión del espacio del problema. Esta labor la efectúa una función denominada kernel. Los algoritmos de entrenamiento tienen la característica de que trabajan sobre optimizaciones de tipo convexo (es decir existe una única solución) construyendo una estructura formada por un subconjunto de los datos (vectores). A éste conjunto se le denomina vectores soporte.

En los últimos años, el uso de las SVMs se ha incrementado especialmente en el área de la biomedicina y de las ciencias aplicadas. Entre los trabajos destacables [81] que utilizan SVMs se pueden citar: el reconocimiento de dígitos escritos a mano (Cortes y Vapnik, 1995; Schölkopf, Burges y Vapnik, 1995,1996; Burges and Schölkopf, 1997), reconocimiento de objetos (Blanz et al., 1996), identificación de voz (Schmidt, 1996), reconocimiento de objetos en 3D (Pontil y Verri, 1998), detección de rostros en imágenes (Osuna, Freund y Girosi, 1997), categorización de textos (Joachims, 1997), categorización de spam (Drucker y Vapnik, 1999), entre otros trabajos.

\subsubsection{Clasificación de clases con SVM.}

El reconocimiento de patrones implica el desarrollo y la aplicación de algoritmos que puedan reconocer clases o patrones en los datos de partida. Las SVMs pertenecen a la familia de clasificadores lineales y están dirigidas especialmente a la tarea de clasificación de dos clases. Están especialmente indicadas para resolver problemas de clasificación con una distribución de probabilidad desconocida.

Aprenden desde un conjunto de datos de entrenamiento e intentan generalizar para conseguir una correcta clasificación. El conjunto de datos de entrenamiento provienen de problemas reales, generalmente limitados, dispersos y de alta dimensión.

Las SVMs construyen separadores lineales o hiperplanos de separación [82] en espacios de dimensión elevada durante el aprendizaje, adquiriendo el conocimiento a partir de los datos correspondientes de las dos clases. Asumiendo que los datos son linealmente separables, la idea es seleccionar un hiperplano que equidiste de 
los datos de cada clase. Es decir, el hiperplano que se encuentre en la posición más neutra entre ambas clases sin que esté sesgado hacia la clase más numerosa. Puede existir un conjunto infinito de hiperplanos que logren el objetivo, por lo que se suele introducir un sesgo llamado margen máximo, que equivale a seleccionar el hiperplano de separación con máximo margen (margen geométrico). Es una forma de minimizar la complejidad del conjunto de hiperplanos y a la vez contribuir a mejorar la cota superior sobre el error de clasificación, y por ende a tener una mejor generalización para separar a los ejemplos que no participaron en el aprendizaje.

Desde el punto de vista algorítmico, las SVMs están planteadas como problemas de optimización convexa. La convexidad del problema de optimización garantiza la existencia de un mínimo global, evitando la existencia de mínimos locales.

Para construir clasificadores no lineales, se utiliza una transformación no lineal de las características del espacio de entrada, hacia un espacio de características de una dimensión mayor, en donde los datos, ahora ya si, pueden ser separados linealmente. Para llevar a cabo esta labor, se recurre a una función kernel o función núcleo que calcula el producto escalar en el espacio de características.

Muchas veces, incluso en el espacio de características los datos de entrenamiento no son separables linealmente. Pueden contener ruido, estar mal etiquetados, existir valores atípicos, características mal calculadas, haber incongruencias, etc ... Lo que obliga a construir un modelo de SVM que admita ciertos errores, evitando que el hiperplano de separación los tome en cuenta durante su construcción, esto se consigue con las SVMs de margen flexible. La función objetivo a minimizar tiene dos términos, uno representa el margen geométrico y el otro es un término de regularización que implementa un parámetro $\mathrm{C}$ que debe ser elegido por el usuario.

Encontrar la solución del hiperplano de separación equivale a seleccionar los individuos de la clase sobre los cuales se construye dicho hiperplano, es decir, encontrar aquellos vectores de cada clase más cercanos. Éstos son los que se conoce como vectores soporte.

El problema de clasificación de dos clases está dado por un conjunto de $N$ datos $\left\{\left(\vec{x}_{1}, y_{1}\right),\left(\vec{x}_{2}, y_{2}\right), \ldots\left(\vec{x}_{N}, y_{N}\right)\right\}$. Donde cada dato es un par $\left(\vec{x}_{i}, y_{i}\right)$ formado por $\vec{x}_{i} \in X \subseteq \mathfrak{R}^{n}$ e $y_{i} \in Y \subseteq \Re$ para $i=1 \ldots N$. El conjunto de $N$ datos está compuesto por muestras a los que arbitrariamente se les llama muestras o vectores y son representados con letras o signos con una flecha sobre ellos (por ejemplo $\vec{x}_{i}$ ). Cada elemento $\vec{x}_{i}$ es un vector con $n$ características en el espacio de entrada $\mathfrak{R}^{n}$, es decir $\vec{x}_{i}=\left(x_{1}, x_{2}, \ldots, x_{n}\right)$, donde cada $x_{i} \in \mathfrak{R}$ es un número real para $i=1,2, \ldots, n$. Los elementos $y_{i}$ son etiquetas e indican la clase a la que pertenece $\vec{x}_{i}$, para la clasificación binaria $y_{i} \in\{+1,-1\}$ refiriéndonos a la clase 1 si un vector está etiquetada como "+1" o a la clase 2 si el vector está etiquetado con "-1". 


\subsubsection{Superficies de decisión (hiperplanos).}

Un hiperplano [83] es una superficie de decisión lineal que divide a un espacio n-dimensional $\mathfrak{R}^{n}$ en dos partes, al que se le puede implementar una regla de clasificación de dos clases. Los ejemplos que se encuentren a un lado de la superficie de decisión son clasificados como una clase y los que se encuentran en el otro lado son clasificados como la otra clase. En el espacio n-dimensional $\mathfrak{R}^{n}$, la superficie de decisión es un subespacio de dimensión n-1. Para un espacio de dimensión uno, dos, tres o más altas, la superficie de decisión son puntos, curvas, superficies o hiperplanos, respectivamente. Como generalmente los datos son vectores con muchas características, la dimensión del espacio suele ser $n>3$ por lo que la superficie de decisión se denomina hiperplano.

La expresión matemática para un hiperplano en un espacio $\mathfrak{R}^{3}$ está definido por un punto $P_{0}$ que pertenece al hiperplano y un vector $\vec{w}$ ortogonal a dicho hiperplano (Figura 4.26).

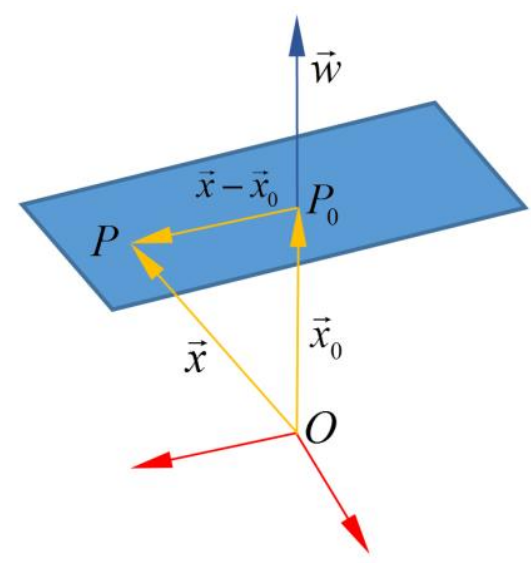

Figura 4.26: Definición de un hiperplano

$P$ es un punto cualquiera sobre el hiperplano, $O$ es el origen de coordenadas y los vectores $\vec{x}_{0}=\overline{O P}_{0}$ y $\vec{x}=\overline{O P}$ representan a los puntos $P_{0}$ y $P$ respectivamente desde el origen, la condición para que el punto $P$ pertenezca al hiperplano es que el vector $\vec{x}-\vec{x}_{0}$ sea perpendicular a $\vec{w}$. El producto escalar entre dos vectores perpendiculares es igual a cero $\vec{w} \cdot\left(\vec{x}-\vec{x}_{0}\right)=0$ ó lo que es lo mismo $\vec{w} \cdot \vec{x}-\vec{w} \cdot \vec{x}_{0}=0$, si se define al coeficiente $b=-\vec{w} \cdot \vec{x}_{0}$ entonces se obtiene la ecuación del hiperplano que es válida para todo $\mathfrak{R}^{n}$ si $n>3$.

$$
\vec{w} \cdot \vec{x}+b=0
$$

Cuando el valor de $b$ cambia en la ecuación del hiperplano, el hiperplano se desplaza de forma paralela a lo largo de la dirección de $\vec{w}$ dando lugar a hiperplanos paralelos. 
Considerando que un hiperplano está definido por la ecuación $H(\vec{x})=\vec{w} \cdot \vec{x}+b$, donde $\vec{w} \in \mathfrak{R}^{n}$ es el vector de pesos, $\vec{x} \in \mathfrak{R}^{n}$ es la representación vectorial de los datos y $b$ es el bias del umbral de decisión, se puede plantear el producto escalar en el espacio $\mathfrak{R}^{n}$, en donde un hiperplano se define:

$$
\left\{\vec{x} \in \mathfrak{R}^{n} \mid \vec{w} \cdot \vec{x}+b=0\right\}, \vec{w} \in \mathfrak{R}^{n}, b \in \mathfrak{R}
$$

Y el producto escalar de (4-46) se define por:

$$
\vec{w} \cdot \vec{x}=\sum_{i=1}^{n} w_{i} x_{i}
$$

Un hiperplano $H(\vec{x})$ puede definirse como un par $(\vec{w}, b)$. Un conjunto de vectores de entrenamiento puede considerarse separable si existe al menos un hiperplano definido por $(\vec{w}, b)$ que separe correctamente a todos los datos.

La pertenencia de un vector $\vec{x}_{k}$ a una clase $\mathrm{u}$ otra está dada por la regla de clasificación, tal que:

$$
\text { clase }\left(\vec{x}_{k}\right)=\left\{\begin{array}{lll}
+1 & \text { si } & \vec{w} \cdot \vec{x}_{k}+b>0 \\
-1 & \text { si } & \vec{w} \cdot \vec{x}_{k}+b<0
\end{array}\right.
$$

Si se considera un conjunto de datos de entrenamiento linealmente separables, entonces existe un número infinito de hiperplanos que los pueden separar de forma correcta. Aunque todos estos hiperplanos clasificadores pueden separar los datos de aprendizaje correctamente, sus capacidades de predicción no son iguales.

El objetivo sería hallar el hiperplano de separación o el clasificador lineal que maximice la distancia de separación o "margen" entre los vectores más cercanos de cada clase con el hiperplano, equidistando de las dos clases. El hiperplano con máximo margen se conoce como hiperplano de separación óptimo (HSO) y está situado en la posición más neutra con respecto a las clases representadas por el conjunto de datos, sin que éste se encuentre sesgado hacia la clase del conjunto de ejemplos más numeroso.

La Figura 4.27 muestra un hiperplano HSO que separa los datos en dos clases y tiene la mayor distancia o margen entre los ejemplos de cada clase más cercanos al hiperplano, dichos ejemplos son conocidos como vectores de soporte. Cabe mencionar que sólo se considera como vectores soporte a los vectores que se encuentran en las fronteras del margen del hiperplano de separación óptima. 


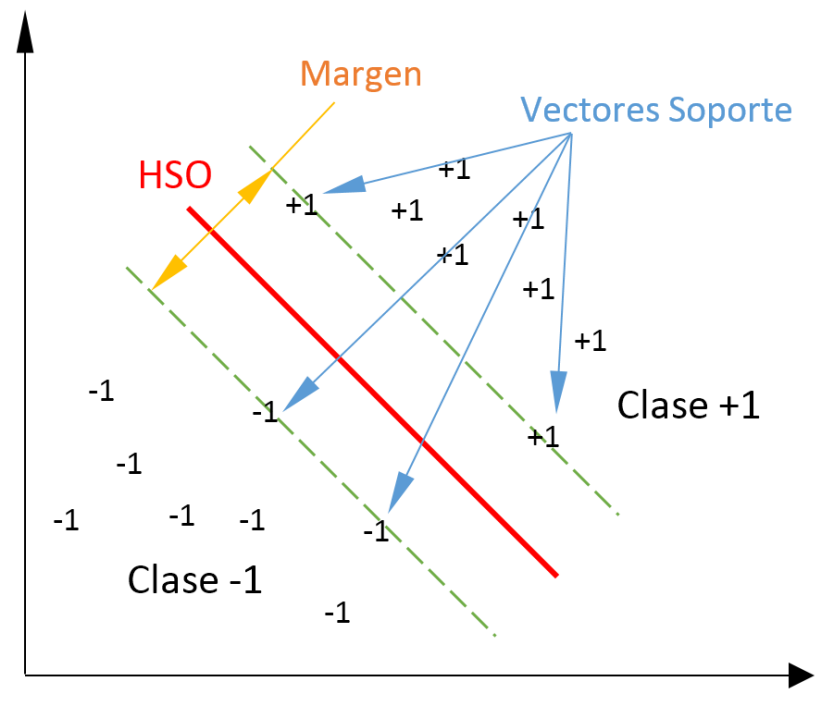

Figura 4.27: Hiperplano óptimo.

\subsubsection{Cálculo de distancia de un hiperplano al origen.}

La distancia entre un vector $\vec{x}$ y un hiperplano $H$ está definida por el par $(\vec{w}, b)$ como [84]:

$$
d(\vec{x} ; \vec{w}, b)=\frac{|\vec{w} \cdot \vec{x}+b|}{\|\vec{w}\|}
$$

Donde el término $\|\vec{w}\|=\sqrt{(\vec{w} \cdot \vec{w})}$ es la norma euclidiana del vector $\vec{w}$ asociada al producto escalar en el espacio $\mathfrak{R}^{n}$.

La distancia entre un hiperplano $H$ y el origen de coordenadas, está definida por:

$$
d(0, H)=\frac{|b|}{\|\vec{w}\|}
$$

\subsubsection{Concepto de margen máximo de un hiperplano.}

Ya se ha comentado anteriormente que el hiperplano de separación óptimo HSO está determinado por el hiperplano de margen máximo. Es necesario determinar el hiperplano $H$ de máxima separación descrito por la ecuación $\vec{w} \cdot \vec{x}+b=0$ representado por la línea azul en la Figura 4.28, los dos hiperplanos $H_{1}$ y $H_{2}$ representados por líneas discontinuas, son hiperplanos de separación de ambas clases: "-1" y "+1" respectivamente. Además son hiperplanos paralelos al hiperplano $H$ y sólo se diferencian en el coeficiente $b$. No existen vectores de entrenamiento entre los hiperplanos $H_{1}$ y $H_{2}$. 


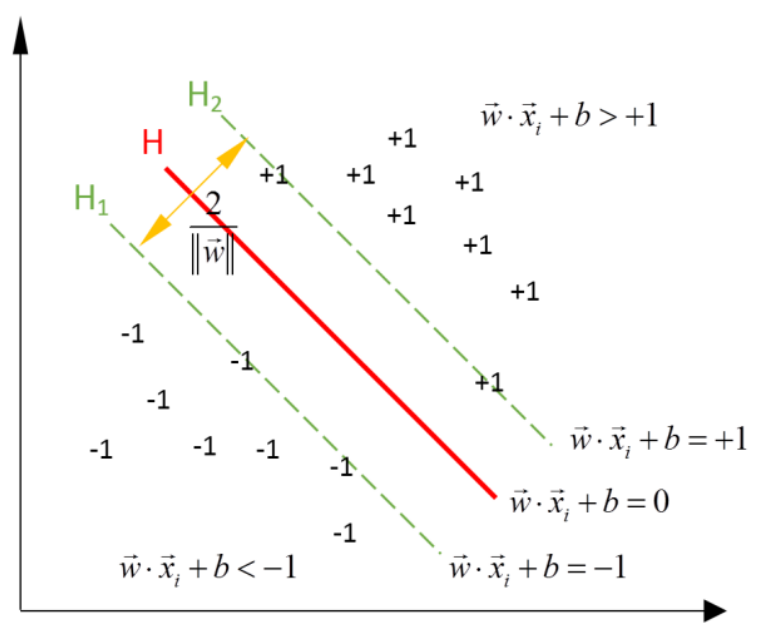

Figura 4.28: Hiperplano de separación de margen máximo (HSO).

Asumiendo que el conjunto de datos de entrenamiento es linealmente separable, se puede reescalar $\vec{w}$ y $b$ a 1 de forma que la distancia de los vectores más cercanos al hiperplano de separación sea $1 /\|\vec{w}\|$, y así al multiplicar $\vec{w}$ y $b$ por una constante la distancia no varía. Los hiperplanos $H_{1}$ y $H_{2}$ tienen la misma forma que $H$, es decir:

$$
\begin{array}{llll}
H_{1}: & \vec{w} \cdot \vec{x}+b=-1 & o & \vec{w} \cdot \vec{x}+(b+1)=0 \\
H_{2}: & \vec{w} \cdot \vec{x}+b=+1 \quad & o & \vec{w} \cdot \vec{x}+(b-1)=0
\end{array}
$$

Con (4-51), la ecuación (4-50) determina la distancia desde el hiperplano $H_{1}$ al origen:

$$
d\left(O, H_{1}\right)=\frac{|b+1|}{\|\vec{w}\|}
$$

Y con (4-52) la distancia del hiperplano $\mathrm{H}_{2}$ al origen es:

$$
d\left(O, H_{2}\right)=\frac{|b-1|}{\|\vec{w}\|}
$$

El máximo margen del clasificador lineal (osea del hiperplano de separación óptimo) $H$, está dada por la distancia entre los hiperplanos $H_{1}$ y $H_{2}$, siendo función de la norma euclidiana de $\vec{w}$, por lo que se tiene:

$$
\text { máx margen }=d\left(O, H_{1}\right)-d\left(O, H_{2}\right)=\frac{|b+1|}{\|\vec{w}\|}-\frac{|b-1|}{\|\vec{w}\|}=\frac{b+1-b+1}{\|\vec{w}\|}=\frac{2}{\|\vec{w}\|}
$$

Dado que el algoritmo de la SVM busca el hiperplano de separación $\vec{w} \cdot \vec{x}+b=0$ de margen máximo, se debe maximizar $2 /\|\vec{w}\|$, o lo que es lo mismo, minimizar 
$\|\vec{w}\|^{2} / 2$. Sin embargo, para que el hiperplano de separación óptimo pueda clasificar todos los vectores de manera correcta, deberá cumplir ciertas restricciones:

$$
\left\{\begin{array}{lll}
\vec{w} \cdot \vec{x}_{i}+b \geq+1 & \text { si } & y_{i}=+1 \\
\vec{w} \cdot \vec{x}_{i}+b \leq-1 & \text { si } & y_{i}=-1
\end{array}\right.
$$

Es decir (y como se puede apreciar en la Figura 4.28), todos los ejemplos que se encuentren en la región debajo del hiperplano $H_{1}$ deben ser clasificados como negativos y todos los ejemplos que se encuentran en la región sobre el hiperplano $\mathrm{H}_{2}$ deben ser clasificados como positivos.

Matemáticamente, ambas restricciones (4-56) equivalen a:

$$
y_{i}\left(\vec{w} \cdot \vec{x}_{i}+b\right) \geq 1 \quad i=1, \ldots, N
$$

\subsubsection{SVMs lineales.}

Las SVMs lineales son el modelo más sencillo e intuitivo, y sobre las que se apoyan las SVMs no lineales. Una de las condiciones de estas máquinas es que el conjunto de datos de entrenamiento sea finito y linealmente separable en el espacio de entrada, es decir que los datos no necesiten de ninguna transformación para que puedan ser clasificados correctamente (sin errores) en dos clases.

Se van a estudiar los siguientes casos de SVMs lineales:

- SVM lineales de margen rígido para datos linealmente separables.

- SVM lineales de margen flexible para datos casi linealmente separables.

El término "margen rígido" (hard-margin) se emplea para indicar que todos los datos son linealmente separables y que la clasificación se realiza correctamente sin producirse errores, por un hiperplano de separación de margen máximo. Los datos reales afectados por tipo de escala (magnitud medida) por lo general, no son linealmente separables (problemas de ruido e inexactitud de la medida). Más adelante, este problema se afrontará con la extensión del "margen flexible" (softmargin).

\subsubsection{SVM lineal de margen rígido para datos linealmente separables.}

En el caso de que los datos sean linealmente separables, el conjunto de vectores de entrenamiento debe ser finito y el hiperplano seleccionado debe ser de separación óptima $\vec{w} \cdot \vec{x}+b=0$ que tenga el máximo margen (Figura 4.29). 


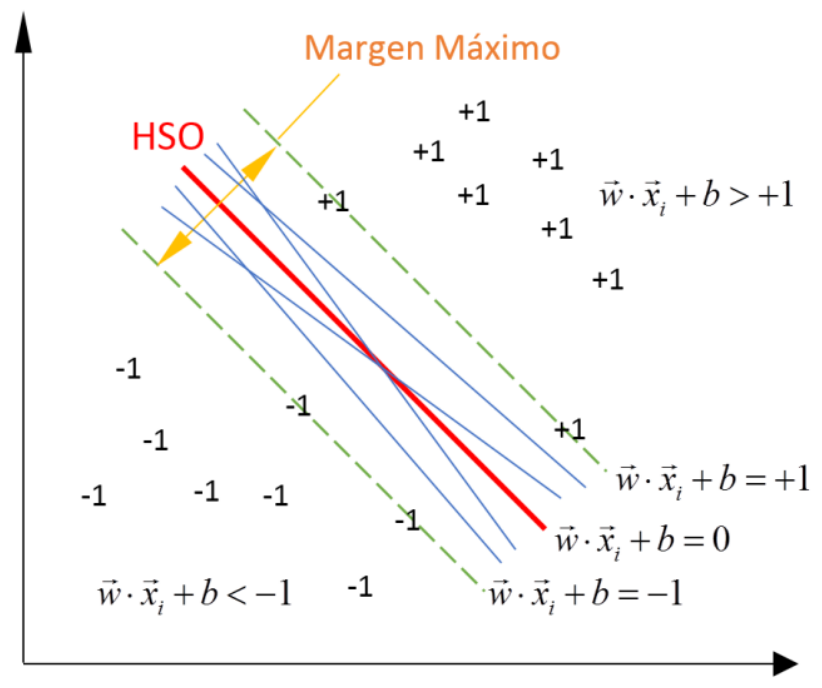

Figura 4.29: HSO para datos linealmente separables

En la sección 4.7.4 se establecieron las condiciones necesarias para determinar el hiperplano de separación óptimo con el margen máximo. Según la Figura 4.29, dado un conjunto de $N$ datos de entrenamiento $\left\{\left(\vec{x}_{1}, y_{1}\right),\left(\vec{x}_{2}, y_{2}\right), \ldots\left(\vec{x}_{N}, y_{N}\right)\right\}$, el hiperplano definido por la ecuación $\vec{w} \cdot \vec{x}+b=0$ se construye durante el entrenamiento. Los hiperplanos $\vec{w} \cdot \vec{x}+b=+1 \quad$ y $\vec{w} \cdot \vec{x}+b=-1 \quad$ son paralelos al hiperplano $\vec{w} \cdot \vec{x}+b=0$ y pasan por los ejemplos fronterizos de cada clase. La distancia entre estos hiperplanos fronterizos es el margen máximo (margen geométrico) del hiperplano de separación óptima, que posteriormente se calcula maximizando $\|\vec{w}\|^{2} / 2$. Imponiendo las restricciones para que clasifique correctamente se obtendrá finalmente un SVM de margen rígido. La optimización se consigue mediante la formulación primal.

\section{Formulación Primal.}

La formulación primal es un problema de optimización convexa. La minimización de una función cuadrática bajo restricciones de desigualdad lineal, utilizando programación cuadrática (QP). Donde el hiperplano $\vec{w} \cdot \vec{x}+b=0$ queda definido por los valores de los " $\mathrm{n}$ " atributos del vector de pesos $\vec{w}$.

Se plantea encontrar los valores de $\vec{w}$ y $b$ que cumplan:

$$
\begin{gathered}
\text { Minimizar: } f(\vec{x})=\frac{1}{2}\|\vec{w}\|^{2} \\
\text { Restricción: } y_{i}\left(\vec{w} \cdot \vec{x}_{i}+b\right) \geq 1 \quad i=1, . ., N
\end{gathered}
$$

La solución que se obtiene no es eficiente cuando el conjunto de datos de entrenamiento tiene un número de características mucho más elevado que el número de muestras. Los modelos de las SVMs resuelven el problema de 
optimización utilizando la función de Lagrange, transformando la formulación primal en su formulación dual.

Existen dos razones para cambiar el problema a una formulación de Lagrange:

- La primera es que la restricción (4-59) se reemplaza por los multiplicadores de Lagrange, facilitando el cálculo al incluir un número inferior de variables.

- La segunda, que en esta reformulación, la solución se expresa como una combinación lineal de los ejemplos de aprendizaje, es decir sólo aparecerán los ejemplos de entrenamiento en forma de productos escalares. Ésta es una propiedad importante que nos permitirá generalizar el procedimiento para el caso de datos que no sean separables linealmente.

\section{Formulación Dual.}

Una manera de resolver el problema de minimización con restricción es aplicar la función lagrangiana a la función objetivo (4-58) sujeto a la restricción (4-59). Para que la restricción pueda ser introducida en la función Langraniana debe ser de la forma $g_{i}(\vec{x}) \leq 0$. Dado que $y_{i}\left(\vec{w} \cdot \vec{x}_{i}+b\right) \geq+1$, se reescribe la desigualdad como $1-y_{i}\left(\vec{w} \cdot \vec{x}_{i}+b\right) \leq 0$, de donde:

$$
g_{i}(\vec{x})=1-y_{i}\left(\vec{w} \cdot \vec{x}_{i}+b\right) \leq 0
$$

Aplicando los multiplicadores de Lagrange en la formulación primal del problema $L_{P}$ junto con la restricción (4-60) se tiene:

$$
\begin{aligned}
\underset{\alpha_{i}}{\operatorname{maximizar}} \inf _{\vec{w}, b} & L_{P}(\vec{w}, b, \vec{A})=f(\vec{x})+\sum_{i=1}^{N} \alpha_{i} g_{i}(\vec{x}) \\
& =\frac{1}{2}\|\vec{w}\|^{2}+\sum_{i=1}^{N} \alpha_{i}\left(1-y_{i}\left(\vec{w} \cdot \vec{x}_{i}+b\right)\right) \\
= & \frac{1}{2} \|(\vec{w} \cdot \vec{w})-\sum_{i=1}^{N} \alpha_{i} y_{i} \vec{w} \cdot \vec{x}_{i}-\sum_{i=1}^{N} \alpha_{i} y_{i} b+\sum_{i=1}^{N} \alpha_{i}
\end{aligned}
$$

Donde $\vec{A}=\left(\alpha_{1}, \alpha_{2}, \ldots, \alpha_{N}\right)$ es el conjunto de multiplicadores de Lagrange con los que se "calibran" los ejemplos de entrenamiento con $\alpha_{i} \geq 0$, para $i=1, \ldots, N$. Ahora la función objetivo es la función Lagrangiana en la formulación primal $L_{P}(\vec{w}, b, \vec{A})$. Para hallar el punto de silla de $L_{P}(\vec{w}, b, \vec{A})$, debe ser minimizada con respecto a $\vec{w}, b$ y maximizar con respecto a $\alpha_{i}$, sujeto a la restricción $\alpha_{i} \geq 0$ para $i=1, \ldots, N$. Lo anterior es equivalente a resolver el problema dual de Wolfe (Fletcher, 1987), es decir, a maximizar la formulación primal $L_{P}$ con respecto a la variable $\alpha_{i}$, sujeto a 
las restricciones de que el gradiente de $L_{P}$ con respecto a $\vec{w}, b$ debe ser igual a cero y que $\alpha_{i} \geq 0$.

Dado que la restricción de las gradientes igual a cero no es lineal y la función objetivo $L_{P}(\vec{w}, b, \vec{A})$ no es cóncava, el problema dual de Wolfe es un problema de optimización no convexa y puede ser resuelto utilizando las condiciones KarushKuhn-Tucker (KKT) como restricciones lineales:

\section{Condiciones del gradiente:}

$$
\begin{aligned}
& \frac{\partial L_{P}(\vec{w}, b, \vec{A})}{\partial \vec{w}}=0 \\
& \frac{\partial L_{P}(\vec{w}, b, \vec{A})}{\partial b}=0
\end{aligned}
$$

Aplicando (4-64) en (4-65) se tiene:

$$
\frac{\partial L_{P}(\vec{w}, b, \vec{A})}{\partial \vec{w}}=0 \quad \Rightarrow \quad \vec{w}=\sum_{i=1}^{N} \alpha_{i} y_{i} \vec{x}_{i}
$$

Del mismo modo aplicando (4-65) en (4-63) se tiene:

$$
\frac{\partial L_{P}(\vec{w}, b, \vec{A})}{\partial b}=0 \Rightarrow \sum_{i=1}^{N} \alpha_{i} y_{i}=0
$$

Condiciones de Ortogonalidad:

$$
\alpha_{i}\left[y_{i}\left(\vec{w} \cdot \vec{x}_{i}+b\right)-1\right]=0 \quad i=1, \ldots, N
$$

Condición de existencia Primal:

$$
y_{i}\left(\vec{w} \cdot \vec{x}_{i}+b\right)-1 \geq 0 \quad i=1, \ldots, N
$$

Condición de existencia Dual de no Negatividad:

$$
\alpha_{i} \geq 0 \quad i=1, . ., N
$$


En este punto se pueden hacer algunas aclaraciones [85]: si la restricción (4-59) no se cumple en (4-62), es decir cuando $y_{i}\left(\vec{w} \cdot \vec{x}_{i}+b\right)<1$ y la función $L_{P}(\vec{w}, b, \vec{A})$ incrementa debido al aumento de los correspondientes $\alpha_{i}$, entonces al mismo tiempo $\vec{w}$ y $b$ deben cambiar para que $L_{P}(\vec{w}, b, \vec{A})$ disminuya y así cumplir con la condición (4-69).

De igual manera, para que la condición de ortogonalidad (4-68) se cumpla y evitar que $\alpha_{i}\left[y_{i}\left(\vec{w} \cdot \vec{x}_{i}+b\right)-1\right]$ llegue a ser un valor negativo muy alto $\vec{w}$ y $b$ deberán variar asegurando la separabilidad satisfaciendo la restricción.

Cuando la condición (4-69) primal se cumple como una desigualdad, es decir cuando $y_{i}\left(\vec{w} \cdot \vec{x}_{i}+b\right)-1>0$ entonces $\alpha_{i}=0$; pero si $y_{i}\left(\vec{w} \cdot \vec{x}_{i}+b\right)-1=0$ entonces $\alpha_{i} \neq 0$, y éstos son los que maximizan la función $L_{P}(\vec{w}, b, \vec{A})$.

Resolver la formulación primal $L_{P}(\vec{w}, b, \vec{A})$ equivale a encontrar una solución a las condiciones de $\mathrm{KKT}$, formulando el problema dual de Wolfe, maximizando $W_{D}(\vec{A})$ en función de los multiplicadores $\alpha_{i}$. Reemplazando (4-66) y (4-67) en (4-63) se obtiene la función a maximizar:

$$
\begin{gathered}
W_{D}(\vec{A})=\frac{1}{2} \sum_{i=1}^{N} \alpha_{i} y_{i} \vec{x}_{i} \cdot \sum_{j=1}^{N} \alpha_{j} y_{j} \vec{x}_{j}-\sum_{i=1}^{N} \sum_{j=1}^{N} \alpha_{i} \alpha_{j} y_{i} y_{j} \vec{x}_{i} \cdot \vec{x}_{j}+\sum_{i=1}^{N} \alpha_{i} \\
=\sum_{i=1}^{N} \alpha_{i}-\frac{1}{2} \sum_{i, j=1}^{N} \alpha_{i} \alpha_{j} y_{i} y_{j}\left(\vec{x}_{i} \cdot \vec{x}_{j}\right)
\end{gathered}
$$

Sujeto a las restricciones:

$$
\alpha_{i} \geq 0 \sum_{i=1}^{N} \alpha_{i} y_{i}=0 \quad i=1, \ldots, N
$$

La solución de maximizar la función objetivo (4-72) sujeto a las restricciones (4-73) de la formulación dual, también es un problema de optimización convexa pero con $\mathrm{N}$ variables para $\alpha_{i}, i=1, \ldots N$, donde $N$ es el número de muestras del conjunto de entrenamiento. Los $\alpha_{i}$ definirán el vector de pesos $\vec{w}$ y el umbral $b$. Para ello se requiere de un algoritmo de optimización cuadrática. El algoritmo más utilizado para las SVMs es el de optimización mínima secuencial SMO propuesta por Platt, 1999.

Hay que tener en cuenta que las funciones Lagrangianas $L_{P}$ y $W_{D}$ provienen de la misma función objetivo (4-58) pero con diferentes restricciones y la solución viene 
determinada mediante la minimización de $L_{P}(\vec{w}, b, \vec{A})$ o la maximización de $W_{D}(\vec{A})$, por lo que la función objetivo tendrá el mismo valor en ambos casos. Según la formulación dual no es necesario acceder a los datos originales de cada vector $\vec{x}_{i}$, sino que teniendo el producto escalar entre pares de los vectores de entrada es suficiente. Esto conlleva un ahorro computacional cuando el número de características es mucho mayor que el número de vectores.

\section{Vectores Soporte.}

Al plantear la función Lagrangiana (4-62), se introdujo los multiplicadores de Lagrange $\alpha_{i}$ a cada ejemplo del conjunto de entrenamiento a través de la restricción.(4-60). Los elementos del vector $\vec{A}^{0}=\left(\alpha_{1}^{0}, \alpha_{2}^{0}, \ldots \alpha_{N}^{0}\right)$ son los multiplicadores de Lagrange pertenecientes a un subconjunto de vectores de entrenamiento. Donde si $\alpha_{i}^{0}>0$ los vectores $\vec{x}_{i}$ están exactamente sobre el hiperplano $\vec{w} \cdot \vec{x}_{i}+b=+1$ o $\vec{w} \cdot \vec{x}_{i}+b=-1$ Figura 4.28. Es decir, sólo si se cumple que el margen funcional sea igual a uno $y_{i}\left(\vec{w} \cdot \vec{x}_{i}+b\right)=1$, éstos ejemplos son denominados vectores soporte (SV). El número de vectores soporte se representa por $N_{S V}$.

Por otro lado, los vectores de entrenamiento $\vec{x}_{i}$ donde $\alpha_{i}^{0}=0$ no son necesarios para obtener el hiperplano, con un margen funcional mayor a uno, pueden ser eliminados sin que afecten a la solución. Por tanto, se puede decir que cualquier modelo de SVM está definido por el conjunto de vectores de soporte y sus correspondientes multiplicadores de Lagrange.

\section{Hiperplano de Separación Óptimo (HSO).}

Una vez obtenidos los vectores soporte y sus respectivos multiplicadores $\alpha_{i}^{0}$, se puede calcular el vector de pesos $\vec{w}$, que define el hiperplano de separación óptimo HSO con máximo margen $\vec{w} \cdot \vec{x}_{i}+b=0$ (Figura 4.29), utilizando la ecuación (4-66). $\vec{w}^{*}$ se puede expresar como una combinación lineal de los $N_{S V}$ en términos de $\alpha_{i}^{0}$ :

$$
\vec{w}^{*}=\sum_{i=1}^{N_{S V}} \alpha_{i}^{0} y_{i} \vec{x}_{i}
$$

El umbral $b^{*}$ del hiperplano de separación óptimo se calcula considerando la condición KKT (4-68), sustituyendo por el vector $\vec{w}^{*}$ (4-74) y tomando dos ejemplos 
arbitrarios con diferentes etiquetas de clasificación $\vec{x}_{i}$ y $\vec{x}_{j}$ con $\alpha_{i}^{0}$ y $\alpha_{j}^{0}$ positivos respectivamente:

Para la etiqueta $y_{i}=+1$ :

$$
y_{i}\left(\vec{w} \cdot \vec{x}_{i}+b\right)=1 \quad \Rightarrow \vec{w} \cdot \vec{x}_{i}+b=1
$$

Para la etiqueta $y_{i}=-1$ :

$$
y_{i}\left(\vec{w} \cdot \vec{x}_{i}+b\right)=-1 \quad \Rightarrow-\left(\vec{w} \cdot \vec{x}_{i}+b\right)=1
$$

Igualando (4-75) y (4-76) se tiene:

$$
\vec{w} \cdot \vec{x}_{i}+b=-\left(\vec{w} \cdot \vec{x}_{j}+b\right) \quad \Rightarrow \quad b^{*}=-\frac{1}{2}\left(\vec{w}^{*} \cdot \vec{x}_{j}+\vec{w}^{*} \cdot \vec{x}_{i}\right)
$$

Lo que es igual a:

$$
b^{*}=-\frac{1}{2} \sum_{k=1}^{N_{S V}} \alpha_{k} y_{k}\left(\vec{x}_{k} \cdot \vec{x}_{j}+\vec{x}_{k} \cdot \vec{x}_{i}\right)
$$

Hay que tener en cuenta que mientras que $\vec{w}^{*}$ se determina de manera explícita por el procedimiento de entrenamiento, el umbral $b^{*}$ no, éste se determina de forma implícita.

Por tanto, la formulación del hiperplano de separación óptimo es:

$$
H S O \rightarrow f\left(\vec{x}, \vec{A}^{0}, b^{*}\right)=\sum_{i=1}^{N_{S V}} \alpha_{i}^{0} y_{i}\left(\vec{x}_{i} \cdot \vec{x}_{k}\right)+b^{*}
$$

\section{Clasificación de nuevos datos.}

Para clasificar nuevos vectores, es decir, el conjunto de vectores de prueba, utilizando $\vec{w}^{*}$ y $b^{*}$ obtenidos durante la fase de entrenamiento, se emplea la función "sign", que es igual a +1 si su argumento es positivo y -1 si su argumento es negativo. 


\section{Formulación primal.}

Para clasificar un vector $\vec{x}_{k}$ en la formulación primal, se usarán el vector de pesos $\vec{w}$ y $b$ encontrados por el algoritmo de aprendizaje empleado.

$$
f\left(\vec{x}_{k}\right)=\operatorname{sign}\left(\vec{w} \cdot \vec{x}_{k}+b\right)
$$

\section{Formulación dual.}

Si se utiliza la formulación dual para la clasificación de nuevos vectores $\vec{x}_{k}$, se debe tener en cuenta que los vectores que no son soporte, es decir los que tienen $\alpha_{i}=0$, no influyen en la clasificación del nuevo vector.

Después del entrenamiento y la obtención del hiperplano de separación óptimo con margen máximo, se puede predecir la clase de pertenencia de un nuevo vector diferente a los usados en el entrenamiento. La clase a la que pertenece el nuevo vector $\vec{x}_{k}$ está determinada por (4-48), y dependerá del signo de la expresión $\vec{w}^{*} \cdot \vec{x}_{k}+b^{*}$.

La ecuación (4-79) ofrece la posibilidad de predecir la clase a la que pertenece el nuevo ejemplo solamente utilizando los vectores soporte con sus correspondientes multiplicadores de Lagrange:

$$
f\left(\vec{x}_{k}\right)=\operatorname{sign}\left(\sum_{i=1}^{N_{S V}} \alpha_{i}^{0} y_{i}\left(\vec{x}_{i} \cdot \vec{x}_{k}\right)+b^{*}\right)
$$

La ecuación (4-81) presenta una importante ventaja y es que para clasificar el nuevo patrón $\vec{x}_{k}$ solamente es necesario calcular el producto escalar entre $\vec{x}_{k}$ y cada vector soporte, lo que significa un ahorro en el tiempo de cálculo, teniendo en cuenta que el número de vectores de soporte es pequeño comparado con el número de vectores del conjunto de entrenamiento $\mathrm{N}$.

Esta solución sólo es válida para muestras linealmente separables desde el espacio de entrada, pero la ecuación (4-81) puede adaptarse fácilmente a vectores no linealmente separables eligiendo unas nuevas variables $\xi$. Éstas cuantifican si alguna de las restricciones no se cumplen debido a errores por atípicos o vectores mal etiquetados, lo que da origen a una nueva formulación de SVM de margen flexible. 


\subsubsection{SVM lineal de margen flexible para datos linealmente no separables.}

La separación lineal no suele ser una alternativa válida para problemas de aplicación de la vida real. En estos casos, el algoritmo anterior no encuentra una solución satisfactoria. Con el fin de permitir cierta flexibilidad, cuando los datos son linealmente separables pero existen mediciones erróneas, ejemplos mal etiquetados o valores atípicos (Figura 4.30). Se puede introducir una modificación en la SVM que permita incluir dichos casos sin cambiar la familia de funciones de decisión. Buscando un hiperplano que separe el conjunto de vectores de entrenamiento con el error más pequeño a partir de un parámetro $C$. Dicho valor se utilizará para crear un margen flexible para permitir algunos errores en la clasificación, al mismo tiempo dichos vectores de error serán penalizados.

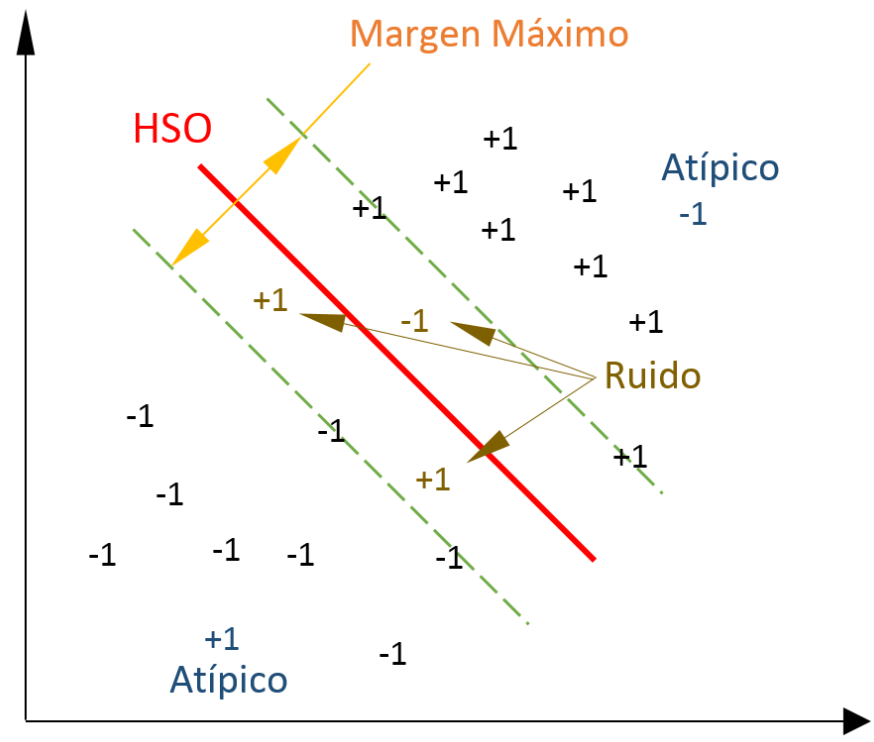

Figura 4.30: Representación de ruido y atípicos.

Dado un conjunto de $N$ vectores $\left\{\left(\vec{x}_{1}, y_{1}\right),\left(\vec{x}_{2}, y_{2}\right), \ldots\left(\vec{x}_{N}, y_{N}\right)\right\}$, donde cada vector está representado por un par $\left(\vec{x}_{i}, y_{i}\right)$, siendo el vector $\vec{x}_{i} \in X \subseteq \mathfrak{R}^{n}$ y la etiqueta $y_{i} \in Y \subseteq \Re$ para $i=1 \ldots N$, representados como se muestra en la Figura 4.31, los datos pueden ser separados linealmente, excepto para un pequeño número de vectores. Dado que los datos son no linealmente separables, no existe un hiperplano que separe en dos clases el conjunto de entrenamiento sin errores, las ecuaciones (4-58) y (4-59) no proporcionarán una solución.

Anteriormente se determinó que el hiperplano de separación óptima está definido por el par $(\vec{w}, b)$, siendo una frontera entre las dos clases "+1" y "-1" y tiene margen máximo. La frontera hacia la clase " $+1 "$ está definida por el hiperplano $\vec{w} \cdot \vec{x}+b=-1$ mientras que la frontera hacia la clase "-1" está definido por el hiperplano $\vec{w} \cdot \vec{x}+b=+1$. Para el hiperplano de separación óptimo todos los datos de la clase "+1" satisfacen $\vec{w} \cdot \vec{x}+b \geq 1$ y para los datos de la clase "-1" satisface $\vec{w} \cdot \vec{x}+b \leq 1$ Para obtener un clasificador óptimo para los vectores no separables la máquina de soporte 
vectorial asigna a cada vector un valor no negativo $\xi_{i} \geq 0, i=1, \ldots, N$ denominado "variable de holgura", tal y como se puede apreciar en la Figura 4.31.

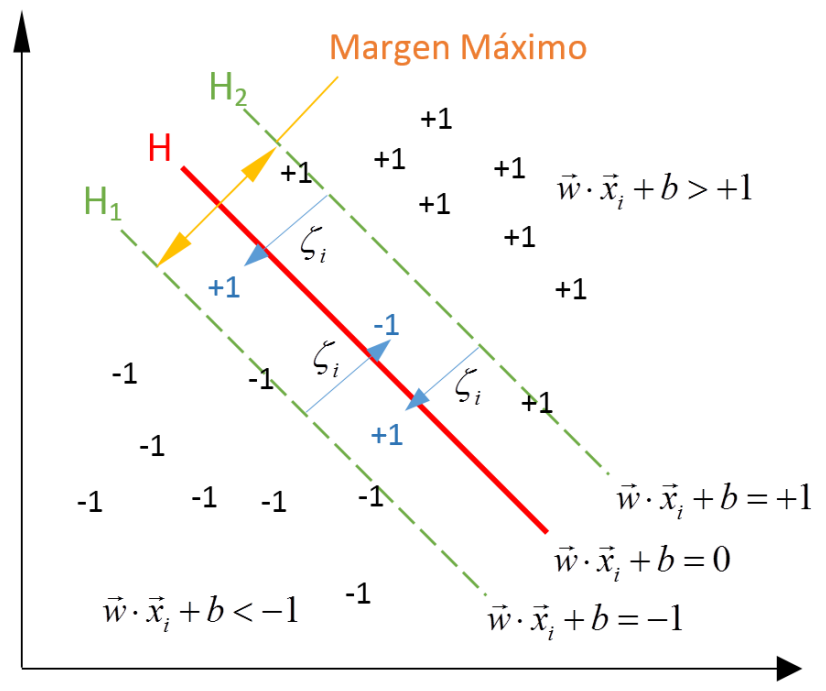

Figura 4.31: Introduciendo la variable de holgura

Para un vector $\left(\vec{x}_{i}, y_{i}\right)$ que pertenezca a la clase " $+1 "$, la variable de holgura $\xi_{i}$ está definida como la distancia (relativa a la mitad del tamaño del margen) desde el vector al hiperplano $\vec{w} \cdot \vec{x}+b=+1$ si el patrón $\vec{x}_{i}$ es positivo y no se encuentra en la región que le corresponde a su clase, caso contrario si el vector fue clasificado correctamente y se encuentra en su región correspondiente $\xi_{i}=0$, es decir:

$$
\xi_{i}(\vec{w}, b)=\left\{\begin{array}{lll}
1-\left(\vec{w} \cdot \vec{x}_{i}+b\right) & \text { si } & \vec{w} \cdot \vec{x}_{i}+b \leq+1 \\
0 & \text { si } & \vec{w} \cdot \vec{x}_{i}+b \geq+1
\end{array}\right.
$$

De igual forma para un vector $\left(\vec{x}_{i}, y_{i}\right)$ de la clase "-1", la variable de holgura está definida como la distancia (relativa a la mitad del tamaño del margen) desde el vector al hiperplano $\vec{w} \cdot \vec{x}+b=-1$ si el vector $\vec{x}_{i}$ es negativo y no se encuentra en la región que le corresponde a su clase, caso contrario si el vector es clasificado correctamente y se encuentra en su región correspondiente $\xi_{i}=0$, por lo que:

$$
\xi_{i}(\vec{w}, b)=\left\{\begin{array}{lrl}
1+\left(\vec{w} \cdot \vec{x}_{i}+b\right) & \text { si } & \vec{w} \cdot \vec{x}_{i}+b \geq+1 \\
0 & \text { si } & \vec{w} \cdot \vec{x}_{i}+b \leq+1
\end{array}\right.
$$

De las ecuaciones (4-82) y (4-83) y de la Figura 4.31 puede observarse que la variable de holgura $\xi_{i}(\vec{w}, b)$ es igual a cero para todos los vectores "+1" clasificados 
correctamente por el hiperplano $\vec{w} \cdot \vec{x}_{i}+b \geq+1$, y para todos los vectores "-1" clasificados correctamente por el hiperplano $\vec{w} \cdot \vec{x}_{i}+b \leq-1$. Por otro lado, la variable de holgura $\xi_{i}(\vec{w}, b)$ toma valores positivos, almacenando la distancia entre un vector $\vec{x}_{i}$ y el correspondiente hiperplano $\vec{w} \cdot \vec{x}_{i}+b=y_{i}$. Para los vectores de la clase "+1" situados en la región comprendida entre los hiperplanos $H_{2} \mathrm{y} H$, y para los vectores de la clase "-1" situados en la región comprendida entre los hiperplanos $H_{1}$ y $H$, la variable de holgura toma valores entre 0 y 1 y no son considerados como mal clasificados, pero tienen una penalización añadida a la función objetivo.

Si algún vector $\vec{x}_{i}$ está localizado en una región de la clase que no le corresponde, entonces la variable de holgura es mayor a uno $\xi_{i}(\vec{w}, b)>1$ y el ejemplo es considerado como clasificado erróneamente.

Combinando las ecuaciones (4-82) y (4-83) para la variable de holgura de las dos clases de vectores, se tiene:

$$
\xi_{i}(\vec{w}, b)=\left\{\begin{array}{lrl}
1-y_{i}\left(\vec{w} \cdot \vec{x}_{i}+b\right) & \text { si } & y_{i}\left(\vec{w} \cdot \vec{x}_{i}+b\right) \leq+1 \\
0 & \text { si } & y_{i}\left(\vec{w} \cdot \vec{x}_{i}+b\right) \geq+1
\end{array}\right.
$$

Cuando se tienen en cuenta las variables de holgura de cada vector para penalizar aquellos están mal clasificados (vectores que están situados en las zonas comprendidas entre el hiperplano $H$ y los hiperplanos paralelos $H_{1}$ y $H_{2}$ ) las restricciones que se imponen a la función objetivo son las siguientes:

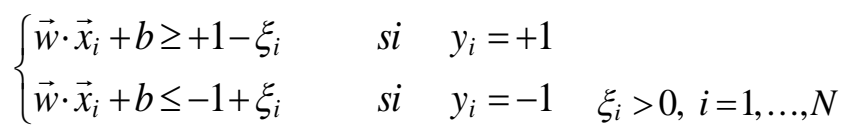

Matemáticamente, ambas restricciones de (4-85) equivalen a:

$$
y_{i}\left(\vec{w} \cdot \vec{x}_{i}+b\right) \geq+1-\xi_{i}
$$

Con la ecuación (4-86), encontrar el hiperplano de separación óptimo es mucho más difícil porque el clasificador debe cumplir dos condiciones opuestas. La primera condición es que el mejor hiperplano clasificador con el margen más amplio posible garantice un buen rendimiento en la predicción de nuevos vectores, que se obtiene con la minimización de la función objetivo (4-58). La segunda condición es que el hiperplano de separación óptimo debe minimizar el número de errores de clasificación, lo que se traduce en minimizar el número de variables de holgura positiva y a la vez minimizar el valor de cada variable de holgura. 
La segunda condición tiene la tendencia de disminuir el ancho del margen del hiperplano óptimo de clasificación, siendo una contradicción a la primera condición.

Una manera sencilla de combinar estas dos condiciones y asignar una penalización a los errores de clasificación es cambiar la función objetivo (4-58). Introduciendo un término de regularización que depende de las variables de holgura, estableciendo un compromiso entre el margen y la magnitud de las mismas, de tal modo:

$$
f(\vec{x})=\frac{1}{2}\|\vec{w}\|^{2}+C\left(\sum_{i=1}^{N} \xi_{i}\right)^{k}
$$

\section{Parámetro C.}

El término de regularización incluye una constante $C$ que puede ser ajustado por el usuario, determinando la holgura del margen flexible, aumentando o disminuyendo la penalización para los errores de clasificación.
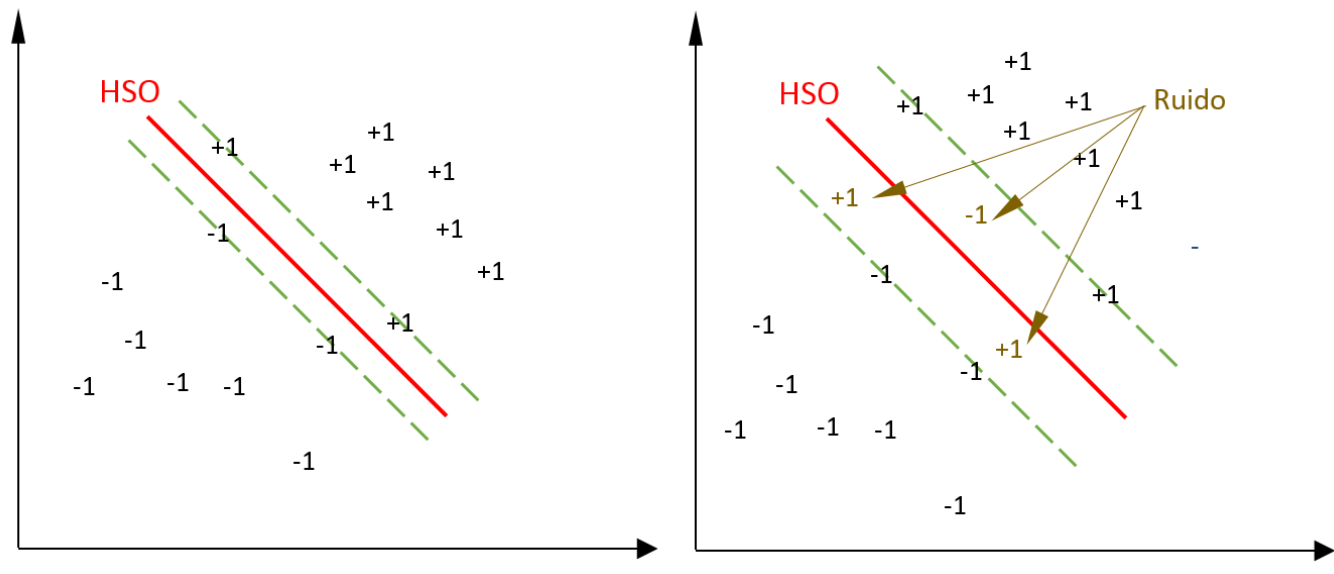

Figura 4.32: Influencia de C. C grande izq., C pequeño der.

Cuando $C$ tiene un valor grande (Figura 4.32 izq.) para cada $\xi_{i}$ diferente de cero, la contribución a la función (4-87) será mayor, por lo que se asigna una penalización a la clasificación de errores, minimizando así el número de vectores de entrenamiento mal clasificados, y al mismo tiempo se reduce el margen, siendo equivalente a una SVM de margen rígido.

Si $C$ toma un valor pequeño (Figura 4.32 der.) para cada $\xi_{i}$ diferente de cero, la contribución a la ecuación (4-87) es muy pequeña, maximizando el margen y haciendo menos sensible el hiperplano de separación óptimo a los errores de 
aprendizaje. Pueden existir más vectores erróneamente clasificados en el entrenamiento y la norma del vector de pesos $\vec{w}$ tiende a ser más pequeña.

Utilizando un valor muy grande de $C$ es como si tuviéramos una SVM de margen rígido, con lo que tendríamos un buen hiperplano, sin embargo, en la mayoría de los casos interesará trabajar con una SVM de margen flexible y optimizar el valor de $C$.

La ecuación (4-87) es un problema de programación convexa y tanto para $k=1$ o para $k=2$ sigue siendo un problema de programación cuadrática. Con $k=1$ tiene la ventaja de que ninguna variable de holgura $\xi_{i}$ y ninguno de sus multiplicadores de Lagrange aparecen en la formulación del problema dual de Wolfe.

Con estas consideraciones se define la formulación primal para un clasificador lineal con errores de clasificación.

\section{Formulación Primal.}

La formulación primal para las SVM lineales de margen flexible, se define en la siguiente expresión:

$$
\text { Maximizar } \quad f(\vec{x})=\frac{1}{2}\|\vec{w}\|^{2}+C \sum_{i=1}^{N} \xi_{i}
$$

Sujeto a las restricciones:

$$
\begin{aligned}
& \left\{\begin{array}{l}
y_{i}(\vec{w} \cdot \vec{x}+b) \geq+1-\xi_{i} \\
\xi_{i} \geq 0
\end{array}\right. \\
& \text { Con } C>0 \text { definido por el usuario. }
\end{aligned}
$$

La restricción $y_{i}(\vec{w} \cdot \vec{x}+b) \geq+1-\xi_{i}$ implica que cada vector $\vec{x}_{i}$ es clasificado correctamente o clasificado incorrectamente pero que se encuentra dentro de la distancia $\xi_{i}$ desde el hiperplano de separación, es decir su error de clasificación se encuentra limitado por $\xi_{i}$, que es mayor a cero.

El problema de optimización de la formulación primal para un clasificador de margen flexible necesita encontrar los valores de $n$ variables del vector de pesos $\vec{w}$ y de $\mathrm{N}$ variables de holgura $\xi_{i}$ que definan el hiperplano $\vec{w} \cdot \vec{x}+b=0$. Este objetivo puede ser muy costoso computacionalmente si el conjunto de datos de entrenamiento tiene un gran número de características.

Como en el caso del algoritmo de la SVM lineal de margen rígido, se puede replantear la formulación primal de la SVM lineal de margen flexible a su 
formulación dual de Lagrange, matemáticamente equivalente, pero que presenta menos variables a optimizar.

\section{Formación Dual.}

Para resolver el problema de optimización cuadrática restringida de la formulación primal, se aplica la función Lagrangiana $L_{p}$, definiendo los multiplicadores de Lagrange $\vec{A}=\left(\alpha_{1}, \alpha_{2}, \ldots, \alpha_{N}\right)$ para cada restricción $y_{i}(\vec{w} \cdot \vec{x}+b) \geq+1-\xi_{i}$ y los multiplicadores de Lagrange $\vec{M}=\left(\mu_{1}, \mu_{2}, \ldots, \mu_{N}\right)$ para cada restricción $\xi_{i} \geq 0$ e $i=1, \ldots, N$. Las restricciones (4-89) para poder ser introducidas en la función Lagrangiana tienen que ser de la forma $g_{i}(\vec{x}) \leq 0$ y $h_{i}(\vec{x}) \leq 0$, cambiando la notación se tiene:

$$
\begin{gathered}
g_{i}(\vec{x})=1-\xi_{i}-y_{i}(\vec{w} \cdot \vec{x}+b) \leq 0 \\
h_{i}(\vec{x})=-\xi_{i} \leq 0
\end{gathered}
$$

Teniendo en cuenta esta notación y aplicando la función primal Lagrangiana a la función objetivo (4-87) y las restricciones (4-90) y (4-91) se tiene:

$$
\begin{gathered}
\underset{\alpha_{i}, \mu_{i}}{\operatorname{maximizar}} \inf _{\vec{w}, b} L_{P}(\vec{w}, b, \vec{A}, \vec{M})=f(\vec{x})+\sum_{i=1}^{N} \alpha_{i} g_{i}(\vec{x})+\sum_{i=1}^{N} \mu_{i} h_{i}(\vec{x}) \\
=\frac{1}{2}\|\vec{w}\|^{2}+C \sum_{i=1}^{N} \xi_{i}+\sum_{i=1}^{N} \alpha_{i}\left[1-\xi_{i}-y_{i}(\vec{w} \cdot \vec{x}+b)\right]+\sum_{i=1}^{N} \mu_{i}\left(-\xi_{i}\right) \\
=\frac{1}{2}\|\vec{w}\|^{2}+C \sum_{i=1}^{N} \xi_{i}-\sum_{i=1}^{N} \alpha_{i} y_{i}\left(\vec{w} \cdot \vec{x}_{i}\right)-\sum_{i=1}^{N} \alpha_{i} y_{i} b+\sum_{i=1}^{N} \alpha_{i}-\sum_{i=1}^{N} \alpha_{i} \xi_{i}-\sum_{i=1}^{N} \mu_{i} \xi_{i}
\end{gathered}
$$

Para encontrar el límite inferior del problema de minimización primal, al igual que en las SVM lineales de margen rígido, se resuelve el problema dual de Wolfe maximizando la formulación primal $L_{P}$ y utilizando las condiciones Karush-KuhnTucker (KKT) como restricciones lineales:

\section{Condiciones de gradiente.}

$$
\frac{\partial L_{P}(\vec{w}, b, \vec{A}, \vec{M})}{\partial \vec{w}}=0 \quad \frac{\partial L_{P}(\vec{w}, b, \vec{A}, \vec{M})}{\partial b}=0 \quad \frac{\partial L_{P}(\vec{w}, b, \vec{A}, \vec{M})}{\partial \xi_{i}}=0
$$

Aplicando las derivadas parciales (4-95) en (4-94) se tiene: 


$$
\begin{gathered}
\frac{\partial L_{P}(\vec{w}, b, \vec{A}, \vec{M})}{\partial \vec{w}}=0 \Rightarrow \vec{w}=\sum_{i=1}^{N} \alpha_{i} y_{i} \vec{x}_{i} \\
\frac{\partial L_{P}(\vec{w}, b, \vec{A}, \vec{M})}{\partial b}=0 \Rightarrow \sum_{i=1}^{N} \alpha_{i} y_{i}=0 \\
\frac{\partial L_{P}(\vec{w}, b, \vec{A}, \vec{M})}{\partial \xi_{i}}=0 \Rightarrow C-\sum_{i=1}^{N} \alpha_{i}-\sum_{i=1}^{N} \mu_{i}=0 \Rightarrow C-\alpha_{i}-\mu_{i}=0
\end{gathered}
$$

\section{Condiciones de Ortogonalidad:}

$$
\alpha_{i}\left[y_{i}\left(\vec{w} \cdot \vec{x}_{i}+b\right)-1+\xi_{i}\right]=0 \quad i=1, \ldots, N
$$

\section{Condición existencia Primal:}

$$
y_{i}\left(\vec{w} \cdot \vec{x}_{i}+b\right)-1+\xi_{i} \geq 0 \quad i=1, . ., N
$$

\section{Condición de existencia Dual y no Negatividad:}

$$
\xi_{i} \geq 0 \quad \alpha_{i} \geq 0 \quad \mu_{i} \geq 0 \quad \mu_{i} \xi_{i}=0 \quad i=1, . ., N
$$

Reemplazando las condiciones de gradiente KKT (2.70), se tiene la formulación dual de Wolfe que equivale a encontrar los multiplicadores $\alpha_{i}$ que maximicen $L_{D}(\vec{A})$

Maximizar:

$$
\begin{gathered}
L_{D}(\vec{A})=\frac{1}{2} \sum_{i=1}^{N} \alpha_{i} y_{i} \vec{x}_{i} \cdot \sum_{j=1}^{N} \alpha_{j} y_{j} \vec{x}_{j}+C \sum_{i=1}^{N} \xi_{i}-\sum_{i=1}^{N} \sum_{j=1}^{N} \alpha_{i} \alpha_{j} y_{i} y_{j} \vec{x}_{i} \cdot \vec{x}_{j}+\sum_{i=1}^{N} \alpha_{i}-\sum_{i=1}^{N} \alpha_{i} \xi_{i}-\sum_{i=1}^{N} \mu_{i} \xi_{i} \\
=\sum_{i=1}^{N} \alpha_{i}-\frac{1}{2} \sum_{i=1}^{N} \sum_{j=1}^{N} \alpha_{i} \alpha_{j} y_{i} y_{j} \vec{x}_{i} \cdot \vec{x}_{j}+\sum_{i=1}^{N} \xi_{i}\left(C-\alpha_{i}-\mu_{i}\right) \\
=\sum_{i=1}^{N} \alpha_{i}-\frac{1}{2} \sum_{i, j=1}^{N} \alpha_{i} \alpha_{j} y_{i} y_{j}\left(\vec{x}_{i} \cdot \vec{x}_{j}\right)
\end{gathered}
$$

Sujeto a las restricciones: 


$$
0 \leq \alpha_{i} \leq C \quad \sum_{i=1}^{N} \alpha_{i} y_{i}=0 \quad i=1, \ldots, N
$$

Se observa que la función dual de la SVM de margen flexible es idéntica a la función dual de la SVM de margen rígido, solamente difiere en el valor de las restricciones. El vector peso $\vec{w}^{*}$ se obtiene de la misma forma que en la SVM lineal de margen flexible, utilizando la ecuación (4-98).

El umbral $b^{*}$ se obtiene como en la ecuación (4-78), pero solamente con los vectores de entrenamiento de las dos clases que tienen los multiplicadores de Lagrange comprendidos en el intervalo: $0 \leq \alpha_{i}<C . b^{*}$ proviene de las condiciones de KKT, de la ecuación (4-99) y reemplazando el multiplicador $\mu_{i}$ de la ecuación (4-98) en la cuarta condición de (4-101), obteniendo:

$$
\alpha_{i}\left[y_{i}\left(\vec{w} \cdot \vec{x}_{i}+b\right)-1+\xi_{i}\right]=0 \quad\left(C-\alpha_{i}\right) \xi_{i}=0
$$

De las ecuaciones anteriores se tiene que la variable de holgura $\xi_{i}=0$ si $\alpha_{i}<C$, $b^{*}$ será promediada solamente utilizando aquellos vectores con holgura cero y que caigan sobre los hiperplanos de separación.

Analizando la relación que existe entre la posición de un ejemplo $\vec{x}_{i}$ y los correspondientes valores $\alpha_{i}, \xi_{i}$ y $C$ se distinguen las siguientes situaciones:

$\alpha_{i}=0 ; \xi_{i}=0$ : cuando los multiplicadores de Lagrange $\alpha_{i}=0$, los vectores de entrenamiento se encuentran en las regiones que le corresponde a su clase y ninguno de ellos son vectores soporte, por lo que no son importantes para definir el modelo de la SVM. No influyen en la solución y pueden ser eliminados del aprendizaje sin ningún efecto. Si $\xi_{i}=0$ implica que no existen errores de clasificación, en esta situación los vectores se encuentran clasificados correctamente dentro de sus respectivas regiones: $\vec{w} \cdot \vec{x}_{i}+b>1$ para la clase " +1 " y $\vec{w} \cdot \vec{x}_{i}+b<-1$ para la clase "-1". Es decir, la distancia desde el hiperplano de separación al vector es más grande que ${ }^{1 /\|\vec{w}\|}$.

$0<\alpha_{i}<C ; \xi_{i}=0$ : con $\xi_{i}=0$ implica que no existen errores en la clasificación de los vectores que cumplen esta igualdad. El multiplicador de Lagrange comprendido en este intervalo $0<\alpha_{i}<C$ indica que se trata de los vectores que se encuentran sobre los hiperplanos (Figura 4.31) $H_{2}: \vec{w} \cdot \vec{x}_{i}+b=+1$ y $H_{1}: \vec{w} \cdot \vec{x}_{i}+b=-1$. La distancia entre estos vectores y el hiperplano de separación es $1 /\|\vec{w}\|$. Serían los vectores soporte. 
$\alpha_{i}=C ; 0<\xi_{i} \leq 1$ : Los vectores que cumplen con estas condiciones son clasificados correctamente por el hiperplano de separación óptima (Figura 4.31). Pero son los vectores de la clase "+1" que se encuentran en la zona comprendida entre el hiperplano $H: \vec{w} \cdot \vec{x}_{i}+b=0$ y el hiperplano de la región "+1" $H_{2}: \vec{w} \cdot \vec{x}_{i}+b=+1$. También son los vectores de la clase "-1" que se encuentran en la zona comprendida entre el hiperplano $H: \vec{w} \cdot \vec{x}_{i}+b=0$ y el hiperplano de la región "-1" $H_{1}: \vec{w} \cdot \vec{x}_{i}+b=-1$ . La distancia de estos vectores al hiperplano de separación es más pequeño que $1 /\|\vec{w}\|$.

$\alpha_{i}=C ; \xi_{i}>1$ : Estos vectores son los que están clasificados incorrectamente, los vectores de la clase "+1" situados en la región de la clase "-1" definido por el hiperplano $\vec{w} \cdot \vec{x}_{i}+b<0$, mientras que para los vectores de la clase "-1" se encuentran en la región de la clase "+1" definido por el hiperplano $\vec{w} \cdot \vec{x}_{i}+b>0$.

De igual forma, para definir el hiperplano óptimo se utiliza la expresión (4-79) y para la clasificación de nuevos vectores $\vec{x}_{k}$ se utiliza la función signo de la ecuación (4-81), que sólo depende de los vectores soporte y sus respectivos multiplicadores de Lagrange. El valor óptimo de $b^{*}$ y el vector $\vec{w}^{*}$ no necesita calcularse, por lo que la dimensión del vector $\vec{w}^{*}$ no es significativa.

\subsubsection{SVMs no lineales.}

En el caso de los dos tipos de máquinas evaluados, las aplicaciones son limitadas, ya que normalmente, en muchos casos, las clases se sobreponen haciendo imposible encontrar un plano que divida completamente a las dos.

\subsubsection{Mapeo de los datos de entrada al espacio de características.}

El hiperplano de separación o superficie de decisión, en muchos problemas de clasificación podría no ser lineal. Las máquinas de soporte vectorial pueden manipular datos no separables linealmente construyendo superficies no lineales. Dichas funciones no lineales son las denominadas funciones de características $\varphi(\vec{x})$ . La aplicación de las SVMs a conjuntos de datos no lineales pasa por el mapeo de los vectores de entrada $\Re^{n}$ a un espacio de características de dimensión más alto $\mathfrak{R}^{h}$. Un espacio de Hilbert de dimensión finita o infinita donde sea posible llevar a cabo una clasificación lineal.

Considerando un conjunto de $N$ vectores de entrenamiento y cada uno con sus respectivas clases $\left\{\left(\vec{x}_{1}, y_{1}\right),\left(\vec{x}_{2}, y_{2}\right), \ldots\left(\vec{x}_{N}, y_{N}\right)\right\}$ donde cada $\vec{x}_{i}$ es un vector con $n$ características en el espacio de entrada $\mathfrak{R}^{n}$, es decir $\vec{x}_{i}=\left(x_{1}, x_{2}, \ldots, x_{n}\right)$. Definiendo un conjunto de funciones características $\varphi_{1}, \varphi_{2}, \ldots, \varphi_{h}$. Cualquier vector será transformado a un vector real $\varphi(\vec{x})$ de la siguiente forma:

$$
\vec{x}=\left(x_{1}, x_{2}, \ldots, x_{n}\right) \quad \rightarrow \quad \phi(\vec{x})=\left(\phi_{1}(\vec{x}), \phi_{2}(\vec{x}) \ldots, \phi_{h}(\vec{x})\right)
$$


Después de realizar el mapeo de los $N$ vectores de entrenamiento, se obtienen los puntos en el espacio de características $\mathfrak{R}^{\text {h }}$ :

$$
\left\{\left(\phi\left(\vec{x}_{1}\right), y_{1}\right),\left(\phi\left(\vec{x}_{2}\right), y_{2}\right), \ldots\left(\phi\left(\vec{x}_{N}\right), y_{N}\right)\right\}
$$

Si las funciones de características $\varphi(\vec{x})$ se eligen adecuadamente el conjunto (4-108) será separable linealmente en el espacio de características, aplicando la formulación de las SVMs lineales. Si se sustituyen los vectores $\vec{x}$ por los $\varphi(\vec{x})$ en la SVM de margen flexible, el problema de optimización es similar a (4-88) con las restricciones de (4-89) y la función de decisión para nuevos ejemplos (4-81) estará determinado por:

$$
f\left(\vec{x}_{k}\right)=\operatorname{sign}\left(\sum_{i=1}^{N_{S V}} \alpha_{i}^{0} y_{i}\left[\phi\left(\vec{x}_{i}\right) \cdot \phi\left(\vec{x}_{k}\right)\right]+b^{*}\right)
$$

La función (4-109) es un hiperplano de decisión (clasificador lineal) en el espacio de características $\mathfrak{R}^{h}$. Será una hipersuperficie de separación no lineal en el espacio de entrada $\mathfrak{R}^{n}$.

No existe un procedimiento que indique qué tipo de funciones características son las más adecuadas para una separación óptima. Además existe otro problema en el momento de seleccionar la dimensión del espacio de características final, debido a que computacionalmente puede ser intratable si el número de características es muy grande. Afortunadamente, en la función (4-109) existe el término $\varphi\left(\vec{x}_{i}\right) \cdot \varphi\left(\vec{x}_{k}\right)$, como ya se comentó, es suficiente conocer el producto escalar y no es necesario conocer en forma explícita las funciones $\varphi(\vec{x})$.

\subsubsection{Funciones Kernel para SVM.}

Se trata de eliminar el producto escalar de las funciones $\varphi(\vec{x})$ que puede conducir a un espacio de dimensión demasiado alto. Para ello se introduce una nueva clase de funciones llamadas funciones kernel o funciones núcleo, que permiten calcular el producto escalar en el espacio definido por el conjunto de datos de entrenamiento. Es decir en el espacio de entrada, en lugar de hacerlo en el espacio de características. Una función kernel es:

$$
K\left(\vec{x}_{i}, \vec{x}_{j}\right)=\phi\left(\vec{x}_{i}\right) \cdot \phi\left(\vec{x}_{j}\right) \quad K\left(\vec{x}_{i}, \vec{x}_{j}\right): \Re^{n} \times R^{n} \rightarrow \mathfrak{R}
$$

La expresión (4-110) se puede definir sólo bajo ciertas condiciones. Sea $K$ una función simétrica positiva en el espacio de entrada, puede representar un producto escalar en el espacio de características si satisface las condiciones de Mercer [86] (Vapnik, 1995):

$$
K\left(\vec{x}_{i}, \vec{x}_{j}\right)=\sum_{k=1}^{\infty} a_{k} \phi_{k}\left(\vec{x}_{i}\right) \cdot \phi_{k}\left(\vec{x}_{j}\right), \quad a_{k} \geq 0
$$




$$
\iint K\left(\vec{x}_{i}, \vec{x}_{j}\right) g\left(\vec{x}_{i}\right) g\left(\vec{x}_{j}\right) d \vec{x}_{i} d \vec{x}_{j}>0 \quad \forall g \in L_{2}\left(R^{n}\right)
$$

Donde $g(\cdot)$ es cualquier función con una norma $L_{2}$ finita en el espacio de entrada, es decir, una función para la cual $\int g^{2}(\vec{x}) d \vec{x}<\infty$. Las condiciones de Mercer, según la teoría de Hilbert-Schmidt (Courant y Hilbert, 1953), caracterizan a las funciones simétricas aceptables $K\left(\vec{x}_{i}, \vec{x}_{j}\right)$ (Mercer, 1909).

Como ejemplo, sea un vector $\vec{x}_{i}=\left(x_{1}, x_{2}\right) \in \mathfrak{R}^{2}$ y sean las funciones características de dicho vector $\varphi(\vec{x})=\left(\vec{x}_{1}^{2}, \vec{x}_{2}^{2}, \sqrt{2} \vec{x}_{1} \vec{x}_{2}\right)$. La función kernel correspondiente a partir de las funciones características es:

$$
K\left(\vec{x}_{i}, \vec{x}_{j}\right)=\phi\left(\vec{x}_{i}\right) \cdot \phi\left(\vec{x}_{j}\right)=\left(\vec{x}_{i} \cdot \vec{x}_{j}\right)^{2}
$$

A continuación se relacionan las funciones kernel más utilizadas en el reconocimiento de patrones por medio de las SVMs:

Kernel lineal: Este kernel se define mediante el producto escalar. Se suele utilizar como una prueba de no linealidad en el conjunto de datos de entrenamiento, así como cuando el conjunto de datos es disperso.

$$
K\left(\vec{x}_{i}, \vec{x}_{j}\right)=\vec{x}_{i} \cdot \vec{x}_{j}
$$

Kernel polinomial: Es uno de los más utilizados por sus buenos resultados a la hora de modelar datos no separables linealmente. Tiene como desventaja que cuando aumenta el grado del polinomio $d$ la hipersuperficie de decisión se hace más compleja, lo que conlleva a un sobreajuste en muchas ocasiones.

$$
K\left(\vec{x}_{i}, \vec{x}_{j}\right)=\left(p+\vec{x}_{i} \cdot \vec{x}_{j}\right)^{d} \quad p \in \mathfrak{R}, d \in \aleph
$$

Kernel Gaussiano (RBF): Es el más utilizado y recomendo cuando no existe información del comportamiento de los datos. La salida del kernel depende de la distancia euclidia $\left\|\vec{x}_{i}-\vec{x}_{j}\right\|^{2}$, entre un vector soporte y un dato de prueba. El parámetro libre $\sigma$ determinará el área de influencia que este vector soporte tiene sobre el espacio de datos, aumentando o disminuyendo el ancho de la campana. Puede optimizarse utilizando técnicas de validación cruzada. 


$$
K\left(\vec{x}_{i}, \vec{x}_{j}\right)=\exp \left(-\frac{\left\|\vec{x}_{i}-\vec{x}_{j}\right\|^{2}}{2 \sigma^{2}}\right) \quad \sigma>0
$$

Kernel Exponencial: Es un kernel adecuado para cuando el hiperplano acepta discontinuidades.

$$
K\left(\vec{x}_{i}, \vec{x}_{j}\right)=\exp \left(-\frac{\left\|\vec{x}_{i}-\vec{x}_{j}\right\|}{2 \sigma^{2}}\right) \quad \sigma>0
$$

Kernel Sigmoidal: Utiliza la función tangente hiperbólica, con una forma sigmoide, ya utilizada en los perceptrones multicapa.

$$
K\left(\vec{x}_{i}, \vec{x}_{j}\right)=\tanh \left(s \vec{x}_{i} \cdot \vec{x}_{j}+r\right) \quad s, r \in \mathfrak{R}
$$

\subsubsection{Aplicaciones de las SVMs.}

Debido a la gran profusión de estos clasificadores, son multitud los casos y ejemplos de aplicación, en una gran diversidad de áreas y objetivos. Por citar algunos, directamente relacionados con aplicaciones en ayudas a los procesos de diagnóstico, podríamos mencionar [87] donde utilizando técnicas de enjambre (PSO) y clasificadores SVM, se plantea un procedimiento para la diagnosis prematura del cáncer de mama. Mediante la máquina de soporte vectorial se optimizan los parámetros del enjambre para posteriormente obtener resultados óptimos en el algoritmo PSO. En [88] se propone el uso de SVMs para la diagnosis del cáncer usando varios marcadores en el caso de: cáncer de colon, cáncer de estómago y cáncer de pulmón. Para el caso del cáncer de piel en [89] proponen un sistema de reconocimiento y preprocesado de imagen, con posterior clasificación basándose en la intensidad y la textura como características principales. Posteriormente las muestras son utilizadas para entrenar una SVM. En [90] se utiliza una SVM para la ayuda al diagnóstico del cáncer de tiroides a partir de las características proporcionadas por señales microscópicas, utilizando técnicas basadas en el reconocimiento probabilístico de texturas. En [91] se hace un estudio comparativo entre redes neuronales, SVMs y algoritmos genéticos para la diagnosis de arritmias. Las características planteadas/utilizadas se obtienen a partir de la información de la señal del electroencefalograma (ECG).

En otras áreas, como en el del mantenimiento y funcionamiento de bombas, en [92] se contrasta la eficacia entre SVMs y redes neuronales en la detección de faltas en bombas centrífugas. A partir de seis características: flujo, temperatura, presión de succión, caída de presión, velocidad y vibración; se propone detectar dos tipos de faltas o fallos. En [93] se trata la problemática de los controles de calidad en procesos industriales complejos. Donde ha de decidirse si un producto en 
fabricación es considerado válido para continuar su producción o si ha de retirarse como unidad defectuosa. Para ello utilizan una SVM con análisis de componentes principales previo del espacio de características. En las centrales térmicas de producción de energía eléctrica es importante la mejora constante de la eficiencia energética del proceso. La correcta puesta a punto de todos los componentes y sistemas así como un mantenimiento predicitivo eficaz resultan cruciales para lograr el objetivo. Para ello en [94] utilizan una SVM para la detección de faltas en las instalaciones de las turbinas. En [95] se presenta una aplicación de turbinas de gas, donde la SVM se utiliza para detectar fallas y malfuncionamientos a partir de las variables termodinámicas características del modelo de la turbina. En el transporte y distribución de energía eléctrica resultan cruciales el uso de transformadores. Para el correcto funcionamiento de estas máquinas estáticas es importante asegurar el buen estado del aceite que actúa como refrigerante. Para ello en [96] se plantea un clasificador basado en SVM para detectar bolsas de gas disuelto en el aceite de los transformadores. Un exceso de gas en suspensión con el aceite puede suponer un malfuncionamiento y por tanto un riesgo para la integridad de la instalación. 


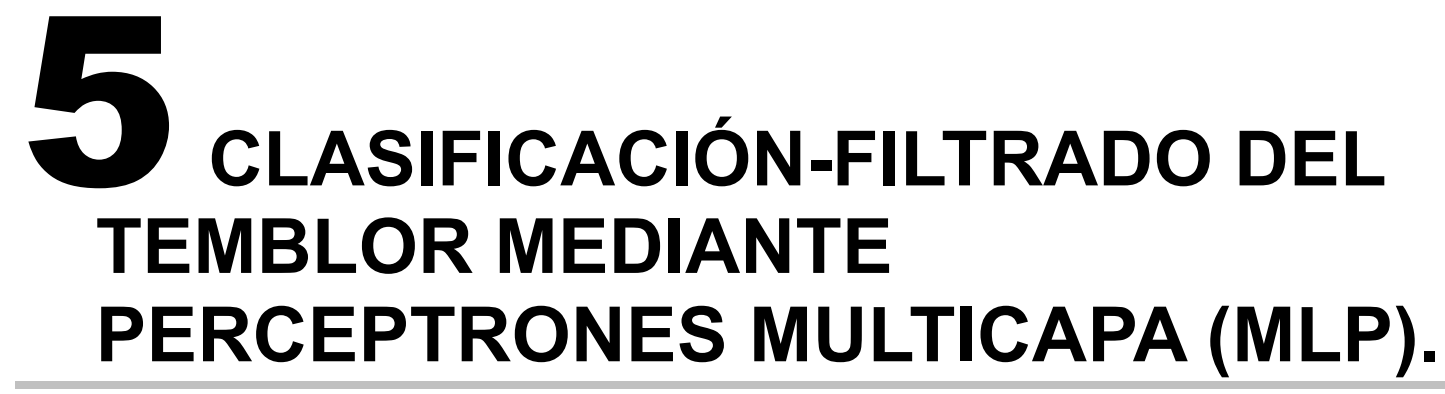

Los primeros trabajos que se desarrollaron tanto para intentar eliminar el temblor de las muestras (filtrado) como para la caracterización, fueron empleando los perceptrones multicapa (MLP). Los motivos se comentaron ya en el capítulo 4, pero podrían volver a mencionarse resumidos en:

- Aprendizaje supervisado mediante el algoritmo de propagación hacia atrás.

- Buena generalización.

- Computación robusta ante fallos.

Como en casi todas las actividades de la vida, pero mucho más cuando se pretende resolver una problemática compleja conviene actuar siguiendo unas pautas, un método. Por lo que se proponen los siguientes pasos a seguir para afrontar el problema/objetivo con una red:

- Análisis del problema

- Elección el tipo de red más adecuado.

- Elección de las variables usadas como entrada y la codificación, típicamente $[-1 \ldots 1]$ o [0...1], y si se usan valores discretos o continuos.

- Elección de las salidas y su codificación.

- Implementación de la red.

- Dimensión de la red: Número de capas y número de unidades en cada capa.

- Elegir funciones de activación para las capas ocultas y la capa de salida. 
- Elegir regla de aprendizaje y fijar los parámetros de entrenamiento: coeficiente de aprendizaje, error cuadrático máximo, etc.

- Entrenamiento de la red.

- Preparar un fichero con los ejemplos de entrenamiento: los patrones de entrada y los patrones de salida con los que se debe asociar.

- Para conseguir redes más robustas se puede añadir ruido a los datos de entrada, para evitar caer en mínimos locales se puede añadir ruido a las conexiones.

- Entrenar a la red. Si la red no aprende correctamente se pueden cambiar diversos parámetros y volver a entrenar.

- Realizar un test o simulación.

- Preparar un fichero con datos distintos a los usados para el entrenamiento para probar la capacidad de generalizar a datos nuevos o la capacidad de reconocer datos aprendidos previamente pero distorsionados.

- Evaluar la ejecución de la red y si no es satisfactoria modificar algún parámetro, cambiar la estructura o crear un nuevo fichero de entrenamiento y repetir todos los pasos.

\subsection{Dimensión de la red.}

Seleccionar la dimensión de la red que permita obtener resultados razonables con un periodo de tiempo bajo y con una carga computacional adecuada, resulta difícil, ya que no hay una método exacto. En general, con tres capas, una de entrada, otra de salida y con una sola capa oculta será suficiente, aunque hay veces que redes con más de una capa oculta aprenden más deprisa.

El número de neuronas en la capa de entrada y en la capa de salida viene en cada caso fijado por el número de entradas y el número de salidas que necesite la red.

Determinar el número de unidades que hay que utilizar en la capa oculta no es tan evidente como para las capas de entrada y salida. El objetivo principal consiste en utilizar el menor número posible de unidades en la capa oculta, ya que cada unidad aumenta la carga computacional de la CPU. Para elegir el número de unidades de las capas ocultas será necesario, en la mayoría de los casos, probar con un numero variable. Si la red no llega a converger, serán necesarios introducir más elementos de procesado en la capa oculta, y si la red converge se puede probar a disminuir el número. 
Es importante que se definan los parámetros de entrenamiento: número máximo de épocas de entrenamiento, el coeficiente de aprendizaje y el error cuadrático máximo. Este último valor significa el error cuadrático por debajo del cual la red puede dejar de ser entrenada, ya que los resultados que con ella se obtienen a partir de ese momento son lo suficientemente aceptables. El error cuadrático medio es la suma de los errores respecto a las salidas ideales al cuadrado, de todas las componentes de todos los vectores de entrenamiento.

También es importante, a la hora de determinar el error cuadrático máximo que permitimos a la red, tener en cuenta que cuanto más entrenemos la red, esta aprenderá mejor los vectores de entrenamiento propuestos, pero si se entrena demasiado comenzará a reconocer sólo los vectores que se asemejen mucho a los de entrenamiento, esto es, provocaremos que la red no sea capaz de interpolar. Ya se comentó en el capítulo 4 que este fenómeno denominado sobre-entrenamiento puede ocurrir por un exceso y ser muy perjudicial para la red.

A la hora del entrenamiento, no se deben utilizar todos los vectores para entrenar la red. Se debe reservar un subconjunto para probar la eficacia de la misma, con el objetivo de verificar que la red puede llevar a cabo la asociación deseada aun cuando los vectores de entrada no coincidan con ninguno de los vectores de entrenamiento.

Si se está entrenando una red que funcione en un entorno con ruido, hay que incluir unos cuantos vectores de entrada con ruido en el conjunto de datos de entrenamiento. Algunas veces la adición de ruido a los vectores de entrada durante el entrenamiento ayuda a la red a converger, incluso en el caso de que no se espere ruido en las entradas.

La red no deberá ser entrenada por completo con los vectores de una clase, pasando después a otra clase, ya que la red se olvidará del entrenamiento anterior, aprendiendo sólo el último patrón que se haya entrenado.

Si la función de activación de las neuronas de la capa de salida es una sigmoide, será preciso aplicar una escala a los vectores de entrada, ya que la función sigmoidea toma valores entre 0 y 1 .

\subsection{Filtrado del temblor mediante MLP's.}

Ya se comentó en el capítulo 2 que uno de los principales síntomas y por desgracia también de los efectos discapacitantes (desde el punto de vista funcional mayoritariamente), de algunas enfermedades neurológico-motrices, es el temblor producido en las extremidades superiores. Este temblor impide a las personas afectadas realizar tareas tan sencillas como teclear un código en un cajero automático o realizar un movimiento en una trayectoria determinada. 
La terapia funcional, como también se mencionó en el estado del arte, está dirigida fundamentalmente a paliar este trastorno mediante el empleo de fármacos o las intervenciones quirúrgicas. Pero no en todos los casos se consigue el objetivo buscado y el temblor no se puede eliminar. Por esta razón, resultaría muy conveniente otro tipo de ayuda.

Entre los trabajos desarrollados durante esta tesis se han efectuado varios intentos para la supresión o eliminación parcial del temblor. En este capítulo vamos a exponer los resultados obtenidos con el perceptrón multicapa.

Se planteó el diseño de un filtro capaz de eliminar la componente involuntaria que acompaña al movimiento, de tal forma, que mediante su empleo, una persona que sufra este trastorno pueda dirigir, por ejemplo, el ratón del ordenador hasta el icono deseado y pulsarlo, de la misma manera que lo realizaría una persona sana.

Todos los resultados obtenidos han sido a partir de las muestras proporcionadas por el DIMETER, por lo que se basaron en muestras reales de pacientes enfermos bien de Párkinson o de temblor esencial, así como las muestras que se poseían de sujetos de control, a los que en todo caso se les podría asociar una componente fisiológica.

El objetivo principal en las diferentes etapas, ha sido encontrar la parte invariante del temblor, entendiendo ésta como la señal fundamental que una vez conocida nos permitirá la creación de un filtro capaz de eliminarlo.

El problema se afrontó desde dos perspectivas, la primera actuar desde el dominio temporal, utilizando las muestras registradas de posición de los diferentes patrones. La segunda opción fue trabajar desde el dominio de la frecuencia.

\subsubsection{Dominio temporal.}

Como primera toma de contacto, se pretende filtrar las series temporales para conservar la parte de la señal afectada por el temblor, eliminando el movimiento y las tensiones de offset. Esto es necesario debido a que las series temporales utilizadas se obtienen siguiendo diferentes patrones de trayectoria. El filtro que se utiliza es un filtro digital paso alto con frecuencia de corte de $3 \mathrm{~Hz}$, ya que el temblor se produce en un margen de frecuencias aproximado de entre 4 o 5 a $20 \mathrm{~Hz}$. Las series temporales utilizadas varían entre 8 y 15 segundos aproximadamente.

El siguiente paso se basa en dividir la muestra filtrada en un número variable de vectores de entrenamiento. El número de puntos que completan los vectores también se considera variable.

A continuación, se procede a entrenar la red utilizando como entrada vectores formados por los valores de tiempo y como salida vectores con la serie del temblor filtrada. 
Una vez la red es entrenada, se resta la salida de la red a la señal inicial y se obtiene la señal sin temblor.

La siguiente figura representa la estructura implementada:

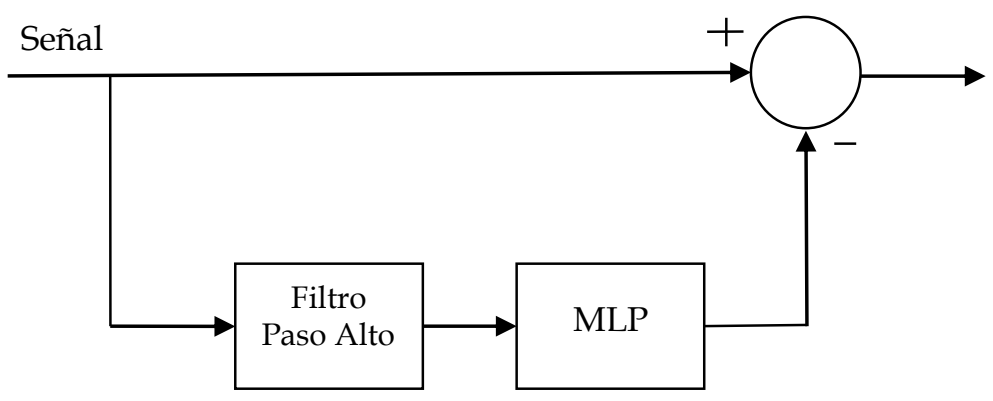

Figura 5.1: Filtrado mediante MLP.

Después de realizar diferentes pruebas para elegir la configuración más apropiada se ha considerado el uso de una red con tres capas. La capa de entrada contiene una única neurona, que representa el valor de tiempo en cada instante. La capa salida también está compuesta por una única neurona, que en este caso tendrá el valor de la señal filtrada en el valor de tiempo introducido a la entrada. Por último, la dimensión de la capa oculta se ha ajustado experimentalmente para obtener la mejor habilidad de generalización de la red, variando el número de neuronas entre 20 y 50. La función de activación utilizada en las neuronas de la capa oculta y de salida ha sido la función tansig.

Debido a que las redes neuronales no siguen ninguna regla fija en cuanto al entrenamiento más apropiado se han realizado diferentes pruebas modificando:

- Número de vectores de entrenamiento.

- Número de épocas de entrenamiento.

- Número de neuronas en la capa oculta.

- Número de puntos de cada vector utilizados para el entrenamiento.

El filtrado de las señales, la creación de la matriz de entrenamiento, la creación de la red neuronal MLP, su entrenamiento mediante el algoritmo backpropagation y por último, la simulación de la red se han integrado dentro de una misma función para facilitar la obtención de resultados.

\subsubsection{Resultados.}

Inicialmente, se ha entrenado una red con una señal de una duración de 12 segundos, pero se ha observado una gran dificultad para manejar tanta 
información, por lo que se ha dividido el problema en varias redes haciéndose carga cada una de un número más reducido de muestras.

En la Figura 5.2 se puede observar el problema de aprendizaje de una única red, los resultados no son muy buenos.

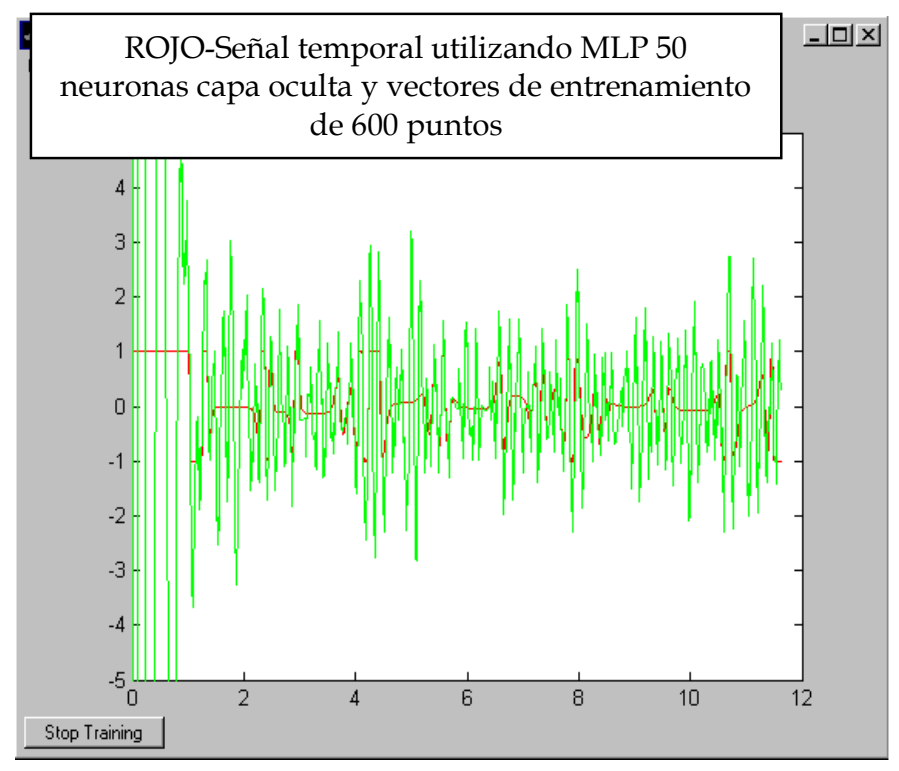

Figura 5.2: Resultados de modelado del temblor para una única red MLP.

Las neuronas de la capa de salida al tener una función de activación tansig (tangente hiperbólica) su rango está limitado entre -1 y 1 por lo que se ha realizado un escalado para ajustar los vectores de entrenamiento, tanto los de entrada como los de salida, dentro de este rango.

Utilizando tres redes para el aprendizaje de un vector de 12 segundos se han realizado entrenamientos con las siguientes características: 


\section{Caso 1:}

- 25 vectores de entrenamiento.

- 100 épocas por vector.

- 25 neuronas en la capa oculta.

- 200 puntos por vector.

\section{Salida de la red:}

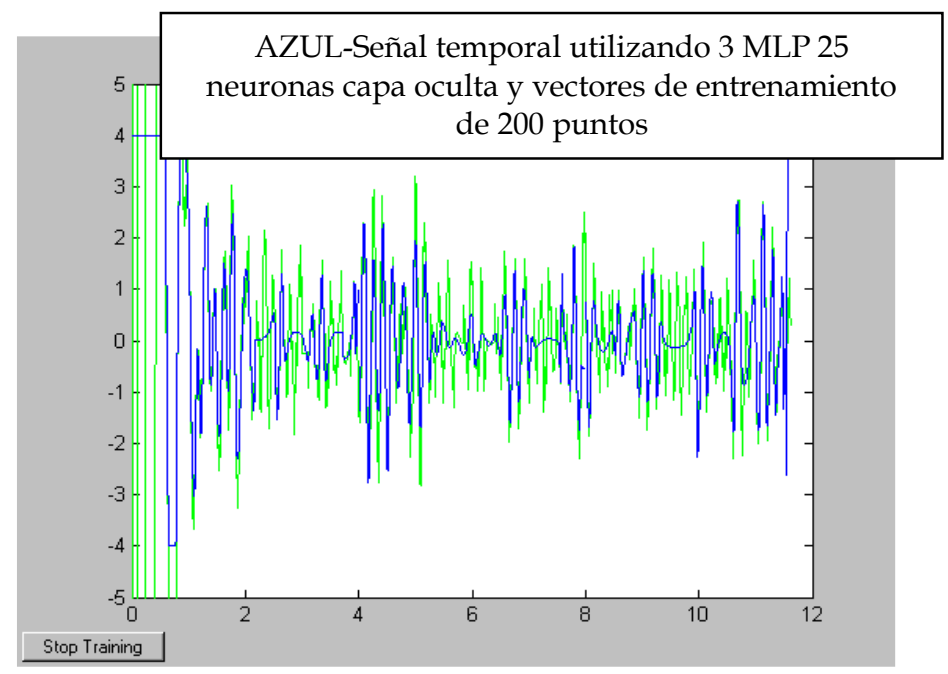

Figura 5.3: Resultados del modelado del temblor con MLP.

Comparación entre el resultado obtenido al restar la salida de las redes a la señal inicial y el resultado real una vez restado la salida del filtro, a la señal inicial.

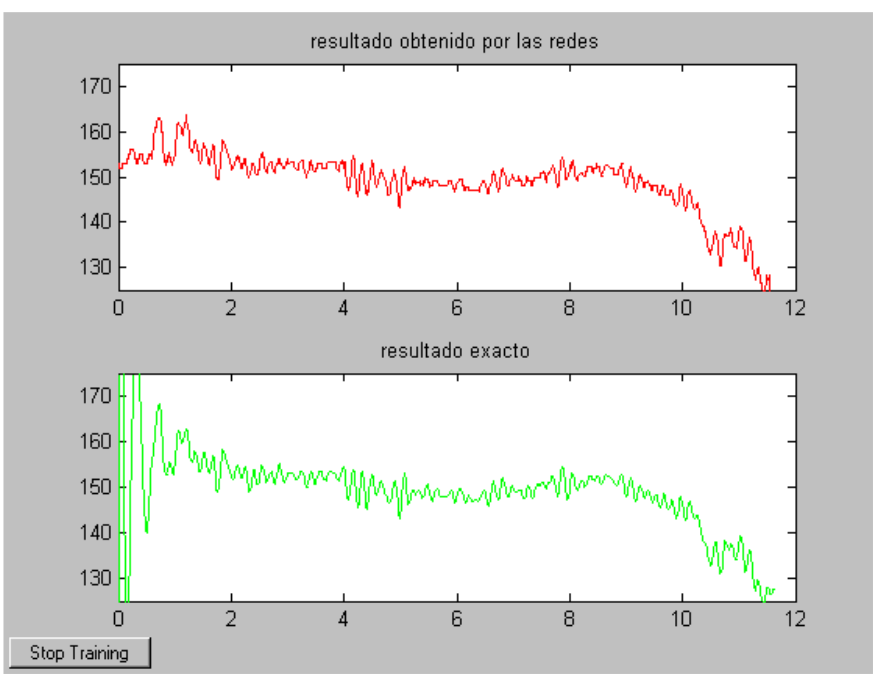

Figura 5.4: Señales filtradas. Sup.: utilizando las MLPs. Inf.: utilizando un filtro paso bajo. 


\section{Caso 2:}

- 50 vectores de entrenamiento.

- 100 épocas por vector.

- 50 neuronas en la capa oculta.

- 200 puntos por vector.

\section{Salida de la red:}

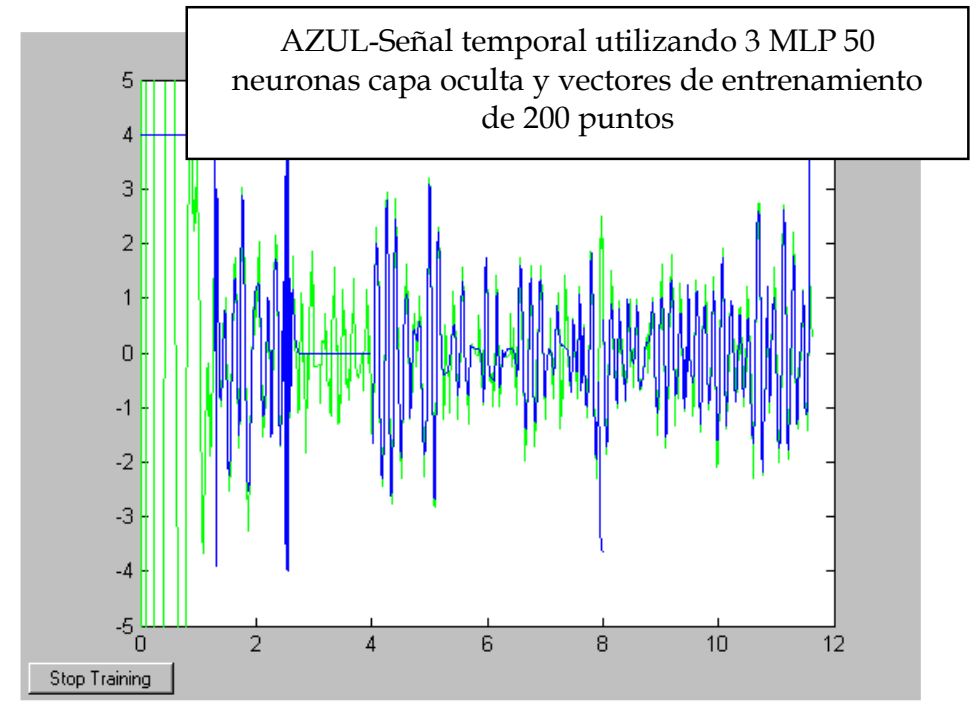

Figura 5.5: Resultados del modelado del temblor con MLP.

Comparación entre el resultado obtenido al restar la salida de las redes a la señal inicial y el resultado real una vez restado la salida del filtro a la señal inicial.

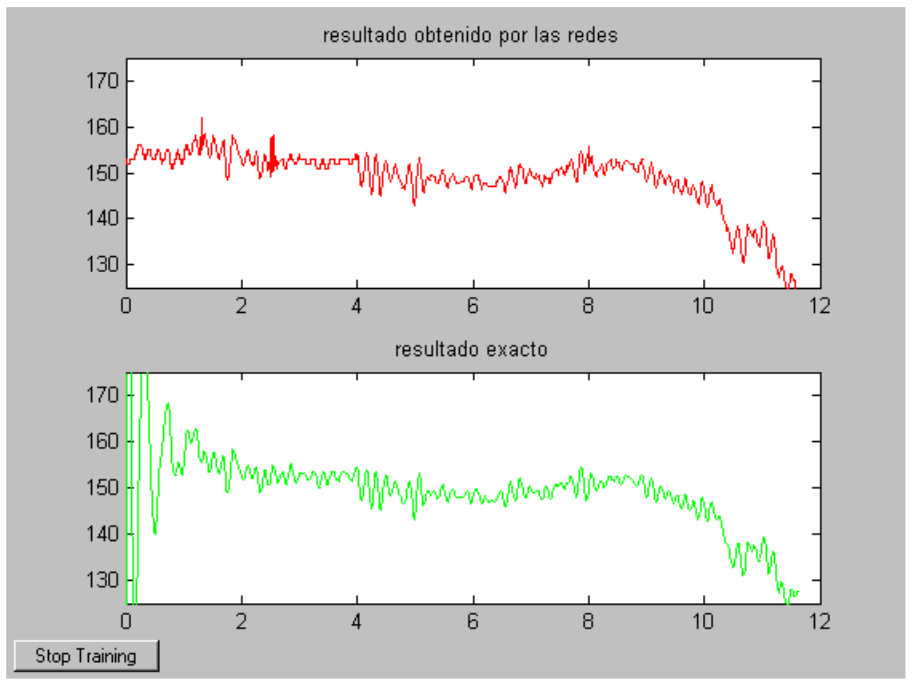

Figura 5.6: Señales filtradas. Sup.: utilizando las MLPs. Inf.: utilizando un filtro paso bajo. 


\section{Caso 3:}

- 50 vectores de entrenamiento.

- 100 épocas por vector.

- 25 neuronas en la capa oculta.

- 200 puntos por vector.

\section{Salida de las redes:}

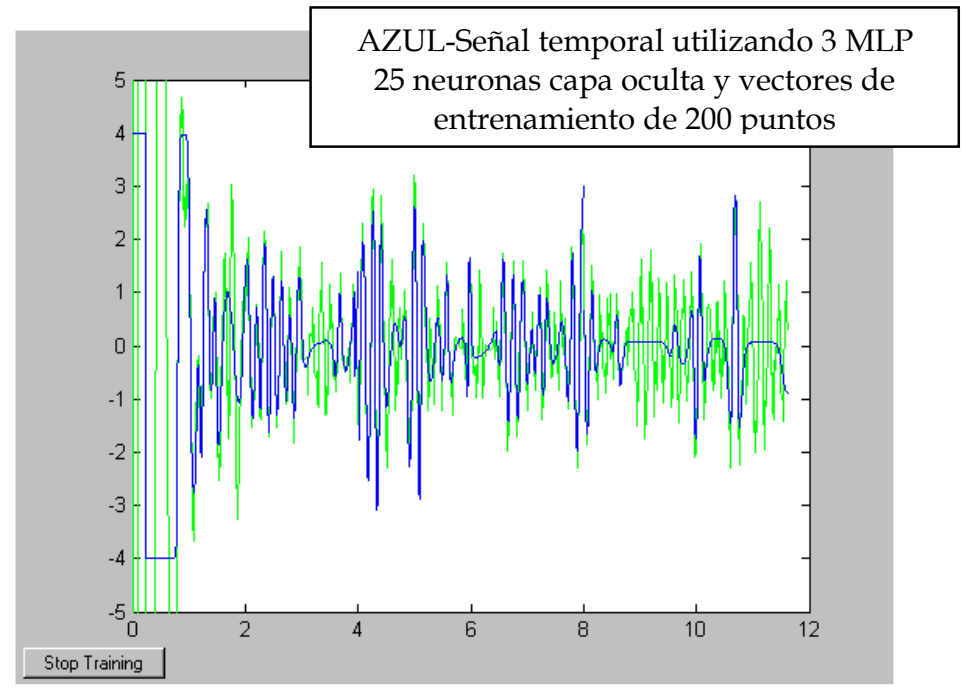

Figura 5.7: Resultados del modelado del temblor con MLP.

Comparación entre el resultado obtenido al restar la salida de las redes a la señal inicial y el resultado real una vez restado la salida del filtro a la señal inicial.

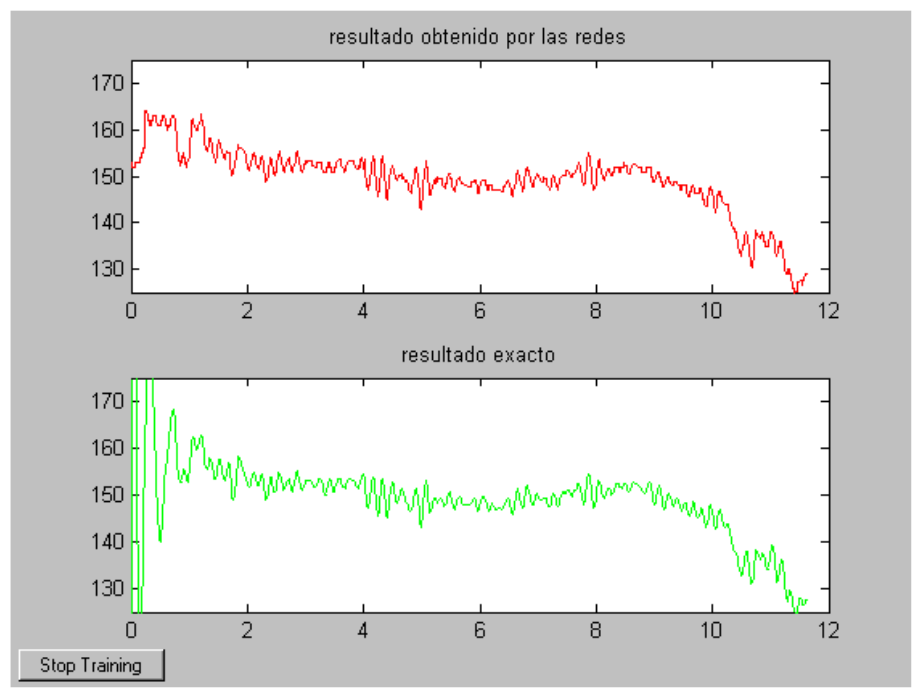

Figura 5.8: Señales filtradas. Sup.: utilizando las MLPs. Inf.: utilizando un filtro paso bajo. 


\section{Caso 4:}

- 25 vectores de entrenamiento.

- 100 épocas por vector.

- 50 neuronas en la capa oculta.

- 200 puntos por vector.

Salida de las redes:

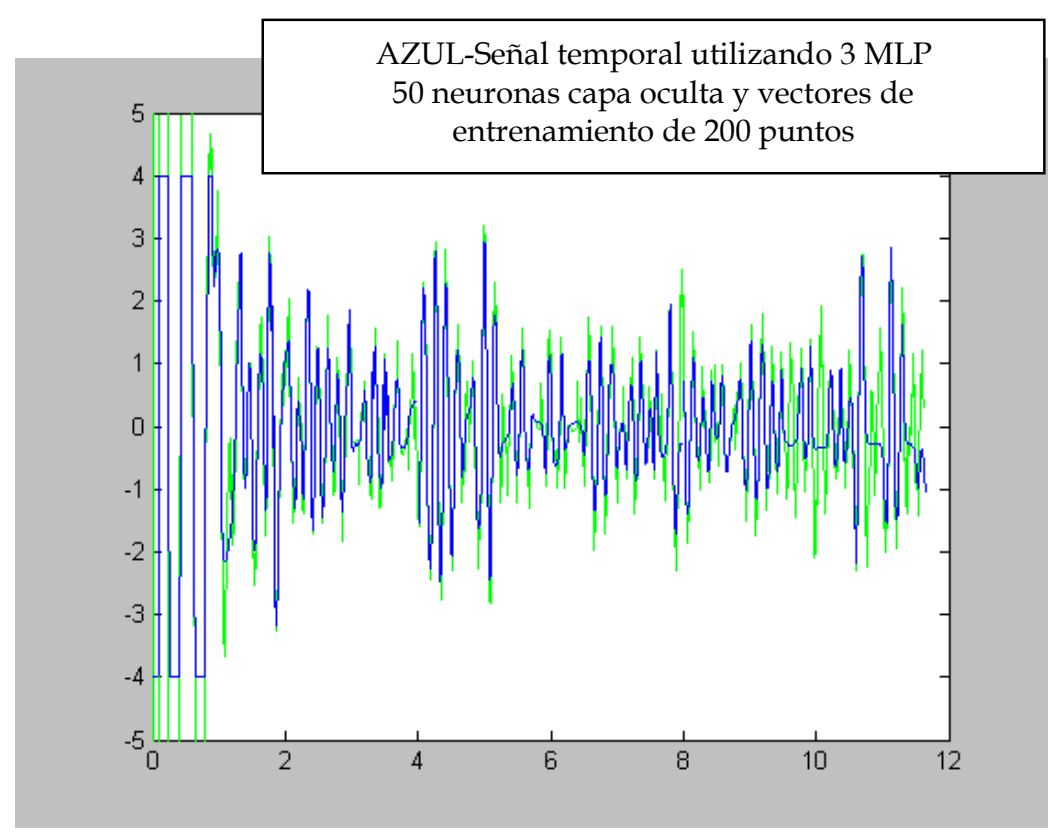

Figura 5.9: Resultados del modelado del temblor con MLP.

Comparación entre el resultado obtenido al restar la salida de las redes a la señal inicial y el resultado real una vez restado la salida del filtro a la señal inicial. 


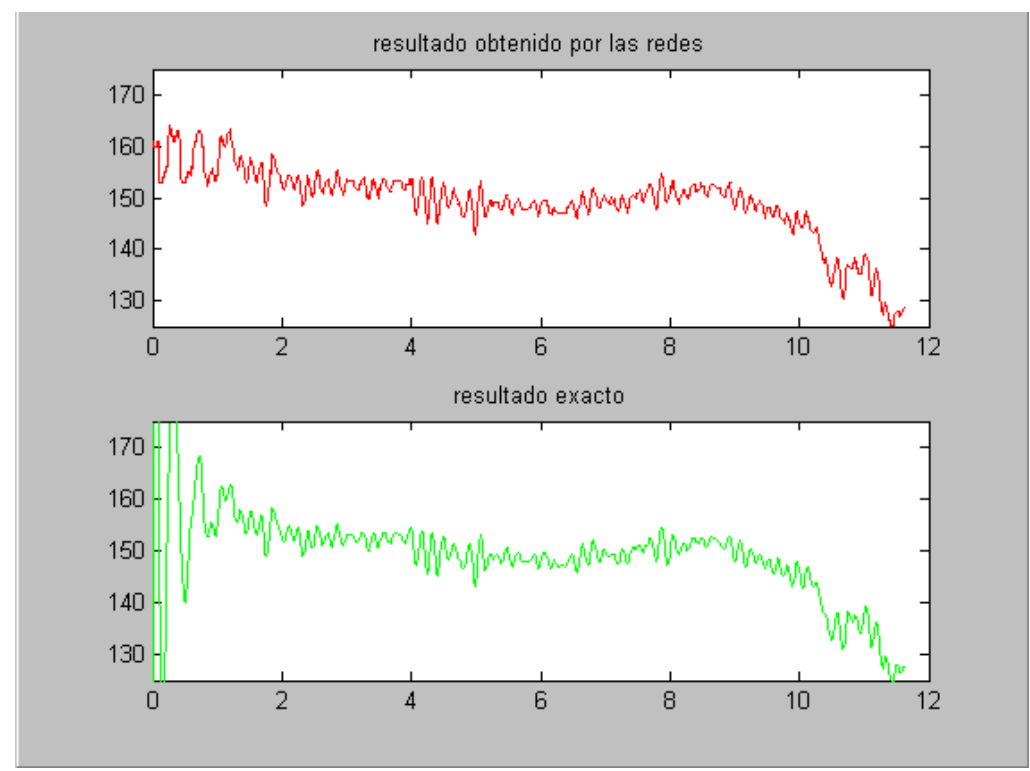

Figura 5.10: Señales filtradas. Sup.: utilizando las MLPs. Inf.: utilizando un filtro paso bajo.

\section{Caso 5:}

- 25 vectores de entrenamiento.

- 100 épocas por vector.

- 50 neuronas en la capa oculta.

- 800 puntos por vector.

\section{Salida de las redes:}

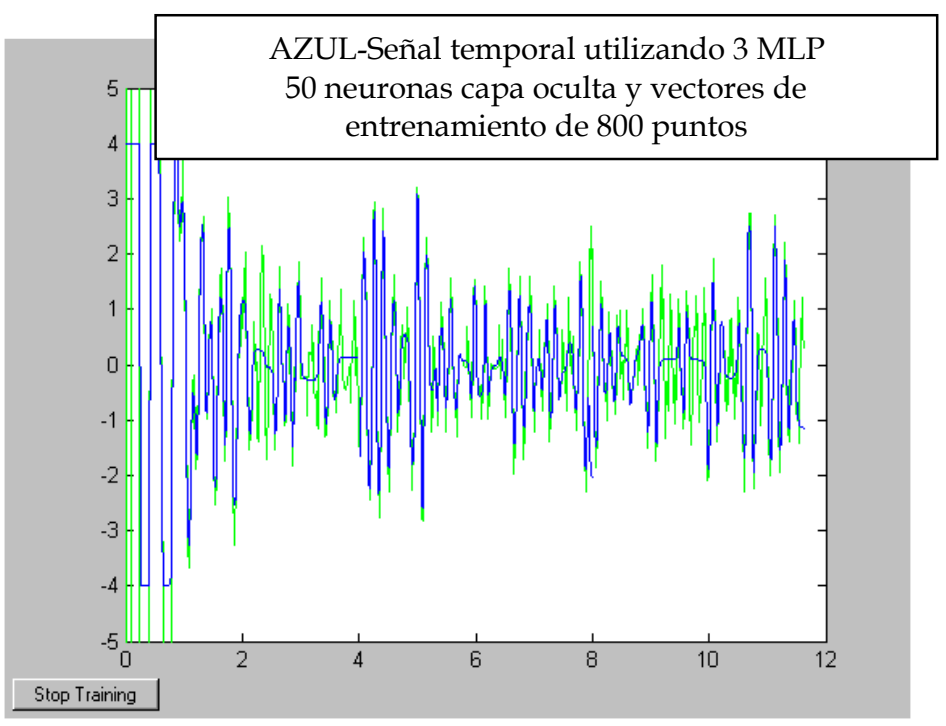

Figura 5.11: Resultados del modelado del temblor con MLP. 
Comparación entre el resultado obtenido al restar la salida de las redes a la señal inicial y el resultado real una vez restado la salida del filtro a la señal inicial.

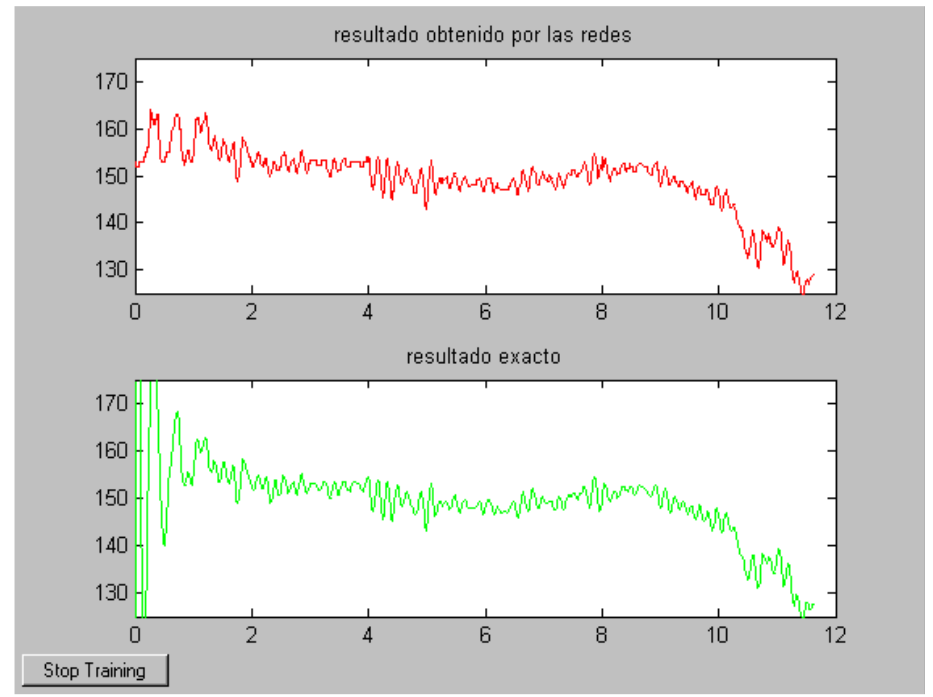

Figura 5.12: Señales filtradas. Sup.: utilizando las MLPs. Inf.: utilizando un filtro paso bajo.

\section{Caso 6:}

- 25 vectores de entrenamiento.

- 100 épocas por vector.

- 25 neuronas en la capa oculta.

- 800 puntos por vector.

\section{Salida de las redes.}

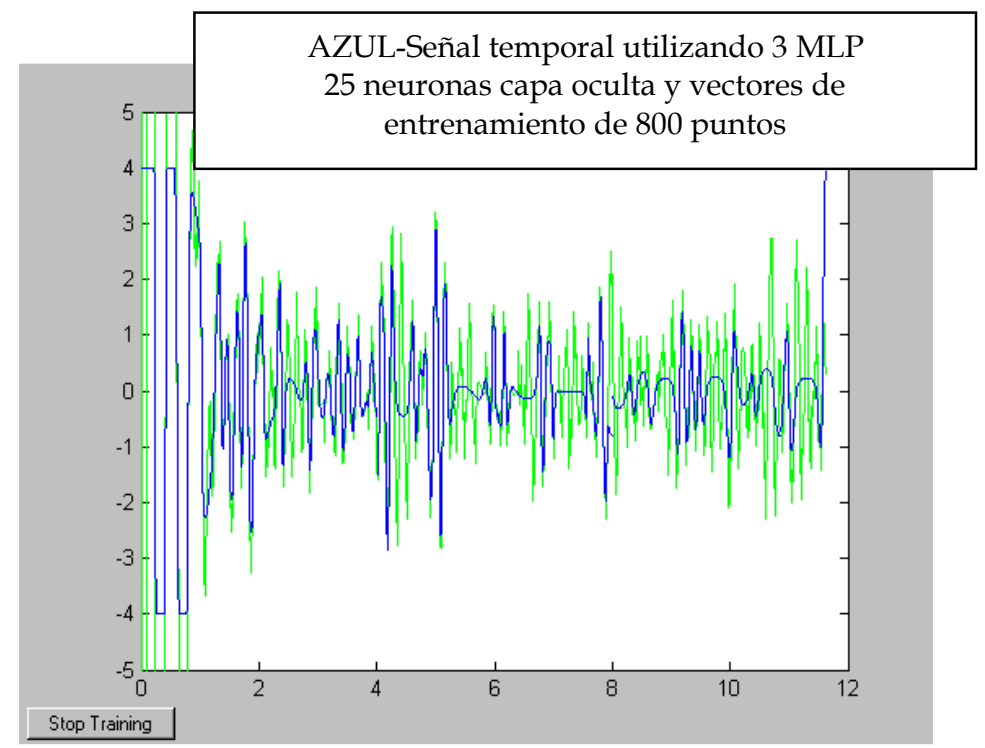

Figura 5.13: Resultados del modelado del temblor con MLP. 
Comparación entre el resultado obtenido al restar la salida de las redes a la señal inicial y el resultado real una vez restado la salida del filtro a la señal inicial.

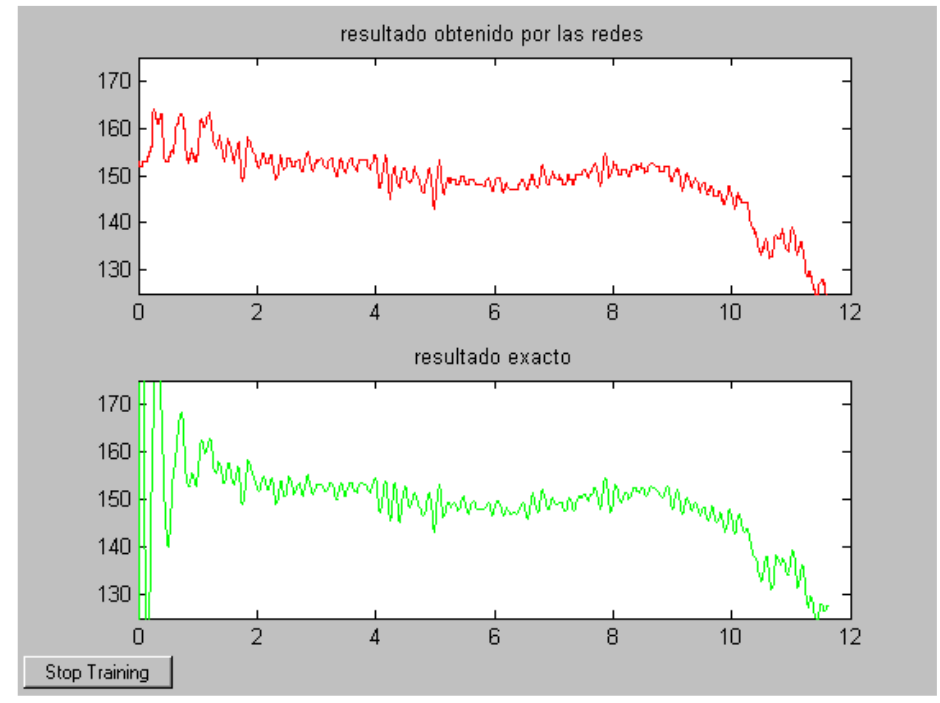

Figura 5.14: Señales filtradas. Sup.: utilizando las MLPs. Inf.: utilizando un filtro paso bajo.

Los mejores resultados se han obtenido con las siguientes condiciones (caso 4):

- 3 redes de entrenamiento.

- 25 vectores de entrenamiento.

- 50 neuronas capa oculta.

- 200 puntos por cada vector.

Analizando los datos obtenidos, la primera conclusión es que utilizando un número mayor de MLPs quizás los resultados mejorarían. También es importante hacer notar que no se observa desfase entre las señales tras la actuación de la red por lo que estaría garantizado su uso en tiempo real si los resultados se considerasen suficientemente aceptables. El principal problema que nos encontramos es la dependencia temporal y de cómo afectará esta circunstancia desde el punto de vista de que las características del temblor cambien sustancialmente. Por dicho motivo, este estudio-ensayo no puede considerarse como definitivo.

Como alternativa, para buscar una vía que proporcione resultados aceptables se va a proceder al estudio en el dominio frecuencial.

\subsubsection{Procedimiento.}

$\mathrm{Al}$ analizar las pruebas en el dominio frecuencial se puede observar que las respuestas no siguen un patrón constante. En algunos casos existe una frecuencia claramente predominante y en otros aparecen picos consecutivos que entorpecen la decisión de que frecuencia elegir como dominante. Esto dificulta en cierta medida el filtrado. Siempre se puede recurrir a filtros rechaza-banda, pero reducir o acotar 
la banda siempre resulta más eficiente para conseguir un mejor resultado, pues los filtros más selectivos permiten reducir el orden y con ello un factor fundamental: el retardo.
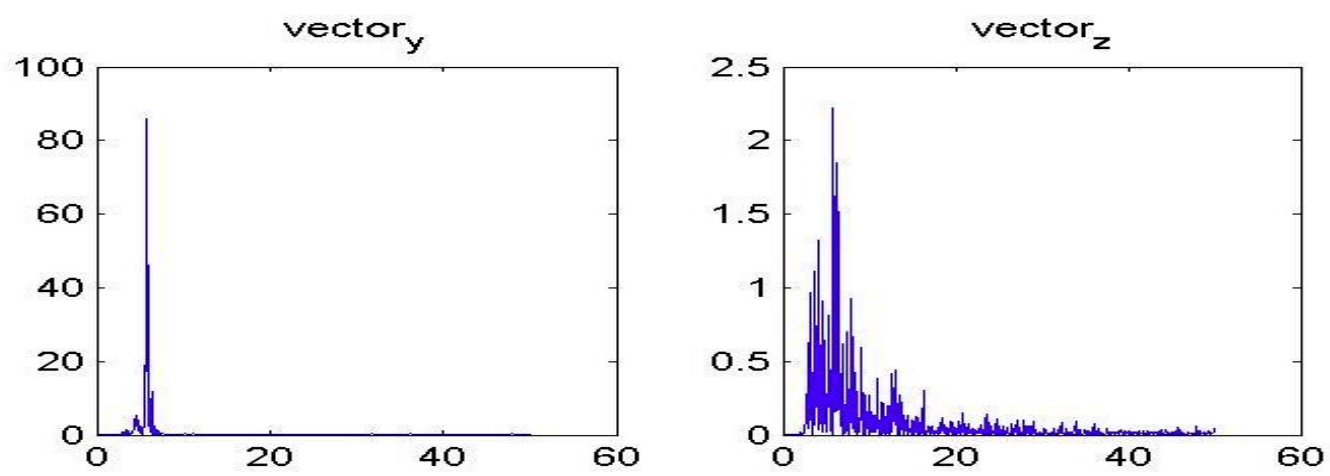

Figura 5.15: Diferenciación entre una señal "pico" (izq.) y una señal "meseta" (der.)

Viendo que introducir la red directamente en línea para filtrar en el dominio temporal no es una solución admisible, se planteó una variante en el dominio frecuencial: utilizar la red para seleccionar la selectividad del filtro. En este caso la red diferenciaría entre las diferentes respuestas frecuenciales de los pacientes y daría como salida la distinción entre señales pico y señales meseta. Siendo las primeras aquellas que tienen un armónico claramente diferenciable por su amplitud y las segundas las que se dispone de un conjunto de ellos próximos.

Una vez la red haya clasificado la señal se procede a tomar el valor de los parámetros que en cada caso sean apropiados: la frecuencia de corte, el ancho de banda y el tipo de filtro.

Al igual que en el dominio temporal, se comienza filtrando las series facilitadas por el sistema DIMETER para conservar la parte de la señal afectada por el temblor. El filtro que se utilizó mantuvo las características del que se usó en el estudio anterior.

A continuación, se han generado unos archivos con los valores del espectro de potencia para unas frecuencias comprendidas entre 0 y $25 \mathrm{~Hz}$. de las diferentes señales clasificadas entre vectores pico y vectores meseta. El número de puntos que se han tomado entre estas frecuencias han sido 256 para cada vector.

La dimensión de la capa de entrada a la red está determinada por el número de puntos de los vectores (256 puntos). La dimensión de la capa de salida queda determinada por el número de patrones que se quieren diferenciar. Por lo tanto, el patrón 1 será señales pico y el patrón 2 será señales meseta Cada patrón está representado por un vector de salida, este vector de dimensión 2, tendrá todas sus componentes con valor cero salvo la componente correspondiente al patrón que valdrá 1. Así para el caso del patrón 1, el vector de salida asignado será [1 0] y para el patrón 2 [0 1]. 
Como en el caso anterior se partirá de una red inicial con una configuración tipo y se irán comprobando resultados a medida que se vayan variando los valores de partida.

La dimensión de la capa oculta se ajustará experimentalmente para obtener la mejor habilidad de generalización de la red, esta es la propiedad más eficiente del reconocimiento de patrones. Un número demasiado grande de neuronas en la capa oculta provoca una mala generalización, mientras que un número demasiado bajo hace que el proceso de aprendizaje sea ineficiente y provoque un nivel de error muy alto. Por lo tanto, el número de neuronas en la capa oculta debe de ser el más bajo pero suficiente para reducir la función de error al nivel mínimo.

La función de activación elegida para las neuronas de la capa oculta, así como las de la capa de salida, ha sido la función sigmoidea del tipo tangente hiperbólica (tansig).

El número de vectores con los que se ha podido trabajar asciende a 500, clasificados en 300 vectores pico y 200 vectores meseta. En el entrenamiento se han utilizado 300 vectores, 175 pico y 125 meseta dejando 200 en la simulación.

\subsubsection{Resultados.}

Se utilizó para el entrenamiento el mismo algoritmo que en el estudio anterior: backprogation o de propagación hacia atrás. Los vectores de entrada se han escalado utilizando el método de la media nula y la desviación unidad para mejorar el aprendizaje y se ha reducido el vector de entrada al estar sus componentes altamente relacionadas, mediante un análisis de las componentes principales.

Se han realizado 10 pruebas para cada una de las redes creadas y se han entrenado variando el número de épocas de entrenamiento, en el primer caso se han utilizado 200 épocas y en el segundo 2000 épocas para cada vector de entrenamiento, con lo que los resultados se muestran a continuación.

\section{Caso 1:}

Utilizando 200 épocas por vector el error medio que se comete está en torno a un 39\%, un valor elevado. Siguiendo el desarrollo de la gráfica se observa como el error oscila entre diferentes valores hasta llegar al correspondiente para 10 neuronas en la capa oculta, donde comienza un descenso constante, tal y como puede observarse en la Figura 5.16.

Las redes con menos de 10 neuronas en la capa oculta no han llegado a converger y por lo tanto no son capaces de generalizar de forma adecuada. 


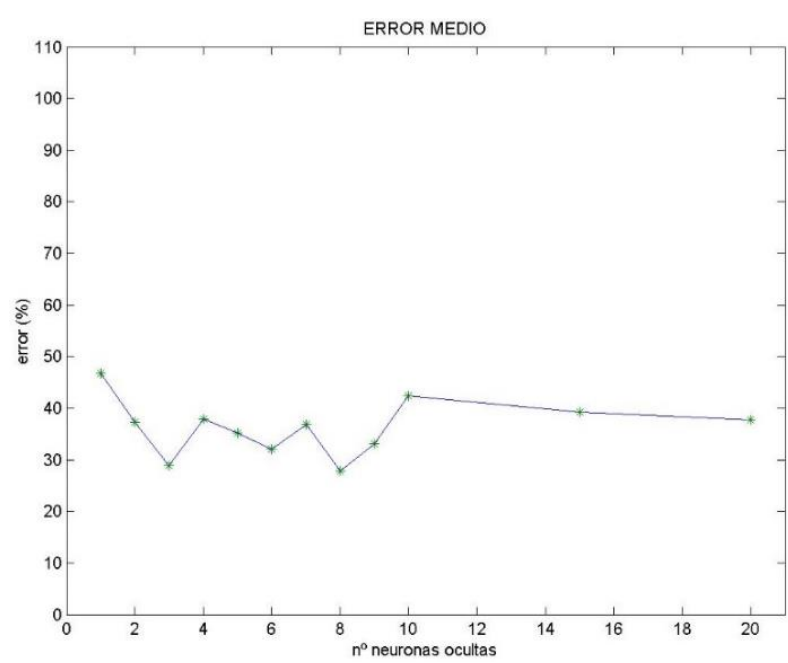

Figura 5.16: Error medio de clasificación total (señales "pico" y "meseta").

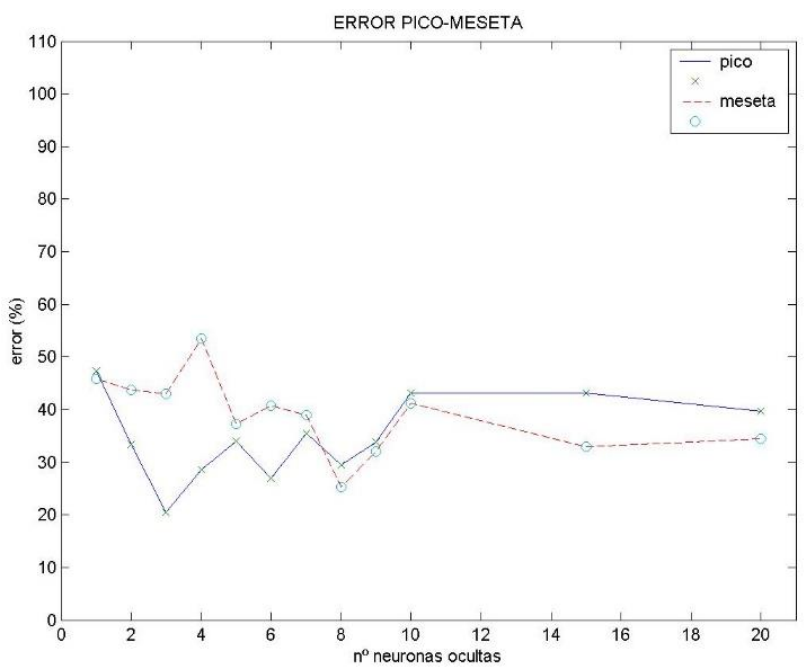

Figura 5.17: Error entre clases (señales "pico" y "meseta").

\section{Caso 2:}

Utilizando 2000 épocas por vector, el error medio que se comete ha descendido a un $34 \%$ pero se obtiene el mínimo del 17\% para redes con 20 neuronas en la capa oculta. Siguiendo el desarrollo de la gráfica se observa como el error que se comete ha descendido a partir de 6 neuronas en la capa oculta hasta alcanzar el mínimo en 20 neuronas. 


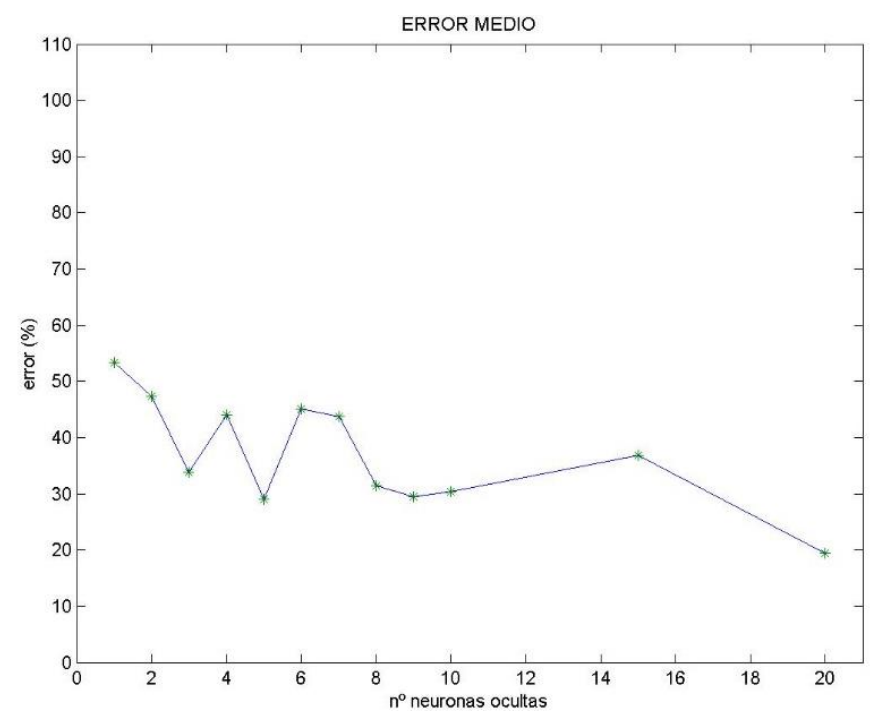

Figura 5.18: Error medio de clasificación total (señales "pico" y "meseta").

La siguiente grafica muestra el error cometido en las dos clases que se quieren diferenciar.

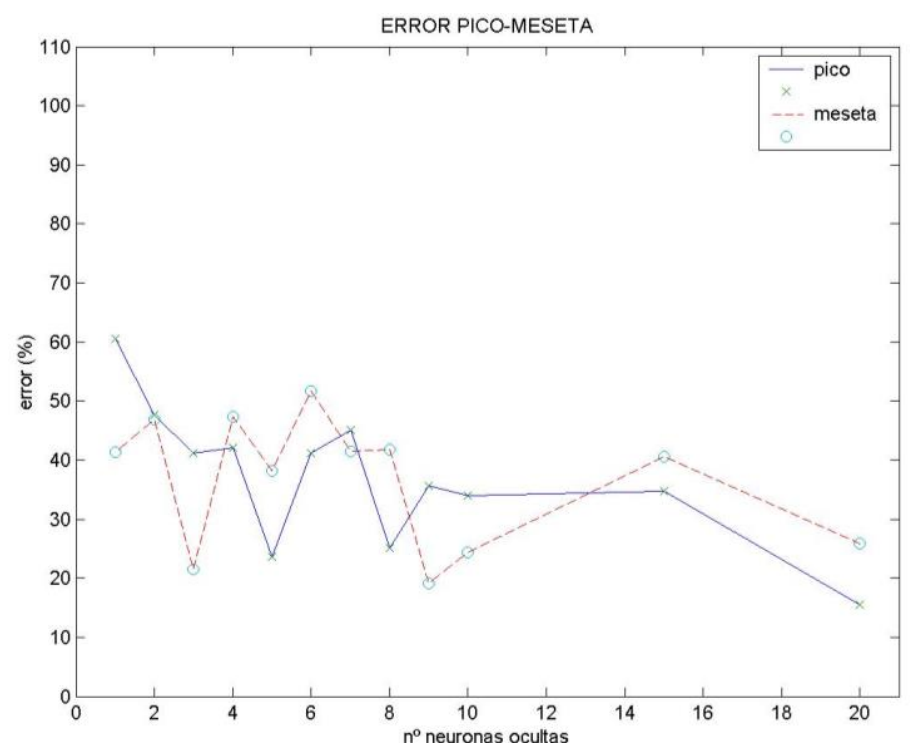

Figura 5.19: Error entre clases (señales "pico" y "meseta").

De acuerdo con los resultados, se observa como para redes con menos de 10 neuronas en la capa oculta se produce sobreentrenamiento al entrenar con 2000 épocas, alcanzándose errores más bajos empleando 200 épocas. Pero con redes con un mayor número de neuronas ocultas, el error disminuye al entrenar la red con 2000 épocas. Por lo tanto, ya que los resultados obtenidos con 20 neuronas y 2000 épocas son los mejores, se considera como una opción acertada, en este caso, aumentar el número de épocas de entrenamiento y aumentar el número de neuronas en la capa oculta. 
A continuación, se realiza una última prueba entrenando redes de 15, 20, 25, 30 y 50 neuronas ocultas para comprobar hasta qué punto desciende el error. Las épocas de entrenamiento se ajustan en 2000.

Los resultados del error medio se representan en la Figura 5.20.

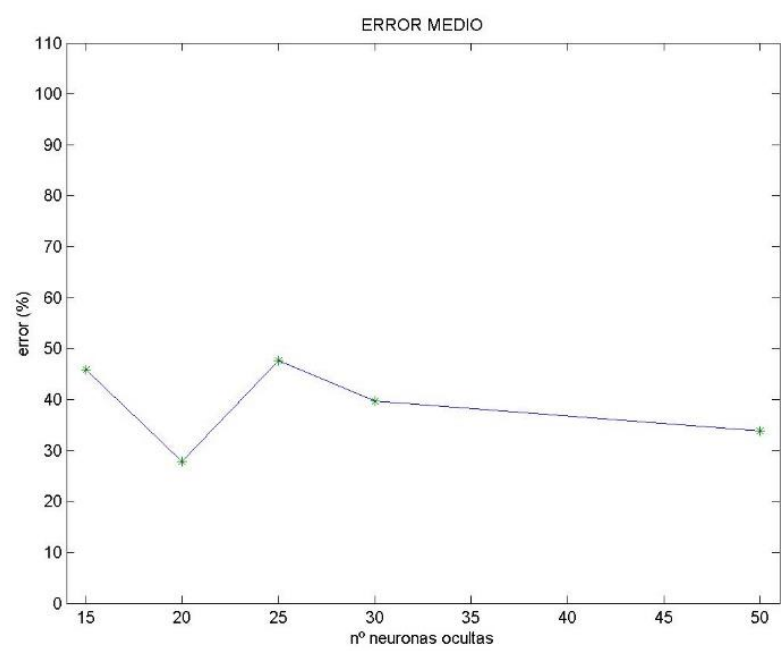

Figura 5.20: Error medio de clasificación total (señales "pico" y "meseta").

La figura muestra como al aumentar el número de neuronas disminuye el error, pero se produce muy lentamente permaneciendo alrededor del $30 \%$. Solo en el caso de redes con 20 neuronas en la capa oculta parece de nuevo estar el error más próximo al $20 \%$.

En la gráfica del error cometido en cada patrón, no se observan diferencias significativas, manteniéndose muy cerca los dos errores y muy similares al error medio.

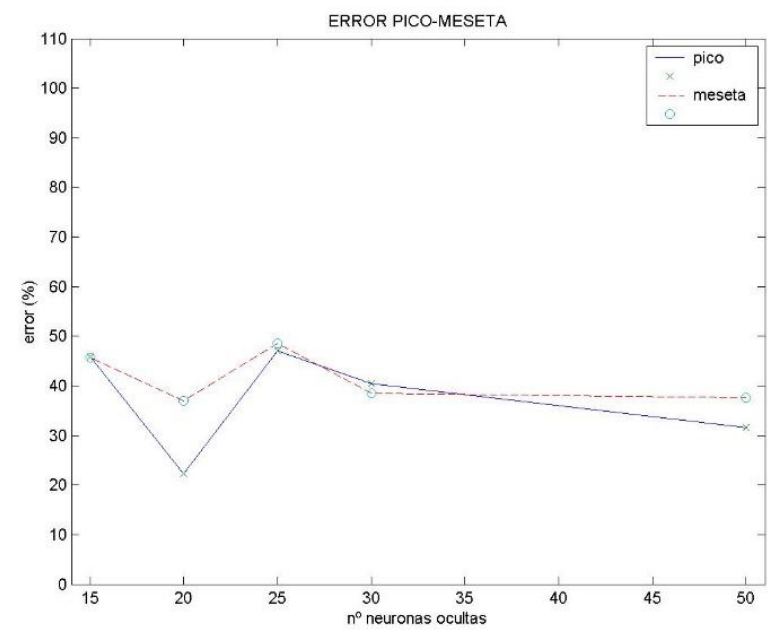

Figura 5.21: Error entre clases (señales "pico" y "meseta"). 
En base a los resultados obtenidos se considera como la red más apropiada la formada por 20 neuronas en la capa oculta con función de activación "tansig". El error alcanzado con estos parámetros es de un $20 \%$.

En cualquier caso, los resultados no fueron todo lo satisfactorios que esperábamos por lo que se decidió tomar otra dirección dejando a un lado los MLP's y probar con otras técnicas.

\subsection{Filtrado empleando otras técnicas.}

Además de los filtros digitales clásicos, como el paso bajo o el rechazabanda, se abordaron más alternativas, aprovechando el extenso banco de datos proporcionado por el DIMITER. Los filtros clásicos, debido a la fase que introduce la función de transferencia del filtro, provoca que existan retardos muy significativos cuando el objetivo es obtener una salida en tiempo real. Esta fue la motivación de buscar otras alternativas que evitasen estos inconvenientes.

A continuación se mencionan los que mejores resultados proporcionaron, teniendo como objetivo filtrar tanto los patrones correspondientes a enfermos de Párkinson como de temblor esencial.

\subsubsection{Filtro FLC.}

Consiste en modelizar el temblor como una serie de Fourier truncada y tratar de minimizar el error (mediante mínimos cuadrados) entre el modelo, y la señal de movimiento captada. De este modo, una vez identificado el temblor en línea, este puede ser extraído del movimiento. Este tipo de filtro presenta un buen comportamiento para el caso de temblores de pequeña amplitud y frecuencias altas.

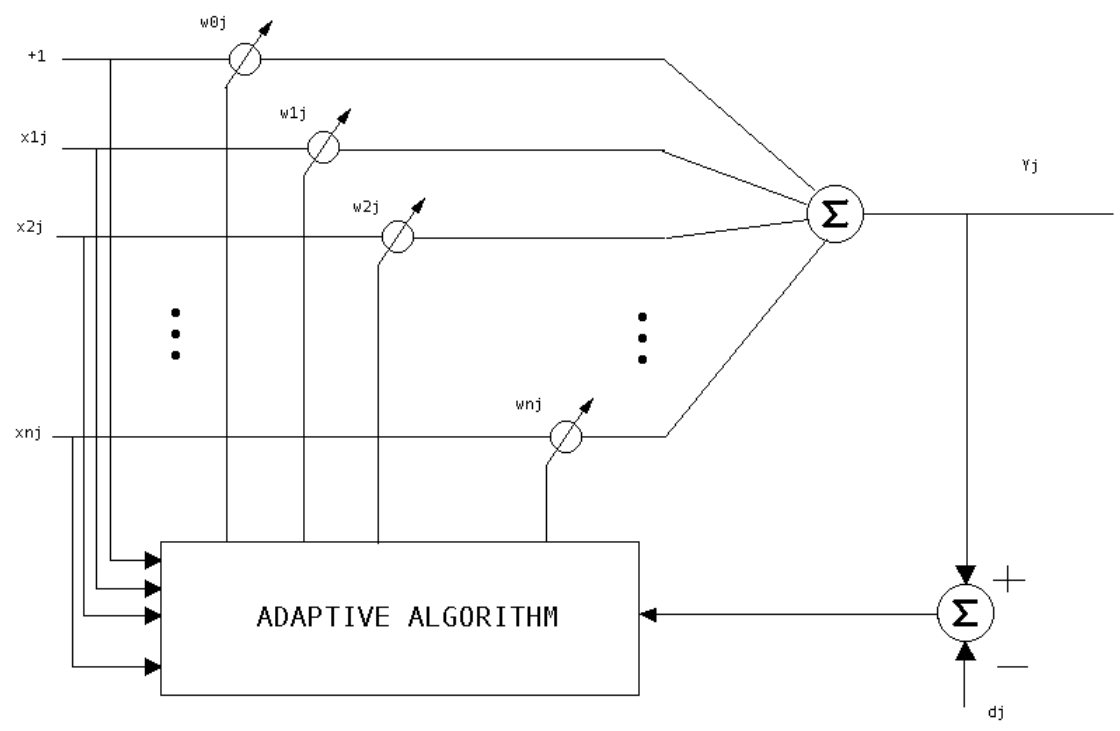

Figura 5.22: Algoritmo Filtro FLC 


\subsubsection{Filtro WFLC.}

Se diferencia del anterior en que el modelo del temblor se identifica tanto en cuanto a las amplitudes de cada componente senoidal, como en cuanto a la frecuencia de las mismas. Se consigue así la compensación de los efectos de perturbaciones aproximadamente periódicas de frecuencia y amplitud desconocidas.

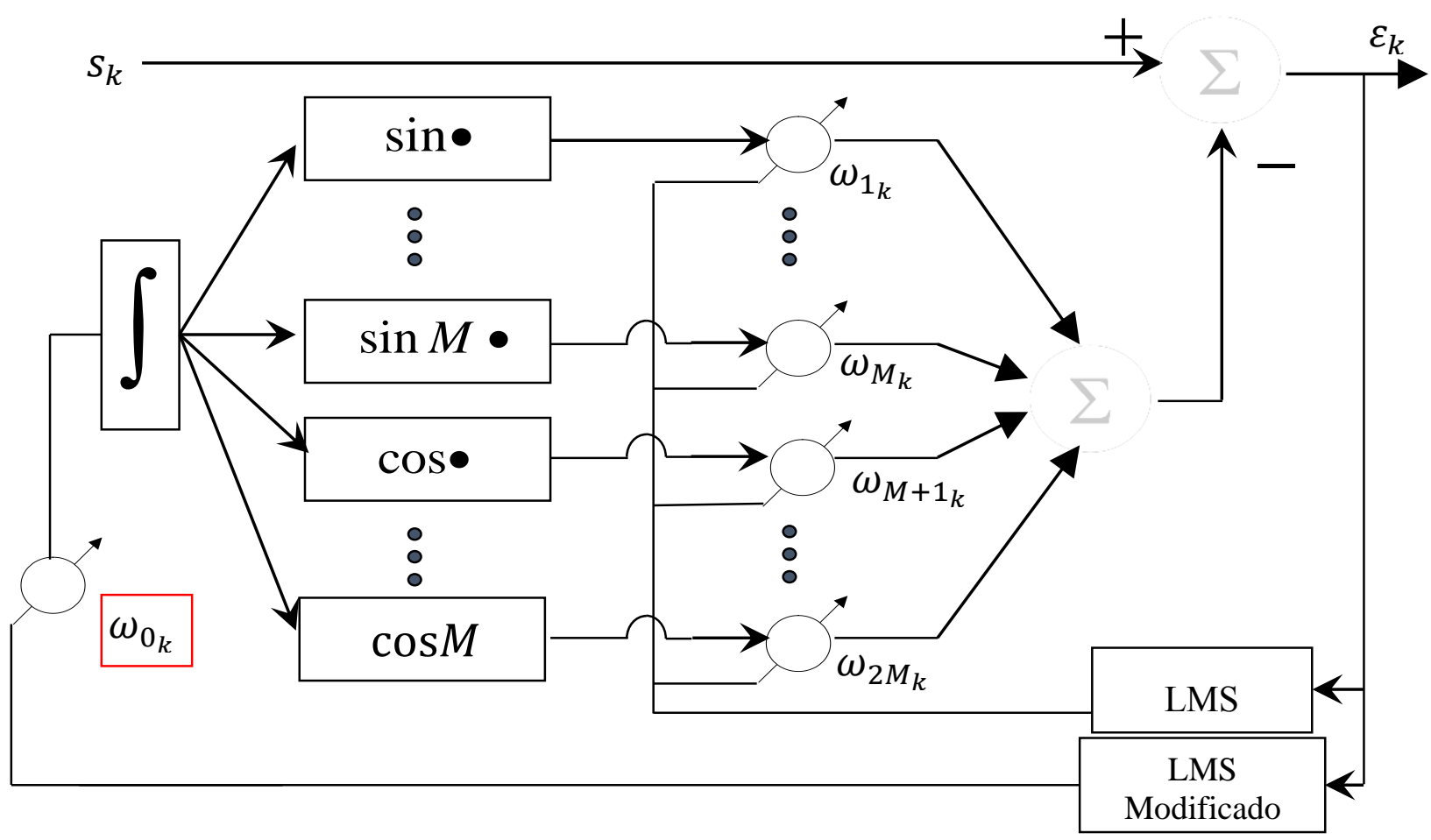

Figura 5.23: Algoritmo filtro WFLC

\subsubsection{Filtro LC.}

Variante de los anteriores, consigue resultados muy satisfactorios, presentando un retraso mínimo y una atenuación importante (comparables a los obtenidos con los paso bajo). Su aplicación es en particular recomendada en los temblores de tipo esencial.

El Linear Combiner (LC). está basado en la adaptibilidad de un único peso $w$ actuando sobre la unidad (es decir $x_{k}=1$ siempre), que se actualiza según la misma técnica: de forma tal que el error en media cuadrática entre la señal y el peso $w$ sea mínimo, usando también la aproximación de Widrow-Hoff del algoritmo LMS. 


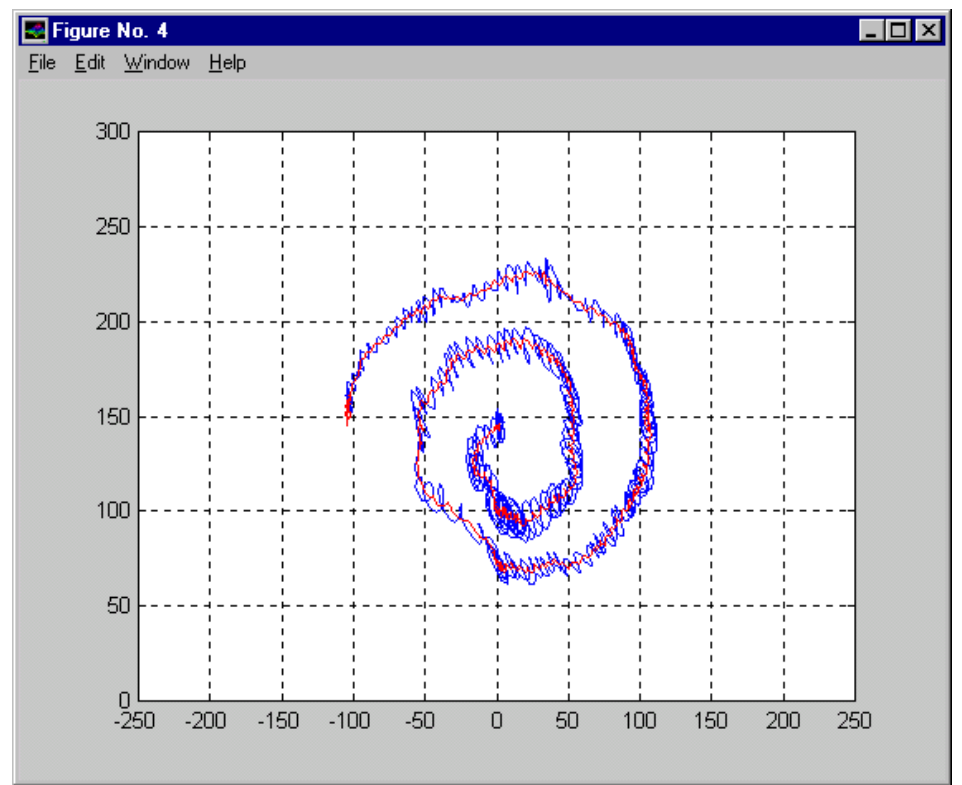

Figura 5.24: Captura de la salida del filtro LC sobre una muestra tomada a un paciente de Parkinson. La línea roja es la salida y la azul la original

Lo que se toma como salida del algoritmo no es la resta entre lo estimado con el peso $w$ y la señal principal, sino únicamente lo estimado con el peso $w$. De esta forma se tiene un filtro que se comporta como paso-bajo. Esto se puede ver intuitivamente de la siguiente forma. Al intentar que el error en media cuadrática sea mínimo, el LMS hace que la señal dada por $w$ se intente aproximar lo máximo posible a la de entrada. Ahora bien, para conseguir esa aproximación hay muy poca libertad (un solo peso) por lo que no es capaz de seguir exactamente a la señal principal. Obviamente como las perturbaciones del temblor son mucho más bruscas que lo que puede ser un movimiento voluntario, el filtro elimina esas perturbaciones, ya que son aquellas a las que no es capaz de adaptar la señal de estimación $w$.

Los resultados de este filtro son bastante interesantes, ya que se consigue unos resultados buenos sin introducir a penas retardo.

Para poder evaluar la fidelidad y el éxito de los filtros se estudió la manera de implementar los mismos en alguna tarea cotidiana, diaria, y someterlo a la prueba de los potenciales destinatarios: los enfermos con patologías asociadas al temblor. Bajo el marco del acuerdo ACORTE, también con el CEAPAT se propuso desarrollar un sistema que fuese capaz de facilitar el acceso al ordenador a aquellas personas que sufren problemas discapacitantes por el temblor. La principal barrera que sufren estos enfermos cuando se sientan delante de un ordenador personal, es manejar el ratón de manera eficaz. Debido al temblor, las personas que consiguen mantener el ratón sobre la alfombrilla, después se encuentran con el problema de que es completamente inutilizable ya que las oscilaciones de su extremidad no le permiten conseguir su uso de manera eficaz. Para evitar que en muchos casos el ratón ni siquiera apoyara en la mesa, se propuso la utilización de un joystick como elemento de entrada. 
Para llevar a la práctica las técnicas de filtrado antes expuestas caben dos alternativas. La primera de ellas desarrollar los filtros mediante una aplicación que corra dentro del propio sistema operativo del ordenador. De esta forma, sería el propio ordenador el que filtraría la señal introducida, actuando sobre los movimientos del ratón para todas las aplicaciones instaladas en el ordenador. Esta alternativa, adolece de falta de flexibilidad por dos motivos:

- En primer lugar, debe particularizarse en gran medida de acuerdo al sistema utilizado (tipo de ordenador y sistema operativo empleado). Por otra parte, su validez se ve sujeta a los previsiblemente frecuentes cambios o actualizaciones en los sistemas operativos de los ordenadores personales. Sin embargo como ventaja se puede citar el bajo coste de su futura distribución (que puede ser nulo) pues no precisa de equipamiento adicional ninguno.

- Como segunda alternativa, se barajó el desarrollo de una interfaz basada en un hardware específico, que intercalado entre el periférico de entrada y el puerto de conexión del ordenador realice las funciones de captura de datos y filtrado, resultando así un funcionamiento totalmente transparente para el ordenador y universal para al usuario. De este modo su compatibilidad está garantizada para cualquier aplicación y sistema operativo que funcione con un ratón conectado a un puerto convencional. El coste en este caso, vendrá determinado por la solución hardware adoptada, debido a lo cual es preciso desarrollar éste con las premisas de coste posibilite la fácil adquisición o distribución posterior al colectivo de usuarios.

Finalmente para el diseño se optó por la segunda solución (Figura 5.25 y Figura 5.26), utilizando un microcontrolador sobre el que se desarrollaron tanto los programas de captura y análisis frecuencial necesarios para identificar en línea las características del temblor, como los filtros citados. Asimismo se implementaron los programas específicos para realizar un preajuste (set-up) de los filtros.

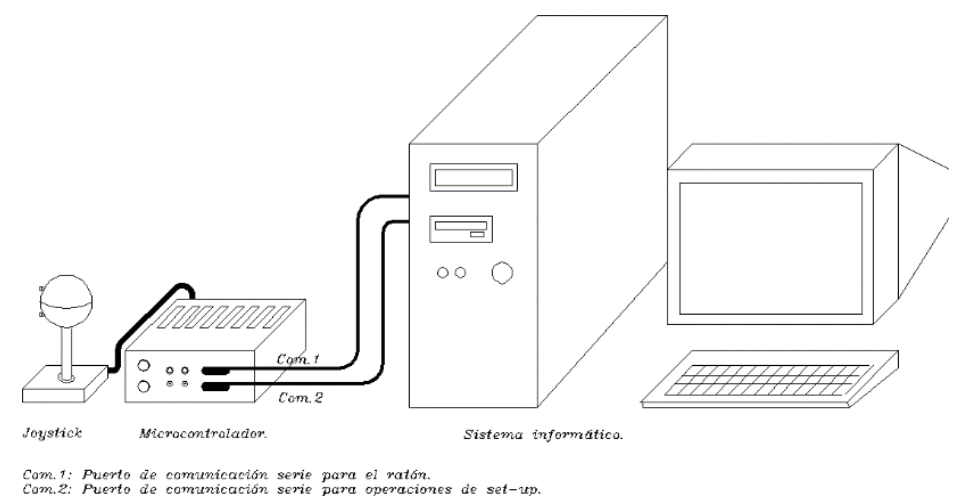

Figura 5.25: Componentes del sistema ACORTE 


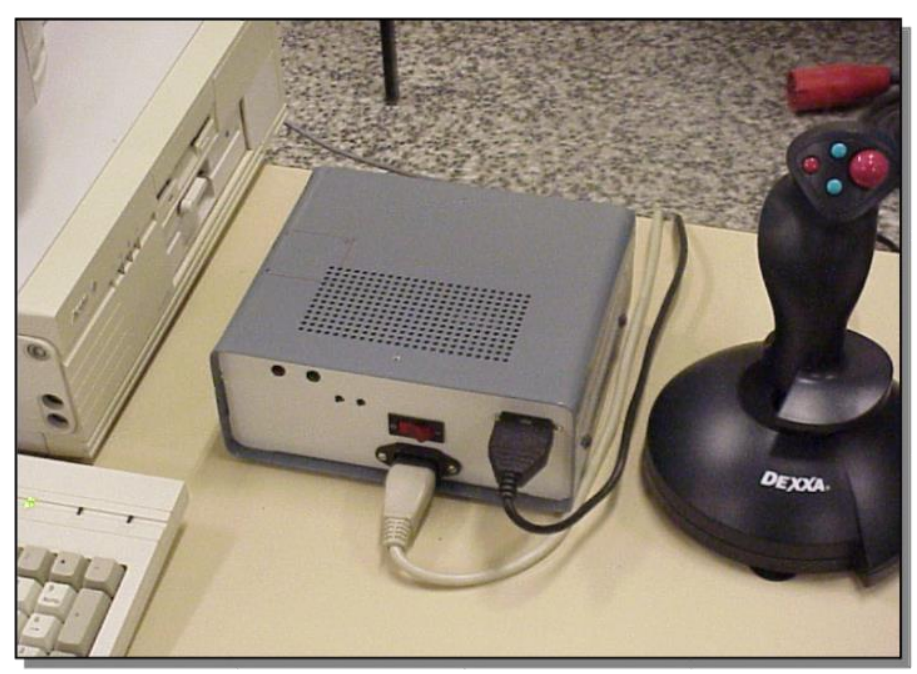

Figura 5.26: Dispositivo de entrada y sistema de filtrado.

\subsection{Procedimiento de uso del sistema ACORTE.}

El modo operativo del sistema comienza por la introducción de una serie de datos que definen el "perfil" del usuario permitiendo de este modo que un mismo sistema pueda ser utilizado por diferentes usuarios. Se utiliza para ello el propio ordenador, que funciona en este caso como interfase con el microcontrolador.

Los datos a introducir incorporan información sobre la patología que origina el temblor y, si se dispone de ella, información suministrada por el sistema DIMETER de medida objetiva del temblor. Esta información hace referencia al tipo de temblor, frecuencia media del mismo, amplitud, efectos de la aplicación de fuerzas, etc. Se permite así al sistema preseleccionar que tipo que filtros son a priori más adecuados para el usuario.

Tras esta primera preselección, se puede pasar a una etapa de ajuste fino automático, en la que mediante una serie de pruebas controladas, el sistema aprende del usuario y realiza una actualización de los parámetros de filtrado o un ajuste fino de los mismos.

Las dos etapas anteriores son optativas no siendo preciso realizarlas más que la primera vez o en el caso de que el usuario haya experimentado cambios significativos en su temblor. Los datos que proporcionan quedan almacenados en la memoria del sistema ACORTE (que puede ser trasladado de un ordenador a otro) como el perfil del usuario.

Una vez seleccionado el perfil de usuario el sistema queda listo para trabajar, utilizándose del mismo modo que un ratón convencional. 


\subsection{Pruebas realizadas.}

Como primera evaluación del sistema, este ha sido utilizado por pacientes de temblor esencial y Parkinson del Hospital de la Princesa y por afiliados a la Asociación de Párkinson de Madrid. El proceso de evaluación ha consistido en 2 tipos de pruebas.

- En la primera se han propuesto una serie de tareas específicas, como la selección de una serie de iconos o el despliegue de menús, controlando el tiempo empleado y la salida del cursor del icono objetivo una vez alcanzado éste. Los resultados de esta primera prueba han servido para validar la preselección de filtros antes descrita en base a características generales de la enfermedad causante del temblor.

- En el segundo grupo de pruebas, cinco afiliados de la Asociación de Parkinson de Madrid sin práctica alguna previa en el uso de un ordenador, han realizado un recorrido preestablecido por una serie de páginas WEB (previamente cargadas en disco para evitar los retrasos propios de Internet) cuantificándose el tiempo empleado en esta tarea así como la valoración subjetiva con y sin el uso del sistema ACORTE. Asimismo han utilizado un programa de dibujo y un procesador de textos.

Previamente se ha permitido a todos los usuarios un periodo de conocimiento general del ordenador, suficiente (al menos de 2 horas) como para que se sintiesen familiarizados con el uso del mismo.

El resultado ha sido que en determinados casos, en los que resultaba imposible la "navegación" por hipervínculos sin el sistema, ésta se ha podido realizar haciendo uso del sistema. En otros casos el ahorro de tiempo ha sido del orden del $30 \%$ y en algunos caso de hasta el $45 \%$.

Se recogen a continuación la descripción y los resultados del análisis de los ensayos realizados con el sistema

\subsubsection{Protocolo de pruebas.}

Para verificar la bondad y comportamiento de los diferentes filtros desarrollados, así como la idoneidad de los tipos en función de las disfunciones o patologías, se han planteado una serie de pruebas basadas en actividades típicas de uso dentro del entorno del PC. Entre las actividades más generales y frecuentes, que pueden afectar a un número mayor de usuarios se han considerado las tareas asociadas al manejo de los clientes de páginas web (internet explorer, netscape, mosaic, etc ...). Puesto que se piensa en que tanto aquellos que se dediquen de forma profesional o personal (búsqueda de información, ocio, etc ...) en labores informáticas tendrán que encontrarse tarde o temprano con el uso o utilización de dichas aplicaciones.

Dada la naturaleza de los usuarios involucrados en las pruebas, se ha intentado simplificar todo lo posible el trasfondo conceptual de las mismas, reduciéndose su 
complejidad al máximo. Del mismo modo, se ha procedido de forma que la simplicidad no llevase consigo una reducción exagerada de la realidad, en el sentido de que las tareas aun siendo simples, se realizan de forma cotidiana cuando se lleva a cabo el uso de las aplicaciones mencionadas anteriormente.

El colectivo en el que se han efectuado las pruebas lo constituye la población de asociados en la Asociación de Parkinson de Madrid. Las características de dicha población son un poco especiales en el sentido de que no está en su mayoría muy familiarizada con el uso del ordenador personal (en parte debido a la edad media de su población). En la práctica ha sido muy difícil encontrar usuarios con edades inferiores a los 55 años, puesto que si bien es verdad que los datos de incidencia y prevalencia denotan edades tempranas de afectación ( $<40$ años) de la enfermedad de Parkinson, no es entonces cuando se dan de alta en las asociaciones o incluso acuden a los facultativos para diagnóstico, sino cuando los síntomas les son realmente limitantes para la vida diaria y necesitan de ayuda terapéutica.

Dentro de dicho colectivo se ha procedido a una meticulosa selección de candidatos. En primer lugar, se han tenido que detectar aquellos que poseían limitaciones por temblor dentro de la patología. Como ya es conocido, la afectación del temblor en los enfermos de Parkinson está en torno al 15\%, de ahí que ni mucho menos se tenga la totalidad de los asociados.

Las pruebas se han realizado en un entorno cordial y afable, intentando en lo posible que el usuario desconozca el carácter de evaluación de las tareas planteadas, de tal forma que para ellos parezca una mera actividad práctica o de diversión después de haber recibido unas etapas de formación sobre el uso de las aplicaciones utilizadas. Con esta dinámica se pretende eliminar las componentes de sesgo debidas a la inquietud o nerviosismo por conseguir un objetivo evaluable.

Todos los usuarios han recibido nociones sobre el funcionamiento y manejo del ordenador ya que en la mayoría de los casos no habían tenido ocasión de usarlo con anterioridad. Del mismo modo, se les ha permitido un tiempo previo de prácticas repartido en varias sesiones para familiarizarse con el uso de las aplicaciones de visualización de páginas web. Dichas sesiones no se han realizado de forma continuada en el mismo día sino repartidas en varios días coincidiendo con aquellas actividades que regularmente vienen efectuando en la asociación, interfiriendo lo menos posible en su horario cotidiano.

\subsubsection{Pruebas sobre uso de un navegador de Internet.}

Para establecer un criterio de evaluación de los diferentes algoritmos de filtrado la metodología ha sido la siguiente:

- Se ha dado a elegir un área de interés dentro de los temas siguientes:

- Prensa de deportes.

- Prensa del corazón. 
- Parajes naturales, lugares típicos de la geografía española.

- Se han preestablecido unas tareas tipo dentro de cada área de interés buscando una homegeneidad en la complicación o dificultad de las mismas, garantizando de esta forma que los resultados obtenidos puedan ser comparables.

- Se ha procedido a una sesión de introducción sobre las posibilidades del ordenador como herramienta de consulta y acceso a la información disponible en la red Internet.

- Dentro de la misma sesión se ha explicado el manejo y funcionamiento del cliente web Internet Explorer, disponible en todos los entornos del sistema operativo Windows.

- Durante dos sesiones posteriores se ha permitido el manejo al libre albedrío de la herramienta en los temas por cada uno elegidos para motivar su interés e incentivarles en el uso. En todo momento han recibido el apoyo y tutorización para cubrir las dudas que pudieran surgir sobre la marcha.

Basándose en el uso intensivo de páginas web se les ha propuesto las siguientes tareas:

- Nivel 1: Desde un punto inicial central de la página se les ha pedido que se aproximen a un hipertexto situado en un extremo e hicieran clic con el botón izquierdo del ratón seleccionando de esta manera la página del subnivel asociada a dicho link.

- Nivel 2: Del mismo modo, y partiendo igualmente de la misma posición inicial, han tenido que dirigirse a un hipertexto situado en un extremo y al igual que en la tarea anterior pulsar el botón izquierdo del ratón, accediendo a la nueva página seleccionada. Una vez en ella, han tenido que dirigirse a un nuevo hipertexto y seleccionarlo.

- Nivel 1 + botón: En esta tarea fue planteado la misma operación que en el caso del nivel 1, finalizando con la subtarea de pulsar el botón Anterior del navegador para retornar a la página de partida.

- Nivel 1 + barra desplazamiento: Al igual que en las tareas anteriores, inicialmente se parte de una posición central en la página y se propone la selección de un link en el extremo de la pantalla, una vez cargada la nueva página se plantea el uso de la barra deslizadora para poder acceder al contenido del final de la página.

Cada tarea planteada no sólo se ha evaluado con la alternativa adecuada de filtrado de cada paciente, sino con las demás también para poder efectuar una comparativa de resultados entre los diferentes algoritmos. 


\subsubsection{Resultados.}

Como conclusión general en base a los datos mostrados los resultados obtenidos con los filtros son sobradamente mejores que sin ellos.

Otra conclusión importante es que los tiempos empleados por los usuarios de Parkinson son considerablemente mayores que los obtenidos por usuarios con temblor esencial. Del mismo modo, también hay que dejar constancia, que si bien no existe una homogeneidad dentro del colectivo de Parkinson, las dificultades para asimilar los conceptos fueron muy superiores en este último.

Los enfermos de Parkinson poseen una cadencia de movimiento mucho más lenta que otro tipo de afectados por temblor, por lo que los requerimientos de respuesta en cuanto a velocidad de estos usuarios no es muy exigente. Motivo por el cual, queda justificado el mejor resultado obtenido con los filtros convencionales (paso bajo), dichos algoritmos poseen una respuesta frecuencial en módulo muy buena, logrando atenuaciones grandes comparativamente hablando respecto de otras técnicas, y su inconveniente característico de poseer un retardo considerable. No es crítico en aquellas circunstancias en las que el usuario posee unos requerimientos de velocidad poco exigentes. Por todo lo mencionado, el temblor característico parkinsoniano encaja de forma muy acertada en las características de estas técnicas de filtrado, ya que si además de considerar que el retardo en estas patologías no es determinante, si lo es la amplitud del temblor, que en general, suele ser considerablemente mayor, de ahí que con otras técnicas como el FLC y WFLC los resultados no sean tan buenos respecto al paso bajo, ya que éstos no poseen unas características de atenuación tan grandes como los paso bajo y la característica de ser más rápidos desde el punto de vista del retardo en estos casos no supone una ventaja.

Sin embargo, cuando se tratan los casos con patologías donde predomina el temblor de tipo intencional, el comportamiento es muy diferente. El perfil del individuo en este caso, al contrario que en el Parkinson, suele tener una edad menor por lo que las facultades intelectuales son menos restrictivas. Del mismo modo las características del temblor requieren tiempos de respuesta menores y por el contrario no se aprecian discinesias en el movimiento, por lo que éstos a pesar de estar sesgados por componentes patológicas, suelen ser rápidos. De una forma subjetiva también se aprecia que el introducir algún tipo de retardo en la respuesta del sistema también les afecta negativamente, consiguiendo que eleven el estado de nerviosismo y estrés. Por lo mencionado anteriormente el efecto del paso bajo en determinadas ocasiones no sólo es neutro sino que empeora la respuesta respecto al caso transparente. Como puede también puede verse en los resultados, las mediciones obtenidas son considerablemente mejores en los casos en que se ha seleccionado alguno de los tipos autoadaptativos (WFLC, FLC y LC). Dependiendo del usuario, funcionará mejor uno u otro en función de a qué se dé mayor prioridad si a la atenuación o a la velocidad de respuesta. Por lo general, el WFLC tendrá una mejor respuesta dinámica pero por el contrario se conseguirán atenuaciones inferiores que con los otros filtros. El LC es el mejor compromiso entre atenuación 
y rapidez de respuesta, por lo que será a priori idóneo para asignar a aquellos temblores de tipo mixto.

Una vez hecha la selección de los posibles candidatos para evaluar el dispositivo, se procede a proporcionar una sesión explicativa sobre el uso de la herramienta a utilizar, así como una introducción sobre las características de utilización del PC orientado tanto a uso profesional como personal.

Posteriormente, se deja transcurrir un par de sesiones para proporcionar unos niveles mínimos de práctica en el manejo, permitiendo que cada uno consulte aquellas páginas relacionadas con el tema de su interés particular. Al mismo tiempo, durante estas sesiones preparatorias se les proporciona el soporte adecuado para resolver posibles dudas y curiosidades. Una vez concluidas las sesiones de entrenamiento se procede a efectuar las pruebas en una sesión continuada y de forma que el usuario no se sienta vigilado o evaluado para eliminar en lo posible cualquier sesgo debido a la tensión o estrés.

La batería de pruebas se ha llevado a cabo sobre un grupo de cinco usuarios, tres de los cuales su afectación consistía en temblor predominantemente de reposo (Parkinson) y los otros 2 con un temblor de predominio de intención (esencial).

Los tiempos empleados en cada prueba han de considerarse principalmente relevantes de forma relativa a cada individuo. El establecer comparaciones entre usuarios debe hacerse con cautela y teniendo en cuenta condicionantes externos como la edad, nivel cognitivo, etc ... Normalmente, a mayor edad, el usuario necesita un mayor tiempo de adaptación y asimilación, así como de aprendizaje. Del mismo modo, aunque aún no se ha verificado empíricamente, es muy probable que aunque se efectúe un entrenamiento más intensivo con aquellas personas que posean una menor destreza, éstos con toda seguridad, en muchos casos no llegarán al nivel que poseen otros con muchas menos horas de práctica, por lo que establecer comparaciones absolutas entre individuos será relevante desde el punto de vista casuístico pero no para obtener conclusiones sobre la idoneidad de una u otra técnica dentro de una misma patología. 


\begin{tabular}{|c|c|c|c|c|c|}
\hline 1 nivel & Transparente & P.B. & FLC & WFLC & $\mathrm{LC}$ \\
\hline Usuario1 & 30 & 11 & 15 & 20 & 18 \\
\hline Usuario2 & 35 & 15 & 20 & 19 & 21 \\
\hline Usuario3 & 28 & 14 & 18 & 20 & 19 \\
\hline Usuario4 & 18 & 20 & 9 & 11 & 9 \\
\hline Usuario5 & 22 & 25 & 14 & 16 & 13 \\
\hline 2 niveles & Transparente & P.B. & FLC & WFLC & $\mathrm{LC}$ \\
\hline Usuario1 & 48 & 21 & 28 & 37 & 28 \\
\hline Usuario2 & 49 & 25 & 30 & 32 & 31 \\
\hline Usuario3 & 45 & 20 & 26 & 24 & 22 \\
\hline Usuario4 & 30 & 30 & 20 & 18 & 14 \\
\hline Usuario5 & 36 & 34 & 25 & 25 & 18 \\
\hline 1 nivel + botón & Transparente & P.B. & FLC & WFLC & $\mathrm{LC}$ \\
\hline Usuario1 & 45 & 25 & 31 & 35 & 30 \\
\hline Usuario2 & 40 & 22 & 25 & 27 & 25 \\
\hline Usuario3 & 36 & 22 & 29 & 30 & 28 \\
\hline Usuario4 & 25 & 23 & 16 & 17 & 15 \\
\hline Usuario5 & 31 & 28 & 20 & 18 & 16 \\
\hline $\begin{array}{l}1 \text { nivel + barra } \\
\text { desplazamiento }\end{array}$ & Transparente & P.B. & FLC & WFLC & $\mathrm{LC}$ \\
\hline Usuario1 & $>2 \min$ & 50 & 80 & 85 & 90 \\
\hline Usuario2 & $>2 \min$ & 62 & 86 & 94 & 85 \\
\hline Usuario3 & 85 & 49 & 67 & 69 & 65 \\
\hline Usuario4 & 20 & 18 & 15 & 16 & 12 \\
\hline Usuario5 & 35 & 30 & 21 & 25 & 18 \\
\hline
\end{tabular}

Tabla 5.1: Resultados de los diferentes filtros ensayados.

En la Tabla 5.1 se muestran los resultados en la realización de cada una de las tareas por cada uno de los individuos aplicando en cada caso una técnica de filtrado diferente. El valor correspondiente está expresado en segundos. 


\subsection{Caracterización o clasificación del temblor mediante MLPs.}

Vamos a intentar caracterizar o diferenciar con doble objetivo: entre sanos (temblor fisiológico) y enfermos (temblor patológico). En otros trabajos ya se han empleado los MLPs para caracterizar o predecir el temblor [97] De entre los enfermos, hemos centrado el estudio en la diferenciación entre enfermos de Párkinson y en temblor esencial, por varios motivos, primero y el más limitante ha sido por sólo disponer de ese tipo de enfermos. Tanto en el Hospital Ramón y Cajal como en el Hospital de la Princesa, ambos especializados en terapias contra el Párkinson (el primero de ellos como ya se ha mencionado, centro referencial a nivel nacional español), y el segundo porque desde el punto de vista de las terapias practicadas, resulta de fundamental interés para los facultativos médicos, la temprana diferenciación de la patología. Administrar los fármacos correspondientes o definir las dianas asociadas en las intervenciones quirúrgicas es vital en la estimulación cerebral profunda (CBS)

La labor de diagnóstico recae siempre en los especialistas, los expertos en neurología, neurofisiología, etc ..., por supuesto, pero en determinadas ocasiones el disponer de una información complementaria, objetiva, robusta y determinista puede llegar a facilitar mucho el acierto y por tanto la terapia de éxito. Hasta el momento, esta labor es complicada debido a la similitud de los síntomas entre las diferentes enfermedades y a la gran dificultad para encontrar propiedades discriminatorias para caracterizar las series temporales del temblor. Se ha podido demostrar que las descripciones estadísticas de segundo orden no son suficientes para distinguir entre estos tres tipos de temblor y es necesario utilizar estadísticas de orden superior (HOS), como los cumulantes de tercer y cuarto orden, biespectros y triespectros para conseguir la caracterización de las series de tiempo del temblor.

Lo que se pretende es, por lo tanto, caracterizar el temblor mediante la aplicación de redes MLP al procesamiento de señal utilizando para ello estadísticas de orden superior (HOS).

\subsubsection{Estadísticos de segundo orden.}

La transformada de Fourier (FFT) aplicada a las series temporales de temblor de los pacientes afectados por la enfermedad de parkinson revela la desigualdad de las señales en los periodos observados. El temblor tiene amplitud y frecuencia irregular que cambia con el tiempo. También, en algunas ocasiones, el valor del pico de la densidad de espectral de potencia (PSD), así como la frecuencia a la que se produce, cubren similares rangos de valores para temblores de parkinson y esencial, lo que hace que sean difícilmente diferenciables. Estas características son importantes para el reconocimiento pero no ofrecen una descripción suficiente del temblor.

La principal razón de la ineficacia de los estadísticos de segundo orden para la caracterización del temblor, es que las distribuciones del temblor esencial y parkinsoniano son "no-gaussianas" y es necesario utilizar estadísticas de orden superior. En la Figura 5.27 se puede observar la distribución de frecuencias para un ejemplo típico de Párkinson, de temblor esencial y de temblor fisiológico (sanos). 

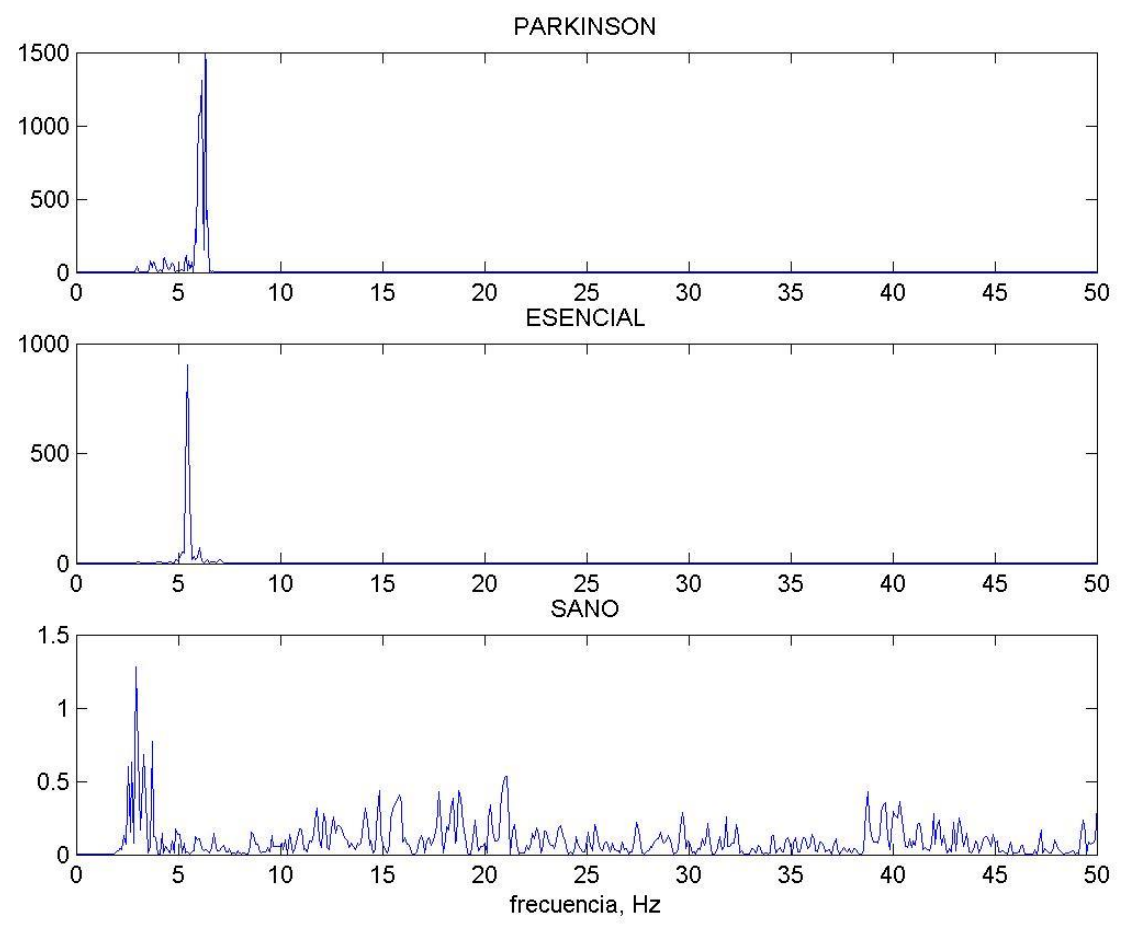

Figura 5.27: Análisis frecuencial de un enfermo de Párkinson, de temblor esencial y fisiológico o sano.

\subsubsection{Estadísticos de orden superior (HOS).}

Tomando como punto de partida el trabajo de Jakubowski at al [98] en el que se proponen una batería de estadísticos de orden superior para la caracterización del temblor, se propusieron los seleccionados en la Tabla 5.2.

Para la obtención de las diferentes características se utilizó la toolbox de MATLAB "HOSA", de fácil manejo desde la línea de comandos así como también fácimente utilizable desde cualquier función programada por el usuario. 


\begin{tabular}{|c|c|}
\hline Descripción de la medida & Expresión \\
\hline 1. Máximo valor de PSD. & $\max (P S D)$ \\
\hline 2. Máximo de la frecuencia de PSD. & $f_{\max }(P S D)$ \\
\hline 3. Número de muestras del espectro para valores de PSD por encima del $0.72 \%$. & $N_{0.72 \%}(P S D)$ \\
\hline 4. Número de muestras del espectro para valores de PSD por encima del $2.42 \%$. & $N_{2.42 \%}(P S D)$ \\
\hline 5. Número de muestras del espectro para valores de PSD por encima del $95.3 \%$. & $N_{95.3 \%}(P S D)$ \\
\hline 6. Momento de primer orden de PSD (media). & $m_{1}(P S D)$ \\
\hline 7. Momento de segundo orden de PSD (varianza). & $m_{2}(P S D)$ \\
\hline 8. Momento de cuarto orden de PSD. & $m_{4}(P S D)$ \\
\hline 9. Momento de quinto orden de PSD. & $m_{5}(P S D)$ \\
\hline 10. Suma de los valores de la diagonal del biespectro. & $S($ diag $\mid$ bisp $\mid)$ \\
\hline 11. Suma de los valores del biespectro. & $S(|b i s p|)$ \\
\hline 12. Suma de los logaritmos de los valores de la diagonal del biespectro. & $S(\log (\operatorname{diag}|\operatorname{bisp}|))$ \\
\hline 13. Suma de los logaritmos de los valores del biespectro. & $S(\log (|b i s p|))$ \\
\hline 14. Momento de primer orden de la diagonal del biespectro. & $m_{1}(\operatorname{diag} \mid$ bisp $\mid)$ \\
\hline 15. Momento de segundo orden de la diagonal del biespectro. & $m_{2}(\operatorname{diag} \mid$ bisp $\mid)$ \\
\hline 16. Momento de primer orden del logaritmo de la diagonal del biespectro. & $m_{1}(\log (\operatorname{diag}|\operatorname{bisp}|))$ \\
\hline 17. Valor máximo de la diagonal del triespectro. & $\max ($ diag $\mid$ trisp $\mid)$ \\
\hline 18. Suma normalizada de los valores de la diagonal del triespectro. & $S_{r}($ diag $\mid$ trisp $\mid)$ \\
\hline 19. Momento de primer orden de la diagonal del triespectro. & $m_{l}($ diag $\mid$ trisp $\mid)$ \\
\hline 20. Momento de segundo orden de la diagonal del triespectro. & $m_{2}(\operatorname{diag}|\operatorname{trisp}|)$ \\
\hline 21. Momento de tercer orden de la diagonal del triespectro. & $m_{3}(\operatorname{diag}|\operatorname{trisp}|)$ \\
\hline 22. Número de muestras de la diagonal del biespectro por encima del $0.29 \%$. & $N_{0.29 \%}(\operatorname{diag} \mid$ bisp $\mid)$ \\
\hline 23. Número de muestras de la diagonal del biespectro por encima del $4.3 \%$. & $N_{4.3 \%}(\operatorname{diag} \mid$ bisp $\mid)$ \\
\hline 24. Número de muestras de la diagonal del triespectro por encima del $0.15 \%$. & $N_{0.15 \%}($ diag $\mid$ trisp $\mid)$ \\
\hline 25. Número de muestras de la diagonal del triespectro por encima del $5.6 \times 10^{-6} \%$. & N5.6e-6\% (diag $\mid$ trisp $\mid)$ \\
\hline 26. Momento de quinto orden de la diagonal del biespectro. & $m_{5}(\operatorname{diag} \mid$ bisp $\mid)$ \\
\hline
\end{tabular}

Tabla 5.2: Propuesta de características.

Antes de nada, lo primero sería eliminar las componentes debidas al propio patrón, así como los offset y bias (valor de continua) que la muestra pueda tener. El objetivo será quedarse únicamente con la componente del temblor a estudiar. Para lo cual simplemente aplicando un paso alto con frecuencia de corte lo suficientemente baja para que sólo nos queden las componentes del movimiento no intencional es suficiente $(2-3 \mathrm{~Hz})$. Para conseguir información suficientemente representativa y estable de las muestras se ha seleccionado un periodo de observación de aproximadamente 10 segundos.

La dimensión de la capa de salida queda determinada por el número de clases objetivo que se quieren diferenciar. De este modo se fijó como criterio:

- La clase 1: temblor de Párkinson.

- La clase 2: temblor esencial.

- La clase 3: sano 
Cada clase está representada por un vector de salida. Este vector de dimensión 3, tendrá todas sus componentes con valor cero salvo la componente correspondiente a la clase seleccionada que valdrá 1 . Así que para el caso de haber un positivo para la clase 1 el vector de salida asignado será $\left[\begin{array}{ll}1 & 0\end{array}\right]$, para la clase 2 [0 $10]$ y para la clase $3\left[\begin{array}{lll}0 & 0 & 1\end{array}\right]$.

Al igual que con el filtrado la dimensión de la capa oculta se ha ajustado experimentalmente para obtener la mejor habilidad de generalización de la red. Por lo tanto, el número de neuronas en la capa oculta debe de ser el más bajo pero suficiente para reducir la función de error al nivel mínimo.

La obtención de las características se ha automatizado utilizando las toolbox y creando sendas funciones para coordinar las llamadas.

El vector de características utilizadas determina la dimensión de la capa de entrada a la red.

La dimensión de la capa oculta se ha ajustado experimentalmente para obtener la mejor habilidad de generalización de la red, esta es la propiedad más eficiente del reconocimiento de patrones. Un número demasiado grande de neuronas en la capa oculta provoca una mala generalización de la red, mientras que un número demasiado bajo hace que el proceso de aprendizaje sea ineficiente y provoque un nivel de error muy alto. Por lo tanto, el número de neuronas en la capa oculta debe de ser el más bajo pero suficiente para reducir la función de error al nivel mínimo.

Tras realizar algunas pruebas, la función de activación elegida para las neuronas de la capa oculta, así como las de la capa de salida, ha sido la función sigmoidea del tipo tangente hiperbólica (tansig).

De un total de 364 vectores, se emplearon 156 para la fase de prueba y el resto para el entrenamiento. De todos los casos hay 210 vectores de sanos, 34 de esenciales y 120 parkinsonianos. Debido a la disponibilidad menor de casos de esenciales y parkinsonianos respecto al de sanos, se decidió mantener la proporción también en los vectores de prueba por lo que la simulación se realizó con 90 sanos, 10 esenciales y 56 parkinsonianos.

El estudio ha sido planteado tomando grupos de características dentro de las veintiséis propuestas de la siguiente manera:

- El primer grupo (G1) está formado por las características basadas en el espectro de potencia, PSD (características desde la 1 a la 9). Estadísticos de segundo orden.

- El segundo grupo (G2) contiene solamente las características obtenidas de las estadísticas de orden superior (HOS) sin contar con las de PSD (características de la 10 a la 26).

- Y por último el tercer grupo (G3), incluye la totalidad de características la 1 a la 26. 
Por cada grupo se han realizado 10 pruebas para cada una de las redes creadas para que así los resultados obtenidos sean lo suficientemente representativos. La toolbox "Neural Networks" de MATLAB, elige aleatoriamente la inicialización de los pesos iniciales, hecho que pudiera quizás sesgar el resultado realizando una sola prueba.

\subsubsection{Resultados.}

El primer resultado corresponde al error medio cometido en el G1.

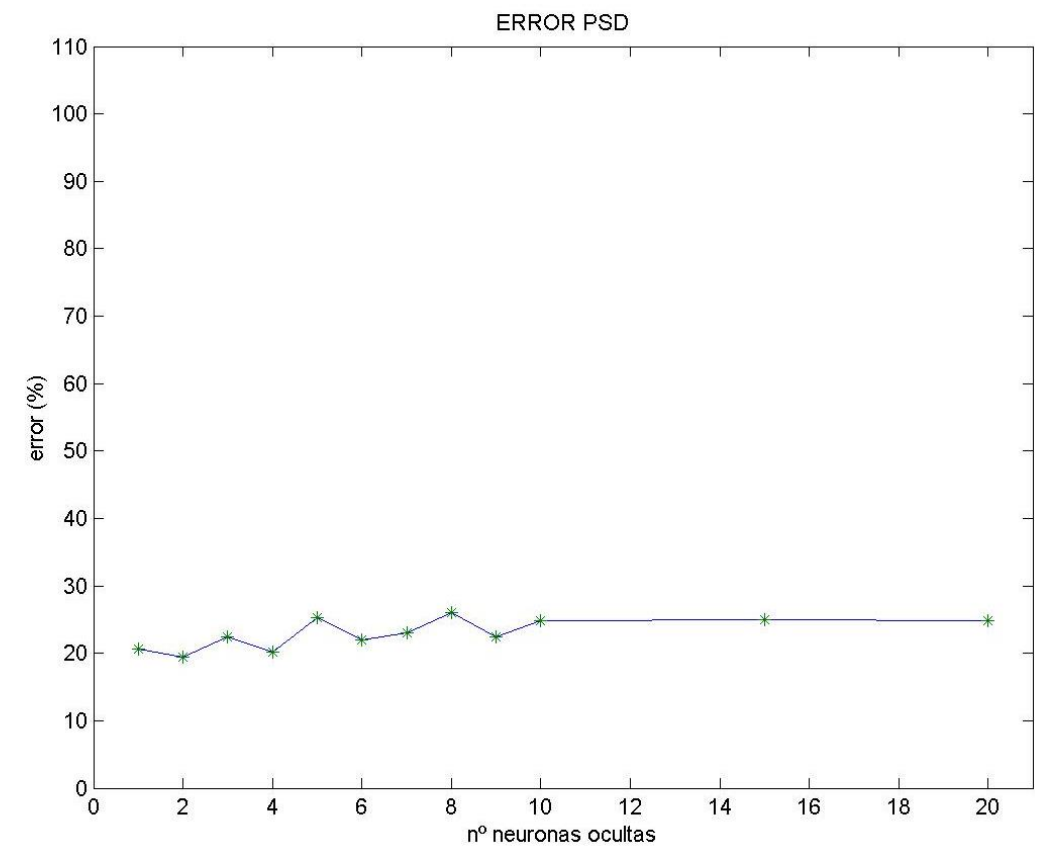

Figura 5.28: Error medio con las primeras 9 características (PSD)

$\mathrm{Al}$ entrenar la red con las características del G1, pertenecientes exclusivamente al espectro de potencia PSD, se ha obtenido un error mínimo del 19,42\% para redes con 2 neuronas en la capa oculta. Con 10 neuronas en la capa se estabiliza en un $24 \%$ el error (valor más fiable y estable).

El resultado medio obtenido del error para las redes entrenadas con las características del G1 es relativamente bajo, pero hay que considerar los errores cometidos en cada una de las clases (sujetos). Así, se puede observar en la Figura 5.29 como el error para los vectores representantes del temblor esencial se encuentra en torno al 90\%, hasta llegar a las redes con 6 neuronas en la capa oculta que comienza a descender desde un $88 \%$ hasta un $71 \%$ para las redes con 15 neuronas ocultas. El error para el temblor de Párkinson también es muy variable con una media alrededor del 40\%. En cambio, el error para los vectores del patrón 3 es bastante constante y se mantiene alrededor de $4 \%$. 


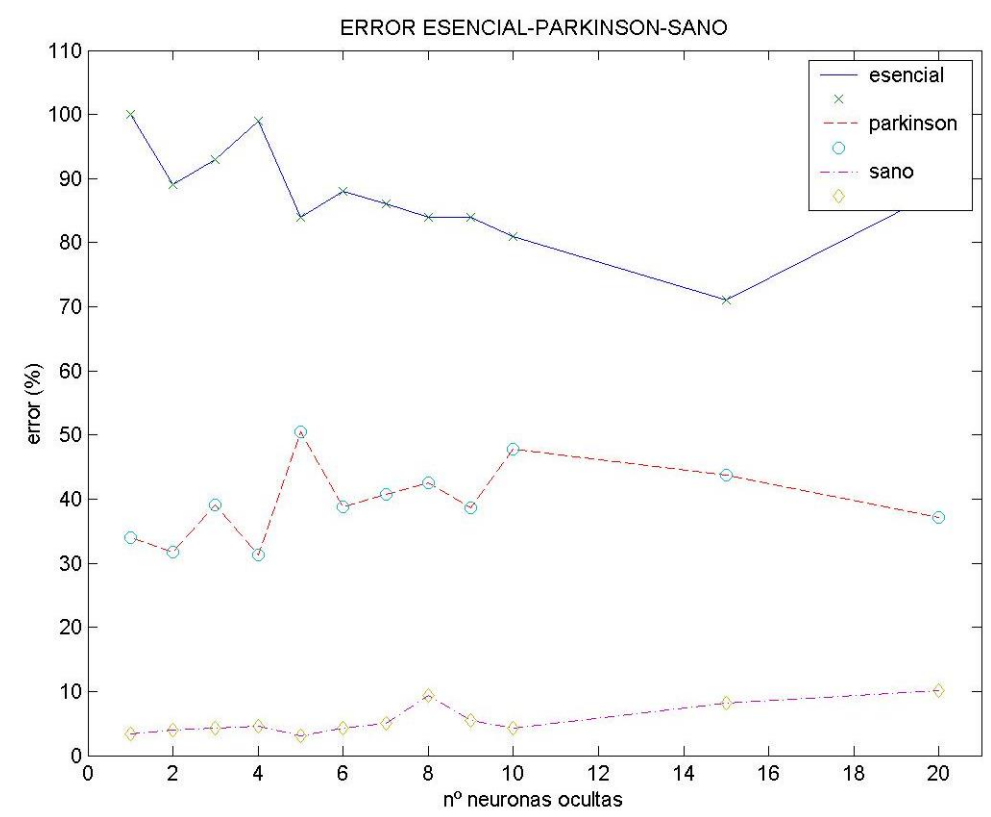

Figura 5.29: Error en cada clase con las primeras 9 características (PSD).

Repitiendo el proceso con las características del G2, pertenecientes a las estadísticas de orden superior, se ha obtenido un error mínimo del $24 \%$ para redes con 4 neuronas ocultas. Con esta configuración se comete un error del 86\% para vectores representantes del temblor esencial, un $42 \%$ para los representantes de temblor de Párkinson y un $8 \%$ para vectores de pacientes sanos.

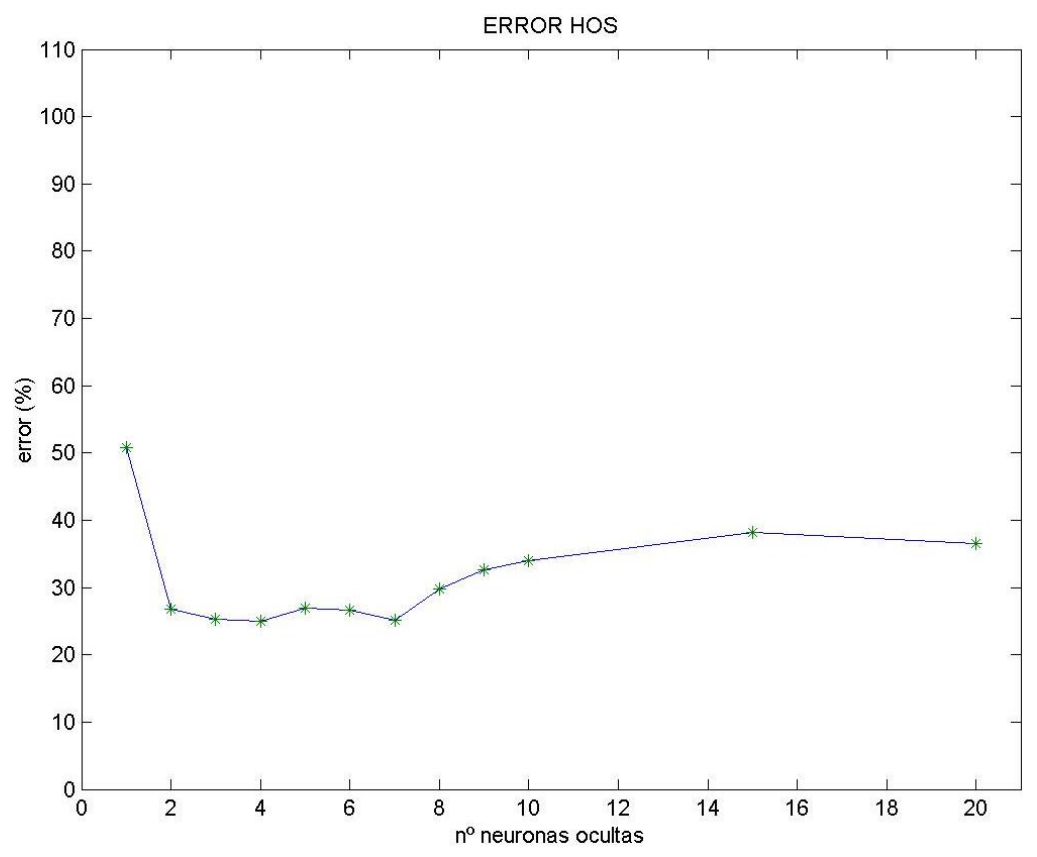

Figura 5.30: $\quad$ Error medio con las características 10 a 26 (HOS). 
La media del error del temblor esencial ha disminuido hasta un $82 \%$, alcanzándose la mínima en un $71 \%$ para redes con 9 neuronas en la capa intermedia. Sin embargo, para esta configuración el error aumenta para los vectores de las otras dos clases.

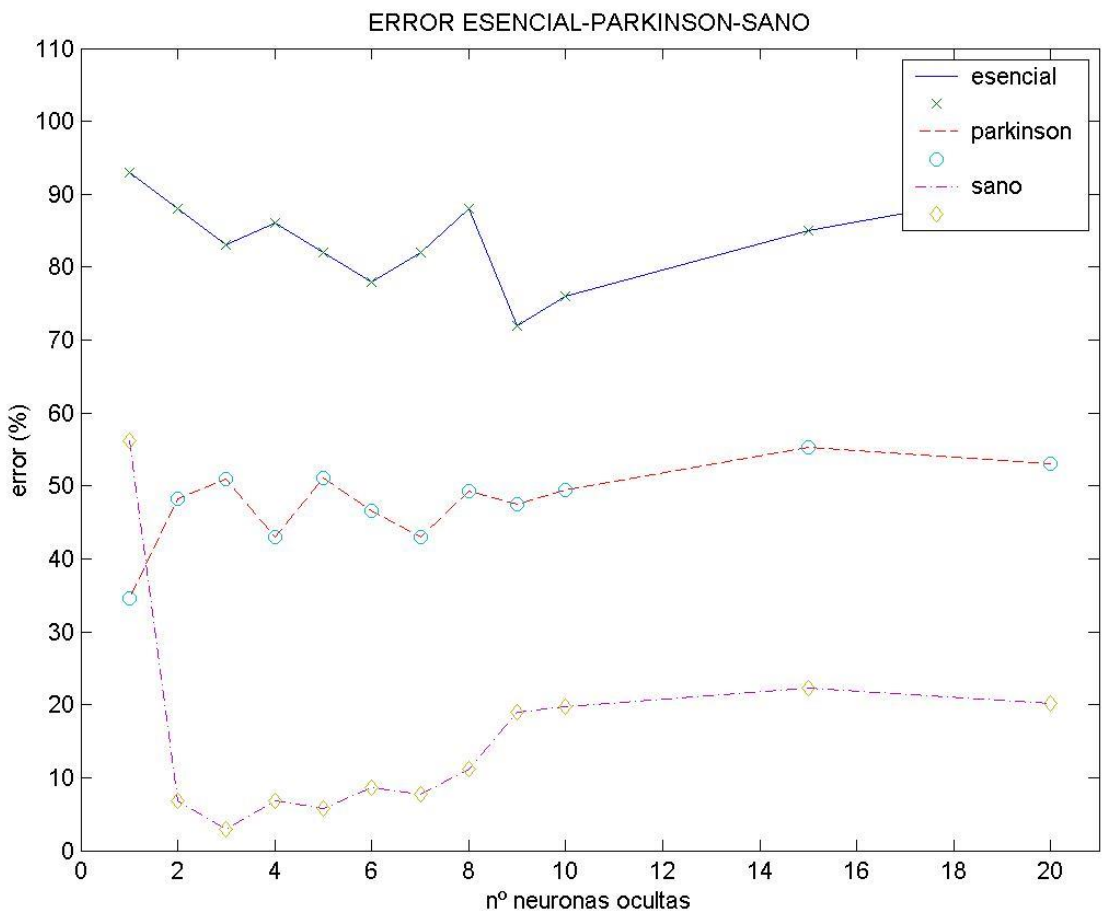

Figura 5.31: Error en cada clase con las características 10 a 26 (HOS).

Por último, se ha realizado el entrenamiento de las características del G3, que incluyen las características del PSD y las HOS.

En este caso el error medio permanece bastante estable alrededor de un $24 \%$. Éste se estabiliza a partir del caso con cuatro neuronas en la capa oculta. Con esta configuración, el error que se comete para los vectores que representan al temblor esencial es de un 70\%, valor muy elevado pero el más bajo de todas las pruebas realizadas. 


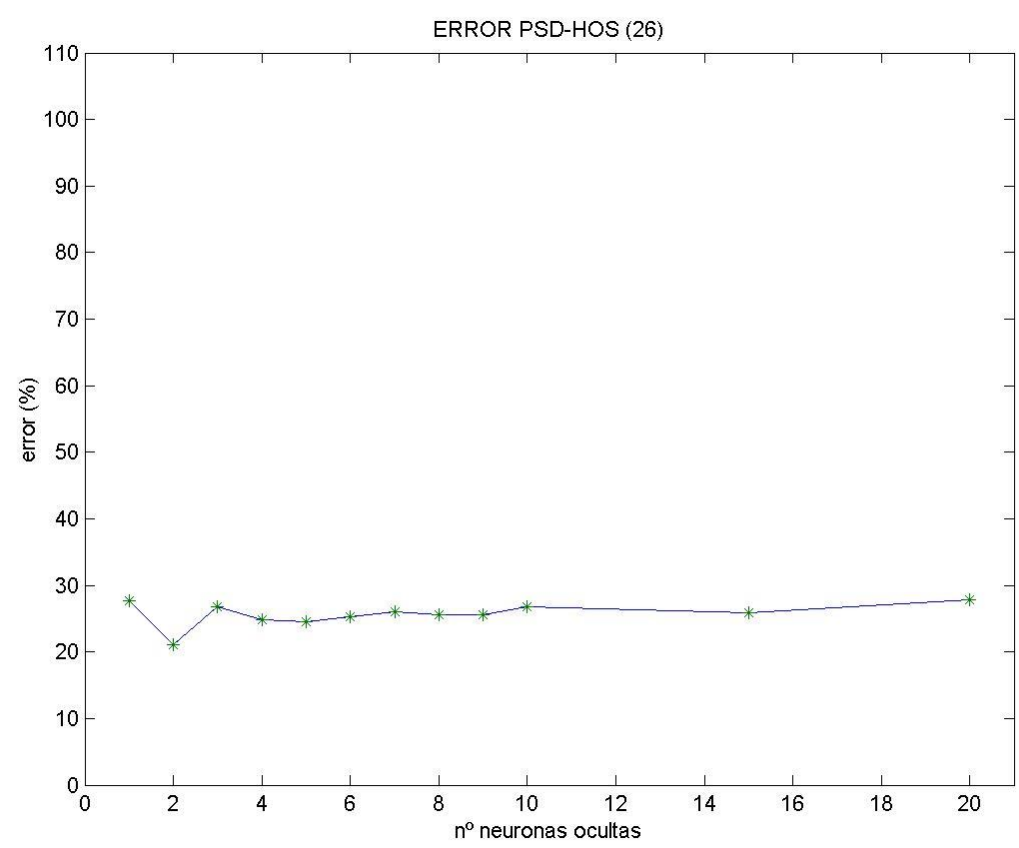

Figura 5.32: Error medio con todas las características (PSD+HOS).

El error medio cometido para los vectores de la clase 2 (esenciales) se mantiene en un $80 \%$, el error de los vectores de la clase 1 (Párkinson) en un $40 \%$ y el cometido para los vectores de la clase 3 en un $10 \%$.

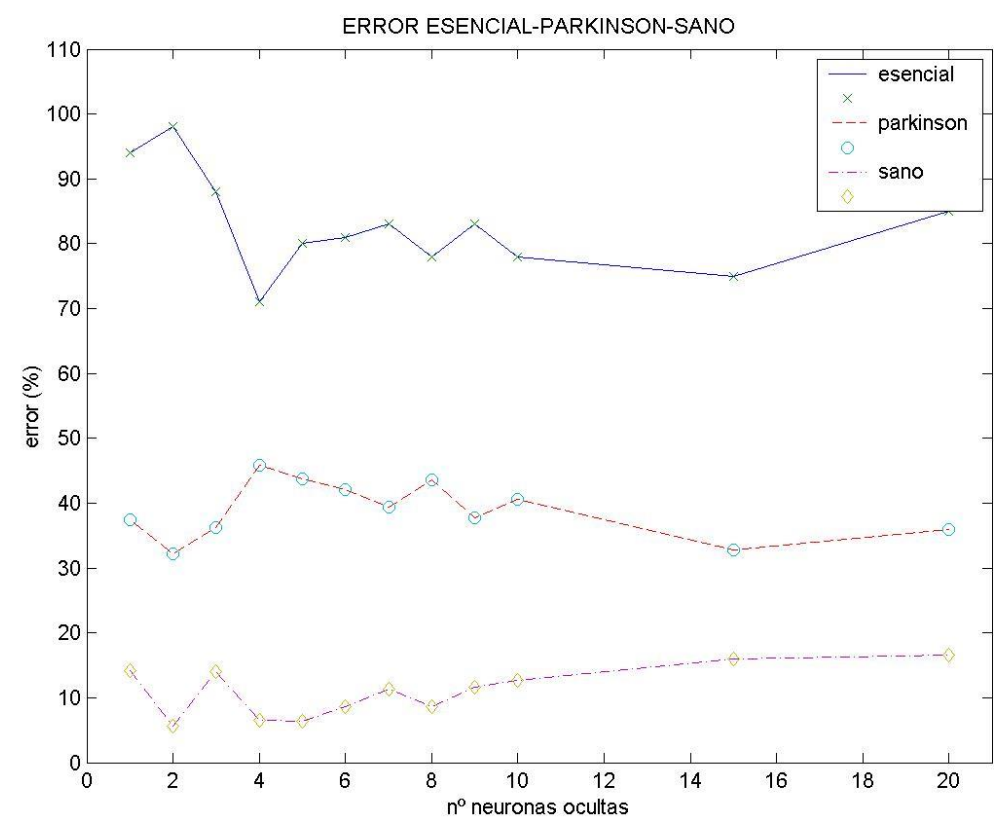

Figura 5.33: Error en cada clase con todas las características (PSD+HOS). 
Los resultados obtenidos no han sido tan satisfactorios como se esperaban. El error mínimo obtenido ha sido del $20 \%$, y este se ha visto aumentado debido al alto grado de error observado en el reconocimiento del temblor esencial. Este error tan elevado se ha debido principalmente al limitado número de muestras disponibles para los experimentos o pruebas.

\subsubsection{Conclusiones.}

El error de clasificación entre enfermos y sanos ha sido muy aceptable, puesto que incluso sólo con las primeras características (9 primeras, PSD), el nivel de acierto de encuentra por encima del $90 \%$ (4\% de error para el mejor de los casos). Añadir las características HOS no mejora el resultado.

Los resultados, sin embargo, atendiendo a la clasificación entre tipos de temblor no son demasiado buenos, tanto parkinsoniano como esencial, siendo éste último el peor con diferencia. Si bien es cierto que en los vectores de temblor esencial no existe una situación clara que les beneficie (en ambos casos, con PSD y HOS no se baja del 70\%), los parkinsonianos para el G3 (todas las características) obtienen su menor tasa de error: con 15 neuronas en la capa oculta llegan a rozar el 30\%. Parece razonable pensar, que en un futuro la solución que se pueda plantear, debería de considerar las veintiséis características en cuanto a la diferenciación entre Párkinson y temblor esencial se refiere.

Por otro lado, también se puede plantear la opción de tener en cuenta el patrón de la prueba, pues es posible que la tarea influya de manera diferente en unos y en otros enfermos. Ya se comentó en el capítulo 2, en el estado del arte, que ciertos temblores eran más evidentes ante determinadas circunstancias, por ejemplo en el caso de los enfermos esenciales el predominio del temblor de acción provocaba una mayor discapacidad en las labores que implican movimiento (patrones cinéticos), mientras que el temblor asociado a la enfermedad de Párkinson la componente principal era de reposo (patrones estáticos). Del mismo modo los patrones dinámicos también deberían tener un efecto diferenciador en ambos ya que el temblor de acción debería agudizarse ante la oposición del dispositivo (fuerza virtual) y el temblor parkinsoniano atenuarse.

Todas estas premisas y alguna hipótesis más se plantearán en el siguiente capítulo (capítulo 6), cuando se muestre el estudio realizado con redes LVQ. 


\section{6 clasificación del temblor CON REDES NEURONALES LVQ.}

Para afrontar este nuevo estudio partiremos de las conclusiones obtenidas a partir de los resultados que se obtuvieron en la clasificación mediante perceptrones multicapa o MLPs. En una de ellas, se mencionaba que parecía razonable pensar que para profundizar/mejorar en la clasificación diferencial entre parkinsonianos y esenciales, sería conveniente mantener el uso de ambos grupos de características simultáneamente (PSD y HOS). Por esta razón, la situación de partida será trabajar en un espacio de 26 características o dimensiones.

Simultáneamente al estudio con MLPs, se abordaron otras posibles maneras de ampliar el espacio de características para disminuir la varianza no explicada y mejorar así, el error de la clasificación. En este sentido se barajó la posibilidad de utilizar las discontinuidades proporcionadas por la transformada wavelet. Tras analizar cada una de las pruebas y descontar el número de discontinuidades intrínsecas asociadas al patrón, podríamos definir un par de nuevas características (para eje $\mathrm{x} y$ eje $y$ ), que introdujera el número de discontinuidades asociadas al tipo de temblor.

Por otra parte, también se va a afrontar la reducción de la dimensión del espacio de entrada mediante el análisis de componentes principales (ACP) y así simplificar el modelo de la red, comprobando qué influencia tiene este factor en el error de clasificación. La idea sería trabajar únicamente con aquellas variables más representativas en un sistema de referencia distinto. Se estudiarán los modelos en ambas situaciones para ver la influencia sobre el error de clasificación.

\subsection{Procedimiento para el cálculo de discontinuidades.}

En primer lugar, para eliminar la distorsión inicial en las wavelets, que se manifestarían como discontinuidades, confundiéndose con las que realmente se han producido a lo largo de la prueba como consecuencia del temblor, se empleó el siguiente procedimiento: tanto al comienzo como al final de la señal se añaden 
muestras especulares de las 100 primeras y últimas muestras de la señal, respectivamente. Una vez se haya filtrado la señal y se hayan calculado los coeficientes de la wavelet se eliminarán las muestras añadidas para posteriormente proceder a la detección de las discontinuidades.

En la figura Figura 6.1 se muestra una señal correspondiente a un paciente de Parkinson, realizando una trayectoria de ida y vuelta en el eje x (patrón 3).

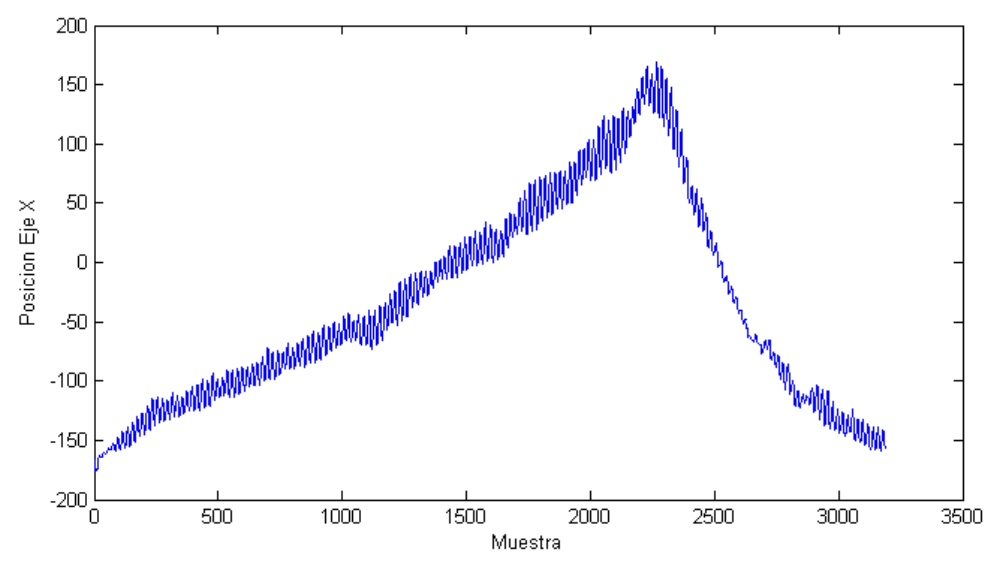

Figura 6.1: Señal de temblor de Párkinson.

La señal con las muestras especulares añadidas tanto al principio como al final presenta el siguiente aspecto

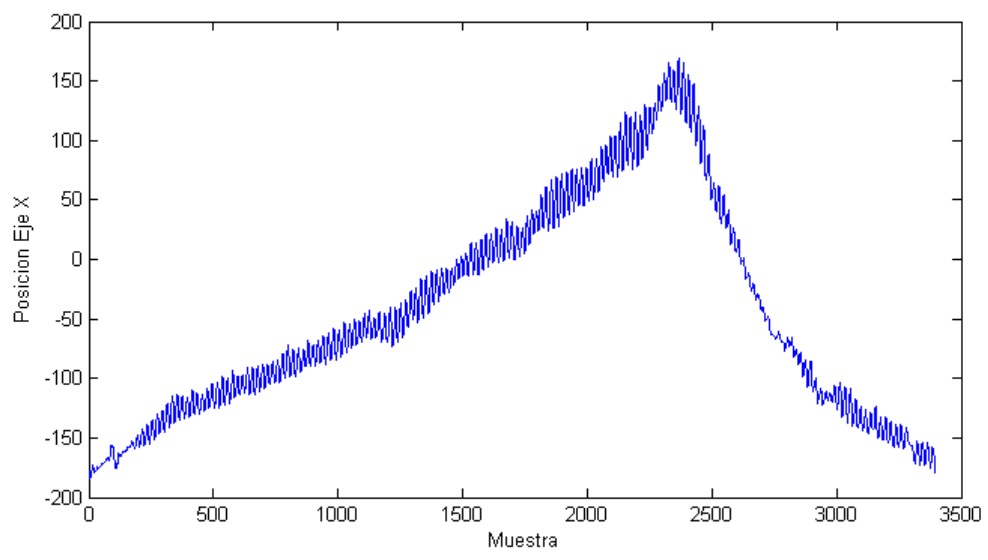

Figura 6.2: Señal de temblor de Párkinson con muestras especulares.

Para eliminar la componente de temblor se empleó un filtro paso-bajo adaptativo para poder variar la frecuencia de corte y así garantizar que la entrada al análisis de wavelets únicamente tuviera la información de baja frecuencia, fuera cual fuera el tipo de temblor (incluso fisiológico). 
Se decidió tras numerosas pruebas, establecer la frecuencia de corte según la energía relativa de la señal. En la Figura 6.3 se muestra cómo se distribuye la potencia de la señal a lo largo de su espectro y cómo va aumentando la energía a medida que va aumentando la banda de frecuencia que se considere.
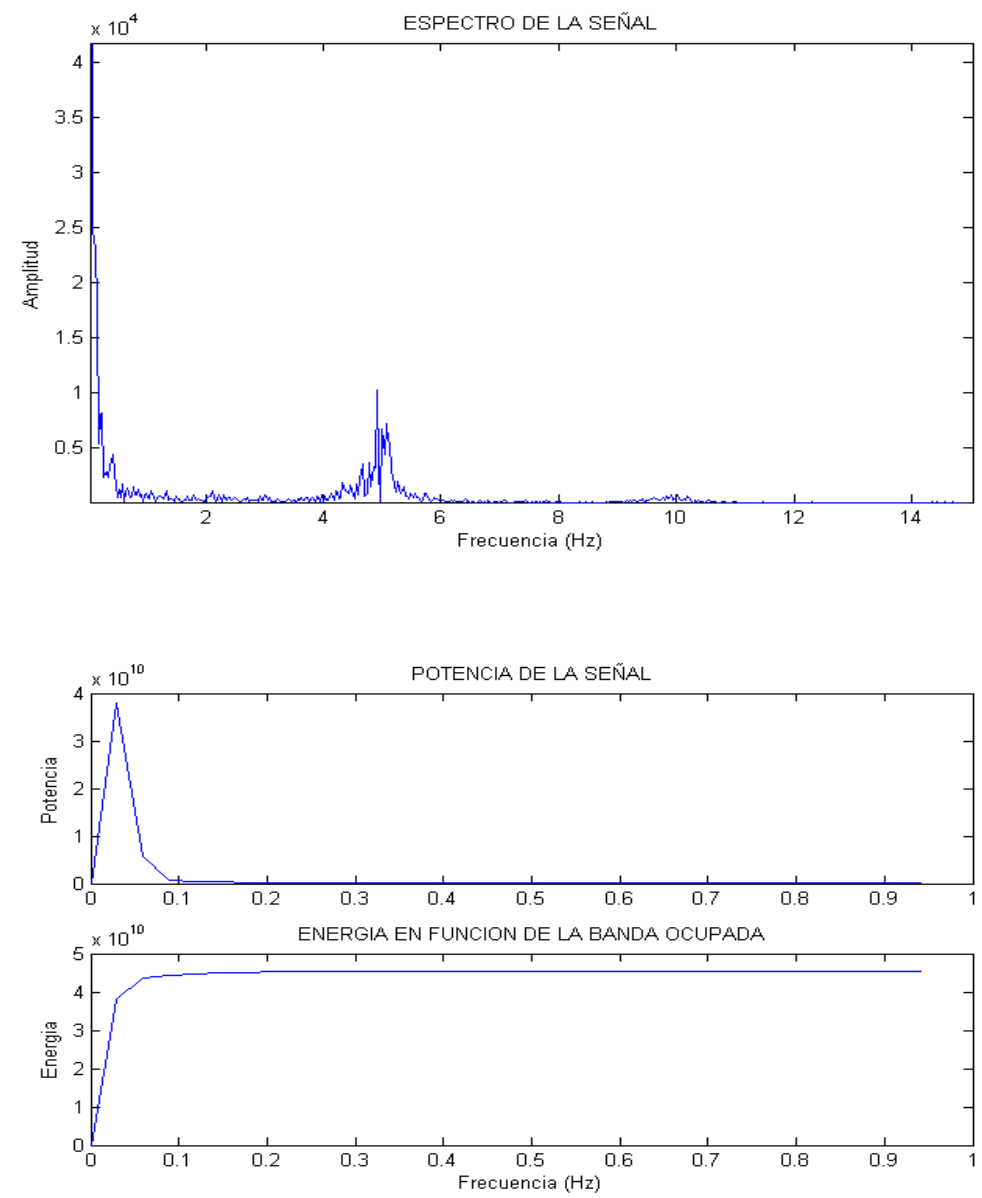

Figura 6.3: Distribución de la potencia y energía en función de la frecuencia.

Hallando el cociente entre la potencia para cada frecuencia con la energía en esa determinada banda se obtiene la contribución de cada frecuencia a la energía total relativa en esa banda. El criterio que se tomó para seleccionar la frecuencia de corte del filtro paso-bajo fue el de tomar aquella en la cual esta aportación energética fuese igual o inferior a un valor umbral determinado.

Una vez determinada la frecuencia del filtro paso bajo, se hallan los coeficientes para un filtro de Butterworth de tercer orden y se filtra la señal obteniéndose el resultado que se muestra en la Figura 6.4. 


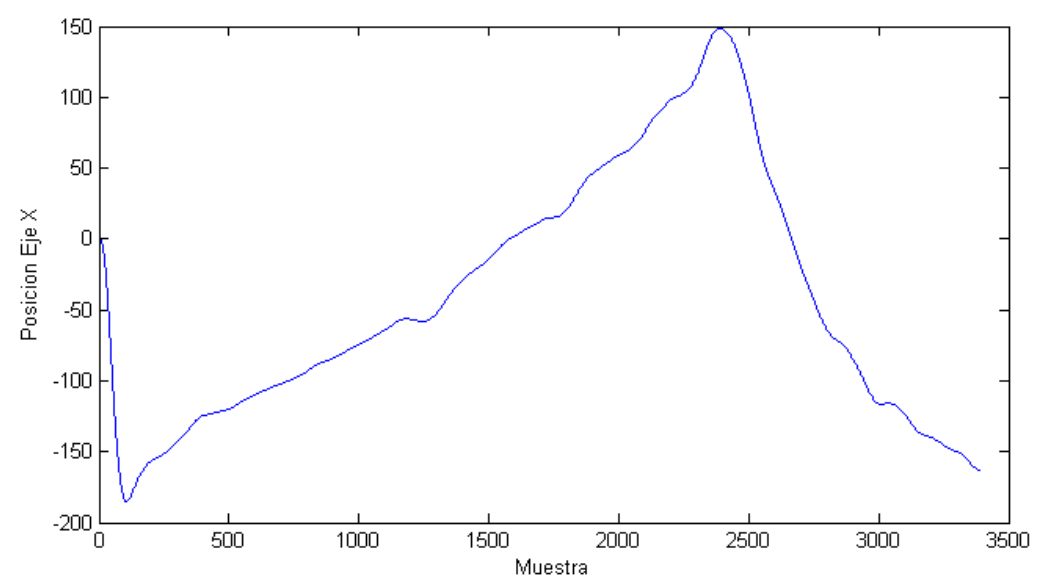

Figura 6.4: Señal filtrada.

Tras filtrar la señal, ya se puede obtener la transformada wavelet y eliminar las 100 primeras y últimas muestras que se añadieron originalmente. A continuación se calculan los coeficientes realizando una descomposición de la señal original de 1 nivel, con lo que se obtiene una componente de alta frecuencia de la señal $c d 1$ y otra de baja frecuencia $c a 1$.
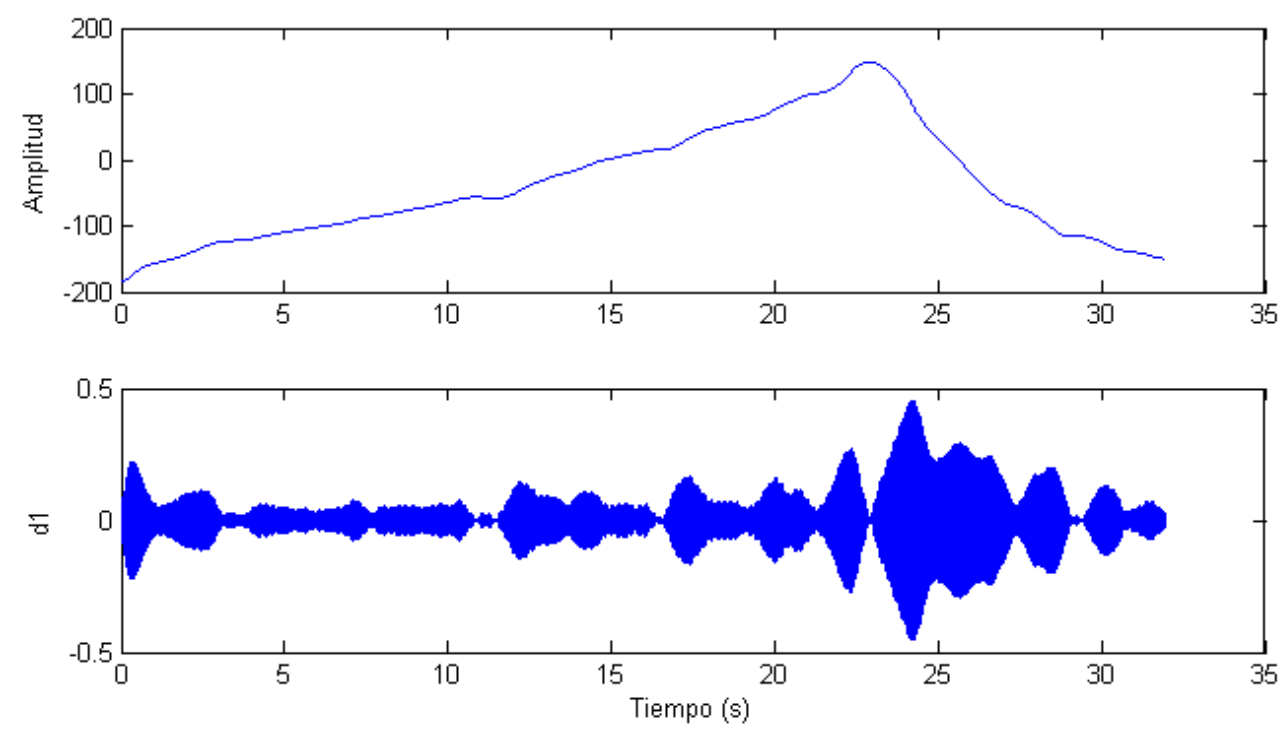

Figura 6.5: Obtención de las discontinuidades de la prueba.

En la Figura 6.5 se observa que las discontinuidades en la señal se producen en aquellas zonas donde el trazado de los detalles de la wavelet muestra valores de coeficientes muy pequeños, prácticamente nulos. Por lo tanto, para la detección de 
las zonas donde se producen las discontinuidades hay que definir aquellos umbrales que permitan definir tales zonas. Se considera discontinuidad cuando el coeficiente se hace inferior a la décima parte del coeficiente de mayor valor, y se mantiene en la misma discontinuidad mientras no se supere la tercera parte de este mismo coeficiente de mayor valor.

A continuación se muestran los valores que toman los coeficientes. Nótese que el número de muestras es la mitad del de la señal original, debido al submuestreo que se produce al descomponer la señal original en dos niveles.

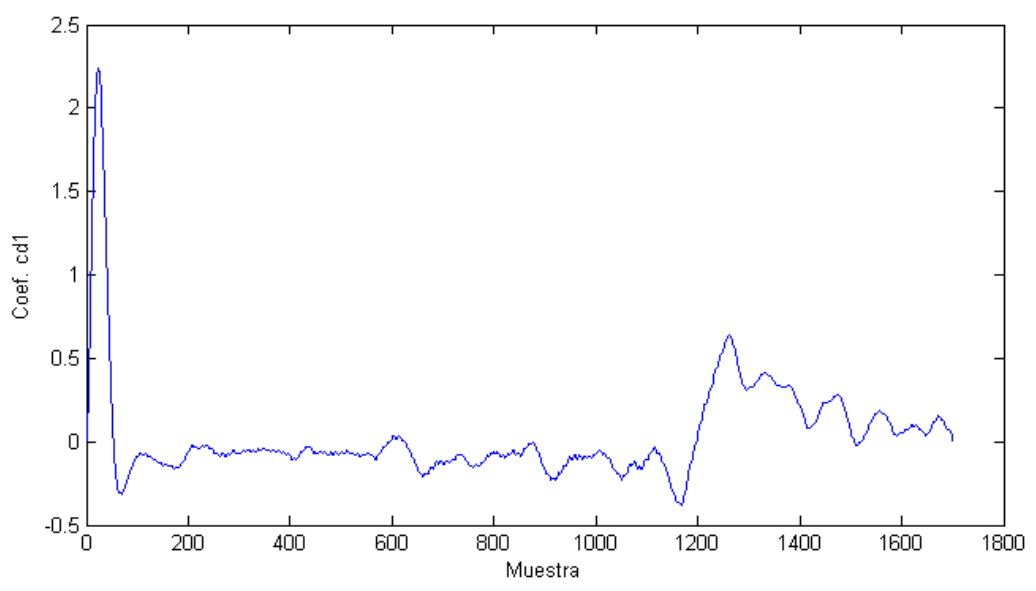

Figura 6.6: Valores de los coeficientes de la wavelet.

$\mathrm{Al}$ haber eliminado las 100 primeras y últimas muestras de la señal y del dibujo de detalles de wavelets, las discontinuidades del principio y del final no se tendrán en cuenta en la detección de las mismas. Una vez calculado el número de discontinuidades en la señal, antes de su introducción en la red neuronal, debe eliminarse del valor calculado las discontinuidades propias del patrón.

Para un paciente sano, sin trastorno en el movimiento, el número de discontinuidades contabilizado mediante este procedimiento ha de ser relativamente bajo. Idealmente ha de coincidir con las discontinuidades propias del patrón seguido en la prueba. Para un paciente enfermo el número de discontinuidades detectado en su movimiento debería rebasar ampliamente al de las que son propias del patrón y por tanto a las que son producidas por un paciente sano.

Es importante recordar que el análisis de discontinuidades sólo cobra sentido para el movimiento intencional del paciente, por lo que las discontinuidades detectadas en aquellos patrones que son estáticos, así como en aquellos ejes de los demás patrones en los que no se realiza el movimiento involuntario, no deberían tenerse en cuenta en este análisis. 
Otro detalle que se tuvo en cuenta al realizar el estudio de discontinuidades es que no se consideró el primer segundo prueba, al considerar que este periodo era de adaptación del paciente y que por lo tanto podría tener un carácter perturbador y de sesgo para la detección de las discontinuidades.

En la figura Figura 6.7 se muestran representaciones de las componentes de alta frecuencia correspondientes a algunos de los patrones para una persona sin transtorno de movimiento, apreciándose claramente los instantes en donde se produce un cambio inherente al patrón.
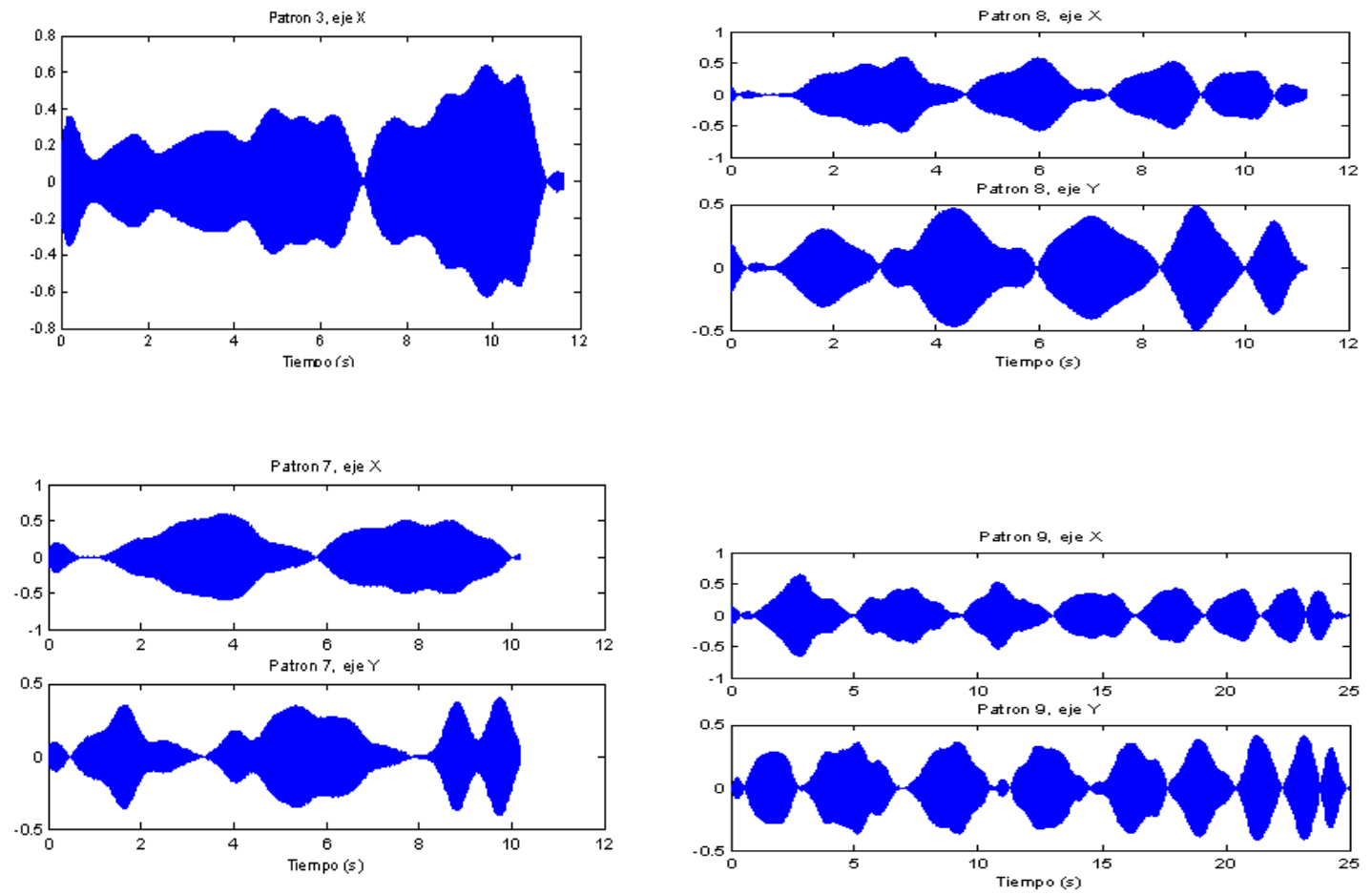

Figura 6.7: Componentes de alta frecuencia para un individuo sano.

\subsection{Metodología}

En este estudio además de introducir las discontinuidades como característica número 27 y 28 (eje X y eje Y), se estudiará la influencia del patrón. Tal y como se comentó en el capítulo 3, los patrones se dividen en tres grupos: estáticos, cinéticos y dinámicos. Basándose en los protocolos de pruebas de las escalas del temblor (capítulo 2). Con cierto grado de intención, ya se propuso la diferenciación del patrón en la clasificación, y quedó demostrado en el análisis de la varianza (mostrado en el capítulo 3), donde el patrón es significativo para los pacientes enfermos. Esto es consecuencia de que los enfermos no se comportan igual ante situaciones de reposo (patrón 1 - estático), de movimiento (patrones cinéticos) y con realimentación de esfuerzo en el extremo (patrones dinámicos). 
Del mismo modo, desde el punto de vista de la influencia de la característica, se recurrirá al análisis de componentes principales $(\mathrm{ACP})$ y así disminuir la dimensión del espacio de entrada eligiendo aquellas características que mejor expliquen la muestra de datos.

El primer estudio se llevará a cabo sin $\mathrm{ACP}$, utilizando el espacio de características inicial.

En un segundo paso, se incluirá el ACP comprobando la influencia de reducir el espacio de características de entrada.

\subsection{Importancia de la elección del número de pesos}

El comportamiento de una red, una vez seleccionados los vectores de entrenamiento, depende de dos factores fundamentales: los pesos y el número de épocas de entrenamiento. De los dos el más importante con diferencia es el primero, sin embargo, las épocas también tienen un papel importante puesto que pueden sobre-entrenar la red. Durante el entrenamiento los pesos se van moviendo por todo el espacio intentando posicionarse de tal forma que se puedan caracterizar los diferentes subespacios. En problemas complejos en donde es muy difícil llegar al error 0 , los pesos pueden desplazarse de forma indeterminada, a medida que se entrena la red. Este fenómeno se observa en los resultados de los entrenamientos con variación del número de épocas.

En primer lugar se determina el número de pesos idóneo. Para ello se somete a la red a distintos entrenamientos. A continuación, puede observarse en la Figura 6.8 gráficamente los resultados obtenidos de un ejemplo, en el que mediante la variación del número de pesos se puede llegar a determinar la red que menos error proporciona:

Variación de Pesos, características: 4 - 6 - 9 - 16 - 18,

Patrones: 3 - 4 - 7 - 10 - 11 - 14 - 16

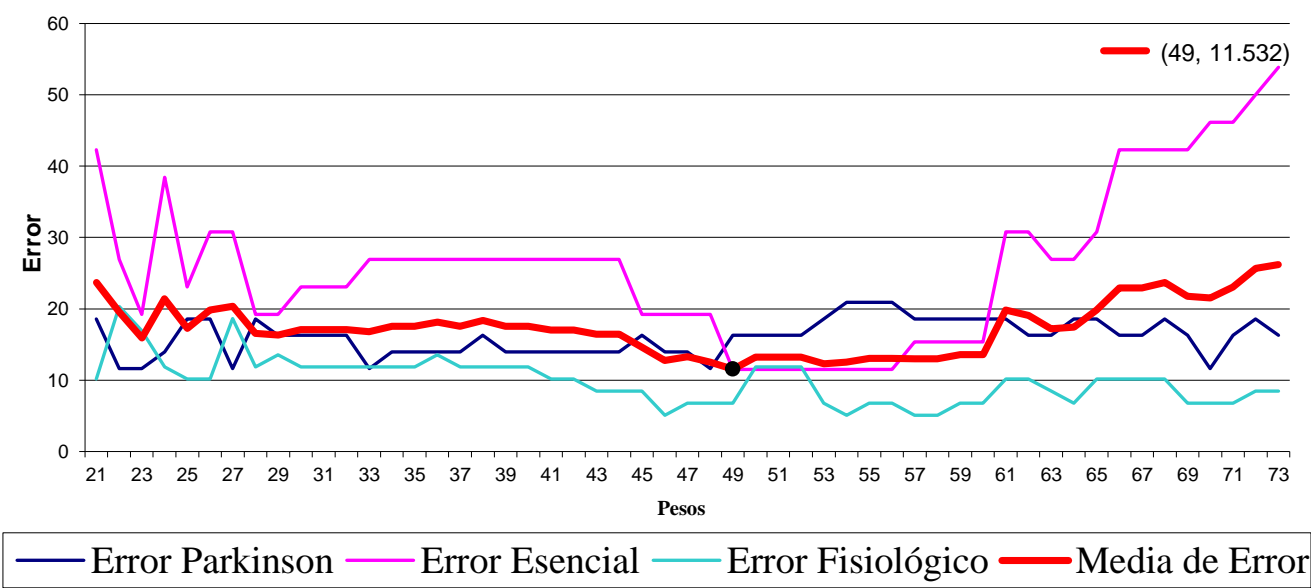

Figura 6.8: Variación del error obtenido en función del número de pesos. 
Para este caso, el número de pesos que proporciona menos error (11.53) son 49 pesos. Cabe destacar que en toda esta zona existe un error medio muy bajo. También habrá que tener en cuenta el valor relativo entre el número de pesos y el de vectores de entrenamiento. Este ratio será un parámetro importante pues nos permitirá extrapolar para diferentes casos y situaciones.

\subsection{Resultados en el espacio de características inicial.}

Sin análisis previo de ACP, probando diferentes combinaciones de características y patrones, de entre todos los experimentos realizados, a continuación se puede observar un resumen de los mejores resultados obtenidos. Dicha selección son las mejores situaciones encontradas respecto al error.

\subsubsection{Diferenciación entre temblor patológico y temblor fisiológico.}

Siguiendo un procedimiento de elección tanto del patrón como de las características, estudiando para cada caso el número de pesos más conveniente, se llegaron a estas conclusiones de los dos clasificadores mejores para diferenciar el temblor fisiológico y patológico.

\begin{tabular}{|l|l|}
\hline Características & $3-4-7-12$ \\
\hline Patrones & $3-8-9-10-13-14-18$ \\
\hline Pesos & $70^{\star} 0.80=56$ \\
\hline Épocas & 75 \\
\hline Porcentaje vectores simulación & $20 \%$ \\
\hline Vectores entrenamiento & 131 \\
\hline Vectores simulación & 32 \\
\hline
\end{tabular}

\begin{tabular}{|l|c|c|}
\hline & Con discontinuidades & Sin discontinuidades \\
\hline Media del error & 22.77 & 23.70 \\
\hline
\end{tabular}




\begin{tabular}{|l|l|}
\hline Características & $3-4-7-12$ \\
\hline Patrones & $3-8-9-10-13-14-18$ \\
\hline Pesos & $83^{*} 0.80=\sim 66$ \\
\hline Épocas & 75 \\
\hline Porcentaje vectores simulación & $20 \%$ \\
\hline Vectores entrenamiento & 131 \\
\hline Vectores simulación & 32 \\
\hline
\end{tabular}

\begin{tabular}{|l|c|c|}
\hline & Con discontinuidades & Sin discontinuidades \\
\hline Media del error & 21.61 & 23.41 \\
\hline
\end{tabular}

Los resultados obtenidos como pueden observarse no son mejores que con el perceptrón multicapa, que proporcionaba un error menor en la clasificación entre temblor fisiológico y temblor parkinsoniano. Se podrá comprobar más adelante que cuando se tratan previamente los datos (inclusión de ACP) se puede conseguir un mejor resultado.

\subsubsection{Diferenciación entre temblor de Párkinson y temblor esencial}

De la misma manera, efectuando el estudio entre Párkinson y temblor esencial, eligiendo de entre todas las combinaciones, el mejor resultado se obtuvo:

\begin{tabular}{|l|l|}
\hline Características & $4-6-18-24$ \\
\hline Patrones & $2-5-6-8-10-11-15-16$ \\
\hline Pesos & $50^{*} .80=40$ \\
\hline Épocas & 510 \\
\hline Porcentaje vectores simulación & $20 \%$ \\
\hline Vectores entrenamiento & 106 \\
\hline Vectores simulación & 26 \\
\hline
\end{tabular}

\begin{tabular}{|l|c|c|}
\hline & Con discontinuidades & Sin discontinuidades \\
\hline Media del error & $27.58 \%$ & $26.20 \%$ \\
\hline
\end{tabular}


Aquí sí que se aprecia una ganancia significativa respecto del resultado obtenido con el MLP. El error medio cometido en la diferenciación entre Párkinson y esencial está en torno a valores por debajo del 50\% del error que obtuvimos con el MLP. Este caso, aun siendo un resultado reseñable por el valor del error obtenido, sin embargo, es el único en el que el empleo de las discontinuidades no aportó una mejora en el resultado.

A continuación se muestra el resultado mejor de todos respecto al error medio conseguido:

\begin{tabular}{|l|l|}
\hline Características & $4-6-18-24$ \\
\hline Patrones & $2-8-10-11-15-16$ \\
\hline Pesos & $33^{*} .80=\sim 26$ \\
\hline Épocas & 90 \\
\hline Porcentaje vectores simulación & $20 \%$ \\
\hline Vectores entrenamiento & 80 \\
\hline Vectores simulación & 18 \\
\hline
\end{tabular}

\begin{tabular}{|l|c|c|}
\hline & Con discontinuidades & Sin discontinuidades \\
\hline Media del error & $18.61 \%$ & $26.66 \%$ \\
\hline
\end{tabular}

Este caso es el único en el que se ha bajado del 20\% y donde el efecto de las características 27 y 28 (la discontinuidad), resulta significativo en el resultado.

\subsubsection{Incluyendo el análisis de componentes principales (ACP).}

Cada vector de la base de datos está representada por 28 variables o componentes. El número de variables utilizadas para describir el movimiento del temblor puede llegar a ser demasiado alto. Para intentar resolver el problema se utilizará el Análisis de Componentes Principales. Reduciremos de esta forma dimensión del espacio de entrada a partir de la combinación lineal de variables.

Se aplicará el ACP a la base de datos total, formada por las pruebas realizadas a pacientes de Párkinson y temblor esencial.

Previo a la aplicación del ACP los valores son bastante dispares, esto es debido a que cada componente tiene magnitudes diferentes (por ejemplo la primera componente representa la amplitud, y la segunda la frecuencia). Por este motivo la nube de puntos de la población está muy dispersa. Una ventaja que ofrece el ACP es la estandarización de los datos. Esto se consigue dividiendo cada componente por su desviación estándar.

Realizando un cálculo de la varianza explicada sobre cada componente se obtiene el resultado mostrado en la Tabla 6.1: 


\begin{tabular}{|c|c|}
\hline Componentes & \% Varianza Explicada \\
\hline $\mathbf{1}$ & 30,37 \\
\hline $\mathbf{2}$ & 18,551 \\
\hline $\mathbf{3}$ & 12,556 \\
\hline $\mathbf{4}$ & 9,4542 \\
\hline $\mathbf{6}$ & 5,0265 \\
\hline $\mathbf{7}$ & 4,2437 \\
\hline $\mathbf{8}$ & 3,9253 \\
\hline $\mathbf{9}$ & 3,4782 \\
\hline $\mathbf{1 0}$ & 3,0239 \\
\hline $\mathbf{1 1}$ & 2,3643 \\
\hline $\mathbf{1 2}$ & 2,1046 \\
\hline $\mathbf{1 3}$ & 1,1918 \\
\hline $\mathbf{1 4}$ & 0,89873 \\
\hline $\mathbf{1 5}$ & 0,766 \\
\hline $\mathbf{1 6}$ & 0,59552 \\
\hline $\mathbf{1 7}$ & 0,43232 \\
\hline $\mathbf{1 8}$ & 0,32246 \\
\hline $\mathbf{1 9}$ & 0,21613 \\
\hline $\mathbf{2 0}$ & 0,21171 \\
\hline $\mathbf{2 1}$ & 0,13949 \\
\hline $\mathbf{2 2}$ & 0,090548 \\
\hline $\mathbf{2 3}$ & 0,024472 \\
\hline $\mathbf{2 4}$ & 0,0089388 \\
\hline $\mathbf{2 5}$ & 0,0017098 \\
\hline $\mathbf{2 6}$ & 0,0012156 \\
\hline $\mathbf{2 7}$ & 0,00096548 \\
\hline $\mathbf{2 8}$ & $2,1786 \mathrm{e}-010$ \\
\hline & $5,8073 \mathrm{e}-011$ \\
\hline
\end{tabular}

Tabla 6.1: Varianza explicada de cada característica tras el Análisis de Componentes Principales $(\mathrm{ACP})$.

Se observa claramente en los datos, que la inclusión de las últimas componentes respecto a la varianza explicada total, es mínima. Habrá que discriminar aquellas componentes que no aportan información con respecto a la varianza.

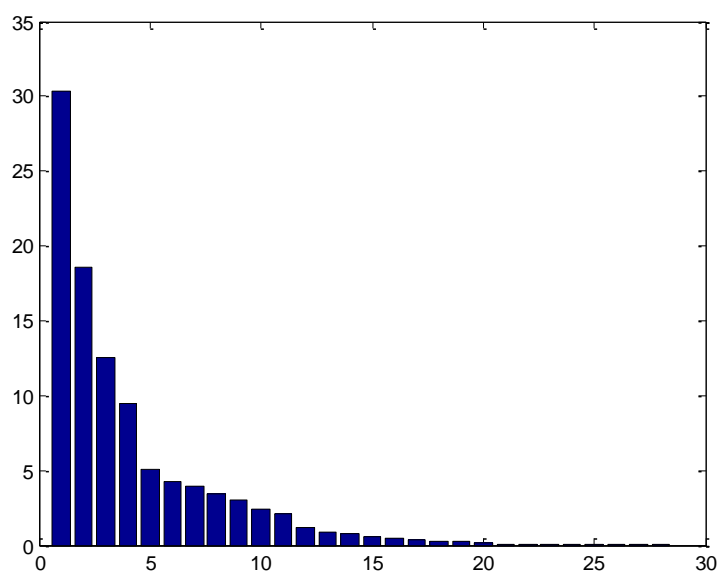

Figura 6.9: Diagrama de barras del tanto por ciento de varianza explicada. 
Utilizando un criterio, por ejemplo el de mantener las componentes que aporten el $99 \%$ de la varianza total y eliminar el resto, se reduce considerablemente el número de variables. El número de componentes que cumplen este requisito es de 17. Incluso con 10 componentes se consigue más del $90 \%$ de la varianza explicada total.

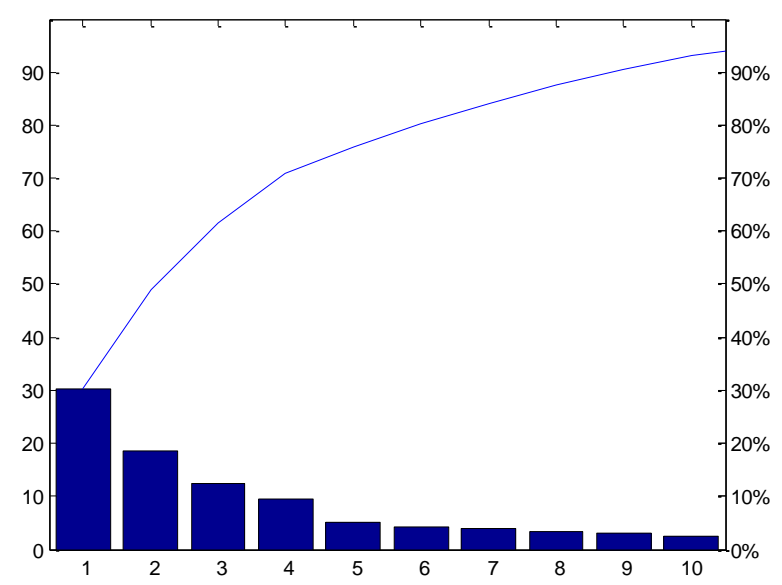

Figura 6.10: Gráfico de Pareto de las 10 primeras componentes.

Para visualizar de forma más clara la influencia del ACP sobre la base de datos inicial, se va a representar el espacio muestral respecto dos componentes originales Figura 6.11, y dos componentes trasformadas Figura 6.12.

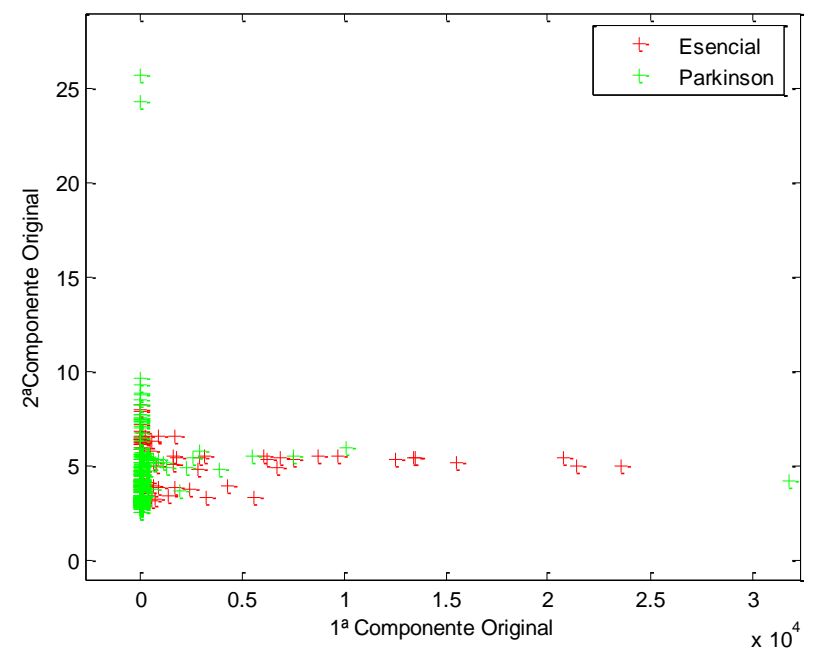

Figura 6.11: Espacio muestral representado respecto de dos componentes originales. 


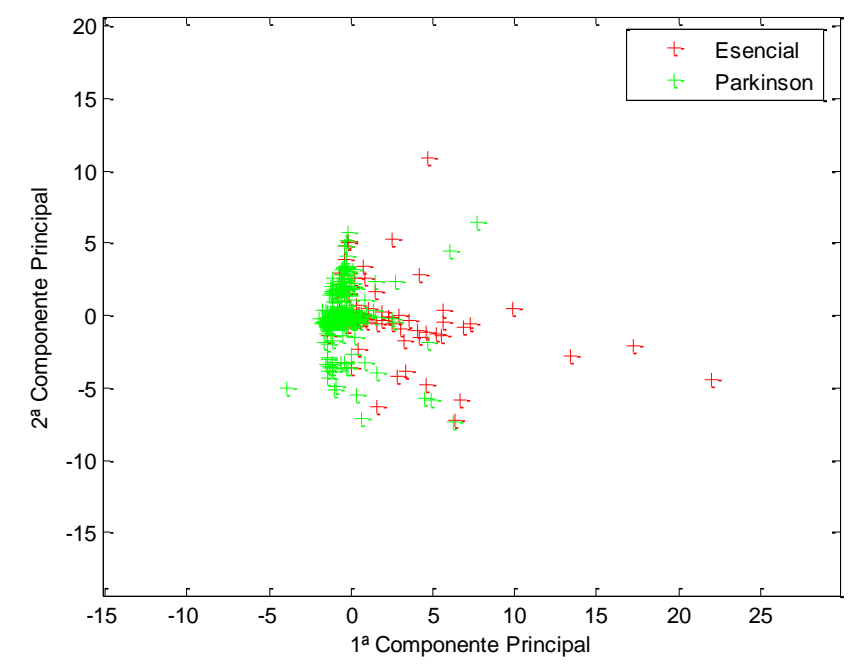

Figura 6.12: Espacio muestral representado mediante dos componentes principales.

En la Figura 6.11 y la Figura 6.12, se puede comprobar las ventajas de aplicar el Análisis de Componentes Principales. En la primera de ellas, se puede observar cómo la población de puntos está totalmente dispersa (el eje $\mathrm{X}$ representa cantidades de $10^{4}$ ). Esto es debido a que cada componente tiene diferentes unidades. Con la normalización que se aplica en el ACP, se observa en la segunda grafica como el rango de valores es el mismo. La segunda ventaja de la aplicación de ACP sobre la información de entrada a la red, es la separación de los subespacios de la nube de puntos.

A continuación se va a mostrar un pequeño resumen de los resultados obtenidos. Mostrando las condiciones del modelo de LVQ así como las condiciones del ensayo, respecto al número de vectores de entrenamiento y de prueba, así como si se incluyó ACP o no. 
Ensayo: 5

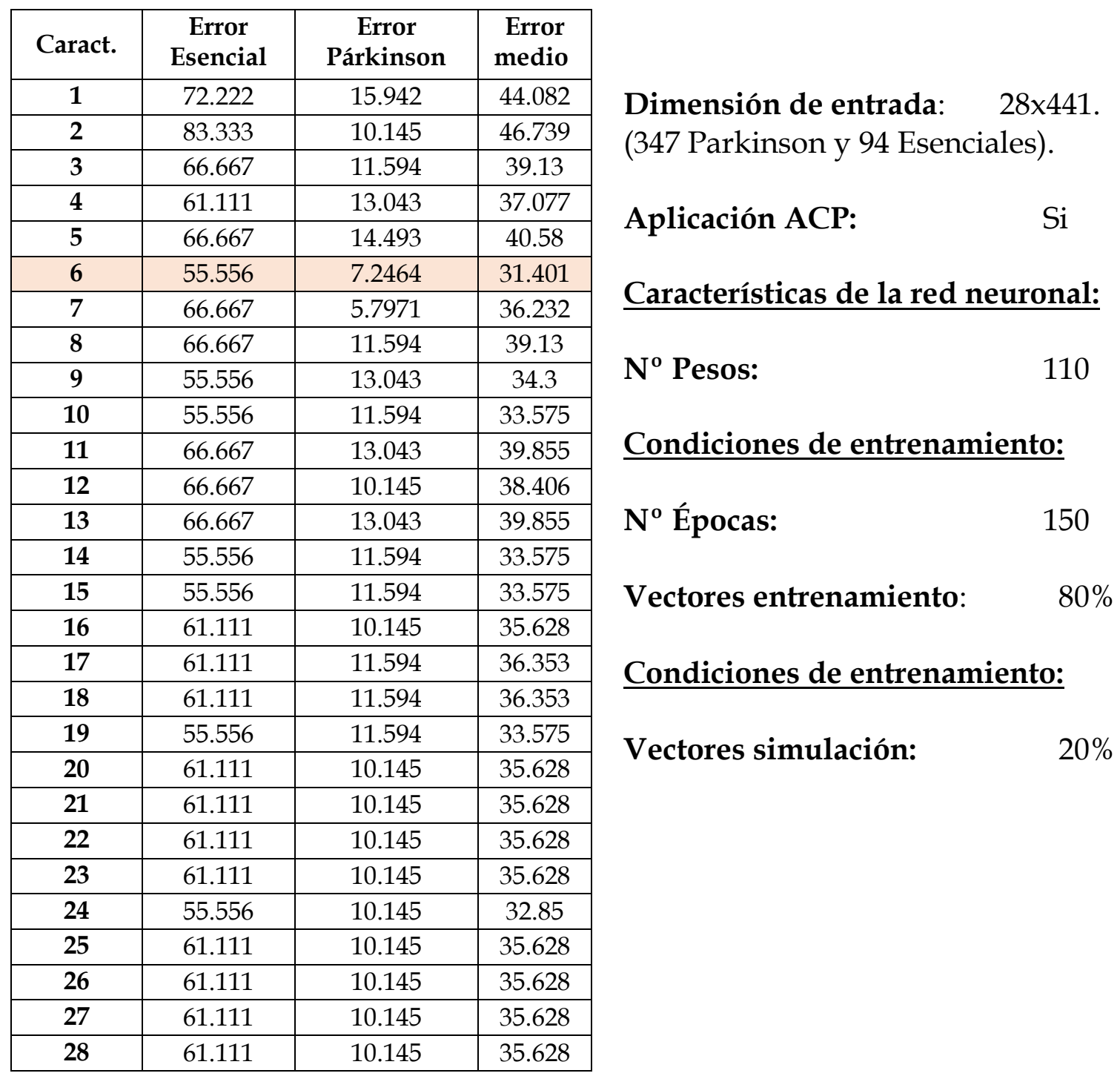
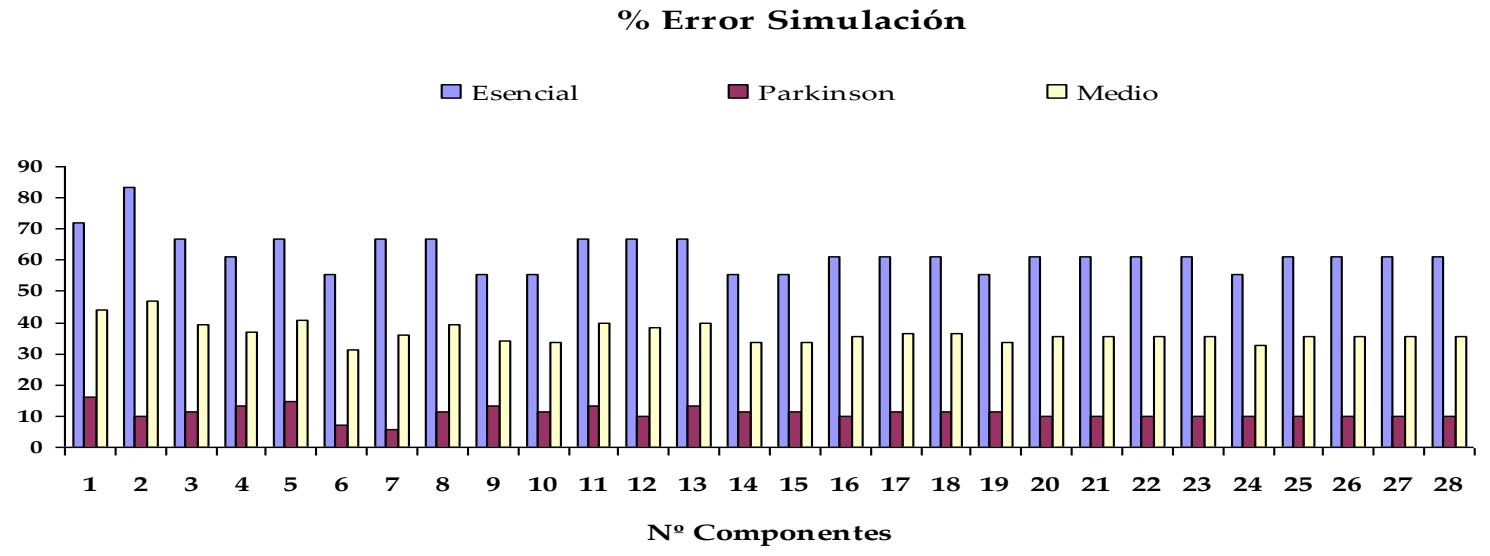


\section{Ensayo: 7}

\begin{tabular}{|c|c|c|c|}
\hline Caract. & $\begin{array}{c}\text { Error } \\
\text { Esencial }\end{array}$ & $\begin{array}{c}\text { Error } \\
\text { Párkinson }\end{array}$ & $\begin{array}{c}\text { Error } \\
\text { medio }\end{array}$ \\
\hline $\mathbf{1}$ & 22.222 & 15 & 18.611 \\
\hline $\mathbf{2}$ & 11.111 & 0 & 5.5556 \\
\hline $\mathbf{3}$ & 11.111 & 0 & 5.5556 \\
\hline $\mathbf{4}$ & 22.222 & 15 & 18.611 \\
\hline $\mathbf{5}$ & 16.667 & 5 & 10.833 \\
\hline $\mathbf{6}$ & 16.667 & 5 & 10.833 \\
\hline $\mathbf{7}$ & 16.667 & 5 & 10.833 \\
\hline $\mathbf{8}$ & 22.222 & 20 & 21.111 \\
\hline $\mathbf{9}$ & 27.778 & 15 & 21.389 \\
\hline $\mathbf{1 0}$ & 27.778 & 15 & 21.389 \\
\hline $\mathbf{1 1}$ & 27.778 & 15 & 21.389 \\
\hline $\mathbf{1 2}$ & 27.778 & 10 & 18.889 \\
\hline $\mathbf{1 3}$ & 27.778 & 10 & 18.889 \\
\hline $\mathbf{1 4}$ & 27.778 & 10 & 18.889 \\
\hline $\mathbf{1 5}$ & 27.778 & 10 & 18.889 \\
\hline $\mathbf{1 6}$ & 27.778 & 10 & 18.889 \\
\hline $\mathbf{1 7}$ & 33.333 & 10 & 21.667 \\
\hline $\mathbf{1 8}$ & 33.333 & 10 & 21.667 \\
\hline $\mathbf{1 9}$ & 33.333 & 10 & 21.667 \\
\hline $\mathbf{2 0}$ & 33.333 & 10 & 21.667 \\
\hline $\mathbf{2 1}$ & 33.333 & 10 & 21.667 \\
\hline $\mathbf{2 2}$ & 33.333 & 10 & 21.667 \\
\hline $\mathbf{2 3}$ & 33.333 & 10 & 21.667 \\
\hline $\mathbf{2 4}$ & 33.333 & 10 & 21.667 \\
\hline $\mathbf{2 5}$ & 27.778 & 5 & 16.389 \\
\hline $\mathbf{2 6}$ & 27.778 & 5 & 16.389 \\
\hline $\mathbf{2 7}$ & 33.333 & 10 & 21.667 \\
\hline $\mathbf{2 8}$ & 33.333 & 10 & 21.667 \\
\hline & & & \\
\hline
\end{tabular}

Grupos de entrada: $\quad 28 \times 195$

Esencial:

-Todos los patrones (94)

Párkinson:

- Patrones dinámicos (101)

Aplicación ACP: $\quad$ Si.

Características de la red neuronal:

No Pesos: $\quad 40$

Condiciones de entrenamiento:

No Épocas: $\quad 150$

Vectores entrenamiento: $\quad 80 \%$

Condiciones de simulación:

Vectores simulación: $\quad 20 \%$

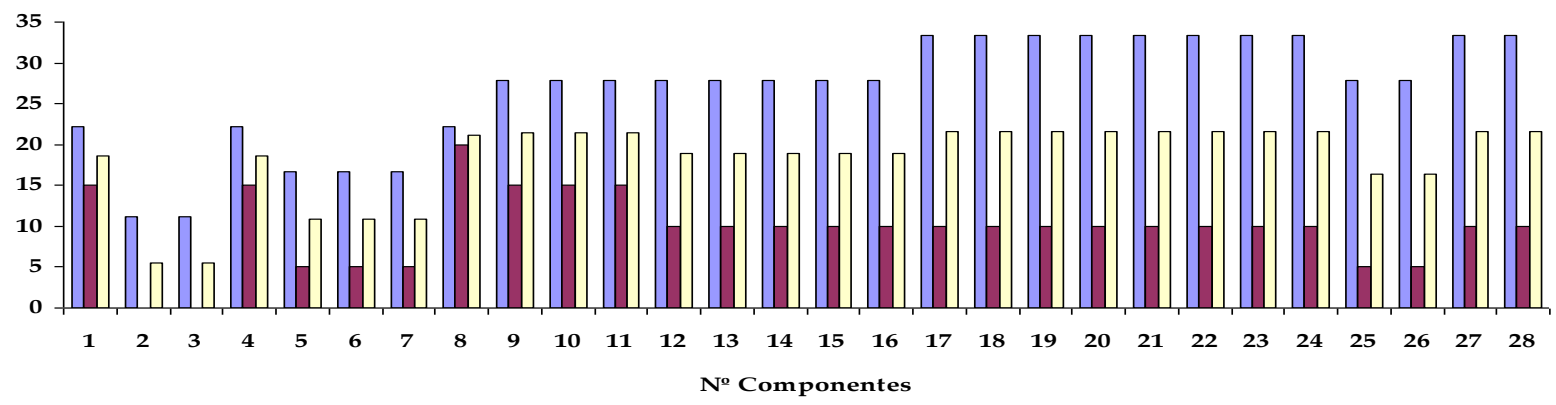




\section{Ensayo: 15}

\begin{tabular}{|c|c|c|c|}
\hline Caract. & $\begin{array}{c}\text { Error } \\
\text { Esencial }\end{array}$ & $\begin{array}{c}\text { Error } \\
\text { Párkinson }\end{array}$ & $\begin{array}{r}\text { Error } \\
\text { medio }\end{array}$ \\
\hline 1 & 27.778 & 42.105 & 34.942 \\
\hline 2 & 33.333 & 26.316 & 29.825 \\
\hline 3 & 44.444 & 21.053 & 32.749 \\
\hline 4 & 22.222 & 15.789 & 19.006 \\
\hline 5 & 33.333 & 21.053 & 27.193 \\
\hline 6 & 33.333 & 31.579 & 32.456 \\
\hline 7 & 33.333 & 21.053 & 27.193 \\
\hline 8 & 44.444 & 21.053 & 32.749 \\
\hline 9 & 33.333 & 10.526 & 21.93 \\
\hline 10 & 38.889 & 15.789 & 27.339 \\
\hline 11 & 38.889 & 21.053 & 29.971 \\
\hline 12 & 27.778 & 10.526 & 19.152 \\
\hline 13 & 38.889 & 10.526 & 24.708 \\
\hline 14 & 50 & 21.053 & 35.526 \\
\hline 15 & 50 & 26.316 & 38.158 \\
\hline 16 & 50 & 21.053 & 35.526 \\
\hline 17 & 50 & 15.789 & 32.895 \\
\hline 18 & 50 & 21.053 & 35.526 \\
\hline 19 & 50 & 21.053 & 35.526 \\
\hline 20 & 50 & 21.053 & 35.526 \\
\hline 21 & 50 & 10.526 & 30.263 \\
\hline 22 & 50 & 21.053 & 35.526 \\
\hline 23 & 50 & 21.053 & 35.526 \\
\hline 24 & 50 & 21.053 & 35.526 \\
\hline 25 & 50 & 21.053 & 35.526 \\
\hline 26 & 50 & 10.526 & 30.263 \\
\hline 27 & 50 & 21.053 & 35.526 \\
\hline 28 & 50 & 10.526 & 30.263 \\
\hline
\end{tabular}

Grupos de entrada: $\quad 28 \times 192$

Esencial:

- Todos los patrones (94)

Párkinson:

- Todos los patrones (98)

Aplicación ACP:

Si.

Características de la red neuronal:

$N^{0}$ Pesos:

40

Condiciones de entrenamiento:

No Épocas:

150

Vectores entrenamiento: $\quad 80 \%$

Condiciones de simulación:

Vectores simulación: $\quad 20 \%$

\% Error Simulación

$\square$ Esencial $\square$ Parkinson $\square$ Medio

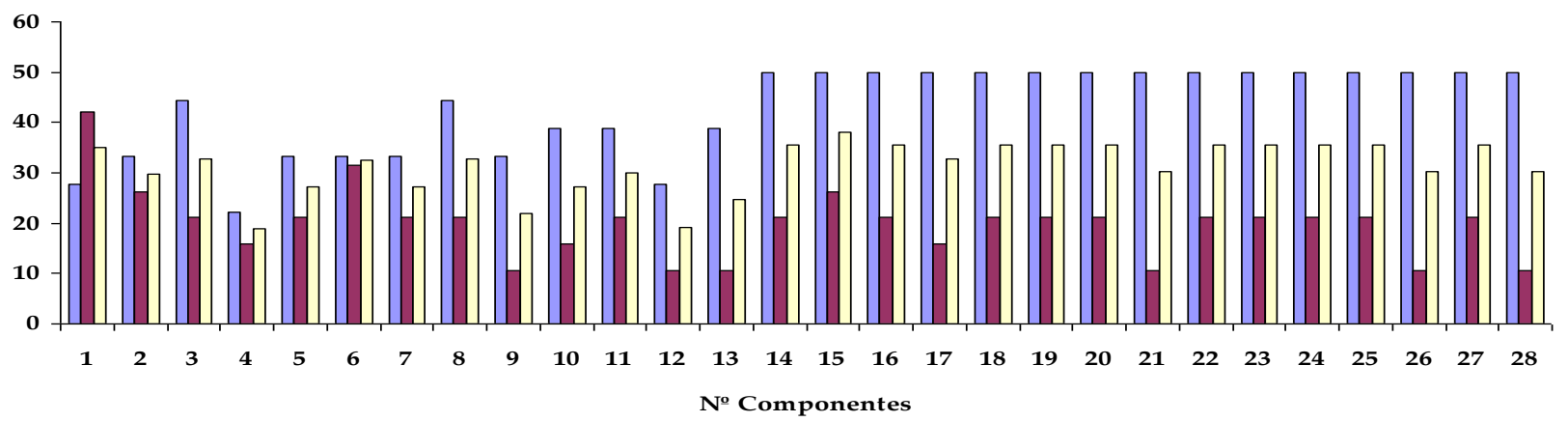


Ensayo: 19

\begin{tabular}{|c|c|c|c|}
\hline Caract. & $\begin{array}{c}\text { Error } \\
\text { Esencial }\end{array}$ & $\begin{array}{c}\text { Error } \\
\text { Párkinson }\end{array}$ & $\begin{array}{c}\text { Error } \\
\text { medio }\end{array}$ \\
\hline $\mathbf{1}$ & 27.778 & 25 & 26.389 \\
\hline $\mathbf{2}$ & 16.667 & 20 & 18.333 \\
\hline $\mathbf{3}$ & 22.222 & 15 & 18.611 \\
\hline $\mathbf{4}$ & 11.111 & 30 & 20.556 \\
\hline $\mathbf{5}$ & 11.111 & 15 & 13.056 \\
\hline $\mathbf{6}$ & 27.778 & 15 & 21.389 \\
\hline $\mathbf{7}$ & 16.667 & 15 & 15.833 \\
\hline $\mathbf{8}$ & 22.222 & 15 & 18.611 \\
\hline $\mathbf{9}$ & 16.667 & 35 & 25.833 \\
\hline $\mathbf{1 0}$ & 16.667 & 20 & 18.333 \\
\hline $\mathbf{1 1}$ & 22.222 & 20 & 21.111 \\
\hline $\mathbf{1 2}$ & 27.778 & 25 & 26.389 \\
\hline $\mathbf{1 3}$ & 33.333 & 20 & 26.667 \\
\hline $\mathbf{1 4}$ & 27.778 & 20 & 23.889 \\
\hline $\mathbf{1 5}$ & 16.667 & 20 & 18.333 \\
\hline $\mathbf{1 6}$ & 33.333 & 25 & 29.167 \\
\hline $\mathbf{1 7}$ & 33.333 & 25 & 29.167 \\
\hline $\mathbf{1 8}$ & 22.222 & 15 & 18.611 \\
\hline $\mathbf{1 9}$ & 27.778 & 20 & 23.889 \\
\hline $\mathbf{2 0}$ & 27.778 & 20 & 23.889 \\
\hline $\mathbf{2 1}$ & 27.778 & 20 & 23.889 \\
\hline $\mathbf{2 2}$ & 27.778 & 20 & 23.889 \\
\hline $\mathbf{2 3}$ & 27.778 & 20 & 23.889 \\
\hline $\mathbf{2 4}$ & 27.778 & 20 & 23.889 \\
\hline $\mathbf{2 5}$ & 27.778 & 20 & 23.889 \\
\hline $\mathbf{2 6}$ & 27.778 & 20 & 23.889 \\
\hline $\mathbf{2 7}$ & 27.778 & 20 & 23.889 \\
\hline $\mathbf{2 8}$ & 27.778 & 20 & 23.889 \\
\hline & & & \\
\hline
\end{tabular}

Grupos de entrada: $\quad 28 \times 196$

Esencial:

-Todos los patrones (94)

Parkinson:

- Estáticos y dinámicos (102)

Aplicación ACP: Si.

Características de la red neuronal:

No Pesos: $\quad 40$

Condiciones de entrenamiento:

No Épocas: $\quad 150$

Vectores entrenamiento: $\quad 80 \%$

Condiciones de simulación:

Vectores simulación: $\quad 20 \%$

\% Error Simulación

$\square$ Esencial $\square$ Parkinson $\square$ Medio

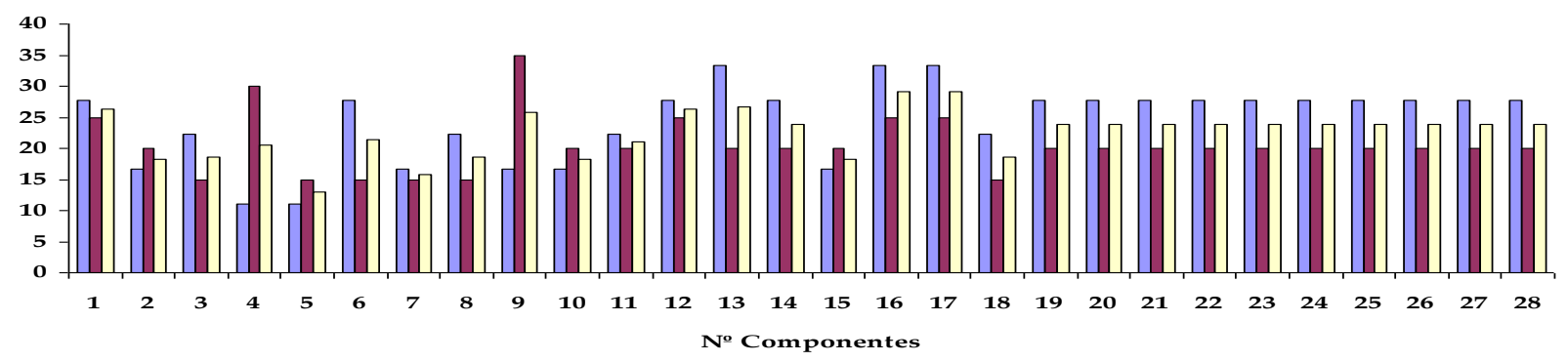


Ensayo: 25

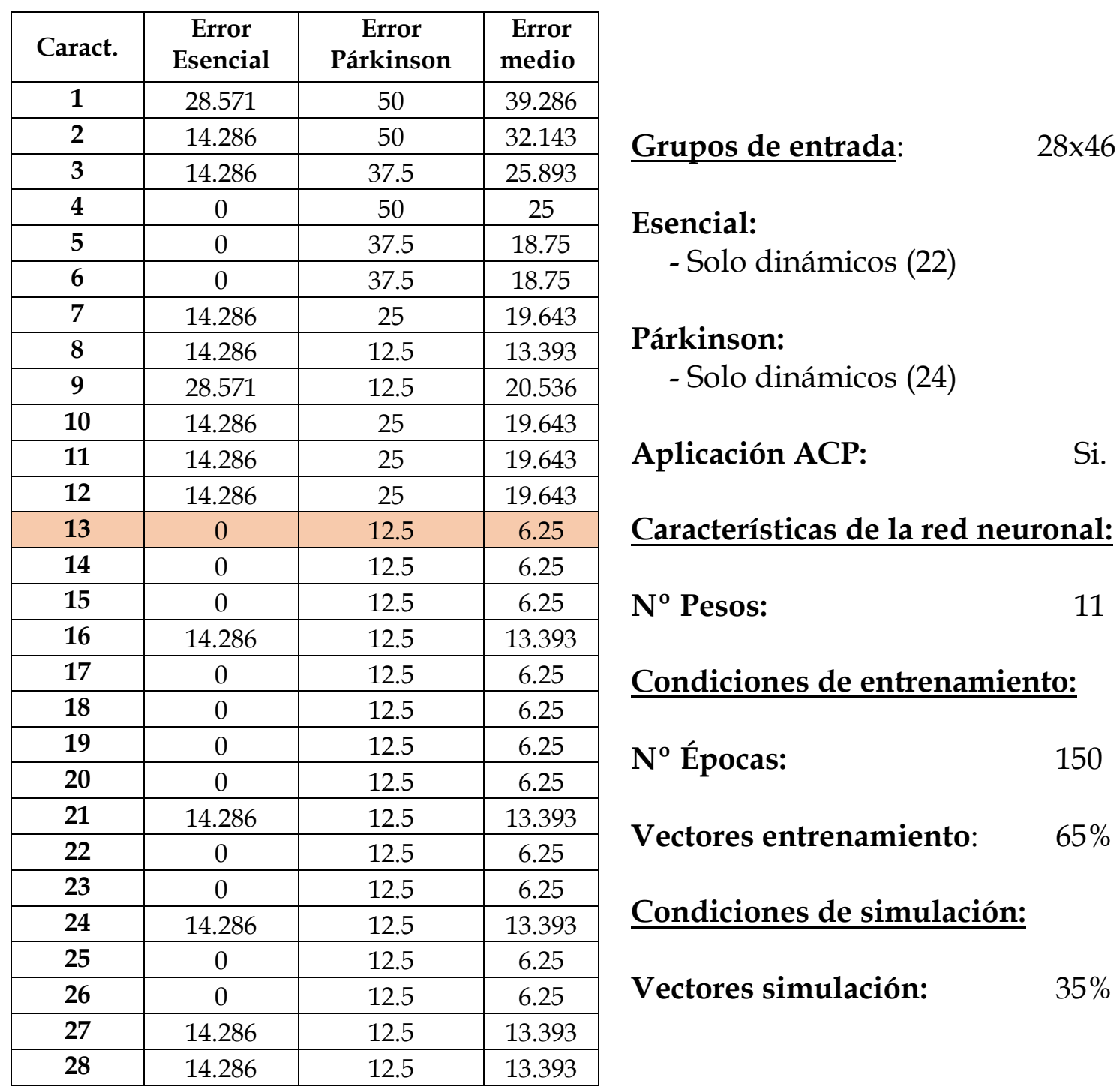

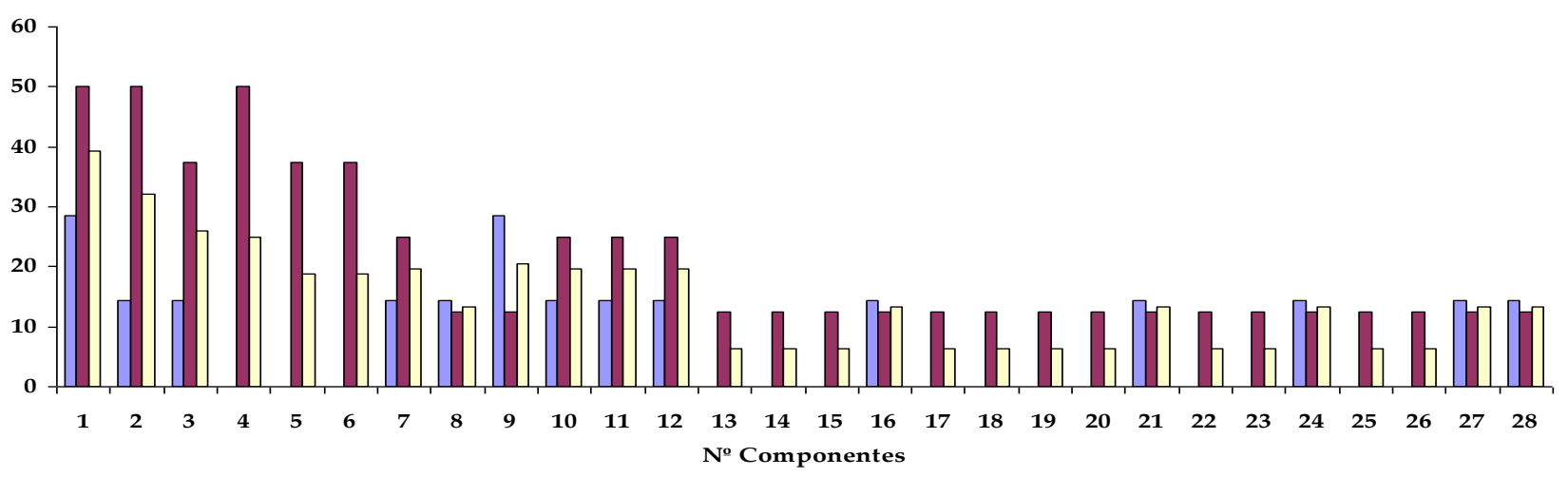


Ensayo: 31

\begin{tabular}{|c|c|c|c|}
\hline Caract. & $\begin{array}{c}\text { Error } \\
\text { Esencial }\end{array}$ & $\begin{array}{c}\text { Error } \\
\text { Párkinson }\end{array}$ & $\begin{array}{c}\text { Error } \\
\text { medio }\end{array}$ \\
\hline $\mathbf{1}$ & 0 & 63.636 & 31.818 \\
\hline $\mathbf{2}$ & 9.0909 & 27.273 & 18.182 \\
\hline $\mathbf{3}$ & 18.182 & 18.182 & 18.182 \\
\hline $\mathbf{4}$ & 18.182 & 18.182 & 18.182 \\
\hline $\mathbf{5}$ & 9.0909 & 36.364 & 22.727 \\
\hline $\mathbf{6}$ & 18.182 & 9.0909 & 13.636 \\
\hline $\mathbf{7}$ & 18.182 & 18.182 & 18.182 \\
\hline $\mathbf{8}$ & 9.0909 & 27.273 & 18.182 \\
\hline $\mathbf{9}$ & 9.0909 & 18.182 & 13.636 \\
\hline $\mathbf{1 0}$ & 0 & 27.273 & 13.636 \\
\hline $\mathbf{1 1}$ & 0 & 27.273 & 13.636 \\
\hline $\mathbf{1 2}$ & 9.0909 & 18.182 & 13.636 \\
\hline $\mathbf{1 3}$ & 0 & 18.182 & 9.0909 \\
\hline $\mathbf{1 4}$ & 9.0909 & 9.0909 & 9.0909 \\
\hline $\mathbf{1 5}$ & 9.0909 & 9.0909 & 9.0909 \\
\hline $\mathbf{1 6}$ & 9.0909 & 9.0909 & 9.0909 \\
\hline $\mathbf{1 7}$ & 9.0909 & 9.0909 & 9.0909 \\
\hline $\mathbf{1 8}$ & 18.182 & 9.0909 & 13.636 \\
\hline $\mathbf{1 9}$ & 9.0909 & 9.0909 & 9.0909 \\
\hline $\mathbf{2 0}$ & 9.0909 & 9.0909 & 9.0909 \\
\hline $\mathbf{2 1}$ & 9.0909 & 9.0909 & 9.0909 \\
\hline $\mathbf{2 2}$ & 9.0909 & 9.0909 & 9.0909 \\
\hline $\mathbf{2 3}$ & 9.0909 & 9.0909 & 9.0909 \\
\hline $\mathbf{2 4}$ & 9.0909 & 9.0909 & 9.0909 \\
\hline $\mathbf{2 5}$ & 9.0909 & 9.0909 & 9.0909 \\
\hline $\mathbf{2 6}$ & 9.0909 & 9.0909 & 9.0909 \\
\hline $\mathbf{2 7}$ & 9.0909 & 9.0909 & 9.0909 \\
\hline $\mathbf{2 8}$ & 9.0909 & 9.0909 & 9.0909 \\
\hline & & & \\
\hline
\end{tabular}

Grupos de entrada:

$28 \times 111$

Esencial:

- Solo cinéticos (55)

Parkinson:

- Solo cinéticos (56)

Aplicación ACP: $\quad$ Si.

Características de la red neuronal:

$N^{0}$ Pesos:

25

Condiciones de entrenamiento:

No Épocas: $\quad 150$

Vectores entrenamiento: $\quad 80 \%$

Condiciones de simulación:

Vectores simulación: $\quad 20 \%$

\% Error Simulación

$\square$ Esencial $\square$ Parkinson $\square$ Medio

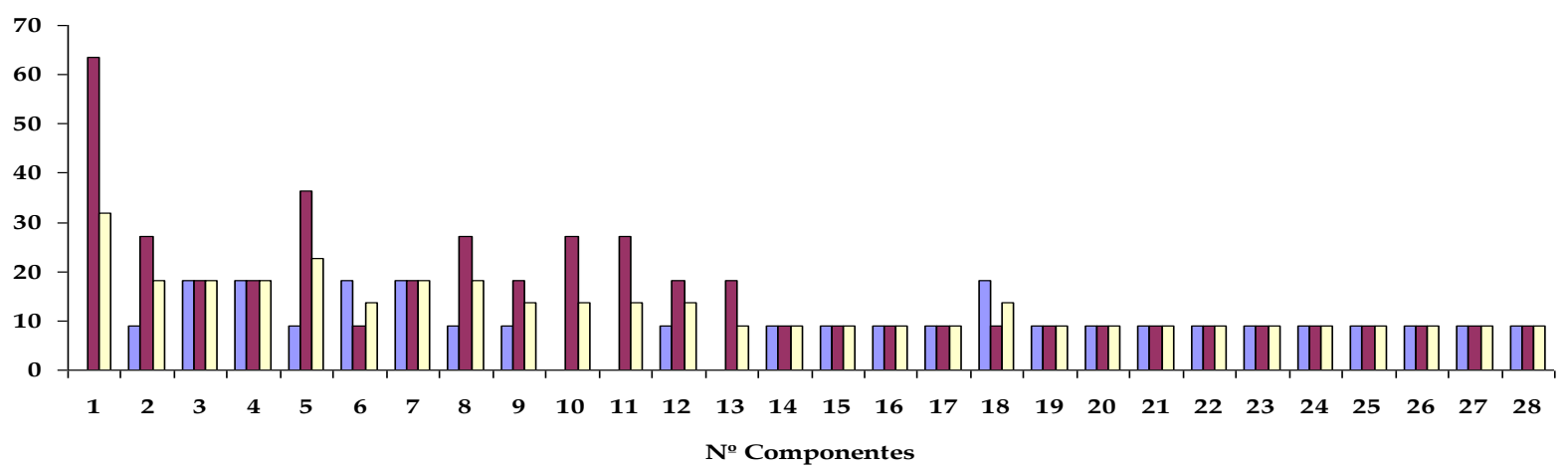


En la Tabla 6.2 se muestran los resultados obtenidos a modo de resumen considerando todos los casos y condiciones estudiadas.

\section{TABLA RESUMEN DE RESULTADOS}

\begin{tabular}{|c|c|c|c|c|c|c|c|c|c|c|}
\hline \multirow{3}{*}{$\begin{array}{l}\text { ENSAYOS } \\
\text { Todos (1) }\end{array}$} & \multicolumn{10}{|c|}{ CARACTERISTICAS } \\
\hline & \multicolumn{2}{|c|}{$\begin{array}{c}\text { TAMAÑO } \\
\text { G.ENTRADA }\end{array}$} & \multirow{2}{*}{$\begin{array}{c}\text { PESOS } \\
110 \\
\end{array}$} & \multirow{2}{*}{$\frac{\text { EPOCAS }}{150}$} & \multirow{2}{*}{$\frac{\mathrm{ACP}}{\mathrm{NO}}$} & \multirow{2}{*}{\begin{tabular}{|l|}
$\% E-S$ \\
$80-20$
\end{tabular}} & \multicolumn{3}{|c|}{$\begin{array}{l}\text { Error }(\%) \\
\text { E-P - Medio }\end{array}$} & \multirow{2}{*}{$\begin{array}{c}\text { CRTC } \\
1\end{array}$} \\
\hline & $28 \times 94$ & $28 \times 347$ & & & & & 50 & 24 & 37 & \\
\hline Todos (2) & $28 \times 94$ & $28 \times 347$ & 110 & 150 & $\mathrm{NO}$ & $80-20$ & 55 & 11 & 33 & 3 \\
\hline Todos (3) & $28 \times 94$ & $28 \times 347$ & 110 & 150 & NO & $80-20$ & 55 & 13 & 62 & 13 \\
\hline Todos (4) & $28 \times 94$ & $28 \times 347$ & 110 & 150 & SI & $80-20$ & 44 & 11 & 28 & 8 \\
\hline Todos (5) & $28 \times 94$ & $28 \times 347$ & 110 & 150 & $\mathrm{SI}$ & $80-20$ & 55 & 7 & 31 & 6 \\
\hline Todos (6) & $28 \times 94$ & $28 \times 347$ & 110 & 150 & SI & $80-20$ & 61 & 10 & 36 & 7 \\
\hline P: Din E:todos (7) & $28 \times 94$ & $28 \times 101$ & 40 & 150 & $\mathrm{SI}$ & $80-20$ & 11 & 0 & 6 & 2,3 \\
\hline P: Din E:todos (8) & $28 \times 94$ & $28 \times 101$ & 40 & 150 & SI & $80-20$ & 22 & 15 & 19 & 6,26 \\
\hline P: Din E:todos (9) & $28 \times 94$ & $28 \times 101$ & 60 & 150 & SI & $80-20$ & 5 & 25 & 15 & $8 \ldots$ \\
\hline P: Din E:todos (10) & $28 \times 94$ & $28 \times 101$ & 60 & 150 & SI & $80-20$ & 22 & 20 & 21 & 1 \\
\hline P: Din E:todos (11) & $28 \times 94$ & $28 \times 101$ & 70 & 150 & $\mathrm{SI}$ & $80-20$ & 11 & 15 & 13 & 5 \\
\hline P: Din E:todos (12) & $28 \times 94$ & $28 \times 101$ & 40 & 150 & SI & $60-40$ & 21 & 17 & 19 & 24,26 \\
\hline P: Din E:todos (13) & $28 \times 94$ & $28 \times 101$ & 40 & 150 & $\mathrm{SI}$ & $70-30$ & 28 & 10 & 19 & $12,17,20$ \\
\hline P: Din E:todos (14) & $28 \times 94$ & $28 \times 101$ & 40 & 150 & SI & $80-20$ & 11 & 0 & 6 & 2,3 \\
\hline P: Todos E: todos (15) & $28 \times 94$ & $28 \times 98$ & 40 & 150 & SI & $80-20$ & 22 & 16 & 19 & 4 \\
\hline P: Todos E: todos (16) & $28 \times 94$ & $28 \times 98$ & 40 & 150 & SI & $80-20$ & 16 & 15 & 16 & 5 \\
\hline P: Todos E: todos (17) & $28 \times 94$ & $28 \times 98$ & 40 & 150 & SI & $80-20$ & 22 & 26 & 24 & 2 \\
\hline P: Todos E: todos (18) & $28 \times 94$ & $28 \times 98$ & 40 & 150 & SI & $80-20$ & 27 & 10 & 19 & 7 \\
\hline P: Est_Din E: todos (19) & $28 \times 94$ & $28 \times 102$ & 40 & 150 & $\mathrm{SI}$ & $80-20$ & 11 & 15 & 13 & 5 \\
\hline P: Est_Din E: todos (20) & $28 \times 94$ & $28 \times 102$ & 40 & 150 & $\mathrm{SI}$ & $80-20$ & 22 & 20 & 21 & 2 \\
\hline P: Est_Din E: todos (21) & $28 \times 94$ & $28 \times 102$ & 40 & 150 & SI & $80-20$ & 22 & 20 & 21 & 5 \\
\hline P: Est_Din E: todos (22) & $28 \times 94$ & $28 \times 102$ & 40 & 150 & $\mathrm{SI}$ & $80-20$ & 33 & 20 & 27 & 2 \\
\hline P: Din E: Din (23) & $28 \times 22$ & $28 \times 24$ & 9 & 150 & $\mathrm{SI}$ & $80-20$ & 50 & 0 & 25 & $2-3$ \\
\hline P: Din E: Din (24) & $28 \times 22$ & $28 \times 24$ & 11 & 150 & SI & $80-20$ & 25 & 25 & 25 & 3 \\
\hline P: Din E: Din (25) & $28 \times 22$ & $28 \times 24$ & 11 & 150 & SI & $65-35$ & 0 & 12 & 6 & $13 .$. \\
\hline P: Din E: Din (26) & $28 \times 22$ & $28 \times 24$ & 9 & 150 & $\mathrm{SI}$ & $65-35$ & 42 & 25 & 34 & $10 \ldots$ \\
\hline P: Din E: Din (27) & $28 \times 22$ & $28 \times 24$ & 11 & 150 & $\mathrm{SI}$ & $70-30$ & 16 & 0 & 8 & 7,8 \\
\hline P: Din E: Din (28) & $28 \times 22$ & $28 \times 24$ & 11 & 150 & SI & $70-30$ & 0 & 28 & 14 & $18 \ldots$ \\
\hline P: Cin E: Cin (29) & $28 \times 55$ & $28 \times 56$ & 25 & 150 & $\mathrm{SI}$ & $80-20$ & 27 & 27 & 27 & $6-8$ \\
\hline P: Cin E: Cin (30) & $28 \times 55$ & $28 \times 56$ & 25 & 150 & SI & $80-20$ & 18 & 27 & 23 & $15,20,21$ \\
\hline P: Cin E: Cin (31) & $28 \times 55$ & $28 \times 56$ & 25 & 150 & $\mathrm{SI}$ & $80-20$ & 9 & 9 & 9 & 14. \\
\hline P: Cin E: Cin (32) & $28 \times 55$ & $28 \times 56$ & 25 & 150 & $\mathrm{SI}$ & $80-20$ & 9 & 9 & 9 & 11 \\
\hline
\end{tabular}

Tabla 6.2: Resumen de resultados con LVQ. 
El primer comentario que se puede hacer en vista de los resultados, es que el ACP resulta ser todo un éxito en la mejora del error. La segunda conclusión general es que con la red LVQ se mejora considerablemente el éxito en la clasificación entre temblor esencial y temblor de Párkinson. Bajando por debajo ya de la mitad del error obtenido con los MLPs en los primeros ensayos sin ACP.

Otra conclusión evidente es la importancia del tipo de patrón en la clasificación. Como se esperaba desde un principio, el hecho de que los temblores parkinsonianos tiendan a comportarse, en líneas generales, diferente a los temblores esenciales ante la presencia de estímulos (fuerzas virtuales), permite arrojar unos resultados francamente buenos. Para el caso del ensayo 25 (Tabla 6.2), en donde sólo se utilizan los patrones dinámicos, el error de clasificación para los enfermos de temblor esencial ha sido del $0 \%$, y para los temblores parkinsonianos del $12 \%$. El error medio de este caso arroja un 6\% que es una cifra realmente baja. Aunque desde el punto de vista del éxito de clasificación de los enfermos de Párkinson fue el ensayo número 7 , donde tomando también como base los patrones dinámicos, el grado de acierto de los enfermos de Párkinson fue del 100\%. Sin embargo, el de esencial fue del 89\%. Dando como media un error idéntico al del caso anterior (ensayo 25) sobre el $6 \%$. También puede concluirse en que los patrones cinéticos también aportan a la ayuda del diagnóstico diferencial, ya que aun siendo el error levemente superior a los casos citados anteriormente (9\%), también arrojan unos buenos resultados, siendo el comportamiento del clasificador mucho más homogéneo.

En conclusión de conjunto, ante estos resultados, queda patente que las redes LVQ pueden ser un clasificador válido para el diagnóstico diferencial entre enfermos (temblor patológico) y que dicha clasificación eficaz se sostiene por la elección de los tipos de patrones planteados inicialmente. 


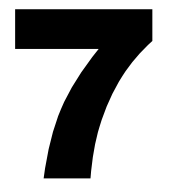

\section{CLASIFICACIÓN DEL TEMBLOR} MEDIANTE MÁQUINAS DE SOPORTE VECTORIAL (SVM).

Empezaremos el estudio de aplicación de las SVMs a la clasificación del temblor considerando las mismas pruebas que se utilizaron para los perceptrones multicapa (MLP) y las redes LVQ.

Vamos a desglosar los objetivos planteando varias hipótesis de trabajo. Primero estudiaremos los resultados de clasificación utilizando únicamente los dos factores que demostraron ser relevantes en el análisis de la varianza del capítulo 3: la amplitud y la frecuencia del temblor. En segundo lugar utilizaremos el conjunto de 26 características iniciales que se consideraron en los MLP: PSD y HOS. Y por último añadiremos el estudio de componentes principales (ACP).

\subsection{Selección de la función kernel.}

Como ya se mencionó en el capítulo 4 la función kernel es la encargada de convertir las características del espacio de entrada en un espacio de nivel superior. Partimos de la base de que nos enfrentamos a un problema no separable linealmente, por lo que se tendrá que recurrir al uso de dichas funciones.

El kernel gaussiano (RBF) tiene generalmente un buen comportamiento siempre que los parámetros $C$ y $\gamma$ sean seleccionados con un procedimiento de validación cruzada. Una característica de la función kernel es que mantiene los valores en un rango $0<K\left(\vec{x}_{i}, \vec{x}_{j}\right) \leq 1$, disminuyendo así la complejidad numérica.

Un kenel lineal es un caso particular de kernel gaussiano [99], dado que el kernel lineal con un parámetro $C$ tiene un comportamiento similar que un gaussiano cuando $\sigma^{2} \rightarrow \infty$ y $C=\sigma^{2} \tilde{C}$. De igual modo el kernel sigmoidal puede asemejarse también a un kernel guassiano bajo ciertas condiciones, sin embargo la función sigmoidal no siempre garantiza que la matriz sea definida semi-positiva, siendo una 
de las condiciones fundamentales. La función kernel polinomial puede presentar algunos problemas, ya que $\left(p+\vec{x}_{i} \cdot \vec{x}_{j}>1\right)^{d}$ puede tender a infinito, a la vez que $\left(p+\vec{x}_{i} \cdot \vec{x}_{j}<1\right)^{d}$ puede tender a cero si $d$ es alto.

\subsection{Selección de parámetros. Validación cruzada.}

Hay ciertos parámetros que han de seleccionarse antes de proceder al entrenamiento. Son los prámetros del kernel y el valor de regulación $C$. Existen algoritmos de optimización para garantizar una elección adecuada de dichos parámetros. En el trabajo desarrollado en esta tesis se utilizó la herramienta LIBSVM [101], no sólo para la optimización de los parámetros del modelo de cada máquina, sino también para la selección y normalización de los vectores de entrenamiento (prueba y entrenamiento), el propio entrenamiento en sí, así como las pruebas de simulación de cada modelo.

Por lo mencionado en el apartado anterior, se centrará el estudio en los kernels gaussianos:

$$
K\left(\vec{x}_{i}, \vec{x}_{j}\right)=\exp \left(\gamma\left\|\vec{x}_{i}-\vec{x}_{j}\right\|^{2}\right)
$$

Donde $\gamma=-1 / 2 \sigma^{2}$ según la expresión ya expuesta en (4-116). El error dependerá de la elección de la pareja $(C, \gamma)$. Al utilizar la librería antes citada se pueden dejar que por defecto la propia función los inicialice, inicializarnos manualmente de manera heurística o utilizar el algoritmo de validación cruzada.

La validación cruzada consiste en partir del conjunto de vectores de entrenamiento subdividiendo la muestra en $n$ subconjuntos de igual tamaño. De manera rotativa o secuencial, el subconjunto se prueba con el clasificador entrenado con los n-1 restantes. De esta manera todos los vectores de entrenamiento son sometidos a simulación alguna vez. Este procedimiento permite prevenir problemas de sobreajuste o sobre-entrenamiento.

\subsection{Metodología de los ensayos.}

A continuación se relacionan los pasos que se han llevado a cabo para cada uno de los ensayos o pruebas.

- Elección de porcentajes de entrenamiento y simulación.

- Normalización de los datos

- Elección del kernel.

- Selección de parámetros mediante validación cruzada.

- Entrenamiento de la máquina.

- Clasificación de los vectores de prueba. 


\subsection{Análisis con la amplitud y la frecuencia del temblor.}

Los datos sobre los que se realizó el estudio son los siguientes:

\begin{tabular}{|c|c|c|c|c|}
\hline \multicolumn{3}{|c|}{ Pruebas del estudio } & \multicolumn{2}{c|}{$\begin{array}{c}\text { Porcentaje entrenamiento - } \\
\text { simulación (\%) }\end{array}$} \\
\hline \multirow{2}{*}{$\begin{array}{c}\text { Temblor } \\
\text { fisiológico }\end{array}$} & $\begin{array}{c}\text { Temblor patológico } \\
\text { Temblor } \\
\text { esencial (TE) }\end{array}$ & $\begin{array}{c}\text { Enfermedad de } \\
\text { Parkinson (EP) }\end{array}$ & $\begin{array}{c}\text { Conjunto de } \\
\text { vectores de } \\
\text { entrenamiento }\end{array}$ & $\begin{array}{c}\text { Conjunto de } \\
\text { vectores de } \\
\text { prueba }\end{array}$ \\
\hline 36 & 10 & 30 & 70 & 30 \\
\hline
\end{tabular}

Tabla 7.1: Resumen de los datos.

Los vectores de entrada tanto para el entrenamiento como para la simulación tienen dos características únicamente: la amplitud máxima y la frecuencia del armónico máximo en cada uno de los ejes $x, y$ y $z$.

Los patrones utilizados fueron un conjunto de los que mejores resultados proporcionaron en el estudio anterior de LVQs.

Los resultados obtenidos para los distintos kernel probados fueron los siguientes:

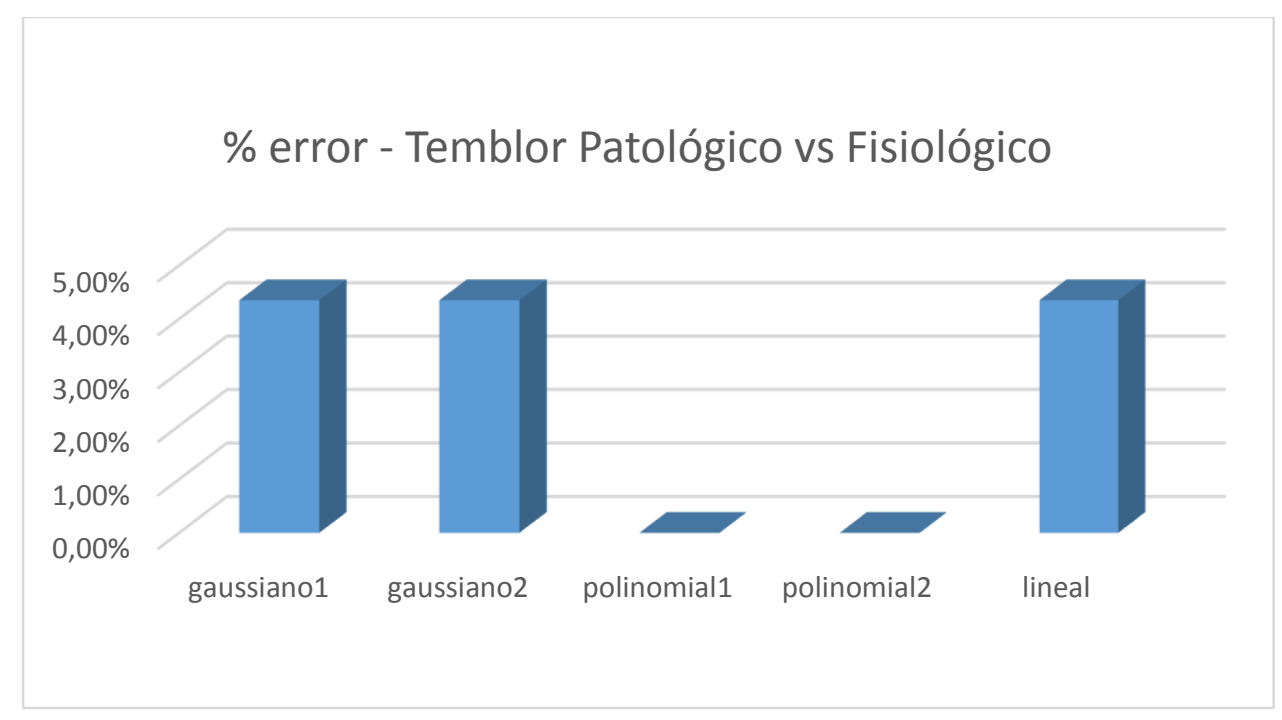

Figura 7.1: Clasificación Temblor Fisiológico vs Temblor Patológico. 


\begin{tabular}{|c|c|c|c|c|c|c|c|}
\hline \multicolumn{2}{|c|}{$\begin{array}{c}\text { Selección del } \\
\text { modelo }\end{array}$} & \multirow{2}{*}{\multicolumn{2}{|c|}{$\begin{array}{c}\text { Fase de } \\
\text { Entrenamiento } \\
\text { Parámetros de ajuste } \\
\end{array}$}} & \multicolumn{2}{|c|}{$\begin{array}{l}\text { Modelo del } \\
\text { Clasificador }\end{array}$} & \multicolumn{2}{|c|}{ Resultados } \\
\hline \multirow{2}{*}{\multicolumn{2}{|c|}{$\begin{array}{c}\text { Función } \\
\text { Kernel }\end{array}$}} & & & \multirow[b]{2}{*}{ bias (b) } & \multirow{2}{*}{$\begin{array}{c}\mathrm{N}^{\mathrm{o}} \\
\text { vectores } \\
\text { soporte, } \\
\text { VS }\end{array}$} & \multirow[b]{2}{*}{$\begin{array}{l}\text { Error de } \\
\text { entrenam. }\end{array}$} & \multirow[b]{2}{*}{$\begin{array}{c}\text { Error de } \\
\text { prueba }\end{array}$} \\
\hline & & $\mathrm{C}$ & gamma $(\Upsilon)$ & & & & \\
\hline \multirow{2}{*}{\multicolumn{2}{|c|}{$\begin{array}{c}\text { Gaussiano } \\
\text { RBF }\end{array}$}} & 128 & 0.0039 & -0.98 & 14 & $1.89 \%$ & $4.35 \%$ \\
\hline & & 64 & 0.0039 & -0.93 & 17 & $1.89 \%$ & $4.35 \%$ \\
\hline \multirow{2}{*}{ Polinomial } & 2 & 128 & - & 1.12 & 24 & - & $0.00 \%$ \\
\hline & 3 & 1024 & - & 0.97 & 29 & - & $0.00 \%$ \\
\hline \multicolumn{2}{|l|}{ Lineal } & 2 & - & 2.24 & 14 & $24.53 \%$ & $4.35 \%$ \\
\hline
\end{tabular}

Tabla 7.2: Clasificación Temblor Fisiológico vs Temblor Patológico.

La Figura 7.1 y la Tabla 7.2 muestran los mejores resultados obtenidos hasta ahora para la clasificación entre temblor fisiológico y temblor patológico: 100\% de acierto para kernel polinomial y $96 \%$ aproximadamente para el kérnel de base radial.

\section{\% error - Párkinson vs Esencial}

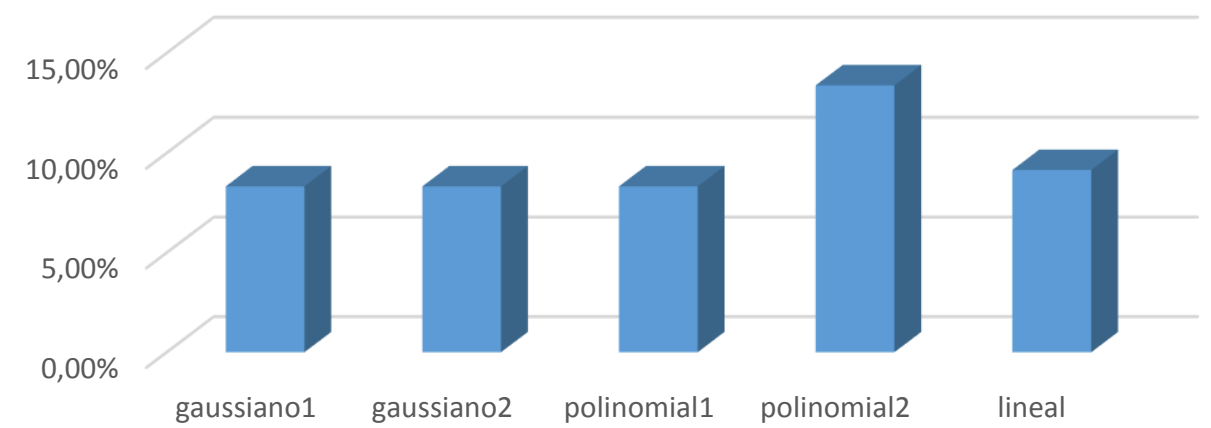

Figura 7.2: Clasificación Temblor Esencial vs Temblor de Párkinson. 


\begin{tabular}{|c|c|c|c|c|c|c|c|}
\hline \multicolumn{2}{|c|}{\begin{tabular}{|c|}
$\begin{array}{c}\text { Selección del } \\
\text { modelo }\end{array}$ \\
\end{tabular}} & \multirow{2}{*}{\multicolumn{2}{|c|}{$\begin{array}{c}\begin{array}{c}\text { Fase de } \\
\text { Entrenamiento }\end{array} \\
\text { Parámetros de ajuste } \\
\end{array}$}} & \multicolumn{2}{|c|}{$\begin{array}{l}\text { Modelo del } \\
\text { Clasificador }\end{array}$} & \multicolumn{2}{|c|}{ Resultados } \\
\hline \multirow{2}{*}{\multicolumn{2}{|c|}{$\begin{array}{c}\text { Función } \\
\text { Kernel }\end{array}$}} & & & \multirow[b]{2}{*}{ bias (b) } & \multirow{2}{*}{$\begin{array}{c}\mathrm{N}^{\mathrm{o}} \\
\text { vectores } \\
\text { soporte, } \\
\text { VS }\end{array}$} & \multirow[b]{2}{*}{$\begin{array}{c}\text { Error de } \\
\text { entrenam. }\end{array}$} & \multirow[b]{2}{*}{$\begin{array}{c}\text { Error de } \\
\text { prueba }\end{array}$} \\
\hline & & $\mathrm{C}$ & gama $(\Upsilon)$ & & & & \\
\hline \multirow{2}{*}{\multicolumn{2}{|c|}{$\begin{array}{l}\text { Gaussiano } \\
\text { RBF }\end{array}$}} & 32 & 0.0078 & -0.42 & 13 & $10.71 \%$ & $8.33 \%$ \\
\hline & & 8 & 0.0156 & -0.20 & 15 & $10.71 \%$ & $8.33 \%$ \\
\hline \multirow{2}{*}{ Polinomial } & 2 & 256 & - & 1.49 & 14 & - & $8.33 \%$ \\
\hline & 3 & 256 & - & 1.09 & 14 & - & $25.00 \%$ \\
\hline \multicolumn{2}{|l|}{ Lineal } & 0.03125 & - & 1.35 & 15 & $25.00 \%$ & $16.67 \%$ \\
\hline
\end{tabular}

Tabla 7.3: Clasificación Temblor Esencial vs Temblor de Párkinson.

\begin{tabular}{|c|c|c|c|c|c|c|c|}
\hline \multirow{3}{*}{\multicolumn{2}{|c|}{$\begin{array}{c}\begin{array}{c}\text { Selección del } \\
\text { modelo }\end{array} \\
\text { Función } \\
\text { Kernel }\end{array}$}} & \multirow{2}{*}{\multicolumn{2}{|c|}{$\begin{array}{c}\text { Fase de } \\
\text { Entrenamiento }\end{array}$}} & \multicolumn{2}{|c|}{$\begin{array}{l}\text { Modelo del } \\
\text { Clasificador }\end{array}$} & \multicolumn{2}{|c|}{ Resultados } \\
\hline & & & & \multirow[b]{2}{*}{ bias (b) } & \multirow{2}{*}{$\begin{array}{c}\mathrm{N}^{\mathrm{o}} \\
\text { vectores } \\
\text { soporte, } \\
\text { VS }\end{array}$} & \multirow[b]{2}{*}{$\begin{array}{c}\text { Error de } \\
\text { entrenam. }\end{array}$} & \multirow[b]{2}{*}{$\begin{array}{c}\text { Error de } \\
\text { prueba }\end{array}$} \\
\hline & & $\mathrm{C}$ & gama $(\Upsilon)$ & & & & \\
\hline \multirow{2}{*}{\multicolumn{2}{|c|}{$\begin{array}{c}\text { Gaussiano } \\
\text { RBF }\end{array}$}} & 512 & 0.125 & 13.47 & 123 & $15.76 \%$ & $9.15 \%$ \\
\hline & & 32 & 0.5 & 3.22 & 125 & $16.36 \%$ & $9.86 \%$ \\
\hline \multirow{2}{*}{ Polinomial } & 2 & 512 & - & 1.46 & 125 & - & $9.86 \%$ \\
\hline & 3 & 512 & - & 1.09 & 131 & - & $13.38 \%$ \\
\hline \multicolumn{2}{|l|}{ Lineal } & 8 & - & 2.12 & 128 & $16.36 \%$ & $9.15 \%$ \\
\hline
\end{tabular}

Tabla 7.4: Clasificación Temblor Esencial vs Temblor de Párkinson.

En la clasificación entre el temblor esencial y temblor parkinsoniano el mejor de los resultados en este ensayo fue de una tasa de acierto del $92 \%$ aproximadamente. Un gran avance teniendo en cuenta que únicamente se utilizan dos características principales.

\subsection{Análisis con PSD y HOS.}

Al igual que en los casos anteriores con los otros tipos de redes MLP y LVQ, se va abordar también con las máquinas de soporte vectorial el uso de las características PSD y HOS.

En el primer ensayo se ha detectado un inconveniente respecto de las muestras de entrada. Al ser el número de vectores disponibles mucho mayor en el caso del Párkinson que en el de temblor esencial durante la fase de aprendizaje se genera una región mucho mayor para la clase mayoritaria, posibilitando el hecho de que algunos vectores de la clase minoritaria se clasifiquen erróneamente. Para paliar esta situación se ha decidido estudiar los atípicos que puedan existir dentro del espacio muestral. Para ello se calcularán los coeficientes de Curtosis y la distancia de Mahalanobis. 
El coeficiente de Curtosis (7-2) nos muestra el grado de concentración de la muestra en torno al valor principal de la distribución, en muchos casos la media. La principal característica que proporciona es que es independiente del valor que tome la varianza.

$$
k=\frac{n \cdot \sum_{i=1}^{n}\left(x_{i}-x_{m}\right)^{2}}{\left(\sum_{i=1}^{n}\left(x_{i}-x_{m}\right)^{2}\right)^{2}}-3
$$

Donde $x_{i}$ es cada uno de los valores; $n$ número de datos y $x_{m}$ media aritmética.

Si se consigue que exista una concentración de los datos en torno a la media, se puede utilizar la distancia de Mahalanobis para determinar los vectores atípicos que pueden influenciar negativamente en el éxito de la clasificación. Para que la mayoría de vectores esté concentrado en torno al valor principal: $k>0$. Caso contrario de que exista más dispersión: $k<0$.

La distancia de Mahalanobis (7-3) es una manera de determinar la similitud entre dos variables aleatorias multidimensionales.

$$
d_{m}^{2}(\vec{x}, \vec{y})=(\vec{x}-\vec{y})^{T} \sum^{-1}(\vec{x}-\vec{y})
$$

Donde: $\sum$ es la matriz de covarianza entre $\vec{x}$ e $\vec{y}, \Sigma^{-1}$ es su inversa.

El valor de la dicha distancia disminuye a medida que aumenta la correlación entre las variables. Por lo que valores pequeños implicarán individuos cercanos. Al contrario si los valores son grandes se podrá considerar que son datos atípicos y por tanto, ser sustituidos.

\begin{tabular}{|c|c|c|}
\hline \multicolumn{3}{|c|}{ Pruebas del estudio } \\
\hline \multirow[b]{2}{*}{$\begin{array}{l}\text { Temblor } \\
\text { fisiológico }\end{array}$} & \multicolumn{2}{|c|}{ Temblor patológico } \\
\hline & $\begin{array}{c}\text { Temblor } \\
\text { esencial (TE) }\end{array}$ & $\begin{array}{l}\text { Enfermedad de } \\
\text { Parkinson (EP) }\end{array}$ \\
\hline 36 & 10 & 47 \\
\hline
\end{tabular}

En la Tabla 7.5 se expone el espacio muestral utilizado:

Tabla 7.5: Resumen de los datos

Para normalizar el espacio muestral de entrada se ha aplicado ACP a los vectores del espacio de entrada. Tras obtener componentes principales se calcula el 
coeficiente de Curtosis de cada una de las características de cada vector. Fijándonos en las dos primeras, siendo las más representativas, los valores obtenidos son:

\begin{tabular}{|c|c|c|}
\cline { 2 - 3 } \multicolumn{1}{c|}{} & \multicolumn{2}{c|}{ COEFICIENTE CURTOSIS (k) } \\
\cline { 2 - 3 } \multicolumn{1}{c|}{} & $\begin{array}{c}\text { 1er } \\
\text { Componente }\end{array}$ & $\begin{array}{c}2 \text { do } \\
\text { Componente }\end{array}$ \\
\hline Muestras de TE & 6.44 & 2.10 \\
\hline Muestras de EP & 37.41 & 12.96 \\
\hline
\end{tabular}

Tabla 7.6: Valores del coeficiente de Curtosis para las dos primeras componentes del ACP

Puede verse claramente como los vectores de Párkinson están mucho más concentrados que los de temblor esencial. Además el número de vectores de esencial es bastante más reducido, por lo que se procederá a eliminar los atípicos de la población de Párkinson.

En la Tabla 7.7 se muestran en rojo aquellos vectores que son candidatos a ser eliminados por tener un valor significativamente más grande que el resto.

\begin{tabular}{|ll|ll|ll|ll|ll|ll|}
\hline $\mathbf{1}$ & 0.391 & $\mathbf{9}$ & 0.135 & $\mathbf{1 7}$ & 0.156 & $\mathbf{2 5}$ & 0.504 & $\mathbf{3 3}$ & 3.872 & $\mathbf{4 1}$ & 0.246 \\
$\mathbf{2}$ & 0.342 & $\mathbf{1 0}$ & 0.208 & $\mathbf{1 8}$ & 0.511 & $\mathbf{2 6}$ & 5.276 & $\mathbf{3 4}$ & 0.398 & $\mathbf{4 2}$ & 0.505 \\
$\mathbf{3}$ & 0.422 & $\mathbf{1 1}$ & 3.525 & $\mathbf{1 9}$ & 0.340 & $\mathbf{2 7}$ & 0.211 & $\mathbf{3 5}$ & 0.352 & $\mathbf{4 3}$ & 0.679 \\
$\mathbf{4}$ & 0.389 & $\mathbf{1 2}$ & 0.201 & $\mathbf{2 0}$ & 0.288 & $\mathbf{2 8}$ & 0.697 & $\mathbf{3 6}$ & 0.431 & $\mathbf{4 4}$ & 0.846 \\
$\mathbf{5}$ & 0.456 & $\mathbf{1 3}$ & 0.293 & $\mathbf{2 1}$ & 0.227 & $\mathbf{2 9}$ & 0.740 & $\mathbf{3 7}$ & 0.270 & $\mathbf{4 5}$ & 0.383 \\
$\mathbf{6}$ & 0.235 & $\mathbf{1 4}$ & 0.241 & $\mathbf{2 2}$ & 0.918 & $\mathbf{3 0}$ & 0.565 & $\mathbf{3 8}$ & 0.261 & $\mathbf{4 6}$ & 0.754 \\
$\mathbf{7}$ & 0.542 & $\mathbf{1 5}$ & 0.316 & $\mathbf{2 3}$ & 0.333 & $\mathbf{3 1}$ & 0.464 & $\mathbf{3 9}$ & 0.775 & $\mathbf{4 7}$ & 0.575 \\
$\mathbf{8}$ & 0.175 & $\mathbf{1 6}$ & 0.402 & $\mathbf{2 4}$ & 0.648 & $\mathbf{3 2}$ & 0.443 & $\mathbf{4 0}$ & 0.111 & & \\
\hline
\end{tabular}

Tabla 7.7: Distancia de Mahalanobis de los vectores de Párkinson respecto de su media.

Cada vez que se eliminen atípicos del espacio muestral, se repite el proceso de nuevo (ACP, Curtosis y Mahalanobis). Una vez nos hemos quedado con los vectores de Párkinson más homogéneos, procedemos al ensayo.

Los resultados obtenidos para los distintos kernel seleccionados fueron los siguientes: 


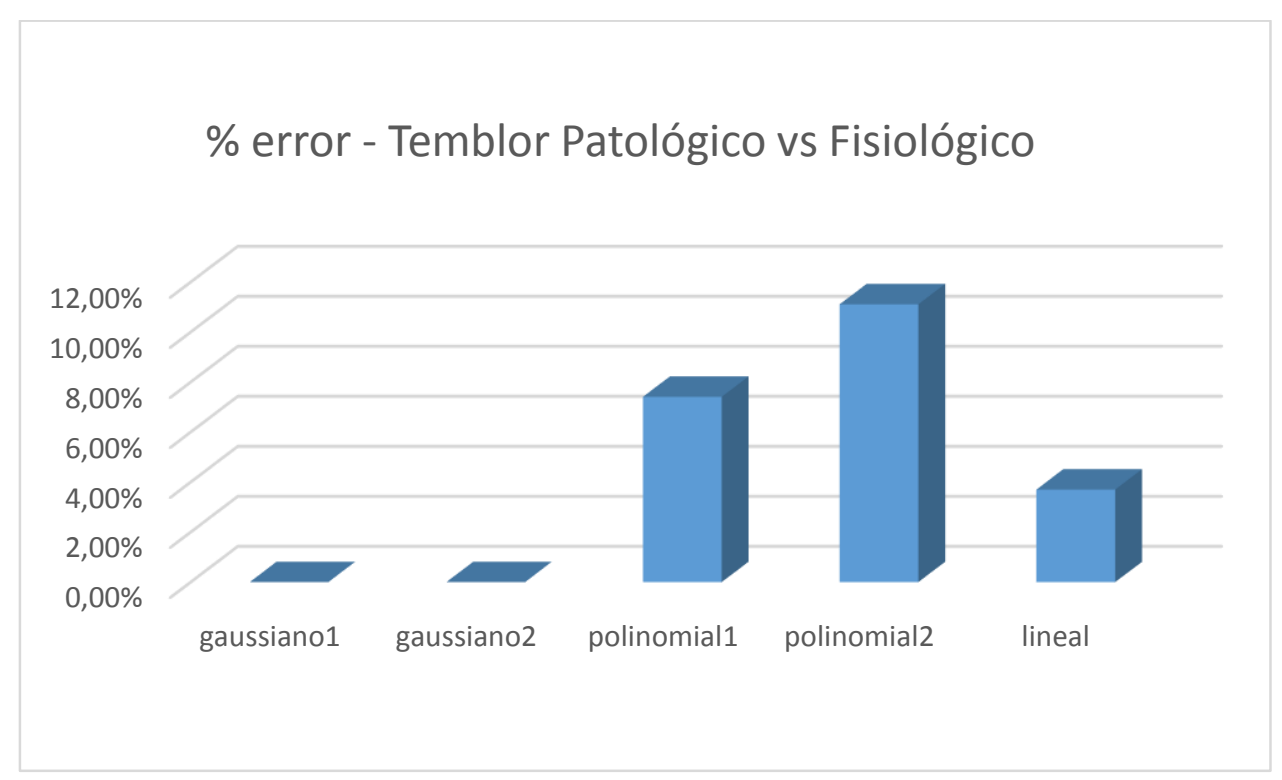

Figura 7.3: Clasificación Temblor Fisiológico vs Temblor Patológico.

\begin{tabular}{|c|c|c|c|c|c|c|c|}
\hline \multicolumn{2}{|c|}{$\begin{array}{c}\text { Selección del } \\
\text { modelo }\end{array}$} & \multirow{2}{*}{\multicolumn{2}{|c|}{$\begin{array}{c}\text { Fase de Entrenamiento } \\
\text { Parámetros de ajuste }\end{array}$}} & \multicolumn{2}{|c|}{$\begin{array}{l}\text { Modelo del } \\
\text { Clasificador }\end{array}$} & \multicolumn{2}{|c|}{ Resultados } \\
\hline \multirow{2}{*}{\multicolumn{2}{|c|}{$\begin{array}{l}\text { Función } \\
\text { Kernel }\end{array}$}} & & & \multirow[b]{2}{*}{$\begin{array}{l}\text { bias } \\
\text { (b) }\end{array}$} & \multirow{2}{*}{$\begin{array}{c}\mathrm{N}^{\mathrm{o}} \\
\text { vectores } \\
\text { soporte, } \\
\text { VS }\end{array}$} & \multirow[b]{2}{*}{$\begin{array}{c}\text { Error de } \\
\text { entrenam. }\end{array}$} & \multirow[b]{2}{*}{$\begin{array}{c}\text { Error de } \\
\text { prueba }\end{array}$} \\
\hline & & $\mathrm{C}$ & gama $(\Upsilon)$ & & & & \\
\hline \multirow{2}{*}{\multicolumn{2}{|c|}{$\begin{array}{c}\text { Gaussiano } \\
\text { RBF }\end{array}$}} & 512 & 0.000488 & 2.68 & 35 & $9.38 \%$ & $0.00 \%$ \\
\hline & & 512 & 0.000127 & 2.79 & 39 & $7.81 \%$ & $0.00 \%$ \\
\hline \multirow{2}{*}{ Polinomial } & 2 & 512 & - & 1.08 & 35 & - & $7.41 \%$ \\
\hline & 3 & 512 & - & 1.19 & 41 & - & $11.11 \%$ \\
\hline \multicolumn{2}{|l|}{ Lineal } & 32 & - & 1.28 & 35 & $35.94 \%$ & $3.70 \%$ \\
\hline
\end{tabular}

Tabla 7.8: Clasificación Temblor Fisiológico vs Temblor Patológico.

Distintas configuraciones de los datos para la clasificación entre temblor esencial y temblor parkinsoniano que se ensayaron en los clasificadores se muestran en la Tabla 7.9: 


\begin{tabular}{|c|c|c|c|c|}
\hline & $\begin{array}{c}\text { Patrones } \\
\text { EST.+CIN.+DIN. (13) }\end{array}$ & $\begin{array}{c}\text { Patrones } \\
\text { ESTÁTICOS (2) } \\
\text { PT1, PT2 }\end{array}$ & $\begin{array}{c}\text { Patrones } \\
\text { CINÉTICOS (7) } \\
\text { PT3, PT5, PT6, PT8, } \\
\text { PT9, PT10, PT11. }\end{array}$ & $\begin{array}{c}\text { Patrones } \\
\text { DINÁMICOS (4) } \\
\text { PT15, PT16, PT17, } \\
\text { PT18. } \\
\end{array}$ \\
\hline $\begin{array}{l}\text { Muestras TE/EP } \\
\text { Caracterist. (25) }\end{array}$ & $\begin{array}{c}9 / 27 \\
975 \\
\text { Tabla } 7.10\end{array}$ & $\begin{array}{c}9 / 27 \\
150 \\
\text { Tabla } 7.11\end{array}$ & $\begin{array}{c}9 / 27 \\
525 \\
\text { Tabla 7.12 }\end{array}$ & $\begin{array}{c}7 / 27 \\
300 \\
\text { Tabla } 7.13\end{array}$ \\
\hline $\begin{array}{l}\text { Muestras TE/EP } \\
\text { Caracterist. (25) }\end{array}$ & $\begin{array}{c}106 / 341 \\
75 \\
\text { Tabla } 7.14 \\
\end{array}$ & $\begin{array}{c}18 / 54 \\
75 \\
\text { Tabla } 7.15 \\
\end{array}$ & $\begin{array}{c}63 / 189 \\
75 \\
\text { Tabla } 7.16 \\
\end{array}$ & $\begin{array}{c}25 / 98 \\
75 \\
\text { Tabla } 7.17\end{array}$ \\
\hline
\end{tabular}

Tabla 7.9: Condiciones de los modelos de clasificación.

\section{Resultados:}

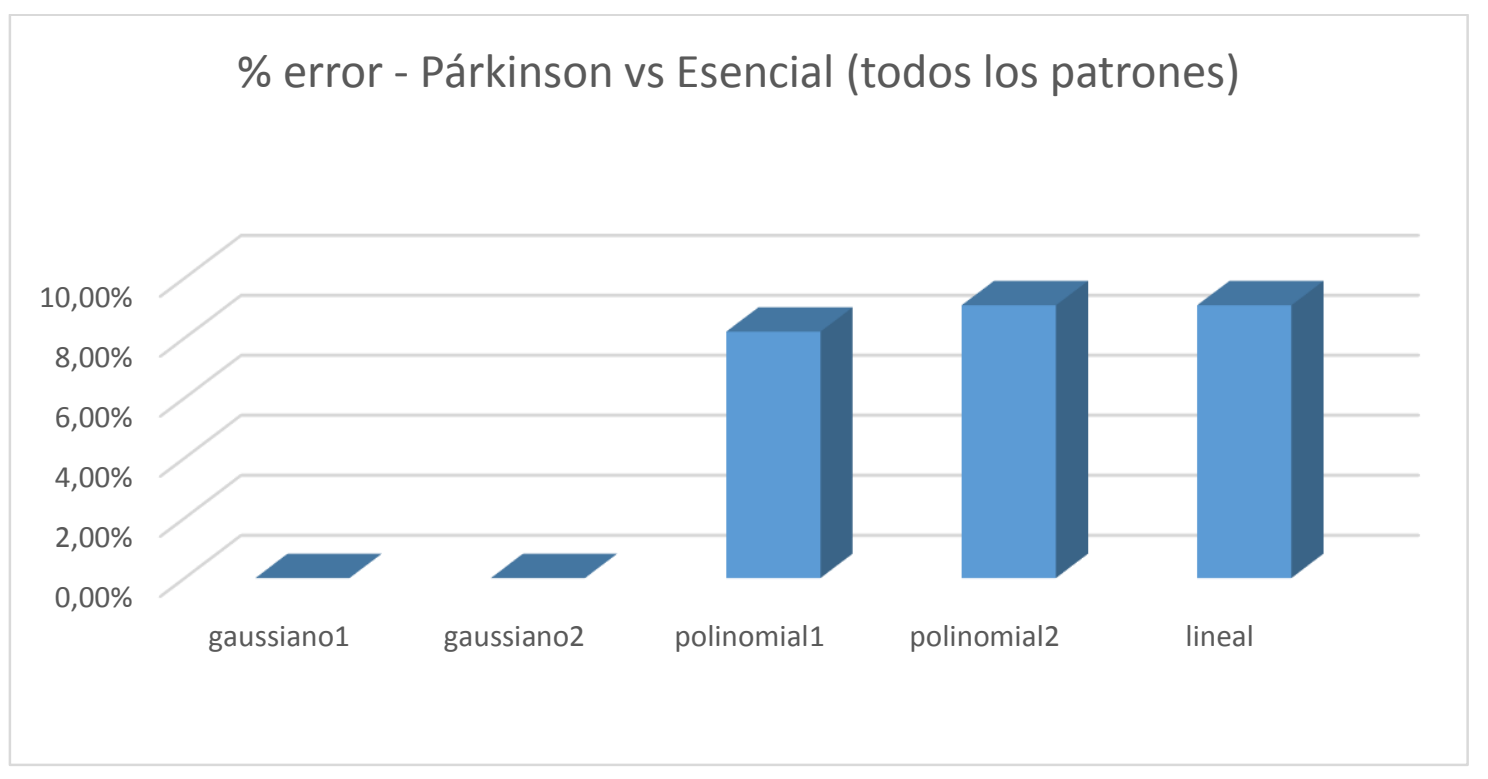

Figura 7.4: Clasificación Temblor Esencial vs Temblor de Párkinson (Todos los patrones).

\begin{tabular}{|c|c|c|c|c|c|c|c|}
\hline \multicolumn{2}{|c|}{$\begin{array}{c}\begin{array}{c}\text { Selección del } \\
\text { modelo }\end{array} \\
\end{array}$} & \multirow{2}{*}{\multicolumn{2}{|c|}{$\begin{array}{c}\text { Fase de Entrenamiento } \\
\text { Parámetros de ajuste }\end{array}$}} & \multicolumn{2}{|c|}{$\begin{array}{l}\text { Modelo del } \\
\text { Clasificador }\end{array}$} & \multicolumn{2}{|c|}{ Resultados } \\
\hline \multirow{2}{*}{\multicolumn{2}{|c|}{$\begin{array}{l}\text { Función } \\
\text { Kernel }\end{array}$}} & & & \multirow[b]{2}{*}{ bias (b) } & \multirow{2}{*}{$\begin{array}{c}\mathrm{N}^{\mathrm{O}} \\
\text { vectores } \\
\text { soporte, } \\
\mathrm{VS} \\
\end{array}$} & \multirow[b]{2}{*}{$\begin{array}{c}\text { Error de } \\
\text { entrenam. }\end{array}$} & \multirow[b]{2}{*}{$\begin{array}{l}\text { Error de } \\
\text { prueba }\end{array}$} \\
\hline & & $\mathrm{C}$ & gama $(\Upsilon)$ & & & & \\
\hline \multirow{2}{*}{\multicolumn{2}{|c|}{$\begin{array}{c}\text { Gaussiano } \\
\text { RBF } \\
\end{array}$}} & 16 & 0.00195 & -0.37 & 18 & $15.38 \%$ & $0.00 \%$ \\
\hline & & 64 & 0.00781 & -0.33 & 22 & $15.38 \%$ & $0.00 \%$ \\
\hline \multirow{2}{*}{ Polinomial } & 2 & 128 & - & -1.34 & 15 & - & $9.09 \%$ \\
\hline & 3 & 256 & - & -0.97 & 15 & - & $9.09 \%$ \\
\hline \multicolumn{2}{|l|}{ Lineal } & 1 & - & -1.87 & 16 & $23.08 \%$ & $9.09 \%$ \\
\hline
\end{tabular}

Tabla 7.10: Clasificación Temblor Esencial vs Temblor de Párkinson (Todos los patrones). 


\section{\% error - Párkinson vs Esencial (patrones estáticos)}

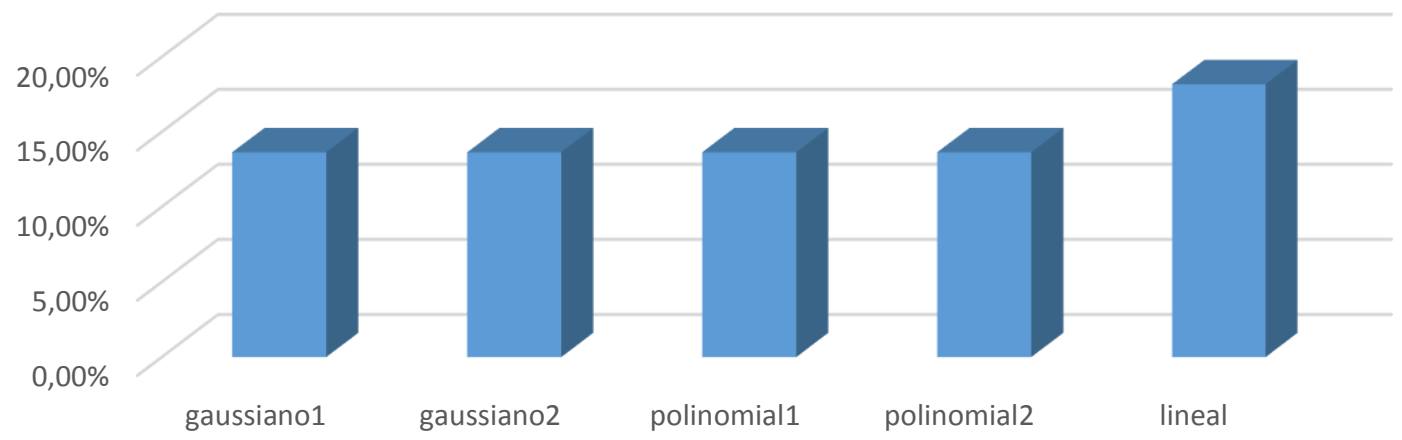

Figura 7.5: Clasificación Temblor Esencial vs Temblor de Párkinson (Patrones estáticos).

\begin{tabular}{|c|c|c|c|c|c|c|c|}
\hline \multirow{2}{*}{\multicolumn{2}{|c|}{$\begin{array}{c}\begin{array}{c}\text { Selección del } \\
\text { modelo }\end{array} \\
\end{array}$}} & \multirow{2}{*}{\multicolumn{2}{|c|}{$\begin{array}{c}\text { Fase de Entrenamiento } \\
\text { Parámetros de ajuste }\end{array}$}} & \multicolumn{2}{|c|}{$\begin{array}{l}\text { Modelo del } \\
\text { Clasificador }\end{array}$} & \multicolumn{2}{|c|}{ Resultados } \\
\hline & & & & \multirow{2}{*}{ bias (b) } & \multirow{2}{*}{$\begin{array}{l}\mathrm{N}^{\mathrm{o}} \text { vectores } \\
\text { soporte, VS }\end{array}$} & \multirow{2}{*}{$\begin{array}{l}\text { Error de } \\
\text { entrenam. }\end{array}$} & \multirow{2}{*}{$\begin{array}{l}\text { Error de } \\
\text { prueba }\end{array}$} \\
\hline \multicolumn{2}{|c|}{ Función Kernel } & $\mathrm{C}$ & gama $(\Upsilon)$ & & & & \\
\hline \multirow{2}{*}{\multicolumn{2}{|c|}{ Gaussiano RBF }} & 64 & 0.00097 & -0.25 & 18 & $20.00 \%$ & $18.18 \%$ \\
\hline & & 16 & 0.00390 & -0.21 & 19 & $20.00 \%$ & $18.18 \%$ \\
\hline \multirow{2}{*}{ Polinomial } & 2 & 16 & - & 0.83 & 18 & - & $18.18 \%$ \\
\hline & 3 & 128 & - & 0.81 & 19 & - & $18.18 \%$ \\
\hline \multicolumn{2}{|l|}{ Lineal } & 0.03125 & - & 0.71 & 18 & $24.00 \%$ & $18.18 \%$ \\
\hline
\end{tabular}

Tabla 7.11: Clasificación Temblor Esencial vs Temblor de Párkinson (Patrones estáticos).

$$
\text { \% error - Párkinson vs Esencial (patrones cinéticos) }
$$

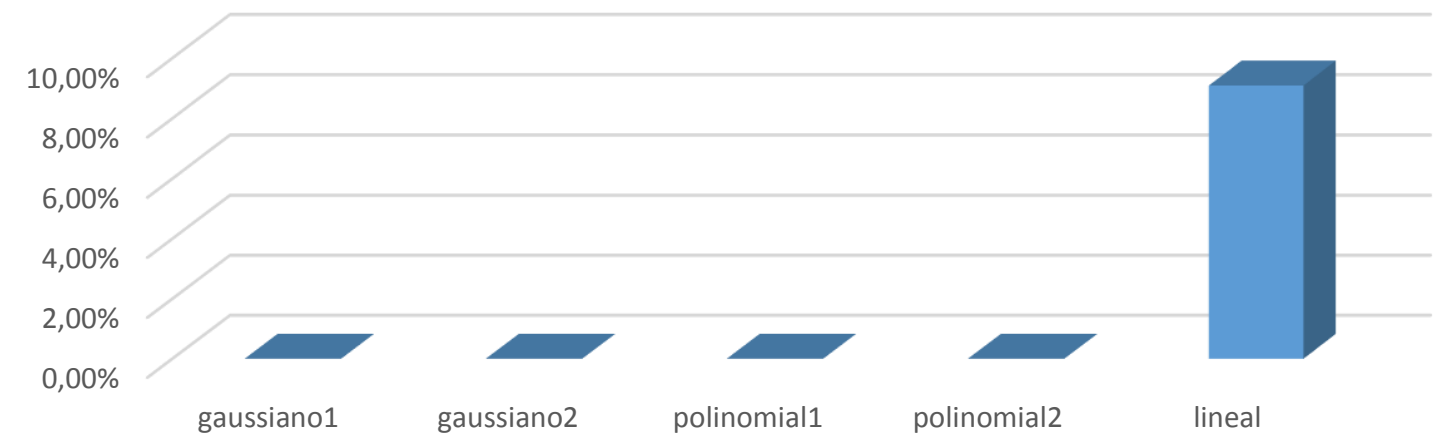

Figura 7.6: Clasificación Temblor Esencial vs Temblor de Párkinson (Patrones cinéticos). 


\begin{tabular}{|c|c|c|c|c|c|c|c|}
\hline \multirow{3}{*}{\multicolumn{2}{|c|}{\begin{tabular}{|c|}
$\begin{array}{c}\text { Selección del } \\
\text { modelo }\end{array}$ \\
Función Kernel
\end{tabular}}} & \multirow{2}{*}{\multicolumn{2}{|c|}{$\begin{array}{c}\text { Fase de Entrenamiento } \\
\text { Parámetros de ajuste } \\
\end{array}$}} & \multicolumn{2}{|c|}{$\begin{array}{l}\text { Modelo del } \\
\text { Clasificador }\end{array}$} & \multicolumn{2}{|c|}{ Resultados } \\
\hline & & & & \multirow{2}{*}{ bias (b) } & \multirow{2}{*}{$\begin{array}{l}\mathrm{N}^{\mathrm{o}} \text { vectores } \\
\text { soporte, VS }\end{array}$} & \multirow{2}{*}{$\begin{array}{l}\text { Error de } \\
\text { entrenam. }\end{array}$} & \multirow{2}{*}{$\begin{array}{c}\text { Error de } \\
\text { prueba }\end{array}$} \\
\hline & & $\mathrm{C}$ & gama $(\Upsilon)$ & & & & \\
\hline \multirow{2}{*}{\multicolumn{2}{|c|}{ Gaussiano RBF }} & 8 & 0.00781 & -0.08 & 17 & $12.00 \%$ & $0.00 \%$ \\
\hline & & 64 & 0.00781 & -0.06 & 17 & $12.00 \%$ & $0.00 \%$ \\
\hline \multirow{2}{*}{ Polinomial } & 2 & 64 & - & -0.43 & 15 & - & $0.00 \%$ \\
\hline & 3 & 256 & - & -0.37 & 16 & - & $0.00 \%$ \\
\hline \multicolumn{2}{|l|}{ Lineal } & 0.03125 & - & -0.49 & 16 & $24.00 \%$ & $9.09 \%$ \\
\hline
\end{tabular}

Tabla 7.12: Clasificación Temblor Esencial vs Temblor de Párkinson (Patrones cinéticos).

\section{\% error - Párkinson vs Esencial (patrones dinámicos)}

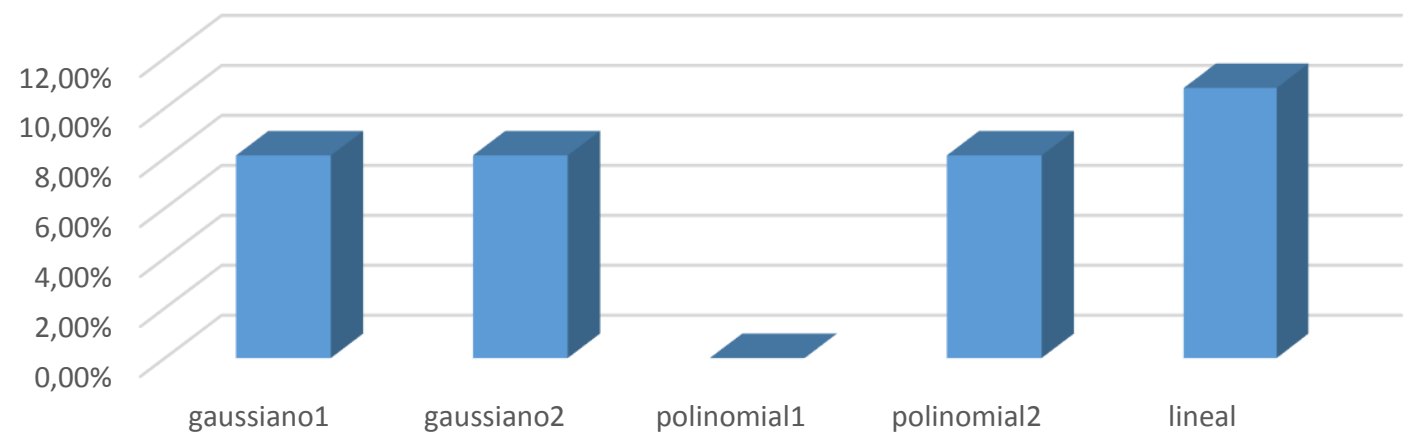

Figura 7.7: Clasificación Temblor Esencial vs Temblor de Párkinson (Patrones dinámicos).

\begin{tabular}{|c|c|c|c|c|c|c|c|}
\hline \multirow{3}{*}{\multicolumn{2}{|c|}{$\begin{array}{c}\begin{array}{c}\text { Selección del } \\
\text { modelo }\end{array} \\
\text { Función Kernel }\end{array}$}} & \multirow{2}{*}{\multicolumn{2}{|c|}{$\begin{array}{c}\text { Fase de Entrenamiento } \\
\text { Parámetros de ajuste }\end{array}$}} & \multicolumn{2}{|c|}{$\begin{array}{l}\text { Modelo del } \\
\text { Clasificador }\end{array}$} & \multicolumn{2}{|c|}{ Resultados } \\
\hline & & & & \multirow{2}{*}{ bias (b) } & \multirow{2}{*}{$\begin{array}{l}\mathrm{N}^{\mathrm{o}} \text { vectores } \\
\text { soporte, VS }\end{array}$} & \multirow{2}{*}{$\begin{array}{l}\text { Error de } \\
\text { entrenam. }\end{array}$} & \multirow{2}{*}{$\begin{array}{c}\text { Error de } \\
\text { prueba }\end{array}$} \\
\hline & & $\mathrm{C}$ & gama $(\Upsilon)$ & & & & \\
\hline \multirow{2}{*}{\multicolumn{2}{|c|}{ Gaussiano RBF }} & 128 & 0.000488 & -0.03 & 16 & $17.39 \%$ & $9.09 \%$ \\
\hline & & 32 & 0.001953 & -0.03 & 16 & $17.39 \%$ & $18.18 \%$ \\
\hline \multirow{2}{*}{ Polinomial } & 2 & 2 & - & 0.97 & 16 & - & $0.00 \%$ \\
\hline & 3 & 64 & - & 0.86 & 19 & - & $9.09 \%$ \\
\hline \multicolumn{2}{|l|}{ Lineal } & 0.03125 & - & 0.57 & 16 & $21.74 \%$ & $18.18 \%$ \\
\hline
\end{tabular}

Tabla 7.13: Clasificación Temblor Esencial vs Temblor de Párkinson (Patrones dinámicos). 


\begin{tabular}{|c|c|c|c|c|c|c|c|}
\hline \multirow{3}{*}{\multicolumn{2}{|c|}{$\begin{array}{c}\begin{array}{c}\text { Selección del } \\
\text { modelo }\end{array} \\
\text { Función Kernel }\end{array}$}} & \multirow{2}{*}{\multicolumn{2}{|c|}{$\begin{array}{c}\text { Fase de Entrenamiento } \\
\text { Parámetros de ajuste }\end{array}$}} & \multicolumn{2}{|c|}{$\begin{array}{l}\text { Modelo del } \\
\text { Clasificador }\end{array}$} & \multicolumn{2}{|c|}{ Resultados } \\
\hline & & & & \multirow{2}{*}{ bias (b) } & \multirow{2}{*}{$\begin{array}{l}\mathrm{N}^{\mathrm{o}} \text { vectores } \\
\text { soporte, VS }\end{array}$} & \multirow{2}{*}{$\begin{array}{l}\text { Error de } \\
\text { entrenam. }\end{array}$} & \multirow{2}{*}{$\begin{array}{c}\text { Error de } \\
\text { prueba }\end{array}$} \\
\hline & & $\mathrm{C}$ & gama $(\Upsilon)$ & & & & \\
\hline \multirow{2}{*}{\multicolumn{2}{|c|}{ Gaussiano RBF }} & 8 & 0.5 & -0.18 & 134 & $11.18 \%$ & $7.46 \%$ \\
\hline & & 4 & 1 & -0.06 & 158 & $11.18 \%$ & $9.70 \%$ \\
\hline \multirow{2}{*}{ Polinomial } & 2 & 1024 & - & 1.13 & 105 & - & $8.21 \%$ \\
\hline & 3 & 1024 & - & 0.27 & 117 & - & $9.70 \%$ \\
\hline \multicolumn{2}{|l|}{ Lineal } & 4 & - & 2.45 & 101 & - & $10.45 \%$ \\
\hline
\end{tabular}

Tabla 7.14: Clasificación Temblor Esencial vs Temblor de Párkinson (Todos los patrones).

\begin{tabular}{|c|c|c|c|c|c|c|c|}
\hline \multirow{3}{*}{\multicolumn{2}{|c|}{$\begin{array}{c}\begin{array}{c}\text { Selección del } \\
\text { modelo }\end{array} \\
\text { Función Kernel }\end{array}$}} & \multirow{2}{*}{\multicolumn{2}{|c|}{$\begin{array}{c}\text { Fase de Entrenamiento } \\
\text { Parámetros de ajuste } \\
\end{array}$}} & \multicolumn{2}{|c|}{$\begin{array}{l}\text { Modelo del } \\
\text { Clasificador }\end{array}$} & \multicolumn{2}{|c|}{ Resultados } \\
\hline & & & & \multirow{2}{*}{ bias (b) } & \multirow{2}{*}{$\begin{array}{l}\mathrm{N}^{\mathrm{o}} \text { vectores } \\
\text { soporte, VS }\end{array}$} & \multirow{2}{*}{$\begin{array}{l}\text { Error de } \\
\text { entrenam. }\end{array}$} & \multirow{2}{*}{$\begin{array}{c}\text { Error de } \\
\text { prueba }\end{array}$} \\
\hline & & $\mathrm{C}$ & gama $(\Upsilon)$ & & & & \\
\hline \multirow{2}{*}{\multicolumn{2}{|c|}{ Gaussiano RBF }} & 16 & 0.015625 & -0.14 & 32 & $22.00 \%$ & $13.64 \%$ \\
\hline & & 64 & 0.00390625 & -0.21 & 30 & $22.00 \%$ & $13.64 \%$ \\
\hline \multirow{2}{*}{ Polinomial } & 2 & 128 & - & 0.41 & 32 & - & $13.64 \%$ \\
\hline & 3 & 512 & - & 0.66 & 33 & - & $13.64 \%$ \\
\hline \multicolumn{2}{|l|}{ Lineal } & 0.03125 & - & 0.80 & 29 & $26.00 \%$ & $18.18 \%$ \\
\hline \multicolumn{8}{|c|}{ Conjunto de entrenamiento (70\%):50 muestras. Conjunto de prueba (30\%): 22 muestras. } \\
\hline
\end{tabular}

Tabla 7.15: Clasificación Temblor Esencial vs Temblor de Párkinson (Patrones estáticos).

\begin{tabular}{|c|c|c|c|c|c|c|c|}
\hline \multicolumn{2}{|c|}{$\begin{array}{c}\text { Selección del } \\
\text { modelo }\end{array}$} & \multirow{2}{*}{\multicolumn{2}{|c|}{$\begin{array}{c}\text { Fase de Entrenamiento } \\
\text { Parámetros de ajuste }\end{array}$}} & \multicolumn{2}{|c|}{$\begin{array}{l}\text { Modelo del } \\
\text { Clasificador }\end{array}$} & \multicolumn{2}{|c|}{ Resultados } \\
\hline \multirow{2}{*}{\multicolumn{2}{|c|}{ Función Kernel }} & & & hizs (b) & $\mathrm{N}^{\mathrm{o}}$ vectores & Error de & Error de \\
\hline & & $\mathrm{C}$ & gama $(\Upsilon)$ & bras (b) & soporte, VS & entrenam. & prueba \\
\hline \multirow{2}{*}{\multicolumn{2}{|c|}{ Gaussiano RBF }} & 32 & 0.12500 & 0.67 & 55 & $10.23 \%$ & $2.63 \%$ \\
\hline & & 256 & 0.03125 & 1.94 & 51 & $9.09 \%$ & $3.95 \%$ \\
\hline \multirow{2}{*}{ Polinomial } & 2 & 1024 & - & -0.13 & 54 & - & $5.26 \%$ \\
\hline & 3 & 1024 & - & -0.66 & 63 & - & $7.89 \%$ \\
\hline \multicolumn{2}{|l|}{ Lineal } & 2 & - & 0.08 & 57 & $21.02 \%$ & $6.58 \%$ \\
\hline \multicolumn{8}{|c|}{ Conjunto de entrenamiento (70\%): 176 muestras. Conjunto de prueba (30\%): 76 muestras. } \\
\hline
\end{tabular}

Tabla 7.16: Clasificación Temblor Esencial vs Temblor de Párkinson (Patrones cinéticos). 


\begin{tabular}{|c|c|c|c|c|c|c|c|}
\hline \multirow{3}{*}{\multicolumn{2}{|c|}{$\begin{array}{c}\begin{array}{c}\text { Selección del } \\
\text { modelo }\end{array} \\
\text { Función } \\
\text { Kernel }\end{array}$}} & \multirow{2}{*}{\multicolumn{2}{|c|}{$\begin{array}{c}\text { Fase de Entrenamiento } \\
\text { Parámetros de ajuste }\end{array}$}} & \multicolumn{2}{|c|}{ Modelo del Clasificador } & \multicolumn{2}{|c|}{ Resultados } \\
\hline & & & & \multirow{2}{*}{ bias (b) } & \multirow{2}{*}{$\begin{array}{l}\mathrm{N}^{\mathrm{o}} \text { vectores } \\
\text { soporte, VS }\end{array}$} & \multirow{2}{*}{$\begin{array}{l}\text { Error de } \\
\text { entrenam. }\end{array}$} & \multirow{2}{*}{$\begin{array}{c}\text { Error de } \\
\text { prueba }\end{array}$} \\
\hline & & $\mathrm{C}$ & gama $(\Upsilon)$ & & & & \\
\hline \multirow{2}{*}{\multicolumn{2}{|c|}{ Gaussiano RBF }} & 512 & 0.007812 & 1.25 & 38 & $12.79 \%$ & $8.11 \%$ \\
\hline & & 2048 & 0.001953 & -0.48 & 38 & $13.95 \%$ & $8.11 \%$ \\
\hline \multirow{2}{*}{ Polinomial } & 2 & 512 & - & 0.82 & 42 & - & $8.11 \%$ \\
\hline & 3 & 2048 & - & 0.29 & 42 & - & $8.11 \%$ \\
\hline \multicolumn{2}{|l|}{ Lineal } & 2 & - & 1.73 & 38 & $18.60 \%$ & $10.81 \%$ \\
\hline
\end{tabular}

Tabla 7.17: Clasificación Temblor Esencial vs Temblor de Párkinson (Patrones dinámicos).

Mediante los coeficientes de Curtosis y las distancias de Mahalanobis, se vuelve a conseguir un $100 \%$ de acierto en la clasificación entre sanos y enfermos, y un 100\% también para la clasificación entre Párkinson y esencial (kernels polinomiales). Haciendo el estudio por patrones, se constata que el mejor resultado se obtiene en cinéticos y dinámicos ( $0 \%$ de error en ambos).

\subsection{Clasificación mediante análisis de componentes principales (ACP).}

Al igual que en el caso de las redes LVQ, previamente, en el espacio de características de entrada vamos a realizar un ACP a los datos para intentar quedarnos únicamente con las características que posean más varianza.

Eliminando los atípicos como en el caso anterior (ACP, Curtosis y Mahalanobis), a los datos de partida:

\begin{tabular}{|c|c|c|}
\hline $\begin{array}{c}\text { TEMBLOR } \\
\text { FISIOLÓGICO }\end{array}$ & $\begin{array}{c}\text { TEMBLOR } \\
\text { ESENCIAL }\end{array}$ & $\begin{array}{c}\text { TEMBLOR } \\
\text { PARKINSONIANO }\end{array}$ \\
\hline 34 & 9 & 27 \\
\hline
\end{tabular}

Tabla 7.18: Número de pruebas de cada clase.

El número de componentes a elegir depende de la varianza que queramos incluir en la prueba. En la Tabla 7.19 puede verse un ejemplo en el que se utilizó los 6 primeros componentes, dado que la información contenida es con ellos ya del $90.89 \%$. El componente principal 1 contiene la máxima información con un $38.46 \%$, el segundo componente un $16.64 \%$ y así sucesivamente hasta el componente 6 que 
contiene un $5.05 \%$ de la información. Los demás componentes no se toman en consideración debido a que contienen muy poca información.

\begin{tabular}{|c|c|c|c|c|c|c|c|c|c|c|}
\hline $\begin{array}{c}\text { Componente } \\
\text { Principal }\end{array}$ & 1 & 2 & 3 & 4 & 5 & 6 & $\ldots$. & 26 & 27 & 28 \\
\hline $\begin{array}{c}\text { Varianza } \\
\text { acumulada }\end{array}$ & $38.46 \%$ & $55.11 \%$ & $68.55 \%$ & $78.18 \%$ & $85.84 \%$ & $90.89 \%$ & $\ldots$. & $99.33 \%$ & $99.99 \%$ & $100.00 \%$ \\
\hline $\begin{array}{c}\text { Incremento } \\
\text { de varianza }\end{array}$ & & $16.64 \%$ & $13.44 \%$ & $9.63 \%$ & $7.66 \%$ & $5.05 \%$ & $\ldots$. & $0.02 \%$ & $0.01 \%$ & $0.00 \%$ \\
\hline
\end{tabular}

Tabla 7.19: Peso de la varianza sobre cada componente principal.

\section{Resultados:}

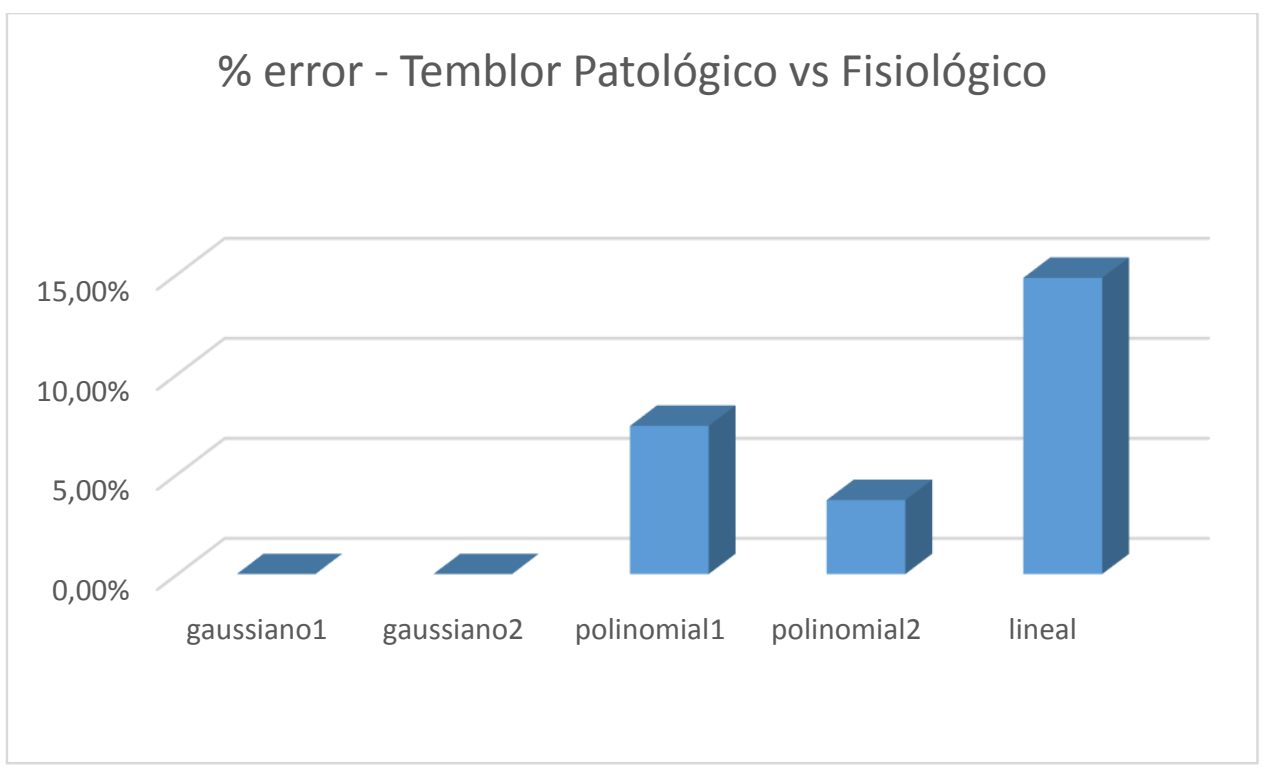

Figura 7.8: Clasificación Temblor Fisiológico vs Temblor Patológico.

\begin{tabular}{|c|c|c|c|c|c|c|c|}
\hline \multirow{3}{*}{\multicolumn{2}{|c|}{$\begin{array}{c}\begin{array}{c}\text { Selección del } \\
\text { modelo }\end{array} \\
\text { Función Kernel }\end{array}$}} & \multirow{2}{*}{\multicolumn{2}{|c|}{$\begin{array}{c}\text { Fase de Entrenamiento } \\
\text { Parámetros de ajuste }\end{array}$}} & \multicolumn{2}{|c|}{ Modelo del Clasificador } & \multicolumn{2}{|c|}{ Resultados } \\
\hline & & & & \multirow{2}{*}{ bias (b) } & \multirow{2}{*}{$\begin{array}{l}\mathrm{N}^{\mathrm{o}} \text { vectores } \\
\text { soporte, VS }\end{array}$} & \multirow{2}{*}{$\begin{array}{c}\text { Error de } \\
\text { entrenam. }\end{array}$} & \multirow{2}{*}{$\begin{array}{l}\text { Error de } \\
\text { prueba }\end{array}$} \\
\hline & & $\mathrm{C}$ & gama $(\Upsilon)$ & & & & \\
\hline \multirow{2}{*}{\multicolumn{2}{|c|}{ Gaussiano RBF }} & 8 & 0.5 & 1.36 & 36 & $9.52 \%$ & $0.00 \%$ \\
\hline & & 32 & 0.5 & 1.90 & 28 & $7.94 \%$ & $0.00 \%$ \\
\hline \multirow{2}{*}{ Polinomial } & 2 & 512 & - & 0.28 & 27 & - & $7.41 \%$ \\
\hline & 3 & 2048 & - & -0.51 & 26 & - & $3.70 \%$ \\
\hline \multicolumn{2}{|l|}{ Lineal } & 8 & - & 2.01 & 33 & $9.52 \%$ & $14.81 \%$ \\
\hline
\end{tabular}

Tabla 7.20: Clasificación Temblor Fisiológico vs Temblor Patológico.

En la Tabla 7.21 se muestran distintas configuraciones para la clasificación entre temblor esencial y temblor parkinsoniano que se ensayaron en los clasificadores: 


\begin{tabular}{|c|c|c|c|c|c|}
\hline & \multicolumn{2}{|c|}{$\begin{array}{c}\text { Patrones } \\
\text { EST.+CIN.+DIN. (13) }\end{array}$} & $\begin{array}{c}\text { Patrones } \\
\text { ESTÁTICOS (2) } \\
\text { PT1, PT2 }\end{array}$ & $\begin{array}{c}\text { Patrones cinéticos (8) } \\
\text { PT3, PT5, PT6, PT8, PT9, } \\
\text { PT10, PT11. PT13. }\end{array}$ & $\begin{array}{l}\text { Patrones dinámicos (4) } \\
\text { PT15, PT16, PT17, PT18. }\end{array}$ \\
\hline Muestras TE/EP & $\begin{array}{c}9 / 27 \\
\text { Tabla } 7.22\end{array}$ & $\begin{array}{c}100 / 310 \\
\text { Tabla } 7.23\end{array}$ & $\begin{array}{c}14 / 43 \\
\text { Tabla } 7.24\end{array}$ & $\begin{array}{c}69 / 184 \\
\text { Tabla } 7.25\end{array}$ & $\begin{array}{c}32 / 90 \\
\text { Tabla } 7.26\end{array}$ \\
\hline
\end{tabular}

Tabla 7.21: Condiciones de los modelos de clasificación.

\section{Resultados:}

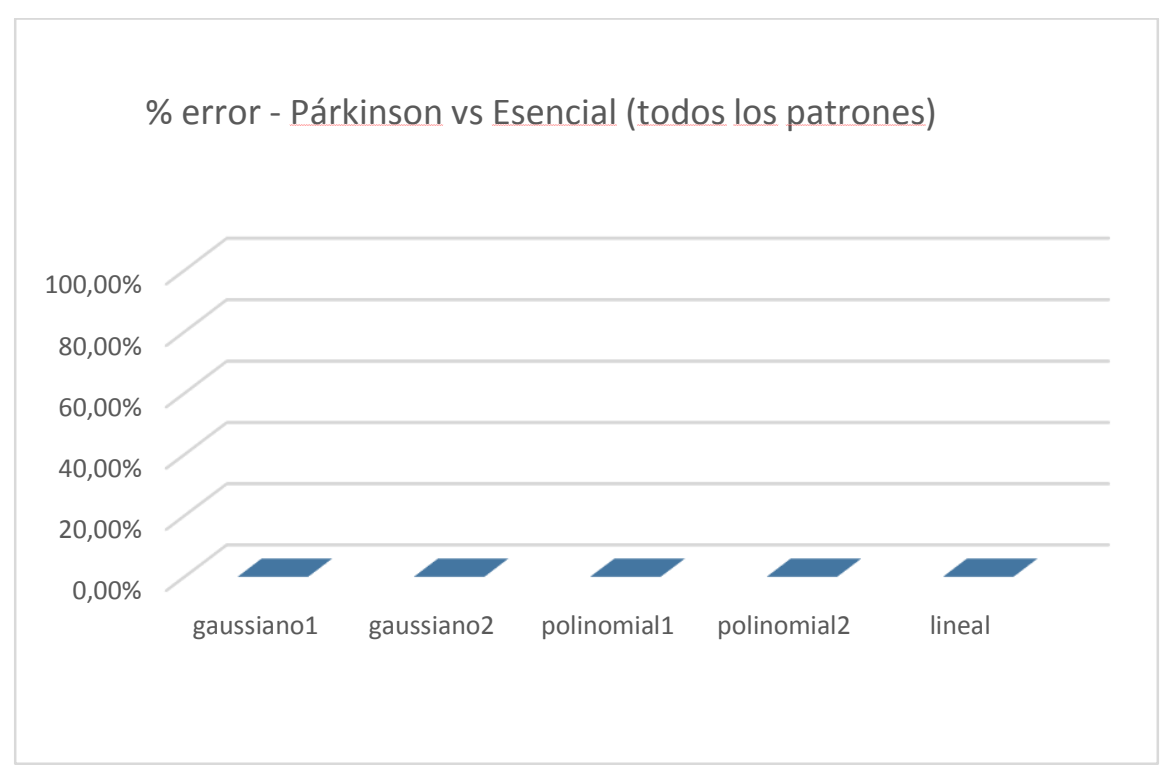

Figura 7.9: Clasificación A: Temblor Esencial vs Temblor de Párkinson (Todos los patrones).

\begin{tabular}{|c|c|c|c|c|c|c|c|}
\hline \multicolumn{2}{|c|}{$\begin{array}{c}\text { Selección del } \\
\text { modelo }\end{array}$} & \multicolumn{2}{|c|}{ Fase de Entrenamiento } & \multicolumn{2}{|c|}{$\begin{array}{l}\text { Modelo del } \\
\text { Clasificador }\end{array}$} & \multicolumn{2}{|c|}{ Resultados } \\
\hline \multirow{2}{*}{\multicolumn{2}{|c|}{ Función Kernel }} & \multicolumn{2}{|c|}{ Parámetros de ajuste } & \multirow{2}{*}{ bias (b) } & \multirow{2}{*}{$\begin{array}{l}\mathrm{N}^{\mathrm{o}} \text { vectores } \\
\text { soporte, VS }\end{array}$} & \multirow{2}{*}{$\begin{array}{l}\text { Error de } \\
\text { entrenam. }\end{array}$} & \multirow{2}{*}{$\begin{array}{l}\text { Error de } \\
\text { prueba }\end{array}$} \\
\hline & & $\mathrm{C}$ & gama $(\Upsilon)$ & & & & \\
\hline \multirow{2}{*}{\multicolumn{2}{|c|}{ Gaussiano RBF }} & 512 & 0.5 & -0.09 & 5 & $0.00 \%$ & $0.00 \%$ \\
\hline & & 1024 & 0.25 & -0.10 & 5 & $0.00 \%$ & $0.00 \%$ \\
\hline \multirow{2}{*}{ Polinomial } & 2 & 1024 & - & -17.53 & 4 & - & $0.00 \%$ \\
\hline & 3 & 1024 & - & -13.53 & 4 & - & $0.00 \%$ \\
\hline \multicolumn{2}{|l|}{ Lineal } & 512 & - & -30.23 & 5 & $0.00 \%$ & $0.00 \%$ \\
\hline
\end{tabular}

Tabla 7.22: Clasificación A: Temblor Esencial vs Temblor de Párkinson (Todos los patrones). 


\begin{tabular}{|c|c|c|c|c|c|c|c|}
\hline \multicolumn{2}{|c|}{$\begin{array}{c}\text { Selección del } \\
\text { modelo }\end{array}$} & \multirow{2}{*}{\multicolumn{2}{|c|}{$\begin{array}{c}\text { Fase de Entrenamiento } \\
\text { Parámetros de ajuste }\end{array}$}} & \multicolumn{2}{|c|}{ Modelo del Clasificador } & \multicolumn{2}{|c|}{ Resultados } \\
\hline \multirow{2}{*}{\multicolumn{2}{|c|}{ Función Kernel }} & & & \multirow{2}{*}{ bias (b) } & \multirow{2}{*}{$\begin{array}{l}\mathrm{N}^{\mathrm{o}} \text { vectores } \\
\text { soporte, VS }\end{array}$} & \multirow{2}{*}{$\begin{array}{c}\text { Error de } \\
\text { entrenam. }\end{array}$} & \multirow{2}{*}{$\begin{array}{c}\text { Error de } \\
\text { prueba }\end{array}$} \\
\hline & & $\mathrm{C}$ & gama $(\Upsilon)$ & & & & \\
\hline \multirow{2}{*}{\multicolumn{2}{|c|}{ Gaussiano RBF }} & 8192 & 0.5 & -6.50 & 73 & $11.50 \%$ & $4.07 \%$ \\
\hline & & 4096 & 2 & -0.85 & 67 & $9.76 \%$ & $3.25 \%$ \\
\hline \multirow{2}{*}{ Polinomial } & 2 & 2048 & - & -9.76 & 71 & - & $4.88 \%$ \\
\hline & 3 & 2048 & - & -11.47 & 71 & - & $6.50 \%$ \\
\hline \multicolumn{2}{|l|}{ Lineal } & 512 & - & -7.27 & 83 & $12.20 \%$ & $6.50 \%$ \\
\hline
\end{tabular}

Tabla 7.23: Clasificación B: Temblor Esencial vs Temblor de Párkinson (Todos los patrones).

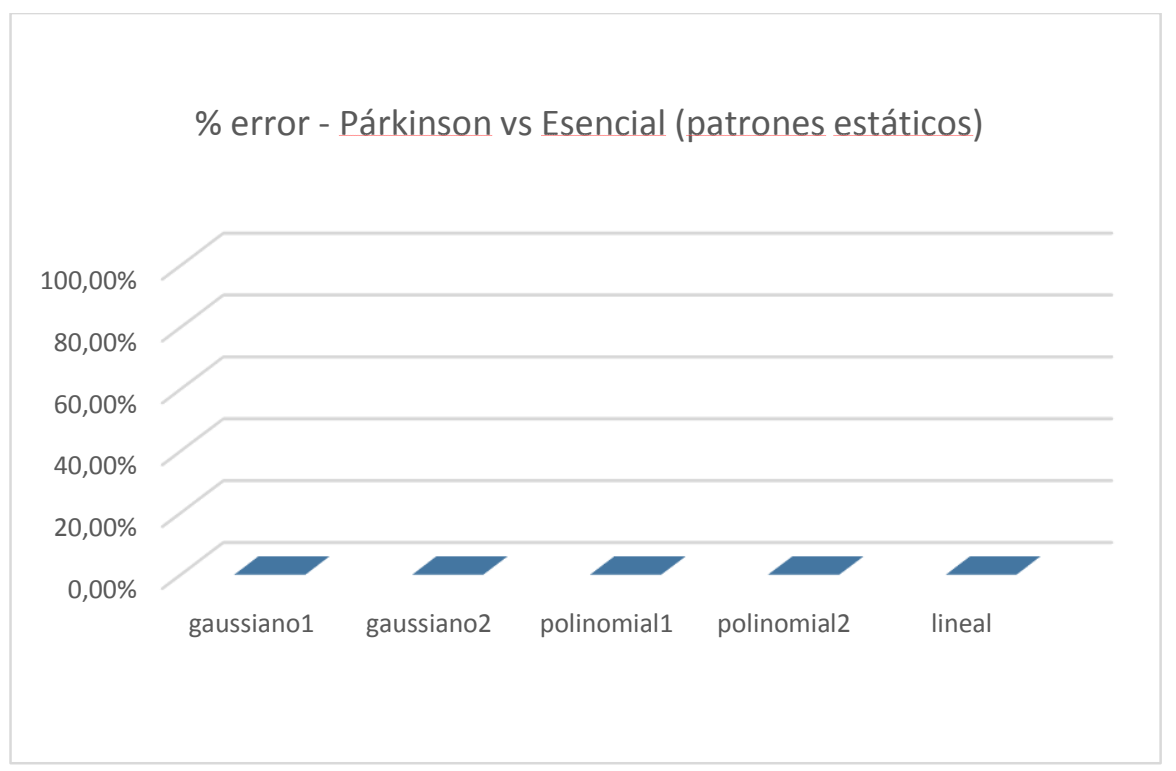

Figura 7.10: Clasificación Temblor Esencial vs Temblor de Párkinson (Patrones estáticos).

\begin{tabular}{|c|c|c|c|c|c|c|c|}
\hline \multicolumn{2}{|c|}{$\begin{array}{c}\begin{array}{c}\text { Selección del } \\
\text { modelo }\end{array} \\
\end{array}$} & \multirow{2}{*}{\multicolumn{2}{|c|}{$\begin{array}{c}\text { Fase de Entrenamiento } \\
\text { Parámetros de ajuste } \\
\end{array}$}} & \multicolumn{2}{|c|}{$\begin{array}{l}\text { Modelo del } \\
\text { Clasificador }\end{array}$} & \multicolumn{2}{|c|}{ Resultados } \\
\hline \multirow{2}{*}{\multicolumn{2}{|c|}{ Función Kernel }} & & & hias (h) & $\mathrm{N}^{\circ}$ vectores & Error de & Error de \\
\hline & & $\mathrm{C}$ & gama (Y) & bias (b) & soporte, VS & entrenam. & prueba \\
\hline \multirow{2}{*}{\multicolumn{2}{|c|}{ Gaussiano RBF }} & 2048 & 0.5 & 12.24 & 15 & $12.50 \%$ & $0.00 \%$ \\
\hline & & 1024 & 0.25 & 18.33 & 17 & $10.00 \%$ & $0.00 \%$ \\
\hline \multirow{2}{*}{ Polinomial } & 2 & 128 & - & -5.95 & 20 & - & $0.00 \%$ \\
\hline & 3 & 256 & - & -4.37 & 19 & - & $0.00 \%$ \\
\hline \multicolumn{2}{|l|}{ Lineal } & 64 & - & -13.95 & 19 & $20.00 \%$ & $0.00 \%$ \\
\hline
\end{tabular}

Tabla 7.24: Clasificación Temblor Esencial vs Temblor de Párkinson (Patrones estáticos). 


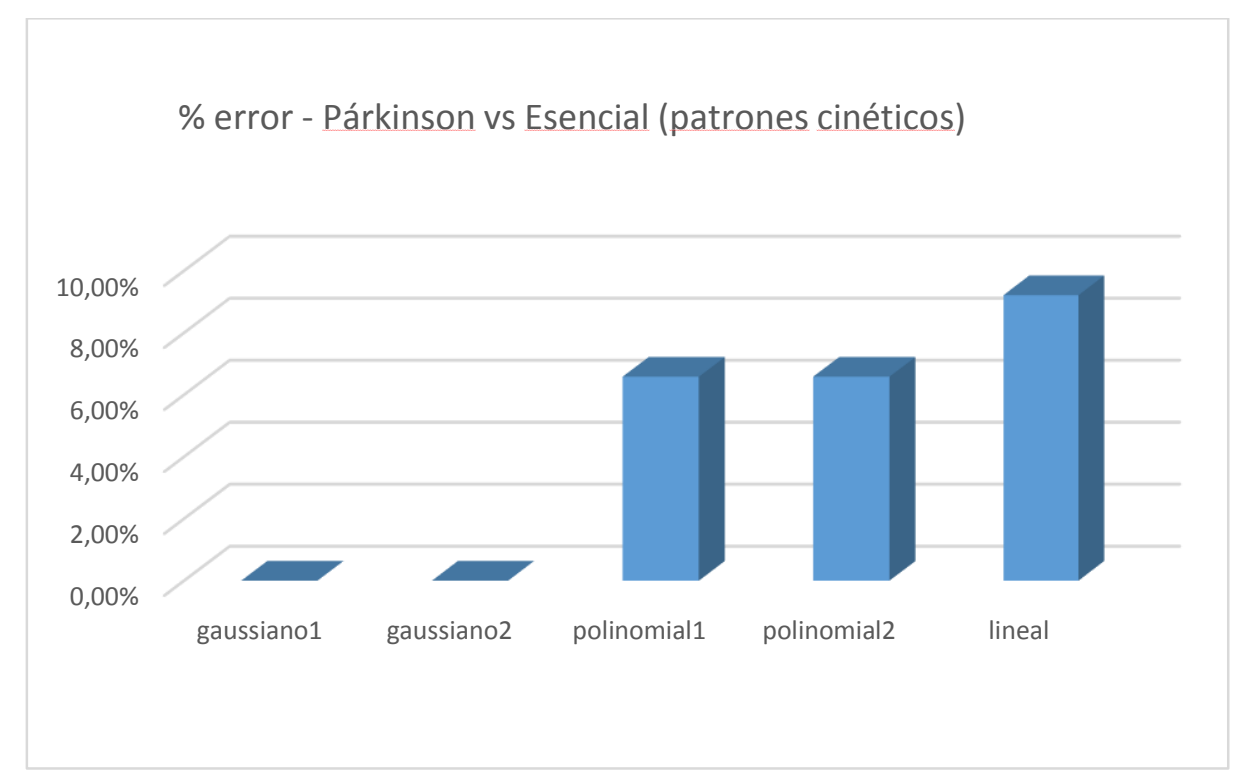

Figura 7.11: Clasificación Temblor Esencial vs Temblor de Párkinson (Patrones cinéticos).

\begin{tabular}{|c|c|c|c|c|c|c|c|}
\hline \multirow{3}{*}{\multicolumn{2}{|c|}{$\begin{array}{c}\begin{array}{c}\text { Selección del } \\
\text { modelo }\end{array} \\
\text { Función Kernel }\end{array}$}} & \multirow{2}{*}{\multicolumn{2}{|c|}{$\begin{array}{c}\text { Fase de Entrenamiento } \\
\text { Parámetros de ajuste } \\
\end{array}$}} & \multicolumn{2}{|c|}{$\begin{array}{l}\text { Modelo del } \\
\text { Clasificador }\end{array}$} & \multicolumn{2}{|c|}{ Resultados } \\
\hline & & & & \multirow{2}{*}{ bias (b) } & \multirow{2}{*}{$\begin{array}{l}\mathrm{N}^{\mathrm{o}} \text { vectores } \\
\text { soporte, VS }\end{array}$} & \multirow{2}{*}{$\begin{array}{l}\text { Error de } \\
\text { entrenam. }\end{array}$} & \multirow{2}{*}{$\begin{array}{l}\text { Error de } \\
\text { prueba }\end{array}$} \\
\hline & & $\mathrm{C}$ & gama $(\Upsilon)$ & & & & \\
\hline \multirow{2}{*}{\multicolumn{2}{|c|}{ Gaussiano RBF }} & 512 & 8 & -2.98 & 27 & $7.91 \%$ & $0.00 \%$ \\
\hline & & 1024 & 8 & -2.69 & 27 & $7.91 \%$ & $0.00 \%$ \\
\hline \multirow{2}{*}{ Polinomial } & 2 & 512 & - & -12.09 & 54 & - & $6.58 \%$ \\
\hline & 3 & 512 & - & -6.45 & 54 & - & $6.58 \%$ \\
\hline \multicolumn{2}{|l|}{ Lineal } & 8192 & - & -18.82 & 50 & $8.47 \%$ & $9.21 \%$ \\
\hline
\end{tabular}

Tabla 7.25: Clasificación Temblor Esencial vs Temblor de Párkinson (Patrones cinéticos).

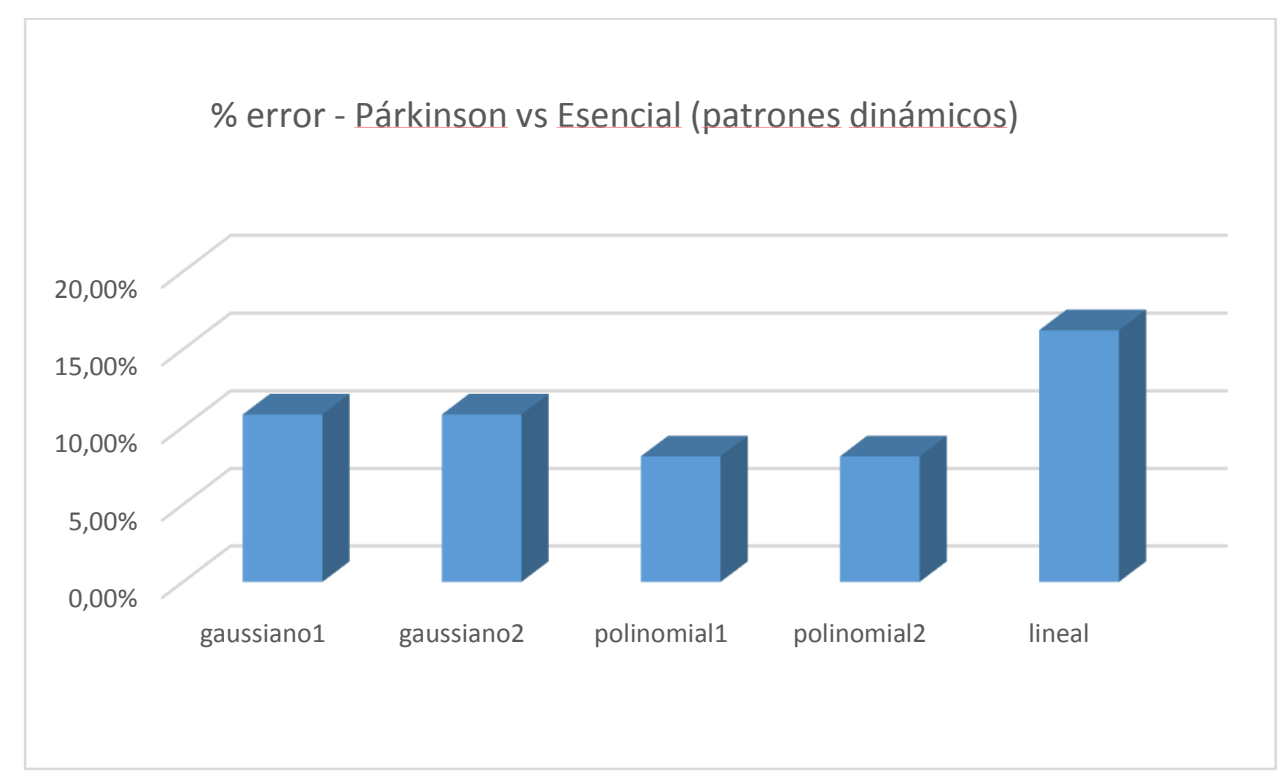

Figura 7.12: Clasificación Temblor Esencial vs Temblor de Párkinson (Patrones dinámicos). 


\begin{tabular}{|c|c|c|c|c|c|c|c|}
\hline $\begin{array}{l}\text { Selección } \\
\text { modelo }\end{array}$ & & Fase $d$ & enamiento & Modelo d & Clasificador & Resu & ados \\
\hline Función & & Parár & de ajuste & & $\mathrm{N}^{\mathrm{o}}$ vectores & Error de & Error de \\
\hline Kernel & & $\mathrm{C}$ & gama $(\Upsilon)$ & bias (b) & soporte, VS & entrenam. & prueba \\
\hline Calccian & & 2048 & 0.0078125 & 5.45 & 35 & $18.82 \%$ & $10.81 \%$ \\
\hline Gaussiano & $\mathrm{BF}$ & 2048 & 0.00390625 & 2.60 & 36 & $18.82 \%$ & $10.81 \%$ \\
\hline Dolinomis & 2 & 4096 & - & 0.09 & 33 & - & $8.11 \%$ \\
\hline Polinomial & 3 & 8192 & - & 0.31 & 36 & - & $8.11 \%$ \\
\hline Lineal & & 2 & - & 0.75 & 40 & $20.00 \%$ & $16.22 \%$ \\
\hline
\end{tabular}

Tabla 7.26: Clasificación Temblor Esencial vs Temblor de Párkinson (Patrones dinámicos).

Eliminados los atípicos igualmente (coeficientes de Curtosis y distancias de Mahalanobis), aplicando el ACP con los vectores finales muestrales, y trabajando únicamente con las 6 características principales vuelve a repetirse el ratio de $0 \%$ de error en la clasificación de temblor fisiológico frente a temblor patológico con kernel gaussiano y 28 vectores soporte. Mientras que el mejor resultado para la clasificación entre Párkinson y temblor esencial, un 100\% de acierto, vuelve a obtenerse para el caso de los patrones estáticos y cinéticos.

Por patrón, con kernel gaussiano:

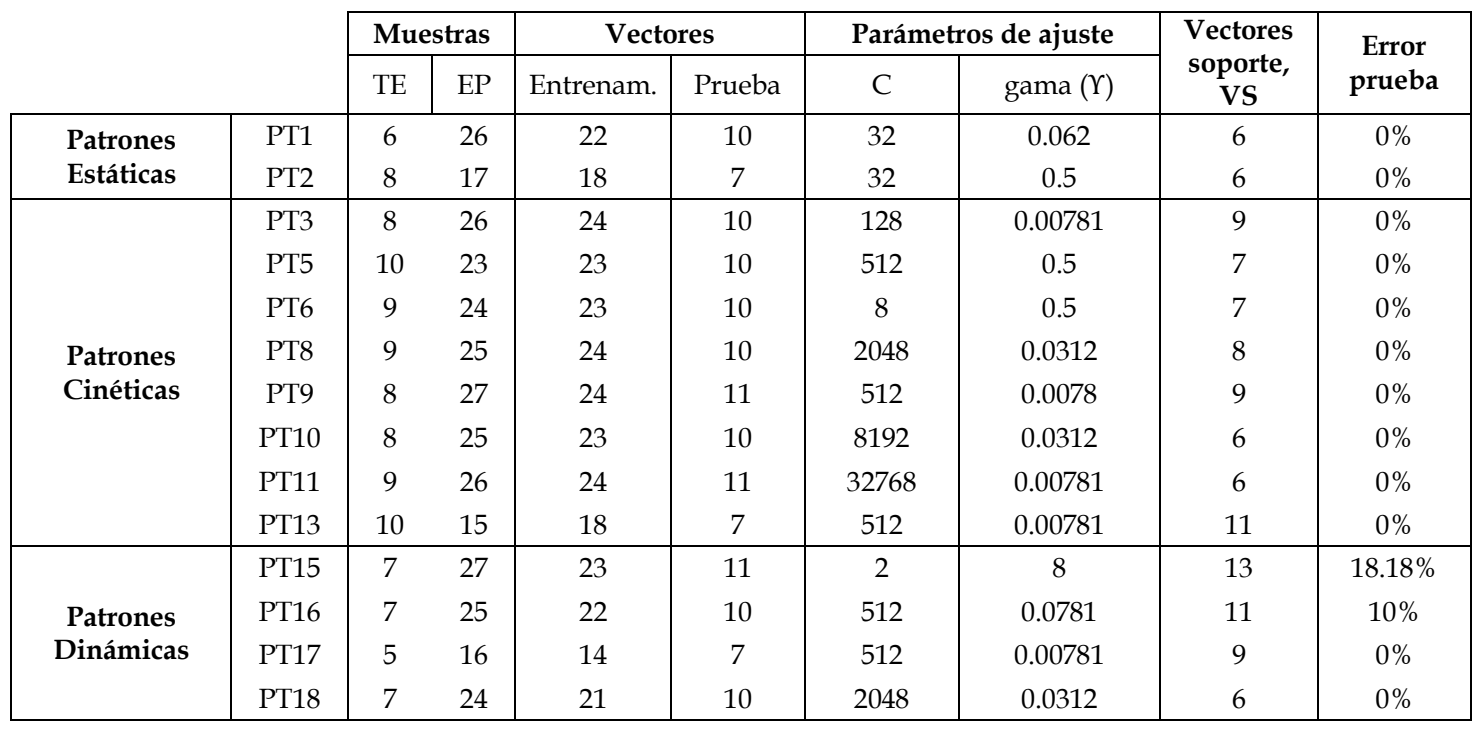

Por patrones, los dinámicos PT17 y PT18 también obtienen un 100\% de éxito en la clasificación entre temblor parkinsoniano y temblor esencial. Igualmente se obtiene el mismo resultado en cinéticos y estáticos. 
Este capítulo tiene como objetivo el aglutinar todos los resultados obtenidos en los diferentes ensayos y proporcionar una visión global sobre el cumplimiento de los objetivos planteados inicialmente.

Por un lado, se comentarán los resultados del sistema de filtrado (ACORTE), para permitir el acceso al ordenador de las personas discapacitadas por temblor. Se enumerarán los objetivos y se hará una argumentación de los resultados abalados por las pruebas efectuadas.

Por otro, se van a analizar los resultados obtenidos con cada una de las técnicas empleadas para la clasificación del temblor. El que la plataforma DIMETER sea un sistema capaz de proporcionar una ayuda al diagnóstico eficaz, depende del grado de certeza de los clasificadores a la hora de diferenciar primero, entre temblor patológico y temblor fisiológico; y también, y más complicado, diferenciar dentro del patológico, entre temblor parkinsoniano y temblor esencial. Desde un principio, se planteó como objetivo el estudio del temblor de Párkinson, por un lado, que como ya se desarrolló en el capítulo 2, suele ser un temblor de reposo fundamentalmente, aunque puede llevar asociados otros tipos con un grado de significación variable; el temblor esencial, fundamentalmente un temblor de acción, de naturaleza desconocida, con posibilidad de tener una causa familiar (o genética) y el temblor fisiológico, que es aquel que suelen presentar todos los individuos sanos, en menor o mayor medida debida a condiciones exógenas, también ya mencionadas en dicho capítulo.

\subsection{Resultados del filtrado del temblor. Dispositivo ACORTE.}

Inicialmente, se abrieron dos vías para conseguir el objetivo: filtrado mediante técnicas clásicas y compensación mediante redes MLPs.

Las primeras pruebas que se hicieron mediante filtros clásicos, no dieron los resultados esperados. Si bien la atenuación conseguida por los filtros paso bajo y rechaza banda fue muy buena, los retardos que produce la función de transferencia 
entre entrada-salida no les proporciona características mínimas para trabajar en tiempo real. Descartadas estas posibilidades se trabajó en dos líneas.

\subsubsection{Filtrado mediante MLP.}

Con los perceptrones multicapa se afrontó el problema trabajando en dominios distintos: dominio temporal y dominio frecuencial. La primera vía consistió en intentar modelar el temblor mediante un conjunto de MLPs y sustraer la estimación del mismo a la señal de partida. Probando diferentes configuraciones del clasificador tal y como se muestra en el capítulo 5, los resultados obtenidos en el dominio temporal no son admisibles. En el dominio frecuencial se plantea utilizar la MLP para discriminar la banda de rechazo del filtro. Optimizando el armónico y su selectividad, quizás se pueda conseguir un filtro lo suficientemente rápido. Para ello se entrena una MLP que discrimine entre señales "pico" y señales "meseta". Dicha característica permitirá la parametrización óptima del filtro. Los resultados obtenidos no han sido los suficientemente buenos ya que en el mejor de los casos se obtuvo un error en torno al $20 \%$ en la clasificación, por lo que se decidió abandonar esta vía y centrar los esfuerzos en otras técnicas.

\subsubsection{Filtros FLC, WFLC y LC.}

Para modelar el temblor en este estudio, se recurrió a estructuras de filtros adaptativos como el FLC o el WFLC. Estas técnicas se basan en el modelado del temblor mediante series de Fourier truncadas. El LC, que es al final el que mejores resultados proporcionó, es una variante simplificada en la que se utiliza un único peso en la etapa de salida del algoritmo de estimación. Las conclusiones fueron concluyentes y muy satisfactorias. Según se muestra en la Tabla 5.1, todos los usuarios del dispositivo ACORTE en las pruebas realizadas a los miembros de la Asociación de Párkinson de Madrid, consiguen los objetivos disminuyendo en torno al 50\% el tiempo de ejecución cuando están activos los filtros respecto a la situación "transparente" del dispositivo. Salvo algunos casos, el LC ofrece siempre los mejores resultados. Sin embargo, se proporciona la capacidad de configuración a medida del algoritmo de filtrado, mediante una etapa de "setup" para la elección del más idóneo en cada caso (dependiendo del perfil del usuario). Por lo general, el FLC y el WFLC ofrecen una respuesta mejor desde el punto de vista dinámico, sin embargo las atenuaciones no son tan buenas. El LC es el que ofrece el mejor compromiso entre respuesta dinámica y grado de atenuación.

\subsection{Resultados de los clasificadores.}

\subsubsection{Etapa 1. Clasificadores MLP.}

En la primera técnica propuesta de clasificación, los perceptrones multicapa o MLP, se planteó la hipótesis de partida, basándose en dos grupos principales de características: estadísticos de segundo orden (PSD) y estadísticos de orden superior (HOS). Se concluirá sin lugar a dudas, que para el primero de los objetivos, la clasificación del temblor patológico, es suficiente con únicamente las primeras 
características (PSD). Se pudo constatar, tal y como se concluyó en el capítulo 3 con el análisis de la varianza, que las características del dominio frecuencial (transformada de Fourier y densidad espectral de potencia armónica) resultan ser significativos para la tarea de discriminación. Plantear las primeras características de entrada a los MLPs en términos de energía (PSD) en vez de distancias, ha tenido como objetivo el mejorar la generalización, intentando que la información de partida se viese afectada lo menos posible por la escala que las unidades pudieran introducir.

En esta primera etapa queda patente que la discriminación entre individuos sanos y enfermos es eficaz, incluso utilizando únicamente las primeras nueve características (PSD). El grado de acierto se sitúa por encima del $90 \%$. Concretamente para el caso del G1 para 10 neuronas en la capa oculta se obtiene un error de aproximadamente del $4 \%$. Siendo un resultado bastante bueno si lo comparamos con el de otros trabajos, como en [102], donde los errores obtenidos en la clasificación están en la horquilla entre el 6\% y el 13\% (el primero con MLP y el segundo con funciones de base radial). Utilizando un total de 16 características de entrada sobre las muestras de un repositorio de individuos sanos y enfermos de Párkinson, de los cuales 23 eran enfermos y 7 sanos. Los autores comentan en el estudio que sometiendo a la MLP a simulación con los mismos vectores que se utilizaron en el entrenamiento, el error disminuye a un 3\%-4\%, que es el resultado que se ha obtenido en este trabajo de tesis utilizando únicamente vectores en la simulación distintos a los de la fase de entrenamiento. En [103] prueban también varios tipos de clasificadores para la ayuda al diagnóstico del Párkinson, entre ellos el MLP. Sobre un total de 23 características en el espacio de entrada, los resultados obtenidos con vectores de simulación o prueba exclusivamente, utilizando un MLP, están en torno al 90\% de acierto, resultado inferior al del estudio anterior, y por debajo también como consecuencia, del obtenido en la presente tesis. Cabe constatar también que en ninguno de dichos estudios se afronta la diferenciación entre el temblor esencial y el temblor parkinsoniano.

Sin embargo, la conclusión que hemos sacado sobre este clasificador desde el punto de vista de la diferenciación entre patologías (Párkinson y esencial), es muy mejorable. Como se comenta en el capítulo 5, los mejores resultados arrojan unas tasas del $70 \%$ de error para el temblor esencial, incluso incluyendo todo el bloque de características (PSD+HOS), y en las mismas condiciones, ante el temblor de Párkinson presenta una tasa mínima del error del 30\%. Estos resultados claramente no son suficientes por lo que se debió de seguir el estudio, haciendo uso de técnicas y herramientas que se exponen en los capítulos 6 y 7.

\subsubsection{Etapa 2. Clasificadores LVQ.}

Partiendo de la premisa que la clasificación o diferenciación entre individuos sanos y enfermos ya se consiguió con los perceptrones multicapa, en esta fase de la tesis, se focalizaron los esfuerzos en la mejora de los ratios de éxito a la hora de clasificar el temblor esencial y el temblor de Párkinson. 
Los primeros resultados con este tipo de redes fueron ya un paso sustancial hacia delante, pues incluso sin recurrir al Análisis de Componentes Principales $(\mathrm{ACP})$, la primera tanda de ensayos, en donde se estudió la influencia del patrón y de la característica de entrada, arrojaron unos resultados del 18\% de error, en el mejor de los casos, incluyendo por primera vez también el análisis de Wavelet. Es decir, mediante la transformada wavelet se añadieron dos características nuevas en el espacio de entrada (la 27 y la 28), correspondiente a las discontinuidades detectadas en cada una de las pruebas. Tal y como se expone en el capítulo 4 y en el capítulo 6, algunos enfermos de Párkinson presentan "intermitencias" en el ritmo o la velocidad cuando se encuentran realizando un movimiento de intención (bradicinesias). Esta característica, de aparecer, puede apreciarse de manera inconfundible en el desarrollo del movimiento de cada patrón. Utilizando la transformada wavelet se puede automatizar la detección, y mediante la aplicación software del DIMETER contabilizarlas para su posterior inclusión en el espacio de entrada de los clasificadores.

En posteriores fases del estudio realizado con LVQs se introdujo el ACP para disminuir la dimensión del espacio muestral de entrada y conseguir también una normalización de los datos de entrada. En el capítulo 6 se han reproducido los ensayos más significativos de aquellos clasificadores, con las condiciones del modelo de la red, que mejores resultados aportaron. También se continuó en el objetivo de estudiar la influencia de los diferentes tipos de patrones propuestos. En las tablas mostradas en dicho capítulo puede apreciarse el resultado de los clasificadores en función del número de características elegidas. Con unos índices claramente mejores a los conseguidos sin ACP, se pudo llegar a las siguientes conclusiones:

- La influencia del patrón es significativa, ya que los mejores clasificadores que obtienen los errores más pequeños, lo hacen con la información de los patrones dinámicos (Ensayos número 7 y número 25). En un caso, el error de clasificación para los enfermos de Párkinson arroja un 0\%. El mismo resultado para los enfermos de temblor esencial en el otro, también $100 \%$ de acierto. El error medio cometido en ambos casos sería del 6\%. El clasificador más homogéneo, desde el punto de vista del error, en el que se obtuvo un $9 \%$ de desacierto para ambas clases, y por tanto, para el error medio también, fue el del ensayo 31, donde los protagonistas fueron los patrones cinéticos. Queda por tanto demostrado que el factor diferencial del patrón es de suma importancia, obteniéndose los mejores resultados cuando se utiliza la información de los patrones dinámicos (realimentación de fuerza gracias al dispositivo háptico).

- Con una tasa media de error en torno al 6\%, o lo que es lo mismo, con un índice de acierto del 94\%, utilizando los patrones dinámicos, las redes LVQs se proponen como un clasificador eficaz para la ayuda al diagnóstico, dotando al sistema DIMETER de las capacidades suficientes para no sólo proponerse como una plataforma de adquisición, medida y cuantificación del temblor, sino también como un elemento de apoyo al 
diagnóstico diferencial, mediante métodos totalmente objetivos $\mathrm{y}$ repetibles.

A modo de cita, otros estudios que utilizaron clasificadores LVQ para el estudio del Párkinson, como [104], en donde se plantea una comparativa entre diferentes técnicas, a parte de LVQs: métodos basados en estructuras en árbol (LMT) mediante funciones de regresión y análisis basados en clusters utilizando la entropía como medida de la distancia entre clases, arrojaron unos resultados, en el mejor de los casos, en torno al $84 \%$ de acierto. Coincidiendo este mejor caso, precisamente al caso del clasificador LVQ. Además hay que reseñar, que este estudio sólo trabaja con enfermos de Párkinson, no con temblores esenciales, luego su objetivo no es el diagnóstico diferencial entre ambos.

\subsubsection{Etapa 3. Clasificadores SVM.}

El estudio de los clasificadores SVM se afronta desde tres puntos de vista. Primero se retoma una premisa inicial del análisis de la varianza, con la que se obtuvo una significación clara de los parámetros frecuencia y amplitud en el análisis de la varianza mostrada en el capítulo 3. Segundo se aborda, de manera metodológica, la eliminación de atípicos en el conjunto del espacio muestral. Y por último se utiliza el análisis de componentes principales para reducir la dimensión del espacio de entrada, tal y como se llevó a cabo con las redes LVQ en el capítulo 6.

Respecto de los atípicos, se había observado en alguna ocasión de manera intuitiva, en base a los datos obtenidos por DIMETER, que algunos pacientes mostraban resultados contradictorios en el análisis previo de características. Esto puede deberse a dos causas principales: una a pacientes con un diagnóstico que pudiera haber evolucionado y cambiado, y dos porque algunos pacientes no tengan un cuadro clínico único de temblor. Ya en el capítulo 2, se hizo referencia al posible hecho de que un paciente pudiera estar afecto de una patología como el Párkinson (temblor de reposo) y manifestar también temblor de intención (temblor esencial).

Utilizando un procedimiento analítico y riguroso, en el segundo ensayo, previamente a someter a los clasificadores a entrenamiento, se hace un estudio mediante el coeficiente de Curtosis y la distancia de Mahalanobis, para proponer vectores que se alejan del epicentro de la clase, pudiendo caer en zonas de confusión provocando un error significativo en el entrenamiento. Una vez eliminadas las muestras atípicas, se procede al entrenamiento y prueba de las máquinas planteadas en el estudio.

El primer ensayo, tomando como características la frecuencia del primer armónico y la amplitud, arroja unos resultados en la clasificación de enfermos-sanos del $4.35 \%$ de error para kérnel gaussiano y del $0 \%$ para kérnel polinimial, es decir, un ratio de acierto aproximado del $96 \%$ y del 100\% respectivamente. El primero con 14 vectores soporte y el segundo con 24 . Este resultado mejora todos los ratios obtenidos hasta ahora, reafirmando lo que ya se comprobó con los MLP's, que para la clasificación entre temblor fisiológico y temblor patológico era suficiente con las 
características de segundo orden (valores de frecuencia y sus estadísticos derivados, y módulo o amplitud). Sin embargo, es el primer clasificador con el que se obtiene un grado de acierto del 100\%. En la clasificación entre temblor esencial y temblor de Párkinson el mejor resultado se obtiene con el kernel gaussiano arrojando un ratio de error del $8.33 \%$. Es un buen resultado también, en la línea de los mejores obtenidos con LVQ y ACP.

En el segundo ensayo, tomando como parámetros de entrada todas las características estudiadas en MLPs y LVQs (PSD+HOS), y haciendo un filtro de atípicos en el espacio muestral, como se comentaba anteriormente, mediante los coeficientes de Curtosis y las distancias de Mahalanobis, se vuelve a conseguir un $100 \%$ de acierto en la clasificación entre sanos y enfermos, y un 100\% también para la clasificación entre Párkinson y esencial (kernels polinomiales). Haciendo el estudio por patrones, se constata que el mejor resultado se obtiene en cinéticos y dinámicos ( $0 \%$ de error en ambos).

En el tercer y último ensayo, eliminados los atípicos igualmente (coeficientes de Curtosis y distancias de Mahalanobis), aplicando el ACP con los vectores finales muestrales, y trabajando únicamente con las 6 características principales vuelve a repetirse el ratio de $0 \%$ de error en la clasificación de temblor fisiológico frente a temblor patológico con kernel gaussiano y 28 vectores soporte. Mientras que el mejor resultado para la clasificación entre Párkinson y temblor esencial, un $100 \%$ de acierto, vuelve a obtenerse para el caso de los patrones estáticos y cinéticos.

Finalmente, también se muestra por patrones, que los dinámicos PT17 y PT18 también obtienen un 100\% de éxito en la clasificación entre temblor parkinsoniano y temblor esencial.

Como cita de otros resultados en los que también se trabajó con las máquinas de soporte vectorial como clasificadores para el diagnóstico diferencial del temblor de Párkinson y el temblor esencial, cabe destacar [105] donde obtienen un 9.5\% de error como mejor resultado para la clasificación entre sanos y enfermos, y un $14.3 \%$ para la diferenciación entre Párkinson y temblor esencial. En este trabajo también se menciona que dichos ratios de acierto-error están dentro de los márgenes en los que se mueven los errores de diagnóstico de la enfermedad de Párkinson, según estudios realizados post mortem analizando las historias clínicas de pacientes, desde un $26 \%$ [106] hasta un $10 \%$ como valor mínimo [107], de fallos en el diagnóstico.

En [108] obtuvieron mejores ratios de acierto, presentando un 94\% para kernel lineal, un $95 \%$ para polinomial y un $98 \%$ para kernel gaussiano.

Las conclusiones que se pueden obtener ante estos resultados son:

- Mejora del ratio de acierto para la clasificación de temblor patológico y temblor fisiológico (enfermos-sanos), hasta llegar al 100\% en todas las condiciones de los ensayos practicados. 
- Mejora absoluta del error de clasificación entre temblor esencial y temblor de Párkinson, siendo el único clasificador de los tres con el que se ha obtenido un $0 \%$ de error en la clasificación. Obteniendo modelos de clasificadores que proporcionan índices de acierto del 100\% tanto con todos los patrones, como particularizando para estáticos, para cinéticos y para dinámicos.

- Cumpliendo de manera holgada con los ratios admisibles de error en el diagnóstico clínico convencional marcados por [107] y [106] (10\%-26\%), se considera conseguido plenamente el objetivo de que el DIMETER como plataforma clínica de pruebas clínicas, pueda ser considerado un sistema de ayuda al diagnóstico eficaz, determinista y objetivo de los trastornos del movimiento asociados a la enfermedad de Párkinson y el temblor esencial. 


\subsection{Principales logros de la tesis.}

A continuación se describen los logros conseguidos en esta tesis, dando respuesta directa a los objetivos planteados en el capítulo 1.

\section{DIMETER: sistema integrado para la adquisición, evaluación y diagnóstico del temblor.}

Con el diseño y desarrollo del DIMETER se ha conseguido un sistema completo integrado para la adquisición, medida, evaluación objetiva y ayuda al diagnóstico del temblor.

Entre los objetivos cumplidos, hay que mencionar, la definición de los protocolos de pruebas, con la participación y validación de los equipos de expertos (neurólogos y neurofisiólogos del Hospital Ramón y Cajal y del Hospital de la Princesa). Los patrones correspondientes a las tareas fijadas en las pruebas, se incluyeron en la aplicación software del sistema, para cumplir así con los protocolos predefinidos. El sistema fue implantado durante casi año y medio de manera continuada e ininterrumpida, en las dependencias de investigación y de ensayos/ pruebas clínicas de dichos centros sanitarios. Durante todo este tiempo, se pudo someter a prueba al sistema, con las diferentes sesiones que tuvieron lugar tanto de sujetos con trastornos del movimiento (enfermedad de Párkinson y temblor esencial) como individuos de control (temblor fisiológico). Los individuos con alguna de las patologías mencionadas fueron evaluados tanto es estadios de medicación OFF como ON (sin ingesta farmacológica y con medicación). En aquellos casos en los que fue posible (no sobrepaso de los límites dimensionales y dinámicos del dispositivo háptico), también se sometieron al protocolo de pruebas a aquellos sujetos que estando intervenidos quirúrgicamente (electroestimulación profunda unilateral y bilateral), fue posible la desconexión de su estimulador (generador de señal). Durante todo este periodo de pruebas, se realizaron multitud de registros que posteriormente sirvieron como base para el estudio y elección del 
filtro más eficiente, así como para el análisis y clasificación diferenciada de los tipos de temblor. En total se efectuaron 40 pruebas de enfermos de Párkinson, 7 de temblor esencial y 30 de sujetos de control o temblor fisiológico.

Cabe mencionar también que, la aplicación software desarrollada de la que consta DIMETER, además de permitir la ejecución de las baterías de pruebas y por tanto, el registro de las trayectorias temblorosas de los pacientes, es capaz de proporcionar una serie herramientas para el posterior estudio y análisis de las muestras. Entre ellas, podríamos destacar por su utilidad, el acceso inmediato a la historia clínica, las diferentes condiciones en las que fue evaluado el paciente (medicación - electroestimulación), el cálculo en el dominio frecuencial de los espectogramas de frecuencia, las tranformadas wavelets de las señales para el estudio de las discontinuidades, representación gráfica tanto del resultado final como de la simulación de todas aquellas pruebas realizadas (patrones), cuadros resumen de resultados de discontinuidades y frecuenciales, etc ...

\section{Sistema ACORTE: dispositivo de filtrado para permitir el acceso al ordenador a personas discapacitadas por temblor.}

Gracias a los datos suministrados por DIMETER se pudieron estudiar en profundidad las características de las dos patologías que fueron objeto de estudio. Fruto de esta investigación se pudieron concretar las técnicas de filtrado más idóneas para conseguir resultados válidos en el manejo del entorno de la interfaz gráfica del ordenador.

Se diseñó y fabricó un sistema basado en microcontrolador para permitir el acceso mediante un dispositivo externo, que garantice el manejo por parte del usuario (tipo joystick), y que implemente las técnicas de filtrado más convenientes en función del perfil del usuario. Del mismo modo, se consiguió que el sistema sea multiplataforma ya que "emula" el protocolo de cualquier ratón comercial. Plantear el uso de un de un dispositivo distinto a un ratón, fue porque en muchos casos, a los afectados por temblor, les es difícil mantener una posición del ratón que garantice su correcto funcionamiento.

Se definieron una serie de pruebas para validar el funcionamiento del dispositivo. Para la realización de dichas pruebas se contó con la colaboración de la Asociación de Párkinson de Madrid. Algunos de sus miembros asociados participaron de manera altruista y desinteresada en la evaluación del dispositivo, mediante pruebas sencillas de uso frecuente del ordenador (manejo del navegador web, abrir y cerrar ventanas, etc...).

Como conclusión, se puede considerar que el objetivo se cumplió en su totalidad ya que las pruebas demostraron que los filtros elegidos y el dispositivo empleado permitieron conseguir un uso eficaz del entorno, disminuyendo los tiempos de reacción y posibilitando la consecución de las tareas, así como muestran los resultados expuestos en el capítulo 3. 


\section{Clasificador para ayuda al diagnóstico.}

Mediante el uso de diferentes técnicas de clasificación, se ha trabajado en el objetivo por un lado de identificar el temblor patológico frente al fisiológico, y segundo más novedoso a la vez que ambicioso, de conseguir un diagnóstico diferencial entre el temblor parkinsoniano y el temblor esencial. El primer objetivo se consigue prácticamente con unos niveles aceptables de error, con los clasificadores basados en perceptrones multicapa (MLP), capítulo 5. Aciertos en torno al $90-95 \%$ son posibles incluso sin tener en cuenta todas las características inicialmente planteadas para el espacio de entrada (26). Con el uso de las variables de segundo orden (PSD) únicamente incluso se obtienen mejores resultados en prácticamente todas las ocasiones. Esto no quiere decir que los ratios de acierto no hayan mejorado con las técnicas posteriores, donde incluso llegó a proporcionarse un valor nulo o cercano a cero del valor medio del error para las SVMs ensayadas.

La clasificación diferencial entre el temblor parkinsoniano y el temblor esencial, sin embargo, fue una tarea más complicada. Como se ha expuesto en la tesis (capítulo 2), estos tipos de temblores algunas veces superponen sus características (respecto de la banda de frecuencias por ejemplo). Además sus síntomas pueden cursar simultáneamente en algunos enfermos (componente de temblor intencional en algunos enfermos de Párkinson). Con el primer clasificador, el perceptrón multicapa (MLP) los resultados no fueron aceptables, incluso trabajando con los estadísticos de segundo orden (PSD) más los de orden superior (HOS).

La transformación del espacio de características inicial mediante el análisis de componentes principales (ACP), la inclusión de la transformada wavelet para añadir las características 27 y 28 , así como el uso de las redes de tipo mixto LVQ ofrecieron un paso muy significativo en el resultado de la clasificación. Llegando a valores de acierto en el margen de los proporcionados en la clasificación entre sanos y enfermos por los MLPs. Es en esta fase donde queda probada la significación de los patrones que involucran fuerzas virtuales en la realización de la tarea. Puesto que en los ensayos donde se entrenan las redes únicamente con estos patrones, la clasificación diferencial entre la clase de Párkinson y la de esencial obtiene unos resultados excelentes de acierto.

Es finalmente, con la utilización de las máquinas de soporte vectorial (SMVs) cuando se consigue errores medios nulos o cercanos a cero en la clasificación del temblor patológico. Quedando plenamente conseguido el objetivo inicialmente planteado de obtener un clasificador eficaz para diferenciar ambas patologías y proponer de esta manera, una solución real de ayuda al diagnóstico.

\subsection{Contribuciones más destacables.}

Como aportaciones más reseñables podrían citarse:

- Se ha diseñado y desarrollado un sistema de medida objetiva del temblor utilizando un dispositivo háptico, capaz de mediante estímulos basados 
en la realimentación de esfuerzos, proponer tareas a los pacientes para su posterior diferenciación y clasificación.

- Mediante una batería de patrones, se ha fijado una metodología para las pruebas y ensayos clínicos, y poder proporcionar de esta manera, una información objetiva para el posterior análisis y clasificación. Son pruebas cuantificables y deterministas, que no dependen de la subjetividad que pueda plantear la aplicación de unas escalas con baremos interpretativos.

- Se ha obtenido un conjunto de clasificadores eficaces, no sólo para la diferenciación entre temblor patológico y temblor fisiológico, sino también para la diferenciación certera entre temblor parkinsoniano y temblor esencial. Los niveles de acierto (y por tanto en relación inversa del error), son más que aceptables (en algún caso el 100\% o cercano a éste), para considerar que el sistema DIMETER es una herramienta de ayuda al diagnóstico eficaz.

\subsection{Futuros desarrollos.}

Mediante el uso del sistema DIMETER en un futuro, podría plantearse abordar el estudio de otros tipos de temblores asociados a trastornos del movimiento que tienen como causa $u$ origen otros tipos de enfermedades neurológicas. Continuar con su implantación en los servicios clínicos de los centros sanitarios y poder efectuar así más pruebas con pacientes de otras patologías, para proceder posteriormente a su estudio y evaluación. Los datos así obtenidos podrían proporcionar un camino posible a la evaluación y estudio de clasificadores capaces de proponer resultados para la ayuda al diagnóstico de otras enfermedades que cursan con otros tipos de trastornos del movimiento.

De igual manera, cabría la posibilidad de añadir nuevas capacidades a la plataforma DIMETER para evaluar características adicionales, como el tiempo de reacción ante estímulos o eventos, permitiendo así poder analizar otro tipo de síntomas que puedan cursar con otras enfermedades.

Del mismo modo, para patalogías como las córeas o las esclerosis quizás debería pensarse en aumentar el volumen de trabajo del dispositivo háptico, así como las fuerzas máximas que son posibles generar en el extremo de los patrones dinámicos. Algunos enfermos, debido a la intensidad y amplitud de los movimientos, sobre todo cuando no están medicados o no tienen activo el estimulador, pueden provocar que las sacudidas excedan del rango máximo del dispositivo. También, en algún caso hubo que parar la sesión porque los esfuerzos que sufrían los motores, sobrepasaban los valores de caliento máximos, teniendo que esperar el tiempo necesario para que el descenso de la temperatura volviese a permitir continuar con las pruebas.

Respecto del filtrado, resultando eficaz y perfectamente usables tanto el dispositivo como los algoritmos, se podría obtener fácilmente una versión mucho 
más reducida, disminuyendo el tamaño de la placa microcontrolador, su caja de protección y contención, estudiando otros tipos de elementos o dispositivos de entrada. 
[1] Rijk MC, Launer LJ, Berger K, Breteler MM, Dartigues JF, Baldereschi M, Fratiglioni L, Lobo A, Marínez-Lage J, Trenkwalder C, Hofman A, "Prevalence of Parkinson's disease in Europe: A collaborative study of population-based cohorts. Neurologic Diseases in the Ederly Research Group.". Neurology [2000, 54(11 Suppl 5):S21-3].

[2] S. Campenhausen, B. Bornschein, R. Wick, K. Bötzel, C. Sampaio, W. Poewe, W. Oertel, U. Siebert, K. Berger y R. Dodel, "Prevalence and incidence of Parkinson's disease in Europe.", European Neuropsychopharmacology, Volume 15, Issue 4, pag. 473-490. Aug. 2005.

[3] G.K. Wenning, S. Kiechl, K. Seppi, J. Müller, B. Högl, M. Saletu, G. Rungger, A. Gasperi, J. Willeit y W. Poewe, "Prevalence of movement disorders in men and women aged 50-89 years: a population-based estudy", The Lancet Neurology, vol. 4, issue 12, pag. 815-820. Dec. 2005.

[4] M. Ferreiro Gómez, "Temblor”, Guías clínicas, vol. 5, 2005.

[5] Deuschl G, Bain P, Brin M. “Consensus statement of the Movement Disorder Society on Tremor". Ad Hoc Scientific Committee. Mov Disord. 1998; 13 Suppl. 3:2-23.

[6] Hallett, M. “Overview of Human Tremor Physiology. Movement Disorders", p.43-48, 1998. ISSN 1531-8257.

[7] Parkinson's Disease Foundation. Statistics on Parkinson's in USA. http://www.pdf.org/en/parkinson_statistics.

[8] Grimaldi G, Manto M. Tremor: "From Pathogenesis to Treatment". San Rafael, California: Morgan \& Claypool Publishers 2008.

[9] Crawford P, MD, and Zimmerman E., MD. "Differentiation and Diagnosis of Tremor", Nellis Family Medicine Residency, Nellis Air Force Base, Nevada. Volume 83, Number 6, March 15, 2011. 
[10] D. Kasper y E. Braunwald, Harrison. "Principios de Medicina Interna", Madrid: McGraw Hill, 2005.

[11] S. von Campenhausen, B. Bornschein, R. Wick, K. Bötzel, C. Sampaio, W. Poewe, W. Oertel, U. Siebert, K. Berger, y R. Dodel, "Prevalence and incidence of Parkinson's disease in Europe", European Neuropsychopharmacology, vol. 15, pag. 473-490. Aug. 2005.

[12] Y.M. Hoehn M, Yahr M, "Parkinsonism: onset, progression and mortality", Neurology, vol. 17, 1967, pag. 427-42.

[13] F. Gillingham y M. Donaldson, "Medicine: Schwab and England Activities of Daily Living", Edinburgh, Scotland: E\&S Livingstone, 1969, pag. 152-7.

[14] E. de la Cruz Estrada y E. Otero Siliceo, "Temblor esencial", Archivos de Neurociencias, vol. 11, 2006, pag. 200-209.

[15] J. Benito-León, F. Bermejo-Pareja, y E.D. Louis, “Incidence of essential tremor in three elderly populations of central Spain", Neurology, vol. 64, 2005, pag. 1721.

[16] Salemi G, Savettieri G, Rocca WA, et al. "Prevalence of essential tremor: $a$ door-to-door survey in Terrasini, Sicily". Neurology. 1994; 44:61-64.

[17] F. Bermejo-Pareja, "Más de cien escalas en neurología”, Grupo Aula Médica, 2008.

[18] E.D. Louis, L. Barnes, K.J. Wendt, B. Ford, M. Sangiorgio, S. Tabbal, L. Lewis, P. Kaufmann, C. Moskowitz, C.L. Comella, C.C. Goetz, y A.E. Lang, "A teaching videotape for the assessment of essential tremor", Movement Disorders: Official Journal of the Movement Disorder Society, vol. 16, Ene. 2001, pag. 89-93.

[19] D. García Urra, “Temblor”, Jano, vol. 39, 1990, pág. 1289:1301.

[20] E.S. Berner, "Diagnostic error in medicine: introduction", Advances in Health Sciences Education: Theory and Practice, vol. 14 Suppl 1, Sep. 2009, pag. 1-5.

[21] J.S. Barrett, J.T. Mondick, M. Narayan, K. Vijayakumar, y S. Vijayakumar, "Integration of modeling and simulation into hospital-based decision support systems guiding pediatric pharmacotherapy", BMC Medical Informatics and Decision Making, vol. 8, pag. 6-6.

[22] J. Lederberg, "How DENDRAL Was Conceived and Born”, Nov. 1987.

[23] E.H. Shortliffe, "A rule-based computer program for advising physicians regarding antimicrobial therapy selection", Proceedings of the 1974 annual ACM conference - Volume 2, ACM, 1974, pag. 739-739.

[24] R. Davis, B.G. Buchanan, y E.H. Shortliffe, "Retrospective on production rules as a representation for a knowledge-based consultation program", MIT Press, 1994, pag. 181-189. 
[25] V.L. Yu, B.G. Buchanan, E.H. Shortliffe, S.M. Wraith, R. Davis, A.C. Scott, y S.N. Cohen, "Evaluating the performance of a computer-based consultant", Computer Programs in Biomedicine, vol. 9, pag. 95-102. Jan. 1979.

[26] W.J. Clancey, "The epistemology of a rule-based expert system, a framework for explanation", Artificial Intelligence, vol. 20, May. 1983, pag. 215-251.

[27] Piédrola Gil, “Medicina preventiva y salud pública”, Elsevier, 2008.

[28] B. Bojduj, "Extraction of Causal-Association Networks from Unstructured Text Data", Master's Theses and Project Reports, Jun. 2009.

[29] S.M. Weiss, C.A. Kulikowski, S. Amarel, y A. Safir, “A model-based method for computer-aided medical decision-making", Artificial Intelligence, vol. 11, Ago. 1978, pag. 145-172.

[30] M. Stefik, "Planning with constraints (MOLGEN: Part 1)", Artificial Intelligence, vol. 16, 1981, pag. 111-139.

[31] M. Stefik, "Planning and meta-planning (MOLGEN: Part 2)", Artificial Intelligence, vol. 16, 1981, pag. 141-169.

[32] J.S. Aikins, J.C. Kunz, E.H. Shortliffe, y R.J. Fallat, “PUFF: an expert system for interpretation of pulmonary function data", Computers and Biomedical Research, an International Journal, vol. 16, Jun. 1983, pag. 199-208.

[33] H.G. McAllister, P.J. McCullagh, y J. Kelly, "Quantification of body tremor", Engineering in Medicine and Biology Society, 1989. Images of the TwentyFirst Century., Proceedings of the Annual International Conference of the IEEE Engineering in, IEEE, 1989, pag. 1985-1986 vol.6.

[34] R.C. Eberhart, "Tremor quantification using digital actigraphy", BMES/EMBS Conference, 1999. Proceedings of the First Joint, IEEE, 1999.

[35] R.C. Eberhart y X. Hu, "Human tremor analysis using particle swarm optimization", in proceedings of the congress on Evolutionary Computation Washington D.C, USA, 1999, pag. 1927--1930.

[36] Mansur P, Cury L, Andrade A, Pereira A, Miotto G, Soares A, Naves EL. “A review on techniques for tremor recording and quantification." Crit Rev Biomed Eng.; 35(5):343-62. 2007.

[37] Tsipouras M, Tzallas A, Rigas G, Tsouli S, Fotiadis D, Konitsiotis S. "An automated methodology for levodopa-induced dyskinesia: assessment based on gyroscope and accelerometer signals." Artif Intell Med. 55(2):127-35. Jun 2012.

[38] J. Jakubowski, K. Kwiatos, A. Chwaleba, y S. Osowski, "Higher order statistics and neural network for tremor recognition", Biomedical Engineering, IEEE Transactions on, vol. 49, pag. 152-159. 2002.

[39] de Lima ER, Andrade AO, Pons JL, Kyberd P, Nasuto SJ. “Empirical mode decomposition: a novel technique for the study of tremor time series". Med Biol Eng Comput.; 44(7):569-82. Jul 2006. 
[40] A. Salarian, H. Russmann, C. Wider, P.R. Burkhard, F.J.G. Vingerhoets, y K. Aminian, "Quantification of tremor and bradykinesia in Parkinson's disease using a novel ambulatory monitoring system", IEEE Transactions on BioMedical Engineering, vol. 54, pag. 313-322. Feb. 2007.

[41] M.C. Barroso, G.P. Esteves, T.P. Nunes, L.M. Silva, A.C. Faria, y P.L. Melo, "A telemedicine instrument for remote evaluation of tremor: design and initial applications in fatigue and patients with Parkinson's Disease", vol. 10, pag. 14-14.

[42] Zwartjes DG, Heida T, van Vugt JP, Geelen JA, Veltink PH. “Ambulatory monitoring of activities and motor symptoms in Parkinson's disease". IEEE Trans Biomed Eng. 57(11). Nov 2010.

[43] C.N. Riviere y N.V. Thakor, "Adaptive human-machine interface for persons with tremor", Engineering in Medicine and Biology Society, IEEE 17th Annual Conference, IEEE, pag. 1193-1194 vol.2. 1995.

[44] J.G. Gonzalez, E.A. Heredia, T. Rahman, K.E. Barner, y G.R. Arce, “Optimal digital filtering for tremor suppression", IEEE Transactions on Bio-Medical Engineering, vol. 47, pag. 664-673. May. 2000.

[45] Milanov I. "Electromyographic differentiation of tremors." Clin. Neurophysiol. 112(9):1626-32. Sep. 2001.

[46] A. Ünlü, R. Brause, y K. Krakow, "Handwriting Analysis for Diagnosis and Prognosis of Parkinson's Disease", 2006.

[47] L.A. Gusev y O.Y. Khutorskaya, "On an estimation of the effectiveness of computer diagnosis of movement disorders", Automation and Remote Control, vol. 64, pag. 1928-1937. Dec. 2003

[48] Sturman MM, Vaillancourt DE, Corcos DM. "Effects of aging on the regularity of physiological tremor." J Neurophysiol. 93(6):3064-74. Epub Feb 162005.

[49] Hellwig B, Schelter B, Guschlbauer B, Timmer J, Lücking CH. "Dynamic synchronisation of central oscillators in essential tremor." Clin Neurophysiol. 114(8):1462-7. Aug. 2003.

[50] L.F.N. Squire y Squire, Lucy Frank; Novelline, Robert A., “Squire's fundamentals of radiology", Cambridge: Harvard University Press, 1997.

[51] A.K. Kono, K. Ishii, K. Sofue, N. Miyamoto, S. Sakamoto, y E. Mori, "Fully automatic differential diagnosis system for dementia with Lewy bodies and Alzheimer's disease using FDG-PET and 3D-SSP", European Journal of Nuclear Medicine and Molecular Imaging, vol. 34, pag. 1490-1497. Sep. 2007.

[52] K.L. Leenders, E.P. Salmon, P. Tyrrell, D. Perani, D.J. Brooks, H. Sager, T. Jones, C.D. Marsden, y R.S. Frackowiak, "The nigrostriatal dopaminergic system assessed in vivo by positron emission tomography in healthy volunteer subjects and patients with Parkinson's disease", Archives of Neurology, vol. 47, pag. 1290-1298. Dec. 1990. 
[53] R.B. Innis, J.P. Seibyl, B.E. Scanley, M. Laruelle, A. Abi-Dargham, E. Wallace, R.M. Baldwin, Y. Zea-Ponce, S. Zoghbi, y S. Wang, "Single photon emission computed tomographic imaging demonstrates loss of striatal dopamine transporters in Parkinson disease." , Proceedings of the National Academy of Sciences of the United States of America, vol. 90, pag. 11965-11969. Dec. 1993.

[54] U. Sommer, T. Hummel, K. Cormann, A. Mueller, J. Frasnelli, J. Kropp, y H. Reichmann, "Detection of presymptomatic Parkinson's disease: combining smell tests, transcranial sonography, and SPECT", Movement Disorders: Official Journal of the Movement Disorder Society, vol. 19, pag. 1196-1202. Oct. 2004.

[55] A. Ericsson, M.N. Lonsdale, K. Astrom, L. Edenbrandt, y L. Friberg, "Decision Support System for the Diagnosis of Parkinson's Disease", Image Analysis, H. Kalviainen, J. Parkkinen, y A. Kaarna, Eds., Berlin, Heidelberg: Springer Berlin Heidelberg, pag. 740-749. 2005.

[56] S. Kim, J. Mcnames, y K. Burchiel, “Comparison of Phase-Coupling Indices for Tremor», 2005.

[57] S. Kim y J. McNames, "Tracking tremor frequency in spike trains using the extended Kalman filter», Engineering in Medicine and Biology Society, 2005. IEEE-EMBS 2005. 27th Annual International Conference, pag. 7576-7579. 2005.

[58] R. Das, "A comparison of multiple classification methods for diagnosis of Parkinson disease", Expert systems with applications, vol. 37, pag. 15681572. 2010.

[59] A. Jobbagy, E. Furnee, P. Harcos, y M. Tarczy, "Early detection of Parkinson's disease through automatic movement evaluation", Engineering in Medicine and Biology Magazine, IEEE, vol. 17, pag. 81-88. 1998.

[60] R.-S. Chang, J.-H. Chiu, F.-P. Chen, J.-C. Chen, y J.-L. Yang, “A Parkinson's Disease Measurement System Using Laser Lines and a CMOS Image Sensor", Sensors, vol. 11, pag. 1461-1475. Jan. 2011.

[61] A. Barrientos Cruz, M. Ferre Pérez, R. García de Sola, A. Mora Cases, y R. González Herranz, "Sistema para la caracterización objetiva del temblor mediante patrones que aplican fuerzas virtuales.", Patente ES 2161641 B1, Octubre, 2002.

[62] R.G.B.\& P.Y.C. Hwang y Robert Grover Brown \& Patrick Y.C. Hwang, "Introduction to Random Signals and Applied Kalman Filtering", John Wiley \& Sons, 1997.

[63] I. Güler, F. Hardalaç, y E.D. \Übeylı, "Determination of Behcet disease with the application of FFT and AR methods", Computers in biology and medicine, vol. 32, pag. 419-434. 2002.

[64] D. Peña Sánchez de Rivera, "Estadística, modelos y métodos", Madrid: Aliana Editorial, 1986. 
[65] B. Martín del Brío y A. Sanz Molina, "Redes Neuronales y Sistemas Borrosos", Ra-Ma, 1997.

[66] Sibanda W, Pretorius P. "Novel application of Multi-Layer Perceptrons (MLP) neural networks to Model HIV in South Africa using seroprevalence data from Antenatal Clinics." International Journal of Computer Applicattions. Volume 35 - No5, Dec. 2011.

[67] Venkata K, Rahul B., Gopichand G. “Application of perceptron networks in recommending medical diagnosis". International Journal of Computer Applications. Volume 113 - No 4, March 2105.

[68] Hongmei Y, Yingtao J, Jun Z, Chenglin P, Oinghui L. "A multilayer perceptron-based medical decision support system for heart disease diagnosis". Expert Systems with Applications: An international journal. Volume 30 Issue 2. February, 2006

[69] Manaswini P, Ranjit K. "Multilayer perceptron network in HIV/AIDS application." International Journal of Computer Applications in Engineering Sciences. Vol 1. Issue 1. March 2011.

[70] Devashri R, Kulkarni PS. "Application of artificial neural networks and rough set theory for the analysis of various medical problems and nephritis disease diagnosis." Proceedings of the International Conference on Frontiers of Intelligent Computing: Theory and Applications (FICTA), Volume 247 of the series Advances in Intelligent Systems and Computing. Pag. 83-90. 2013.

[71] Polakovic O. "Backpropagation and his application in ECG classification". Research report $\mathrm{N}^{\circ}$ 75, Institute for Research and Application of Fuzzy Modeling. University of Ostrava. Czech Republic. 2005.

[72] Song P, Serdar I, Kevin W, Tipu A. "Parkingson's Disease tremor classification - A comparison between support vector machines and neural networks." Expert Systems with Applications: An International Journal. Volume 39 Issue 12, pag. 10764-10771. Sep. 2012.

[73] Andrés O, Juan MG, Javier R, FJ Martínez. “LVQ-SVM based CAD tool applied to structural MRI for the diagnosis of the Alzheimer's disease". Elsevier Pattern Recognition Letters 34, pag. 1725-1733. 2013.

[74] Taо Xu. "Research on sensor fault diagnosis method based LVQ neural network and clustering analysis". Intelligent Control and Automation. WCICA 2008 7th World Gongress. Chongquing, pag. 6017-6020. 2008.

[75] Liu X, Du H, Wang G, Zhou S, Zhang H. “Automatic diagnosis of premature ventricular contraction based on Lyapunov exponents and LVQ neural network". Comput Methods Programs Biomed, pag. 47-55. Oct. 2015.

[76] Pesonen E, Ohmann C, Eskelinen M, Juhola M. “Diagnosis of acute apendicitis in two database. Evaluation of different neighborhoods with an LVQ neural network". Methods Inf. Med, pag. 59-63. 1998.

[77] RR Janghel, Ritu T, Anupam S. “Breast cancer diagnostic system using hierarchical learning vector quantization". National Seminar on Application 
of Artificial Intelligence in Life Science. Proceedings published in International Journal of Computer Applications (IJCA), pag. 14-18. 2013.

[78] Tianlei Z, Dayun Z, Fei H, Ning S. "Combined three feature selection mechanisms with LVQ neural network for colon cancer diagnosis". Advances in Neural Networks. Volume 6677 of the series Lecture Notes in Computer Science, pag. 467-474. 2011.

[79] Dimitrios M, George A, Lazaros I, Konstantinos K, Harris P. “A soft computing approach for osteoporosis risk factor estimation". Proceedings of Artificial Intelligence Applications and Innovations. $6^{\text {th }}$ IFIP WG International Conference, AIAI. Larnaca Cyprus. 2010.

[80] Dolly G, Gour S, Abhishek. “Detection of gallbladder stone using Learning Vector Quantization Neural Networks". International Journal of Computer Science and Information Technologies, vol 3, pag. 3934-3937. 2012.

[81] Burgues Christopher J. C. "A tutorial on support vector machines for pattern recognition, data mining and knowledge discovery" 2. Kluwer Academic Publishers, Boston. Manufactured in The Netherlands. 1998.

[82] Hernández Orallo J., Ramírez Quintana Ma. J., Ferri Ramírez C., "Introducción a la Minería de Datos". Pearson Educación, S.A., Madrid, 2004. ISBN 84-205-4091-9.

[83] Statnikov Alexander, Aliferis Constantin, Hardin Douglas, and Guyon Isabelle. "A gentle introduction to support vector machines in biomedicine." Volume 1: Theory and Methods. USA, 2011.

[84] Ovidiu Ivanciuc. "Applications of Support Vector Machines in Chemistry". In: Reviews in Computational Chemistry, Volume 23, Eds.: K. B. Lipkowitz and T. R. Cundari. Wiley-VCH, Weinheim, , pag. 301-337. 2007

[85] Scholköpf Bernhard, Smola Alexander J., "Learning with Kernels." The MIT press, Cambridge Massachusetts, London, England, pag. 1-21. 2000.

[86] Mercer J., Phil. "Functions of positive and negative type and their connection with the theory of integral equations". Trans. Roy. Soc. London A, 209, 415446. 1909.

[87] Chen HL, Yang B, Wang G., Wang SJ, Liu J, Liu DY. “Support vector machine based diagnostic system for breast cancer using swarm intelligence". Journal of Medical Systems, volume 36, issue 4, pag. 2505-2519. Aug. 2012.

[88] Hui W, Gang H. "Application of support vector machine in cancer diagnosis." Medical Oncology. Volume 28. Supplement 1, pag. 613-618. Sep. 2010 .

[89] Ammara Masood, Adel AJ. “SA-SVM based automated diagnostic system for skin cancer". Proceedings SPIE 6th International Conference on Graphic and Image Processing. Volume 9443. March 2015. 
[90] Gopinath B, Shanthi N. "Support Vector Machine based diagnostic system for thyroid cancer using statistical texture features." Asian Pacific Journal of Cancer Prevention, vol. 14, pag. 97-102. 2013.

[91] Martis R, Chakraborty C. "Arrhythmia disease diagnosis using neural network, SVM and genetic algorithm-optimized k-means clustering." Journal of Mechanics in Medicine and Biology, vol 11, issue 04. Sept 2011.

[92] Saberi M, Azadeh A, Nourmohammadzadeh A, Pahoheshfar P. “Comparing performance and robustness of SVM and ANN for fault diagnosis in a centrifugal pump". 19th International Congress on Modeling and Simulation. Perth-Australia. Dec. 2011.

[93] Fang W, Shen Y, Hamid R. "Fault detection and diagnosis in process data using support vector machines." Journal of Applied Mathematics, vol. 2014. March 2014.

[94] Kai-Ying C, Long-Sheng C, Mu-Chen C, Chia-Lung L. "Using SMV based method for equipment fault detection in a thermal power plant." Computers in Industry, vol 62, pag. 42-50. 2011.

[95] Aretakis H, Kalathakis C, Mathioudakis K, Ronesis C. "Fault diagnosis of thermal turbomachines using support vector machines (SVM)." American Institute of Aeronautics and Astronautics, vol. 2, pag. 833-841. NY 2013.

[96] Guoxia S, Haijiang W, Guojon C, Cuntao M. “Dissolved gases in oil diagnosis based on support vector machine." $2^{\circ}$ International Conference on Electronic \& Mechanical Engineering and Information Technology. EMEIT 2012.

[97] C Waterhouse, "Prediction of Parkinson tremor's using a MLP network", Proc. 11 th School Conf. for Annual Research Projects, V F Ruiz (Ed), pag. 503-506, University of Reading, 29 May 2012

[98] Jakubowski J1, Kwiatos K, Chwaleba A, Osowski S. "Higher order statistics and neural network for tremor recognition". IEEE Trans Biomed Eng. 49(2):152-9. Feb. 2002.

[99] Keerthi S. Sathiya. and Lin Chih-Jen. "Asymptotic Behaviors of Support Vector Machines with Gaussian Kernel. Neural Computation"., 15(7):16671689, 2003. URL http://www.csie.ntu.edu.tw/ cjlin/papers/limit.pdf.

[100] Lin H. T. and Lin C.-J. “A study on Sigmoid Kernels for SVM and the Training of non-PSD Kernels by SMO-type methods." Technical report, Department of Computer Science, National Taiwan University, 2003. URL http:// www.csie.ntu.edu.tw/ cjlin/ papers/tanh.pdf.

[101] Chih-Chung Chang and Chih-Jen Lin, "LIBSVM: a library for support vector machines." ACM Transactions on Intelligent Systems and Technology, 2:27:1-27:27, 2011. Software at: http://www.csie.ntu.edu.tw/ cjlin/libsvm.

[102] Soleimanian F, Mohammadi P. "A case study of Parkinson's disease diagnosis using artificial neural networks." International of Computer Applications, vol. 73, n¹9. July 2013. 
[103] Caglar M, Cetisli B, Toprak I. “Automatic recognition of Parkinson's disease from sustained phontion tests using ANN and adaptive neuro-fuzzy classifier." Journal of Engineering Science and Design, vol 1, nº 2, pag. 59-64. 2010.

[104] Magesh K. "Classification of Parkinson's disease using MultiPass LVQ, logistic model tree, K-Star for audio data set." Master Thesis Computer Engineering. 2011

[105] Patrick M, Arturas S, Julius G. “Support vector machine classification of Parkinson's disease, essential tremor and healthy control subjects based on upper extremity motion". International Conference on Biomedical Engineering and Biotechnology. IEEE 2012.

[106] Hughes AJ, Daniel SE, Kilford L, Lees AJ. “Accuracy of clinical diagnosis of idiopatic Parkinson's disease: a clinic-pathological study of 100 cases". Journal of Neurology, Neurosurgery and Psychiatry. Vol. 55, n 3, pag. 181184. Mar. 1992.

[107] Hughes AJ, Daniel SE, Lees AJ. “Improved accuracy of clinical diagnosis of Lewy body Parkinson's disease". Neurology, vol. 57, n 8, pag. 1497-1499. Oct. 2001.

[108] Lingmei A, Jue W, Ruoxia Y. “Classification of parkinsonian and essential tremor using empirical mode decomposition and support vector machine". Digital Signal Processing, pag. 543-550. Jan. 2011. 


\section{Anexo I - Escala unificada para la evaluación del Párkinson (Unified Parkinson Disease Rating Scale UPDRS)}

\section{Estado mental, conducta y humor (puntuación total $=16$ ).}

1. Discapacidad intelectual.

$0=$ Ninguna.

1 = Leve pérdida de memoria con recuperación parcial de los acontecimientos y sin otras dificultades.

2 = Pérdida de memoria moderada, con desorientación y dificultad moderada tratando problemas complejos. Leve pero definida discapacidad de la función doméstica con necesidad ocasional de sugerencias.

3 = Pérdida grave de memoria, con desorientación temporal y frecuentemente para situarse. Importante discapacidad en solución de problemas.

4 = Pérdida de memoria grave, con orientación reservada a una persona solamente. No puede hacer juicios o resolver problemas. Requiere mucha ayuda con el cuidado personal. No se le puede dejar solo.

2. Trastornos del pensamiento (debido a demencia o intoxicación por fármacos).

$0=$ No hay

1 = Sueños vívidos.

2 = Alucinaciones "benignas", conservando la capacidad de discernir.

3 = Alucinaciones o delirios de ocasionales a frecuentes. Sin capacidad de discernir. Pueden interferir con las actividades diarias.

4 = Alucinaciones o delirios persistentes o psicosis florida. Incapaz de cuidar de sí mismo.

3. Depresión.

$0=$ No hay

1 = Períodos de tristeza o sentimientos de culpa mayores de lo normal, aunque nunca mantenidos durante días o semanas. 
2 = Depresión mantenida (1 semana o más).

3 = Depresión mantenida con síntomas vegetativos (insomnio, anorexia, pérdida de peso, pérdida de interés).

4 = Depresión mantenida, con síntomas vegetativos y pensamientos o intento de suicidio.

\section{Motivación/Iniciativa.}

$0=$ Normal

1 = Menos pujante de lo habitual; más pasivo .

2 = Pérdida de iniciativa o desinterés en cuanto a actividades opcionales (no rutinarias).

3 = Pérdida de iniciativa o desinterés en la actividades de cada día (rutinarias).

4 = Aislado, apartado; pérdida total de la motivación.

\section{Actividades de la vida diaria (Para sendos on y off. Puntuación total =16).}

\section{Lenguaje.}

$0=$ Normal

$1=$ Discretamente alterado. No hay dificultad para entender.

2 = Moderadamente alterado. A veces hay que pedirle que repita algo.

3 = Muy alterado. Hay que pedirle con frecuencia que repita.

$4=$ Ininteligible la mayor parte del tiempo.

\section{Salivación.}

$0=$ Normal

1 = Exceso de saliva en la boca, discreto pero evidente; puede haber babeo durante la noche.

2 = Moderado exceso de saliva; puede haber mínimo babeo.

$3=$ Marcado exceso de saliva con cierto grado de babeo.

4 = Marcado babeo; requiere constantemente gasa o pañuelo.

\section{Deglución.}

$0=$ Normal

$1=$ Rara vez se atraganta.

$2=$ Se atraganta ocasionalmente.

$3=$ Requiere dieta blanda. 
4 = Requiere alimentación por sonda nasogástrica o gastrostomía.

\section{Escritura.}

$0=$ Normal

$1=$ Discretamente lenta o pequeña.

2 = Moderadamente lenta o pequeña; todas las palabras son legibles.

3 = Muy alterada; no son legibles todas las palabras.

$4=$ La mayoría de las palabras son ilegibles

\section{Cortar alimentos y utensilios de mano.}

$0=$ Normal

$1=$ Algo lento $y$ torpe, pero no necesita ayuda.

2 = Puede cortar la mayoría de los alimentos, aunque con torpeza y lentitud; necesita cierta ayuda.

3 = Le tienen que cortar los alimentos, pero aún puede alimentarse con lentitud.

$4=$ Necesita ser alimentado.

\section{Vestimenta.}

$0=$ Normal

$1=$ Algo lento, pero no requiere ayuda.

2 = Requiere ayuda en ocasiones para abotonarse, introducir los brazos por las mangas.

$3=$ Requiere bastante ayuda, puede hacer algunas cosas solo.

$4=$ Incapacitado

\section{Higiene.}

$0=$ Normal

$1=$ Algo lento, pero no necesita ayuda.

2 = Necesita ayuda para ducharse o bañarse, o es muy lento en la actividades higiénicas.

$3=$ Requieren ayuda para lavarse, cepillarse los dientes, peinarse, ir al retrete.

4 = Sonda de Foley $\mathrm{u}$ otras ayudas mecánicas .

12. Dar la vuelta en la cama y ajustar la ropa de cama.

$0=$ Normal 
$1=$ Algo lento $y$ torpe, pero no precisa ayuda

2 = Puede volverse solo o ajustar las sábanas, pero con gran dificultad .

3 = Puede iniciar la acción, pero no puede volverse o ajustar las sábanas solo.

$4=$ Incapacitado

13. Caídas (no relacionadas con el fenómeno de "congelación").

$0=$ Ninguna .

$1=$ Rara vez

2 = Se cae ocasionalmente (menos de una vez a día).

3 = Se cae un promedio de una vez al día.

4 = Se cae más de una vez al día.

14. “Congelación” al caminar.

$0=$ No hay .

1 = Rara vez aparece "congelación" al caminar; puede haber titubeo al inicio.

2 = “Congelación" ocasional al caminar.

3 = “Congelación" frecuente. A veces se cae por causa de este fenómeno.

4 = Caídas frecuentes por "congelación".

\section{Caminar.}

$0=$ Normal

1 = Leve dificultad. Puede no balancear los brazos o puede tender a arrastrar las piernas.

2 = Dificultad moderada, pero requiere poca o ninguna ayuda.

$3=$ Trastorno grave de la marcha que requiere ayuda.

$4=$ No puede caminar, incluso con ayuda.

16. Temblor.

$0=$ Ausente

1 = Discreto; infrecuentemente presente. No resulta molesto para el paciente.

2 = Moderado; molesto para el paciente

$3=$ Intenso; interfiere con muchas actividades.

4 = Marcado; interfiere la mayoría de las actividades. 
17. Molestias sensoriales relacionadas con el parkinsonismo.

$0=$ Normal

$1=$ Ocasionalmente tiene entumecimiento, hormigueo o dolorimiento discreto.

2 = Con frecuencia tiene entumecimiento, hormigueo o dolorimiento discreto; no resulta penoso.

$3=$ Frecuentes sensaciones dolorosas.

$4=$ Dolor extremo

III. Sección motora (Puntuación total = 16).

18. Lenguaje.

$0=$ Normal

1 = Pérdida discreta de expresión, dicción y/ volumen.

2 = Monótono; farfullado, pero comprensible; moderadamente alterado .

$3=$ Muy alterado, difícil de comprender.

$4=$ Ininteligible

19. Expresión facial.

$0=$ Normal

1 = Mínimo hipomimia; podría ser una cara inexpresiva ("cara de póker") normal.

2 = Disminución discreta, pero claramente anormal, de la expresión facial.

3 = Hipomimia moderada; labios separados la mayor parte del tiempo.

4 = Cara de "máscara" o expresión fija con pérdida acusada o completa de la expresión facial; labios separados más de $6 \mathrm{~mm}$.

20. Temblor de reposo en miembros superiores.

$0=$ Ausente

$1=$ Discreto e infrecuentemente presente.

2 = Discreto en amplitud y persistente, $\mathrm{o}$ de amplitud moderada pero presente sólo de forma intermitente.

$3=$ De amplitud moderada y presente la mayor parte del tiempo.

\section{Temblor de reposo en miembros inferiores.}

$0=$ Ausente

$1=$ Discreto e infrecuentemente presente 
2 = Discreto en amplitud y persistente, $\mathrm{o}$ de amplitud moderada pero presente sólo de forma intermitente.

$3=$ De amplitud moderada y presente la mayor parte del tiempo.

22. Temblor de acción o postural de las manos.

$0=$ Ausente

1 = Leve; presente con la acción.

2 = De amplitud moderada; presente con acción.

3 = De amplitud moderada al mantener la postura en el aire; así como con la acción.

4 = De gran amplitud; interfiere la alimentación.

23. Rigidez axial (valorada según el movimiento pasivo de las grandes articulaciones, con el paciente relajado y sentado).

$0=$ Ausente

1 = Discreta o detectable solamente cuando se activa por movimientos en espejo o de otro tipo.

$2=$ Discreta a moderada

3 = Intensa pero se consigue con facilidad el movimiento en toda su amplitud.

4 = Muy intensa; la amplitud del movimiento se logra con dificultad. .

24. Rigidez en miembros superiores (Valorada según el movimiento pasivo de las grandes articulaciones, con el paciente relajado y sentado. No considerar la rigidez "en rueda dentada").

$0=$ Ausente

$1=$ Discreta o detectable solamente cuando se activa por movimientos en espejo o de otro tipo.

$2=$ Discreta a moderada.

$3=$ Intensa, pero se consigue con facilidad el movimiento en toda su amplitud.

4 = Muy intensa; la amplitud del movimiento se logra con dificultad.

25. Rigidez en miembros inferiores (Valorada según el movimiento pasivo de las grandes articulaciones, con el paciente relajado y sentado. No considerar la rigidez "en rueda dentada").

$0=$ Ausente

$1=$ Discreta o detectable solamente cuando se activa por movimientos en espejo o de otro tipo.

$2=$ Discreta a moderada. 
3 = Intensa, pero se consigue con facilidad el movimiento en toda su amplitud.

4 = Muy intensa; la amplitud del movimiento se logra con dificultad .

26. Golpeteo de los dedos (El paciente golpea el pulgar con el índice en rápida sucesión y con la mayor amplitud posible; realizar con cada mano por separado).

$0=$ Normal (15/5 segundos)

1 = Enlentecimiento discreto y/o reducción de la amplitud (11-14/5 segundos).

2 = Moderadamente alterado. Fatigoso de manera evidente y precoz. Puede haber detenciones ocasionales en el movimiento (7-10/5 segundos).

3 = Muy alterado. Frecuentes titubeos al iniciar los movimientos o detenciones mientras se realiza el movimiento (3-6/5 segundos).

4 = Apenas puede realizar la acción (0-2/5 segundos).

27. Levantarse de una silla.

$0=$ Normal.

$1=$ Discreto enlentecimiento $y /$ o reducción de la amplitud.

2 = Alteración moderada. Fatigoso de manera evidente y precoz. Puede haber detenciones ocasionales en el movimiento.

3 = Muy alterados. Frecuentes titubeos al iniciar los movimientos o detenciones mientras se realizan los movimientos.

$4=$ Apenas puede realizarlos.

28. Postura (Movimientos de pronación-supinación de las manos, en sentido vertical, con la mayor amplitud posible y simultáneamente con ambas manos).

$0=$ Normal.

$1=$ Discreto enlentecimiento y/o reducción en amplitud.

2 = Moderadamente alterados. Fatigoso de manera evidente y precoz. Puede haber ocasionales detenciones en el movimiento.

3 = Muy alterados. Frecuentes titubeos al iniciar los movimientos o detenciones mientras se realizan los movimientos.

$4=$ Apenas puede realizarlos.

29. Agilidad con los miembros inferiores (El paciente golpea con el talón en rápida sucesión levantando el pie entero del suelo; la amplitud del movimiento debe ser alrededor de $7,5 \mathrm{~cm})$.

$0=$ Normal

1 = Discreto enlentecimiento y/o reducción en amplitud. 
2 = Moderadamente alterados. Fatigoso de manera evidente y precoz. Puede haber ocasionales detenciones en el movimiento.

3 = Muy alterados. Frecuentes titubeos al iniciar los movimientos o detenciones mientras se realizan los movimientos.

$4=$ Apenas puede realizarlos

30. Levantarse de la silla (El paciente intenta levantarse de una silla de madera o metal de respaldo recto, con los brazos cruzados ante el pecho).

$0=$ Normal

1 = Lento, o puede necesitar más de un intento.

$2=$ Tiene que impulsarse con los brazos en la silla.

3 = Tiende a caer hacia atrás y puede tener que intentarlo más de una vez, pero puede conseguirlo sin ayuda.

4 = Incapaz de levantarse sin ayuda.

31. Postura.

$0=$ Erecta normal.

1 = Postura no muy erecta, discretamente encorvada; podía ser normal en una persona mayor.

2 = Postura moderadamente encorvada, claramente anormal. Puede inclinarse discretamente a un lado.

3 = Postura muy encorvada, con cifosis. Puede inclinarse moderadamente a un lado.

4 = Flexión marcada con alteración postural extrema.

32. Marcha.

$0=$ Normal

1 = Camina lentamente; pueden arrastrar los pies, con pasos cortos, pero sin festinación ni propulsión.

2 = Camina con dificultad, pero no requiere ayuda o muy escasa. Puede haber festinación, pasos cortos o propulsionados.

3 = Trastornos graves de la marcha que requieren ayuda.

$4=$ No puede caminar, incluso con ayuda.

33. Estabilidad postural (Respuesta al desplazamiento súbito posterior producido por un tirón de los hombros mientras el paciente permanece en bipedestración con los ojos abiertos y los pies discretamente separados; el paciente está avisado).

$0=$ Normal

$1=$ Retropopulsión, pero se recupera sin ayuda. 
2 = Ausencia de respuesta postural; se caería si no le sujetara el examinador.

3 = Muy inestable; tiende a perder el equilibrio espontáneamente.

$4=$ Incapaz de permanecer en pie sin ayuda.

34. Bradiquinesia e hipoquinesia (Combina lentitud, titubeo, disminución del braceo, pequeña amplitud y pobreza de movimiento en general).

$0=$ No hay .

1 = Mínima lentitud que da al movimiento un carácter deliberado; podría ser normal en algunas personas. Amplitud posiblemente reducida.

2 = Lentitud y pobreza de movimientos, en grado leve, que es claramente anormal. Como alternativa, cierto grado de reducción en la amplitud.

$3=$ Lentitud, pobreza o pequeña amplitud de movimientos moderada.

4 = Lentitud, pobreza o pequeña amplitud de movimientos marcada.

\section{Complicaciones del tratamiento (En la semana previa. Historia. Puntuación total $=23$ ).}

\section{A) Discinesias:}

35. Duración ¿Qué proporción del día vigil están presentes las discinesias?

$0=$ Ninguna

$1=1-25 \%$ del día.

$2=26-50 \%$ del día

$3=51-75 \%$ del día

$4=76-100 \%$ del día

36. Incapacidad ¿Hasta qué punto son incapacitadoras las discinesias? (Información por historia; puede ser modificado por exploración en la consulta).

$0=$ No incapacitan en absoluto.

$1=$ Discretamente incapacitantes

$2=$ Moderadamente incapacitantes

$3=$ Importantemente incapacitantes

$4=$ Completamente incapacitantes.

37. Discinesias dolorosas ¿Son dolorosas las discinesias?

$0=$ No son dolorosas

$1=$ Discretamente 
$2=$ Moderadamente

$3=$ Importantemente

4 = Marcadamente

38. Presencia de distonía matutina.

$0=$ No.

1 = Sí.

B) Fluctuaciones clínicas:

39. ¿Hay períodos off predecibles en relación temporal con las dosis de medicación?

$0=$ No.

1 = Sí.

40. ¿Hay períodos off impredecibles en relación temporal con las dosis de medicación?

$0=$ No.

1 = Sí.

41. ¿Hay períodos off de instauración súbita? (P. ej., en unos segundos).

$0=$ No.

1 = Sí.

42. ¿Qué proporción del día vigil está el paciente en off, de promedio?

$0=$ Ninguna .

$1=1-25 \%$ del día.

$2=26-50 \%$ del día

$3=51-75 \%$ del día

$4=76-100 \%$ del día.

C) Otras complicaciones:

43. ¿Tiene el paciente anorexia, náuseas o vómitos?

$0=$ No.

1 = Sí.

44. ¿Tiene el paciente trastornos del sueño (P. ej., insomnio o hipersomnia?

$0=$ No.

1 = Sí. 
45. ¿Tiene el paciente ostostatismo sintomático?

$0=$ No.

1 = Sí. 
Anexo II - Escala de temblor de Fahn, Tolosa y Marín (FTM). Criterios de valoración y definiciones 


\section{Criterios de valoración y definiciones}

\section{A. Valoración del temblor en nueve localizaciones (1-9) según amplitud}

1. Labios

Reposo Postura Acción

2. Mandíbula

3. Lengua

4. Voz

5. Cabeza

6. Miembros superiores (D/I)

- Manos extendidas

- Índices opuestos

7. Tronco

8. Miembros inferiores (D/l)

9. Otras localizaciones

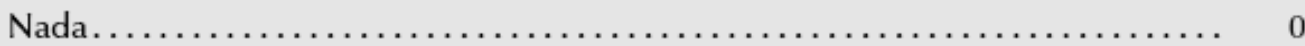

Leve (amplitud $<0,5 \mathrm{~cm}$ ). Puede ser intermitente $\ldots \ldots \ldots \ldots \ldots \ldots \ldots \ldots \ldots \ldots$

Moderada amplitud $(0,5-1 \mathrm{~cm})$. Puede ser intermitente $\ldots \ldots \ldots \ldots \ldots \ldots \ldots \ldots \ldots \ldots \ldots \ldots \ldots \ldots \ldots \ldots$

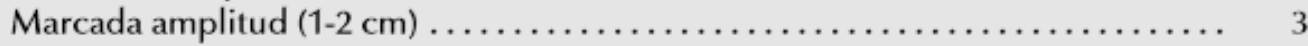

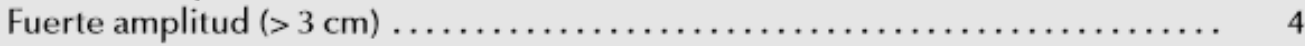

B. Valoración del temblor de miembros superiores

10. Escritura:

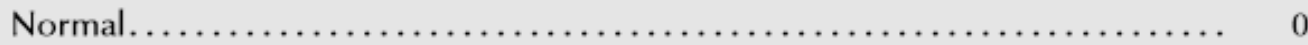

Mínimamente anormal. Levemente tembloroso $\ldots \ldots \ldots \ldots \ldots \ldots \ldots \ldots \ldots \ldots$. 1

Moderadamente anormal. Legible, pero con considerable temblor ........ 2

Marcadamente anormal. Ilegible .............................. 3

Fuertemente anormal. Incapaz de poner la pluma o bolígrafo en el papel

sin sujetar la mano con la otra mano. ..................... 4

11-13. Delinear:

Normal. . . . . . . . . . . . . . . . . .

Temblor leve. Puede cruzar las líneas ocasionalmente $\ldots \ldots \ldots \ldots \ldots \ldots \ldots \ldots . \quad 1$

Temblor moderado o cruza las líneas frecuentemente $\quad \ldots \ldots \ldots \ldots \ldots \ldots \ldots .2$

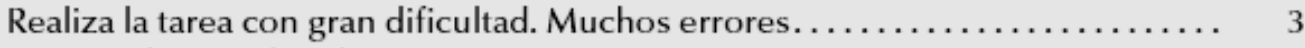

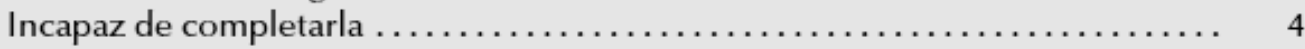

14. Verter:

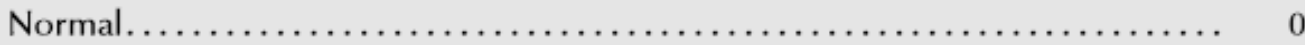

Más cuidadoso que una persona sin temblor, pero sin derramar agua....... 1

Derrama una pequeña cantidad de agua (alrededor del $10 \%$ ) $\ldots \ldots \ldots \ldots \ldots .2$

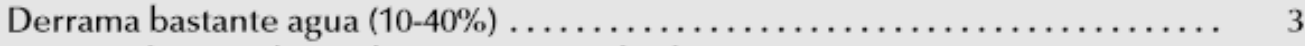

Incapaz de verterla sin derramar casi toda el agua $\ldots \ldots \ldots \ldots \ldots \ldots \ldots \ldots$

C. Incapacidad funcional que origina el temblor

15. Habla:

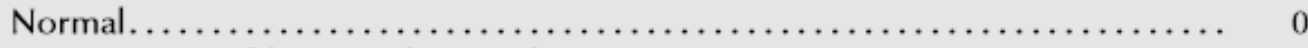

Levemente temblorosa sólo cuando está nervioso $\ldots \ldots \ldots \ldots \ldots \ldots \ldots \ldots \ldots$.

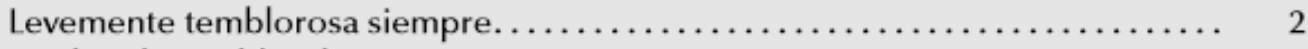

Moderado temblor de voz. . . . . . . . . . . . . . . . . . . . . 3

Fuerte temblor de voz. Algunas palabras difíciles de entender. . . . . . . . 4 


\section{Criterios de valoración y definiciones}

16. Comer:

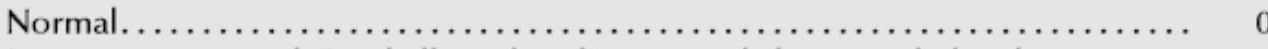

Levemente anormal. Puede llevar los alimentos a la boca y sólo los derrama

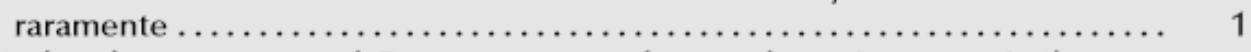

Moderadamente anormal. Frecuentemente derrama los guisantes y similares .. 2

Marcadamente anormal. Incapaz de cortar o no usar las dos manos para comer .. 3

Fuertemente anormal. Necesita ayuda para comer .................. 4

17. Llevar líquidos a la boca:

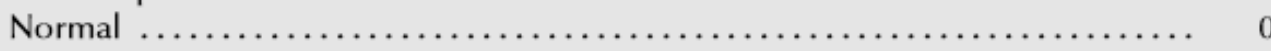

Levemente anormal. Puede usar la cuchara, pero no si está completamente

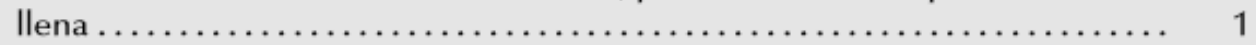

Moderadamente anormal. Incapaz de usar cuchara. Usa copa o vaso ....... 2

Marcadamente anormal. Puede beber en vaso, pero necesita las dos manos... 3

Fuertemente anormal. Necesita usar una cañita $\ldots \ldots \ldots \ldots \ldots \ldots \ldots \ldots \ldots$

18. Higiene:

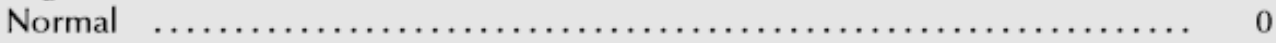

Levemente anormal. Lo realiza todo, pero cuidadosamente $\ldots \ldots \ldots \ldots \ldots \ldots$. 1

Moderadamente anormal. Lo realiza todo pero con errores, debe utilizar

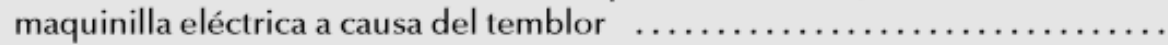

Marcadamente anormal. Incapaz de realizar las tareas finas, tales como pintarse los labios o afeitarse, incluso con máquina eléctrica, sin usar las dos manos ..

Fuertemente anormal. Incapaz de realizar solo cualquier tarea fina ...........

19. Vestirse:

Normal. . . . . . . . . . . .

Levemente anormal. Capaz de hacerlo todo, pero de una forma cuidadosa..... 1

Moderadamente anormal. Capaz de hacerlo todo, pero con errores ........ 2

Marcadamente anormal. Necesita asistencia para abotonarse $u$ otras actividades,

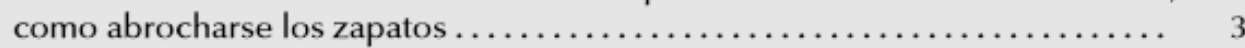

Fuertemente anormal. Requiere asistencia incluso en las tareas básicas ...... 4

20. Escribir:

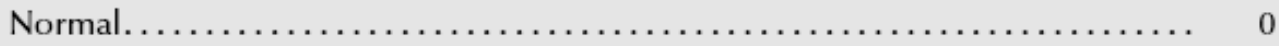

Levemente anormal. Legible; capaz de escribir cartas largas............. 1

Moderadamente anormal. Legible; no puede escribir cartas largas.......... 2

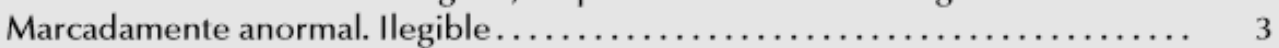

Fuertemente anormal. Incapaz de firmar...................... 4

21. Trabajo:

El temblor no interfiere en el trabajo $\ldots \ldots \ldots \ldots \ldots \ldots \ldots \ldots \ldots \ldots \ldots \ldots \ldots \ldots$

Capaz de trabajar, pero necesita ser más cuidadoso que una persona normal... 1

Capaz de trabajar, pero con errores. Empeoramiento de su rendimiento laboral por causa del temblor. . . . . . . . . . . . . . 2

Incapaz de un trabajo regular. Puede haber cambiado de trabajo a causa

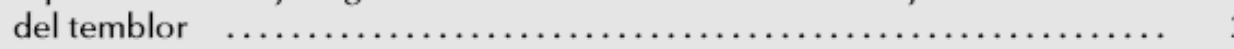

El temblor limita las labores del hogar, como el planchado. Incapaz de realizar cualquier trabajo. Las labores de la casa están muy limitadas...... 


\title{
Plantilla de evaluación:
}

\author{
Apartado A \\ 1. Temblor facial \\ 2. Temblor lingual \\ 3. Temblor voz \\ 4. Temblor cabeza \\ 5. Temblor ESD \\ 6. Temblor EID \\ 7. Temblor tronco \\ 8. Temblor ESI \\ 9. Temblor ElI
}

Rep. Post. Acción/Int. Total D/l dominancia

Subtotal A ..........

Derecha Izquierda Total

10. Escritura (sólo mano dominante)

11. Dibujar A

12. Dibujar B

13. Dibujar C

14. Verter

\section{Apartado C \\ 15. Habla \\ 16. Comer \\ 17. Beber \\ 18. Higiene \\ 19. Vestirse \\ 20. Escribir \\ 21. Trabajar}

Subtotal C ..........

Total $(A+B+C) \ldots \ldots$

Nombre

\section{Fecha}

Escritura: esta es una muestra de mi escritura.

Dibujar: mano derecha/mano izquierda.

Dibujar una línea que una las dos cruces inicial y final entre las espirales y entre las líneas
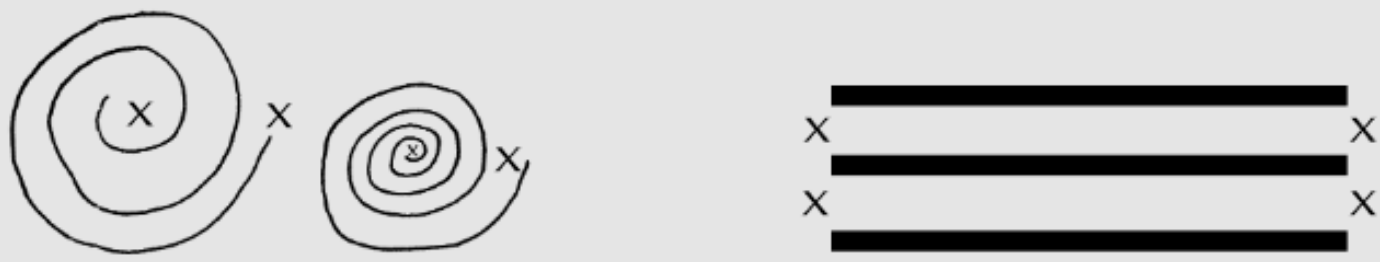


\section{Plantilla de evaluación:}

\section{Valoración apartado C*}

\section{Valoración global por el examinador:}

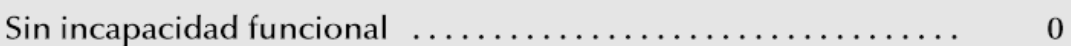

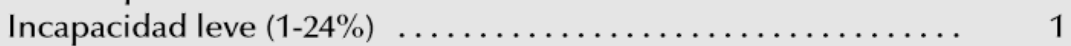

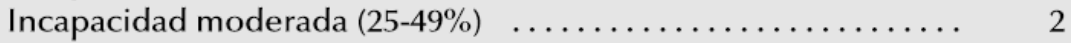

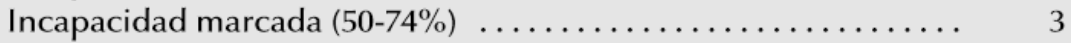

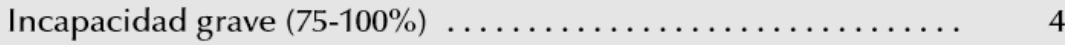

\section{Puntuación}

\section{Valoración global por el paciente:}

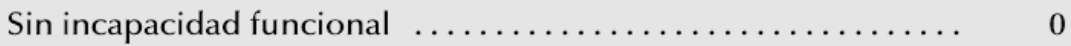

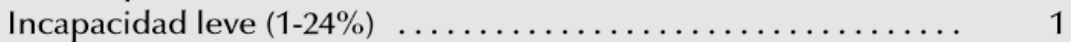

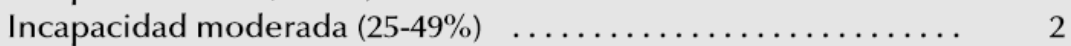

Incapacidad marcada $(50-74 \%) \quad \ldots \ldots \ldots \ldots \ldots \ldots \ldots \ldots \ldots . \ldots \ldots$

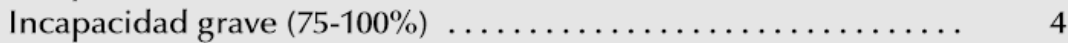

Valoración subjetiva del paciente en relación con la última visita:

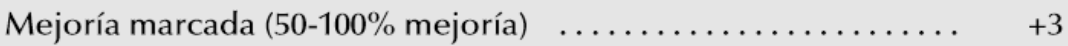

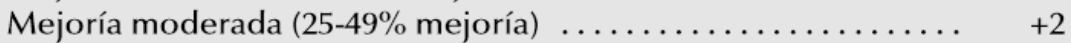

Mejoría leve $(10-24 \%$ mejoría) $\ldots \ldots \ldots \ldots \ldots \ldots \ldots \ldots \ldots \ldots \ldots \ldots+1$

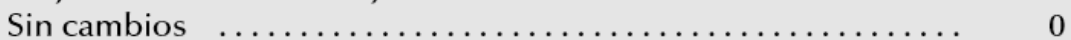

Empeoramiento leve $(10-24 \%$ empeoramiento $) \ldots \ldots \ldots \ldots \ldots-1$

Empeoramiento moderado (25-49\% empeoramiento) ....... -2

Empeoramiento marcado $(50-100 \%$ empeoramiento) $\ldots \ldots \ldots . .3$

\section{Puntuación}

*Cálculo: Puntuación total/puntuación máxima posible = \% de gravedad (la puntuación máxima posible es 144). 


\section{Anexolll Protocolo de pruebas DIMETER}




\section{SISTEMA DIMETER \\ PROTOCOLO DE PRUEBAS \\ A completar previamente a la sesión}

\begin{tabular}{|l|l|}
\hline SESIÓN & FECHA \\
\hline
\end{tabular}

\begin{tabular}{|l|l|}
\hline \multicolumn{2}{|c|}{ DATOS DEL PACIENTE } \\
\hline NOMBRE & APELLIDOS \\
\hline EDAD & SEXO \\
\hline TELEFONO & DOMICILO \\
\hline FAX & email \\
\hline
\end{tabular}

\begin{tabular}{|l|l|}
\hline $\begin{array}{c}\text { CENTRO DE } \\
\text { PROCEDENCIA }\end{array}$ & \\
\hline PATOLOGÍA & \\
\hline DATOS CLÍNICOS RELEVANTES \\
\hline OBSERVACIONES \\
\hline
\end{tabular}

\begin{tabular}{|l|l|l|}
\hline \multicolumn{2}{|l|}{ CONDICIONES DE LA SESIÓN } \\
\hline $\begin{array}{l}\text { REPONSABLE DE LA } \\
\text { SESIÓN }\end{array}$ & Ingeniero & \\
\hline $\begin{array}{l}\text { LUGAR DE } \\
\text { REALIico }\end{array}$ & \\
\hline HORA DE COMION & \multicolumn{2}{|l|}{} \\
\hline
\end{tabular}




\begin{tabular}{|c|c|c|c|c|}
\hline \multicolumn{5}{|c|}{ PATRONES ESTÁTICOS } \\
\hline $\begin{array}{l}\text { NOMBRE } \\
\text { PATRÓN }\end{array}$ & DESCRIPCIÓN & 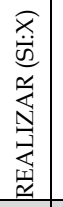 & 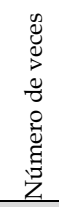 & OBSERVACIONES \\
\hline PT1 & Punto en Pantalla & & & \\
\hline PT2 & $\begin{array}{l}\text { Línea recta } \\
\text { horizontal }\end{array}$ & & & \\
\hline
\end{tabular}




\section{PATRONES CINÉTICOS}

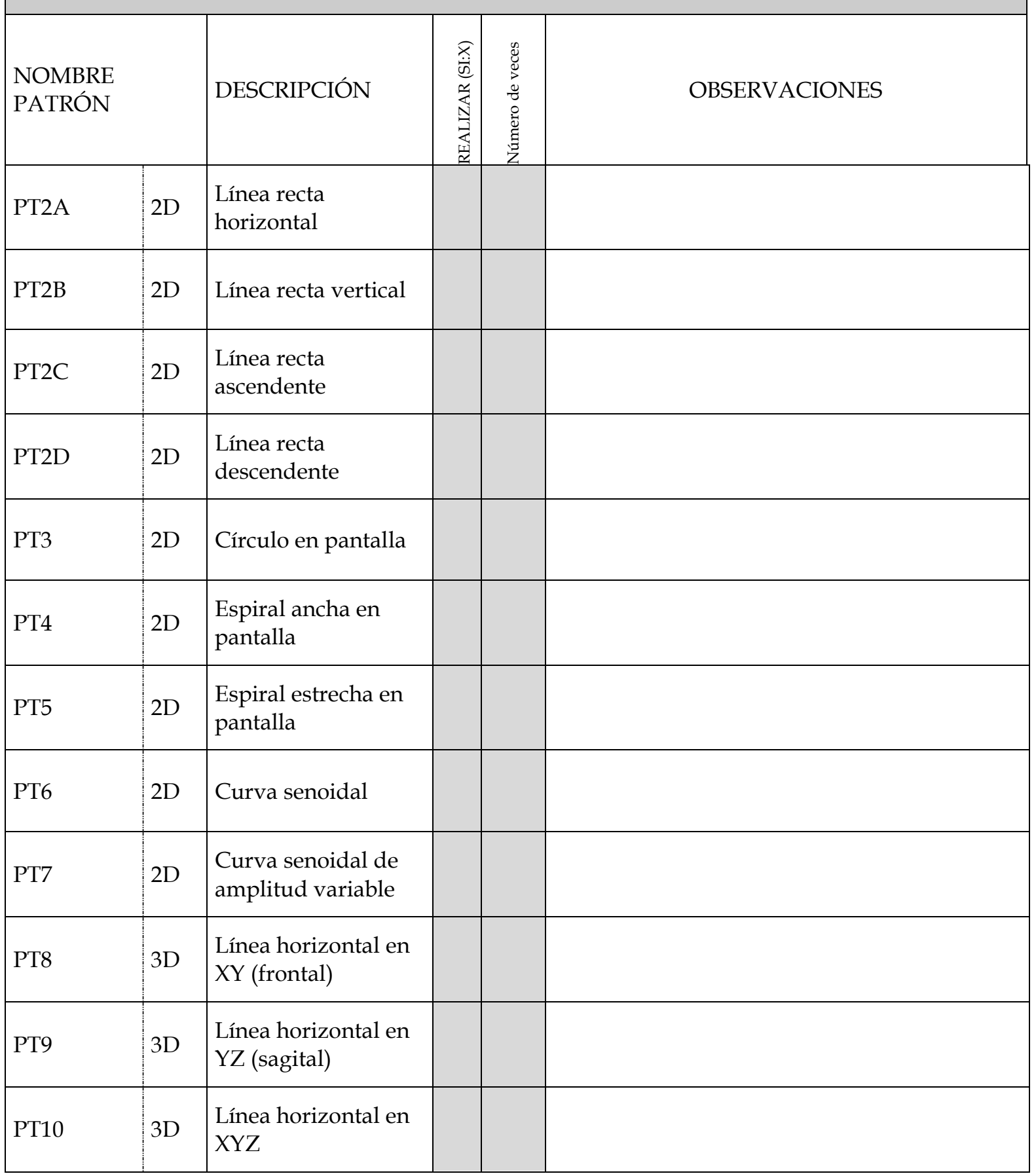




\begin{tabular}{|c|c|c|c|c|c|}
\hline \multicolumn{6}{|c|}{ PATRONES DINÁMICOS } \\
\hline \multicolumn{2}{|c|}{$\begin{array}{l}\text { NOMBRE } \\
\text { PATRÓN }\end{array}$} & \multirow{2}{*}{$\begin{array}{l}\text { DESCRIPCIÓN } \\
\text { Punto en el espacio }\end{array}$} & \multirow{2}{*}{ 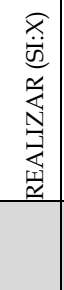 } & \multirow{2}{*}{ 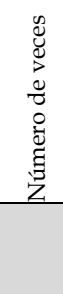 } & \multirow[t]{2}{*}{ OBSERVACIONES } \\
\hline PT11 & $2 \mathrm{D}$ & & & & \\
\hline PT12 & $2 \mathrm{D}$ & Línea horizontal & & & \\
\hline PT13 & $3 \mathrm{D}$ & $\begin{array}{l}\text { Línea horizontal en } \\
\text { XY (frontal) }\end{array}$ & & & \\
\hline PT14 & $2 \mathrm{D}$ & Espiral ancha & & & \\
\hline
\end{tabular}


